Mariana Cabral de Oliveira

\title{
Origem e evolução das algas eucarióticas e de seus cloroplastos com ênfase nas algas vermelhas (Rhodophyta)
}

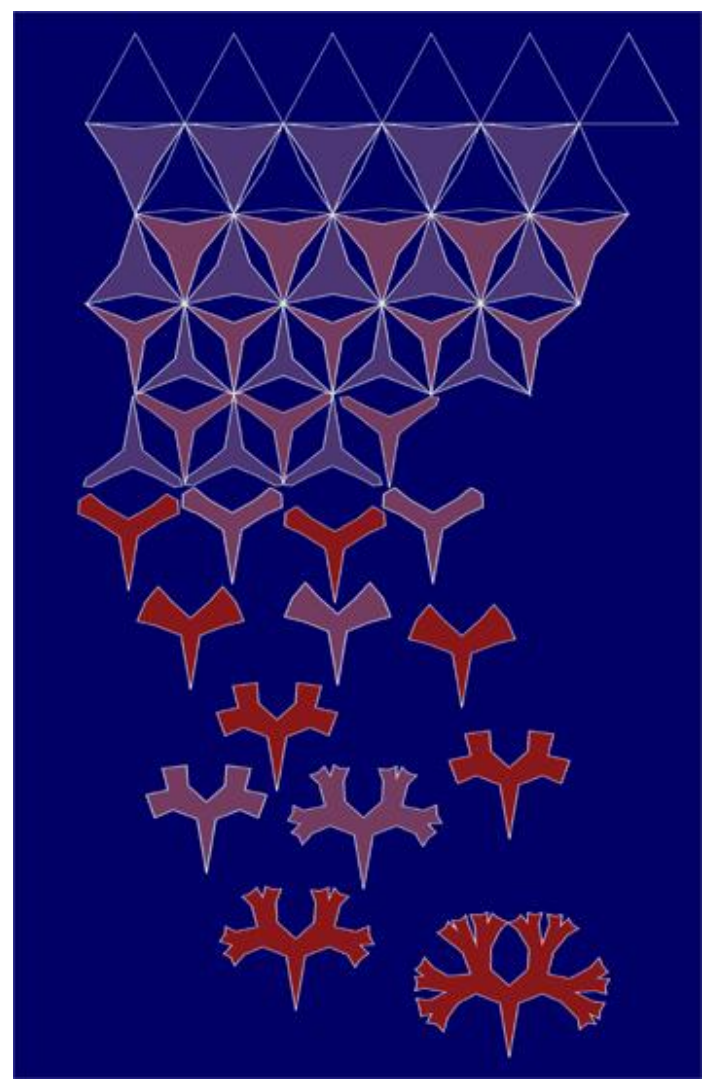

Texto apresentado ao Instituto de Biociências da Universidade de São Paulo para concurso de Livre-Docência no Departamento de Botânica

São Paulo 
"Nothing in biology makes sense except in the light of evolution".

Dobzhansky

Para Pedro e Lucas 


\section{Agradecimentos}

Ao Departamento de Botânica e Instituto de Biociências da Universidade de São Paulo.

Este trabalho não seria possível sem o apoio financeiro de diversas entidades, agradeço: à FAPESP; ao CNPq; ao DAAD (Alemanha); ao STINT (Suécia); à IFS (Suécia) e à PróReitoria de Pesquisa-USP pelo apoio aos projetos de pesquisa e bolsas.

Ao Eurico Cabral de Oliveira Filho pela revisão do texto e pelo apoio fundamental na minha carreira acadêmica.

Este trabalho foi realizado com a colaboração de alunos e pesquisadores, co-autores dos trabalhos incluídos. Agradeço à: Alexis M. Bellorin, Carlos F. M. Menck, Daniela Milstein, Debashish Bhattacharya, Eurico C. de Oliveira, João P. Kitajima, João C. Setubal, Jonas Collén, Jonathan C. Hagopian, Kirsten M. Müller, Marcelo Reis, Marianne Pedersén, Pio Colepicolo, Robert G. Sheath e Suzanne Pi Nyvall.

Agradeço o apoio e a colaboração dos alunos e pesquisadores: Alessandro M. Varani, Angela P. Tonon, Cíntia S. Coimbra, Estela M. Plastino, Flávio A. S. Berchez, Fungyi Chow Ho, Maria do Carmo Bittencourt-Oliveira, Marie-Anne Van Sluys, Mônica M. Takahashi, Mutue T. Fujii, Nair Yokoya, Orlando Nechi Jr., Sônia M. B. Pereira, Vanessa R. Falcão, e Yocie Yoneshigue.

Agradeço a toda equipe do Laboratório de Algas Marinhas Edison J. de Paula (LAM) e do Laboratório de Biologia Molecular de Plantas (LBMP) pelo apoio prestado e pela amizade e companheirismo.

Agradeço o apoio técnico imprescindível de Rosario Petti e Silvia R. Blanco, e do pessoal da secretaria do Departamento de Botânica: Carlos, Cezario e Norberto. Agradeço a Vanessa Sato pela ajuda com o Memorial.

Agradeço a Alexis Bellorin pela figura da capa.

À minha família e ao Lalo, sem os quais esse trabalho não seria possível. 


\section{Índice:}

Lista dos Anexos

Abreviaturas

Abstract 7

Resumo

Apresentação

1. As diferentes linhagens filogenéticas de algas eucarióticas ........................................... 13

2. Origem e diversificação dos cloroplastos

2.1. Endossimbiose secundária: origem dos plastos complexos 21

2.2. Plastos secundários da linhagem vermelha 22

3. O genoma dos plastos

3.1. Seqüenciamento e análise do genoma do plasto de Gracilaria tenuistipitata .............. 25

4. A linhagem filogenética das Rhodophyta

4.1. As subclasses Bangiophycidae e Florideophycidae 27

4.2. Filogenia das ordens de Bangiophycidae 27

4.3. Filogenia de espécies de Bangiales (Bangiophycidae) baseada no seqüenciamento do gene SSU rDNA

4.4. Introns do grupo I e biogeografia de Porphyra spiralis var. amplifolia ….................. 32

4.5. Filogenia de espécies de Gracilariaceae (Florideophycidae) baseada no seqüenciamento do gene SSU rDNA 36

5. Genômica 37

5.1. Seqüenciamento de ‘Expressed Sequence Tags’ (EST) de G. tenuistipitata _.............. 38

6. Perspectivas

6.1. Caracterização do genoma mitocondrial e banco de dados genéticos para Gracilaria tenuistipitata 39

6.2. Obtenção de transformantes estáveis de Gracilariales _ 40

6.3. Filogenia molecular de algas

6.4. Introns do grupo I e biogeografia de Porphyra spiralis var. amplifolia …................... 41

Referências 


\section{$\operatorname{Anexos}^{1}$}

Oliveira M.C. \& Bhattacharya D. 2000. Phylogeny of the Bangiophycidae (Rhodophyta) and the secondary endosymbiotic origin of algal plastids. American Journal of Botany 87: 482492. (Anexo 1)

Bhattacharya D. \& Oliveira M.C. 2000. The SSU rDNA coding region of a filose amoeba contains a group I intron lacking the universally conserved $G$ at the 3 '-terminus. Journal of Eukaryotic Microbiology 47: 585-589. (Anexo 2)

Oliveira M.C. \& Menck C.F.M. 2001. O mundo de RNA e a origem da complexidade da vida. In Matioli S.R. (ed.), Biologia Molecular e Evolução. Holos Editora, Ribeirão Preto. pp: 15-26. (Anexo 3)

Oliveira M.C. 2001. Estudios de la macro y micro biodiversidad de las algas. Secuenciamiento del DNA ribosomal (rDNA). In Alveal K. \& Antezana T. (eds), Sustentabilidad de la Biodiversidad, un Problema Actual. Bases Cientifico-Técnicas, Teorizaciones Y Proyecciones. Univ. de Concepción, Concepción, Chile, 85-96. (Anexo 4)

Müller K.M., Oliveira M.C., Sheath R.G. \& Bhattacharya D. 2001. Ribosomal DNA phylogeny of the Bangiophycidae (Rhodophyta) and the origin of secondary plastids. American Journal of Botany 88: 1390-1400. (Anexo 5)

Bellorin A.M., Oliveira M.C. \& Oliveira E.C. 2002. Phylogeny and systematic of Gracilariaceae (Rhodophyta) revisited: ribosomal gene sequencing. Journal of Phycology 38: 551-563. (Anexo 6)

Hagopian J.C., Nyvall P. \& Oliveira M.C. 2002. Purification of plastid DNA from an enriched rhodoplast fraction of the red alga Gracilaria tenuistipitata. Plant Molecular Biology Reporter 20: 399-406. (Anexo 7)

Hagopian J.C., Reis M., Kitajima J.P., Bhattacharya D. \& Oliveira M.C. 2004. Comparative analysis of the complete plastid genome sequence of the red alga Gracilaria tenuistipitata var. liui provides insights on the evolution of rhodoplasts and their relationship to other plastids. Journal of Molecular Evolution. 59: 464-477. (Anexo 8)

Bellorin A.M., Oliveira M.C. \& Oliveira E.C. 2004. Gracilaria vermiculophylla: A western Pacific species of Gracilariaceae (Rhodophyta) first recorded from the eastern Pacific. Phycological Research 52: 69-79. (Anexo 9)

\footnotetext{
${ }^{1}$ para esse trabalho foram incluídas apenas publicações selecionadas a partir de 2000, publicações anteriores estão citadas como referências
} 
Milstein D. \& Oliveira M.C. 2005. Molecular phylogeny of Bangiales (Rhodophyta) based on small subunit rDNA sequencing: Emphasis on Brazilian Porphyra species. Phycologia, 44: 212-221. (Anexo 10)

Bellorin A.M. \& Oliveira M.C. Plastid origin: a driving force for the evolution of algae. In Sharma A.K. \& Sharma A. (eds.), Plant Genome, Biodiversity and Evolution, Volume 2B. Capítulo de livro aceito. (Anexo 11)

Nyvall P., Collén J., Reis M.S., Pedersén M., Setubal J.C., Colepicolo P. \& Oliveira M.C. 2005. Assessment of gene diversity in the red alga Gracilaria tenuistipitata (Rhodophyta) based on expressed sequences tags (EST). Manuscrito em preparação para publicação. (Anexo 12)

\author{
Abreviaturas \\ EST - 'Expressed Sequence Tags' ou etiquetas de seqüências expressas. \\ Indel - inserção/deleção \\ ITS - 'Internal Transcribed Spacer' ou espaçador transcrito interno. \\ Kb - kilo base (1 Kb = 1000 nucleotídeos $)$. \\ mRNA - RNA mensageiro. \\ nt - nucleotídeos. \\ ORF - 'Open Reading Frame' ou quadro de leitura aberto. \\ pb - pares de bases \\ PCR - 'Polymerase Chain Reaction' ou reação em cadeia de polimerase. \\ $r b c \mathbf{L}$ - gene que codifica para o a subunidade grande da RuBisCO \\ RuBisCo - Ribulose-1,5-bifosfato carboxilase/oxigenase \\ rRNA - RNA ribossômico.
}

SSU rDNA - gene que codifica para o RNA da subunidade pequena do ribossomo.

tRNA - RNA transportador. 


\section{Origin and evolution of eukaryotic algae and their chloroplasts with emphasis on red algae (Rhodophyta)}

\section{Abstract}

Chlorophyll $a$ is present in all organisms that release oxygen during the photosynthesis. The development of this molecule altered the earth atmosphere causing a great impact in the history of the planet, redirecting the evolution of life. The oxygenic photosynthesis was developed early in the history of life by a group of prokaryotes, the cyanobacteria. This ability was later laterally transferred to the eukaryotic realm by the acquisition of photosynthetic organelles (plastids) through the engulfment and retention of formerly free living cyanobacteria by an ancient eukaryotic cell. Such kind of cellular merging, called primary endosymbiosis, likely occurred only once. Three lineages of extant algae (including the ancestors of land plants) vertically evolved from the cells which first acquired plastids. Later on, the photosynthetic apparatus was laterally transferred to other unrelated eukaryotic lineages through independent secondary endosymbiosis, i.e., the acquisition of plastids by engulfing an eukaryote, already equipped with plastids. This gave rise to the 'second-hand' or secondary plastid-containing algae, a diverse assemblage including disparate organisms such as euglenoids, dinoflagellates and kelps. Thus, the history of photosynthesis acquisition by eukaryotes is extremely complex, making very difficult to briefly define algae and to discriminate them from other organisms. Current data support the view that plastid acquisition is a rather rare event and, accordingly, a single primary endosymbiosis followed by a few very ancient secondary endosymbiosis probably account for all extant plastid diversity.

The Rhodophyta is one of three extant lineages which arose from the primary endosymbiosis and one of the main monophyletic groups within the eukaryotes. Traditionally the Rhodophyta has been divided in two subclasses, the paraphyletic Bangiophycidae and the monophyletic Florideophycidae. The Bangiophycidae are the ancestral pool for the more morphologically complex taxa in the Florideophycidae and from which the chromist algae chloroplasts have originated through secondary endosymbiosis. Besides their evolutionary relevance, the Rhodophyta present great economic importance, especially as human feed and phycocolloid production. Even so, the knowledge about their genome and metabolism is very restricted. DNA sequencing has significantly contributed to a better understanding of the origin and evolution of algae and their plastids, besides providing information on metabolic and physiological potentials of those organisms. To gain further insights on the origin, phylogeny and evolution of the red algae we have used molecular techniques to better understand: 1 . the origin and evolution of chloroplasts based on phylogenetic analysis and plastid genome 
sequencing; 2. the phylogeny of the Bangiophycidae; 3. the phylogeny and biogeography of Bangiales species, and the phylogeny of Gracilariaceae species, both include genera which are widespread in the world and which have considerable economic importance; and 4. sequencing of EST (Expressed Sequence Tags) from Gracilaria. The comparison of the complete plastid genome of Porphyra and Gracilaria reveals strong gene conservation, supporting a close evolutionary relationship between the Florideophycidae and the Bangiales. The monophyly of plastids in chromist algae was not recovered in analyses of the 41-protein data set, but was recovered when the relatively more slowly evolving components of the photosynthetic apparatus were used in the tree reconstructions. Gracilaria maintains a surprisingly ancient gene content in its plastid genome and together with other Rhodophyta contain the most complete repertoire of plastid genes known in photosynthetic eukaryotes. The phylogenetic data available now show a need to review the taxonomy of the Bangiophycidae, as well as of Porphyra which is polyphyletic. The data also show that the actual assemblage of south Atlantic Porphyra spp. came from different geographic regions. A group I intron used as population marker for $P$. spiralis var. amplifolia for biogeography studies indicates a colonization of the Brazilian coast from South to North. The Gracilariaceae present three lineages, a basal one including Curdiea and Melanthalia, followed by two others: Gracilariopsis and Gracilariophila; and the lineages including Gracilaria species. Gracilariopsis is a paraphyletic genus while Gracilaria is monophyletic. The sequencing of the chloroplast genome and of around 3600 EST from Gracilaria generated a large genetic dataset, which opens up a window to a better understanding of these organisms, which will certainly lead to an improved utilization of those resources. 


\section{Resumo}

A clorofila $a$ está presente em todos os organismos que liberam oxigênio durante a fotossíntese. O desenvolvimento dessa molécula alterou a atmosfera terrestre causando um grande impacto na história do planeta, redirecionando a evolução da vida. A fotossíntese com liberação de oxigênio foi desenvolvida cedo na evolução da vida por um grupo de procariotos, as cianobactérias. Essa habilidade foi posteriormente transferida lateralmente para os eucariotos pela aquisição das organelas responsáveis pela fotossíntese, os cloroplastos, através do engolfamento e retenção de uma cianobactéria de vida livre por uma célula eucariótica ancestral. Esse tipo de fusão celular, denominado de endossimbiose primária, possivelmente ocorreu apenas uma vez e deu origem a três linhagens atuais de algas (incluindo os ancestrais das plantas terrestres). Posteriormente, o aparato fotossintético foi transferido lateralmente para outras linhagens de eucariotos através de eventos independentes de endossimbiose secundária, i.e., a aquisição de cloroplastos pelo engolfamento de um eucarioto já equipado com essa organela. Esses eventos deram origem a um diverso grupo de algas contendo cloroplastos de 'segunda-mão', incluindo organismos tão distintos como as euglenófitas, dinoflagelados e as grandes algas pardas. Portanto, a história da aquisição da fotossíntese pelos eucariotos é extremamente complexa, tornando muito difícil definir de uma maneira simples as algas e discriminá-las de outros organismos. Dados atuais apóiam a idéia de que a aquisição dos cloroplastos é possivelmente um evento raro e, portanto, um único evento primário de endossimbiose seguido por alguns poucos eventos ancestrais secundários explicariam toda a atual diversidade de plastos.

O filo Rhodophyta é uma das três linhagens que se originaram a partir do evento de endossimbiose primária e é uma das principais linhagens monofiléticas dentro dos eucariotos. Tradicionalmente, Rhodophyta é dividida em duas subclasses, Bangiophycidae (parafilética) e Florideophycidae (monofilética). As Bangiophycidae formam o grupo ancestral que deu origem às Florideophycidae, grupo que apresenta uma maior complexidade morfológica e de ciclo de vida, e ao cloroplasto das algas cromófitas através de endossimbiose secundária. Além de sua importância evolutiva, as Rhodophyta apresentam grande importância econômica, principalmente como alimento humano e produção de ficocolóides. Mesmo assim, o conhecimento que temos do genoma e do metabolismo das Rhodophyta é ainda muito restrito. O seqüenciamento de DNA tem contribuído significativamente para um maior entendimento da origem e evolução das algas e seus cloroplastos, além de trazer informações sobre o potencial metabólico e fisiológico desses organismos. Apesar do interesse econômico de algumas espécies e da grande importância evolutiva do grupo, as Rhodophyta, especialmente as 
Bangiophycidae, são relativamente pouco estudadas. Nosso grupo de pesquisa e colaboradores tem usado técnicas moleculares para diferentes tipos de análises, incluindo: 1. a origem e evolução dos cloroplastos baseado em análises filogenéticas e seqüenciamento genômico do cloroplasto; 2. a filogenia das Bangiophycidae; 3. a filogenia e biogeografia de espécies de Bangiales e filogenia de espécies de Gracilariaceae, ambos incluem gêneros de grande importância econômica e distribuição geográfica mundial; e 4. seqüenciamento de EST ('Expressed Sequence Tags') de Gracilaria. A comparação dos genomas completos dos cloroplastos de Porphyra e Gracilaria revela uma ampla conservação tanto na ordem quanto na seqüência dos genes, indicando uma relação evolutiva próxima entre as Bangiales e as Florideophycidae. A monofilia dos plastos nos cromistas não foi recuperada usando uma matriz com 41 proteínas, mas sim quando seqüências de proteínas que evoluem mais lentamente, como as do aparato fotossintético, foram utilizadas nas análises. Surpreendentemente, Gracilaria mantém um genoma plastidial com uma organização bastante ancestral considerando-se seu conteúdo gênico e, juntamente com outras Rhodophyta, possui um dos mais completos repertórios de genes plastidiais dentro dos eucariotos fotossintetizantes. Análises filogenéticas indicam a necessidade de rever a taxonomia das Bangiophycidae, assim como dos gêneros Porphyra e Bangia. Essas análises também mostram uma origem diversa a partir de diferentes regiões geográficas para as espécies de Porphyra do Atlântico Sul. Além disso, um intron do grupo I foi usado como marcador populacional para P. spiralis var. amplifolia para estudos de biogeografia e corroboram uma colonização da costa brasileira a partir do Sul e em direção ao Norte. As Gracilariaceae apresentam três linhagens, uma basal contendo os gêneros Curdiea e Melanthalia, seguida das duas outras linhagens: Gracilariopsis e Gracilariophila; e a linhagem contendo as espécies de Gracilaria. Gracilariopsis é um gênero parafilético enquanto que Gracilaria se apresenta monofilético. O seqüenciamento do genoma do cloroplasto e de cerca de 3600 EST de Gracilaria gerou uma enorme quantidade de informação genética, abrindo caminho para um melhor conhecimento desses organismos, o que certamente terá reflexos em sua melhor utilização. 


\section{Apresentação}

Hoje está bem estabelecido que o termo alga não apresenta nenhum sentido taxonômico ou filogenético, mas é apenas um coletivo que abrange linhagens muito diversas de organismos. Em conseqüência, a disciplina conhecida tradicionalmente como Ficologia é o ramo da biologia que congrega a maior diversidade de filos incluindo grupos de dois dos três domínios de seres vivos (Eubacteria e Eucaria). Mesmo assim, a Ficologia segue como um ramo coeso dentro da ciência, não somente devido à tradição, mas também à certas características que, a despeito de toda a diversidade filogenética apontada, reúne sob um denominador comum a maioria dos organismos que convencionalmente ainda chamamos de algas. A principal dessas características é a ocorrência universal da fotossíntese baseada em clorofila $a$, embora nem tudo que faça fotossíntese seja denominado de alga (e.g. embriófitas) e nem toda alga faça fotossíntese. Uma outra característica comum é a vida no ambiente aquático, seja de água doce ou salgada, embora também aqui existam exceções.

Dentre os vários grupos de algas, três são mais amplamente reconhecidos e tradicionalmente designados pela sua cor predominante: as algas vermelhas, as verdes e as pardas. Quando vamos à praia e observamos num costão rochoso esses três grupos crescendo lado a lado, freqüentemente com morfologias semelhantes, é surpreendente saber que se tratam de três grupos filogeneticamente muito distantes, cuja divergência remonta a possivelmente mais de um bilhão de anos. Devido a essa ampla diversidade de linhas filogenéticas distintas, associada à dificuldade de estabelecer relações evolutivas entre essas linhagens baseando-se apenas em caracteres ditos 'tradicionais' (e.g. morfologia, anatomia, ciclos de vida etc.), os ficólogos têm-se utilizado de forma crescente de técnicas de análises da ultraestrutura celular e de filogenia baseada em dados moleculares para tentar entender como as várias linhagens de algas estão relacionadas entre si e com os demais grupos de organismos.

Estima-se que as algas marinhas são responsáveis por cerca de metade da fotossíntese do planeta, sendo, conseqüentemente, importantes produtores do oxigênio atmosférico e consumidoras do dióxido de carbono, contribuindo assim para minorar o efeito estufa no planeta. As algas têm, portanto, um papel crucial no balanço de gases da atmosfera. A fotossíntese nas algas eucarióticas é realizada em organelas celulares especializadas denominadas de cloroplastos. Os organismos fotossintetizantes eucarióticos apresentam uma grande diversidade de cloroplastos que diferem em sua forma, ultraestrutura e pigmentação. Entender as origens e as relações das diferentes linhagens de organismos fotossintéticos e de seus cloroplastos é um importante problema da biologia evolutiva. 
A evolução dos eucariotos fotossintetizantes e a origem dos seus cloroplastos têm sido alvos de intensa pesquisa, a qual foi significativamente impulsionada pelo desenvolvimento de métodos moleculares nos tempos atuais. Neste trabalho serão discutidos, baseado principalmente em dados moleculares com especial destaque aos obtidos por nosso grupo de pesquisa, diferentes aspectos da origem e evolução das algas com ênfase nas algas vermelhas (Rhodophyta). Além disso, será discutido de que forma ferramentas moleculares selecionadas podem ser utilizadas desde análise de populações, até para o esclarecimento de relações evolutivas amplas como as que existem entre filos.

As Rhodophyta têm sido alvo de nossa atenção porque constituem um grupo peculiar de organismos que ocupa uma posição chave na árvore evolutiva dos organismos eucarióticos, além de serem ainda muito pouco estudadas em seus aspectos evolutivos. Dentre as Rhodophyta selecionamos para as principais análises um representante de cada subclasse: no caso das Bangiophycidae foi selecionado o gênero Porphyra e dentre as Florideophycidae optamos pelo gênero Gracilaria. Ambos os gêneros são muito diversificados, amplamente distribuídos em termos globais e apresentam grande importância econômica.

Embora esse trabalho contemple muito mais os aspectos acadêmicos ligados à evolução das algas, com reflexos na taxonomia tradicional, os gêneros alvo de nossa pesquisa abrigam as espécies de algas de maior significado econômico em todo o mundo. 0 gênero Porphyra, que junto com outras algas usadas na indústria de alimento movimentam cerca de 3-5 bilhões de dólares por ano [77], e o gênero Gracilaria, matéria prima para a indústria do ágar, a qual também é responsável por uma indústria que rende mais de cem milhões de dólares por ano. Dentre os subprodutos dos estudos moleculares que realizamos estão, além da contribuição para esclarecer problemas taxonômicos de ambos os gêneros, notoriamente reconhecidos como muito difíceis de identificar, a viabilização da produção de espécies transgênicas de algas de valor comercial, e também a possibilidade de fornecer pistas sobre a origem de espécies criptogênicas (i.e. espécies de origem desconhecida). Este último aspecto é hoje bastante relevante porque permite detectar a presença de espécies exóticas introduzidas voluntária ou involuntariamente, assunto de pesquisa atual em todo o mundo e motivo de grande preocupação no Brasil (Projeto PROBIO, Min. Meio Ambiente, 2005). 


\section{As diferentes linhagens filogenéticas de algas eucarióticas.}

As algas eram tradicionalmente tidas como seres fotossintetizantes mais 'simples ou primitivos' que apresentam clorofila $a$ e a partir dos quais surgiram as plantas terrestres consideradas mais 'complexas' e coletivamente conhecidas como embriófitas ${ }^{2}$ (briófitas e plantas vasculares). Este conceito de algas era suficientemente amplo para incluir organismos extremamente distintos como procariotos e eucariotos. De modo geral, as algas eram supostamente unidas pelo fato de fazerem fotossíntese com desprendimento de oxigênio, apresentarem um talo simples e viverem predominantemente no ambiente aquático. Entretanto, agora está claro que a fotossíntese, per se, não pode ser considerada como um marcador inequívoco de uma maior proximidade evolutiva. Hoje sabemos que dentro dos eucariotos algumas linhagens de algas são relacionadas geneticamente às plantas terrestres, enquanto que outras são mais proximamente relacionadas a linhagens de organismos não fotossintetizantes.

A clorofila $a$ está presente em todos organismos que liberam oxigênio durante o processo de fotossíntese. O surgimento dessa molécula alterou a atmosfera terrestre causando um enorme impacto e redirecionou a história evolutiva da vida no planeta (Anexo 3, item 2.5.2). A fotossíntese baseada na clorofila $a$ com desprendimento de oxigênio foi desenvolvida cedo na história da vida por um grupo de procariotos, as cianobactérias que formam uma linhagem bem definida dentro das eubacteria Gram-negativas $[51,52,120]$. A molécula de clorofila $a$ e os sistemas químicos e fotoquímicos a que está associada são muito complexos para terem surgido independentemente mais de uma vez na história evolutiva dos seres vivos. Posteriormente, essa capacidade foi transferida lateralmente para os eucariotos através do engolfamento e retenção de uma cianobactéria de vida livre, a qual deu origem às organelas fotossintetizantes denominadas de cloroplastos, ou mais simplesmente de plastos. Esse tipo de fusão celular foi denominado de endossimbiose primária e gerou cloroplastos envolvidos por duas membranas que são descendentes diretos das cianobactérias, as quais se adaptaram completamente à condição de endossimbionte de uma célula hospedeira eucariótica (Figura 2.6, Anexo 3; Figura 1, Anexo 11). Após esse evento primário, o aparato fotossintético foi transferido lateralmente várias vezes em eventos que foram denominados de endossimbiose secundária, i.e., a aquisição de cloroplastos por um eucarioto através do engolfamento de outro eucarioto que já os possuía devido à endossimbiose primária [4]. Esses eventos secundários deram origem a distintas linhagens de algas que incluem organismos muito diferentes como as euglenófitas, os dinoflagelados e as algas pardas, entre outros. Portanto, a

\footnotetext{
${ }^{2}$ os nomes em português dos diferentes grupos foram utilizados seguindo a tradução do livro de Margulis e Schwartz [70] e Plastino et al. [102]
} 
história da aquisição da fotossíntese pelos eucariotos é extremamente complexa não tendo sentido o esforço de se tentar definir, de maneira puramente artificial, e discriminar de outros organismos, o grupo que era tradicionalmente designado como alga [101].

Em 1836, Harvey separou as algas em quatro grandes grupos, as marrons que ele denominou de Melanospermae, as vermelhas, Rhodospermae, as verdes, Chlorospermae e as diatomáceas [14]. Não está claro se Harvey tinha conhecimento da grande relevância dos diferentes tipos de pigmentos na separação dos grandes grupos de algas, ou se foi apenas uma inspiração bem sucedida de um observador arguto. Na Tabela 1 (Anexo 11) estão listados os grupos atuais que possuem plastos incluindo as plantas terrestres (que são uma linhagem adaptada ao ambiente terrestre, proveniente das algas verdes [63]), e alguns protistas heterotróficos que possuem plastos não funcionais e nunca foram considerados como algas. Esse grupo, denominado de apicomplexa, é composto por parasitas intracelulares, incluindo os agentes causadores da malária e da toxoplasmose, e possuem um plasto peculiar, altamente reduzido denominado de apicoplasto [41]. Além disso, é preciso salientar que a literatura recente sugere que vários protistas heterotróficos que não possuem cloroplastos provavelmente evoluíram a partir de ancestrais fotossintetizantes [3], estendendo significativamente o âmbito da evolução das algas e tornando-o indissociável da filogenia global dos eucariotos.

Devido à constituição frágil do talo da maioria das algas seu registro fóssil é extremamente incompleto e, quando presente, difícil de interpretar. Portanto, hipóteses evolutivas têm que ser inferidas comparando-se os grupos atuais. O surgimento de técnicas de microscopia eletrônica e de biologia molecular na segunda metade do século 20 revolucionou a nossa visão de evolução e diversidade. Apesar disso, algumas descobertas visionárias foram feitas usando-se apenas um simples microscópio, como a proposição da endossimbiose para origem de cloroplastos e mitocôndrias feitas por pesquisadores como Schimper [110], Mereschkowski [78] e Altmann [1]. Estudos bioquímicos também geraram dados muito relevantes, como a descrição dos diferentes tipos de pigmentos fotossintetizantes, a composição da parede celular e dos produtos de reserva, entre outros, que foram utilizados para refinar e caracterizar os diferentes grupos de algas e tentar estabelecer possíveis relações evolutivas entre eles.

Dados de ultraestrutura e bioquímica abriram uma janela para relações evolutivas, desconhecidas até então, entre linhagens de eucariotos fotossintetizantes e linhagens heterotróficas e confirmam algumas hipóteses evolutivas levantadas previamente. Por exemplo, a relação evolutiva próxima entre as algas verdes e as plantas terrestres, formando o que hoje é 
denominado de Viridiplantae, [20, 23], ou entre as euglenófitas e os Kinetoplastida, formando o que hoje é denominado de euglenozoa [32]. Além disso, foi reconhecido que muitos grupos de algas com clorofilas $a$ e $c$ geralmente classificadas em grupos separados (i.e. algas pardas, diatomáceas e crisofíceas sensu lato), assim como alguns protozoários (e.g. opalinídeos, bicosoecídeos, proteromônadas) e alguns grupos semelhantes aos fungos (e.g. oomicetos, hifoquitrídeos, labirintulídeos), são proximamente relacionados e possuem células heterocontes (células com dois flagelos dissimilares, um liso e outro plumoso). Este agrupamento grande e diverso, presumivelmente monofilético foi denominado de Heterokonta [22] ou Estramenópilas [100] e é atualmente considerado uma das principais linhagens dentro dos eucariotos.

Seguindo o desenvolvimento da ultramicroscopia ocorreu o desenvolvimento das técnicas de biologia molecular, as quais permitiram a manipulação direta dos ácidos nucléicos (DNA e RNA) e proteínas. Dentre essas técnicas, duas metodologias fundamentais abriram o caminho para o uso de marcadores moleculares para reconstruções filogenéticas, o seqüenciamento de DNA na década de 1970 [109] e a PCR ('Polymerase Chain Reaction') na década de 1980 [108]. Um enorme progresso nos estudos de filogenia de seres vivos foi obtido através da comparação de seqüências homólogas de nucleotídeos em diferentes organismos (Anexo 4). Moléculas de DNA são compostas por seqüências de nucleotídeos cujas posições homólogas podem ser comparadas em organismos diferentes, auxiliando na resolução de problemas taxonômicos e evolutivos. Atualmente o seqüenciamento genético é a técnica mais poderosa para ajudar a esclarecer as relações filogenéticas entre os organismos, tendo tido um grande impacto nas ciências biológicas. Seqüências moleculares fornecem uma fonte rica e independente de dados, com os quais podem ser testadas hipóteses desenvolvidas a partir de outros tipos de informações.

Dentre os vários genes utilizados em análises filogenéticas os genes ribossomais (rDNA) e suas regiões espaçadoras têm contribuído significativamente para um maior entendimento da macro e microbiodiversidade, principalmente nas algas (Anexo 4). Entretanto, de acordo com o grupo, diversos outros marcadores moleculares também têm sido analisados. Os primeiros estudos foram justamente baseados na comparação do gene que codifica para o RNA da subunidade pequena do ribossomo (SSU rDNA; Figura 1, Anexo 4). As árvores filogenéticas geradas para o SSU rDNA foram estabelecidas como um modelo para a evolução global dos procariotos [121] e eucariotos [113]. Nesse modelo, os eucariotos apresentavam um eixo ou 'tronco' basal do qual irradiavam algumas linhagens de protistas, e uma 'coroa' ou 'copa' ('crown group') que incluía os fungos, animais e plantas juntamente com outras linhagens de protistas. Vários protistas amitocondriados (diplomônadas, 
microsporídeos e parabasalídeos) estavam entre as linhagens basais dando suporte a hipótese dos arquezoa [21], que prevê que esses grupos se diversificaram antes da aquisição da mitocôndria por endossimbiose (Figura 2.4, Anexo 3). Entretanto, a posição dessas linhagens amitondriadas nas árvores de SSU rDNA não foi corroborada por seqüências de genes codificantes para proteínas [e.g. 16, 38, 59, 106]. Essas e outras discrepâncias estimularam um período intenso de revisionismo que levou a novos modelos para explicar a evolução dos eucariotos, baseados em bancos de dados maiores e mais completos, incluindo um número maior de táxons e análises multigênicas $[$ e.g. 6, 8, 79, 125]. Além disso, o avanço no conhecimento de alguns eventos genômicos raros e possivelmente irreversíveis, como duplicações, substituições ou fusões de genes que podem ser usados como marcadores [e.g. $[40,56,99,114]$, assim como o avanço na genômica comparativa $[34,72]$ levaram à produção de um cenário mais plausível para a evolução dos eucariotos. Nesse cenário, a maioria dos grupos também apresenta o apoio de dados de ultraestrutura e em muitos casos também das seqüências de SSU rDNA. Essas análises $[$ e.g. 7, 26] mostram uma diversificação quase que simultânea, a partir de um ancestral eucariótico desconhecido, de cinco a oito super-grupos que não possuem propriamente uma hierarquia taxonômica (Figura 2, Anexo 11). Obviamente, alguns desses super-grupos apresentam-se melhor sustentados que outros, além do que, muitas outras questões e visões conflitantes ainda não estão esclarecidas [85], embora seja correntemente aceito que a evolução dos eucariotos foi um evento explosivo [34]. A Figura 2 (Anexo 11) também mostra um possível cenário para a aquisição de cloroplastos. Esse espalhamento dos cloroplastos via transferência lateral parece ter sido um fator preponderante na evolução dos eucariotos uma vez que, se considerarmos os cinco super-grupos, quatro deles possuem linhagens fotossintetizantes.

Na Figura 2 (Anexo 11) podemos observar cinco super-grupos principais: 1. Unicontes, não possuem nenhuma linhagem fotossintetizante conhecida, incluem dois grupos os opistocontes (fungos, animais e protistas relacionados) que possuem um flagelo basal em células reprodutivas e cristas mitocondriais achatadas, e os amebozoa (mixomicetos, amebas e outros organismos relacionados) que são principalmente amebas com pseudópodos lobosos e sem testas; 2. Excavados, podem apresentar uma fenda alimentar e se dividem basicamente em dois grupos, os excavados que não apresentam mitocôndrias (diplomônadas, retortomonas, etc.) e os discicristados (euglenófitas, tripanossomatídeos, etc.) que apresentam cristas mitocondriais discóides; 3. Rizária ou Cercozoa (foraminíferos, cercomonadas, cloraraquiniófitas, etc.), são amebas com pseudópodos filosos e freqüentemente apresentando testas; 4. Plantas, seriam derivadas do evento de endossimbiose primária, apresentando 
portanto cloroplastos envoltos por duas membranas; incluem as Viridiplantae (algas verdes e embriófitas), as Rhodophyta (algas vermelhas) e as Glaucophyta; 5. Cromoalveolados, suas linhagens fotossintetizantes apresentam clorofila $a$ e $c$ (freqüentemente chamadas de cromófitas), incluem os alveolados (ciliados, dinoflagelados e apicomplexa) que apresentam um sistema de alvéolos logo abaixo da membrana plasmática, e os cromistas que incluem os heterocontes (algas pardas, diatomáceas, crisofíceas, oomicetos, labirintulomicetos, etc.), também chamados de estramenópilas, além das Haptophyta e as Criptophyta, que possivelmente também fazem parte desse grupo.

\section{Origem e diversificação dos cloroplastos.}

Uma questão central na origem e evolução dos organismos fotossintéticos é o cloroplasto. Esta organela, além de fazer a fotossíntese, tem outras importantes funções como a participação na biossíntese de ácidos graxos, isoprenóides, carotenóides, hemes e diversos aminoácidos, e na redução de nitrito a amônia, entre outras [47]. Existem diferentes tipos de plastos em relação à pigmentação, incluindo os 'cloroplastos' ${ }^{3}$ das algas verdes e plantas terrestres (com clorofilas $a$ e $b$ ), os 'rodoplastos' das algas vermelhas (com clorofilas $a$ e ficobiliproteínas) e os 'cromoplastos' das cromófitas (grupos cujos plastos apresentam clorofilas $a \mathrm{e} c$ ). Além disso, existem também os plastos não pigmentados como os leucoplastos e amiloplastos das plantas terrestres e os plastos reduzidos encontrados em algumas algas heterotróficas (e.g. na euglenófita Astasia) e nos apicomplexa. Além das diferenças bioquímicas e funcionais, os plastos dos diferentes grupos apresentam também diferenças na sua ultraestrutura em relação à disposição e arranjo das lamelas fotossintetizantes, os tilacóides, e ao número de membranas que os circundam o que se acredita ser resultado do tipo de endossimbiose que deu origem àquele plasto. A presença de duas membranas nesses plastos primários tem sido explicada de diferentes maneiras [47]. A explicação mais tradicional diz que a membrana mais interna seria originada do plasmalema do endossimbionte, enquanto que a mais externa seria originada do fagossomo da célula hospedeira. Uma explicação alternativa é que ambas as membranas do cloroplasto representam a dupla membrana típica de bactérias Gram-negativas, e assume que o fagossomo foi perdido.

\footnotetext{
${ }^{3}$ o termo cloroplasto aqui se refere a plastos contendo pigmentação específica, i.e. clorofilas a e b; além das clorofilas, os plastos apresentam diversos outros pigmentos acessórios (e.g. carotenóides) cujas quantidades e tipos variam de acordo com o grupo de organismos.
} 
A idéia de que os plastos são cianobactérias endossimbiontes extremamente reduzidas não é nova. Essa idéia foi proposta há mais de um século por Schimper [110] e Mereschkowski [78] e a partir da década de 1970 ganhou apoio de dados de ultraestrutura e da biologia molecular (item 2.5.2 no Anexo 3; para uma revisão histórica ver $[47,76]$ ). Da mesma maneira, a origem da mitocôndria a partir de um evento de endossimbiose com uma $\alpha$ proteobacteria foi proposta por Altmann em 1890 [1], e atualmente também está apoiada em diversas evidências [50]. Em ambos os casos o genoma dos endossimbiontes sofreu uma dramática redução em tamanho e conteúdo de genes levando à dependência do endossimbionte da célula hospedeira. A maioria das proteínas necessárias para o funcionamento dos plastos são codificadas no núcleo da célula hospedeira; isso se deu através de uma maciça transferência lateral de genes do genoma do endossimbionte para o núcleo (Figura 1, Anexo 11; [71]). Os produtos dos genes plastidiais que migraram para o núcleo são expressos no citoplasma e direcionados aos plastos pela adição pós-traducionalmente de peptídeos de trânsito na região N-terminal da proteína [27, 75]. Esses peptídeos de trânsito são reconhecidos por proteínas translocadoras específicas (complexos TICs e TOCs) nas membranas dos plastos [58]. Dados recentes indicam que a aquisição de cloroplastos é um evento relativamente raro, dada a enorme complexidade do sistema, e que uma única endossimbiose primária seguida de algumas poucas endossimbioses secundárias provavelmente teriam gerado toda a diversidade de plastos observada nos grupos atuais [10, 25]. Uma consequiência das aquisições de plastos ocorrendo cedo na evolução dos eucariotos é que múltiplos eventos independentes de perda desses plastos ocorreram em diferentes linhagens que divergiram posteriormente, mas que ainda podem conter em seus genomas genes provenientes do genoma plastidial.

Uma vez ocorrida a endossimbiose, existe um contato próximo entre genomas com origens distintas, facilitando eventos de transferência lateral de material genético. Transferência lateral, assim como perda e substituição de genes são provavelmente eventos randômicos, mas parece existir um certo direcionamento, já que o núcleo da célula hospedeira tende a receber genes do endossimbionte, enquanto que o genoma desses tende a perder genes [12]. Uma possível explicação para essas tendências opostas dos genomas do hospedeiro e do endossimbionte é que o núcleo seria um 'ambiente' mais estável geneticamente, e portanto menos sujeito às ocorrências de perdas e rearranjos. É interessante notar que esse processo de transferência de genes leva a uma dependência parcial do endossimbionte pela célula hospedeira, e é provavelmente essencial para a manutenção da associação endossimbiótica. Os genomas dos cloroplastos, assim como o das mitocôndrias, são altamente reduzidos ( 34 a 
200 mil pares de base, Tabela 1, Anexo 8) se comparados aos de cianobactérias atuais ( 1.7 to 9 milhões de pares de base) [http://www.ncbi.nlm.nih.gov/].

O evento de endossimbiose primária deu origem à uma célula eucariótica fotossintetizante ancestral a partir da qual surgiram três linhagens atuais e bem definidas dentro dos eucariotos, que possuem plastos simples (envoltos por duas membranas): as Chlorophyta (algas verdes, incluindo o ancestral da plantas terrestres), as Rhodophyta (algas vermelhas) e um pequeno grupo de algas unicelulares flageladas as Glaucophyta (Tabela 1, Anexo 11; Figura 1, Anexo 1; [98]). Todas as demais linhagens fotossintetizantes adquiriram plastos através do engolfamento não de uma cianobactéria, mas sim de um outro eucarioto fotossintetizante (Figura 3, Anexo 11). As glaucófitas (também referidas como glaucocistófitas) são um pequeno grupo de algas unicelulares, flageladas e de água doce, cujos plastos fornecem um convincente conjunto de evidências para sua origem a partir de cianobactérias. Os plastos desse grupo são chamados de 'cianelas' por terem mantido uma fina camada de peptidoglicano (o principal componente do envelope celular das cianobactérias) entre as duas membranas do plasto e um corpo central que se assemelha a um carboxissomo, uma organela típica de cianobactérias [64]. Além disso, as cianelas, assim como os plastos da algas vermelhas, apresentam pigmentos típicos de cianobactérias (clorofila $a$ e ficobilinas) e tilacóides isolados com grânulos de ficobilinas (ficobilissomas). Em ambos os grupos, glaucófitas e algas vermelhas, os genomas plastidiais, apesar de serem bastante reduzidos, se comparados aos genomas das cianobactérias, contém o maior repertório de genes encontrados nessas organelas nas diferentes linhagens já analisadas [Tabela 1, Anexo 8]. Na linhagem das Viridiplantae, os cloroplastos se distinguem das cianobactérias pela ausência de ficobilinas e de tilacóides empilhados dentre outros atributos. Mesmo assim esses cloroplastos mantiveram outras características típicas de cianobactérias como genes envolvidos na formação da camada de peptidoglicano, dentre outras [118].

Atualmente as principais questões em relação à origem endossimbiótica dos cloroplastos são: quantas vezes esse processo ocorreu e quem foram os parceiros nos diferentes eventos [36, 97, 98]. A pigmentação diferencial encontrada nas algas verdes e nas algas vermelhas/glaucófitas sugere origens a partir de eventos de endossimbiose distintos para esses grupos (o cenário polifilético). Entretanto, algumas características conservadas em todos os cloroplastos, e consideradas extremamente complexas para terem surgido e se fixado independentemente mais de uma vez, como por exemplo o sistema de endereçamento de proteínas, sugerem uma única origem primária [97]. Além disso, a maior parte dos dados moleculares, especialmente dados obtidos dos genomas dos cloroplastos, indicam uma origem 
monofilética (Figura 1, Anexo 1). Praticamente todas as seqüências de genes plastidiais comparadas individualmente, como SSU rDNA [e.g. 9, 120], tufA, atpB, rpoC1 e psbA [97], assim como dos genes que codificam para proteínas que compõem a antena de captação de luz [37, 122], consistentemente indicam uma origem única para os plastos primários das algas verdes e vermelhas, formando um clado único e robusto dentro das cianobactérias. Os únicos genes que contam uma história diferente são os $r b c \mathrm{~L}$ e $r b c \mathrm{~S}$ que codificam respectivamente para as subunidades grande e pequena da ribulose 1,5-bifosfato carboxilase/oxigenase (RuBisCO). Entretanto, esses genes sofreram de múltiplas duplicações e transferências laterais, e não são bons marcadores para divergências muito antigas [35]. Infelizmente, as análises multigênicas disponíveis $[71,72,118]$ incluem apenas um representante de cianobactéria e portanto, não são informativas sobre o número de eventos. Outras características dos plastos, como as repetições invertidas que contém os genes codificantes para os rRNA e dois agrupamentos de genes ( $p s b \mathrm{~B} / \mathrm{N} / \mathrm{H}$ e atp/rps/rpo) presentes na maioria dos plastos primários, mas ausentes nas cianobactérias, são interpretadas como características derivadas após o evento de endossimbiose sugerindo uma única origem para os plastos [97]. Adicionalmente, a maquinaria de importação de proteínas que apresenta o mesmo mecanismo geral em todos os plastos [75], também sugere uma origem monofilética para eles. Os peptídeos de trânsito das glaucófitas, das algas vermelhas e das algas verdes podem ser trocados entre os plastos sem perda significativa de função [116]. Por outro lado, as similaridades do conteúdo gênico, uma evidência freqüentemente assumida favorecendo a monofilia dos plastos, foi recentemente posta em dúvida uma vez que essa similaridade é consistente com um processo de convergência [117]. O evento de endossimbiose primária é bastante antigo ( 1,6 bilhões de anos [126]) o que torna extremamente difícil recuperar sua história evolutiva. De maneira geral, mais dados apóiam uma origem única, apesar de que o cenário alternativo de origens múltiplas a partir de cianobactérias proximamente relacionadas não pode ser completamente descartado.

Entretanto, neste ano (2005) foram apresentados dados convincentes de pelo menos mais um evento de endossimbiose primária independente do que deu origem às três linhagens mencionas acima [83]. Paulinella chromatophora é um cercozoa (uma ameba com testa) cuja célula contem duas cianelas. Não é possível cultivar estas cianelas quando isoladas e elas se dividem dentro da célula hospedeira sendo herdadas verticalmente. Essas observações sugerem que essas cianelas são organelas e não cianobactérias endossimbiontes. Sequiências do SSU rDNA das cianelas foram analisadas e mostram que essas cianelas não são relacionadas aos 
demais cloroplastos, mas sim ao gênero de cianobactéria Synechococcus e à proclorófita Prochlorococcus [83].

\subsection{Endossimbiose secundária: origem dos plastos complexos.}

A inovação biológica que deu origem aos eucariotos fotossintetizantes não ficou limitada às linhagens primárias. Outras linhagens de eucariotos adquiriram seus plastos secundariamente engolfando um eucarioto já fotossintetizante. Essa simbiogênese secundária é responsável por grande parte da diversidade algal [10] incluindo os plastos complexos (i.e. plastos envoltos por mais de duas membranas) de euglenófitas, algas heterocontes, dinoflagelados, haptófitas, criptófitas e cloraraquiniófitas (Figura 3, Anexo 11). Além disso, também existem plastos de origem secundária no grupo irmão dos dinoflagelados, os apicomplexa (Tabela 1, Anexo 11). A principal característica que indica uma origem secundária é o número de membranas ao redor desses plastos: três membranas ao redor dos plastos das euglenófitas e dos plastos da maioria dos dinoflagelados, e quatro membranas ao redor dos plastos do demais grupos. Essas membranas extras seriam resultado do engolfamento do eucarioto fotossintetizante por um fagossomo, e sua posterior retenção e redução, sendo as duas membranas mais internas remanescentes do envelope duplo do plasto primário; a terceira membrana seria correspondente à membrana plasmática do eucarioto endocitado e a quarta membrana provavelmente corresponde originalmente ao fagossomo produzido pela célula hospedeira (Figura 1d-f, Anexo 11). Os plastos com apenas três membranas poderiam ter se originado a partir da perda de uma das membranas [24, 27].

Um evento de endossimbiose secundária implica na aquisição simultânea pela célula hospedeira de três genomas distintos (do núcleo, da mitocôndria e do cloroplasto provenientes do organismo fagocitado). Nesse processo de endossimbiose ocorre uma maciça transferência de genes para o núcleo da célula hospedeira e redução do genoma do endossimbionte. Isso implica na evolução de um sistema de endereçamento e transporte de proteínas direcionadas ao cloroplasto através de três ou quatro membranas ao redor dessas organelas. A tomada de uma célula eucariótica como endossimbionte é mais aparente em dois grupos: as criptófitas e as cloraraquiniófitas, uma vez que o plasto dessas algas ainda retém um núcleo eucariótico vestigial denominado de nucleomorfo (Figura 1e, Anexo 11).

Os eucariotos que possuem plastos complexos são tão diversos quanto seus plastos, que teriam se originado por múltiplos eventos de endossimbiose secundária. Os plastos de origem secundária podem ser divididos em dois grandes grupos: 1) aqueles derivados das algas verdes, que contêm clorofilas $a$ e $b$ como pigmentos principais e que estão presentes nas 
euglenófitas e nas cloraraquiniófitas, e 2) aqueles derivados das algas vermelhas, que incluem as criptófitas cujos plastos mantiveram as ficobilinas mais um pigmento típico de eucariotos, a clorofila $c$, que teria aparecido apenas após a endossimbiose primária, além dos demais grupos que perderam as ficobilinas, mas mantiveram as clorofilas $a$ e $c$ (Tabela 1, Figura 3, Anexo 11). A origem do plasto não pigmentado dos apicomplexa é ainda bastante controversa, mas a hipótese mais aceita postula que esses plastos são derivados de algas vermelhas (Figura 1, Anexo 1; [98]).

Apesar de existir uma certa segurança em afirmar se um cloroplasto complexo derivou de um evento de endossimbiose com uma alga verde ou vermelha, o número de eventos independentes é ainda bastante controverso. Alguns autores argumentam que um processo complexo como esse seria muito 'oneroso' do ponto de vista evolutivo e, portanto, seriam eventos extremamente raros [23, 24, 27]. O cenário mais parcimonioso sugere apenas dois eventos secundários, um a partir de uma alga verde e outro a partir de uma alga vermelha [24]. Entretanto, o cenário que a maior parte dos dados apóia é o com três eventos separados. Dois eventos seriam a partir de algas verdes [10], um dando origem ao plasto das euglenófitas [e.g., 55; 73] e outro dando origem ao plasto das cloraraquiniófitas [48, 5]. Análises filogenéticas que fizemos do SSU rDNA de uma ameba filosa não fotossintetizante agruparam de maneira consistente este organismo na base das cloraraquiniófitas indicando que o evento de endossimbiose secundária que deu origem ao cloroplasto desse grupo tenha ocorrido posteriormente (Anexo 2). O terceiro evento seria a partir de uma alga vermelha dando origem ao plasto das criptófitas, algas heterocontes, haptófitas, dinoflagelados e apicomplexa [4, 10, 60] e teria ocorrido à cerca de 1,2 bilhões de anos atrás [126].

Além da endossimbiose secundária, existem dados demonstrando para os dinoflagelados a endossimbiose terciária onde um eucarionte toma como plasto um outro eucarionte contendo plasto secundário (ver Anexo 11 para uma revisão).

\subsection{Plastos secundários da linhagem vermelha.}

As algas vermelhas deram origem, através de endossimbiose secundária, aos cloroplastos que contém clorofila $c$. Entretanto, o número de eventos que deu origem às diferentes linhagens permanece controverso. Não está claro se estes cloroplastos surgiram a partir de eventos múltiplos de endossimbiose entre algas vermelhas e diferentes células hospedeiras, ou se todas estas linhagens têm um ancestral comum que surgiu da endossimbiose entre uma alga vermelha e uma célula hospedeira. Devido à presença de clorofila $c$ nos Chromista (criptófitas, haptófitas, e estramenópilas) e nos 
Alveolata (dinoflagelados), Cavalier-Smith [22] propôs a hipótese de que os cromalveolados constituem um grupo monofilético. 0 plasto de um cromalveolado teria sido originado a partir de um único evento de endossimbiose secundária, após o qual houve o surgimento de clorofila $c$ [125]. Este cenário, entretanto, necessita ainda da corroboração da análise de genes nucleares da célula hospedeira [10]. Considerando-se a hipótese dos cromalveolados, os plastos teriam sido perdidos na linhagem dos ciliados e nas linhagens de estramenópilas não fotossintetizantes, como oomicetos; no caso dos apicomplexa o genoma plastidial teria sido reduzido a cerca de $35 \mathrm{~Kb}[3,76]$. As algas vermelhas, de uma maneira ou de outra, contribuíram para a origem da organela fotossintetizante de um dos ramos principais da árvore da vida.

Os Chromista são unidos primariamente com base em dados moleculares [40, 56, 125] e no fato de possuírem clorofila $c$ em um cloroplasto envolto por quatro membranas [30, 10]. Uma análise prévia por Yoon et al. [125] com ampla amostragem de táxons (36 espécies) e a seqüência de cinco genes plastidiais (5827 nt) resultou numa árvore robusta, onde quase todos os nós apresentavam suporte significativo de análises de 'Bootstrap' e Bayesiana, que mostrava a monofilia dos plastos dos Chromista a partir de uma alga vermelha basal. Entretanto, outras filogenias de genes plastidiais inferidas a partir de um número mais limitado de táxons (i.e., que não incluíam uma haptófita) não apóiam a monofilia dos Chromista [e.g. 72, 74, 88], deixando a questão em aberto.

Os desafios atuais na pesquisa sobre endossimbiose são: 1. documentar a evolução dos genomas nos diferentes plastos, 2. entender a natureza da transferência de genes para o compartimento nuclear; 3. gerar análises filogenéticas robustas a partir de múltiplos genes; 4. testar definitivamente a monofilia dos plastos secundários derivados de algas vermelhas; e 5. prover um modelo para mapear as transferências de genes e a evolução das características associadas à fotossíntese.

Com o objetivo de contribuir para um melhor entendimento de alguns dos pontos listados acima foram feitas análises que estão nos Anexos 1, 2, 5 e 8. Análises filogenéticas que fizemos usando o SSU rDNA plastidial de várias algas vermelhas, com os mesmos genes de outros grupos de algas, sugerem que as Bangiophycidae deram origem, em eventos de endossimbiose secundária múltiplos e independentes, aos cloroplastos presentes nas algas heterocontes, nas Haptophyta e nas Cryptophyta (Figura 2, Anexo 1). As análises filogenéticas com as sequiências de $r b c \mathrm{~L}$ mostram que os cloroplastos das algas heterocontes estão mais proximamente relacionados com os membros das Cyanidiales e que não estão diretamente relacionados aos cloroplastos dos grupos de algas criptófitas e haptófitas (Figura 3, Anexo 5). 
Nossos resultados baseados nesses dois genes, portanto, apontam para origens independentes para estes cloroplastos obtidos através de endossimbiose secundária de diferentes membros das Bangiophycidae.

\section{O genoma dos plastos.}

Investigações moleculares sobre os genomas plastidiais geram informações que ajudam a elucidar as relações evolutivas das diferentes linhagens de algas e os processos de endossimbiose primária e secundária envolvidos em sua origem. Sequiências de genes plastidiais têm sido usadas para determinar relações filogenéticas entre eucariotos fotossintetizantes. Entretanto, a informação obtida a partir da comparação de genes individuais é limitada, principalmente para análises mais amplas. A comparação de características genômicas, como a composição gênica, ordem dos genes (colinearidade) e análise da sequiência de diversos genes fornecem dados que permitem o estabelecimento de relações filogenéticas com maior precisão.

O genoma plastidial varia aproximadamente de 35 a 200 Kb. O número e composição de genes varia nas diferentes linhagens, assim como a presença e abundância de introns, regiões repetidas, etc. Os genomas dos cloroplastos contendo clorofila $a$ e $b$ e rodoplastos contendo clorofila $a$ e ficobilinas apresentam diferenças quanto à sua organização, apesar da sua origem comum. Essas discrepâncias foram acumuladas durante suas longas e separadas histórias evolutivas (1,5 bilhões de anos [126]). Os cloroplastos de plantas e algas verdes apresentam um conteúdo gênico bastante conservado com cerca de 110 a 118 genes, incluindo 11 genes para o complexo NADPH desidrogenase, que está ausente das demais linhagens de plastos [96]. Dentro deste grupo, a alga verde basal, Mesostigma viridae, contem o maior repertório gênico conhecido para o grupo, com 135 genes. Em contraste, os rodoplastos contém genomas plastidiais com praticamente o dobro de genes (232-251), e mesmo os plastos derivados de endossimbiose secundária nessa linhagem codificam para um número relativamente elevado de genes (Tabela 1, Anexo 8). A maioria dos cloroplastos da linhagem verde, especialmente das plantas terrestres, apresentam numerosos introns. Exceções são as algas verdes consideradas linhagens basais Mesostigma viridae e Nephroselmis olivacea. A glaucófita Cyanophora paradoxa tem apenas um intron do grupo I no gene trnL (UUA). Esse intron em trnL é considerado bastante antigo e é conservado em cianobactérias e em genomas plastidiais da linhagem verde, mas está ausente da linhagem vermelha, com exceção de algumas algas pardas, indicando que provavelmente o intron foi perdido na maioria dos táxons mas se manteve nos estramenópilas (Tabela 1, Anexo 8; [112]). A invasão e proliferação de introns 
auto-catalíticos (ver Anexo 3, pg 15-16) parece ter ocorrido secundariamente na linhagem verde e provavelmente está associada com os rearranjos substanciais observados nessa linhagem [119].

Os genomas plastidiais possuem, tipicamente, duas regiões de seqüência única e duas regiões inversamente repetidas contendo os genes que codificam para os rRNAs $(5-30 \mathrm{~kb}$; Tabela 1, Anexo 8). Entretanto, à medida que o número de genomas plastidiais seqüenciados aumenta fica patente a presença de mais e mais variações nessa organização.

Atualmente existem 721 seqüências completas de genomas mitocondriais no GenBank (julho/05, http://www.ncbi.nlm.nih.gov/genomes/ORGANELLES/organelles.html) e apenas 43 sequiências de genomas de cloroplastos, sendo 32 seqüências de plastos das Viridiplantae contendo clorofila $b$. Dentro das algas vermelhas somente as seqüências dos genomas dos plastos de Porphyra purpurea [105], Cyanidium caldarium [49] e, mais recentemente, Cyanidioschyzon merolae [88] haviam sido determinadas. Os três gêneros estão entre os grupos mais antigos de algas vermelhas (Bangiophycidae, ver abaixo). Para tentar minimizar a lacuna no conhecimento dos genomas plastidiais, principalmente em relação às Rhodophyta, propusemos o seqüenciamento do genoma plastidial de uma alga vermelha mais derivada (Florideophycidae), sendo escolhido o gênero Gracilaria.

\subsection{Seqüenciamento e análise do genoma do plasto de Gracilaria tenuistipitata.}

Após dificuldades iniciais no isolamento do DNA de cloroplastos de Gracilaria desenvolvemos uma metodologia que permitiu o isolamento de DNA de alta qualidade e com baixos índices de contaminação de DNA nuclear e mitocondrial. O desenvolvimento dessa metodologia (Anexo 7) permitiu a obtenção de bibliotecas de 'shotgun' com alto grau de pureza (89\%) e baixa contaminação com DNA nuclear e mitocondrial. A partir do seqüenciamento de clones dessas bibliotecas e de uso de PCR e 'primer walking' para fechar os buracos restantes, o genoma do cloroplasto de $G$. tenuistipitata foi completamente seqüenciado pelo nosso grupo (disponível no GenBank NC 006137; Anexo 8). A seqüência finalizada, ou seja, em que cada uma das suas bases apresenta um critério mínimo de qualidade, foi completamente anotada. O genoma circular do cloroplasto de G. tenuistipitata tem 183.883 pares de base (pb), com conteúdo GC de 29,1\% e codifica para 238 genes, incluindo os genes para tRNA e um operon único para os genes de rRNA (Figura 1, Anexo 8, http://gracilaria.ib.usp.br/mirror/gt-chloroplast/). Análises comparativas com o genoma plastidial de outra alga vermelha, Porphyra purpurea, mostraram uma grande conservação do conteúdo e colinearidade dos genes; entretanto, rearranjos genômicos e regiões específicas 
para Gracilaria foram observadas (Figura 2, Anexo 8). A maior parte dos rearranjos genômicos possivelmente está relacionada a genes de tRNA [33]; entretanto, a ausência de tRNAs em alguns pontos de quebra indicam que outros mecanismos podem estar envolvidos. Análises filogenéticas (Figura 3, Anexo 8) que incluíram a sequiência concatenada de 41 proteínas de 23 plastos e 2 cianobactérias dão suporte à monofilia dos rodoplastos e à relação evolutiva de grupos irmãos entre Florideophycidae e Bangiales (ver abaixo). A monofilia dos plastos nos cromistas não foi recuperada usando a matriz das 41 proteínas, mas sim quando seqüências de proteínas que evoluem mais lentamente, como as do aparato fotossintético, são utilizadas nas análises. Nossas análises não acabam com este debate, mas provêem uma nova percepção do comportamento de diferentes proteínas que podem ser usadas para reconstrução de árvores filogenéticas.

Surpreendentemente, Gracilaria mantém um genoma plastidial com uma organização bastante ancestral considerando-se seu conteúdo gênico e, juntamente com outras Rhodophyta, possui um dos mais completos repertórios de genes plastidiais dentro dos eucariotos fotossintetizantes (Tabela 1, Anexo 8).

A comparação que fizemos dos genomas de Porphyra e Gracilaria gerou dados sobre a evolução de cloroplastos em geral e também sobre a evolução das algas vermelhas. Comparações entre os plastos das Rhodophyta e de outras linhagens de algas ajudaram a esclarecer as relações filogenéticas entre as diferentes linhagens de cloroplastos e dos eventos de endossimbiose. Além disto, geraram informações sobre a evolução dos genomas dos cloroplastos e sobre a transferência lateral de genes; este foi, possivelmente, o caso da região do genoma contendo os genes $l e u \mathrm{C}$ e $l e u \mathrm{D}$, que podem ter se originado através da integração de um plasmídeo no genoma plastidial de Gracilaria (Anexo 8). Nossos dados também abrem a possibilidade de se usar técnicas de engenharia genética em uma espécie de Gracilaria de importância econômica [13, 46].

\section{A linhagem filogenética das Rhodophyta.}

O filo Rhodophyta, como mencionado anteriormente, constitui uma das principais linhagens monofiléticas dentro dos eucariotos e é tradicionalmente dividido em duas subclasses [61], a parafilética Bangiophycidae que possui cerca de $1 \%$ dos gêneros conhecidos de algas vermelhas e a monofilética Florideophycidae com cerca de $99 \%$ dos gêneros. As Bangiophycidae apresentam grande interesse do ponto de vista evolutivo, uma vez que formam o grupo ancestral que deu origem ao cloroplasto das algas cromófitas, possivelmente através de um único evento de endossimbiose secundária (conforme já discutido acima), e que também 
deu origem às Florideophycidae, grupo que em geral apresenta uma maior complexidade morfológica e de histórico de vida. Apesar disso, as Bangiophycidae são relativamente pouco estudadas. Para incrementar o conhecimento sobre a origem, filogenia e evolução dentro desse grupo usamos técnicas moleculares onde foram investigados: 1. origem e evolução dos cloroplastos baseado em análises filogenéticas (já discutido acima, Anexos 1 e 8); 2. filogenia de Bangiophycidae (Anexos 1 e 5); 3. filogenia e biogeografia de espécies do gênero Porphyra (Anexo 10); e 4. filogenia de espécies do gênero Gracilaria (Anexos 6 e 9).

\subsection{As subclasses Bangiophycidae e Florideophycidae.}

A subclasse Bangiophycidae é claramente parafilética, ou seja não incluí todos os seus descendentes, uma vez que a linhagem das Florideophycidae, que é claramente monofilética e derivada das Bangiophycidae, é excluída (Figura 2, Anexos 1 e Figuras 1, 2,e 3, Anexo 5). A solução mais simples seria abandonar a divisão em duas subclasses e adotar apenas a classe monofilética Rhodophyceae [44]. Uma solução alternativa seria manter a subclasse Florideophycidae e estabelecer novas subclasses dentro das Bangiophycidae de modo a manter unidades monofiléticas. Entretanto, o conhecimento das Bangiophycidae é ainda muito fragmentário e não permite que essas novas subclasses possam ser estabelecidas sem um amplo estudo, incluindo dados de diferentes naturezas, mas principalmente de ultraestrutura e de biologia molecular. Um outro problema de abandonar de vez a divisão em duas subclasses é a sua extrema praticidade, principalmente em se tratando de Florideophycidae, que além de ser monofilética, inclui grupos unidos por uma série de características de ultraestrutura, reprodução, histórico de vida, etc. Devido a sua praticidade essa divisão em duas subclasses continua sendo usada, inclusive aqui nesse texto; entretanto, deve-se ter em mente que o grupo que chamamos de Bangiophycidae inclui diversas linhagens basais de algas vermelhas, morfologicamente simples, mas geneticamente bastante distintas.

\subsection{Filogenia das ordens de Bangiophycidae.}

Ragan et al. [104] usaram seqüências de SSU rDNA nuclear para inferir a filogenia de Rhodophyta; entretanto, foram analisados apenas seis gêneros de bangiofíceas pertencentes a três ordens. Apesar dessa limitação os autores postularam que Bangiophycidae era parafilética e possivelmente incluía linhagens distintas. Nós estudamos o SSU rDNA plastidial de espécies de Bangiophycidae e de Florideophycidae (Anexo 1). Esse marcador confirmou Florideophycidae como um grupo monofilético, irmão da ordem Bangiales, também monofilética, além de confirmar a natureza parafilética de Bangiophycidae (Figura 2, Anexo 
1). Neste trabalho também já fica claro que a ordem Porphyridiales não representa um grupo monofilético, sendo composta por pelo menos três linhagens distintas, e que Cyanidiales é possivelmente uma ordem independente.

No Anexo 5 apresentamos a seqüência do SSU rDNA nuclear de várias espécies de Bangiophycidae e de duas Florideophycidae. Além disso, foram incluídas também análises para o marcador $r b c$ L. Este foi, e tem sido até o momento, o trabalho mais abrangente sobre filogenia molecular de Bangiophycidae, sendo o primeiro a incluir diversos táxons, e todas as cinco ordens. Os principais resultados obtidos mostram que nossas análises são consistentes com uma origem monofilética das Florideophycidae como grupo-irmão das Bangiales para ambos os marcadores utilizados e com apoio das análises de 'bootstrap' (Figuras 1, 2 e 3, Anexo 5). Embora este trabalho mostre que as Bangiales formam um grupo monofilético, os gêneros Bangia e Porphyra são respectivamente parafilético e polifilético. As Bangiophycidae também aparecem como um grupamento parafilético, e a ordem Porphyridiales se apresenta dividida em pelo menos três linhagens independentes (resultado semelhante ao obtido com o SSU rDNA plastidial). As Compsopogonales sensu stricto, constituída por duas famílias de ocorrência em águas continentais, Compsopogonaceae e Boldiaceae, formam um agrupamento monofilético consistente. O único táxon de Rhodochaetales, Rhodochaete parvula, está posicionado na base das Erythropeltidales. Por fim, as Cyanidiales, formam um grupo basal e distinto dentro das Rhodophyta (Figura 1 e 2, Anexo 5).

Nossos trabalhos apresentam análises com três marcadores moleculares diferentes (um nuclear e dois do cloroplasto), confirmando diversas outras análises publicadas anteriormente, além de deixar claros alguns pontos que, embora já houvessem sido mencionados na literatura, ainda eram tidos como incertos (Anexos 1 e 5). Um desses pontos é a próxima relação filogenética entre as Bangiales e as Florideophycidae, predita por Magne [69], implicando que as Bangiophycidae são um agrupamento definitivamente parafilético. A associação Bangiales/Florideophycidae encontra apoio em várias outras características como o tipo de células reprodutivas, definido por Magne [69], a associação do Complexo de Golgi com a mitocôndria [45], a presença de conexões citoplasmáticas ('pit connections') nas Florideophycidae e na fase Conchocelis das Bangiales, a presença de introns do grupo I no SSU rDNA nuclear (nas Bangiales e nas Hildenbrandiales, esta uma ordem basal dentro das Florideophycidae, [104]), e as análises com $r b c L$ [42]. Além disso, a comparação do genoma completo do cloroplasto de Porphyra (Bangiales) e Gracilaria (Gracilariales, ordem derivada dentro das Florideophycidae) revela uma ampla conservação tanto na ordem, quanto na 
sequiência dos genes indicando uma relação evolutiva próxima entre as Bangiales e as Florideophycidae (Anexo 8).

Outros pontos também reforçados por nossos trabalhos (Anexos 1 e 5) são o reconhecimento da ordem Cyanidiales proposta por Seckbach e Ott [111] e a necessidade de revisão das ordens de Bangiophycidae, especificamente em relação às Porphyridiales. A resolução da taxonomia dessa ordem é atividade bastante complexa, uma vez que ela se divide em pelo menos três linhagens diferentes.

\subsection{Filogenia de espécies de Bangiales (Bangiophycidae) baseada no seqüenciamento do gene SSU rDNA.}

A ordem Bangiales era composta por apenas dois gêneros: Porphyra e Bangia, sendo uma das principais ordens dentro das Bangiophycidae. Recentemente, três novos gêneros, baseados principalmente em análises moleculares, foram descritos para a ordem: Pseudobangia [82], Dione e Minerva [84].

Enquanto o gênero Bangia é separado em apenas duas espécies: Bangia fuscopurpurea (Dillwyn) Lyngbye para as populações marinhas e Bangia atropurpurea (Roth) C. Agardh para as populações de água doce [80,81], o gênero Porphyra inclui mais de uma centena de espécies [127].

Espécies do gênero Porphyra, conhecidas como 'nori', têm sido tradicionalmente utilizadas como alimento humano nos países orientais há vários séculos. O gênero inclui as espécies de algas marinhas de maior importância econômica em todo o mundo, movimentando só no Japão recursos da ordem de 1,5 bilhões de US dólares por ano [86], ultrapassando os valores envolvidos no cultivo de qualquer outro organismo marinho. No Brasil, espécies de Porphyra vêm sendo coletadas e processadas há algumas décadas artesanalmente, não havendo controle de qualidade e nem estatísticas de sua biomassa e produção [92].

A taxonomia do gênero Porphyra é problemática, decorrente de um grande número de espécies amplamente distribuídas, de uma morfologia simples com poucos caracteres para serem descritos ou mensurados, e pela plasticidade fenotípica. Outro problema é a sua relação com o gênero Bangia. Já em 1993, Stiller e Waaland [115] levantaram a hipótese de que Bangia e Porphyra não eram gêneros monofiléticos. Isso foi confirmado com diversos trabalhos de filogenia molecular (ver Anexo 10 para uma revisão). Além disso, o registro fóssil do grupo é muito antigo: Campbell [19] reportou um fóssil da fase conchocelis de Porphyra de 425 milhões de anos; Butterfield et al. [18] descreveram um fóssil muito semelhante a gametófitos de Bangia com células rizoidais semelhantes às de Porphyra, datando entre 750 a 
1.250 milhões de anos; e Xiao et al. [123] descreveram um fóssil bastante semelhante a Porphyra de 570 milhões de anos. Com uma longa história evolutiva e uma morfologia simples, a convergência das características morfológicas de Bangiales mascara uma grande divergência genética.

Devido ao grande interesse em entender as relações filogenéticas dentro das Bangiophycidae pelas razões já explicadas anteriormente, a dificuldade taxonômica na distinção de espécies dentro de Bangiales, além da importância econômica do gênero Porphyra, temos utilizado o seqüenciamento do gene SSU rDNA para estudar espécies de Porphyra que ocorrem no Atlântico Sul ([93, 94, 95]; Anexo 10).

Oliveira e Coll [89] fizeram uma revisão do gênero Porphyra para a costa brasileira, descrevendo duas novas espécies, Porphyra spiralis E.C. Oliveira e Coll e P. acanthophora E.C. Oliveira e Coll, cada uma com duas variedades. Posteriormente, Yoneshigue [124] encontrou mais três espécies no Brasil, todas descritas por Coll e Oliveira [30] para o Uruguai: P. leucosticta Thuret, P. rizzinii Coll e E.C. Oliveira, e P. pujalsii Coll e E.C. Oliveira. Estas três espécies, no entanto, estariam restritas, no Brasil, a áreas influenciadas pelas águas frias da ressurgência de Cabo Frio, RJ. Tendo em vista a limitação dos estudos de taxonomia baseada apenas em morfologia para este gênero, Oliveira et al. [95] seqüenciaram o SSU rDNA de diferentes espécies de Porphyra, incluindo algumas espécies da costa brasileira e da costa atlântica canadense.

Assim como em outros trabalhos $[15,80,93,95]$ as análises feitas por nós para o SSU rDNA plastidial (Anexo 1) e nuclear (Anexos 5 e 10) e para o $r b c \mathrm{~L}$ (Anexo 5) mostraram que os dois gêneros não são entidades monofiléticas, sendo que Porphyra é polifilético e Bangia parafilético.

No Anexo 5 apresentamos seqüências genéticas de várias espécies de Bangiophycidae, entre elas duas Bangiales. A seqüência do SSU rDNA de P. leucosticta do Mar Báltico (Helgoland, Alemanha) e da P. leucosticta do Atlântico Norte (Nova Scotia, Canadá [95]) apresentam apenas 8 nucleotídeos de diferença (em cerca de 1840 nucleotídeos seqüenciados); entretanto, o material do Báltico apresenta um intron na posição 536 do gene, enquanto que o material do Canadá não apresenta introns. Uma análise da morfologia e da seqüência do SSU rDNA para estas duas linhagens mostra que elas estão corretamente incluídas na mesma espécie. Entretanto, se levarmos em conta a presença do intron e as condições ambientais em que cada isolado se encontra (o Báltico apresenta uma salinidade muito inferior à da Nova Scotia) talvez estas duas linhagens já estejam isoladas do ponto de vista reprodutivo. Estas 
duas linhagens de $P$. leucosticta poderiam ser um modelo extremamente interessante para se estudar a mobilidade deste intron, além de testar a hipótese de um evento de especiação.

As análises filogenéticas das espécies do Atlântico Sul (descritas no Anexo 10), mostram que a classificação feita por Oliveira e Coll [89], baseada em caracteres morfológicos, descrevendo duas novas espécies, Porphyra spiralis e $P$. acanthophora, cada uma com duas variedades, foi corroborada pelos nossos dados de seqüenciamento genético. A diferença encontrada entre $P$. acanthophora var. acanthophora e $P$. spiralis var. amplifolia é da ordem de 147 posições (92\% de identidade), enquanto que entre as duas variedades da mesma espécie, a identidade é da ordem de $99 \%$. P. acanthophora var. acanthophora e $P$. acanthophora var. brasiliensis apresentam 99,2 \% de identidade o que representa 15 posições diferentes em 1841 (ver Tabela 4, Anexo 10). Além disso, de modo geral P. spiralis apresenta um intron no SSU rDNA, enquanto que para $P$. acanthophora não foram encontrados introns neste mesmo gene. Uma outra espécie, $P$. drewiana descrita mais recentemente baseada estritamente na morfologia e supostamente endêmica para o litoral do Espírito Santo [31] apresentou alta identidade ( 99,7\%) de seqüência tanto para o SSU rDNA e seu intron, quanto para o ITS com as duas variedades de $P$. spiralis. Coll \& Oliveira [31] consideraram $P$. spiralis var. amplifolia a espécie mais similar morfologicamente a $P$. drewiana. Entretanto, diversas diferenças na morfologia do talo, estruturas reprodutivas, entre outras (ver Anexo 10) apoiaram a separação dessa espécie. Essas diferenças morfológicas entre $P$. drewiana e $P$. spiralis contrastam com sua alta identidade de seqüência, sugerindo que $P$. drewiana deveria ser uma das variedades de $P$. spiralis e não uma espécie independente.

Além das espécies citadas acima, nossas análises mostraram a presença de: $P$. suborbiculata no litoral de São Paulo que é uma espécie cosmopolita descrita até então para o Pacífico Norte e Sul e para o Atlântico Norte [15]; e Porphyra sp. 'Piaui', possivelmente uma nova espécie tropical que precisa ainda ser descrita.

Considerando as espécies de Porphyra do Atlântico Sul analisadas até o momento existem pelo menos três linhagens filogenéticas diferentes (Figura 1 e 2, Anexo 10). As espécies 'brasileiras', Porphyra acanthophora var. acanthophora, Porphyra acanthophora var. brasiliensis, Porphyra drewiana, Porphyra spiralis var. amplifolia, Porphyra spiralis var. spiralis e Porphyra sp. 'Piaui' formam um grupo monofilético dentro de uma politomia que inclui exemplares de Bangia e outras espécies de Porphyra de diferentes localidades geográficas. Uma outra espécie coletada na costa brasileira, Porphyra sp. 'Baleia' apresentou seqüência do SSU rDNA idêntica à Porphyra suborbiculata do Japão e Nova Zelândia indicando que esta espécie cosmopolita também ocorre no Atlântico Sul, sendo que esta 
linhagem forma um clado separado das demais espécies que ocorrem na costa brasileira. Porphyra capensis da África do Sul, por sua vez, agrupou-se com espécies da Nova Zelândia. De acordo com as nossas análises as espécies de Porphyra descritas até agora para o Atlântico Sul teriam chegado a esta região, oriundas de diferentes regiões geográficas através de diferentes rotas de dispersão.

As análises filogenéticas indicam a necessidade de rever a taxonomia dos gêneros Porphyra e Bangia. Uma opção seria fundir os gêneros Porphyra e Bangia em um único gênero [93]. A outra opção, que já vem sendo feito por alguns autores [82, 84], seria a descrição de novos gêneros. A fusão em um único gênero, nesse caso Bangia teria a primazia do nome, tornaria o táxon monofilético e seria justificável com base na morfologia simples do grupo e em seu ciclo de vida característico. Por outro lado, a alta diversidade genética encontrada nas Bangiales e a sua ampla distribuição geográfica favorecem a criação de novos gêneros, o que vem sendo feito por alguns autores $[82,84]$. De uma maneira ou de outra, a taxonomia do grupo será por muito tempo ainda bastante problemática, uma vez que abrange tanto espécies cosmopolitas, quanto espécies endêmicas, sem contar espécies crípticas (morfologia convergente) e espécies com acentuada plasticidade morfológica. A descrição de novos gêneros (uma vez que aparentemente essa é a tendência) terá que ser feita de uma maneira extremamente criteriosa, baseando-se em análises de mais de um marcador molecular (e.g. SSU rDNA e $r b c \mathrm{~L}$ ), em caracteres morfológicos (incluindo ultraestrutura se for preciso), ecológicos e até biogeográficos.

\subsection{Introns do grupo I e biogeografia de Porphyra spiralis var. amplifolia.}

Durante nossa análise filogenética para seqüências do gene SSU rDNA encontramos em Porphyra spiralis var. amplifolia um intron do grupo I na região terminal do gene, o qual apresentava variantes de tamanho em indivíduos provenientes de três diferentes localizações geográficas [94]. Introns do grupo I são caracterizados por uma estrutura secundária bastante conservada e pelo seu mecanismo de excisão, onde o intron catalisa diretamente as duas reações de transesterificação consecutivas requeridas para sua excisão do transcrito primário sendo denominados de auto-catalíticos ('self-splicing'; Figura 2.1, Anexo 3). Apesar da estrutura secundária dos introns do grupo I ser altamente conservada, sua identidade de seqüência de DNA (estrutura primária) é muito baixa (tipicamente menor que 10\%; [28]), o que torna estes elementos excelentes marcadores moleculares para a análise de grupos de organismos muito próximos (e.g. populações). 
Nós verificamos que a distribuição desses introns nas espécies, variedades e indivíduos de Porphyra é bastante complexa e precisa ser mais bem caracterizada [95]. Dados sobre a distribuição dos introns poderão trazer informações relevantes sobre a evolução desses elementos no genoma de eucariotos, sendo que o gênero Porphyra pode ser usado como um modelo experimental para testar hipóteses sobre a mobilidade e herança desses elementos genéticos. Além disto, como já dissemos espécies de Porphyra não são facilmente identificáveis já que apresentam morfologia bastante simples e homogênea, além de uma plasticidade fenotípica acentuada devido a fatores ambientais, o que explica a grande confusão taxonômica existente no gênero (Anexo 10). As populações de P. spiralis var. amplifolia estudadas não são distinguíveis morfologicamente em cerca de $500 \mathrm{Km}$ da costa sudeste do Brasil [89]. Variantes desse intron podem, portanto, fornecer meios de identificar populações em uma escala muito mais acurada do que seria possível em bases morfológicas. Nós temos procurado usar esse tipo de 'impressão digital' populacional para estudos de biogeografia.

Assim, analisamos a presença destes introns em diferentes espécies de Bangiophycidae, mais especificamente em Porphyra, além da distribuição das variantes geográficas do intron encontrado no SSU rDNA de Porphyra spiralis var. amplifolia, baseando-nos no modelo biogeográfico que propusemos em 1993 [93]. Fizemos, também a caracterização de um intron do grupo I que encontramos no SSU rDNA de um contaminante das culturas de Porphyra que foi identificado como uma ameba filosa, organismo relativamente pouco conhecido em todo mundo e que ainda não havia sido registrado para a América do Sul. (Anexo 2). A presença de organismos inconspícuos associados a Porphyra parece ser uma coisa bastante comum, tanto em culturas, como em material coletado na natureza. Já que muitas espécies de Porphyra apresentam introns, a presença de outros organismos (sem introns, ou com introns de tamanhos diferentes do da espécie de Porphyra analisada) é facilmente detectável por PCR. Este tipo de abordagem muitas vezes denominada de 'environmental PCR' pode gerar dados extremamente interessantes.

A metodologia e os resultados obtidos estão detalhadamente descritos e discutidos no Anexo 2. Análises filogenéticas da região codificante do gene agruparam de maneira consistente este contaminante junto com o grupo das amebas filosas, que inclui alguns grupos fotossintetizantes (Paulinella chromatophora e as Chlorarachniophyta). O organismo analisado é não fotossintetizante e está posicionado na base das Chlorarachniophyta (ver item 2.1). O intron do grupo I presente nesta ameba se encontra na posição 943 , e na análise filogenética do intron este se agrupa com os introns de outros organismos que ocupam esta mesma posição no gene SSU rDNA, incluindo o intron de Plasmodiophora brassica, um 
fitopatógeno posicionado na base do grupo das amebas filosas. Os resultados obtidos são consistentes com: 1. um ancestral não-fotossintético das Chlorarachniophyta; 2. com uma origem independente dos cloroplastos das Chlorarachniophyta e de Paulinella chromatophora; e 3. com a presença de um intron do grupo I na posição 943 no ancestral das amebas filosas.

Nas análises do SSU rDNA de espécies de Porphyra e Bangia (Bangiales) que fizemos foram verificados um ou dois introns do grupo I em P. leucosticta e em B. fuscopurpurea (ambas do Mar Báltico; Anexo 5), em P. drewiana, P. spiralis var. spiralis, em diversas populações de P. spiralis var. amplifolia, em Porphyra sp. 'Baleia' (todas da costa Brasileira) e em P. capensis (da África do Sul; Anexo 10). Encontramos também um intron do grupo I no SSU rDNA de Bangiopsis sp. (Goniotrichales). Este fato é surpreendente uma vez que apenas haviam sido descritos introns em Bangiales e em uma Florideophycidae basal, Hildenbrandia rubra [103]. Portanto, esse é o único intron do grupo I presente no SSU rDNA de Rhodophyta fora do clado monofilético Bangiales/Florideophycidae (Anexo 10).

Para analisar a distribuição do intron de grupo I em Porphyra spiralis var. amplifolia, realizamos coletas de material de diferentes populações do Sul e Sudeste da costa Brasileira (Tabela 1). O material coletado em cada localidade foi separado em indivíduos, identificado e preservado em sílica gel para posterior análise de 10 indivíduos por população (a metodologia usada foi a mesma descrita no Anexo 10). Foram preparadas exsicatas para serem depositadas no Herbário Ficológico (SPF), IB-USP, procedimento que é fundamental caso haja necessidade de uma posterior reidentificação do material.

Analisamos oito populações diferentes de Porphyra spiralis var. amplifolia nas quais determinamos cinco variantes de tamanho de intron (Tabela 1) devido à inserção ou deleção de bases na hélice do domínio P1 do intron (Figura 3, Anexo 2). De acordo com os tamanhos dos introns foram caracterizados cinco diferentes alelos, variando de 616 a $1056 \mathrm{pb}$. As populações de Florianópolis e do Litoral Sul do Estado de São Paulo apresentaram os alelos de maior tamanho e de Santos (SP) para o norte, as populações apresentaram alelos de menor tamanho. Duas localidades apresentaram mais de uma variante de tamanho entre seus isolados, Santos e Guarujá, que estão em uma região de grande tráfego de embarcações e portanto isolados de diferentes populações poderiam ter sido trazidos em cascos de barcos, colonizando esta área (Anexo 10). Nesta análise verificamos também a ocorrência de duas variantes de tamanho provenientes de um mesmo isolado. Tendo em vista que os SSU rDNA ocorrem em cópias múltiplas no genoma, mas que estas cópias são extremamente homogêneas, a observação de um único indivíduo com introns de tamanhos diferentes no seu genoma é bastante surpreendente, e talvez seja um indício de hibridação. 
A análise de introns do grupo I presentes no SSU rDNA que realizamos em populações de Porphyra mostrou que a distribuição das populações e seus respectivos introns, de modo geral, corrobora a hipótese que apresentamos anteriormente [93] de uma colonização SulNorte para esta variedade de Porphyra. Além disto, o intron do SSU rDNA de Porphyra se mostrou um eficiente marcador populacional.

Tabela 1. Informação de coleta para as populações de Porphyra spiralis var. amplifolia (PSA).

\begin{tabular}{|c|c|c|c|}
\hline População & Local de Coleta & Coletor/ Data & Intron alelo/tamanho \\
\hline \multirow[t]{2}{*}{$P S A-\mathrm{A}$} & Ponta da Armação, Florianópolis, SC & E.C. Oliveira & Tipo 5 / $1056 \mathrm{pb}$ \\
\hline & & Nov 1997 & \\
\hline \multirow[t]{2}{*}{$P S A-\mathrm{L}$} & Lagoinha, Florianópolis, SC & E.C. Oliveira & Tipo 5 / 1055 pb \\
\hline & & Nov 1997 & \\
\hline \multirow[t]{2}{*}{$P S A-\mathrm{R}^{*}$} & Ilha do Cardoso, SP & E. J. Paula & Tipo 5 / 1055 pb \\
\hline & & Ago 1989 & \\
\hline \multirow[t]{2}{*}{$P S A-\mathrm{I}$} & Cibratel, Itanhaém, SP & M.C. Oliveira & Tipo 5 / 1056 pb \\
\hline & & Ago 1997 & \\
\hline \multirow[t]{3}{*}{$P S A-\mathrm{S}$} & Forte Itaipu, Santos, SP & E.C. Oliveira & Tipo 3 / 792 pb \\
\hline & & Ago 1997 & Tipo 4 / 909 pb \\
\hline & & & Tipo 3+4 / $792+909$ pb \\
\hline \multirow[t]{4}{*}{$P S A-\mathrm{T}$} & Tombo, Guarujá, SP & D. Milstein & Tipo 3 / 792 pb \\
\hline & & Jul 2002 & Tipo 4 / 909 pb \\
\hline & & & Tipo 5 / 1055 pb \\
\hline & & & Tipo $3+5 / 792+1055 \mathrm{pb}$ \\
\hline \multirow[t]{2}{*}{$P S A-\mathrm{G}$} & Tijucopava, Guarujá, SP & D. Milstein & Tipo 3 / 792 pb \\
\hline & & Jul 2002 & \\
\hline \multirow[t]{2}{*}{$P S A-\mathrm{C}$} & Baleia, São Sebastião, SP & D. Milstein & Tipo 3 / $791 \mathrm{pb}$ \\
\hline & & Ago 2002 & \\
\hline \multirow[t]{2}{*}{$P S A-D^{*}$} & Cebimar, São Sebastião, SP & M.C. Oliveira & Tipo 4 / 909 pb \\
\hline & & Out 1990 & \\
\hline \multirow[t]{2}{*}{ PSA-B* } & Fortaleza, Ubatuba, SP & M.C. Oliveira & Tipo 2 / 744 pb \\
\hline & & Out 1990 & \\
\hline \multirow[t]{2}{*}{$P S A-\mathrm{V}$} & Vermelha do Norte, Ubatuba, SP & M.C. Oliveira & Tipo 1 / 616 pb \\
\hline & & Ago 1998 & \\
\hline
\end{tabular}

* Oliveira e Ragan [94] 


\subsection{Filogenia de espécies de Gracilariaceae (Florideophycidae) baseada no sequienciamento do gene SSU rDNA.}

Os gêneros Gracilaria e Gracilariopsis (Gracilariaceae), apresentam espécies de grande importância econômica, sendo cultivados em vários países em tanques ou diretamente no mar para a produção de ágar e agarose. Esses polissacarídeos de parede celular são usados em todo o mundo na industria alimentícia, de tintas e de cosméticos, além de serem fundamentais em biotecnologia, uma vez que a agarose é utilizada para a confecção de géis de eletroforese e meios de cultura para microorganismos. No Brasil, estes dois gêneros são certamente os de maior importância econômica. Existe, portanto, um grande interesse em se chegar à uma melhor compreensão da taxonomia e das relações filogenéticas entre as várias espécies que ocorrem nos litorais brasileiro e caribenho [90, 92].

O gênero Gracilaria apresenta um grande número de espécies (mais de 100) com uma morfologia relativamente simples e ampla distribuição geográfica, sendo várias destas espécies cosmopolitas [91]. Ao contrário de Porphyra, que apresenta sua maior diversidade em águas temperadas e frias, Gracilaria apresenta uma maior diversidade em águas quentes.

Os Anexos 6 e 9 apresentam análises filogenéticas baseadas nas sequiências completas do gene SSU rDNA determinadas para 26 táxons de Gracilaria e duas espécies de Gracilariopsis. Devido ao fato das seqüências do SSU rDNA se apresentarem bastante conservadas dentro das Gracilariales e serem insuficientes para a clarificação das relações filogenéticas entre espécies muito próximas foi também realizado o seqüenciamento da região espaçadora interna transcrita (ITS) dos genes ribossomais para 21 táxons. Outras sequiências foram obtidas dos bancos de dados para análises filogenéticas mais amplas. Os resultados confirmam três linhagens principais em Gracilariaceae, uma linhagem mais basal contendo os gêneros Curdiea e Melanthalia, seguida da separação das duas outras linhagens: Gracilariopsis e Gracilariophila; e a linhagem contendo as espécies de Gracilaria (Figura 1, Anexo 6). Gracilariopsis é um gênero parafilético uma vez que uma espécie de Gracilariophila derivou a partir dele. Nossos estudos têm mostrado que as espécies de Gracilariopsis do Atlântico são monofiléticas e separadas das do Pacífico. O mesmo ocorre com o gênero Gracilaria que se apresenta monofilético com as espécies do Pacífico também separadas das do Atlântico (ver Anexo 6 para um maior detalhamento). A partir de dados moleculares e morfo-anatômicos ficou demonstrada a ocorrência de Gracilaria vermiculophylla na América do Norte, espécie até então somente conhecida para o Japão (Anexo 9). Esta espécie foi descrita recentemente para a Europa como uma alga invasora [107]. 


\section{Genômica.}

O ambiente marinho apresenta uma enorme reserva de biodiversidade que pode ser explorada de uma maneira controlada como fonte de recursos renováveis. Apesar disto, a aplicação de tecnologias moleculares no estudo dos ambientes aquáticos tem sido moderada em comparação ao esforço empregado no ambiente terrestre. Recentemente, alguns esforços em larga escala têm sido feitos para aumentar a amostragem de genomas do ambiente marinho [39, 43]. O campo da biologia molecular marinha tornou-se uma nova fronteira com implicações globais, mas ainda relativamente pouco explorado, principalmente no Brasil. O uso de técnicas moleculares pode gerar informações fundamentais sobre biologia básica e aplicada dos organismos marinhos, contribuindo para o entendimento das relações evolutivas e dos mecanismos que deram origem às espécies atuais.

Nos ecossistemas aquáticos, principalmente no marinho, as algas desempenham um papel fundamental como produtores primários e na ciclagem de nutrientes. Além disto, as algas marinhas macroscópicas vêm sendo utilizadas pelo homem há muitos séculos, seja como alimento, rações, adubos ou para a extração de substâncias químicas de natureza diversa. As algas são fontes exclusivas de certos hidrocolóides como o ágar-ágar, as carragenanas e os alginatos, que são imprescindíveis à vida no mundo moderno e movimentam anualmente algumas centenas de milhões de US dólares. Apesar de sua importância ecológica e econômica, o conhecimento que temos do genoma e do metabolismo das algas e o controle sobre a maricultura através de linhagens selecionadas é ainda ínfimo se comparado a outros grupos como animais e plantas terrestres.

Nos últimos anos a área de Genômica foi plenamente estabelecida no Brasil, sendo que nosso grupo de pesquisa participou em vários dos projetos Genoma e Transcriptoma (EST) financiados pela FAPESP, o que favoreceu a transferência dessas técnicas de análise genômica para a área da Ficologia.

A espécie que tem sido foco dos estudos genômicos em nosso laboratório é Gracilaria tenuistipitata var. liui Chiang et Xia, que apresenta uma ampla tolerância à salinidade (3 a 50 $\%$ ), temperatura $\left(13\right.$ a $\left.33{ }^{\circ} \mathrm{C}\right)$ e $\mathrm{pH}(5,5$ a 10,0) [53, 67]. Essas características associadas a uma alta taxa de crescimento e alta produção de ágar fazem dessa linhagem um excelente material para cultivo [68]. Essa espécie tem sido extensivamente cultivada em lagos no sul da China e em Taiwan [29]. Gracilaria tenuistipitata tem sido usada também como um organismo modelo para algas vermelhas em estudos de fisiologia [e.g. 54, 57, 65]. Entretanto, em comparação às plantas terrestres e a outros organismos modelos pouco é conhecido sobre a fisiologia das algas vermelhas em geral, especialmente a nível molecular. Existe um grande 
interesse em compreender os mecanismos de nutrição e crescimento destas algas, além dos mecanismos que controlam a produção dos ficocolóides

\subsection{Seqüenciamento de 'Expressed Sequence Tags' (EST) de Gracilaria tenuistipitata.}

Além do seqüenciamento completo do genoma do cloroplasto de G. tenuistipitata (item 3.1), uma outra abordagem usando técnicas de genômica foi utilizada para obter informações a respeito do genoma nuclear desta espécie. EST são seqüências de DNA complementar ao RNA mensageiro extraído das células. Estas seqüências nos trazem informações sobre os genes nucleares expressos pelo organismo nas condições do momento da extração. Com esse tipo de dado é possível obter de maneira rápida uma quantidade relativamente grande de informações sobre parte do repertório genético desta alga de importância econômica. Os fragmentos obtidos podem ser posteriormente utilizados como sondas para encontrar o gene que poderá ser então estudado com maior detalhamento.

Foram seqüenciados em nosso laboratório, a partir da extremidade 5', 3.631 clones de EST da fase tetrasporofítica de G. tenuistipitata obtidos de duas bibliotecas, uma com seleção de tamanho para 1600 pb e outra para 600 pb. A análise de agrupamento desses EST geraram 447 seqüências alinhadas e 1.940 seqüências únicas, com uma redundância de 53\%. Dessas 2.387 seqüências (únicas ou 'clusters'), 65\% apresentaram similaridade significativa a seqüências depositadas no banco de dados GenBank (BlastX; [2]), enquanto que 10,7\% apresentaram similaridade significativa com proteínas hipotéticas conservadas, e 35\% são sequiências novas (i.e. não presentes nos bancos de dados). Os grupos gerados pela análise de bioinformática foram completamente anotados. Os três genes mais representados nos EST foram uma ATPase $\mathrm{Na} / \mathrm{K}$-transportadora, uma proteína do tipo 'hedgehog', e uma actina. A maioria dos genes identificados estava envolvida em manutenção celular ('house keeping'), sendo que o maior grupo funcional foi o referente ao metabolismo com 14,2\% dos EST (Tabela 2, Anexo 12). Outras categorias funcionais bem representadas foram energia, transcrição, síntese de proteínas e destinação de proteínas. Estamos preparando um banco de dados para essas sequiências e uma vez publicado o trabalho todas as sequiências serão submetidas ao GenBank.

Usando essa técnica, vários genes de interesse foram identificados para $G$. tenuistipitata. EST tem um potencial enorme para a descoberta de genes, especialmente em organismos para os quais existem poucas sequiências disponíveis. Informação sobre seqüências de genes de Florideophycidae são ainda bastante escassas. Portanto, a adição de 2.422 novas seqüências para esse grupo representa uma importante contribuição para o conhecimento das 
florideofíceas. As análises das seqüências obtidas podem gerar dados básicos sobre genes e sua regulação, que poderão maximizar o potencial econômico deste importante recurso marinho. Além disso seqüências de alguns genes específicos podem ser usadas para análises filogenéticas e evolutivas.

\section{Perspectivas.}

Nos últimos dez anos nosso grupo de pesquisa vem trabalhando no estabelecimento das condições básicas para o uso de técnicas moleculares e bioquímicas aplicadas ao estudo das algas, incluindo infra-estrutura, estabelecimento de metodologias específicas e treinamento de pessoal. Esse esforço gerou publicações e abriu novas fronteiras de estudo das macroalgas no Brasil. Dando continuidade a esses trabalhos pretendemos propor novos objetivos decorrentes do nosso avanço técnico e científico, abordando diferentes aspectos da biologia de gêneros de algas vermelhas (Rhodophyta) sobretudo de Porphyra, Gracilaria e Gracilariopsis que incluem espécies de grande valor econômico e que ainda são pouco estudados em regiões tropicais.

\subsection{Caracterização do genoma mitocondrial e banco de dados genéticos para Gracilaria tenuistipitata.}

Devido à sua importância econômica e a uma grande tolerância a fatores ambientais Gracilaria tenuistipitata var. liui tem sido utilizada em estudos fisiológicos, bioquímicos e moleculares, tornando-se, graças ao nossos trabalhos, um organismo modelo dentre as algas vermelhas para esse tipo de análise. Em nosso laboratório temos utilizado esta espécie para diversos estudos moleculares e bioquímicos como o seqüenciamento completo do genoma do cloroplasto (Anexos 7 e 8) e o seqüenciamento de EST (Anexo 12). Esta espécie também está sendo testada para o desenvolvimento de um protocolo de transformação genética estável (ver a seguir) e para estudos de regulação enzimática $[65,66]$.

Em 1995 foi publicada a primeira seqüência completa de DNA mitocondrial (mtDNA) de uma Rhodophyta, Chondrus crispus [62]. A partir desta data, mais dois trabalhos foram realizados, com Cyanidioschyzon merolae [87] e Porphyra purpurea [17]. Mesmo assim, são apenas 3 seqüências mitocondriais de algas vermelhas num total de 721 seqüências completas existentes no GenBank (julho/05, http://www.ncbi.nlm.nih.gov/genomes/ORGANELLES/ organelles.html). Dando continuidade ao projeto de sequienciamento de G. tenuistipitata pretendemos seqüenciar o genoma mitocondrial dessa alga (projeto de M. M. Takahashi). Essas seqüências mitocondriais serão utilizadas para dar continuidade às análises evolutivas, 
além de ajudar a compor um banco de dados genômicos, com acesso via internet, para essa espécie, a qual incluirá os dados dos EST, e do genoma do cloroplasto que já estão disponíveis no site http://gracilaria.ib.usp.br/mirror/gt-chloroplast/.

Além disso, outros dois projetos em colaboração com P. Colepicolo estão sendo iniciados com essa espécie usando técnicas de biologia molecular, incluindo uma análise de microarray realizada a partir da biblioteca de EST (doutorado de A.P. Tonon) e uma análise da regulação da expressão do gene para a enzima nitrato redutase (doutorado de V.R. Falcão).

\subsection{Obtenção de transformantes estáveis de Gracilariales.}

Este projeto visa o estabelecimento de uma metodologia de transformação estável para macroalgas vermelhas produtoras de ágar, que é um passo fundamental para o aprofundamento das pesquisas genéticas em algas e que pode ter também uma enorme aplicação em maricultura. Esses estudos são básicos para que haja um avanço substancial na compreensão da fisiologia destas algas e na obtenção de linhagens mais eficientes do ponto de vista econômico. Entretanto, existe uma grande lacuna no conhecimento de procedimentos para obter transformantes estáveis de algas de interesse econômico. A combinação de técnicas de cultivo in vitro, cultura de tecidos, biologia molecular e transferência de genes estão sendo adaptadas e otimizadas em nosso laboratório para Gracilariales. Dentre os métodos para a transformação testados por nós, o método de biobalística apresentou resultados promissores, mostrando expressão gênica transiente nas células transformadas. Estes estudos terão prosseguimento com duas espécies, Gracilaria tenuistipitata e Gracilariopsis tenuifrons e está sendo realizado em colaboração com F. Chow Ho, M. Nakabashi, N. Yokoya e M.A. Van Sluys.

\subsection{Filogenia molecular de algas.}

Devido ao grande interesse dos ficólogos na utilização de técnicas de filogenia molecular associada à taxonomia tradicional, e à infra-estrutura montada nos dois laboratórios do Departamento de Botânica a que estou associada (Laboratório de Algas Marinhas Edison J. de Paula e Laboratório de Genética Molecular de Plantas) temos colaborado com diferentes grupos de pesquisa, recebendo e treinando pesquisadores do Brasil e do exterior (Chile, E.U.A, México, Suécia, Tanzânia, Venezuela).

Nosso grupo tem trabalhado com dados moleculares em estudos sobre a taxonomia, filogenia e evolução, usando regiões do rDNA, $r b c \mathrm{~L}$ ou outros marcadores 
moleculares, de diferentes gêneros de Rhodophyta e Cyanophyta [11], e mais recentemente de algumas espécies de Phaeophyta e Chlorophyta. Entre os grupos que já estão sendo analisados: em Rhodophyta, 1. o gênero Porphyra para o qual será continuada a análise filogenética de diferentes espécies e também análises populacionais (Tese de D. Milstein); 2 o gênero Gracilaria que apresenta também uma série de problemas taxonômicos (em colaboração com E.C. Oliveira, A. M. Bellorin e A. Buryo); 3. diferentes espécies de Batrachospermales (em colaboração com O. Nechi Jr.); 4. os gêneros Chondria e Laurencia (em colaboração com M.T. Fujii, D.S. Bacci, V. Cassano, J.D. Larrea); em Chlorophyta 5. será continuada a análise do gênero Cladophora (em colaboração com L.M.S. Gestinari, S.M.B. Pereira e Y. Yoneshigue); 6. Caulerpa (em colaboração com M.T. Fujii, D. Barata); 7. Codium (em colaboração com M.F.O. Carvalho e S.M.B. Pereira); em Phaeophyta, 8. será continuada a análise do gênero Sargassum (doutorado de C.S. Coimbra).

\subsection{Introns do grupo I e biogeografia de Porphyra spiralis var. amplifolia.}

Outras regiões marcadoras estão sendo analisadas para as populações de Porphyra spiralis var. amplifolia. Essas regiões incluem: ITS ('Internal Transcribed Spacer') do SSU rDNA nuclear, a região espaçadora dos genes plastidiais da Rubisco $(r b c \mathrm{~L}-\mathrm{S})$ e a região espaçadora dos genes mitocôndrias para Cox (cox2-3). Será analisada também a capacidade de autoprocessamento das diferentes variáveis de tamanho dos introns, para verificar se as regiões de indel afetam, de alguma maneira, essa capacidade. Além disso, serão analisadas amostras recebidas de Israel. Este trabalho terá continuidade dentro do projeto de doutorado de D. Milstein. 


\section{Referências:}

[1] Altmann R. 1890. Die Elementarorganismen und ihre Beziehungen zu den Zellen (Veit, Leipzig).

[2] Altschul S.F., Madden T.L., Schaffer A.A., Zhang J., Zhang Z., Miller W., Lipman D.J. 1997. Gapped BLAST and PSI-BLAST: a new generation of protein database search programs. Nucleic Acids Res 25: 3389-3402.

[3] Andersson J.O., Roger A.J. 2002. A cyanobacterial gene in nonphotosynthetic protists-An early chloroplast acquisition in Eukaryotes? Curr Biol 12: 115-9.

[4] Archibald J.M., Keeling P.J. 2002. Recycled plastids: a 'green movement' in eukaryotic evolution. Trends Genet 18: 577-584.

[5] Archibald J.M., Rogers M.B., Toop M., Ishida K., Keeling P.J. 2003. Lateral gene transfer and the evolution of plastid-targeted proteins in the secondary plastid-containing alga Bigelowiella natans. Proc Natl Acad Sci USA 100: 7678-7683.

[6] Baldauf S.L., Roger A.F., Wenk-Siefert I., Doolittle W.F. 2000. A kingdom-level phylogeny of eukaryotes based on combined protein data. Science 290: 972-7.

[7] Baldauf S.L. 2003. The deep roots of eukaryotes. Science 300: 1703-6.

[8] Bapteste E., Brinkmann H., Lee J.A., Moore D.V., Sensen C.W., Gordon P., Durufle L., Gaasterland T., Lopez P., Muller M., Philippe H. 2002. The analysis of 100 genes supports the grouping of three highly divergent amoebae: Dictyostelium, Entamoeba and Mastigamoeba. Proc Natl Acad Sci USA 99: 1414-9.

[9] Bhattacharya D., Medlin L. 1995. The phylogeny of plastids: a review based on comparisons of small-subunit ribosomal RNA coding regions. J Phycol 31: 489-98.

[10] Bhattacharya D., Yoon H.S., Hackett J.D. 2004. Photosynthetic eukaryotes unite: endosymbiosis connects the dots. BioEssay 26: 50-60.

[11] Bittencourt-Oliveira, M.C., Oliveira M.C., Bolch C.J.S. 2001. Genetic variability of Brazilian strains of the Microcystis aeruginosa complex (Cyanophyceae/ Cyanobacteria) using the phycocyanin intergenic spacer and flanking regions. J Phycol 37: 810-818.

[12] Blanchard J., Lynch M. 2000. Organellar genes why do they end up in the nucleus? TIG 16: 315-20.

[13] Bock R. 2001. Transgenic plastids in basic research and plant biotechnology. J Mol Biol 312: 425-438.

[14] Bold H.C., Wynne M.J. 1985. Introdution to the algae. Struture and reproduction (2. ed.). Prentice-Hall, Inc., Englewood Cliffs. 720 p.

[15] Broom J.E., Nelson W.A., Yarish C., Jones W.A, Aguilar Rosas R., Aguilar Rosas L.E. 2002. A reassessment of the taxonomic status of Porphyra suborbiculata, Porphyra carolinensis and Porphyra lilliputiana (Bangiales, Rhodophyta) based on molecular and morphological data. Eur J Phycol 37: 227-235.

[16] Bui E.T.N., Bradley P.J., Johnson P.J. 1996. A common evolutionary origin for mitochondria and hydrogenosomes. Proc Natl Acad Sci USA 93: 9651-6.

[17] Burger G., Saint-Louis D., Gray M.W., Lang, B.F. 1999. Complete sequence of the mitochondrial DNA of the red alga Porphyra purpurea. Cyanobacterial introns and shared ancestry of red and green algae. Plant Cell 11: 1675-1694. 
[18] Butterfield N.J., Knoll A.H., Swett K. 1990. A bangiophyte red alga from the Proterozoic of Artic Canada. Science 250: 104-107.

[19] Campbell S.E. 1980. Paleoconchocelis starmachii, a carbonate boring microfossil from the Upper Silurian of Poland (425 milion years old): implications for the evolution of the Bangiaceae (Rhodophyta). Phycologia 19: 25-36.

[20] Cavalier-Smith T. 1981. Eukaryote kingdoms: seven or nine? Biosystems 14: 461-81.

[21] Cavalier-Smith T. 1983. A six-kingdom classification and a unified phylogeny. Endocytobiology 2: 1027-34.

[22] Cavalier-Smith T. 1986. The Kingdom Chromista: origin and systematics. Progress in Phycological Research 4: 309-47.

[23] Cavalier-Smith T. 1998. A revised six-kingdom system of life. Biol Rev Camb Philos Soc 73: 203-66.

[24] Cavalier-Smith T. 1999. Principles of protein and lipid targeting in secondary symbiogenesis: euglenoid, dinoflagellate and sporozoan plastids origins and the eukaryote family tree. J Eukaryot Microbiol 46: 347-66.

[25] Cavalier-Smith T. 2002. Chloroplast evolution: secondary symbiogenesis and multiple losses. Curr Biol 12: R62-R64.

[26] Cavalier-Smith T. 2002. The phagotrophic origin of eukaryotes and phylogenetic classification of protozoa. Int J Syst Evol Microbiol 52: 297-354.

[27] Cavalier-Smith T. 2003. Genomic reduction and evolution of novel genetic membranes and protein-targetin machinery in eukaryote-eukaryote chimaeras (meta-algae). Phil Trans R Soc Lond B 358: 109-134.

[28] Cech T.R. 1990. Self-splicing of group I introns. Annu Ver Biochem 59: 543-568.

[29] Chiang Y.M. 1981. Cultivation of Gracilaria (Rhodophycophyta, Gigartinales) in Taiwan. Proc Int Seaweed Symp 10: 569-575.

[30] Coll J., Oliveira E.C. 1976. The genus Porphyra C.Ag. Rhodophyta - Bangiales in the American South Atlantic. II. Uruguayan species. Botanica Marina 19: 191-196.

[31] Coll J., Oliveira E.C. 2001. Porphyra drewiana, a new species of red algae (Bangiales, Rhodophyta) from Brazil. Phycological Research 49: 67-72.

[32] Corliss J.O. 1984. The kingdom Protista and its 45 phyla. BioSystems 17: 87-126.

[33] Cosner M.E., Jansen R.K., Palmer J.D., Downie S.R. 1997. The highly rearranged chloroplast genome of Trachelium caeruleum (Campanulaceae): multiple inversions, inverted repeat expansion and contraction, transposition, insertions/deletions, and several repeat families. Curr Genet 31: 419-429.

[34] Dacks J.B., Doolittle W.F. 2001. Reconstructing/deconstructing the earliest eukaryotes: how comparative genomics can help. Cell 107: 419-25.

[35] Delwiche C.F., Palmer J.D. 1996. Rampant horizontal transfer and duplication of Rubisco genes in eubacteria and plastids. Mol Biol Evol 13: 873-82.

[36] Delwiche C.F. 1999. Tracing the thread of plastid diversity through the tapestry of life. Am Nat 154: S164-77.

[37] Durnford D.G., Deane J.A., Tan S., McFadden G.I., Gantt E., Green B.R. 1999. A phylogenetic assessment of plastids and eukaryotic light-harvesting antenna proteins. $\mathrm{J}$ Mol Evol 48: 59-68. 
[38] Embley T.M., Hirt R.P. 2004. Early branching eukaryotes? Curr Opin Genet Dev 1998 8: 624-9.

[39] Falkowski, P.G., Vargas C. 2004. Shotgun sequencing in the sea: a blast from the past? Science 304:58-60.

[40] Fast N.M., Kissinger J.C., Roos D.S., Keeling P.J. 2001. Nuclear-encoded, plastidtrageted genes suggest a single common origin for apicomplexan and dinoflagellate plastids. Mol Biol Evol 18: 418-26.

[41] Foth B.J., Mcfadden G.I. 2003. The apicoplast: a plastid in Plasmodium falciparum and other apicomplexan parasites. Int Rev Cytol 224: 57-110.

[42] Freshwater D.W., Fredericq S., Butler B.S., Hommersand M.H., Chase M.W. 1994. A gene phylogeny of the red algae (Rhodophyta) based on plastid $r b c \mathrm{~L}$. Proc Nat Acad Sci USA 91: 7281-7285.

[43] Furhman J., 2003. Genome sequences from the sea. Nature 424: 1001-1002.

[44] Gabrielson P.W., Garbary D.J., Scagel R.F. 1985. The nature of ancestral red algae: inferences from a cladistic analysis. Biosystems 18: 335-346.

[45] Garbary D.J., Gabrielson P.W. 1990. Taxonomy and evolution. In Cole K.M., Sheath R.G. (eds) Biology of the red algae. Cambridge University Press, Cambridge, pp. 477498.

[46] Gewolb J. 2002. Plant scientists see big potential in tiny plastids. Science 295: 258-259.

[47] Gillham N.W. 1994. Organelle Genes and Genomes. Oxford University Press, Oxford. $424 \mathrm{p}$.

[48] Gilson P., McFadden G.I. 1995. The chlorarachniophyte: a cell with two different nuclei and two different telomeres. Chromosoma 103: 635-641.

[49] Glöckner G., Rosenthal A., Valentin K. 2000. The structure and gene repertoire of an ancient red algal plastid genome. J Mol Evol 51:382-390.

[50] Gray M.W., Burger G., Lang B.F. 1999. Mitochondrial evolution. Science 283: 1476-81.

[51] Gupta R.S, Mukhtar T., Singh B. 1999. Evolutionary relationships among photosynthetic prokaryotes (Heliobacterium chlorum, Chloroflexus aurantiacus, cyanobacteria, Chlorobium tepidum and proteobacteria): implications regarding the origin of photosynthesis. Mol Microbiol 32: 893-906.

[52] Gupta R.S. 2000. The phylogeny of proteobacteria: relationships to other eubacterial phyla and eukaryotes. FEMS Microbiol Rev 24: 367-402.

[53] Haglund K., Pedersén M. 1992. Growth of the red alga Gracilaria tenuistipitata at high $\mathrm{pH}$. Influence of some environmental factors and correlation to an increased carbonicanhydrase activity. Botanica Marina 35: 579-587.

[54] Haglund K., Björklund M., Gunnare S., Sandberg A., Olander U., Pedersén M. 1996. New method for toxicity assessment in marine and brackish environments using the macroalga Gracilaria tenuistipitata (Gracilariales, Rhodophyta). Hydrobiologia 326/327: 317-325.

[55] Hannaert V., Saavedra E., Duffieux F., Szikora J.P., Rigden D.J., Michels P.A., Opperdoes F.R. 2003. Plant-like traits associated with metabolism of Trypanosoma parasites. Proc Natl Acad Sci USA 100: 1067-1071. 
[56] Harper J.T., Keeling P.J. 2003. Nuclear-encoded, plastid-targeted glyceraldehydes-3phosphate dehydrogenase (GAPDH) indicates a single origin for chromalveolate plastids. Mol Biol Evol 20: 1730-1735.

[57] Hu S., Tang C.H., Wu M. 1996. Cadmium accumulation by several seaweeds. The Science of the Total Environment 187: 65-71.

[58] Jarvis P., Soll J. 2001. Tic, Toc, and chloroplast protein import. Biochim Biophys Acta 1541: 64-79.

[59] Keeling P.J., Doolittle W.F. 1996. Alpha-tubulin from early-diverging eukaryotic lineages and the evolution of tubulin family. Mol Biol Evol 13: 1297-1305.

[60] Keeling P.J. 2004. Diversity and evolutionary history of plastids and their hosts. Am J Bot 91: 1481-1493

[61] Kylin H. 1956. Die Gattungen der Rhodophyceen. CWK, Gleerups Forlag, Lund.

[62] Leblanc C., Boyen C., Richard O., Bonnard G., Grienenberger J.M., Kloareg B. 1995. Complete sequence of the mitochondrial DNA of the rhodophyte Chondrus crispus (Gigartinales). Gene content and genome organization. J Mol Biol 250: 484-495.

[63] Lewis L.A., McCourt R.M. 2004. Green algae and the origin of land plants. Am J Bot 91: 1535-1556.

[64] Löffelhardt W., Bohnert H.J., Bryant D.A. 1997. The cyanelles of Cyanophora paradoxa. Crit Rev Plant Sci 16: 393-413.

[65] Lopes P.F., Oliveira M.C., Colepicolo P. 1997. Diurnal fluctuation of nitrate reductase activity in the marine red alga Gracilaria tenuistipitata (Rhodophyta). J Phycol 33: 225231.

[66] Lopes P.F., Oliveira M.C., Colepicolo P. 2002. Characterization and daily variation of nitrate reductase in Gracilaria tenuistipitata (Rhodophyta). Biochemical and Biophysical Research Communications 295: 50-54.

[67] Macchiavello J., Paula E., Oliveira E.C. 1998. Growth rate responses of five commercial strains of Gracilaria (Rhodophyta, Gracilariales) to temperature and light. Journal of the World Aquaculture Society 29: 259-266.

[68] Macchiavello J., Saito R., Garofalo G., Oliveira E.C. 1999. A comparative analysis of agarans from commercial species of Gracilaria (Gracilariales, Rhodophyta) grown in vitro. Hydrobiologia 398/399: 397-400.

[69] Magne F, 1989. Classification et phylogénie des Rhodophycées. Crypt. Algol 10: 01-115.

[70] Margulis L., Schwartz K.V. 2001. Cinco reinos, um guia dos filos da vida na terra. Guanabara-Koogan, RJ, $3^{\text {a }}$ edição. 497 p.

[71] Martin W., Stoebe B., Goremykin V., Hansmann S., Hasegawa M., Kowallik K.V. 1998. Gene transfer to the nucleus and the evolution of chloroplasts. Nature 393: 162-165.

[72] Martin W., Rujan T., Richly E., Hansen A., Cornelsen S., Lins T., Leister D., Stoebe B., Hasegawa M., Penny D. 2002. Evolutionary abalysis of Arabidopsis, cyanobacterial, and chloroplast genomes reveals plastid phylogeny and thousand of cyanobacterial genes in the nucleus. Proc Natl Acad Sci USA 99: 12246-12251.

[73] Martin W., Borst P. 2003. Secondary loss of chloroplasts in trypanosomes. Proc Natl Acad Sci USA 100: 765-767. 
[74] Maul J.E., Lilly J.W., Cui L., DePamphilis C.W., Miller W., Harris E.H., Stern D.B. 2002. The Chlamydomonas reinhardtii plastid chromosome: islands of genes in a sea of repeats. Plant Cell 14: 2659-2679.

[75] McFadden G.I. 1999. Plastids and protein targeting. J Eukaryot Microbiol 46: 339-346.

[76] McFadden G.I. 2001. Primary and secondary endosymbiosis and the origin of plastids. J Phycol 37: 951-959.

[77] McHugh, D.J. 2003. A guide to the seaweed industry. FAO Fisheries Technical Paper 441, FAO, Roma. 105p.

[78] Mereschkowsky C. 1905. Über natur und ursprung der chromatoporen im pflanzenreiche. Biologisches Centralblatt 25: 593-604.

[79] Moreira D., Le Guyader H., Philipe H. 2000. The origin of red algae and the evolution of chloroplasts. Nature 405: 69-72.

[80] Müller K.M., Sheath R.G., Vis M.L., Crease T.J., Cole K.M. 1998. Biogeography and systematics of Bangia (Bangiales, Rhodophyta) based on the RuBisCo spacer, $r b c \mathrm{~L}$ gene and 18S rRNA gene sequences and morphometric analyses. 1.North America. Phycologia 37: 195-207.

[81] Müller K.M., Cole K.M., Sheath R.G. 2003. Systematics of Bangia (Bangiales, Rhodophyta) in North America. II. Biogeographical trends in karyology: chromosome numbers and linkage with gene sequence phylogenetic trees. Phycologia 42: 209-219.

[82] Müller K.M., Cannone J.J., Sheath R.G. 2005. A molecular phylogenetic analysis of the Bangiales (Rhodophyta) and description of a new genus and species, Pseudobangia kaycoleia. Phycologia 44: 146-155.

[83] Nakayama T., Ishida K. 2005. Another primary endosymbiosis? Origin of Paulinella chromatophora cyanelles. Phycologia, 44(4-supp.): 74.

[84] Nelson W.A., Farr, J., Broom E.S. 2005. Dione and Minerva, two new genera from New Zealand circuscribed for basal taxa in the Bangiales (Rhodophyta). Phycologia 44: 139145.

[85] Nozaki H., Matsuzaki M., Takahara M., Misumi O., Kuroiwa H., Hasegawa M., Shin-i T., Kohara Y., Ogasawara N., Kuroiwa T. 2003. The phylogenetic position of red algae revealed by multiple nuclear genes from mitochondria-containing eukaryotes and an alternative hypothesis on the origin of plastids. J Mol Evol 56: 485-97.

[86] Ohno M., Largo D.B. 1998. The seaweed from Japan. In Crichley A.T., Ohno M. (eds), Seaweed resources of the world. Japan International Cooperation Agency, Nagai, p: 1-14.

[87] Ohta N., Sato N., Kuroiwa T. 1998. Structure and organization of the mitochondrial genome of the unicellular red alga Cyanidioschyzon merolae deduced from the complete nucleotide sequence. Nucleic Acids Res. 26: 5190-5298.

[88] Ohta N., Matsuzaki M., Misumi O., Miyagishima S.Y., Nozaki H., Tanaka K., Shin-I T., Kohara Y., Kuroiwa T. 2003. Complete sequence and analysis of the plastid genome of the unicellular red alga Cyanidioschyzon merolae. DNA Res. 10: 67-77.

[89] Oliveira E.C., Coll J. 1975. The genus Porphyra C. Ag. (Rhodophyta-Bangiales) in the American South Atlantic. I. Brazilian species. Bot Mar 18: 191-197.

[90] Oliveira E.C. 1984. Taxonomic criteria in the genus Gracilaria Grev. (Rodophyta): an experience with the western Atlantic species. Hydrobiologia 116/ 17: 55-58. 
[91] Oliveira E.C., Plastino E.M. 1994. Gracilariaceae. In Akatsuka, I. Biology of Economic Algae. pp: 185-226. SPB Academic Publishing bv, The Hague.

[92] Oliveira E.C. 1998. The seaweed resources of Brazil. In Crichley A.T., Ohno M. (eds), Seaweed resources of the world. Japan International Cooperation Agency, Nagai, p: 366371.

[93] Oliveira M.C. 1993. Filogenia de Porphyra spp. (Rhodophyta): seqüenciamento do gene nuclear para o RNA da subunidade pequena do ribossomo (rDNA 18S) e estudos morfológicos da fase conchocelis. Tese de Doutorado do Instituto de Biociências, Universidade de São Paulo. 160 p.

[94] Oliveira M.C., Ragan M.A. 1994. Variant forms of a group I intron in nuclear smallsubunit rRNA genes of the marine red alga Porphyra spiralis var.amplifolia. Mol Biol Evol 11:195-207.

[95] Oliveira M.C., Kurniawan J., Bird C.J., Rice E.L., Murphy C.A., Singh R.K., Gutell RR., Ragan M.A. 1995. A preliminary investigation of the order Bangiales (Bangiophycidae, Rhodophyta) based on sequences of nuclear small-subunit ribosomal RNA genes. Phycological Research 43: 71-79.

[96] Palmer J.D. 1991. Plastid chromosomes: Structure and Evolution. In Bogorad L., Vasil I.K. (eds) The Molecular Biology of Plastids. Academic press, San Diego, pp. 5-53.

[97] Palmer J.D. 2000. A single birth of all plastids? Nature 405: 32-3.

[98] Palmer J.D. 2003. The symbiotic birth and spread of plastids: how many times and whodunit? J Phycol 39: 4-11.

[99] Patron N.J., Rogers M.B., Keeling P.J. 2004. Gene replacement of Fructose-1,6 Biphosphate Aldolase supports the hypothesis of a single photosynthetic ancestor of chromalveolates. Eukaryotic Cell 3: 1169-1175.

[100] Patterson D.J. 1989. Stramenopiles: chromophytes from a protistan perspective. In: Green JC, Leadbeater BSC, Diver WL, eds. The Chromophyte algae: problems and perspectives. Oxford: Clarendon Press pp: 357-379.

[101] Patterson D.J. 1999. The diversity of eukaryotes. Am Nat 154: S96-124.

[102] Plastino E.M., Berchez F.A.S., Paula E.J., Oliveira M.C., Oliveira E.C. 2005. Apostila do curso BIB120 - Morfologia e Taxonomia de Criptógamas, Depto. Botânica, Inst. Biociências, Universidade de São Paulo, SP.

[103] Ragan M.A., Bird C.J., Rice E.L., Singh R.K. 1993. The nuclear 18S ribosomal RNA gene of the red algae Hildenbrandia rubra contains a group I intron. Nucl Acids Res 21: 3898 .

[104] Ragan M.A., Bird C.J., Rice E.L., Gutell R.R., Murphy C.A., Singh R.K. 1994. A molecular phylogeny of the marine red algae (Rhodophyta) based on the nuclear smallsubunit rRNA gene. Proc Nat Acad Sci USA 91: 7276-7280.

[105] Reith M.E., Munholland J. 1995. Complete nucleotide sequence of the Porphyra purpurea chloroplast genome. Plant Mol Biol Rep 13: 333-335.

[106] Roger A.J. 1999. Reconstructing early events in eukaryotic evolution. Am Nat 154: S146-163.

[107] Rueness J. 2005. Further observations on Gracilaria vermiculophyla (Gracilariales, Rhodophyta) in Europe. Phycologia 44(4-supp.): 88. 
[108] Saiki R.K., Scharf S., Faloona F., Mullis K.B., Horn G.T., Erlich H.A., Arnheim N. 1985. Enzymatic amplification of beta-globin genomic sequences and restriction site analysis for diagnosis of sickle cell anemia. Science 230: 1350-1354.

[109] Sanger F., Nicklen S., Coulson A.R. 1977. DNA sequencing with chain-terminating inhibitors. Proc Natl Acad Sci USA 74: 5463-5467.

[110] Schimper A.F.W. 1883. Uber die entwicklung der chlorophyll korner und farbkorner. Bot Zeit; 41: 105-114.

[111] Seckbach J., Ott F.D. 1994. Systematic position and phylogenetic status of Cyanidium caldarium Geitler 1933. In Seckbach J. [ed.], Evolutionary pathway and enigmatic algae: Cyanidium caldarium (Rhodophyta) and related cells, 133-143. Kluwer Academic Publishers, Dordrecht.

[112] Simon D., Fewer D., Friedl T., Bhattacharya D. 2003. Phylogeny and self-splicing ability of the plastid tRNA-Leu group I intron. J Mol Evol. 57: 710-720.

[113] Sogin M.L. 1991. Early evolution and the origin of eukaryotes. Curr Opin Genet Dev 1: 457-463.

[114] Stechmann A., Cavalier-Smith T. 2002. Rooting the eukaryote tree by using a derived gene fusion. Science 297: 89-91.

[115] Stiller J.W., Waaland J.R. 1993. Molecular analysis reveals cryptic diversity in Porphyra (Rhodophyta). J Phycol 29: 506-517.

[116] Stiller J.W., Hall B.D. 1997. The origin of red algae: implications for plastid evolution. Proc Natl Acad Sci USA 94: 4520-4525.

[117] Stiller J.W., Reel D.C., Johnson J.C. 2003. A single origin of plastids revisited: convergent evolution in organellar genome content. J Phycol 39: 95-105.

[118] Turmel M., Otis C., Lemieux C. 1999. The complete chloroplast DNA sequence of the green alga Nephroselmis olivacea: Insights into the architecture of ancestral chloroplast genomes. Proc Natl Acad Sci USA 96: 10248-10253.

[119] Turmel M., Otis C., Lemieux C. 2002. The chloroplast and mitochondrial genome sequences of the charophyte Chaetosphaeridium globosum: Insights into the timing of the events that restructured organelle DNAs within the green algal lineage that led to land plants. Proc Natl Acad Sci USA 99: 11275-11280.

[120] Turner S., Pryer K.M., Miao V.P., Palmer J.D. 1999. Investigating deep phylogenetic relationships among cyanobacteria and plastids by small subunit rRNA sequence analysis. J Eukaryot Microbiol 46: 327-338.

[121] Woese C.R. 1987. Bacterial evolution. Microbiol Rev 51: 221-71.

[122] Wolfe G.R., Cunningham F.X., Durnford D.G., Green B.R., Gantt E. 1994. Evidence from a common origin of chloroplasts with light-harvesting complexes of different pigmentation. Nature 367: 566-8.

[123] Xiao S., Zhang Y., Knoll A.H. 1998. Three dimensional preservation of algae and animal embryos in a Neoproterozoic phosphorite. Nature 391: 553-558.

[124] Yoneshigue Y. 1985. Taxonomie et Ecologie des Algues Marine dans la Region de Cabo Frio (RJ, Bresil). Thèse de Docteur d'Etat-Sciences, Univ. d'Aix-Marseille II. 454 p.

[125] Yoon H.S., Hackett J., Pinto G., Bhattacharya D. 2002. The single ancient origin of chromist plastids. Proc Natl Acad Sci USA 99: 15507-15512. 
[126] Yoon H.S., Hackett J., Ciniglia C., Pinto G., Bhattacharya D. 2004. A molecular time line for the origin of photosynthetic eukaryotes. Molecular Biology and Evolution 21: 809-818.

[127] Yoshida T., Notoya M., Kikuchi N., Miyata M. 1997. Catalogue of species of Porphyra in the world, with special reference to the type locality and bibliography. Nat Hist Res Special Issue 3: 5-18. 


\title{
Phylogeny of the Bangiophycidae (RHODOPHYTA) AND THE SECONDARY ENDOSYMBIOTIC ORIGIN OF ALGAL PLASTIDS ${ }^{1}$
}

\author{
Mariana C. Oliveira² And Debashish Bhattacharya ${ }^{3,4}$ \\ ${ }^{2}$ Department of Botany, Institute of Biosciences, University of São Paulo, R. Matão, Travessa 14, N. 321, São Paulo, SP, \\ Brazil CEP 05508-900; and \\ ${ }^{3}$ Department of Biological Sciences, University of Iowa, 239 Biology Building, Iowa City, Iowa 52242-3110 USA
}

\begin{abstract}
The Rhodophyta (red algae) are composed of the subclasses Bangiophycidae and Florideophycidae. Two evolutionarily interesting features of the Bangiophycidae are: (1) they are the ancestral pool from which the more morphologically complex taxa in the Florideophycidae have arisen and (2) they are the sources of the plastids, through secondary endosymbioses, for the Cryptophyta, Haptophyta, and the Heterokonta. To understand Bangiophycidae phylogeny and to gain further insights into red algal secondary endosymbioses, we sequenced the plastid-encoded small subunit ribosomal DNA (rDNA) coding region from nine members of this subclass and from two members of the Florideophycidae. These sequences were included in phylogenetic analyses with all available red algal plus chlorophyll $a+c$ algal plastid rDNA coding regions. Our results are consistent with a monophyletic origin of the Florideophycidae with these taxa forming a sister group of the Bangiales. The Bangiophycidae is of a paraphyletic origin with orders such as the Porphyridiales polyphyletic and distributed over three independent red algal lineages. The plastids of the heterokonts are most closely related to members of the CyanidiumGaldieria group of Porphyridiales and are not directly related to cryptophyte and haptophyte plastids. The phylogenies provide strong evidence for the independent origins of these "complex" algal plastids from different members of the Bangiophycidae.
\end{abstract}

Key words: Bangiophycidae; phylogeny; plastid; Rhodophyta; secondary endosymbiosis; small subunit rRNA.

The Rhodophyta (red algae) comprise a distinct lineage that arises from the "crown" of the eukaryotic radiation (Bhattacharya et al., 1990; Van de Peer et al., 1996; Stiller and Hall, 1997). Red algae are united by a suite of characters that do not occur together in any other eukaryote. These include a complete lack of flagellated stages and basal bodies, a two-membraned "simple" plastid (Bhattacharya and Medlin, 1995) that lacks chlorophyll $b$ or $c$, contains unstacked thylakoids, and food reserves stored as floridean starch (Garbary and Gabrielson, 1990). Traditionally, systematists have divided the red algae into two subclasses, the Bangiophycidae and the Florideophycidae (Gabrielson, Garbary, and Scagel, 1985). The Florideophycidae include morphologically complex red algae in orders such as the Gigartinales and the Ceramiales, and is widely believed to be a derived, monophyletic group (Garbary and Gabrielson, 1990; Ragan et al., 1994; Freshwater et al., 1994; Saunders and Kraft, 1997). The Bangiophycidae, on the other hand, are thought to form the ancestral pool from which the Florideophycidae has evolved. The Bangiophycidae may have a paraphyletic origin because of a lack of shared synapomorphic characters (Gabrielson et al., 1990; Garbary

\footnotetext{
${ }^{1}$ Manuscript received 30 March 1999; revision accepted 29 July 1999.

DB thanks the College of Liberal Arts (University of Iowa) and a grant from the Carver Foundation and K. Weber (Max Planck Institute for Biophysical Chemistry, Göttingen, Germany) for supporting this research. MCO thanks FAPESP and CNPq for research grants and the DAAD for a visiting grant at the Max Planck Institute for Biophysical Chemistry, E. C. Oliveira for useful comments, and C. Bird for help with nomenclature.

${ }^{2}$ Author for correspondence (Ph: 319-335-1977, FAX: 319-335-1069, e-mail:dbhattac@blue.weeg.uiowa.edu).
}

and Gabrielson, 1990). Molecular sequence comparisons generally confirm these views of red algal evolution ( $\mathrm{Ra}-$ gan et al., 1994; Freshwater et al., 1994), although a paucity of data has left unclear the phylogeny of the Bangiophycidae (Dixon, 1973; Garbary, Hansen, and Scagel, 1980; Saunders and Kraft, 1997).

A second, equally interesting and as yet unexplored issue regarding the Bangiophycidae concerns its central position in the endosymbiotic origin of algal plastids (Gray, 1992; Gibbs, 1993; Whatley, 1993; Bhattacharya and Medlin, 1995, 1998). One part of this theory holds that the plastids of many algal groups have originated, not through a primary endosymbiosis involving a cyanobacterium, but rather through the uptake of an existing photosynthetic eukaryote (secondary endosymbiosisLudwig and Gibbs, 1987; Häuber et al., 1994; Gilson and McFadden, 1996; Palmer and Delwiche, 1996). Molecular analyses have substantiated this view and have indicated that a number of algal lineages have gained their so-called "complex" morphology (Sitte, 1993) plastids (three or more bounding membranes) through a secondary endosymbiosis involving, in some cases, a eukaryotic red alga (viz., Cryptophyta, Haptophyta, Heterokonta) and in other cases, a eukaryotic green alga (viz., Chlorarachniophyta, Euglenophyta). An important question that remains regarding red algal secondary endosymbioses is the number of events involved. In other words, have all of these plastids arisen from multiple, independent endosymbioses of red algae or do some of them (and the "host" cells) trace their origins to a single endosymbiotic event followed by separation of the nuclear lineages over evolutionary time? This is an important question because the genome sequence and phylogenetic data that are presently available, although clearly supportive 
TABLE 1. Algal strains obtained from the Sammlung von Algenkulturen (SAG).

\begin{tabular}{llll}
\hline \hline \multicolumn{1}{c}{ Species } & SAG number & \multicolumn{1}{c}{ Collection site } & Order \\
\hline Bangia fuscopurpurea (Dillwyn) Lyngbye & B59.81 & Helgoland, Germany & Bangiales \\
Porphyra leucosticta Thuret in Le Jolis & B55.88 & Helgoland & Bangiales \\
Compsopogon coeruleus (Balbis in C. A. Agardh) Montagne & B36.94 & New Orleans, USA & Compsopogonales \\
Stylonema alsidii (Zanardini) Drew & B2.94 & Helgoland & Porphyridiales \\
Chroothece richteriana Hansgirg & B104.79 & Texas, USA & Porphyridiales \\
Chroodactylon ramosum (Thwaites) Hansgirg & B103.79 & Texas & Porphyridiales \\
Flintiella sanguinaria Ott in Bourelly & B40.94 & Texas (Utex2060) & Porphyridiales \\
Rhodosorus marinus Geitler & 116.79 & Italy & Porphyridiales \\
Galdieria sulphuraria (Galdieri) Merola & 107.79 & California (Utex2393) & Cyanidiales \\
Nemalionopsis tortuosa Yagi et Yoneda & B42.94 & Japan & Batrachospermales \\
Thorea violacea Bory de St. Vincent & 51.94 & & Batrachospermales \\
\hline
\end{tabular}

a Synonyms: Stylonema $=$ Goniotrichum $($ Wynne, 1985).

of a red algal origin of the complex plastids of the Cryptophyta, Haptophyta, and the Heterokonta, are more ambiguous about the number of events that gave rise to them (Kowallik, 1997; Douglas and Penny, 1999). This is because the plastid genomes of these algae are sufficiently different from each other to preclude a clear understanding of their interrelationships. Phylogenies of the host cells, based on nuclear-encoded rRNA sequences, are similarly ambiguous in establishing phylogenetic relationships among these algal lineages relative to other crown group eukaryotes (Bhattacharya et al., 1995). To address these issues and to gain insights into the evolutionary relationships of the Bangiophycidae, we sequenced the plastid-encoded small subunit ribosomal DNA (SSU rDNA) coding region from nine members of this subclass and from two members of the Florideophycidae. These sequences were included in an alignment with all available plastid rDNA sequences from the red algae and taxa containing plastids of a red algal origin and were analyzed with different phylogenetic methods to understand plastid phylogeny.

\section{MATERIALS AND METHODS}

The red algal cultures were obtained from the Sammlung von Algenkulturen (SAG) at the University of Göttingen (Schlösser, 1994). The species and strain numbers of these taxa are listed in Table 1. Algal material (100-400 $\mathrm{mg}$ fresh mass) was ground in liquid nitrogen and total genomic DNA was extracted using the DNeasy Plant Mini Kit (Qiagen, Santa Clarita, California, USA). Polymerase chain reaction (PCR) amplifications were performed using synthetic oligonucleotide primers that recognize conserved sequences at the termini of the plastidencoded SSU rDNA genes (Huss and Giovannoni, 1989; see Table 2). PCR products were purified using the QIAquick PCR Purification kit (Qiagen) and cloned using the TA cloning kit and the plasmid vector pCR2.1 (Invitrogen, Carlsbad, California, USA). Plasmid DNA was isolated and purified using the Plasmid Midi Kit (Qiagen). The rDNA sequences were determined over both strands using an ABI-310 Genetic Analyser (Perkin-Elmer), and the primers listed in Table 2, with the Dye Terminator Cycle Sequencing Ready Reaction Kit (Perkin-Elmer, Norwalk, Connecticut, USA). These plastid coding regions were included in a secondary-structure-based alignment of SSU rDNAs that included sequences from eubacteria and members of all the major algal groups except the dinoflagellates.

Alignments were optimized manually using the SeqApp program (Gilbert, 1992) and a total of 1370 sequence positions were used in the phylogenetic analyses. Two data sets (available from D. B.) were created from the large alignment. The first included cyanobacteria and representatives of the different plastid lineages (567 parsimony informative sites), and the second data set was restricted to the red algae and plastids derived from these taxa with the green algae as the outgroup (489 parsimony informative sites). A matrix was calculated from the first data set using the LogDet (Lockhart, Steel, and Penny, 1994) transformation, and a tree was built using the neighbor-joining method (Saitou and Nei, 1987). This data set was also analyzed with a distance method in which the matrix was calculated with the HKY-85 model

TABLE 2. Primers used for the PCR amplification and sequencing of coding (F) and noncoding (R) strands of the plastid-encoded SSU rDNA coding region (Huss and Giovannoni, 1989).

\begin{tabular}{cl}
\hline \hline PCR primers & \\
SG-1 & GTGCTGCAGAGAGTTYGATCCTGGCTCAGG \\
SG-2 & CACGGATCCAAGGAGGTGATCCANCCNCACC \\
Seq. primers & $\left(5^{\prime}-3^{\prime}\right)$ \\
$227 \mathrm{~F}$ & CTGATTAGCTWGTTGGT \\
$479 \mathrm{~F}$ & GTGCCAGCAGCCGCGGT \\
$651 \mathrm{~F}$ & AGCGGTGAATGCGTAG \\
$874 \mathrm{~F}$ & ACTCAAAGAATTGACG \\
$1056 \mathrm{~F}$ & GCAACGAGGCAACCCT \\
$1288 \mathrm{~F}$ & GAATCGCTAGTAATCGC \\
$243 \mathrm{R}$ & ACCAACWAGCTAATCAG \\
$495 \mathrm{R}$ & ACCGCGGCTGCTGGCAC \\
$667 \mathrm{R}$ & CTACGCATTCACCGCT \\
$890 \mathrm{R}$ & CGTCAATTCCTTTGAGT \\
$1072 \mathrm{R}$ & AGGGTTGCGCTCGTTGC \\
$1304 \mathrm{R}$ & GCGATTACTAGCGATTC \\
\hline
\end{tabular}


(Hasegawa, Kishino, and Yano, 1985) and the tree built with the neighbor-joining method. Bootstrap analyses (Felsenstein, 1985; 2000 replications) were done using both the LogDet transformation and distance method. Missing data and gaps were excluded from the LogDet and distance analyses. All phylogenetic analyses were implemented with the PAUP* version $4.0 b 1$ computer program (Swofford, 1999). We did not implement the parsimony method with the first data set because previous analyses (e.g., Helmchen, Bhattacharya, and Melkonian, 1995; Nelissen et al., 1995) show that this (and often other) method artifactually groups the secondary plastids of the Euglenophyta within the red plastid lineage. This results from divergence rate differences (Van de Peer et al., 1996) and a biased nucleotide content of the euglenophyte rDNA sequences (Helmchen, Bhattacharya, and Melkonian, 1995). The LogDet transformation is applicable under such circumstances (Lockhart, Steel, and Penny, 1994). In our analyses, the distance method also provided the predicted result of a sister-group relationship between the chlorophyll $a+b$ containing plastids of the chlorarachniophytes/euglenophytes and the green algae and, therefore, was also used to calculate bootstrap support for nodes in the LogDet tree.

The second data set was analyzed with the maximum likelihood method (in PAUP*). Starting trees were obtained with stepwise additions (randomly drawn, five rounds) and re-arranged with tree bisectionreconnection. The HKY-85 distance model was used in this analysis with the transition/transversion ratio set to two, empirical determination of nucleotide frequencies, equal divergence rates over all sites, and the starting branch-lengths calculated with the Rogers-Swofford method (Swofford, 1999). The maximum parsimony, LogDet transformation, and distance methods were also used to infer trees with the second data set. In the maximum parsimony analysis, starting trees were obtained with stepwise sequence addition (randomly drawn, ten rounds) and rearranged with tree bisection-reconnection. The sequence positions were weighted in the parsimony analysis (rescaled consistency index over an interval of 1-1000) to reduce the influence of highly divergent sites in the phylogeny reconstruction (Bhattacharya, 1996). The LogDet transformation and distance method were done as described above. Bootstrap analyses (2000 replications) were done with all phylogenetic methods except maximum likelihood. In the bootstrap analyses, consensus trees were calculated, and the resulting bootstrap values were included (for shared monophyletic groups) at the branches of the maximum likelihood tree.

We also tested for congruence of the trees inferred with the maximum likelihood, maximum parsimony, LogDet, and distance trees using the Kishino-Hasegawa test (Kishino and Hasegawa, 1989 [within PAUP*]). In this analysis, all trees were compared to the topology of the maximum likelihood phylogeny to test for significant $(P<0.05)$ differences among them. In addition, we changed the topology of the maximum likelihood tree using the MacClade computer program (version 3.07; Maddison and Maddison, 1997) and compared these rearranged trees to the "best" tree to test different hypotheses about plastid evolution. The taxa used in our study and GenBank accession numbers (the prefix GBAN- has been added to link the online version of American Journal of Botany to GenBank but is not part of the actual accession number) are shown in Table 3. The OM (off Cape Hatteras, North Carolina, USA) and OCS (off the mouth of Yaquina Bay, Oregon, USA) clones derive from open-ocean material collected and analyzed by Rappé et al. (1998). These are environmental samples in which the diverse array of algae were identified through cloning and sequence analysis of rDNA isolated from plankton collections (for details, see Rappé et al., 1998).

\section{RESULTS}

The SSU rDNAs isolated and sequenced in this study did not contain any significant insertions or deletions. These coding regions were easily aligned with homologous rDNAs from the other plastids. The LogDet transformation resulted in a phylogeny that is consistent with previous analyses of plastid SSU rDNAs (e.g., Bhattacharya and Medlin, 1998; Martin et al., 1998). This tree (Fig. 1) shows that the plastids form a monophyletic group with respect to the cyanobacteria included in the analyses, an observation that is consistent with a single primary endosymbiotic origin of these organelles (Cavalier-Smith, 1982; Bhattacharya and Medlin, 1995). Within the plastids, there is a separation into three lineages: (1) defined by the cyanelles of the Glaucocystophyta (strong support); (2) the chloroplasts and secondary endosymbionts derived from these algae (moderate suport); and (3) the rhodoplasts and secondary endosymbionts derived from these algae (weak support). Within the rhodoplasts, the complex plastids of the Cryptophyta, Haptophyta, and Heterokonta form three strongly supported lineages (see also Fig. 2) with weaker bootstrap support for cryptophyte/haptophyte monophyly (69\% LogDet, 60\% distance). The LogDet and distance trees were largely congruent, with the only difference restricted to the divergence point of the cyanelles within the three plastid groups. The LogDet tree (Fig. 1) showed the cyanelles to be positioned as a sister group of the rhodoplasts ( $51 \%$ bootstrap support, not shown), whereas the distance tree showed the cyanelles to be the earliest divergence within plastids (42\% bootstrap support, not shown). Previous rDNA analyses using parsimony and distance have also failed to resolve clearly the evolutionary relationships between the three plastid lineages (Helmchen, Bhattacharya, and Melkonian, 1995; Rappé et al., 1998). A recent analysis of concatenated protein sequences (11039 amino acids) from nine different completely sequenced plastid genomes provides, however, strong support for the early divergence of cyanelles within the plastid radiation (Martin et al., 1998).

The results of the phylogenetic analyses of the second data set are summarized in Fig. 2. These data address the evolutionary relationships of the Bangiophycidae and the origin of rhodoplast-derived complex plastids. The trees resulting from the five rounds of randomized sequence additions in the maximum likelihood analysis of the second data set all resulted in the phylogeny shown in Fig. 2. The Kishino-Hasegawa test did not show a significant difference (see Table 4) between the maximum likelihood tree and the trees inferred with the parsimony $(P=$ $0.6248), \operatorname{LogDet}$ transformation $(P=0.0515)$, and distance methods $(P=0.0866)$. The maximum likelihood tree was nearly identical to the single most parsimonious phylogeny inferred from the unweighted data (2775 steps, $\mathrm{CI}=0.34)$. In these trees, the only difference involved the switching of the divergence points of the haptophyte plastids and the rhodoplasts of the Porphyridiales group that includes $G$. vacuolata and C. coeruleus. The trees inferred from the LogDet and distance analyses were identical and differed from the maximum likelihood tree and maximum parsimony trees with respect to the branching order of different paraphyletic groups within the Bangiophycidae. The Bangiales was a monophyletic, strongly supported group in all the bootstrap analyses (100\% support). In addition, P. purpurea was found to be more closely related to $B$. fuscopurpurea than to $P$. leucosticta in all the trees. The Bangiales were positioned as a sister group of the Florideophycidae in all analyses, with the LogDet and distance methods providing mod- 
TABLE 3. Plastid-encoded SSU rDNAs used in the phylogenetic analyses.

\begin{tabular}{|c|c|c|}
\hline Species & Group & Accession no. ${ }^{a}$ \\
\hline Agrobacterium tumefaciens (Smith and Townsend) Conn & Proteobacteria & GBAN-M11223 \\
\hline Anabaena sp. Bory & Cyanobacteria & GBAN-X59559 \\
\hline Anacystis nidulans Meneghini (= Synechococcus sp.) & - & GBAN-X03538 \\
\hline Gloeobacter violaceus Rippka et al. (1974) & - & $\begin{array}{l}\text { S. Turner, University of Indiana, } \\
\text { unpublished data }\end{array}$ \\
\hline Leptolyngbya boryanum Anagnostidis et Komárek & - & GBAN-X84810 \\
\hline Microcystis aeruginosa NIES 98 Kützing em. Elenkin & - & GBAN-U40337 \\
\hline Prochloron sp. Urbach et al. (1992) & - & GBAN-X63141 \\
\hline Spirulina sp. Turpin & - & GBAN-X75044 \\
\hline Synechococcus elongatus Nägeli & - & GBAN-D83715 \\
\hline Alnus incana (L.) Moench & Streptophyta & GBAN-U03555 \\
\hline Chara sp. Valliant & 12 & GBAN-X75519 \\
\hline Coleochaete orbicularis Pringsheim & - & GBAN-U24579 \\
\hline Equisetum arvense L. & - & GBAN-U24593 \\
\hline Oryza sativa $\mathrm{L}$. & - & GBAN-X15901 \\
\hline Osmunda cinnamomea $\mathrm{L}$. & - & GBAN-U24594 \\
\hline Spirogyra maxima (Hassall) Wittrock & - & GBAN-U24596 \\
\hline Chlorella kessleri Fott et Nováková & Chlorophyta & GBAN-X65099 \\
\hline Clone OCS 162 & - & GBAN-AF001659 \\
\hline Antithamnion sp. Nägeli & Rhodophyta & GBAN-X54299 \\
\hline Bangia fuscopurpurea (Dillwyn) Lyngbye & - & GBAN-AF170716 \\
\hline Chondrus crispus Stackhouse & - & GBAN-Z29521 \\
\hline Chroodactylon ramosum & - & GBAN-AF170712 \\
\hline Chroothece richteriana & - & GBAN-AF170711 \\
\hline Compsopogon coeruleus & - & GBAN-AF170713 \\
\hline Cyanidium caldarium (Allen str. 14-1-1) & - & GBAN-X52985 \\
\hline Cyanidium caldarium (str. RK-1) & - & GBAN-AF022186 \\
\hline Flintiella sanguinaria & - & GBAN-AF170715 \\
\hline Galdieria sulphuraria & - & GBAN-AF170718 \\
\hline Nemalionopsis tortuosa & - & GBAN-AF 170720 \\
\hline Stylonema alsidii & - & GBAN-AF170714 \\
\hline Palmaria palmata (L.) Kuntze & - & GBAN-Z18289 \\
\hline Porphyra leucosticta & - & GBAN-AF 170717 \\
\hline Porphyra purpurea Roth C. Agardh & - & GBAN-U38804 \\
\hline Porphyridium aerugineum Geitler & - & $\begin{array}{l}\text { U. Maid and K. Zetsche, University of Giessen, } \\
\text { unpublished data }\end{array}$ \\
\hline Rhodosurus marinus & - & GBAN-AF170719 \\
\hline Thorea violacea & - & GBAN-AF170721 \\
\hline Cyanophora paradoxa Korshikov & Glaucocystophyta & GBAN-X81840 \\
\hline Glaucocystis nostochinearum Itzigsohn & - & GBAN-X82496 \\
\hline Glaucoshaera vacuolata Korshikov & - & GBAN-X81903 \\
\hline Gloeocochaete wittrockiana Lagerheim & - & GBAN-X82495 \\
\hline Chlorarachnion reptans Geitler & Chlorarachniophyta & GBAN-U21490 \\
\hline Astasia longa Pringsheim & Euglenophyta & GBAN-X14386 \\
\hline Euglena gracilis Klebs & - & GBAN-X12890 \\
\hline Emiliania huxleyi (Lohm.) Hay et Mohler & Haptophyta & GBAN-X82156 \\
\hline Isochrysis sp. Parke & $1+$ & GBAN-X75518 \\
\hline Ochrosphaera sp. Schussnig & - & GBAN-X65101 \\
\hline Clone OCS31 & - & GBAN-AF001655 \\
\hline Clone OM21 & - & GBAN-U32671 \\
\hline Clone OM125 & - & GBAN-U70719 \\
\hline Clone OM153 & - & GBAN-U70720 \\
\hline Clone OM270 & - & GBAN-U70723 \\
\hline Guillardia theta Ehrenberg & Cryptophyta & GBAN-AF041468 \\
\hline Rhodomonas salina Karsten & - & GBAN-X55015 \\
\hline Clone OCS20 & - & GBAN-AF001654 \\
\hline Clone OM283 & - & GBAN-U70724 \\
\hline Heterosigma akashiwo Carter & Heterokonta & GBAN-M34370 \\
\hline Ochromonas danica Pringsheim & - & GBAN-X53183 \\
\hline Odontella sinensis Greville & - & GBAN-Z67753 \\
\hline Pylaiella littoralis (L.) Kjellman & - & GBAN-X14803 \\
\hline Skeletonema costatum (Grev.) Cleve & - & GBAN-X82154 \\
\hline Clone OCS54 & - & GBAN-AF001657 \\
\hline Clone OM20 & - & GBAN-U70723 \\
\hline Clone OM81 & - & GBAN-U70717 \\
\hline Clone OM164 & - & GBAN-U70721 \\
\hline
\end{tabular}

a The prefix GBAN- has been added to link the online version of American Journal of Botany to GenBank but is not part of the actual accession number. 


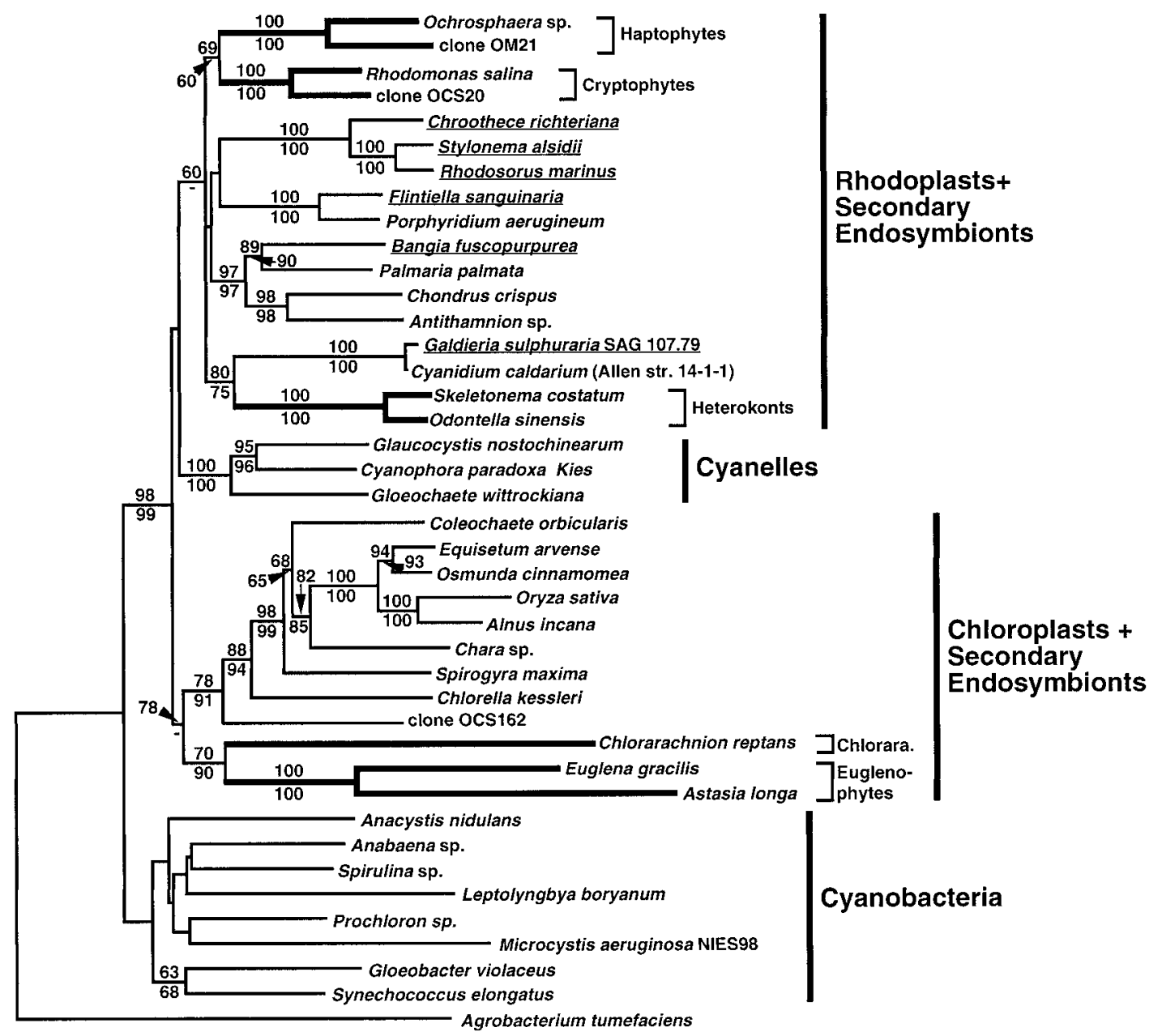

Fig. 1. Phylogeny of plastid-encoded and cyanobacterial SSU rDNA coding regions (1370 positions) inferred using the LogDet transformation and the neighbor-joining method. This tree has been rooted on the branch leading to the Agrobacterium tumefaciens sequence. Gaps and missing data were excluded from the analysis. The results of bootstrap analyses (2000 replications) are shown above the internal nodes. The bootstrap values (2000 replications) shown below the internal were inferred from a distance analysis using the HKY-85 model and the neighbor-joining method. Only bootstrap values $\geq 60 \%$ are shown. Arrows are used to show the position of bootstrap values when they do not fit on the branches. The complex plastid lineages are shown with thick branches. Chlorara. $=$ chlorarachniophytes. Sequences determined in this study have been underlined.

erate bootstrap support (80\%) for this relationship. Although the Florideophycidae was monophyletic in the different phylogenetic analyses, only the weighted parsimony method provided weak bootstrap support for this result $(70 \%)$. The Porphyridiales were divided over three separate lineages (the $F$. sanguinaria-P. aerugineum group, the C. richteriana-C. ramosum-G. alsidii-R. marinus group, and the Cyanidium spp.-G. sulphuraria group). The taxonomy of the Cyanidium-G. sulphuraria group is either as members of the Porphyridiales (as shown here; Garbary, Hansen, and Scagel, 1980) or as members of a separate order, Cyanidiales (Ott and Seckbach, 1994).

With regard to the ancestry of the rhodoplast-derived complex plastids, all phylogenetic analyses provided moderate to strong bootstrap support for the monophyletic origin of the plastids in the cryptophytes, haptophytes, and heterokonts (Fig. 2). The trees also all positioned the cryptophyte plastids as the earliest divergence in the rhodoplast assemblage. This result was, however, not consistent with other analyses (not shown) in which the rRNA sequences in the second data set (including the chloroplasts) were outgroup-rooted with the cyanelles of the Glaucocystophyta. Maximum parsimony, LogDet transformation, and distance analyses of these data all positioned the cryptophyte plastids as a sister group of the heterokonts (as in Fig. 1), though with weak bootstrap support (62\% in LogDet, and $60 \%$ in distance analyses). A general feature of all the phylogenies was a lack of bootstrap support for the position of the cryptophytes and the haptophytes within the paraphyletic radiation of the Bangiophycidae. The analyses did, on the other hand, consistently provide weak to moderate bootstrap support for an evolutionary relationship between the CyanidiumG. sulphuraria group and the heterokont plastids with the maximum likelihood and parsimony analyses suggesting that $C$. caldarium (RK-1) is related to the direct ancestor of heterokont plastids (albeit without bootstrap support). 


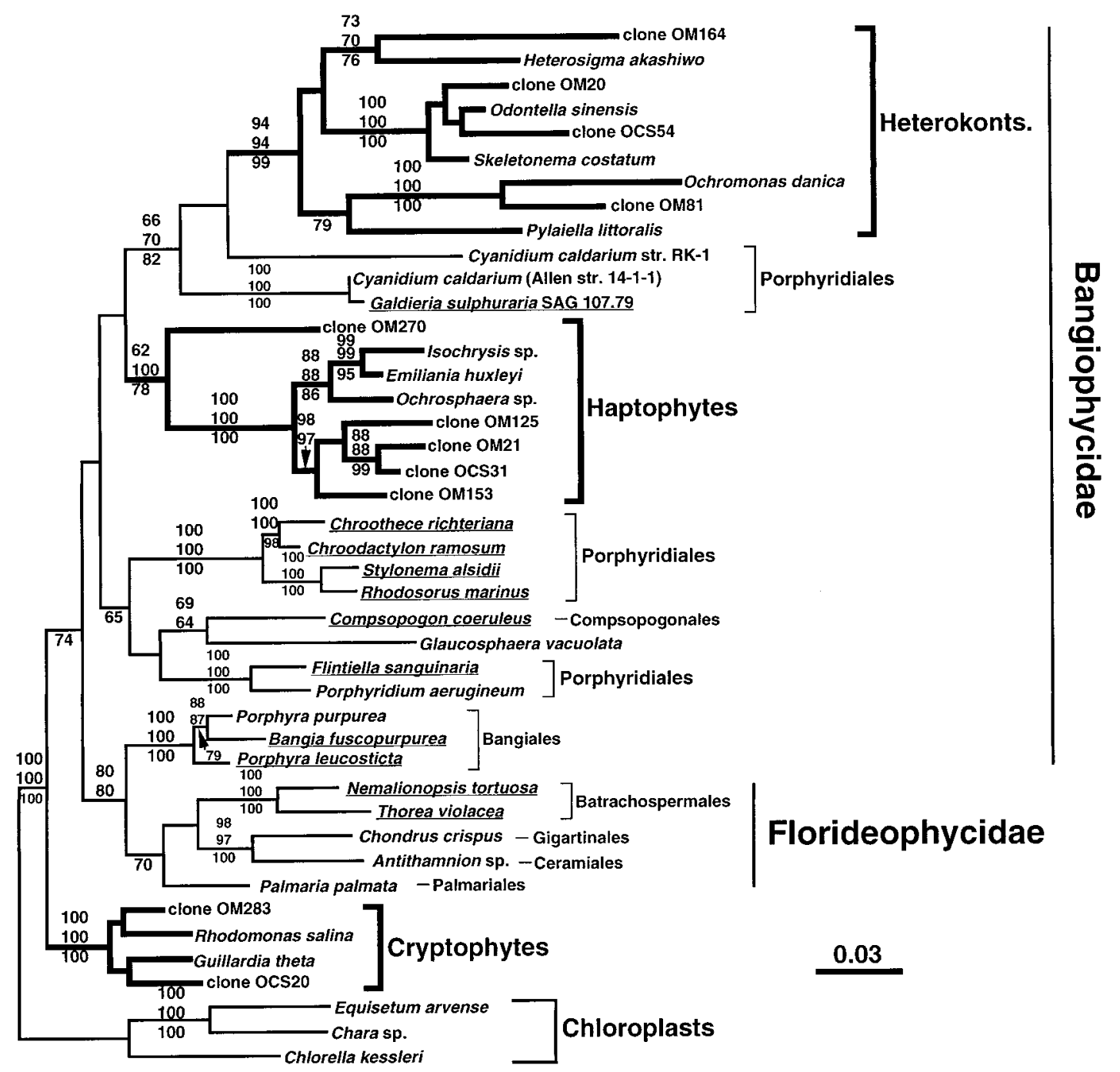

Fig. 2. A maximum likelihood tree inferred from comparisons of plastid-encoded SSU rDNA coding regions (1370 positions) showing the evolutionary relationships of rhodoplasts and rhodoplast-derived complex plastids. This tree has a log likelihood of -16177.3270 and has been rooted on the branch leading to the chloroplast rDNA sequences. The scale bar show 3\% sequence change in the horizontal axis. The topmost bootstrap values shown above the internal nodes are from a LogDet transformation analysis and a neighbor-joining tree construction, whereas the values below these were inferred from a distance analysis using the HKY-85 model and the neighbor-joining method. The bootstrap values shown below the internal nodes result from a weighted maximum parsimony analysis. All bootstrap values were calculated from 2000 replications. Only bootstrap values $\geq 60 \%$ are shown. Arrows are used to show the position of bootstrap values when they do not fit on the branches. The complex plastid lineages are shown with thick branches. Sequences determined in this study have been underlined.

The haptophyte plastids were positioned at the base of or outside the Cyanidium-G. sulphuraria group + heterokont plastids in all the analyses.

The Kishino-Hasegawa test was used to compare the trees shown in Fig. 3. The maximum likelihood tree was used as the standard for these analyses and the different rearrangements tested were: tree 1 forced monophyly of the heterokont and haptophyte plastids, tree 2 forced monophyly of the cryptophyte and haptophyte plastids, tree 3 forced monophyly of the heterokont and cryptophyte plastids, tree 4 forced monophyly of the heterokont, haptophyte, and cryptophyte plastids, tree 5 forced monophyly of plastids of the Cyanidium-G. sulphuraria group and the Porphyridiales group that includes $C$. richteriana and G. alsidii, and tree 6 forced monophyly of plastids of the Cyanidium-G. sulphuraria group and the Por- phyridiales group of $F$. sanguinaria and $P$. aerugineum. The results of these tree comparisons are shown in Table 4.

The Kishino-Hasegawa test showed that trees 3-6 were significantly different from the best tree shown in Fig. 2. Trees 1, 2, and 3, which positioned haptophytes and heterokonts together, cryptophytes and haptophytes together, and cryptophytes and heterokonts together, respectively, were not rejected with the Kishino-Hasegawa test. The rearrangements that were significantly different from the best tree were the forced monophyly of heterokont and cryptophyte plastids (tree $3, P<0.0001$ ), the forced monophyly of all rhodoplast-derived complex plastids (tree $4, P=0.0231$ ), and the inclusion of the Cyanidium$G$. sulphuraria group with other lineages of the Porphyridiales [tree $5, P=0.0337$; tree $6, P=0.0432$ ). 
TABLE 4. Tests of tree congruence with the Kishino-Hasegawa test. The comparisons of the best maximum likelihood tree inferred from the second data set (Fig. 2) with phylogenies calculated with the maximum parsimony (MP), LogDet transformation (LD), and distance (HKY) methods are shown. In addition, the comparisons of the maximum likelihood tree with the topologies of the rearranged trees in Fig. 3 are also shown.

\begin{tabular}{lcccc}
\hline \hline \multicolumn{1}{c}{ Tree } & $-\log$ likelihood & $\begin{array}{c}\text { Diff. in }-\log \\
\text { likelihood }\end{array}$ & \multicolumn{1}{c}{ SD } & $P^{\mathrm{a}}$ \\
\hline Best & 16177.3270 & - & - & - \\
MP & 16186.4868 & 9.1598 & 18.7228 & 0.6248 \\
LD & 16224.0425 & 46.7155 & 23.9664 & 0.0515 \\
HKY & 16222.3389 & 45.0119 & 26.2468 & 0.0866 \\
Tree 1 & 16213.9857 & 36.6588 & 20.0168 & 0.07 \\
Tree 2 & 16189.9711 & 12.6440 & 13.2110 & 0.34 \\
Tree 3 & 16276.3525 & 99.0255 & 23.3380 & $<0.0001^{*}$ \\
Tree 4 & 16230.6603 & 53.3333 & 23.4521 & $0.0231^{*}$ \\
Tree 5 & 16220.1323 & 42.8053 & 20.1329 & $0.0337^{*}$ \\
Tree 6 & 16223.0715 & 45.7445 & 22.6069 & $0.0432^{*}$ \\
\hline
\end{tabular}

a Asterisks indicate trees that differ significantly from the best maximum likelihood tree.

\section{DISCUSSION}

Phylogeny of the Bangiophycidae-Our results indicate that the Bangiales is a monophyletic order. Porphyra appears, however, to be paraphyletic, with $P$. purpurea being more closely related to $B$. fuscopurpurea than to $P$. leucosticta. Both of these observations are supported by comparisons of nuclear-encoded SSU rDNA coding regions (Ragan et al., 1994; Oliveira et al., 1995; Muller et al., 1998). The Bangiales is positioned as a sister group of the Florideophycidae (Figs. 1, 2), being more closely related to the Florideophycidae than to the other lineages of Bangiophycidae. This relationship is supported by the association of the Golgi apparatus with the mitochondrion in these groups (see Table 5; Garbary and Gabrielson, 1990) and the results of $r b c L$ sequence comparisons (Freshwater et al., 1994). Ragan et al. (1994) have shown, based on nuclear SSU rDNA analyses, that the Florideophycidae is monophyletic, with the Hildenbrandiales as

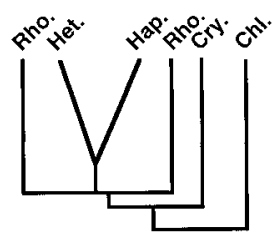

Tree 1

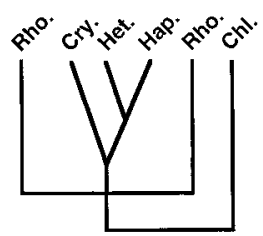

Tree 4

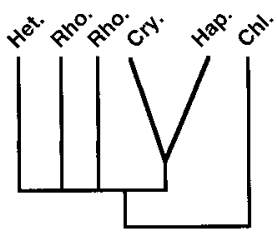

Tree 2

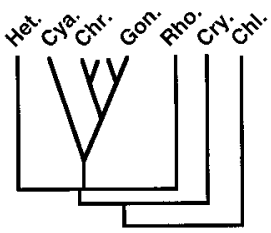

Tree 5

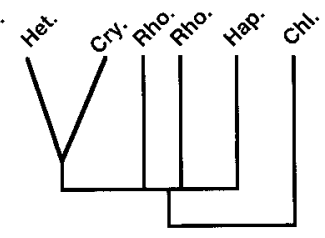

Tree 3

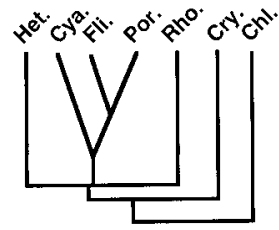

Tree 6
Fig. 3. The rearranged trees that were used to study, using the Kishino-Hasegawa test, the evolutionary positions of different rhodoplastderived complex plastids and of the Cyanidiales. Chl. = chlorophyte, Chr. $=$ Chroothece richteriana, Cry. $=$ cryptophyte, Cya. $=$ Cyanidiales, Fli. = Flintiella sanguinaria, Rho. = rhodophyte, Gon. = Goniotrichum alsidii, Hap. = haptophyte, Het. = heterokont, and Por. = Porphyridium aerugineum.

the first divergence and the NAP complex (Nemaliales, Acrochaetiales, and Palmariales) as the second diverging lineage. Our data also suggest that the Florideophycidae is a monophyletic group.

The Porphyridiales (sensu Garbary, Hansen, and Scagel, 1980) are not a monophyletic order, nor is the family Porphyridiaceae. Garbary and Gabrielson (1990) have shown that the Porphyridiales remain the most problematic order of red algae in terms of classification and evolutionary relationships. This order has been considered a heterogeneous assemblage by many authors (Fritsch, 1945; Lee, 1974; Ott, 1976; Scott, 1986). Others regard the Porphyridiales as an assemblage of organisms united solely by their unicellular to palmelloid habit and suggested that it may be polyphyletic (Garbary, Hansen, and Scagel, 1980; Gabrielson, Garbary, and Scagel, 1985;

TABLE 5. Classification and characteristics of the Bangiophycidae species analyzed. All species have a single plastid (in older cells of Compsopogon coeruleus the chloroplast can fragment into many small chloroplasts; Bold and Wynne, 1985). For ultrastructural details of the red algae, see Pueschel (1990) and Broadwater and Scott (1994). $\mathrm{N}=$ no, $\mathrm{Y}=$ yes, $\mathrm{ER}=$ endoplasmic reticulum, $\mathrm{M}=$ mitochondrion, $\mathrm{Nu}=$ nucleus.

\begin{tabular}{|c|c|c|c|c|c|c|c|c|}
\hline Species & Classification & Thallus & $\begin{array}{l}\text { Pit } \\
\text { con- } \\
\text { nec- } \\
\text { tions }\end{array}$ & $\begin{array}{l}\text { Pyre- } \\
\text { noids }\end{array}$ & $\begin{array}{l}\text { Cell } \\
\text { wall }\end{array}$ & $\begin{array}{l}\text { Periph- } \\
\text { eral } \\
\text { thyla- } \\
\text { koids }\end{array}$ & $\begin{array}{c}\text { Golgi } \\
\text { associations }\end{array}$ & Habitat \\
\hline Chroothece richteriana & Porphyridiaceae, Porphyridiales ${ }^{\mathrm{a}}$ & unicell & $\mathrm{N}$ & $\mathrm{Y}$ & & & & marine \\
\hline Chroodactylon ramosum & Porphyridiaceae, Porphyridiales ${ }^{\mathrm{a}}$ & filamentous & $\mathrm{N}$ & Y & & & & marine \\
\hline Stylonema alsidii & Porphyridiaceae, Porphyridiales ${ }^{\mathrm{a}}$ & filamentous & $\mathrm{N}$ & Y & & & & marine \\
\hline Rhodosorus marinus & Porphyridiaceae, Porphyridiales ${ }^{a}$ & unicell & $\mathrm{N}$ & Y & $\mathrm{N}$ & $\mathrm{N}$ & $\mathrm{ER} / \mathrm{M}$ & marine \\
\hline Compsopogon coeruleus & Compsopogonaceae, Compsopogonales ${ }^{\mathrm{a}}$ & complex filament & $\mathrm{Y}$ & $\mathrm{N}$ & $\mathrm{Y}$ & $\mathrm{Y}$ & ER & fresh water \\
\hline Glaucosphaera vacuolata & Glaucosphaeraceae, Glaucocystophyta ${ }^{\mathrm{b}}$ & unicell & $\mathrm{N}$ & $\mathrm{N}$ & $\mathrm{N}$ & $\mathrm{Y}$ & $\mathrm{Nu}$ & fresh water \\
\hline Flintiella sanguinaria & Phragmonemataceae, Porphyridiales ${ }^{a}$ & unicell & $\mathrm{N}$ & $\mathrm{N}$ & $\mathrm{N}$ & $\mathrm{N}$ & $\mathrm{ER} / \mathrm{M}$ & fresh water \\
\hline Porphyridium purpureum & Porphyridiaceae, Porphyridiales & unicell & $\mathrm{N}$ & Y & $\mathrm{N}$ & $\mathrm{N}$ & $\mathrm{ER} / \mathrm{M}$ & high salinity \\
\hline Porphyra leucosticta & Bangiaceae, Bangiales ${ }^{\mathrm{a}}$ & parenchym./filamentous & $\mathrm{Y}$ & Y & $\mathrm{Y}$ & N/Y & ER/M & marine \\
\hline Bangia fuscopurpurea & Bangiaceae, Bangiales ${ }^{\mathrm{a}}$ & filamentous & $\mathrm{Y}$ & $\mathrm{Y}$ & $\mathrm{Y}$ & N/Y & $\mathrm{ER} / \mathrm{M}$ & marine \\
\hline Galdieria sulphuraria & Cyanidiaceae, Cyanidiales ${ }^{c}$ & unicell & $\mathrm{N}$ & $\mathrm{N}$ & $\mathrm{Y}$ & $\mathrm{Y}$ & ER & thermophilous \\
\hline Cyanidium caldarium & Cyanidiaceae, Cyanidiales ${ }^{c}$ & unicell & $\mathrm{N}$ & $\mathrm{N}$ & $\mathrm{Y}$ & $\mathrm{Y}$ & ER & thermophilous \\
\hline
\end{tabular}

${ }^{\text {a }}$ Following the classification of Garbary, Hansen, and Scagel (1980).

${ }^{\mathrm{b}}$ Following the classification of Kies and Kremer (1986).

${ }^{c}$ Following the classification of Ott and Seckbach (1994). Garbary, Hansen, and Scagel (1980) classify both genera in the Phragmonemataceae (Porphyridiales). 
Scott and Gabrielson, 1987). The well-supported grouping composed of four species of the Porphyridiales, $C$. richteriana, $C$. ramosum, $S$. alsidii, and $R$. marinus, includes both unicells and filaments, with only one chloroplast and one pyrenoid per cell (Table 5). The close relationship of Chroodactylon and Chroothece has been previously pointed out by different authors (Lewin and Robertson, 1971; Garbary, Hansen, and Scagel, 1980). A second Porphyridiales grouping, which is more closely related to the Compsopogonales (however, with no bootstrap support), includes $F$. sanguinaria and $P$. purpureum. Both of these species are unicells with no cell walls and contain a single chloroplast that lacks peripheral thylakoids (Table 5). Scott (1986) pointed out that cell division in Flintiella was similar to that in Batrachospermum and, on this basis, Garbary and Gabrielson (1990) suggested that Flintiella may have evolved through reduction from a Batrachospermum-like ancestor. This scenario is not supported by our phylogenetic analyses.

Compsopogon coeruleus (Compsopogonales) is a complex, multiseriate alga with pit connections, cellulose in the cell walls, and one or more chloroplasts per cell with no pyrenoid (Table 5; Scott and Broadwater, 1989). Glaucosphera vacuolata, which groups weakly with $C$. coeruleus, is classified within the Glaucocystophyta (Kies and Kremer, 1986). Previous analyses of both nuclearand plastid-encoded SSU rDNA sequences have demonstrated that $G$. vacuolata is not directly related to other glaucocystophytes and is a member of the Rhodophyta (Bhattacharya et al., 1995; Helmchen, Bhattacharya, and Melkonian, 1995). Ultrastructural analyses suggest that G. vacuolata is a member of the Porphyridiales (Broadwater et al., 1995). Regarding Cyanidium spp. and $G$. sulphuraria, Seckbach and Ott (1994) have proposed that these genera should be united in a separate order, the Cyanidiales, within the Bangiophycidae. Our analyses support this idea. There is, however, presently no justification to unite both genera, as has been proposed by Seckbach and Ott (1994).

Due to a lack of synapomorphic characters to unite bangiophyte orders into a monophyletic group, Gabrielson, Garbary, and Scagel (1985) have recommended that a single class, Rhodophyceae, be recognized that includes all red algal lineages. Ragan et al. (1994), using comparisons of nuclear SSU rDNA sequences, showed that the Bangiophycidae are the basal rhodophyte line, comprising at least three distinct lineages. Our results add to the bulk of data that indicates a paraphyletic origin of the Bangiophycidae within the Rhodophyta. The generic use of the term bangiophytes is, however, undeniable and it continues to be useful to differentiate the earlier diverging, less complex, red algal lineages from the monophyletic, and more recently diverged florideophytes. Usage of the terms bangiophyte and florideophyte may therefore be used primarily for convenience, and these designations need not necesarily imply acceptance of previous taxonomic definitions of these taxa (Gabrielson and Garbary, 1987).

Secondary endosymbiotic origin of red algal plastids - The origin of the plastids in the Cryptophyta, Haptophyta, and the Heterokonta from a red algal secondary endosymbiont has been previously documented on the basis of sequence comparisons and plastid gene order (Douglas et al., 1991; Bhattacharya and Medlin, 1995; Palmer and Delwiche, 1996; Daugbjerg and Andersen, 1997a; Medlin et al., 1997; Douglas and Penny, 1999; Durnford et al., 1999). The recently sequenced plastid genome of the cryptophyte Guillardia theta, for example, shows remarkable conservation of synteny groups with the genome of the rhodophyte, Porphyra purpurea (Douglas and Penny, 1999). Such data "establish" a red algal origin of the G. theta, and possibly all other cryptophyte plastids. Douglas and Penny (1999) suggest that the cryptophyte endosymbiont may have been a taxon closely related to $P$. purpurea, not only on the basis of conserved synteny groups, but also based on the presence of a protein intein in the $d_{n a B}$ genes of these taxa and the putative origin, through reciprocal recombination, of the inverted repeat in $G$. theta from the nonidentical, directly repeated rDNA cistrons in $P$. purpurea. Gene order data also show conservation of the plastid genomes of the heterokont (diatom) Odontella sinensis and $P$. purpurea (Kowallik et al., 1995; Kowallik, 1997). A haptophyte plastid genome has not yet been sequenced. Given this information, then what can we say about the possible interrelationships of the heterokont and cryptophyte plastids?

Douglas and Penny (1999) noted that the conservation of synteny groups between the $G$. theta and $P$. purpurea genomes was much greater than that between $O$. sinensis and $P$. purpurea. The diatom genome has undergone much greater rearrangement. This was interpreted as indicating either a longer divergence time between the cryptophyte and heterokont endosymbioses (presumably from a closely related red algal cell) or that the host cells had "captured" evolutionarily distantly related red algae (Douglas and Penny, 1999). Kowallik (1997) noted the large number of rearrangements between the plastids of the heterokonts, Dictyota dichotoma and O. sinensis, and suggested that these plastids may have had independent origins. Plastid gene order is, therefore, largely consistent with independent origins of the plastids of the cryptophytes and heterokonts from red algal sources. The alternative hypothesis of a relatively higher rate of gene rearrangement in heterokonts relative to other red algae or red algal-derived plastids cannot, however, be excluded with these data. Our results support the hypothesis of independent plastid origins in the cryptophytes and heterokonts. First, we find a consistent grouping, with weak to moderate bootstrap support, of members of the Cyanidiales with the heterokonts to the exclusion of all other complex plastids (Fig. 2). This suggests that a species related to $C$. caldarium str. RK-1 was the direct ancestor of heterokont plastids, a result that is consistent with previous analyses of smaller data sets (e.g., Bhattacharya and Medlin, 1995; Leblanc, Boyen, and Loiseaux-de Goër, 1995; Medlin et al., 1995, 1997). That the rearranged trees 5 and 6 (Fig. 3) were significantly different from the best tree shown in Fig. 2 is also consistent with the idea that the Cyanidiales are not directly related to other Porphyridiales. This suggests that its divergence at the base of the Heterokonta is not an artifact of our treereconstruction methods.

Second, we find no evidence for independent endosymbiotic origins of the different heterokont plastids. 
This is consistent with extensive analyses of plastid-encoded $r b c L$ sequences from different heterokont and red algae (Daugbjerg and Andersen, 1997a, b). In addition, we have included a partial (665 nt) SSU rDNA sequence of $D$. dichotoma in the second data set to determine its position within the red algal phylogeny. Both the parsimony method and LogDet transformation show $D$. dichotoma to be closely related to the phaeophyte Pylaiella littoralis. This result shows that the great differences in gene order of the $D$. dichotoma and $O$. sinensis plastids are not due to the polyphyletic origins of these organelles from different red algal secondary endosymbionts. Third, our data do not support a monophyletic origin of the heterokont and cryptophyte plastids. The rearranged tree 3 (Fig. 3), which forced the monophyly of these complex plastids, was significantly different from the best tree $(P$ $<0.0001)$. Regarding a possible close evolutionary relationship between the plastids of Porphyra spp. and the cryptophytes (i.e., G. theta), we presently find no support for this theory. The plastids of the cryptophytes and Porphyra spp. (Bangiales) do not group together in any of the phylogenies. The plastids of the Bangiales do, however, form a sister group of the Florideophycidae in all the trees, with bootstrap support in the LogDet transformation and distance analyses (see Fig. 2). What about evidence regarding plastid origin based on comparisons of host cell sequences?

Previous phylogenetic analyses of the nuclear-encoded SSU rDNA trees show conclusively that the photosynthetic members of the Heterokonta are rooted within nonphotosynthetic taxa such as bicosoecids and labyrinthulomycetes (Leipe et al., 1994; Sogin et al., 1996). In addition, rDNA analyses support a sister-group relationship between cryptophytes and glaucocystophytes (Bhattacharya et al., 1995; Van de Peer et al., 1996) with the nonphotosynthetic Goniomonas truncata as the earliest divergence within the Cryptophyta (McFadden, Gilson, and Hill, 1994). Actin and rDNA trees also do not provide any evidence for the monophyly of the Cryptophyta and the Heterokonta (e.g., Bhattacharya and Weber, 1997; Van de Peer et al., 1996). Taken together, these data provide strong support for separate evolutionary histories of the heterokont and cryptophyte hosts and are consistent with the plastid data that show separate secondary endosymbiotic origins of their plastids from different red algae. A similar story is emerging regarding the origin of the plastid in haptophytes. Analyses of host rDNA and actin coding regions fail to show a sister group relationship between haptophytes and heterokonts (Van de Peer et al., 1996; Bhattacharya, Stickel, and Sogin, 1993), the group with which they have most often been allied (for details, see Daugbjerg and Andersen, 1997a; Medlin et al., 1997).

Consistent with this view, we do not find any evidence for the monophyly of heterokont and haptophyte plastids in our analyses. These rDNAs form a weakly supported cluster in Fig. 1 and in trees in which the cyanelle sequences are used to outgroup-root the taxa in the second data set. We interpret these results as consistent with the view that closely related red algae gave rise independently to the heterokont and haptophyte plastids and not that the host lineages share a monophyletic origin. The positioning of the Cyanidiales rDNA sequences between these complex plastids suggests that these organelles result from independent endosymbiotic events. Detailed phylogenetic analyses of $r b c L$ and rDNA sequences support this hypothesis (Daugbjerg and Andersen, 1997a, b; Medlin et al., 1997). And finally, we find no support for the scenario that all rhodoplast-derived complex plastids (and, thereby, their host cells) form a monophyletic group, an idea that was put forth largely on the basis of plastid characters, such as the existence of a plastid endoplasmic reticulum in these taxa (Cavalier-Smith, 1982). The rearranged tree 4 that forced the monophyly of the cryptophyte, haptophyte, and heterokont plastids was significantly different from the best maximum likelihood tree shown in Fig. $2(P=0.0231)$.

In summary, our expanded phylogenetic analyses help to clarify the evolutionary histories of the Bangiophycidae and the Florideophycidae. Most importantly, the subclass Bangiophycidae is found to be a paraphyletic assemblage that should be included in a single red algal class, the Rhodophyceae, which also includes the Florideophycidae (Gabrielson, Garbary, and Scagel, 1985). In addition, we suggest that the cryptophyte, haptophyte, and heterokont plastids were derived from independent secondary endosymbiotic events involving members of the Bangiophycidae. This is supported by the rDNA phylogeny of the plastids and of the host nuclei and is consistent with the differing pigmentations in these organelles. We see our data as a start toward understanding the complex forces that have shaped algal evolution. In this respect, single-gene phylogenies are valuable for providing a broad perspective on cellular evolution and we hope that such data are superceded and improved upon by future plastid genome and multiple-sequence comparisons using the taxa included in this study.

\section{LITERATURE CITED}

Bhattacharya, D. 1996. Analysis of the distribution of bootstrap tree lengths using the maximum parsimony method. Molecular Phylogeny and Evolution 6: 339-350.

, H. J. Elwood, L. J. Goff, AND M. L. Sogin. 1990. The phylogeny of Gracilaria lemaneiformis (Rhodophyta) based on the sequence analysis of its small subunit ribosomal RNA coding region. Journal of Phycology 26: 181-186.

, T. Helmchen, C. Bibeau, and M. Melkonian. 1995. Comparisons of nuclear-encoded small-subunit ribosomal RNAs reveal the evolutionary position of the Glaucocystophyta. Molecular Biology and Evolution 12: 415-420.

, AND L. MEDLIN. 1995. The phylogeny of plastids: a review based on comparisons of small-subunit ribosomal RNA coding regions. Journal of Phycology 31: 489-498.

, AND —. 1998. Algal phylogeny and the origin of land plants. Plant Physiology 116: 9-15.

, S. K. STICKEL, AND M. L. Sogin. 1993. Isolation and molecular phylogenetic analysis of actin coding regions from the prymnesiophyte alga, Emiliania huxleyi, using reverse transcriptase and PCR methods. Molecular Biology and Evolution 10: 689-703.

$\longrightarrow$, AND K. WEBER. 1997. The actin gene of the glaucocystophyte Cyanophora paradoxa: analysis of the coding region and introns and an actin phylogeny of eukaryotes. Current Genetics 31: 439446.

Bold, H. C., And M. J. Wynne. 1985. Introduction to the Algae. Prentice-Hall, Englewood Cliffs, New Jersey, USA.

Broadwater, S., AND J. SCOTT. 1994. Ultrastructure of unicellular red algae. In J. Seckbach [ed.], Evolutionary pathway and enigmatic algae: Cyanidium caldarium (Rhodophyta) and related cells, 215230. Kluwer Academic Publishers, Dordrecht, The Netherlands. 
- J. L. ScotT, S. P. A. Goss, And D. SAunders. 1995. Ultrastructure of vegetative organization and cell division in Glaucosphaera vacuolata Korshikov (Porphyridiales, Rhodophyta). Phycologia 34: 351-361.

Cavalier-Smith, T. 1982. The origins of plastids. Biological Journal of the Linnean Society 17: 289-306.

DaugbJerg, N., AND R. A. Andersen. 1997a. Phylogenetic analyses of the rbcl sequences from haptophytes and heterokont algae suggest their chloroplasts are unrelated. Molecular Biology and Evolution 14: $1242-1251$.

— AND —. 1997b. A molecular phylogeny of the heterokont algae based on analyses of chloroplast-encoded $r b c \mathrm{~L}$ sequence data. Journal of Phycology 33: 1031-1041.

Dixon, P. S. 1973. Biology of the Rhodophyta. Oliver \& Boyd, Edinburgh, UK.

Douglas, S. E., C. A. Murphy, D. F. Spencer, and M. W. Gray. 1991. Molecular evidence that cryptomonad algae are chimaeras of two phylogenetically distinct unicellular eukaryotes. Nature 350: 148151.

, AND S. L. J. PENNY. 1999. The plastid genome of the cryptophyte alga, Guillardia theta: complete sequence and conserved synteny groups confirm its common ancestry with red algae. Journal of Molecular Evolution 48: 236-244.

Durnford, D. G., J. A. Deane, S. Tan, G. I. McFadden, E. Gantt, AND B. R. GREEN. 1999. A phylogenetic assessment of the eukaryotic light-harvesting antenna proteins, with implications for plastid evolution. Journal of Molecular Evolution 48: 59-68.

Felsenstein, J. 1985. Confidence limits on phylogenies: an approach using the bootstrap. Evolution 39: 783-791.

Freshwater, W., S. Fredericq, B. S. Butler, M. H. Hommersand, And M. W. ChASE. 1994. A gene phylogeny of the red algae (Rhodophyta) based on plastid $r b c \mathrm{~L}$. Proceedings of the National Academy of Sciences, USA 91: 7281-7285.

FRITSCH, F. E. 1945. The structure and reproduction of the algae, vol. 2. Cambridge University Press, Cambridge, UK.

Gabrielson, P. W., And D. J. Garbary. 1987. A cladistic analysis of Rhodophyta: Florideophycidean orders. British Phycological Journal 22: 125-138.

algae: inferences from a cladistic analysis. Biosystems 18: 335-346. , M. R. Sommerfeld, R. A. Townsend, And P. L. Tyler. 1990. Phylum Rhodophyta. In L. Margulis, J. O. Corliss, M. Melkonian, and D. J. Chapman [eds.], Handbook of protoctista, 102118. Jones and Bartlett, Boston, Massachusetts, USA.

Garbary, D. J., And P. W. Gabrielson. 1990. Taxonomy and evolution. In K. M. Cole and R. G. Sheath [eds.], Biology of the red algae, 477-498. Cambridge University Press, Cambridge, UK.

, G. I. HANSEN, AND R. F. ScAGEl. 1980. A revised classification of the Bangiophyceae (Rhodophyta). Nova Hedwigia 33: 145-166.

GiBBS, S. 1993. The evolution of algal chloroplasts. In R. A. Lewin [ed.], Origins of plastids, 107-121. Chapman and Hall, New York, New York, USA.

Gilbert, D. G. 1992. SeqApp, version. 1.9a169. Biology Department, Indiana University, Bloomington, Indiana, USA.

Gilson, P. R., AND G. I. MCFADDEN. 1996. The miniaturized nuclear genome of eukaryotic endosymbiont contains genes that overlap, genes that are cotranscribed, and the smallest known spliceosomal introns. Proceedings of the National Academy of Sciences, USA 93: 7737-7742.

Gray, M. W. 1992. The endosymbiont hypothesis revisited. International Review of Cytology 141: 233-357.

Hasegawa, M., H. Kishino, And T. Yano. 1985. Dating of the humanape splitting by a molecular clock of mitochondrial DNA. Journal of Molecular Evolution 22: 160-174.

Häuber, M. M., S. B. Müller, V. Speth, and U.-G. Maier. 1994. How to evolve a complex plastid?-A hypothesis. Botanica Acta 107: 383-386.

Helmchen, T., D. Bhattacharya, and M. Melkonian. 1995. Analyses of ribosomal RNA sequences from glaucocystophyte cyanelles provide new insights into the evolutionary relationships of plastids. Journal of Molecular Evolution 41: 203-210.

Huss, V. A., and S. J. Giovannoni. 1989. Primary structure of the chloroplast small subunit ribosomal RNA gene from Chlorella vulgaris. Nucleic Acids Research 17: 9487.

Kies, L., AND B. P. KREMER. 1986. Typification of the Glaucocystophyta. Taxon 35: 128-135.

Kishino, H., AND M. Hasegawa. 1989. Evaluation of the maximum likelihood estimate of the evolutionary tree topologies from DNA sequence data, and the branching order in hominoidea. Journal of Molecular Evolution 29: 170-179.

KowAlLiK, K. V. 1997. Origin and evolution of chloroplasts: current status and future perspectives. In H. E. A. Schenk, R. G. Hermann, K. W. Jeon, N. E. Müller, and W. Schwemmler [eds.], Eukaryotism and symbiosis, 3-23. Springer-Verlag, Berlin, Germany.

- B. Stöbe, I. Schaffran, AND U. Freier. 1995. The chloroplast genome of a chlorophyll a+c-containing alga, Odontella sinensis. Plant Molecular Biology Reporter 13: 336-342.

Leblanc, C., C. Boyen, And S. LoiseauX-De Goër. 1995. Organization of the plastid genome from the rhodophyte Chondrus crispus (Gigartinales); sequence and phylogeny of the $16 \mathrm{~S}$ rRNA gene. European Journal of Phycology 30: 133-140.

LEE, R. E. 1974. Chloroplast structure and starch grain production as phylogenetic indicators in the lower Rhodophyceae. British Phycological Journal 9: 291-295.

Leipe, D. D., P. O. Wainright, H. J. Gunderson, D. Porter, D. J. Patterson, F. Valois, S. Himmerich, and M. L. Sogin. 1994. The stramenopiles from a molecular perspective: 16S-like rRNA sequences from Labyrinthuloides minuta and Cafeteria roenbergensis. Phycologia 33: 369-377.

LEwIN, R. A., AND J. A. RoBERTSON. 1971. Influence of salinity on the form of Astereocystis in pure culture. Journal of Phycology 7: 236238.

Lockhart, P. J., M. A. Steel, And D. Penny. 1994. Recovering the correct tree under a more realistic model of evolution. Molecular Biology and Evolution 11: 605-612.

Ludwig, M., AND S. P. GiBBs. 1987. Are the nucleomorphs of cryptomonads and Chlorarachnion the vestigial nuclei of eukaryotic endosymbionts? Annals of the New York Academy of Sciences 503: 198-211.

Maddison, W. P., And D. R. MAddison. 1997. MacClade, version 3.07. Sinauer, Sunderland, Massachusetts, USA.

Martin, W., B. Stöbe, V. Goremykin, S. Hansmann, M. Hasegawa, AND K. V. KowAlliK. 1998. Gene transfer to the nucleus and the evolution of chloroplasts. Nature 393: 162-165.

McFadden, G. I., P. R. Gilson, And D. R. A. Hill. 1994. Goniomonas-rRNA sequences indicate that this phagotrophic flagellate is a close relative of the host component of cryptomonads. European Journal of Phycology 29: 29-32.

Medlin, L. K., A. Cooper, C. Hill, S. Wrieden, and U. Wellbrook. 1995. Phylogenetic position of the Chromista plastids based on small subunit rRNA coding regions. Current Genetics 28: 560565.

- W. H. C. F. Kooistra, D. Potter, G. W. Saunders, and R. A. ANDERSEN. 1997. Phylogenetic relationships of the "golden" algae (haptophytes, heterokont chromophytes) and their plastids. In D. Bhattacharya [ed.], Origins of algae and their plastids, 187-220. Springer-Verlag, Wien, Austria.

Muller, K. M., R. G. Sheath, M. L. Vis, J. Crease, and K. M. Cole. 1998. Biogeography and systematics of Bangia (Bangiales, Rhodophyta) based on the rubisco spacer, rbcL gene and $18 \mathrm{~S}$ rRNA gene sequences and morphometric analyses.1. North America. Journal of Phycology 37: 195-207.

Nelissen, B., Y. Van de Peer, A. Wilmotte, and R. De Wachter. 1995. An early origin of plastids within the cyanobacterial divergence is suggested by evolutionary trees based on complete $16 \mathrm{~S}$ rRNA sequences. Journal of Molecular Evolution 12: 1166-1173.

Oliveira, M. C., AND M. A. RAGAN. 1994. Variant forms of a group I intron in nuclear small-subunit rRNA genes of the marine red alga Porphyra spiralis var. amplifolia. Molecular Biology and Evolution 11: 195-207.

, J. Kurniawan, C. J. Bird, E. L. Rice, C. A. Murphy, R. K. Singh, R. R. Gutell, And M. A. Ragan. 1995. A preliminary investigation of the order Bangiales (Bangiophycidae, Rhodophyta) based on sequences of nuclear small-subunit ribosomal RNA genes. Phycological Research 43: 71-79. 
Oтт, F. D. 1976. Further observations on the freshwater alga alga Flintiella sanguinaria Ott in Bourrelly 1970 (Rhodophycophyta, Porphyridiales). Archives Protistenkunde 118: 34-52.

, AND J. SeckBACH. 1994. New Classification for the genus Cyanidium Geitler 1933. In J. Seckbach [ed.], Evolutionary pathway and enigmatic algae: Cyanidium caldarium (Rhodophyta) and related cells, 145-152. Kluwer Academic Publishers, Dordrecht, The Netherlands.

Palmer, J. D., AND C. F. Delwiche. 1996. Second-hand chloroplasts and the case of the disappearing nucelus. Proceedings of the $\mathrm{Na}$ tional Academy of Sciences, USA 93: 7432-7435.

Pueschel, C. M. 1990. Cell structure. In K. M. Cole and R. G. Sheath [eds.], Biology of the red algae, 7-41. Cambridge University Press, Cambridge, UK.

Ragan, M. A., C. J. Bird, E. L. Rice, R. R. Gutell, C. A. Murphy, AND R. K. SingH. 1994. A molecular phylogeny of the marine red algae (Rhodophyta) based on the nuclear small-subunit rRNA gene. Proceedings of the National Academy of Sciences, USA 91: 72767280.

Rappé, M. S., M. T. Suzuki, K. L. Vergin, and S. J. Giovannoni. 1998. Phylogenetic diversity of ultraplankton plastid small-subunit rRNA genes recovered in environmental nucleic acid samples from the Pacific and Atlantic coasts of the United States. Applied and Environmental Microbiology 64: 294-303.

SAITOU, N., AND M. NeI. 1987. The neighbor-joining method: a new method for reconstructing phylogenetic trees. Molecular Biology and Evolution 4: 406-425.

SAUNDERS, G. W., AND G. T. KRAFT. 1997. A molecular perspective on red algal evolution: focus on the Florideophycidae. Plant Systematics and Evolution [Supplement] 11: 115-138.

SeckBACh, J., AND F. D. OTT. 1994. Systematic position and phylogenetic status of Cyanidium caldarium Geitler 1933. In J. Seckbach [ed.], Evolutionary pathway and enigmatic algae: Cyanidium cal- darium (Rhodophyta) and related cells, 133-143. Kluwer Academic Publishers, Dordrecht, The Netherlands.

SCHLÖssER, U. G. 1994. SAG-Sammlung von Algenkulturen at the University of Göttingen. Botanica Acta 107: 111-86.

ScotT, J. 1986. Ultrastructure of cell division in the unicellular red alga Flintiella sanguinaria. Canadian Journal of Botany 64: 516524.

, AND S. BROADWATER. 1989. Ultrastructure of vegetative organization and cell division in the freshwater red alga Compsopogon. Protoplasma 152: 112-122.

, AND P. W. Gabrielson. 1987. Bangiophycidae (Rhdophyta), a polyphyletic taxon: New evidence from ultrastructural studies Journal of Phycology 23[Supplement]: 12.

SiTTE, P. 1993. Symbiogenetic evolution of complex cells and complex plastids. European Journal of Protistology 29: 131-143.

Sogin, M. L., J. D. Silberman, G. Hinkle, and H. G. Morrison. 1996. Problems with molecular diversity in the Eukarya. In D. M. Roberts, P. Sharp, G. Alderson, and M. A. Collins [eds.], Evolution of microbial life, 167-184. Cambridge University Press, Cambridge, UK.

Stiller, J. W., AND B. D. Hall. 1997. The origin of the red algae: implications for plastid evolution. Proceedings of the National Academy of Sciences, USA 94: 4520-4525.

SWOFFORD, D. L. 1999. PAUP: phylogenetic analysis using parsimony, version 4.0b1. Smithsonian Institution, Washington, D.C., USA.

Van de Peer, Y., S. A. Rensing, U.-G. Maier, and R. De Wachter. 1996. Substitution rate calibration of small subunit rRNA identifies chlorarachniophyte endosymbionts as remnants of green algae. Proceedings of the National Academy of Sciences, USA 93: 77327736.

Whatley, J. M. 1993. Membranes and plastid origins. In R. A. Lewin [ed.], Origins of plastids, 77-106. Chapman and Hall, New York, New York, USA.

WynNe, M. J. 1985. Nomenclatural assessment of Goniotrichum Kutzing, Erythrotrichia Areschoug, Diconia Harvey and Stylonema Reinsch (Rhodophyta). Taxon 34: 502-505. 


\title{
The SSU rDNA Coding Region of a Filose Amoeba Contains a Group I Intron Lacking the Universally Conserved $G$ at the $3^{\prime}$-Terminus ${ }^{1}$
}

\author{
DEBASHISH BHATTACHARYA ${ }^{\mathrm{a}}$ and MARIANA C. OLIVEIRA ${ }^{\mathrm{b}}$ \\ University of Iowa, Department of Biological Sciences, Iowa City, Iowa 52242-1324, USA, and \\ ${ }^{b}$ Department of Botany, Institute of Biosciences, University of São Paulo, R. Matão, Travessa 14, N. 321,
} São Paulo, SP, Brazil CEP 05508-900

\begin{abstract}
We sequenced small subunit ribosomal DNA (rDNA) PCR-fragments of sizes $2.3 \mathrm{~kb}$ and $2.9 \mathrm{~kb}$ isolated from a culture of the red alga, Porphyra spiralis var. spiralis. Phylogenetic analysis of the 2.3-kb fragment showed that it encoded the sequence of a contaminant filose amoeba. The Nuclearia-like amoeba (named strain N-Por) was identified with scanning electron microscopy. Its rDNA sequence was positioned with strong bootstrap support within a diverse protist assemblage that includes filose amoebae, chlorarachniophytes, cercomonads, and Plasmodiophora brassicae. The rDNA of N-Por contained a group I intron at the conserved 943 position that remarkably, had a $U$ at the $3^{\prime}$-terminus rather than the universally conserved $G$.
\end{abstract}

Key Words. Cercozoa, group I intron, phylogeny, ribosomal DNA, splicing.

$\mathrm{M}$ OLECULAR sequences are routinely used to resolve taxonomic problems and for sampling biodiversity. The small subunit ribosomal RNA (SSU rRNA) coding region has proven particularly useful in this respect (Rappé et al. 1998; Soltis et al. 1999). Here we provide another example of how environmental samples can provide unexpected insights into gene/species evolution. During a phylogenetic survey of pop ulations of the red alga Porphyra spiralis var. spiralis (Rhodophyta), three PCR-fragments of sizes $1.8 \mathrm{~kb}, 2.3 \mathrm{~kb}$, and 2.9 $\mathrm{kb}$ were found in amplifications of the nuclear SSU rRNA coding region. The 2.3-kb fragment encoded the ribosomal DNA (rDNA) sequence of a previously unknown filose amoeba, which roughly resembled members of the genus Nuclearia (strain N-Por; Nuclearia-like amoeba associated with Porphyra) with the first group I intron described in such taxa.

\section{MATERIALS AND METHODS}

The conchocelis phase of the red alga Porphyra spiralis var. spiralis (Peruíbe, São Paulo, Brazil) was maintained in enriched sea water. Tissue was ground in liquid $\mathrm{N}_{2}$ and DNA was extracted using the QIAamp Kit (Qiagen, Santa Clarita, CA). PCR amplifications were performed with total DNA and primers specific for the nuclear SSU rDNA (Elwood, Olsen, and Sogin 1985). This resulted in the amplification of three PCR products of approximate sizes $1.8 \mathrm{~kb}, 2.3 \mathrm{~kb}$, and $2.9 \mathrm{~kb}$. The $1.8-\mathrm{kb}$ fragment putatively encoded a fungal contaminant and was not studied further whereas the $2.3-\mathrm{kb}$ and $2.9-\mathrm{kb}$ fragments were purified from an agarose gel (QIAquick, Qiagen) and cloned in the pCR 2.1 vector using the TA cloning kit (Invitrogen, Carlsbad, CA). The SSU rDNAs were completely sequenced over both strands using primer-walking (Medlin et al. 1988) and an ABI 310 automated sequencer (Perkin Elmer, Norwalk, CT). They were aligned with available SSU rDNA coding regions from a diversity of eukaryotes using the secondary structurebased alignment available from the Ribosomal Database II (Maidak et al. 2000) to facilitate sequence comparisons. Preliminary phylogenetic analyses showed that the $2.3-\mathrm{kb}$ fragment was derived from a member of the Cercozoa (Cavalier-Smith and Chao 1997). Knowing this, we created a reduced alignment that included a number of available cercozoan rDNA sequences with the animal/fungal clade as the outgroup. A total of 1533 nt (435 parsimony informative sites) were submitted to a heuristic maximum parsimony analysis and to LogDet transfor-

Corresponding Author: D. Bhattacharya-Telephone number: 319 335-1977; FAX number: 319-335-1069; E-mail: dbhattac@blue.weeg. uiowa.edu.

${ }^{1}$ The small subunit rDNA sequence of the filose amoeba described in this study has been deposited in the GenBank database under the accession number: AF289081. mation (Swofford 1999). In the maximum parsimony method, starting trees were obtained with stepwise (simple) addition (1,000 rounds) and rearranged with tree bisection and reconnection. A bootstrap analysis (10 random additions, 2,000 replications) was done using weighted data (rescaled consistency index over an interval of 1-1000) to reduce the influence of highly divergent sites in the phylogeny reconstruction (Bhattacharya 1996). In the LogDet bootstrap analysis (2,000 replications), matrices calculated with the LogDet transformation were used as input for neighbor-joining tree-building. The resulting bootstrap values were included at the branches of the maximum parsimony tree (for shared monophyletic groups). The same methods were used to reconstruct the phylogeny of the 943 group I intron that interrupted the amoebal SSU rDNA sequence. The initial intron alignment included introns at different SSU rDNA insertion sites and was built using secondary structure considerations (Bhattacharya et al. 1994; Michel and Westhof 1990) and a total of $226 \mathrm{nt}$ (147 parsimony informative sites) were used in the phylogenetic analyses. A second alignment including only the 943 introns ( $242 \mathrm{nt}, 112$ parsimony informative sites) was also analyzed. The secondary structure of the amoebal 943 intron was created manually using existing structures as a guide (see Comparative RNA Web Site, Gutell et al. unpubl. data) and the mfold program (Zuker, Mathews, and Turner 1999) to aid in the folding of peripheral helices.

We tested the expression of the amoebal rRNA with the RT/ PCR method. Total RNA was extracted from the algal culture (containing the amoeba) with the Trizol reagent (Gibco, Grand Island, NY) and RT reactions were done with M-MULV reverse transcriptase, followed by PCR, using different primers specific to the amoebal SSU rDNA (forward primers: $1822 \mathrm{~F}$ : 5'GGCACTAACCCTCCGGGGTTGGGTAGAC-3', 2106F: 5'GTACACACCGCCCGTCG-3'; reverse primer: 2134R: 5'AGGCTCACCAAACCATTCA-3'). The primer names show their positions in the amoebal rDNA sequence. For scanning electron microscopy, cells were fixed in $2.5 \%$ glutaraldehyde in $0.1 \mathrm{M} \mathrm{Na}$-cacodylate buffer ( $\mathrm{pH} \mathrm{7.2)}$ for $1 \mathrm{~h}$, followed by three washes in $0.1 \mathrm{M} \mathrm{Na-cacodylate} \mathrm{buffer}$ for $10 \mathrm{~min}$. Dehydration was by an acetone series and the samples were sputter-coated with gold prior to examination in a Zeiss DSM-940 scanning electron microscope.

\section{RESULTS AND DISCUSSION}

We cloned and sequenced the 2.3-kb and 2.9-kb SSU rDNA fragments isolated from the $P$. spiralis conchocelis culture. The larger fragment corresponded to the SSU rDNA coding region of the red alga with an intron positioned at the $3^{\prime}$-terminus (position 1506, data not shown), whereas the $2.3 \mathrm{~kb}$ (exact size $=2277 \mathrm{bp}$ ) fragment encoded the SSU rDNA of a culture contaminant. This contaminant was included in phylogenetic anal- 

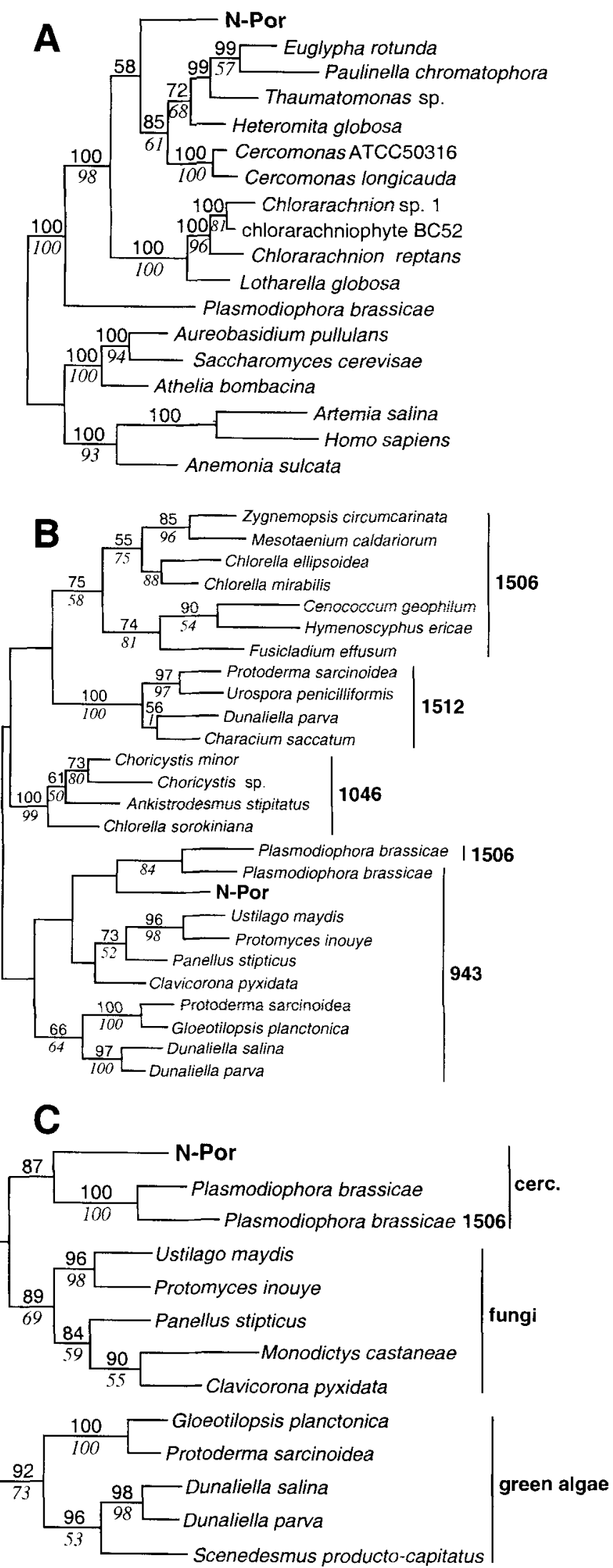

Fig. 1. Phylogenetic analyses of the position of N-Por. The bootstrap values (2000 replications) shown above the nodes resulted from a weighted (rescaled consistency index over an interval of 1-1000) max-

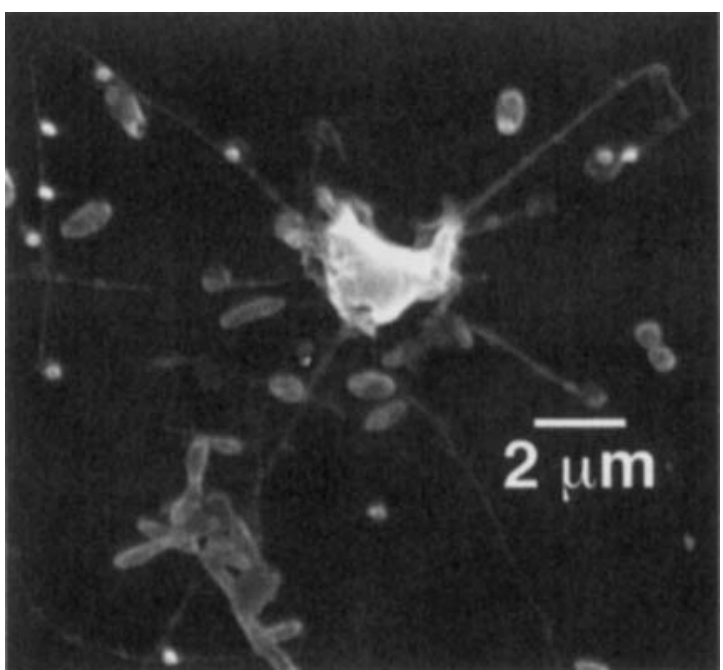

Fig. 2. Scanning electron micrograph of N-Por (cell body diameter $=3 \mu \mathrm{m}$ ) isolated from a culture of Porphyra spiralis var. spiralis showing the filopodia; $5000 \times$ magnification.

yses and grouped with strong bootstrap support with a protist assemblage that included the filose amoebae (e.g. Paulinella chromatophora, Euglypha rotunda), members of the Chlorarachniophyta (Bhattacharya, Helmchen, and Melkonian 1995; Ishida, Green, and Cavalier-Smith 1999), the amoeboflagellates Cercomonas spp. (Cercozoa, Cavalier-Smith, and Chao 1997), and the relatively early-diverging obligate, endobiotic necrotroph, Plasmodiophora brassicae (Fig. 1A). The branch containing the amoeba was, however, unstable within the Cercozoa and was positioned at the base of the Cercomonas spp./filose amoebae in the maximum parsimony analysis and at the base of the chlorarachniophytes in the LogDet analysis (data not shown).

The presence of the amoeba in our culture was verified with scanning electron microscopy (Fig. 2). The amoeba is a naked cell ( $3 \mu \mathrm{m}$ in diam.) with extremely long, thin filopodia similar to those in Nuclearia and chlorarachniophyte-type amoebae (Hibberd 1990). We provisionally named the amoeba, N-Por, until a definite identification can be made (fixed material is available from the Smithsonian Institution, Washington, D. C., under the following Accession Number: USNM51490). Optical microscopic examination (at $1000 \times$ ) of N-Por showed the absence of chloroplasts (results not shown). In general, non-photosynthetic filose amoeba are mostly aquatic (some marine) organisms, which feed largely on bacteria and detritus. These

imum parsimony analysis using 10 random additions in a heuristic tree search. The bootstrap values, for shared monophyletic groups, shown below the internal nodes result from an analysis (2000 replications) using LogDet matrices and trees built with neighbor joining. Only bootstrap values $\geq 50 \%$ are shown. A) Maximum parsimony analysis of small subunit ribosomal DNA (SSU rDNA) sequences resulted in this single most parsimonious tree of length 1591 steps (consistency index $=0.61$ ). B) Maximum parsimony analysis of group I intron sequences at different SSU rDNA insertion sites resulted in 5 most parsimonious trees of length of 912 steps (consistency index eq 0.39). One of these trees is shown. C) Maximum parsimony analysis of only the 943 group I intron sequences resulted in this single most parsimonious tree of length of 456 steps (consistency index $=0.61$ ). All phylogenetic analyses were done with PAUP* (V4.0b2, Swofford 1999). 


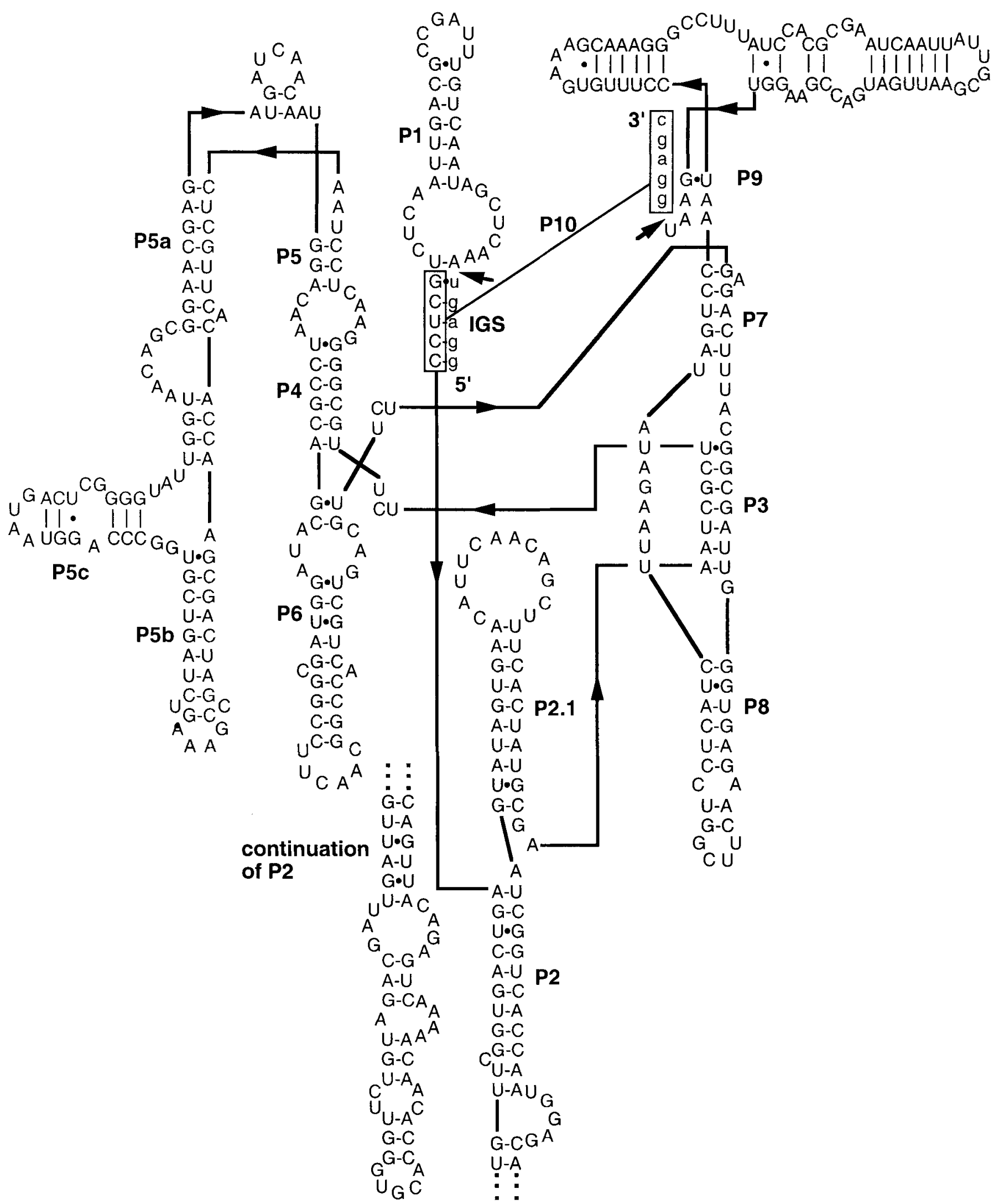

Fig. 3. Putative secondary structure of the 943 group I intron in the precursor small subunit ribosomal RNA of N-Por (drawn according to the conventions of Cech. Damberger, and Gutell 1994). The 5'- and $3^{\prime}$-splice junctions are shown (with arrows) as are the locations of the pairing segments P1-P10 (the P10 interaction is shown with the open boxes). Solid lines are used to position secondary structure elements that are believed to interact in close proximity. 
amoeba are testate or naked cells with long filopodia (slender, clear to granular pseudopodia, sometimes branching or anastomosing). Taken together, this evidence suggests that N-Por is a non-photosynthetic filose amoeba that is a sister group of the Chlorarachniophyta, taxa which have gained their plastid through a green algal secondary symbiosis (McFadden et al. 1994; Van de Peer et al. 1996).

We tried, without success, to isolate the amoeba from the algal culture. In these attempts, conchocelis filaments were fragmented and put over glass slides in a Petri dish with sea water (the amoeba had been observed growing on the glass slide together with attached conchocelis filaments). Two approaches were used to try to isolate the amoeba. In the first, agar plates, which were prepared with sterilized sea water, were inoculated by adding some drops of the sea water from the contaminated culture, by spreading a sample collected from a glass slide on the plate; or by including the conchocelis fragments on the plate. In all cases, the agar plates were quickly overwhelmed by bacterial growth and had to be discarded. In the second approach, the glass slides were isolated after initial inoculation but before the conchocelis fragments became attached. In this case, the amoeba did not establish itself in culture. Based on these preliminary results, it is possible that $\mathrm{N}$ Por may be an algal commensal but our data do not exclude the possibility that it can be grown on bacteria alone.

The N-Por rDNA gene contains a group I intron of length 451 bp at the conserved 943 site (Bhattacharya 1998). The $5^{\prime}-$ and $3^{\prime}$-termini of the intron were unambiguously identified because of the high sequence conservation of the flanking rDNA sequences at this site. The intron (Fig. 3) contains the ten conserved domains (P1-P10) typical of subgroup IC1 introns (Cech, Damberger, and Gutell 1994; Michel and Westhof 1990). This is the first group I intron found in the chlorarachniophytes/filose amoebae or Cercomonas spp. Inclusion of the 943 group I intron in phylogenies showed that it is closely related to the 943 intron in $P$. brassicae. These introns form a monophyletic group that also includes the green algal and fungal 943 introns (Fig. 1B). This result argues for the presence of the 943 intron in the common ancestor of the Cercozoa. It is, however, likely that the 1506 introns in the green algae and fungi have a separate origin from those in the Cercozoa because these taxa are only distantly related to each other and most eukaryotic SSU rDNAs do not contain the 1506 intron.

Direct evidence for group I intron lateral transfer is apparent in the intron trees, which show the $P$. brassicae 1506 intron to have most likely originated from the 943 intron in the same organism (Fig. 1B, 1C). The absence of homing endonucleases in these introns suggests that the transposition may have occurred through reverse-splicing at the RNA-level (Friedl et al. 2000; Woodson and Cech 1989). The N-Por 943 group I intron also has a remarkable feature-the substitution of a $U$ for the universally conserved $G$ at the 3 '-intron terminus (Fig. 3). This result was corroborated with sequences initiated at 4 different primer regions that flank the intron insertion site. Mutagenesis analyses of the Anabaena PC7120 tRNA ${ }^{\text {Leu }}$ group I intron showed that the terminal $\mathrm{G}(\omega \mathrm{G})$ plays an important role in the conformational changes required to allow the second step of intron excision, most importantly, the exchange of the exogenous guanosine for $\omega \mathrm{G}$ in the intron $\mathrm{G}$-binding site (Golden and Cech 1996). The $\omega \mathrm{G}$ in the Anabaena intron drives the splicing reaction in the forward direction by competing with the exogenous guanosine that becomes attached to the $5^{\prime}$ end of the intron after the first step of splicing. Similarly, mutations of the terminal nucleotide in the Tetrahymena thermophila large subunit rDNA intron severely reduced the second step of splicing (Been and Perrotta 1991; Suh and Waring 1990). Given these data, we speculate that the presence of $\omega U$ in the amoebal 943 intron may necessitate a host factor to facilitate its excision. This may provide a mechanism for regulating rRNA maturation. Our RT/PCR analyses with amoebal-specific rDNA primers show that this gene is being transcribed. All PCR reactions resulted in the amplification of fragments of expected size. Usage of the $1822 \mathrm{~F} / 2134 \mathrm{R}$ primer pair, for example, amplified a PCR fragment of $312 \mathrm{bp}$ (data not shown). We have, however, no direct evidence for intron excision from RT/PCR analysis of fragments spanning the intron insertion site or cDNA sequences from this region. Given these preliminary data, we speculate that the presence of $\omega \mathrm{U}$ does not indicate a non-functional group I intron. Such an insertion would not be tolerated in the highly conserved 943 region which contains the $\mathrm{A}$ and $P$ sites of tRNA interaction with the ribosome (Green and Noller 1997). In conclusion, our data provide evidence for the existence of non-photosynthetic chlorarachniophyte-type filose amoebae within the Cercozoa, and for the ancient origin of the 943 intron within this lineage.

\section{ACKNOWLEDGMENTS}

For supporting this research D. B. thanks the College of Liberal Arts (University of lowa) and a grant from the Carver Foundation. M. C. O. thanks FAPESP and CNPq for research grants and the DAAD for a visiting grant at the Max Planck Institute for Biophysical Chemistry.

\section{LITERATURE CITED}

Been, M. D. \& Perrotta, A. T. 1991. Group I intron self-splicing with adenosine:evidence for a single nucleoside-binding site. Science, 252: 434-437.

Bhattacharya, D. 1996. Analysis of the distribution of bootstrap tree lengths using the maximum parsimony method. Mol. Phylogenet. Evol., 6:339-350.

Bhattacharya, D. 1998. The origin and evolution of protist group I introns. Protist, 149:113-122.

Bhattacharya, D., Helmchen, T. \& Melkonian, M. 1995. Molecular evolutionary analyses of nuclear-encoded small subunit ribosomal RNA identify an independent rhizopod lineage containing the Euglyphidae and the Chlorarachniophyta. J. Eukaryot. (Euk.) Microbiol., 42:6569.

Bhattacharya, D., Surek, B., Ruesing, M. \& Melkonian, M. 1994. Group $I$ introns are inherited through common ancestry in the nuclear-encoded rRNA of Zygnematales (Charophyceae). Proc. Natl. Acad. Sci. USA, 91:9916-9920.

Cavalier-Smith, T. \& Chao, E. E. 1997. Sarcomonad ribosomal RNA sequences, rhizopod phylogeny, and the origin of euglyphid amoebae. Arch. Protistenk., 147:227-236.

Cech, T. R., Damberger, S. H. \& Gutell, R. R. 1994. Representation of the secondary and tertiary structure of group-I introns. Nature Struc. Biol., 1:273-280.

Elwood, H. J., Olsen, G. J. \& Sogin, M. L. 1985. The small-subunit ribosomal RNA gene sequences from the hypotrichous ciliates $O x y$ trichia nova and Stylonichia pustulata. Mol. Biol. Evol., 2:399-410.

Friedl, T., Besendahl, A., Pfeiffer, P. \& Bhattacharya, D. 2000. The distribution of group I introns in lichen algae suggests that lichenization facilitates lateral transfer. Mol. Phylogenet. Evol., 14:342-352.

Golden, B. L. \& Cech, T. R. 1996. Conformational switches involved in orchestrating the successive steps of group I RNA splicing. Biochemistry, 35:3754-3763.

Green, R. \& Noller, H. F. 1997. Ribosomes and translation. Annu. Rev. Biochem., 66:679-716.

Hibberd, D. J. 1990. Phylum Chlorarachnida. In: Margulis, L., Corliss, J. O., Melkonian, M. \& Chapman, D. J. (ed.), Handbook of Protoctista. Jones \& Bartlett Publ., Boston. p. 288-292.

Ishida, K., Green, B. R. \& Cavalier-Smith, T. 1999. Diversification of a chimeric algal group, the chlorarachniophytes: phylogeny of nuclear and nucleomorph small-subunit rRNA genes. Mol. Biol. Evol., 16: 321-331.

Maidak, B. L., Cole, J. R., Lilburn, T. G., Parker Jr., C. T., Saxman, 
P. R., Stredwick, J. M., Garrity, G. M., Li, B., Olsen, G. J., Pramanik, S., Schmidt, T. M. \& Tiedje, J. M. 2000. The RDP (Ribosomal Database Project) continues. Nucleic Acids Res., 28:173-174.

McFadden, G. I., Gilson, P. R., Hofmann, C. J., Adcock, G. J. \& Maier, U. G. 1994. Evidence that an amoeba acquired a chloroplast by retaining part of an engulfed eukaryotic alga. Proc. Natl. Acad. Sci. USA, 91:3690-3694.

Medlin, L., Elwood, H. J., Stickel, S. \& Sogin, M. L. 1988. The characterization of enzymatically amplified eukaryotic 16S-like rRNA coding regions. Gene, 71:491-499.

Michel, F. \& Westhof, E. 1990. Modeling of the three-dimensional architecture of group I catalytic introns based on comparative sequence analysis. J. Mol. Biol., 216:585-610.

Rappé, M. S., Suzuki, M. T., Vergin, K. L. \& Giovannoni, S. J. 1998. Phylogenetic diversity of ultraplankton plastid small-subunit rRNA genes recovered in environmental nucleic acid samples from the Pacific and Atlantic coasts of the United States. Appl. Environ. Microbiol., 64:294-303.

Soltis, P. S., Soltis, D. E., Wolf, P. G., Nickrent, D. L., Chaw, S.- M. \& Chapman, R. L. 1999. The phylogeny of land plants inferred from
18 rDNA sequences: pushing the limits of rDNA signal. Mol. Biol. Evol, 16:1774-1784.

Suh, E. R. \& Waring, R. B. 1990. Base pairing between the $3^{\prime}$ exon and an internal guide sequence increases $3^{\prime}$ splice site specificity in the Tetrahymena self-splicing rRNA intron. Mol. Cell. Biol., 10: $2960-2965$.

Swofford, D. L. 1999. PAUP* (Phylogenetic Analysis Using Parsimony, V4.0b2). Smithsonian Institution, Washington.

Van de Peer, Y., Rensing, S. A., Maier, U.- G. \& De Wachter, R. 1996. Substitution rate calibration of small subunit rRNA identifies chlorarachniophyte endosymbionts as remnants of green algae. Proc. Natl. Acad. Sci. USA, 93:7732-7736.

Woodson, S. A. \& Cech, T. R. 1989. Reverse self-splicing of the Tetrahymena group I intron: implication for the directionality of splicing and for intron transposition. Cell, 57:335-345.

Zuker, M., Mathews, D. H. \& Turner, D. H. 1999. Algorithms and Thermodynamics for RNA Secondary Structure Prediction: a practical guide. In: Barciszewski, J. \& Clark, B. F. C. (ed.), RNA Biochemistry and Biotechnology. NATO ASI Series, Kluwer, New York: $11-43$.

Received: 05/15/00, 08/03/00; accepted 08/03/00 


\title{
O mundo de RNA e a origem da complexidade da vida
}

\author{
Profa Dra Mariana Cabral de Oliveira (mcdolive@ib.usp.br)
}

Departamento de Botânica

Instituto de Biociências

Universidade de São Paulo

\section{Prof. Dr. Carlos Frederico Martins Menck (cfmmenck@usp.br)}

Departamento de Microbiologia

Instituto de Ciências Biomédicas

Universidade de São Paulo

\subsection{FUNDAMENTOS DO "MUNDO DE RNA"}

"Nada em Biologia faz sentido exceto à luz da Evolução." (Theodosius Dobzhansky)

No final da década de 1960, Orgel, Crick e Woese propuseram independentemente que o RNA precedeu a formação do DNA, baseado na tripla função que moléculas de RNA exercem nas células: mensageiro (mRNA), transportador (tRNA) e ribossômico (rRNA, Jeffares et al., 1998; Landweber et al., 1998; Szathmáry, 1999). Descobertas mais recentes só vieram fortalecer essa hipótese: a existência de moléculas de RNA com capacidade catalítica, uma propriedade que era considerada exclusiva das proteínas; a presença de algumas moléculas idênticas ou muito semelhantes aos monômeros de RNA em todos os seres vivos, que atuam como cofatores; o fato de o DNA não ser quimicamente tão flexível; e os desoxirribonucleotídeos serem derivados dos ribonucleotídeos -além de um número crescente de funções celulares que estão sendo associadas às moléculas de RNA.

O termo "mundo de RNA" (RNA world, em inglês) foi cunhado por Gilbert (1986) para descrever um cenário onde a principal molécula ativa na origem da vida era o RNA. Isto foi proposto baseado nas descobertas de moléculas de RNA com propriedades catalíticas.

Com a descoberta de RNA catalítico, resolveu-se um paradoxo do tipo "o ovo ou a galinha" sobre a origem da vida: ácidos nucléicos são essenciais à vida, mas parecem necessitar das proteínas para funcionar. Entretanto, se o RNA funcionasse como fonte de informação e também como enzima, as proteínas poderiam ter surgido posteriormente.

A hipótese do mundo de RNA afirma que a reprodução e o metabolismo das primeiras formas de vida dependiam das atividades catalíticas e replicativas do RNA, e que tanto o DNA quanto as proteínas teriam assumido suas funções atuais posteriormente (Gilbert, 1986).

O RNA é único na sua capacidade de armazenar informação genética (em vários vírus, como o da AIDS e o da gripe) e de executar uma série de atividades catalíticas (introns autocatalíticos, ribonuclease P, entre outros), uma propriedade que, até alguns anos atrás, se acreditava limitada às proteínas. Nas células atuais, o RNA está envolvido em uma série de processos, como síntese protéica, replicação de DNA, processamento de RNA etc. As múltiplas funções exercidas pelo RNA dão apoio indireto para a hipótese do mundo de RNA, que considera os RNAs catalíticos atuais como remanescentes de uma época em que a vida teria o RNA como principal mediador de processos informacionais e catalíticos, ou seja, seriam verdadeiros fósseis moleculares (Joyce, 1989).

Neste capítulo, pretendemos descrever e discutir o panorama de como um ancestral universal (progenota) com metabolismo baseado em RNA deu origem à diversidade de seres vivos atuais, que têm como material genético o DNA e o restante do metabolismo realizado por RNA e proteínas.

\subsection{O RNA CATALÍTICO}

Em 1977, foi descoberto que as seqüências codificadoras de vários genes eram interrompidas por seqüências não codificadoras. Esta descoberta foi baseada na comparação entre a seqüência do DNA e do seu 
RNA correspondente. Essas seqüências intervenientes ou intercalantes foram denominadas introns, enquanto que as seqüências codificantes foram denominadas exons. Após a transcrição, os introns têm que ser removidos do pré-RNA (RNA splicing, em inglês) para originar o RNA "maduro", que vai servir de molde para a tradução de uma proteína. Essa remoção tem que ser extremamente acurada para assegurar que os códons sejam lidos corretamente. Cada códon é composto por três nucleotídeos e corresponde a um aminoácido. Portanto, se for inserido ou retirado um nucleotídeo nessa seqüência, isso acarretará um erro de leitura das seqüências de trios de nucleotídeos. Essas descobertas deram o prêmio Nobel a Richard J. Roberts e Philip A. Sharp em 1993.

Introns são comuns em eucariotos (no núcleo e nas organelas), mas também já foram encontrados em arqueobactérias, eubactérias e até em bacteriófagos. Nos eucariotos superiores, a maioria dos genes é interrompida e geralmente os introns são muito mais longos que os exons. Entretanto, não há uma regra. Em levedura, por exemplo, a grande maioria dos genes não é interrompida. Além disso, a distribuição, o número e o tamanho dos introns variam enormemente (Lewin, 1997).

Na década de 1980, foi descrito um grande número de introns, que foram separados em diferentes categorias, de acordo com suas características estruturais e os mecanismos de remoção do pré-RNA. No início da década de 1980, Cech e seus colaboradores mostraram que alguns introns são capazes de catalisar sua própria remoção do pré-RNA sem a ajuda de proteínas. Esses introns foram denominados de autocatalíticos (selfsplicing, em inglês; Cech, 1988, 1990). Cech criou o termo ribozima para RNAs com propriedades catalíticas. O primeiro intron autocatalítico foi descrito no ciliado Tetrahymena thermophila e pertence ao chamado grupo I. Introns do grupo I são caracterizados por uma estrutura secundária altamente conservada e pelo seu mecanismo de excisão, onde o intron catalisa diretamente as duas reações de transesterificação consecutivas requeridas para sua excisão do transcrito primário (Cech e Bass, 1986). No primeiro estágio da reação de autocatálise, o grupo OH-3' de uma guanosina (G) livre ataca a ligação fosfodiéster 3' do último nucleotídeo (em geral uma uridina) do exon $5^{\prime}$. Essa uridina está pareada com um nucleotídeo do intron, em geral uma guanina. Esse ataque resulta na quebra da ligação 5' entre o exon 5' e o intron. No segundo estágio, o grupo $\mathrm{OH}$ 3' do exon 5' ataca a ligação fosfodiéster após o resíduo $\mathrm{G}$ terminal do intron, rompendo a ligação $3^{\prime}$ intron/exon e se ligando ao exon 3' (Figura 2.1). As duas reações de transesterificação são catalisadas pelo próprio intron, que funciona como uma enzima (Michel e Westhof, 1990). Doudna et al. (1989) mostraram que a capacidade catalítica de introns do grupo I reside em suas estruturas secundária e terciária, e não na sua estrutura primária (seqüência de nucleotídeos). Os introns do grupo II também podem ser autocatalíticos, mas estes introns apresentam seqüências de consenso e o mecanismo de excisão semelhantes aos introns que são removidos pela maquinaria riboprotéica (spliceosome, em inglês).

Apesar de algum ceticismo inicial, hoje já está plenamente comprovada a capacidade catalítica do RNA. Existe uma crescente quantidade de dados experimentais demonstrando que moléculas de RNA são realmente catalisadoras surpreendentes e que sua ação não está confinada a substratos de ácidos nucléicos (Lazcano, 1994; Jeffares et al., 1998; Landweber et al., 1998). Vários trabalhos têm mostrado a participação de moléculas de RNA em diferentes atividades celulares. Potter et al. (1995) verificaram na arqueobactéria Sulfolobus a existência de uma endonuclease que contém uma molécula de RNA que catalisa a excisão e a maturação de rRNA. Esta molécula de RNA é muito semelhante ao RNA U3 envolvido na maturação do mRNA em eucariotos e, segundo aqueles autores, estaria presente antes da divergência entre as arqueobactérias e os eucariotos, um verdadeiro fóssil molecular! Young et al. (1991) mostraram que a polimerase do RNA III do bicho-da-seda requer um fator de transcrição que é composto por RNA. Fung et al. (1995) apresentaram indícios de que pequenas moléculas de RNA citoplasmáticas (RNA G8) estão envolvidas em termotolerância no ciliado Tetrahymena thermophila. Além disso, existem diversas coenzimas e grupos prostéticos compostos por ribonucleotídeos (como NAD e FAD) presentes em todos os seres vivos, os quais, na ausência da proteína correspondente, catalisam reações químicas similares às que tomam parte como cofatores (Lazcano, 1994; Szathmáry, 1999). As várias atividades catalíticas das ribozimas serão detalhadamente discutidas no Capítulo 3. As capacidades de autoprocessamento, clivagem, elongação e ligação colocam o RNA num papel central na evolução pré-celular.

Obviamente, nem todas as moléculas de RNA são remanescentes do mundo de RNA. Para Jeffares et al. (1998), as moléculas consideradas fósseis teriam que apresentar uma ou mais das seguintes características: (1) ser catalítica -como as proteínas são melhores catalisadoras do que o RNA, é improvável que o RNA catalisador seja uma aquisição recente do metabolismo; (2) ser ubíqua, indicando que já estava presente no último ancestral comum de todos os seres vivos; (3) ter função central no metabolismo - qualquer RNA que ocupe uma posição central no metabolismo celular dificilmente seria substituído.

A existência do mundo de RNA requer ribozimas capazes de replicar RNA. Esse tipo de atividade catalítica foi demonstrado por Doudna e Szostak (1989). Além disso, seriam necessárias as capacidades de tomar matéria-prima do meio (supondo que as moléculas auto-replicativas de RNA já estivessem envoltas por 
uma membrana) e de coletar energia de outras moléculas com ligações de alta energia (Lazcano, 1994). O RNA não estaria solitário, mas acompanhado de diversas moléculas que poderiam funcionar como cofatores e substratos, incluindo íons metálicos, aminoácidos, polipeptídeos, açúcares, lipídios etc. Essa coexistência levaria à aquisição de outros grupos funcionais. A autoclivagem de alguns introns atuais, por exemplo, é dependente de $\mathrm{Mg}^{++}$, o que sugere a existência de metalo-ribozimas (Gilbert, 1987). Outro exemplo de associação é a existência de um terpenóide hidrofóbico ligado a um ribonucleotídeo existente na membrana da bactéria púrpura Rhodopseudomonas acidophila (Neunlist e Rohmer, 1985). A existência desse composto sugere que uma associação direta entre RNA e lipídios pode ter existido, sendo que esse tipo de associação pode ter facilitado a encapsulação das moléculas de RNA (Lazcano, 1994).

A seqüência de eventos que levaram à síntese protéica direcionada por RNA provavelmente começou com uma simples interação química entre aminoácidos e ribozimas, mas eventualmente levou a uma transformação completa da célula baseada em RNA (Lazcano, 1994).

A primeira protocélula é, por definição, um sistema envolto por membranas, composto de macromoléculas capazes de auto-replicação e de catálise, com mecanismos de tomada de matéria-prima do meio e de obtenção de energia (Deamer et al., 1994) (Figura 2.2). Os genomas de RNA das primeiras células teriam as seguintes propriedades, segundo Ohta (1994): a replicase do RNA seria ineficiente devido a uma alta taxa de erro em termos de substituição de nucleotídeos; o material genético e funcional seria o mesmo, mas as duas formas de RNA deveriam ter-se diferenciado logo no início, sendo o material genômico formado por RNA dupla fita (já que RNA simples fita tem alta taxa de hidrólise, além do fato de que a transição de RNA para DNA seria facilitada se o RNA fosse dupla fita); várias funções genéticas já deveriam existir a partir da diversificação da primeira replicase do RNA; uma estrutura semelhante a um tRNA teria servido como marcação para a transcrição (nesse caso, copiar o RNA genômico para RNA funcional); o genoma de RNA deveria ter aumentado gradualmente para permitir uma maior diversidade funcional.

\subsection{O APARECIMENTO DO CÓDIGO GENÉTICO E A TRANSIÇÃO PARA O “MUNDO DE RNP”}

A origem do código genético e do sistema de tradução foi uma das principais transições na evolução e diversificação da vida. Essa transição modificou radicalmente os sistemas vivos, permitindo a divisão de trabalho entre os ácidos nucléicos (informação) e as proteínas (catálise).

A possibilidade de que genomas de DNA tenham aparecido antes do surgimento da síntese protéica não pode ser completamente descartada. De acordo com a hipótese do mundo de RNA, a síntese protéica mediada por ribossomos surgiu a partir da interação entre aminoácidos e RNA. Existem evidências de que aminoácidos e oligopeptídeos estavam presentes na "sopa" pré-biótica na Terra primitiva (ver Capítulo 1). A síntese protéica é um processo complexo que requer muitos componentes, como rRNA, tRNA, mRNA e diversas proteínas como fatores de elongação e iniciação, sintetases de aminoacil-tRNA, proteínas ribossômicas, entre outras.

Ainda não se sabe com certeza como as ligações peptídicas são formadas no ribossomo, porém existem algumas evidências de que o rRNA é o responsável pela catálise (Noller, 1991; Nitta et al., 1998). Recentemente, foi selecionada uma ribozima capaz de catalisar a formação de uma ligação amida (Szathmáry, 1999). Um dos passos mais críticos na origem da síntese protéica é a formação de uma estrutura altamente complexa como o ribossomo (Poole et al., 1998).

Geralmente é assumido que, no início do mundo de RNA, a precisão da replicação era limitada e que, por isso, as moléculas de RNA não deveriam ultrapassar algumas centenas de bases. À medida que a precisão da replicação foi aumentando, moléculas maiores puderam ser formadas. É possível que os vários sítios ativos dos ribossomos tenham se formado como ribozimas individuais, posteriormente reunidos por recombinação, formando os rRNA (Jeffares et al., 1998; Poole et al., 1998).

Segundo Poole et al. (1998), a síntese protéica baseada numa molécula-molde de RNA teria se originado a partir de uma ribozima com atividade de polimerase do RNA e que adicionasse trinucleotídeos (Figura 2.3). Considere uma molécula semelhante a um tRNA com trinucleotídeos na posição do anticódon; se estes forem complementares aos nucleotídeos presentes na fita de RNA-molde, poderiam emparelhar com ela e o trinucleotídeo poderia ser incorporado na nova fita. Uma vantagem de se adicionarem trinucleotídeos, ao invés de nucleotídeos isolados, seria que um número maior de pontes de hidrogênio manteria os nucleotídeos mais tempo no lugar. Como a catálise realizada por ribozimas é mais lenta do que a realizada por proteínas, esse maior tempo de emparelhamento seria bastante vantajoso. O problema da precisão de replicação, discutido anteriormente, poderia ser minimizado em parte com a adição de mais sítios de reconhecimento, como, por exemplo, a adição de um aminoácido ao tRNA. Ou seja, o código genético já poderia ter sido estabelecido no mundo de RNA (Nagel e Doolitle, 1995; Wetzel, 1995). A afinidade do complexo de replicação por um tRNA 
ligado a um aminoácido poderia ser revertida com a clivagem do aminoácido, o que liberaria o tRNA. Este complexo de replicação seria o proto-ribossomo.

A vantagem desse modelo é que várias das funções catalíticas presumidas podem ser testadas com a evolução in vitro de ribozimas. Uma ribozima desenvolvida in vitro, por exemplo, foi capaz de ligar um aminoácido a um tRNA (Illangasekare et al., 1995).

A origem da informação (mRNA) é provavelmente o passo mais difícil de se explicar. Segundo Poole et al. (1998), os mRNAs podem ter surgido como produtos secundários do processamento de RNA. Nesse modelo, as ribozimas seriam removidas do pré-RNA e as seqüências flanqueadoras seriam reunidas, dando origem a novas seqüências. As ribozimas atuais estão de modo geral localizadas nos introns, motivo pelo qual os autores chamam essa hipótese de introns precoces (introns-first, em inglês). Ou seja, os introns que corresponderiam às moléculas de RNA catalíticas teriam surgido antes do que seus exons flanqueadores. A função dos mRNAs teria surgido a partir de fragmentos de seqüências que teriam sido juntados secundariamente.

Pequenas moléculas de RNA nucleolar (snoRNAs, small nucleolar RNA, em inglês) são processadas a partir de introns encontrados nos genes que codificam para proteínas ribossômicas e para chaperonas. Com base nesse fato, Poole et al. (1998) propõem que essas proteínas -que são universais- estariam provavelmente entre as primeiras proteínas a ter surgido na transição entre o mundo de RNA e o metabolismo das células atuais, baseado em proteínas.

As primeiras proteínas deveriam interagir com o RNA com baixa especificidade e deveriam atuar como chaperonas, ou seja, deveriam auxiliar ou facilitar o correto dobramento da molécula catalítica de RNA (ribozima). Muitas das chaperonas atuais estão envolvidas na resposta ao choque térmico e são denominadas de HSP (Heat Shock Proteins, em inglês). Poole et al. (1998) incluem na categoria de chaperonas as moléculas que se ligam a RNA e que não são em si catalíticas, como as proteínas ribossômicas e aquelas ligadas à remoção de introns, entre outras.

Polipeptídeos carregados positivamente ligariam-se às moléculas de RNA carregadas negativamente, aumentando a sua estabilidade. $\mathrm{O}$ aumento da estabilidade nas estruturas terciárias das ribozimas, que sem as proteínas seriam bastante dependentes das concentrações de íons no meio (por exemplo, $\mathrm{Mg}^{++}$), permitiria um aumento na precisão da replicação e, conseqüentemente, um aumento do tamanho das moléculas de RNA sendo replicadas. Esse aumento na precisão de replicação da informação é fundamental para o surgimento da síntese protéica.

As proteínas são catalisadores mais eficientes e rápidos que o RNA, pois possuem um número muito maior de grupos funcionais (20 aminoácidos) e a capacidade de manter uma estrutura terciária precisa (Jeffares et al., 1998). Atualmente, são raros os catalisadores que são formados unicamente por RNA (alguns introns autocatalíticos e ribozimas virais). Na maioria dos casos, os RNAs catalisadores estão associados a proteínas que ajudam a manter uma estrutura terciária correta. A estrutura terciária de moléculas de RNA varia com a concentração de íons no meio, daí a necessidade de interação com proteínas. Os ribossomos atuais parecem ser exatamente isso, ribozimas estabilizadas por proteínas.

Uma vez que as proteínas se apresentam muito mais eficientes como catalisadores do que as ribozimas, sua síntese e utilização seriam vantajosas para os organismos (Jeffares et al., 1998). A partir dessa interação entre os polipeptídeos e as moléculas de RNA, teria surgido o chamado mundo de RNP (RNP $=$ RNA + proteínas; Figura 2.2).

\subsection{TRANSIÇÃO PARA O "MUNDO DE DNA"}

Atualmente, há uma grande aceitação da hipótese do mundo de RNA. Apesar disso, todas as células vivas hoje têm como material informativo o DNA. Dos seres vivos conhecidos, apenas os vírus podem apresentar o RNA como portador de informação genética, podendo existir com fitas simples ou duplas dessa molécula. Proteínas podem ser sintetizadas na ausência de DNA, mas não na de RNA. Portanto, é razoável assumir que os genomas de DNA surgiram posteriormente à síntese protéica e que seriam monofiléticos, desenvolvendo-se antes da divergência das três linhagens celulares (eubactérias, arqueobactérias e eucariotos). O DNA dupla fita é uma molécula extremamente resistente; os genomas de DNA teriam sido selecionados ao invés dos genomas de RNA pela simples razão de serem mais estáveis (Lazcano, 1994). Além disso, a informação está duplicada (em cada uma das fitas de DNA), o que facilitaria o reparo com precisão em caso de dano em uma das fitas. Por serem mais estáveis, os genomas de DNA puderam aumentar de tamanho através de duplicação gênica. A duplicação de RNA é um processo intrinsecamente pouco fiel, o que limita o tamanho das cópias, já que o número de mutações pontuais é proporcional ao tamanho do molde (Lazcano, 1994).

$\mathrm{O}$ surgimento de genomas de DNA e de polimerases do DNA de alta fidelidade possibilitaram o desenvolvimento de genomas maiores, com capacidade de codificação aumentada. O aparecimento do DNA 
possibilitou a duplicação de genes em grande escala e o embaralhamento dos exons, gerando proteínas com novas capacidades catalíticas. Isso, por sua vez, possibilitou uma grande diversificação das formas de vida e seu aumento de complexidade. Assim, acredita-se que células contendo RNA como material genético devem ter existido com uma capacidade metabólica limitada e lenta, o que as impediram de competir com as células emergentes contendo DNA, resultando em sua extinção gradual.

O processo de transferência de informação genética do RNA para o DNA ocorreu graças à atividade de enzimas conhecidas como transcriptases reversas. Essas enzimas foram inicialmente encontradas em retrovírus, que constituem tipos de vírus que possuem, em seu ciclo de vida, moléculas de RNA empregadas como molde para intermediários de DNA. A existência de transcriptases reversas, no entanto, não está restrita a retrovírus. $\mathrm{Na}$ verdade, esse tipo de atividade enzimática tem sido descrito também em células eucarióticas e procarióticas, indicando sua ancestralidade. É possível, portanto, que, em um mundo de células contendo RNA como material genético, as proteínas já existissem como determinantes importantes do metabolismo celular (mundo de RNP), e que atividades de enzimas como a transcriptase reversa converteriam o genoma, ou parte dele, em DNA. Um fato interessante é que a telomerase, que constitui uma enzima importante na síntese das extremidades repetitivas dos cromossomos de eucariotos (os telômeros), realiza sua função empregando uma molécula de RNA como molde da região repetitiva. Essa ribonucleoproteína sintetiza DNA a partir de RNA, sendo, portanto, uma transcriptase reversa. Assim, acredita-se que essa enzima seja um dos fósseis moleculares remanescentes do mundo de RNP, além de indicar que a função de transcriptase reversa pode também ser realizada com atividades catalíticas de RNAs, ou seja, ribozimas. Essa conversão de RNA em DNA permitiu a origem de células com metabolismo próximo ao que conhecemos hoje e deve ter tido um papel determinante na origem das células atuais, constituindo o que chamamos hoje de progenota.

\subsection{O AUMENTO DA COMPLEXIDADE}

Estudos de filogenia molecular utilizando o gene que codifica para o RNA da subunidade pequena do ribossomo (SSU rDNA, também chamado $16 \mathrm{~S}$ nos procariotos e $18 \mathrm{~S}$ nos eucariotos) feitos por Woese (1987) e Woese et al. (1990) transformaram a dicotomia eucarioto/procarioto em um sistema de três domínios: Bacteria, Archaea e Eucaria (neste capítulo, serão usadas as designações eubactéria, arqueobactéria e eucariotos, respectivamente; Figura 2.4).

Atualmente, muitos caracteres moleculares e fenotípicos indicam que os eucariotos e as arqueobactérias formam um grupo-irmão com a exclusão das eubactérias. Entre as evidências que indicam uma ancestralidade comum entre arqueobactérias e eucariotos podemos citar a ausência de uma parede celular bacteriana, a presença de proteínas semelhantes às histonas associadas ao DNA, de moléculas semelhantes a esteróides em um grupo de arqueobactérias (também denominados de Eócitos), semelhança de várias proteínas e de vias metabólicas. Entretanto, as relações entre os três domínios é ainda bastante controversa (Dyer e Obar, 1994; Katz, 1998; Doolittle, 1999a; Nelson et al., 1999).

Freqüentemente é assumido que os procariotos são anteriores aos eucariotos devido a sua aparente simplicidade, sua presença anterior no registro fóssil e também com base em estudos filogenéticos. Nesse cenário, as características complexas dos eucariotos -como membrana nuclear, processamento de mRNA para remoção de introns e citoesqueleto- seriam aquisições tardias. Os procariotos obviamente antecedem os eucariotos modernos que possuem mitocôndria (Forterre e Philippe, 1999). Entretanto, Poole et al. (1998) sugerem que o genoma do ancestral comum mais antigo seria linear, capaz de recombinação, fragmentado e repleto de fósseis moleculares, ou seja, mais parecido com um eucarioto do que com procariotos.

As moléculas atuais de RNA que apresentam capacidade catalítica seriam relíquias do mundo de RNA (Jeffares et al., 1998), ou seja, de um período anterior ao último ancestral comum que deu origem às linhagens dos organismos atuais. Poole et al. (1998) utilizam estas moléculas fósseis para posicionar a origem da árvore da vida. Segundo eles, o genoma do tipo eucariótico seria anterior ao tipo procariótico, já que o genoma eucariótico contém um maior número de fósseis moleculares (introns autocatalíticos, spliceosomes, snoRNAs, telomerase, entre outros; ver Jeffares et al., 1998). Além disso, a transcrição e a tradução seriam muito mais rápidas e eficientes nos procariotos. A origem de um genoma procariótico a partir de um eucariótico seria relativamente simples e direta se uma forte seleção para ambientes termofilicos e/ou para uma estratégia de vida do tipo $r$ fossem consideradas. $\mathrm{O}$ ambiente termofílico favoreceria um rápido processamento do RNA e sua subseqüente tradução, já que as taxas de hidrólise do RNA aumentam com a temperatura. Organismos de estratégia $r$ (em oposição aos organismos de estratégia $K$ ) apresentam altas taxas reprodutivas, pequeno tamanho, ciclos de vida curtos e freqüentemente são encontrados em ambientes instáveis. Os efeitos combinados de uma adaptação à termofilia e uma pressão seletiva para uma estratégia $r$ teria levado à perda dos fósseis 
moleculares e a uma simplificação no processamento e tradução dos RNAs nos procariotos (Darnell e Doolitle, 1986; Poole et al., 1998).

Alguns autores (Poole et al., 1998; Forterre e Philippe, 1999) argumentam que a confiabilidade de métodos filogenéticos (que indicam uma origem procariótica) na recuperação de divergências tão antigas está sujeita a controvérsias e que a semelhança dos fósseis mais antigos (estromatólitos de cerca de 3,8 bilhões de anos) às atuais cianobactérias não seria conclusiva.

Os genomas dos eucariotos podem apresentar uma enorme complexidade, com regiões espaçadoras, introns, regiões repetitivas, elementos de transposição e famílias multigênicas. Essa grande complexidade é possível, em parte, através da duplicação de genes e processos de recombinação (Ohta, 1994; ver também Capítulo 8). A duplicação gênica possibilita a ocorrência de variabilidade e a diversificação das cópias. Se essas cópias ainda mantêm funções relacionadas, originam as chamadas famílias gênicas. Quando a diversificação é muito grande, novos genes são gerados, que codificam proteínas com novas funções. Novos genes podem ser gerados também pelo mecanismo chamado embaralhamento de exons (exon-shuffling, em inglês), onde exons são embaralhados. A hipótese de embaralhamento de exons foi proposta por Gilbert (1978), mas os mecanismos pelo qual isto acontece permaneceram obscuros até recentemente quando Moran et al. (1999) mostraram que o embaralhamento de exons pode ocorrer através da mobilização de retrotransposons.

Lazcano e Miller (1996) sugerem que a maioria dos genes teria surgido a partir de duplicação gênica. Baseados nas semelhanças entre vias metabólicas e nas funções relacionadas de proteínas, os autores estimam que entre 20 e 100 genes iniciais deveriam coexistir no progenota.

Além do aumento da complexidade na estrutura genética, ocorreu também um aumento da complexidade celular, com o surgimento de diferentes organelas, que delimitam distintos compartimentos internos. Pelo menos duas dessas organelas -mitocôndrias e cloroplastos- foram derivadas de associações endossimbióticas entre os eucariotos e outros organismos (procariotos e eucariotos). Esses eventos endossimbióticos introduziram genomas inteiros no interior da célula hospedeira, possibilitando uma grande transferência lateral de genes. A transferência lateral de genes (também chamada de transferência horizontal) teve provavelmente um papel fundamental na evolução dos genomas. Entretanto, é extremamente difícil estimar qual é a extensão do movimento de genes entre organismos (Dyer e Obar, 1994).

Os Projetos Genoma têm acumulado uma quantidade gigantesca de dados. As análises e comparações de genomas como um todo estão ainda no seu início, mas já têm causado agitação em diversas áreas. Nelson et al. (1999) fizeram uma comparação de 33 genes dos quais foram encontradas cópias homólogas em todas as espécies já seqüenciadas na época. Para a maioria dos genes, as arqueobactérias constituem um grupo monofilético separado das eubactérias, padrão também encontrado para o SSU rDNA. A maioria dos genes de levedura (eucarioto) se agrupa com os genes de arqueobactérias, resultado também encontrado para o SSU rDNA. Entretanto, as árvores geradas para os diferentes genes apresentam uma falta de congruência significativa entre si. Nelson et al. (1999) atribuem essa falta de congruência principalmente a mecanismos como duplicação, perda e transferência lateral de genes. Os autores verificaram também que, para a eubactéria Thermotoga maritima, $52 \%$ de seus genes são mais semelhantes a genes de outras eubactérias, mas $24 \%$ são mais semelhantes aos genes de arqueobactérias. Eles atribuem esta alta similaridade a arqueobactérias a uma extensiva transferência lateral de genes, argumentando que esses genes não estão distribuídos uniformemente nas diferentes categorias, nem nas diferentes regiões do genoma. Além disso, a ordem de distribuição de alguns genes e também algumas regiões repetitivas só foram encontradas em arqueobactérias. Apesar de T. maritima ter um genoma essencialmente eubacteriano, quase um quarto de seu genoma parece ser resultado de um ou mais eventos de transferência lateral de genes provenientes de arqueobactérias.

A maioria dos genes envolvidos na estrutura do genoma, na transcrição e na tradução claramente separa as arqueobactérias das eubactérias. Nesse caso, as filogenias refletem aqueles marcadores que são menos propensos à transferência lateral e explicam a presença de muitos genes em arqueobactérias que são próximos às eubactérias como resultado de transferência lateral (Gogarten et al., 1999). Doolittle (1999a) afirma que a transferência lateral de genes teve e tem um papel crucial na formação dos seres vivos e que as relações filogenéticas formam uma rede intrincada (Figura 2.5). Discutiremos em detalhes, a seguir, a origem de células eucarióticas.

\subsubsection{A origem do núcleo}

A hipótese mais antiga, e talvez a mais aceita ainda, para a origem do núcleo é a hipótese autógena, onde o núcleo teria se originado a partir de uma organização gradual de membranas ao redor do material genético. A membrana nuclear é, em muitos casos, contínua ao retículo endoplasmático e teria se originado diretamente a partir deste (Dyer e Obar, 1994). Uma evidência que favorece a hipótese autógena é que em muitos eucariotos a 
membrana nuclear é completamente desintegrada durante a divisão celular e é formada novamente nas células filhas. Além disso, o envelope nuclear não é composto por duas membranas, mas sim por uma série de vesículas achatadas (Martin, 1999).

Esse sistema de membranas internas que teria circundado o material genético teria se originado por invaginações da membrana plasmática pelo mesmo sistema que permitia a fagocitose. Ou seja, a célula que deu origem aos eucariotos não deveria apresentar parede celular e já deveria ter um sistema de microtúbulos (citoesqueleto) antes da formação do núcleo. Entretanto, não se conhece qualquer procarioto que possua um citoesqueleto verdadeiro. O citoesqueleto seria uma inovação exclusiva da linhagem que deu origem aos eucariotos. O citoesqueleto, formado por microtúbulos, é responsável pela manutenção da forma celular, pela movimentação da célula e de seus componentes internos (por exemplo, a movimentação dos cromossomos durante a divisão celular). Uma importante questão na origem dos eucariotos é saber como esse sistema complexo se originou.

Sogin (1994) propôs um modelo de origem nuclear quimérico para explicar as divergências encontradas nas árvores filogenéticas, geradas usando-se seqüências de diferentes genes, para estabelecer a relação dos três domínios eubactéria, arqueobactéria e eucariotos. Nesse modelo, o progenota já apresentava um sistema primitivo de tradução, mas os eventos celulares ainda eram dominados pelo RNA. Uma linhagem celular, a partir do progenota, teria adquirido uma complexidade do citoesqueleto suficiente para permitir a transição para uma célula nucleada.

Ainda de acordo com o modelo de Sogin, uma outra linhagem celular teria desenvolvido um sistema sofisticado de tradução e possivelmente teria substituído o RNA catalisador pelas proteínas e o RNA repositório da informação pelo DNA. Esta segunda linhagem teria se diferenciado nas arqueobactérias e eubactérias. $\mathrm{O}$ citoesqueleto da primeira linhagem teria permitido o englobamento de outros organismos. Essa linhagem protoeucariótica teria então englobado uma arqueobactéria, a qual teria dado origem a um núcleo quimérico, que incluía o genoma de DNA das arqueobactérias (contribuindo principalmente com os genes para a tradução e para as proteínas) e o genoma de RNA do proto-eucarioto (contribuindo com os rRNAs e a informação para o citoesqueleto; Figura 2.6). Segundo Sogin (1994), essa hipótese é testável, já que proteínas do citoesqueleto estariam limitadas à linhagem eucariótica e proteínas similares estariam ausentes das linhagens procarióticas. Actina, tubulina e os filamentos intermediários têm sido procurados nos procariotos, mas os resultados obtidos até agora não são conclusivos (Dyer e Obar, 1994).

Cavalier-Smith (1987) propôs que os eucariotos teriam surgido a partir de uma linhagem de bactérias que perdeu sua habilidade de formar uma parede celular de mureína (polissacarídeo semelhante à quitina, que é ligado de forma covalente a peptídeos curtos, formando uma parede rija ao redor da célula). O citoesqueleto teria surgido nessas células, mantendo a estrutura rija.

\subsubsection{A origem das organelas}

A fotossíntese baseada em clorofila a é restrita a algumas eubactérias, os eucariotos fotossintéticos adquiriram essa capacidade através de endossimbiose com as eubactérias. Dentro desse domínio, cinco linhagens diversas são fotossintetizantes, levando à especulação de que o ancestral das eubactérias seria fotossintetizante (Woese, 1987; Pierson, 1994). Entretanto, a ausência de fotossíntese baseada em clorofila a nas arqueobactérias argumenta contra a presença de fotossíntese no progenota. Além disso, a molécula de clorofila a e a sua associação em fotossistemas são extremamente complexas para estarem presentes no progenota. Entretanto, isso não significa que o progenota não usava luz como fonte de energia, o que poderia ser feito através de moléculas captadoras de energia radiante bem mais simples (Deamer et al., 1994).

A clorofila a está presente em todos os organismos que fazem fotossíntese com desprendimento de oxigênio $\left(\mathrm{O}_{2}\right)$. $\mathrm{O}$ surgimento da clorofila, uma molécula complexa, alterou completamente a atmosfera, causando um enorme impacto na história do planeta e redirecionando a evolução dos seres vivos (veja Oliveira, 1996). Com o advento da fotossíntese, o $\mathrm{O}_{2}$ começou a ser liberado para a atmosfera terrestre e foi se acumulando gradativamente. Por volta de 2,8 a 2,4 bilhões de anos atrás, o oxigênio já deveria estar presente em pequena quantidade (em torno de 0,5\%), possibilitando a respiração aeróbica (Knoll, 1992). Nessa época, devem ter-se originado os ancestrais da linhagem que mais tarde iria originar as mitocôndrias. Nesse período, teriam surgido também as primeiras defesas celulares contra os efeitos tóxicos do oxigênio, então um gás letal para a maioria das formas de vida existentes no planeta. Apenas há cerca de 2 bilhões de anos é que o oxigênio deve ter-se acumulado na atmosfera em quantidades suficientes para formar uma camada de ozônio $\left(\mathrm{O}_{3}\right)$, a qual diminuiu a incidência de raios ultravioleta sobre a superfície terrestre (Dyer e Obar, 1994).

Os eucariotos, como conhecemos hoje, isto é, células nucleadas e com organelas, teriam surgido de eventos de endossimbiose (simbiogênese) entre uma célula hospedeira e células procarióticas que deram origem 
às mitocôndrias e aos cloroplastos (Figura 2.6). Simbiogênese é o surgimento de uma nova linhagem de organismos como conseqüência de uma associação simbiótica estável. Esse termo foi introduzido pelo biólogo russo Mereschkovsky em 1909 (Margulis e Cohen, 1994). A principal implicação da simbiogênese é que os eucariotos são, de fato, quimeras produzidas pela combinação de diversos genomas.

As evidências que apóiam a simbiogênese das organelas como mitocôndrias e cloroplastos são: (1) as proteínas presentes nas organelas são mais semelhantes aos seus análogos procarióticos do que aos eucarióticos; (2) existem procariotos de vida livre com forte semelhança estrutural, bioquímica e genética com as respectivas organelas; (3) as organelas possuem genoma próprio, com organização semelhante ao genoma procariótico; (4) os RNAs (ribossômico, transportador e mensageiro) das organelas também são mais semelhantes aos de procariotos; (5) as organelas são semi-independentes, com capacidade de replicação; e (6) as organelas e suas funções estão, alternativamente, presentes ou ausentes das células eucarióticas, não sendo encontrados intermediários (Gray, 1992; Dyer e Obar, 1994; Martin, 1999).

Além das características acima, a presença de uma membrana dupla ao redor dessas organelas também é tomada como uma evidência de origem endossimbiótica. A membrana mais interna é de origem procariótica (membrana plasmática do endossimbionte) e a mais externa é de origem eucariótica (membrana do fagosssomo da célula hospedeira). Pela criofratura, é possível verificar a orientação das membranas, pois as duas camadas lipídicas têm aparência diferente quando estão voltadas para o interior ou exterior da célula. A membrana mais interna parece estar na orientação "correta", enquanto que a membrana mais externa parece estar invertida, indicando uma origem a partir do fagossomo (Dyer e Obar, 1994).

Uma vez ocorrida a endossimbiose, genes do endossimbionte podem ser transferidos lateralmente para o núcleo da célula hospedeira. Os produtos desses genes devem ser então direcionados às organelas. Mitocôndrias e cloroplastos são, portanto, semi-independentes, já que necessitam dos produtos de alguns genes que agora são codificados no núcleo. Em alguns complexos enzimáticos, uma parte das subunidades é codificada pelo genoma nuclear e uma parte pelo genoma da organela (por exemplo, a sintetase do ATP na mitocôndria e Rubisco no cloroplasto). Transferências de genes entre mitocôndrias e cloroplastos também podem ter ocorrido. A transferência específica de genes entre os compartimentos celulares varia nos diferentes organismos. $\mathrm{O}$ mecanismo pelo qual se dá esta transferência lateral no interior das células não está estabelecido, mas, em alguns casos, elementos de transposição poderiam estar envolvidos. Esses eventos de transferência intensificam a dependência entre organelas e núcleo, e provavelmente são essenciais para a manutenção da associação endossimbiótica (Dyer e Obar, 1994). Apesar de eventos de transferência e perda de genes ocorrer provavelmente ao acaso, aparentemente existe uma direcionalidade, já que o núcleo apresenta uma tendência de adquirir genes, enquanto que as organelas parecem perder genes redundantes. Uma explicação para essa direcionalidade seria que o núcleo é um ambiente geneticamente mais estável que as organelas.

A maioria das linhagens eucarióticas tem mitocôndrias que foram adquiridas através de um evento de endossimbiose entre uma célula eucariótica e uma bactéria púrpura ( $\alpha$-proteobactéria), provavelmente há cerca de 2,5 bilhões de anos (Dyer e Obar, 1994). O parente atual mais próximo das mitocôndrias é a $\alpha$-proteobactéria Rickettsia, um parasita endocelular causador do tifo, cujo genoma foi seqüenciado recentemente (Andersson et al., 1998).

As mitocôndrias apresentam duas membranas, a mais externa normalmente lisa e a mais interna com dobramentos, que podem assumir diversas conformações (tubular, vesicular ou lamelar). Apesar da variação de forma, número e tamanho das mitocôndrias, seqüências moleculares têm mostrado uma origem monofilética, indicando um único evento de aquisição de mitocôndrias por endossimbiose, seguido de algumas raras perdas secundárias (Dyer e Obar, 1994).

Uma outra organela, os hidrogenossomos, também envoltos por duas membranas, está relacionada ao metabolismo fermentativo em vários protistas anaeróbicos. Estudos moleculares recentes indicam que os hidrogenossomos partilham um ancestral comum com as mitocôndrias. Apesar de a maioria dos hidrogenossomos não possuir um genoma, foi encontrado DNA nessas organelas em alguns ciliados anaeróbicos. Com base nesses genes, foi verificado que os hidrogenossomos parecem ser um tipo de mitocôndria anaeróbica (Embley e Martin, 1998; Martin, 1999).

Existem linhagens eucarióticas que não possuem mitocôndrias e muitas dessas linhagens parecem ter divergido antes da maioria das linhagens atuais de eucariotos (Figura 2.4). Esses protistas sem mitocôndria foram reunidos no grupo arqueozoa (ameboflagelados, diplomonas, retortomonas, microsporídios e tricomonas), que se acreditava ter divergido antes da aquisição de mitocôndrias. Entretanto, nos últimos anos, têm sido achados genes tipicamente mitocondriais no núcleo de todas essas linhagens, indicando que ocorreu uma perda secundária da mitocôndria (Doolittle, 1999b). Isso não significa que esses grupos não são basais na evolução dos eucariotos, ou seja, não invalida as árvores filogenéticas propostas, mas apenas altera a interpretação feita sobre a condição do ancestral comum das linhagens atuais de eucariotos. 
Atualmente não existe um forte candidato a um eucarioto que nunca tenha possuído uma mitocôndria. Segundo Clark (1999), talvez a origem das mitocôndrias tenha sido a força motriz para a origem da membrana nuclear e, conseqüentemente, dos eucariotos propriamente ditos. Muitos dos organismos sem mitocôndria são parasitas internos (por exemplo, Giardia). Isso sugere uma perda da mitocôndria, já que esses ambientes são pobres em oxigênio (Taylor, 1994). Martin (1999) argumenta que, se não forem encontrados eucariotos atuais que nunca tiveram mitocôndrias, a ordem dos eventos que levaram à origem da célula eucariótica deveria ser revista.

A hipótese tradicional diz que a célula hospedeira, quando adquiriu sua mitocôndria, já possuía um núcleo. Martin e Müller (1998) sugerem que o endossimbionte que deu origem às mitocôndrias e hidrogenossomos era uma $\alpha$-proteobactéria anaeróbica facultativa, com considerável flexibilidade metabólica. A célula hospedeira seria semelhante aos atuais metanogêneos (uma arqueobactéria), os únicos procariotos conhecidos que possuem histonas verdadeiras (as proteínas associadas ao DNA, encontradas nos eucariotos).

Baseado no que foi visto até o momento, uma ordem de origem das estruturas eucarióticas mais lógica seria: primeiro o citoesqueleto, possibilitanto a fagocitose, depois a origem da mitocôndria, seguido do sistema de endomembranas e, por fim, o compartimento nuclear.

Todos os organismos que possuem cloroplastos também possuem mitocôndrias, o que sugere que as mitocôndrias precederam os plastos. Entretanto, isto também pode indicar que as mitocôndrias são obrigatórias para a manutenção de plastos (Dyer e Obar, 1994).

A época de origem dos eucariotos tem sido estimada usando o tamanho das células no registro fóssil (Runnegar, 1994). A descoberta de um fóssil denominado Grypania spiralis, com idade estimada em 2,1 bilhões de anos, interpretado como uma alga eucariótica fotossintetizante, indica que a origem do cloroplasto por endossimbiose teria ocorrido antes dessa data (Han e Runnegar, 1992).

A associação simbiótica entre organismos autótrofos e heterótrofos é extremamente comum na natureza. Diversos animais e protozoários apresentam associações com microalgas (como corais, esponjas, ascídias e foraminíferos). Os fungos associam-se às algas, formando os líquens. Em ambientes iluminados e ricos em nutrientes, a fotossíntese tende a ser superprodutiva, a ponto de haver excesso de produção para o organismo hospedeiro (Dyer e Obar, 1994; Margulis e Cohen, 1994).

Existem vários tipos de cloroplastos que diferem em sua forma, ultraestrutura e pigmentação. Entretanto, seqüências de rRNA e de vários outros genes indicam uma origem monofilética para todos os cloroplastos que teriam surgido a partir de um evento endossimbiótico entre uma célula eucariótica (célula hospedeira) e uma cianobactéria semelhante a Synechococcus (Dyer e Obar, 1994; Delwiche e Palmer, 1997). Esse resultado foi uma surpresa para alguns pesquisadores que consideravam a diversidade pigmentar e estrutural encontrada nos organismos fotossintetizantes atuais como indicação de uma origem polifilética dos cloroplastos. Atualmente, a origem endossimbiótica dos cloroplastos já está plenamente estabelecida, embora ainda exista controvérsia quanto ao número de eventos de endossimbiose que levou à formação dos diferentes tipos de cloroplastos. As árvores filogenéticas indicam um único evento primário de endossimbiose. Entretanto, esses dados também poderiam ser interpretados como eventos múltiplos com um grupo de cianobactérias filogeneticamente próximas. Além do evento de endossimbiose primário, múltiplos eventos de endossimbiose secundários ocorreram nas linhagens eucarióticas fotossintéticas. Um evento de endossimbiose secundário é aquele onde uma célula eucariótica engloba uma outra célula eucariótica que já contenha um cloroplasto (produto do evento primário). Eventos de endossimbiose secundários geraram cloroplastos complexos com mais de duas membranas (três ou quatro). Em alguns casos, é ainda possível verificar a presença de um núcleo vestigial (chamado de nucleomorfo) entre a segunda e a terceira membranas do cloroplasto (Figura 2.6). Na endossimbiose secundária, o núcleo da célula englobada sofre o mesmo processo de redução, com perda e transferência lateral de genes para o núcleo da célula hospedeira.

O número de membranas ao redor dos cloroplastos é interpretado como indicativo de uma origem primária ou secundária. Os cloroplastos com duas membranas são considerados como produto de endossimbiose primária, sendo que a membrana mais interna é de origem procariótica (membrana plasmática) e a mais externa de origem eucariótica (membrana do fagossomo). O cloroplasto secundário, além das duas membranas, possui ainda uma terceira (membrana do eucarioto que foi englobado) e quarta (do fagossomo) membranas eucarióticas (Figura 2.6). Em alguns casos, parece ter ocorrido a perda de uma das membranas, como nas euglenófitas e nos dinoflagelados (Tabela 2.1).

Entre os eucariotos fotossintetizantes atuais, reconhecemos três grupos cujo cloroplasto seria produto de um evento primário de endossimbiose: (1) as algas verdes (Chlorophyta) e plantas terrestres; (2) as algas vermelhas (Rhodophyta); e (3) um pequeno grupo de algas unicelulares flageladas (Glaucocystophyta). Esses grupos, por sua vez, teriam originado os plastos de outras linhagens de eucariotos através de eventos de endossimbiose secundária. Essa hipótese baseia-se em evidências de ultraestrutura, bioquímicas e em 
comparação de seqüências moleculares. Por exemplo, o cloroplasto das criptófitas, um pequeno grupo de algas unicelulares flageladas cujo plasto possui um nucleomorfo, teve origem a partir de uma alga vermelha (Douglas et al. 1991; Douglas e Penny, 1999). As algas vermelhas também deram origem aos cloroplastos das algas com clorofila c (heterocontes, haptófitas e dinoflagelados; Oliveira e Bhattacharya, 2000). As algas verdes são apontadas como o grupo que deu origem aos cloroplastos das euglenófitas, de um pequeno grupo de algas amebóides (Chlorarachniophyta) cujo plasto ainda apresenta um nucleomorfo e, possivelmente, do plasto não fotossintetizante dos apicomplexa, grupo que inclui Plasmodium (causador da malária) e Toxoplasma (causador da toxoplasmose).

A origem endossimbiótica dos plastos e mitocôndrias (incluindo hidrogenossomos) já está firmemente estabelecida. Entretanto, endossimbiose também tem sido proposta para explicar a origem de praticamente todas as demais organelas nas células eucarióticas. Para essas outras organelas, como o sistema relacionado à motilidade (sistema microtubular e flagelo), o retículo endoplasmático, peroxissomos, glicossomos, entre outros, não existe evidência molecular ou bioquímica conclusiva de origem endossimbiótica. Ao contrário, os dados existentes favorecem a hipótese de origem autógena, onde essas estruturas teriam se originado e se organizado gradativamente na célula eucariótica (Martin, 1999). Uma possível presença de DNA e RNA nos centros organizadores de microtúbulos não foi confirmada. Cavalier-Smith (1975) propôs que o mesmo sistema de fagocitose, em células com membranas flexíveis e sem parede, poderia ter dado origem a vários dos sistemas internos de membranas, como o retículo endoplasmático, a membrana nuclear e o complexo de Golgi.

Os organismos eucarióticos diversificaram-se em várias linhagens filogenéticas (Figura 2.4), das quais as principais (chamadas, em inglês, de crown lineages) são os animais (Metazoa, incluindo os animais invertebrados e os vertebrados), os fungos verdadeiros, as plantas verdes (com clorofila $\mathbf{a}$ e $\mathbf{b}$, que incluem as algas verdes), as algas vermelhas, os estramenopilas (inclui os oomicetos, labirintulomicetos e as algas heterocontes -pardas, diatomáceas e outras algas com clorofilas a e c) e os alveolados (incluindo os dinoflagelados, ciliados e os apicomplexa). A diversidade molecular e fenotípica encontrada nos estramenopilas e alveolados é equivalente à encontrada nos outros reinos e ambos possuem organismos fotossintetizantes e heterotróficos (Sogin, 1994).

A rápida diversificação das principais linhagens dos eucariotos ocorreu em torno de 1 a 1,5 bilhão de anos atrás e pode ter sido ocasionada por diversos fatores, tais como alterações ambientais; por exemplo, o aumento de oxigênio na atmosfera pode ter atingido patamares que possibilitaram a ocupação de novos nichos. Essa diversificação pode também ter sido causada por mecanismos internos, como por exemplo o surgimento de genes homeobox, que permitiram padrões de diferenciação celular mais complexos em organismos multicelulares (Sogin, 1994). A geração de um organismo multicelular com tecidos diferenciados a partir de uma única célula (zigoto) é um processo altamente complexo e que não será abordado neste capítulo.

\subsection{CONCLUSÕES}

Os RNAs catalíticos são considerados fósseis moleculares que remontam à origem da vida, onde o RNA era a molécula principal e atuava no armazenamento de informações e na atividade catalítica. Entretanto, existe ainda uma grande distância entre o que sabemos das condições na Terra nos primórdios da vida e as propriedades atuais do RNA. Apesar dessas limitações, o grande sucesso da hipótese do mundo de RNA está no fato de que, atualmente, ela é a mais abrangente para explicar a origem da vida e, de certa maneira, vários de seus pressupostos são passíveis de experimentação. Um número cada vez maior de experimentos tem dado suporte à hipótese do mundo de RNA, demonstrando as inúmeras capacidades das ribozimas (Lazcano, 1994; Jeffares et al., 1998; Poole et al., 1998; Szathmáry, 1999).

No futuro, um maior conhecimento sobre as interações entre ácidos nucléicos e proteínas e experimentos de simulação de sistemas de RNA in vitro poderão esclarecer os pontos ainda obscuros. Análises filogenéticas de genes e genomas poderão trazer maiores informações sobre o progenota e quais os prováveis genes e proteínas presentes no início da vida. Muito falta ainda para que possamos ter um cenário mais claro da origem e evolução dos primeiros seres vivos, mas nas duas últimas décadas houve avanços muito significativos.

Embora a existência do mundo de RNA talvez nunca venha a ser comprovada, sua plausibilidade pode ser testada no laboratório investigando as possibilidades das moléculas de RNA de catalisar as reações e armazenar as informações necessárias à vida.

\section{REFERÊNCIAS BIBLIOGRÁFICAS}

Andersson, S.G.E., Zomoeodipour, A., Andersson, I.O. et al. (1998). The genome sequence of Rickettsia prowazekii and the origin of mitochondria. Nature 396:133-140. 
Bhattacharya, D. e Medlin, L. (1998). Algal phylogeny and the origin of land plants. Plant Physiology 116: 915.

Cavalier-Smith, T. (1975). The origin of nuclei and the eukaryotic cells. Nature 256: 463-468.

Cavalier-Smith, T. (1987). The origin of eukaryotic and archaebacterial cells. Ann. N. Y. Acad. Sci. 503: 17-54.

Cech, T.R. (1988). Conserved sequences and structure of group I introns: building an active site for RNA catalists - A review. Gene 73: 259-271

Cech, T.R. (1990). Self-splicing of group I introns. Annu. Rev. Biochem. 59: 543-568.

Cech, T.R. e Bass, B.L. (1986). Biological catalysis of RNA. Annu. Rev. Biochem. 55: 599-629.

Clark, C.G. (1999). The effect of secondary loss on our views of eukaryotic evolution. Biol. Bull. 196: 385-388.

Darnell, J.E. e Doolittle, W.F. (1986). Speculations on the early course of evolution. Proc. Natl. Acad. Sci. USA 83: $1271-1275$.

Deamer, D.W., Mahon, E.H. e Bosco, G. (1994). Self-assembly and function of primitive membrane structures. In Bengtson, S. (ed) Early Life on Earth, Nobel Symposium, no 84. Columbia Univ. Press, New York, 107123.

Delwiche, C.F. e Palmer, J. D. (1997). The origin of plastids and their spread via secondary symbiosis. Pl. Syst. Evol. [suppl.] 11: 53-86.

Doolittle, W.F. (1999a). Phylogenetic classification and the universal tree. Science 284: 2124-2128.

Doolittle, W.F. (1999b). Rethinking the origins of eukaryotes. Biol. Bull. 196: 378-380.

Doudna, J.A. e Szostak, J.W. (1989). RNA-catalyzed synthesis of complementary-strand RNA. Nature 339: 519-522.

Doudna, J.A., Cormack, B.P. e Szostak, J.W. (1989). RNA structure, not sequence, determines the 5' splice-site specificity of a group-I intron. Proc. Nat. Acad. Sci. USA 86: 7402-7406.

Douglas, S.E., Murphy, C.A., Spencer, D.F. e Gray, M.W. (1991). Cryptomonad algae are evolutionary chimaeras of two phylogenetically distinct unicellular eukaryotes. Nature 350:148-151.

Douglas, S.E. e Penny, S.L. (1999). The plastid genome of the cryptophyte alga, Guillardia theta: complete sequence and conserved synteny groups confirms its common ancestry with red algae. J. Mol. Evol. 48: 236-244.

Dyer, B.D. e Obar, R.A. (1994). Tracing the history of eukaryotic cells. The enigmatic smile. Columbia University Press, new York, $259 \mathrm{pp}$.

Embley, T.M. e Martin, W. (1998). A hydrogen-producing mitochondrion. Nature 396: 517-519.

Forterre, P. e Philippe, H. (1999). The last universal common ancestor (LUCA), simple or complex? Biol. Bull. 196: $373-377$.

Fung, P.A., Gaertig, J., Gorovsky, M.A. e Hallberg, R.L. (1995). Requirement of a small cytoplasmic RNA for the establishment of thermotolerance. Science 268: 1036-1039.

Gilbert, W. (1978). Why genes in pieces? Nature 271: 501.

Gilbert, W. (1986). The RNA world. Nature 319: 618.

Gilbert, W. (1987). The exon theory of genes. Cold Spring Harbor Symposia on Quantitative Biology 52: 901-905.

Gogarten, J.P., Murphey, R.D. e Olendzenski, L. (1999). Horizontal gene transfer: pitfalls and promisses. Biol. Bull. 196: 359-362.

Gray, M.W. (1992). The endosymbiont hypothesis revisited. Int. Rev. Cytol. 141: 233-357.

Han, T.-M. e Runnegar, B. (1992). Megascopic eukaryote algae from the 2.1 billion-year-old Negaunee IronFormation, Michigan. Science 257: 232-235.

Illangasekare, M., Sanchez, G., Nickles, T. e Yarus, M. (1995). Aminoacyl-RNA synthesis catalyzed by an RNA. Science 267:643-647.

Jeffares, D.C., Poole, A.M. e Penny, D. (1998). Relics from the RNA world. J. Mol. Evol. 46: 18-36.

Joyce, G.F. (1989). RNA evolution and the origins of life. Nature 338: 217-224.

Katz, L.A. (1998). Changing perspectives on the origin of eukaryotes. TREE 13: 493-497.

Knoll, A. (1992). The early evolution of eukaryotes: a geological perspective. Science 256: 622-627.

Landweber, L.F., Simon, P.J. e Wagner, T.A. (1998). Ribozyme engineering and early evolution. Bioscience 48: 2-103.

Lazcano, A. (1994). The RNA world, its predecessors, and its descendants. In Bengtson, S. (ed) Early Life on Earth, Nobel Symposium, no 84. Columbia Univ. Press, New York, 70-80.

Lazcano, A. e Miller, S.L. (1996). The origin and early evolution of life: prebiotic chemistry, the pre-RNA world, and time. Cell 85: 793-798.

Lewin, B. (1997). Genes VI. Oxford Univ. Press, Oxford, 1272 pp. 
Margulis, L. e Cohen, J.E. (1994). Combinatorial generation of taxonomic diversity: implication of symbiogenesis for the proterozoic fossil record. In Bengtson, S. (ed) Early Life on Earth, Nobel Symposium, no 84. Columbia Univ. Press, New York, 327-333.

Martin, W. (1999). A briefly argued case that mitochondria and plastids are descendants of endosymbionts, but that the nuclear compartment is not. Proc. R. Soc. Lond. 266: 1387-1395.

Martin, W. e Müller, M. (1998). The hydrogen hypothesis for the first eukaryote. Nature 392: 37-41.

Michel, F. e Westhof, E. (1990). Modelling of the 3-dimensional architecture of group-I catalytic introns based on comparative sequence-analysis. J. Mol. Biol. 216: 585-610.

Moran, J.V., DeBerardinis, R.J. e Kazazian, H.H. (1999). Exon shuffling by L1 retrotransposition. Science 283: 1530-1534.

Nagel, G.M. e Doolittle, R.F. (1995). Phylogenetic analysis of the aminoacyl-transfer-RNA synthetases. J. Mol. Evol. 40: 487-498.

Nelson, K.E., Clayton, R.A., Gill, S.R., Gwinn, M.L. et al. (1999). Evidence for lateral gene transfer between Archaea and Bacteria from genome sequence of Thermotoga maritima. Nature 399: 323-329.

Neunlist, S. e Rohmer, M. (1985). A novel hopanoid, 30-(5'-adenosyl)hopane, from the purple non-sulphur bacterium Rhodopseudomonas acidophila, with possible DNA interations. Bioch. J. 228: 769-771.

Nitta, I., Kamada, Y., Noda, H., Ueda, T. e Watanabe, K. (1998). Reconstitution of peptide bond formation with Escherichia coli 23S RNA domains. Science 281: 666-669.

Noller, H.F. (1991). Drugs and the RNA world. Nature 353: 302-303.

Ohta, T. (1994). Early evolution of genes and genomes. In Bengtson, S. (ed) Early Life on Earth, Nobel Symposium, no 84. Columbia Univ. Press, New York, 70-80.

Oliveira, E.C. (1996). Introdução à Biologia Vegetal. EDUSP, São Paulo, 224 pp.

Oliveira, M.C. e Bhattacharya, D. (2000). Phylogeny of the Bangiophycidae (Rhodophyta) and the secondary endosymbiotic origin of algal plastids. Am J. of Botany 87: 482-492.

Pierson, B.K. (1994). The emergence, diversification, and role of photosynthetic eubacteria. In Bengtson, S. (ed) Early Life on Earth, Nobel Symposium, no 84. Columbia Univ. Press, New York, 70-80.

Poole, A.M., Jeffares, D.C. e Penny, D. (1998). The path from the RNA world. J. Mol. Evol. 46: 1-17.

Potter, S., Durovic, P. e Dennis, P.P. (1995). Ribosomal-RNA precursor processing by a eukaryotic U3 small nucleolar RNA-like molecule in an archaeon. Science 268: 1056-1060.

Runnegar, B. (1994). Proterozoic eukaryotes: evidence from biology and geology. In Bengtson, S. (ed.) Early Life on Earth, Nobel Symposium, no 84. Columbia Univ. Press, New York, 287-297.

Sogin, M.L. (1994). The origin of eukaryotes and evolution into major kingdoms. In Bengtson, S. (ed.) Early Life on Earth, Nobel Symposium, no 84. Columbia Univ. Press, New York, 181-192.

Szathmáry, E. (1999). The origin of the genetic code. Trends in Genetics 15: 223-229.

Taylor, F.J.R. (1994). The role of phenotypic comparisons in the determination of protist phylogeny. In Bengtson, S. (ed) Early Life on Earth, Nobel Symposium, no 84. Columbia Univ. Press, New York, 312326.

Wetzel, R. (1995). Evolution of the aminoacyl-transfer-RNA synthetases and the origin of the genetic-code. J. Mol. Evol. 40: 545-550.

Woese, C.R. (1987). Bacterial Evolution. Microbiol. Rev. 51: 221-271.

Woese, C.R., Kandler, O. e Wheelis, M.L. (1990). Towards a natural system of organisms: Proposal for the domains Archaea, Bacteria and Eucarya. Proc. Natl. Acad. Sci. USA 87: 4576-4579.

Young, L.S., Dunstan, H.M., Witte, P.R., Smith, T.P., Ottonello, S. e Sprague, K.U. (1991). A class III transcription factor composed of RNA. Science 252: 542-252. 
Tabela 2.1. Características dos cloroplastos dos eucariontes. cl-a, clorofila a; cl-b, clorofila b; cl-c, clorofila c; fb, ficobilinas. As linhagens com cloroplastos de duas membranas, típicos de um evento primário de endossimbiose são: as algas verdes (Chlorophyta) e plantas terrestres; as algas vermelhas (Rhodophyta); e um pequeno grupo de algas unicelulares flageladas (Glaucocystophyta). As linhagens com cloroplastos resultantes de endossimbiose secundária (com mais de duas membranas) são: um pequeno grupo de algas amebóides (Chlorarachniophyta), cujo plasto, que ainda apresenta um nucleomorfo, foi originado a partir de um evento endossimbiótico entre uma ameba e possivelmente uma Chlorophyta; as euglenófitas, que também sofreram um processo de endossimbiose com uma Chlorophyta; as Cryptophyta, algas unicelulares flageladas, cujo plasto também possui um nucleomorfo que teve origem a partir de uma Rhodophyta; os grupos de algas com clorofila c (heterocontes, haptófitas e dinoflagelados), cujos cloroplastos teriam se originado também a partir de uma Rhodophyta; e os apicomplexa, grupo que inclui Plasmodium (causador da malária) e Toxoplasma (causador da toxoplasmose) e que possuem um plasto não fotossintetizante de origem incerta (modificado de Delwiche e Palmer, 1997).

\begin{tabular}{|c|c|c|c|c|}
\hline $\begin{array}{l}\text { Eucariotos com } \\
\text { cloroplastos }\end{array}$ & $\begin{array}{l}\mathrm{n}^{0} \text { de membranas } \\
\text { do cloroplasto }\end{array}$ & $\begin{array}{l}\text { Presença de } \\
\text { nucleomorfo }\end{array}$ & $\begin{array}{c}\text { Pigmentos } \\
\text { fotossintéticos }\end{array}$ & $\begin{array}{l}\text { ENDOSSIMBIOS } \\
\text { E }\end{array}$ \\
\hline $\begin{array}{l}\text { Chlorophyta e } \\
\text { Plantas terrestres }\end{array}$ & 2 & Ausente & $\begin{array}{l}\text { cl-a, cl-b } \\
\text { cl-a, fb }\end{array}$ & $\begin{array}{l}\text { primária } \\
\text { primária }\end{array}$ \\
\hline Rhodophyta & 2 & Ausente & cl-a, fb & primária \\
\hline Glaucocystophyta & & & & \\
\hline Chlorarachniophyta & $\begin{array}{l}4 \\
3\end{array}$ & $\begin{array}{l}\text { Presente } \\
\text { Ausente }\end{array}$ & $\begin{array}{l}\text { cl-a, cl-b } \\
\text { cl-a, cl-b }\end{array}$ & $\begin{array}{l}\text { secundária } \\
\text { secundária }\end{array}$ \\
\hline Euglenophyta & 4 & Presente & cl-a, cl-c, fb & secundária \\
\hline Cryptophyta & 4 & Ausente & cl-a, cl-c & secundária \\
\hline Heterocontophyta & 4 & Ausente & cl-a, cl-c & secundária \\
\hline Haptophyta & 3 & Ausente & cl-a, cl-c & secundária \\
\hline $\begin{array}{l}\text { Dinophyta } \\
\text { Apicomplexa }\end{array}$ & 4 & Ausente & Não fotoss. & secundária \\
\hline
\end{tabular}



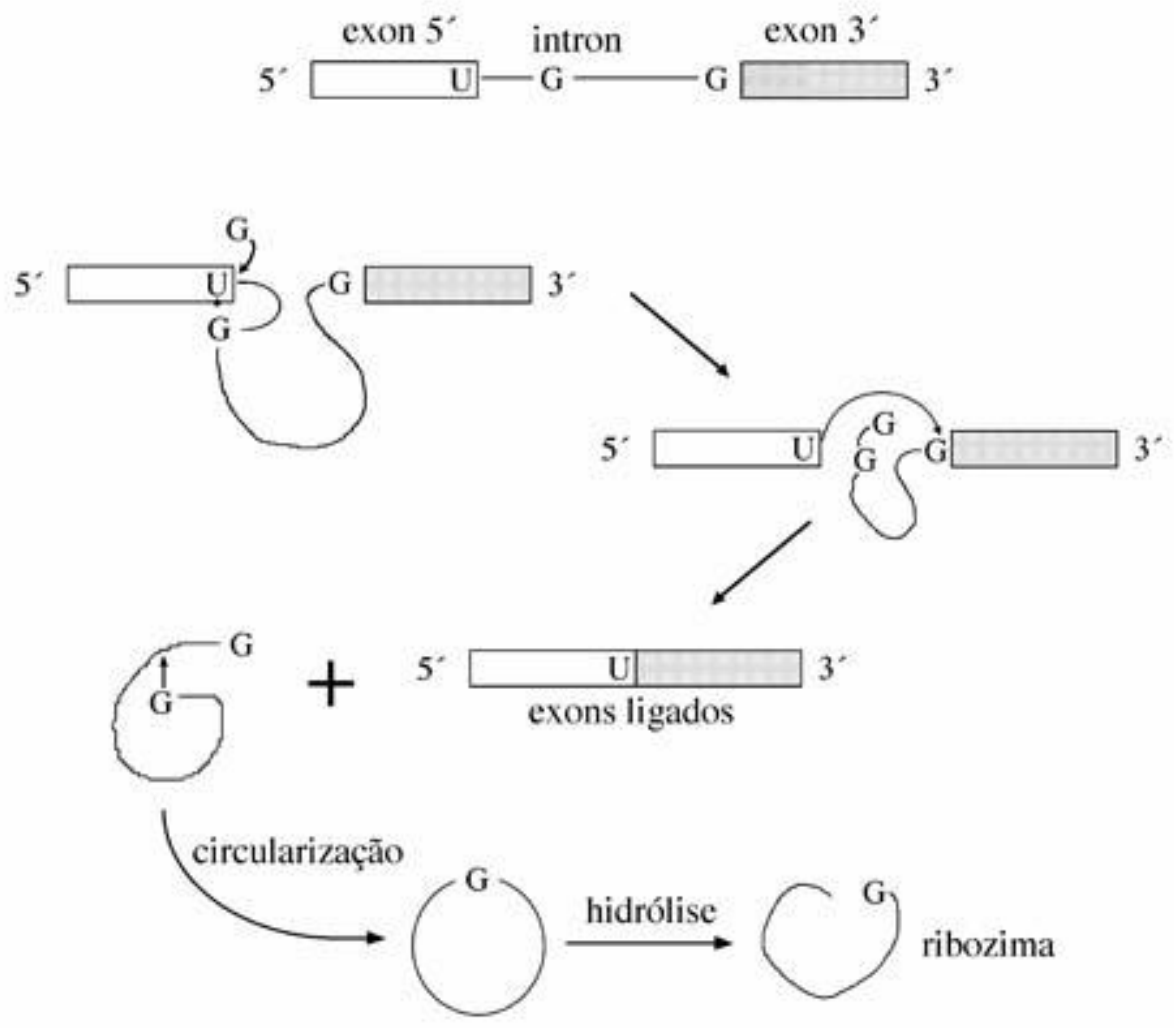

Figura 2.1. Esquema da reação de autoprocessamento de um intron do grupo I. O grupo OH-3' de uma guanina (G) livre ataca a ligação fosfodiéster 3' do último nucleotídeo (em geral uma uridina) do exon 5'. Essa uridina está pareada com uma guanina do intron. $\mathrm{O}$ ataque resulta na quebra da ligação $5^{\prime}$ entre o exon $5^{\prime}$ e o intron. $\mathrm{O}$ grupo $\mathrm{OH}$ 3' do exon 5' ataca a ligação fosfodiéster após o resíduo $\mathrm{G}$ terminal do intron, rompendo a ligação 3' intron/exon e se ligando ao exon '3'. As duas reações de transesterificação são catalisadas pelo próprio intron, que funciona como uma enzima e pode sofrer processos de circularização e hidrólise.

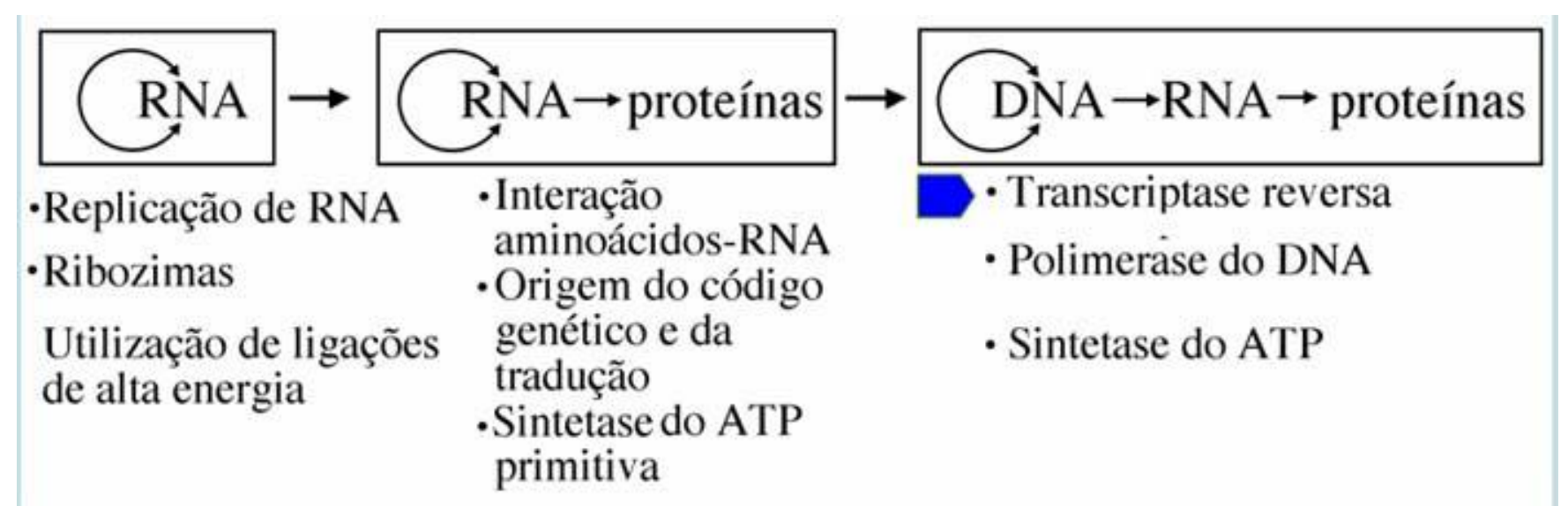

Figura 2.2. Esquema de um possível cenário de transição entre um organismo com metabolismo baseado em RNA até um organismo atual com metabolismo baseado em DNA, RNA e proteínas (modificado de Lazcano, 1994). 


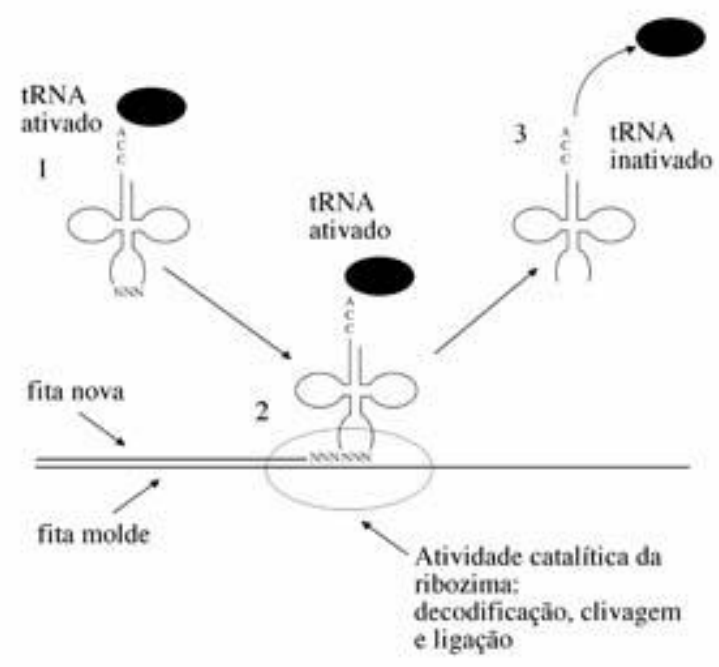

Figura 2.3. Modelo para a origem da síntese protéica baseada numa molécula molde de RNA. 1. Um aminoácido com carga positiva ajudaria uma replicase de RNA a reconhecer o tRNA, aproximando os dois; 2 . O trinucleotídeo no anticódon é adicionado à nova fita de DNA pela replicase de RNA através de clivagem e ligação, semelhantes às realizadas pelos introns atuais; 3. O aminoácido é então clivado do tRNA e este é liberado, semelhante à atividade do 23S rRNA atual (modificado de Poole et al. 1998).

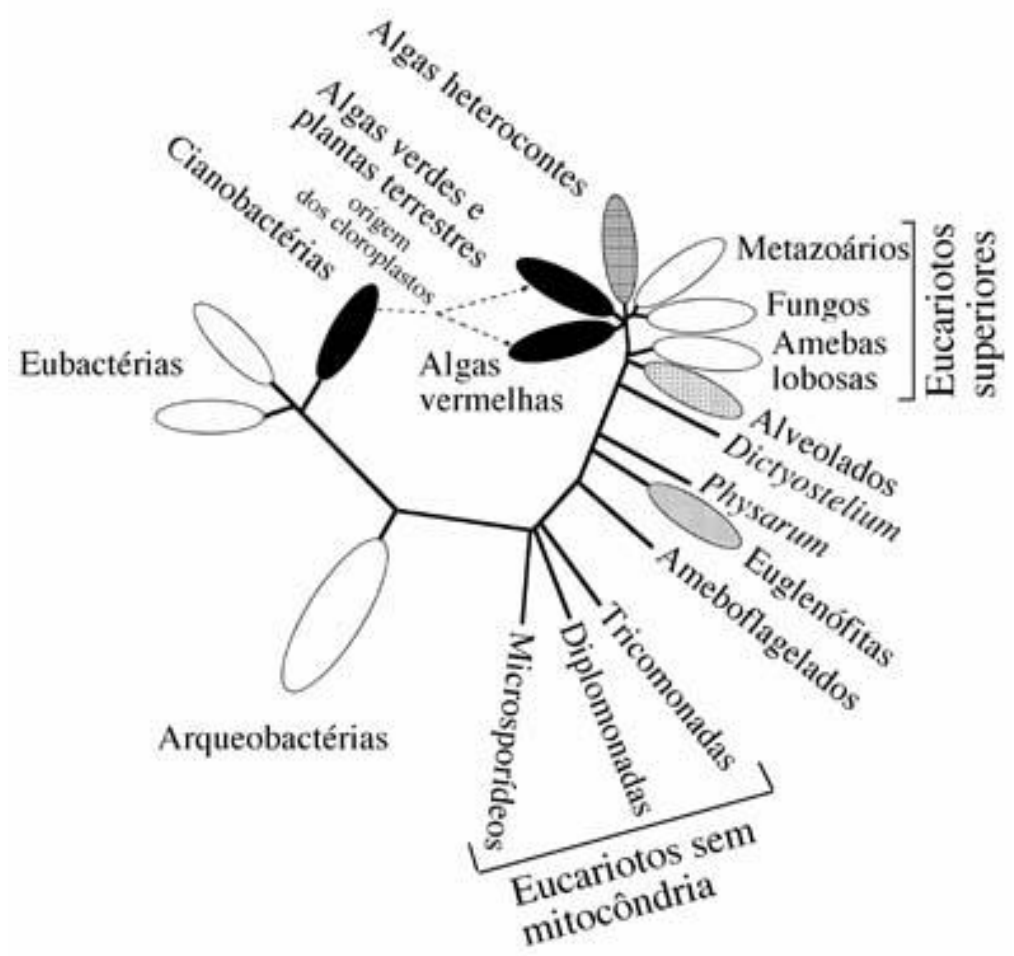

Figura 2.4. Árvore filogenética esquemática baseada nas seqüências do SSU rDNA mostrando os três domínios de seres vivos (Eubactéria, Arqueobactéria e Eucariotos) e detalhando as principais linhagens eucarióticas. As linhagens filogenéticas fotossintetizantes estão em preto ou hachuradas (modificado de Bhattacharya e Medlin, 1998). 


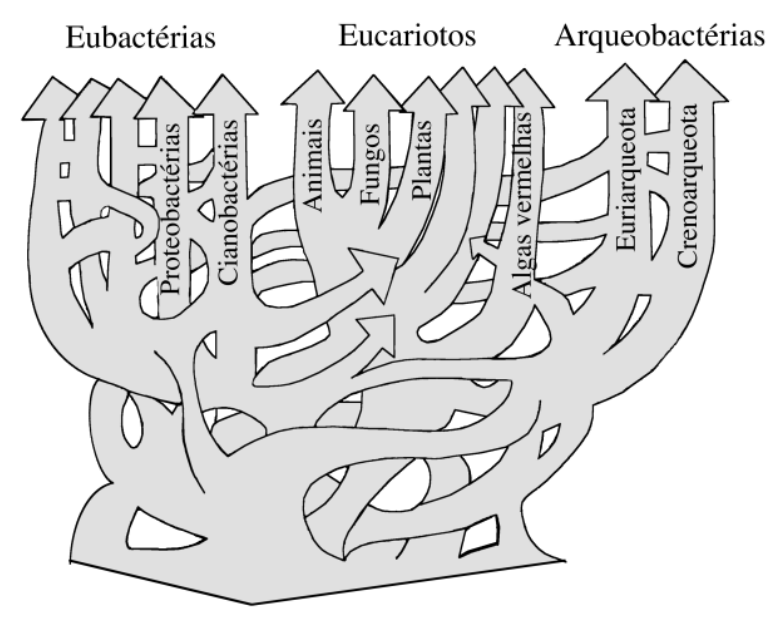

Figura 2.5. Árvore filogenética reticulada representando possíveis eventos de transferência lateral entre os três domínios (adaptado de Doolittle, 1999a). 


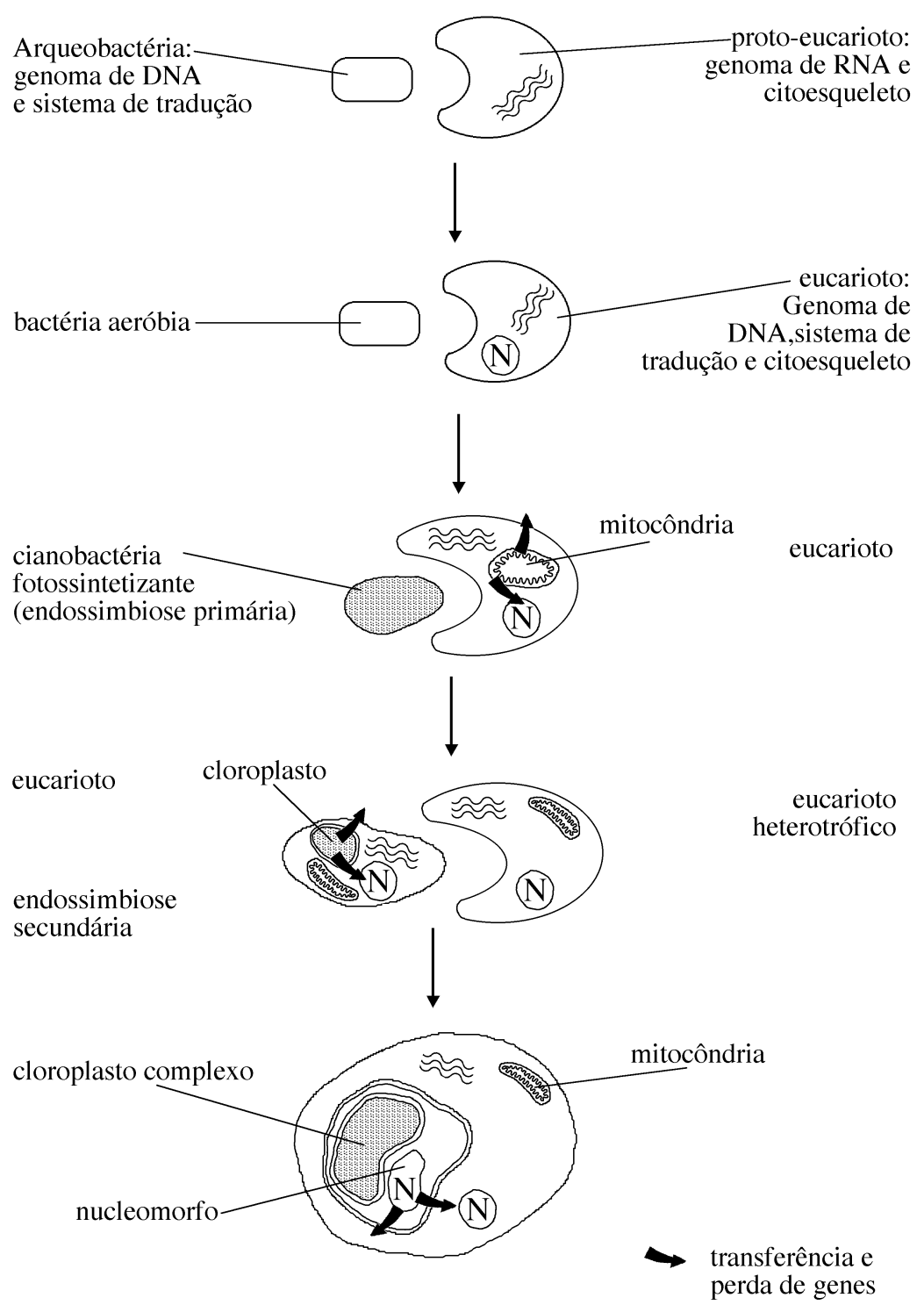

Figura 2.6. Esquema de um possível cenário para a origem e evolução dos eucariotos, baseado em várias hipóteses referidas no texto. 


\title{
Estudios de la macro y microbiodiversidad de las algas. Secuenciamiento del DNA ribosomal (rDNA)
}

\author{
Mariana C. De Oliveira
}

\begin{abstract}
Depto. de Botânica, Instituto e Biociências, Universidade de São Paulo, São Paulo, SP. R. do Matão, Travessa 14, n. 321, cep 05508-900. E-mail: mcdolive@ib.usp.br. Fax: 55-11-38187547. Brasil.
\end{abstract}

\section{RESUMEN}

Actualmente, el secuenciamiento de DNA es la técnica más poderosa para detectar polimorfismos en el genotipo. Los genes ribosomales y sus regiones espaciadoras han sido utilizados para la comparación entre organismos de diferentes niveles taxonómicos. Estas secuencias contribuyen significativamente para un mejor entendimiento de la macro y microdiversidad, principalmente en algas que abarcan diversos grupos de origen filogenéticamente independientes, generalmente con morfologías extremamente simples y de gran plasticidad. En este capítulo se discutirá el uso del secuenciamiento de regiones codificadoras y no codificadoras del DNA ribosomal para estudios de biodiversidad.

\section{ABSTRACT}

Nowadays DNA sequencing is the most powerful technique to detect polymorphism in the genome. Ribosomal genes and its spacing regions have been used to compare organisms at different taxonomic levels. These sequences contribute significantly to a better understanding of the macro and microbiodiversity, specially in algae, which include highly diverse groups of organisms with independent phylogenic origins and often with a very simple and plastic morphology. The use of sequencing of coding and non-coding regions of ribosomal DNA for biodiversity studies is here discussed.

\section{INTRODUCCIÓN}

Actualmente, uno de los grandes problemas de la biología es cómo estimar la biodiversidad de los seres vivos en los diferentes ecosistemas. Estimar la biodiversidad de una macro fauna o flora, ya es un problema bastante difícil, que se agrava aún más cuando se trata de microrganismos (Pedrós-Alió, 1993). En el ambiente acuático, especialmente en el marino, este problema es aún más complejo, no sólo por la dificultad del muestreo, sino también por la gran diversidad de fila y divisiones existentes en el mar, los cuales abarcan el $71 \%$ del planeta (Oliveira, 1998). 
Un paso importante para estimar la biodiversidad de una determinada área es determinar el número de especies presentes (Heywood \& Watson, 1995). Sin embargo, en varios grupos, y principalmente en los organismos microscópicos, estimar el número de especies puede ser difícil al utilizar las técnicas convencionales. El concepto morfológico de especie permite distinciones morfológicas (incluyendo ultra-estructura), pero en las algas es relativamente común la plasticidad morfológica y la presencia de especies crípticas. El concepto biológico de especie puede ser aplicado en el caso de especies crípticas, no obstante, es un proceso que demanda mucho trabajo y tiempo, y además, en muchos casos los grupos no presentan o no se les conoce reproducción sexual. Andersen et al. (1998) proponen el concepto molecular de especie, que utiliza secuencias genéticas como la principal o única evidencia en la distinción de especies. Este concepto es útil principalmente cuando se trabaja con organismos cuya evolución llevó a una reducción extrema de la morfología y del ciclo de vida. A pesar de que el concepto molecular de especie puede parecer muy simplista y reduccionista, él puede ser extremadamente útil y práctico en los estudios de biodiversidad.

El objetivo de este capítulo es describir cómo los genes y los espaciadores ribosomales pueden ser utilizados en los estudios de macro y microdiversidad de las algas, indicando sus ventajas y desventajas.

\section{MARCADORES MOLECULARES}

El concepto molecular de especie implica el uso de marcadores moleculares que contienen informaciones obtenidas directa o indirectamente del genotipo, pudiendo ser utilizados para la caracterización de un organismo o un grupo de organismos de diferentes niveles taxonómicos (Avise, 1994). Por otra parte, los marcadores morfológicos miden el fenotipo y, por lo tanto, sufren la influencia del medio ambiente, además de presentarse en números relativamente limitados. Los marcadores moleculares no solamente son fundamentales para estimar el número de especies de un ecosistema, sino que también son extremadamente importantes para la conservación de esas especies. A través del uso de marcadores moleculares se puede estimar la variabilidad genética de una población y el número mínimo de individuos necesarios para su mantención (Amos \& Hoelzel, 1992), además de ser aplicables en diversos tipos de estudios ecológicos (Bachmann, 1994). Este tipo de estudio ha sido ampliamente utilizado en animales y plantas terrestres, pero muy poco utilizado en ambientes acuáticos.

La información contenida en el DNA es determinada por la combinación de sólo cuatro nucleótidos $(A=$ adenina,$C=$ citosina, $G$ = guanina y $T=$ timidina $)$, pero a pesar de esta aparente simplicidad, el DNA es extremadamente complejo. Apenas una porción del genoma está representada por regiones codificadoras, tradicionalmente denominadas genes; el resto varía entre regiones altamente repetitivas, regiones reguladoras, regiones espaciadoras y regiones aparentemente sin función y distribuidas al azar (Amos \& Hoelzel, 1992). Las proporciones y los tipos de mutaciones varían dentro de las diferentes regiones, existiendo desde porciones del DNA con una tasa tan elevada de variación que pueden ser utilizadas para marcar los diferentes individuos de una población, hasta porciones extremadamente conservadas que pueden ser comparadas entre las diferentes categorías taxonómicas superiores (División o Fila).

La información genética puede ser obtenida directa o indirectamente por diferentes técnicas, incluidas las inmunológicas y citogenéticas, la electroforesis y el secuenciamiento de pro- 
teínas, la hibridación de ácidos nucleicos, la restricción, la amplificación y el secuenciamiento de DNA (Tabla 1). La existencia de un objetivo claro va a determinar la eficiencia de los marcadores moleculares y, por lo tanto, la utilización de un método apropiado. Estas técnicas, desarrolladas en las últimas 3 décadas, permiten analizar de forma rápida y objetiva la variabilidad genética de un gran número de individuos (Olsen, 1990; Amos \& Hoelzen, 1992).

Tabla 1. Comparación de la eficiencia de los marcadores moleculares para diferentes niveles taxonómicos. ISO = isozima; IMUNO = datos inmunológicos; CITO = datos citogenéticos; HIBR = hibridación DNA/DNA; REST = restricción de DNA (RFLP, RAPD y técnicas afines); SEQ = secuenciamiento de DNA; MA = millones de años (Oliveira, 1998). (+) técnica eficiente; (-) técnica ineficiente; (\$) técnica eficiente, pero económicamente más costosa.

\begin{tabular}{|c|c|c|c|c|c|c|}
\hline & ISO & IMUNO & CITO & HIBR & REST & SEQ \\
\hline $\begin{array}{l}\text { SISTEMA DE } \\
\text { CRUZAMIENTO }\end{array}$ & + & - & $+1-$ & - & $+/-$ & $\$$ \\
\hline $\begin{array}{l}\text { DETECCIÓN } \\
\text { CLONAL }\end{array}$ & + & - & $+1-$ & - & + & $\$$ \\
\hline HETEROCIGOSIS & + & - & - & - & + & $+1-$ \\
\hline $\begin{array}{l}\text { VARIACIÓN } \\
\text { GEOGRÁFICA }\end{array}$ & + & - & $+1-$ & - & + & + \\
\hline HIBRIDACIÓN & + & - & + & - & + & $+1-$ \\
\hline $\begin{array}{l}\text { LÍMITE DE } \\
\text { ESPECIE }\end{array}$ & + & - & + & & + & $\$$ \\
\hline $\begin{array}{l}\text { FILOGENIA: } \\
0-5 \text { MA }\end{array}$ & + & $+/-$ & $+1-$ & $+1-$ & + & + \\
\hline $5-50 \mathrm{MA}$ & + & + & + & + & + & + \\
\hline $50-500 \mathrm{MA}$ & $+/-$ & $+1-$ & $+1-$ & $+1-$ & $+1-$ & + \\
\hline $500-3.500 \mathrm{MA}$ & - & - & - & - & - & - \\
\hline
\end{tabular}

\section{GENES RIBOSOMALES COMO MARCADORES MOLECULARES}

En la década de 1970 fue descrita la técnica de secuenciamiento de DNA (Sanger et al., 1977), que tuvo un gran impacto en la biología molecular y que actualmente es la técnica más poderosa para detectar polimorfismos en el genotipo (Tabla 1). En la década de 1980 la técnica de PCR ("Polymerase Chain Reaction") revolucionó la biología celular como un todo, y actualmente es fundamental para variadas áreas que utilizan marcadores moleculares (Avise, 1994).

Para estudiar la biodiversidad, usando secuenciamiento genético, es necesario escoger la 
molécula apropiada. Varios autores han discutido la utilización de las secuencias de los genes que codifican para las moléculas de RNA ribosomales y sus espaciadores (Gray, 1988; Ragan, 1988; Williams et al., 1988; Sogin et al., 1993).

Los ribosomas, presentes en todos los organismos son responsables por la traducción de moléculas de RNA mensajero en proteínas. Los ribosomas son compuestos por proteínas y RNAs ribosomales (rRNA) que se agrupan para formar dos subunidades, una grande y una pequeña. Las moléculas de rRNAs son denominadas según sus coeficientes de sedimentación (S) en una ultracentrifugación. En los eucariontes la subunidad grande posee 3 moléculas de RNA, el 5S, el $5.8 \mathrm{~S}$ y el $28 \mathrm{~S}$, la subunidad pequeña posee sólo una molécula de RNA, el 18S. En los procariontes y en organelos como mitocondria y cloroplasto, la subunidad grande posee dos moléculas de RNA, el $5 \mathrm{~S}$ y el $23 \mathrm{~S}$, y la subunidad pequeña posee el $16 \mathrm{~S}$. Actualmente, la nomenclatura adoptada es: LSU rRNA (LSU = "large subunit") para el $28 \mathrm{~S}$ y el $23 \mathrm{~S}$ y SSU rRNA (SSU = "small subunit") para el 18S y el 16S (Alberts et al., 1994).

Los genes que codifican para estas moléculas de RNA ribosomal (rDNA) están ordenados en unidades de transcripción idénticas y repetidas en muchas veces (Fig. 1). Estas unidades de transcripción están separadas por una secuencia de DNA espaciadora no transcrita, denominada IGS ("intergenic spacers"). Las unidades de transcripción de los eucariontes están compuestas por genes que codifican para el RNA $18 \mathrm{~S}$ (SSU rDNA), 5.8S y 28S (LSU rDNA), y entre estos genes están los espaciadores que son transcritos, denominados ITS ("internal transcribed spacers"). El gen que codifica para la molécula de RNA 5 S está localizado en otra región del genoma.

Diferentes porciones del rDNA pueden ser utilizadas para estudios de macro y microbiodiversidad, dependiendo de su variabilidad dentro del grupo de organismos analizados. Para estudios de macrobiodiversidad, considerada aquí como de nivel taxonómico superior al de especie, normalmente se utilizan las regiones más conservadas, como los genes SSU y LSU rDNA, mientras que para estudios de microbiodiversidad (inter e intraespecífico), las regiones espaciadoras no codificadoras, ITS e IGS, son frecuentemente las más indicadas.

Secuencias de nucleótidos para la SSU rDNA han sido cada vez más utilizadas como criterio para proponer escenarios filogenéticos para diversos grupos de organismos. Woese (1987) utilizó secuencias del SSU rDNA para separar los seres vivos en tres linajes principales: arqueobacterias, eubacterias y eucariontes. También se han reportado secuencias de SSU rDNA para los principales grupos de algas, por ejemplo, Rhodophyta (Ragan et al., 1994; Oliveira et al., 1995; Saunders \& Kraft, 1997), Phaeophyta (Saunders \& Druehl, 1992; Druehl et al., 1997) y Chlorophyta (Friendl, 1997; Huss \& Kranz, 1997). Para otros grupos de algas ver Bhattacharya (1998). Estas secuencias han sido utilizadas para determinar la posición de estos grupos de algas en esquemas filogenéticos más amplios.

El gen que codifica para la SSU rRNA presenta una serie de características que favorecen su utilización para reconstrucciones filogenéticas: i) está universalmente distribuido entre los organismos, inclusive en cloroplastos y mitocondrias, ii) es funcionalmente conservado, y iii) presenta una estructura secundaria muy constante, tratándose casi como un homólogo evolutivo (Ragan, 1988). La secuencia genética, con aproximadamente 1.800 nucleótidos, está compuesta por un mosaico de regiones conservadas (universales), semi-conservadas y variables, las cuales hacen posible trabajar en diferentes niveles de resolución filogenético, permitiendo la comparación a nivel de especie entre taxones muy diversos hasta taxones muy próximos. Además de esto, el gen es experimentalmente accesible, ya que presenta regiones extremada- 
mente conservadas en sus extremos, permitiendo la utilización de "primers" universales para la amplificación completa del gen mediante PCR, además de presentar varias copias del gen por célula, lo cual facilitaría la amplificación.

El gen LSU rDNA posee prácticamente las mismas características de la SSU, sin embargo, se trata de un gen mayor de aproximadamente entre 3.000 a 5.000 nucleótidos, lo que dificultaría un poco la parte metodológica. Por otra parte, la presencia de una mayor extensión de regiones variables permitirá una mejor resolución de las diversificaciones más recientes.

Los genes $5.8 \mathrm{~S}$ y $5 \mathrm{~S}$ también pueden ser utilizados para diferentes análisis (Hori \& Osawa, 1987; Steane et al., 1991), sin embargo, son muy pequeños para ser informativos (cerca de 200 nucleótidos), y actualmente son utilizados sólo junto con otras secuencias (e.g. ITS15.8S-ITS2, Fig. 1).

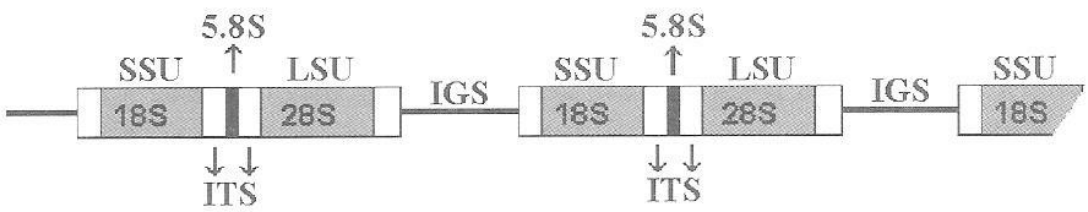

Fig. 1. Estructura de los genes ribosomales. Las unidades de transcripción están representadas por los rectángulos, mientras que las regiones no transcritas (IGS = espaciadores intergénicos) están representadas por una línea. ITS son los espaciadores internos transcritos; SSU o $18 \mathrm{~S}$ corresponden al gen que codifica para el RNA de la subunidad pequeña del ribosoma; LSU o $28 \mathrm{~S}$ corresponden al gen que codifica para el RNA de la subunidad grande del ribosoma; el $5.8 \mathrm{~S}$ codifica para una pequeña molécula de RNA que también es incorporada en la subunidad grande del ribosoma.

Las regiones codificadoras SSU y LSU rDNA también pueden ser utilizadas para delinear especies dentro de un mismo género: dos nucleótidos de diferencia en la SSU rDNA serían suficientes para separar dos especies (Medlin et al., 1997). Por otro lado, otras regiones no codificadoras, como las regiones espaciadoras ITS e IGS, pueden ser utilizadas para verificar la variación inter e intraespecífica. En niveles taxonómicos inferiores o entre especies que evolucionaron más recientemente, se han utilizado las regiones espaciadoras de los genes, transcritas o no, debido a que evolucionan más rápidamente y por lo tanto presentan una mayor tasa de diversificación que los DNAs codificadores (Larsen \& Medlin, 1997). Estas regiones han sido ampliamente utilizadas en algas (Goff et al., 1994; van Oppen et al., 1994; Bakker et al., 1995; Patwary et al., 1998). Los IGS, por ser genes no transcritos, acostumbran ser más variables que los ITS, los cuales son transcritos y cuya estructura secundaria es importante para el procesamiento del RNA. Los genes ribosomales y el ITS, una vez transcritos en RNA, asumirán una conformación espacial característica, debido al apareamiento de las regiones internas. Esta conformación espacial es denominada estructura secundaria (la estructura primaria es la secuencia de nucleótidos) y puede ser utilizada para facilitar el alineamiento de las secuencias entre los organismos. 
Otras regiones no codificadoras, como los intrones, presentes en la SSU rDNA de algunos grupos de algas (Rhodophyta, Oliveira \& Ragan, 1994; y Chlorophyta, Bhattacharya et al., 1996) también pueden ser utilizadas para estudios poblacionales (Oliveira, 1993; Stiller \& Waaland, 1993).

El secuenciamiento de genes ribosomales ha sido utilizado en estudios de biodiversidad de plancton marino, utilizándose los "primers" universales. Las secuencias son hechas para una mezcla de organismos y después son identificadas a través de los bancos de datos (Pedrós-Alió, 1993; Rappe et al., 1995). El rDNA también es frecuentemente utilizado asociado a otras técnicas de marcadores moleculares, como el RFLP ("restriction lengh polymorfism"; Bhattacharya, 1991; Schofield et al., 1991; Stiller \& Waaland, 1993; Adachi et al., 1994; Rowan \& Knowlton, 1995; Coleman, 1996) o la hibridación con sondas especie-específicas (Miller \& Scholin, 1996).

\section{METODOLOGÍA}

La extracción del DNA implica la separación química de las moléculas de DNA de los demás componentes celulares de los organismos. El secuenciamiento molecular de DNA corresponde a la identificación química sucesiva de cada una de las bases que componen el DNA ( $\mathrm{A}, \mathrm{C}$, G, T), de tal forma que se tendría la secuencia de DNA en su forma lineal. La amplificación es un proceso en el cual una determinada región del DNA es copiada miles de veces, por lo cual, esta específica región de interés se torna más abundante, permitiendo su posterior utilización.

El uso del secuenciamiento del rDNA, como marcador molecular, puede ser dividido en las siguientes etapas metodológicas: extracción de DNA, amplificación de la región alba por PCR ("Polymerase Chain Reaction"), secuenciamiento y análisis.

\section{EXTRACCIÓN DE DNA}

Actualmente existen decenas de métodos de extracción de DNA de algas (Oliveira, 1995). Estos métodos varían desde protocolos complejos y demorosos que llegan a durar varios días, hasta protocolos simples y rápidos de sólo 2 horas. Para PCR es necesario sólo una pequeña cantidad de DNA (aproximadamente nanogramos) y, por lo tanto, los métodos de extracción más indicados son los simples y rápidos, que generan pequeñas cantidades de DNA. Además de esto, cuando se trabaja con un gran número de muestras, como en el caso de un análisis poblacional, el costo del método (valor y tiempo) muchas veces se transforma en un factor determinante.

La extracción de DNA puede realizarse desde material fresco o seco (por ejemplo, preservado en silica-gel), y la maceración de los tejidos y de las células puede realizarse usando nitrógeno líquido o directamente en el tampón de extracción (Oliveira, 1995). Para la extracción de DNA de cianófitas, Bolch et al. (1996) usan una resina llamada Instagene (BioRad), un método bastante simple. Para algas eucariónticas, se han descrito varios métodos simples y rápidos (Hong et al., 1992; Shivji et al., 1992; Goff \& Moon, 1993; Saunders, 1993; Sengco et al., 1996; Alberto et al., 1997). Algunos "kits" de extracción para DNA de plantas, ofrecidos en el mercado, también funcionan bien para algas, entre ellos el QIAamp (QIAGEN) y el Trizol (GibcoBRL). 


\section{AMPLIFICACIÓN POR PCR}

Para la amplificación por PCR es necesario un par de "primers" específicos (o DNA iniciadores) que van a delimitar la secuencia alba. Los "primers" son oligonucleótidos (secuencias cortas de DNA, que varían entre 10 a 40 nucleótidos) complementarios a las secuencias albas. Los "primers" se aparearán con las regiones complementarias del DNA molde (DNA que va a servir de modelo para la síntesis), sirviendo de inicio para que la DNA polimerasa pueda sintetizar una nueva hebra de DNA. El PCR es un proceso exponencial, es decir, si se parte de dos copias del gen (una en cada hebra del DNA) al final el número de copias será de 2(n-1), donde $\mathbf{n}$ es el número de ciclos. Las etapas típicas que componen el PCR son las siguientes: desnaturalización a $94^{\circ} \mathrm{C}$ (para desnaturalizar el DNA molde); apareamiento a $37-65^{\circ} \mathrm{C}$ (apareamiento de los "primers" en las regiones específicas del DNA molde); y extensión a $72^{\circ} \mathrm{C}$ (temperatura óptima de la Taq DNA Polimerasa). Estas 3 etapas forman un ciclo que es repetido entre 25 a 40 veces. La temperatura de apareamiento variará según la composición y especificidad del "primer". Existe una descripción detallada sobre el funcionamiento y los protocolos de PCR en las siguientes referencias: Earlich, 1989; Sambrook et al., 1989; Innis et al., 1990.

Un problema fundamental con los marcadores moleculares, particularmente en técnicas que utilizan PCR, es la presencia de contaminantes. Los cultivos axénicos son bastante caros de obtener. Es posible prevenir la amplificación del DNA de contaminantes utilizando "primers" que sean específicos para el organismo o el grupo de organismos (e.g. "primers" específicos para cianobacterias, que no amplifican el DNA de otras bacterias, o "primers" específicos para eucariontes que no amplifican el DNA de procariontes, etc.). Esto es posible utilizando genes bien caracterizados de la SSU rDNA.

Una manera de acceder a regiones altamente variables del DNA es diseñar "primers" para regiones conservadas codificadoras, pero que delimitan regiones no codificadoras como los espaciadores. Por ejemplo, "primers" que amplifiquen la región ITS1 - 5.8 - ITS2 pueden ser diseñados a partir del fragmento final de la SSU rDNA y del fragmento inicial de la LSU rDNA (Fig. 1).

Los "primers" utilizados tanto para PCR como para secuenciamiento, pueden ser diseñados basándose en secuencias ya conocidas y pueden ser sintetizados comercialmente (en general, en cinco días las empresas entregan los "primers" con una secuencia deseada). En muchos casos, los "primers" para PCR y para secuenciamiento de rDNA están localizados en regiones conservadas y, por lo tanto, sirven para cualquier organismo y son denominados "primers" universales.

\section{SeCuenciamiento}

Después del PCR se pueden adoptadar dos estrategias: clonar el fragmento en un vector (Sambrook et al., 1989) o secuenciar directamente el resultado del PCR. La clonación es un proceso largo y más caro, pero en compensación genera una copia prácticamente permanente del DNA albo (amplificado por PCR), ya que la bacteria que contiene esta copia puede ser mantenida indefinidamente y ser cultivada en grandes cantidades. Sin embargo, la mayoría de los estudios actuales han optado por el secuenciamiento directo, donde el producto del PCR pasa por un simple proceso de purificación y es usado directamente para el secuenciamiento. 
El secuenciamiento puede ser hecho manualmente (Sambrook et al., 1989) o a través de un secuenciador automático. Sin embargo, el equipo de secuenciamiento automático tiene un alto costo. A pesar del costo, el secuenciamiento automático tiene varias ventajas en relación al manual, como por ejemplo, uso de fluorescencia en vez de radioactividad, mayor rendimiento para cada "primer" (una media de 600 nucleótidos secuenciados contra aproximadamente 350 del manual), lectura automática de las secuencias por el computador, rapidez y facilidad de la electroforesis.

Cada "primer" en el secuenciamiento automático genera alrededor de 600 nucleótidos de secuencia y, por lo tanto, dependiendo del tamaño de la secuencia alba, deberán utilizarse varios "primers", cada uno generando una secuencia que posteriormente tendrá que ser montada para formar la secuencia final.

\section{ANÁLISIS DE LAS SECUENCIAS}

Una vez hecho el secuenciamiento, las secuencias tienen que ser montadas para obtener la versión final. Las secuencias obtenidas experimentalmente o a través del banco de datos tienen que ser alineadas para ser analizadas. El alineamiento de las secuencias es un paso extremadamente importante. La utilización de secuencias para la comparación de organismos, puede ser dividida en tres pasos críticos: i) elección de la molécula que va a ser secuenciada, ii) alineamiento de las secuencias de los organismos estudiados, y iii) análisis de las secuencias alineadas (Oliveira, 1993). El alineamiento de las secuencias puede ser un proceso extremadamente complicado, ya que, a diferencia de las proteínas, existen solamente 4 unidades informativas (A, G, C y T), permitiendo varios alineamientos posibles. Para alinear las secuencias de los genes ribosomales se puede utilizar la estructura secundaria de la molécula de rRNA. La estructura secundaria permite posicionar nucleótidos homólogos con mayor precisión y eliminar gran parte de la subjetividad en el proceso de alineamiento.

Existen diversos programas para montajes, alineamientos y análisis de secuencias. Algunos son gratuitos y pueden ser obtenidos a través de la Internet (Tabla 2), algunos son obtenidos por una pequeña suma ( $c$. US\$25), otros son vendidos comercialmente y llegan a tener un costo mucho más elevado (Sequencher, $c a$. US\$2.000). Los programas gratuitos muchas veces son mejores que los comerciales, pero normalmente no se preocupan mucho en ser "user friendly".

A partir del alineamiento de las secuencias moleculares, se pueden usar varios métodos para estimar las relaciones filogenéticas entre los taxones estudiados. Nei (1987) y Felsenstein (1988) dividen los métodos de inferencia filogenéticos en tres categorías básicas: los métodos de distancia, los métodos de parsimonia y el método de máxima verosimilitud. La descripción de estos métodos pueden ser encontrados en Hillis et al. (1996).

Las secuencias finales deben ser depositadas en los bancos de datos donde estarán disponibles para que otros investigadores puedan incluirlas en sus análisis. Siempre que se va a secuenciar una determinada región de un organismo es recomendable hacer una revisión en los bancos de datos, primero para verificar si este secuenciamiento no ha sido realizado anteriormente y segundo para obtener otras secuencias que pueden enriquecer sus análisis. 
Tabla 2. Direcciones electrónicas de los bancos de datos y de programas para montaje y análisis de secuencias.

\begin{tabular}{|c|c|c|}
\hline \multicolumn{2}{|l|}{ Bancos de Datos } & Direcciones \\
\hline \multicolumn{2}{|l|}{ GenBank } & $\begin{array}{l}\text { info@ncbi.nlm.nih.gov } \\
\text { http://www.ncbi.nlm.nih.gov }\end{array}$ \\
\hline \multicolumn{2}{|c|}{ EMBL (European Molecular Biology) } & $\begin{array}{l}\text { data@ebi.ac.uk } \\
\text { http://www.embl-heidelberg.de/ }\end{array}$ \\
\hline \multicolumn{2}{|c|}{$\begin{array}{l}\text { Ribosomal database Project (RDP) } \\
\text { The rRNA WWW server }\end{array}$} & $\begin{array}{l}\text { http://www.cme.msu.edu/RDP/ } \\
\text { http://www-rrna.uia.ac.be/rrna/index.html }\end{array}$ \\
\hline Tree of life & \multicolumn{2}{|c|}{ http://phylogeny.arizona.edu/tree/phylogeny.html } \\
\hline TreeBASE & \multicolumn{2}{|c|}{ http://herbaria.harvard.edu/treebase/ } \\
\hline Programas & Tipo & Direcciones \\
\hline $\begin{array}{l}\text { TIGR (The Institute for } \\
\text { Genomic Res.) }\end{array}$ & $\begin{array}{l}\text { acceso a diferentes } \\
\text { bancos de datos y } \\
\text { de programas. }\end{array}$ & http://www.tigr.org/ \\
\hline Phylip & $\begin{array}{l}\text { paquete de programas } \\
\text { de filogenia. }\end{array}$ & joe@genetics.washington.edu \\
\hline Phred/Phrap/Cosed & $\begin{array}{l}\text { programas de montaje } \\
\text { de secuencias. }\end{array}$ & $\begin{array}{l}\text { http://bozema.genome.washington. } \\
\text { edu/consed/consed.html }\end{array}$ \\
\hline SeqPup & $\begin{array}{l}\text { programa de montaje } \\
\text { y alineamiento de } \\
\text { secuencias. (otros } \\
\text { programas pueden ser } \\
\text { encontrados en esta dir }\end{array}$ & $\begin{array}{l}\text { http://iubio.bio.indiana.edu/ } \\
\text { soft/molbio/ }\end{array}$ \\
\hline
\end{tabular}

\section{CONCLUSIONES}

Técnicas moleculares y bancos de datos electrónicos ofrecen un medio para examinar y cuantificar la biodiversidad a través de adquisición, almacenamiento y análisis de secuencias de DNA, RNA y proteínas. Las principales ventajas de la utilización del rDNA son: i) su versatilidad, presentando desde regiones altamente conservadas hasta regiones variables, lo que permite el análisis en diferentes niveles taxonómico, ii) su accesibilidad metodológica, y iii) el vasto banco de datos que facilitan y enriquecen los análisis.

El reciente uso de marcadores moleculares ha posibilitado la evaluación de la biodiversidad de modo rápido y eficiente, principalmente en las algas, ya que el uso de marcadores morfológicos muchas veces es insuficiente para estimar la diversidad existente. 
Los ficólogos, principalmente de países en desarrollo, están apenas iniciando el uso de estas técnicas en el estudio de las algas. Por el momento, los principales desafíos para esa nueva área de la Ficología son: i) formación de centros de investigación y de entrenamiento, ii) adaptación de las técnicas existentes para su uso en las algas, ya que la mayoría de las técnicas han sido desarrolladas para animales y plantas superiores, iii) estandarización de los diferentes métodos, ya que el nivel de información de cada marcador varía mucho, de acuerdo con el grupo estudiado, y iv) desarrollo de nuevas técnicas (Oliveira, 1998). El uso del secuenciamiento de DNA aporta un enorme potencial metodológico que puede ser aprovechado por los ficólogos, principalmente en los estudios de biodiversidad.

\section{BIBLIOGRAFÍA}

Adachi, M., Y. Sako \& Y. Ishida, 1994. Restriction fragment length polymorfism of ribosomal DNA internal transcribed spacer and 5.8S regions in Japanese Alexandrium species (Dinophyceae). J. Phycol. 30: 857-863.

Alberto, F., R. Santos \& J. M. Leitão, 1997. DNA extraction and RAPD markers to assess the genetic similarity among Gelidium sesquipedale (Rhodophyta) populations. J. Phycol. 33: 706-710.

Alberts, B., D. Bray, J. Lewis, M. Raff, K. Roberts \& J. D. Watson, 1994. Molecular Biology of the Cell. Garland, New York, pp. 1294.

Amos, B. \& A. R. Hoelzel, 1992. Applications of molecular genetic techniques to the conservation of small populations. Biological Conservation 61: 133-144.

Andersen, R. A., R. W. Brett, D. Potter \& J. P. Sexton, 1998. Phylogeny of the Eustigmatophyceae based upon $18 \mathrm{~S}$ rDNA, with emphasis on Nannochloropsis. Protist 149: 61-74.

Avise, J. C., 1994. Molecular Markers, Natural History and Evolution. Chapman \& Hall, New York, pp. 511.

Bachmann, K., 1994. Tansley Review No. 63, Molecular markers in plant ecology. New Phytologist 126: 403418.

Bakker, F. T., J. L. Olsen \& W. T. Stam, 1995. Evolution of nuclear rDNA ITS sequences in the Chladophora albida/sericea clade (Chlorophyta). J. Mol. Evol. 40: 640-651.

Bhattacharya, D., 1991. Restriction endonuclease analysis of ribosomal DNA sequence variation in Laminaria (Phaeophyta). J. Phycol. 27: 624-628.

Bhattacharya, D., 1998. The Origin of Algae and Their Plastids. Springer-Verlag, New York, pp.320.

Bhattacharya, D., T. Friedl \& S. Damberger, 1996. Nuclear-encoded rDNA group I introns: origin and phylogenetic relashioships of insertion site lineages in the green algae. Mol. Biol. Evol. 13: 978-989.

Bolch, C. J. S., S. I. Blackburn, B. A. Neilan \& P. M. Grewe, 1996. Genetic characterization of strains of cyanobacteria using PCR-RFLP of the $c p c B A$ intergenic spacer and flanking regions. J. Phycol. 32: 445-451.

Coleman, A. W., 1996. DNA analysis methods for recognizing species invasion: the exemple of Codium, and generally applicable methods for algae. Hydrobiologia 326/327: 29-34.

Druehl, L. D., C. Mayes, I. H. Tan \& G. W. Saunders, 1997. Molecular and morphological phylogenies of kelp and associated brown algae. PI. Syst. Evol. [Suppl.] 11: 221-236.

Earlich, H. A., 1989. PCR Technology: Principles and Applications for DNA Amplification. Stockton Press, New York, pp. 246.

Felsenstein, J., 1988. Phylogenies from molecular sequences: inference and reliability. Annu. Rev. Genet. 22: $521-565$.

Friedl, T., 1997. The evolution of green algae. Pl. Syst. Evol. [Suppl.] 11: 87-102.

Goff, J.L. \& D.A. Moon, 1993. PCR amplifications of nuclear and plastid genes from algal herbarium specimens and algal spores. J. Phycol. 29: 381-384.

Goff, L. J., D. A. Moon \& A. W. Coleman, 1994. Molecular delineation of species and species relationships in the red algal agarophytes Gracilariopsis and Gracilaria (Gracilariales). J. Phycol. 30: 521-537.

Gray, M. W., 1988. Organelle origins and ribosomal RNA. Biochem. Cell Biol. 66: 325-348.

Heywood, V. H. \& R. T. Watson, 1995. Global Biodiversity Assessment. Cambridge Univ. Press, London, pp. 1140. 
Hillis, D. M., C. Moritz \& B. K. Mable, 1996. Molecular Systematics. 2nd ed. Sinauer Ass., Sunderland, pp. 655.

Hong, Y., D. A. Coury, M. Polne-Fuller \& A. Gibor, 1992. Lithium chloride extraction of DNA from the seaweed Porphyra perforata (Rhodophyta). J. Phycol. 28: 717-720.

Hori, H. \& S. Osawa, 1987. Origin and evolution of organisms as deduced from 5 S ribosomal RNA sequences. Mol. Biol. Evol. 4: 445-472.

Huss V. A. R. \& H. D. Kranz, 1997. Charophyte evolution and the origin of land plants Pl. Syst. Evol. [Suppl.] 11: 103-114.

Innis, M. A., D. H. Gelfand, J. J. Sninsky \& T. J. White, 1990. PCR protocols. A guide to methods and applications. Academic Press, San Diego, pp. 482.

Larsen, A. \& L. K. Medlin, 1997. Inter-and intraspecific genetic variation in twelve Prymnesium (Haptophyceae) clones. J. Phycol. 33: 1007-1015.

Medlin, L. K., W. H. C. F. Kooistra, D. Potter, G. W. Saunders \& R. A. Andersen, 1997. Phylogenetic relatioships of the 'golden algae' (haptophytes, heterokont chromophytes) and their plastids. Pl. Syst. Evol. [Suppl] 11: $187-220$.

Miller, P. E. \& C. A. Scholin, 1996. Identification of cultured Pseudo-Nitzschia (Bacillariophyceae) using speciesspecific LSU rRNA-targeted fluorescent probes. J. Phycol. 32: 646-655.

Nei, M., 1987. Molecular Evolutionary Genetics. Columbia Univ. Press, New York, pp. 512.

Oliveira, M. C., 1993. Filogenia de Porphyra spp. (Rhodophyta): seqüenciamento do gene nuclear para o RNA da subunidade pequena do ribossomo (rDNA 18S) e estudos morfológicos da fase conchocelis. Tese de Doutorado, Instituto de Biociências da Universidade de São Paulo, São Paulo, pp. 160.

Oliveira, M. C., 1995. Técnicas de extración de DNA en algas. In K. Alveal, M. Ferrario, E. C. Oliveira \& E. Sar (eds.), Manual de Métodos Ficológicos. Universidad de Concepción, Concepción, Chile, pp: 489-504.

Oliveira, M.C. 1998. O uso de marcadores moleculares no estudo da biodiversidade. Anais do IV Congresso Latino-Americano de Ficologia, II Reunião Ibero-Americana de Ficologia, VII Reuniāo Brasileira de Ficologia: Conservação da Biodiversidade e Novas Tecnologias: Promessas e Perigos. Azevedo, M.T.P. (ed), Soc. Bras. De Ficologia, Vol I: 178-186.

Oliveira, M. C. \& M. A. Ragan, 1994. Variant group I introns in the small subunit ribosomal DNA of the red alga Porphyra spiralis var. amplifolia. Mol. Biol. Evol. 11: 195-207.

Oliveira, M. C., J. Kurniawan, C. J. Bird, E. L. Rice, C. A. Murphy, R. K. Singh, R. R. Gutell \& M. A. Ragan, 1995. A preliminary investigation of the order Bangiales (Bangiophycidae, Rhodophyta) based on sequences of nuclear small-subunit ribosomal RNA genes. Phycol. Res. 43: 71-79.

Olsen, J. L., 1990. Nucleic acids in algal systematics. J. Phycol. 26: 209-214.

Patwary, M. U., C. W. Sensen, R. M. Mackay \& J. P. van der Meer, 1998. Nucleotide sequences of smallsubunit and internal transcribed spacer regions of nuclear rRNA genes support the autonomy of some genera of the Gelidiales (Rhodophyta). J. Phycol. 34: 299-305.

Pedrós-Alió, C., 1993. Diversity in bacterioplankton. Trends in Ecology and Evolution 8: 86-90.

Ragan, M .A., 1988. Ribossomal RNA and the major lines of evolution: a perspective. BioSystems 21: 177 188.

Ragan, M. A., C. J. Bird, E. L. Rice, R. R. Gutell, C. A. Murphy \& R. K. Singh, 1994. A phylogeny of marine red algae (Rhodophyta) based on the nuclear small-subunit rRNA gene. Proc. Natl. Acad. Sci. USA 91: 7276-7280.

Rappe, M. S., P. F. Kemp \& S. J. Giovannoni, 1995. Chromophyte plastid 16S ribosomal RNA genes found in a clone library from Atlantic ocean seawater. J. Phycol. 31: 979-988.

Rowan, R. \& N. Knowlton, 1995. Intraspecific diversity and ecological zonation in coral-algal symbiosis. Proc. Natl. Acad. Sic. USA 92: 2850-2853.

Sambrook, J., E. F. Fritsch \& T. Maniatis, 1989. Molecular Cloning: A Laboratory Manual, 2nd ed., 3 vol. Cold Spring Harbour Laboratories Press, New York. Vol. 1, 2, 3.

Sanger, F., S. Nicklen \& A. R. Coulson, 1977. DNA sequencing with chain-terminating inhibitors. Proc. Natl. Acad. Sci USA 74: 5463-5467.

Saunders, G. W., 1993. Gel purification of red algal genomic DNA: an inexpensive and rapid method for the isolation of polymerase chain reaction friendly DNA. J. Phycol. 29: 251-254. 
Saunders, G.W. \& L. D. Druehl, 1992. Nucleotide sequences of the small-subunit ribossomal RNA genes from selected Laminariales (Phaeophyta): implications for kelp evolution. J. Phycol. 28: 544-549.

Saunders, G.W. \& H. D. Kraft, 1997. A molecular perspective on red algal evolution: focus on the Florideophycidae. Pl. Syst. Evol. [Suppl.] 11: 115-138.

Schofield, C. I., P. Gacesa, J. H. Price, S. J. Russell \& R. Bhoday, 1991. Restriction fragment length polymorphisms of enzymically-amplified small-subunit rRNA-coding regions from Gracilaria and Gracilariopsis (Rhodophyta) - a rapid method assessing 'species' limits. J. Appl. Phycol. 3: 329-334.

Sengco, M. R., M. Bräutigam, M. Kapp \& D. G. Müller, 1996. Detection of virus DNA in Ectocarpus (Phaeophyceae) from various geographic areas. Eur. J. Phycol. 31:73-78.

Shivji, M. S., S. O. Rogers \& M. J. Stanhope, 1992. Rapid isolation of high molecular weight DNA from marine macroalgae. Mar. Ecol. Progress Series 84: 197-203.

Sogin, M. L., 1991. The phylogenetic significance of sequence diversity and length variations in eukaryotic small subunit ribosomal RNA coding regions. In L. Warren \& H. Koprowski (eds.). New Perspective on Evolution. Wiley-Liss Inc., New York, pp. 175-188.

Sogin, M. L., G. Hinkle \& D. D. Lelpe, 1993. Universal tree of life. Nature (Lond.) 362: 795.

Steane, D.A., B. A. McClure, A. E. Clarke \& G. T. Kraft, 1991. Amplification of the polymorphic 5.8S rRNA gene from selected australian gigartinalean species (Rhodophyta) by Polymerase Chain Reaction. J. Phycol. 27: 758-762.

Stiller, J. W. \& J. R. Waaland, 1993. Molecular analysis reveals cryptic diversity in Porphyra (Rhodophyta). J. Phycol. 29: 506-517.

van Oppen, M. J. H., O. E. Diekmann, C. Wiencke, W. T. Stam \& J. L. Olsen, 1994. Tracking dispersal routes: phylogeography of the arctic-antarctic disjunct seaweed Acrosiphonia arcta (Chlorophyta). J. Phycol. 30: 67-80.

Williams, S. M., R. W. DeBry \& J. L. Feder, 1988. A commentary on the use of ribossomal DNA in systematic studies. Syst. Zool. 37: 60-62.

Woese, C. R., 1987. Bacterial evolution. Microbiol. Rev. 51: 221-271. 


\title{
RIBOSOMAL DNA PHYLOGENY OF THE BANGIOPHYCIDAE (RHODOPHYTA) AND THE ORIGIN OF SECONDARY PLASTIDS ${ }^{1}$
}

\author{
Kirsten M. Müller, ${ }^{2,6}$ Mariana C. Oliveira, ${ }^{3}$ Robert G. Sheath, ${ }^{2}$ \\ AND DEBASHISH BHATTACHARYA ${ }^{4,5}$
}

\author{
${ }^{2}$ Department of Botany and Dean's Office, University of Guelph, Guelph, Ontario, Canada, N1G 2W1; \\ ${ }^{3}$ Department of Botany, Institute of Biosciences, University of São Paulo, R. Matão, Travessa 14, N. 321, São Paulo, SP, Brazil, \\ CEP 05508-900; and \\ ${ }^{4}$ Department of Biological Sciences, University of Iowa, 239 Biology Building, Iowa City, Iowa 52242-3110 USA
}

\begin{abstract}
We sequenced the nuclear small subunit ribosomal DNA coding region from 20 members of the Bangiophycidae and from two members of the Florideophycidae to gain insights into red algal evolution. A combined alignment of nuclear and plastid small subunit rDNA and a data set of Rubisco protein sequences were also studied to complement the understanding of bangiophyte phylogeny and to address red algal secondary symbiosis. Our results are consistent with a monophyletic origin of the Florideophycidae, which form a sister-group to the Bangiales. Bangiales monophyly is strongly supported, although Porphyra is polyphyletic within Bangia. Bangiophycidae orders such as the Porphyridiales are distributed over three independent red algal lineages. The Compsopogonales sensu stricto, consisting of two freshwater families, Compsopogonaceae and Boldiaceae, forms a well-supported monophyletic grouping. The single taxon within the Rhodochaetales, Rhodochaete parvula, is positioned within a cluster containing members of the Erythropeltidales. Analyses of Rubisco sequences show that the plastids of the heterokonts are most closely related to members of the Cyanidiales and are not directly related to cryptophyte and haptophyte plastid genomes. Our results support the independent origins of these secondary algal plastids from different members of the Bangiophycidae.
\end{abstract}

Key words: Bangiophycidae; phylogeny; plastid; Rhodophyta; Rubisco; secondary symbiosis; small subunit rRNA.

The Rhodophyta (red algae) form a distinct eukaryotic lineage (Bhattacharya et al., 1990; Van de Peer et al., 1996; Stiller and Hall, 1997) that likely shares a most recent common ancestry with the green algae (Burger et al., 1999; Moreira, Le Guyader, and Philipper, 2000). Members of the red algae share a suite of characters that do not occur together in any other eukaryote, such as a complete lack of flagellated stages and basal bodies, a two-membraned "simple" plastid (Bhattacharya and Medlin, 1995) that lacks chlorophyll $b$ or $c$, have unstacked thylakoids with phycobilisomes, and photosynthetic reserves stored as floridean starch (Garbary and Gabrielson, 1990). Traditionally, systematists have divided the red algae into two groups, sometimes with the taxonomic status of classes, i.e., Bangiophyceae and Florideophyceae (cf. Van den Hoek, Mann, and Jahns, 1995), or subclasses, Bangiophycidae and the Florideophycidae within a single class Rhodophyceae (Gabrielson, Garbary, and Scagel, 1985), with the latter approach being more generally accepted. The Florideophycidae includes morphologically complex red algae in orders such as the Gigartinales and the Ceramiales and is widely considered to be a derived, monophyletic group (Garbary and Gabrielson, 1990; Freshwater et al., 1994; Ragan et al., 1994; Saunders and Kraft, 1997).

The Bangiophycidae (bangiophytes) retain morphological

${ }^{1}$ Manuscript received 14 September 2000; revision accepted 2 February 2001.

D. B. acknowledges a grant from the Carver Foundation and M. C. O. thanks FAPESP and CNPq for research grants. R. S. was funded by NSERC and the University of Guelph and K. M. received an Ontario Graduate Scholarship. The authors thank E. C. Oliveira for useful comments and suggestions.

${ }^{5}$ Author for correspondence (Ph: 319-335-1977; FAX: 319-335-1069; email: dbhattac@blue.weeg.uiowa.edu).

${ }^{6}$ Current address: Department of Biology, University of Waterloo, Waterloo, Ontario, Canada, N2L 3G1. characters that are considered to have been present in the ancestral pool of red algae and range from unicells to multicellular filaments (uniseriate or multiseriate; branched or unbranched) or sheet-like thalli (monostromatic or distromatic; Garbary, Hansen, and Scagel, 1980). Cells typically have a single axial stellate plastid with a large pyrenoid, though some taxa contain a cup-shaped plastid, or a complex, interconnected plastid with no pyrenoid (Gantt, Scott, and Lipschultz, 1986; Broadwater and Scott, 1994). Pit connections are rare, and sexual reproduction has not been described in many members of this subclass (Garbary, Hansen, and Scagel, 1980; Gabrielson et al., 1990). Studies of biochemical, morphological, and ultrastructural characters (Gabrielson and Garbary, 1985; Gabrielson, Garbary, and Scagel, 1985; Garbary and Gabrielson, 1990) and ribosomal DNA (rDNA) sequence comparisons (Ragan et al., 1994; Oliveira et al., 1995; Oliveira and Bhattacharya, 2000) suggest that the Bangiophycidae is a diverse assemblage of algae that includes the Florideophycidae. For this reason, only one class of red algae, the Rhodophyceae, is recognized by some researchers (e.g., Gabrielson et al., 1990). Nevertheless, the name Bangiophycidae continues to be used to identify the early diverging red algae from which the Florideophycidae have evolved. The Bangiophycidae have been divided into four orders: Bangiales, Compsopogonales, Porphyridiales, and Rhodochaetales (Gabrielson et al., 1990; Garbary and Gabrielson, 1990). Recently, two new orders were suggested, the Cyanidiales (Seckbach and Ott, 1994), which is proposed to include thermophilic genera such as Galdieria and Cyanidium, and the order Erythropeltidales (Garbary, Hansen, and Scagel, 1980; Silva, Basson, and Moe, 1996). The latter grouping is based on the greater morphological complexity in members of the Compsopogonaceae than in those of the Erythrotrichiaceae. Nonetheless, Rintoul, Vis, and 
TABLE 1. Algae used in the present study.

\begin{tabular}{|c|c|c|c|}
\hline \multicolumn{2}{|r|}{ Taxa } & \multirow[b]{2}{*}{ Collection information } & \multirow{2}{*}{$\begin{array}{c}\text { GenBank } \\
\text { accession number }\end{array}$} \\
\hline Order & Species & & \\
\hline \multicolumn{4}{|l|}{ Bangiophycidae } \\
\hline \multirow[t]{2}{*}{ Bangiales } & Bangia fuscopurpurea (Dillwyn) Lyngbye & SAG B59.81 b & GBAN-AF342745 \\
\hline & Porphyra leucosticta Thuret in Le Jolis & SAG B55.88 & GBAN-AF342746 \\
\hline \multirow[t]{2}{*}{ Compsopogonales } & Boldia erythrosiphon Herndon & Black River, Ontario, Canada. Coll. T. Rintoul. & GBAN-AF087109 \\
\hline & $\begin{array}{l}\text { Compsopogon coeruleus (Balbis in C. A. } \\
\text { Agardh) Montagne }\end{array}$ & SAG B36.94 & GBAN-AF342748 \\
\hline Cyanidiales & Galdieria sulphuraria (Galdieri) Merola & SAG 107.79 & GBAN-AF342747 \\
\hline \multirow[t]{15}{*}{ Porphyridiales } & Bangiopsis subsimplex (Montagne) Schmitz & $\begin{array}{l}\text { PR21, Guajataca Beach, Puerto Rico. Coll. T. } \\
\text { Rintoul \& A. Sherwood. 19.X.97. }\end{array}$ & GBAN-AF168627 \\
\hline & Chroodactylon ornatum (C. Ag.) Basson & UTEX LB $1633^{\circ}$ (= Asterocytis ramosa) & GBAN-AF168628 \\
\hline & Chroodactylon ramosum (Thwaites) Hansgirg & SAG B103.79 & GBAN-AF342751 \\
\hline & Flintiella sanguinaria F. D. Ott & UTEX LB 2060 & GBAN-AF168621 \\
\hline & F. sanguinaria & SAG B40.94 & GBAN-AF342749 \\
\hline & $\begin{array}{l}\text { Goniotrichopsis sublittoralis Smith in Smith et } \\
\text { Hollenberg }\end{array}$ & UTEX LB 1689 & GBAN-AF168629 \\
\hline & Porphyridium aerugineum Geitler & CCAP $1380 / 4^{\mathrm{d}}$ & GBAN-AF168623 \\
\hline & Porphyridium sordidium Geitler & CCAP 1380/6 & GBAN-AF168630 \\
\hline & Rhodella violacea (Kornmann) Wehrmeyer & UTEX LB 2427 & GBAN-AF168624 \\
\hline & Rhodosorus marinus Geitler & CCMP $769^{\mathrm{e}}$ & GBAN-AF168625 \\
\hline & R. marinus & SAG 116.79 & GBAN-AF342750 \\
\hline & Rhodosorus sp. & CCMP 1530 & GBAN-AF168626 \\
\hline & Stylonema alsidii ${ }^{\mathrm{f}}$ (Zanardini) K. Drew & UTEX LB 1424 & GBAN-AF168633 \\
\hline & S. alsidii (CR) & Coll. R. Sheath \& K. Müller. 17.II.98. & GBAN-AF168632 \\
\hline & Stylonema cornu-cervi Reinsch & CCAP $1367 / 1$ & GBAN-AF168622 \\
\hline \multirow{3}{*}{$\begin{array}{l}\text { Florideophycidae } \\
\text { Batrachospermales }\end{array}$} & & & \\
\hline & Nemalionopsis tortuosa Yagi et Yoneda & SAG B42.94 & GBAN-AF342743 \\
\hline & Thorea violacea Bory de St. Vincent & SAG 51.94 & GBAN-AF342744 \\
\hline
\end{tabular}

\footnotetext{
a The prefix GBAN- has been added to link the online version of American Journal of Botany to GenBank but it is not part of the actual accession number.

${ }^{\mathrm{b}}$ Schlösser (1994).

c Starr and Zeikus (1993).

${ }^{\mathrm{d}}$ http://www.ife.ac.uk/ccap.

e Anderson, Morton, and Sexton (1997).

${ }^{\mathrm{f}}$ Synonyms: Stylonema $=$ Goniotrichum $($ Wynne, 1985).
}

Sheath (1999) provided molecular evidence that does not support recognition of the Eryhtropeltidales.

Previous molecular studies indicate that, whereas the Bangiales and Compsopogonales appear to be monophyletic, other orders, such as the Porphyridiales, may be either biphyletic or paraphyletic within the Bangiophycidae (Ragan et al., 1994; Rintoul, Vis, and Sheath, 1999; Oliveira and Bhattacharya, 2000). In their analysis of red algal orders using a variety of morphological, ultrastructural, and biochemical data, Gabrielson and Garbary (1985), Gabrielson, Garbary, and Scagel (1985), and Garbary and Gabrielson (1990) also hypothesized that the Porphyridiales were probably paraphyletic and found considerable differences in plastid ultrastructure and highly variable vegetative and reproductive morphologies. They noted that the remaining three orders, except perhaps for the Compsopogonales (including the Erythrotrichiaceae), were probably monophyletic.

In this study, we compare nuclear small subunit (SSU) rDNA sequences from members of all the orders of the Bangiophycidae to address the following questions: (1) Is there phylogenetic support for the present ordinal classification of the Bangiophycidae? (2) Which Bangiophycidae order is the sister group of the Florideophycidae? and (3) It is now widely accepted that the cryptophytes have gained their plastid through a secondary symbiosis involving a bangiophyte red alga (Douglas et al., 1991; Bhattacharya and Medlin, 1995; Palmer and Delwiche, 1996; Douglas and Penny, 1999), yet the specific donor of this plastid remains unknown (see also Oliveira and Bhattacharya, 2000). We ask, therefore, if there is a specific evolutionary relationship between the nucleomorphs in cryptophyte algae and any of the Bangiophycidae orders. The goals of this research are to present a phylogenetic hypothesis for the Bangiophycidae that can be tested in future studies to ultimately create a natural classification of the Rhodophyta and to gain further insights into the origin of plastids through red algal secondary symbiosis.

\section{MATERIALS AND METHODS}

Bangiophycidae were either collected in the field or obtained from the culture collections at the University of Texas (UTEX) or the Sammlung von Algenkulturen at the University of Göttingen (SAG; Schlösser, 1994). These taxa are listed in Table 1. Field-collected samples were cleaned of visible epiphytes, bases were removed to prevent contamination, and the specimens were stored at $-20^{\circ} \mathrm{C}$. Thalli were ground in liquid nitrogen, and the DNA was extracted according to the protocol outlined by Saunders (1993) with modifications given in Vis and Sheath (1997). Cultured material (100-400 $\mathrm{mg}$, fresh mass) was ground in liquid nitrogen and total genomic DNA was extracted using the DNeasy Plant Mini Kit (Qiagen, Santa Clarita, California, USA).

For DNA isolated from the SAG cultures, the SSU rDNA coding region was amplified with the polymerase chain reaction (PCR) using synthetic oligonucleotide primers that recognize conserved sequences at the termini of the nuclear-encoded SSU rDNA genes (modified from Medlin et al., 1988): 18S5' (5'-AACCTGGTTGATCCTGCCAGTRGTSAT ATGCTTGT-3') and 18S3' 
(5'-GATCCTTCTGCAGGTTCACCTACGGAA-3'). For the remaining taxa of the Bangiophycidae (excluding the Bangiales), the rDNA coding region was amplified in three subfragments, ranging in size from 500 to 600 base pairs (bp). The following primers were used in these experiments: G01.1 (5' AACCTGATTGATCCTGCC AG-3') and G10.1 (5'-GCGCGCCTGCTGCT TCCTTGG-3'); G02.1 (5'-CGATTCCGGAG AGGGAGCCTG-3') and G08.1 (5'-GAACGGCCATGCACCACCAAC-3') (modified from Saunders and Kraft [1994]); G06 and G07 (Saunders and Kraft, 1994) or the primers designed by White et al. (1990): NS1 and NS2; NS3 and NS4; NS5 and NS8 or primers designed by Medlin et al. (1988). Bangiales SSU rDNA were amplified in two subfragments using the primers G01.1 and G10.1, and G02.1 and G15.1 (modified from Saunders and Kraft [1994]). Coding regions that contained group I introns in position 516 (E. coli numbering; see Bhattacharya, 1998) of the SSU rDNA, required additional primers (not shown) to allow for sequencing of these insertions.

The purified rDNA fragments were then either sequenced directly or cloned using the TA cloning kit and the plasmid vector pCR2.1 (Invitrogen, Carlsbad, California, USA) prior to sequencing. Plasmid DNA was isolated and purified using the Plasmid Midi Kit (Qiagen). The rDNA sequences were determined over both strands using an ABI-310 Genetic Analyzer (Perkin-Elmer, Norwalk, Connecticut, USA), and the primers listed above or in Elwood, Olsen, and Sogin (1985), with the Dye Terminator Cycle Sequencing Ready Reaction Kit (Perkin-Elmer). The GenBank accession numbers of the SSU rDNA sequences determined in this study are shown in Table 1.

Sequences were aligned according to the secondary structure models of Gutell (1996) and Van de Peer et al. (1997), optimized manually using the SeqApp program (Gilbert, 1992), and a total of 1582 sequence positions (626 parsimony-informative characters) were used in the phylogenetic analyses (alignment available from D. Bhattacharya). A tree was inferred with fastDNAml 1.1 (Olsen et al., 1994) for maximum likelihood (ML) analyses using the global search option, transition/transversion ratio $=2$, and a jumbled sequence input. The ML tree was rooted on the branch length leading to green algal (chlorophyte) rDNA sequences. The data set was also analyzed with a distance method in which the matrix was calculated with the HKY-85 model (Hasegawa, Kishino, and Yano, 1985) with equal rates of change across sites and the tree was built with neighbor-joining (Saitou and Nei, 1987). A neighbor-joining tree was also built with LogDet distances (Lockhart, Steel, and Penny, 1994). Bootstrap analyses (Felsenstein, 1985; 2000 replications) were done using both HKY-85 and LogDet distances. Missing data and gaps were excluded from pairwise comparisons in these analyses. All phylogenetic analyses except for fastDNAml were done with PAUP* (V4.0b4a; Swofford, 2000). The GenBank accession numbers of the existing nuclear SSU rDNA sequences are shown in the ML tree.

To test hypotheses generated by the initial tree, we concatenated all available nuclear and plastid SSU rDNA sequences from the same bangiophyte strains (ten sequences) and inferred trees from this data set (2953 total characters, 784 parsimony-informative characters) using PAUP*. The tree was inferred with the ML method in PAUP* using empirically determined nucleotide frequencies, equal rates across sites, with the transition/transversion ratio $=2$, and the HKY-85 model of sequence evolution. Initial trees were built stepwise with ten random-sequence additions, and these trees were rearranged with tree-bisection reconnection (TBR) to find the phylogeny of highest likelihood. Two-hundred bootstrap replicates were analyzed with this method. The ML tree was rooted on the branch length leading to the rDNA sequences of the chlorophyte Mesostigma viride. We also did bootstrap analyses (2000 replications) of this data set using neighbor-joining and HKY-85 or LogDet distances as described above. Finally, unweighted maximum parsimony (MP) was used to calculate bootstrap values (2000 replications) for the concatenated rDNA sequences using the same sequence addition and tree rearrangement protocols as described above for the ML method. The GenBank accession numbers of the existing plastid-encoded SSU rDNA sequences are shown in the ML tree.

A third data set of existing plastid-encoded large subunit sequences of ribulose-1,5-bisphosphate carboxylase/oxygenase (Rubisco, EC 4.1.1.39) from rhodophytes, cryptophytes, haptophytes, and heterokonts was assembled to provide another perspective on bangiophyte phylogeny and secondary sym- biosis. A total of 494 amino acids (161 parsimony-informative characters) were used for the phylogenetic analyses using PAUP*. The tree was built with the unweighted MP method as described above, and the stability of monophyletic groups was tested with the bootstrap method (2000 replications). The MP tree was rooted on the branch length leading to Rubisco sequences from Cyanidiales and heterokonts. Bootstrap analysis (2000 replications) was also done using protein distances (mean character difference). The Rubisco sequences were used as input for quartet puzzling (Strimmer and van Haeseler, 1996) with protein distance (minimum evolution) as the optimality criterion (10000 puzzling steps). Lastly, the first and second positions of Rubisco codons (954 characters, 292 parsimony-informative sites) were analyzed with quartet puzzling with DNA sequence distance (minimum evolution) as the optimality criterion. The GenBank accession numbers of the existing Rubisco sequences are shown in the MP tree. We also changed the topology of the Rubisco tree using the MacClade computer program (version 3.07; Maddison and Maddison, 1997) and compared these rearranged trees to the "best" tree using the Kishino-Hasegawa test (Kishino and Hasegawa, 1989 [within PAUP*]) to test different hypotheses about bangiophyte and secondary plastid evolution. In this analysis, the number of steps required for all trees were compared to test for significant $(P<0.05)$ differences among them.

\section{RESULTS}

The complete SSU rDNA gene was sequenced for all studied Bangiophycidae (except Stylonema alsidii CR for which the $5^{\prime}$-terminal $400 \mathrm{bp}$ could not be obtained, likely due to PCR primer mismatch in this region). All rDNA genes were free of any major insertions or deletions except for Bangia fuscopurpurea and Porphyra leucosticta, which were of lengths 3341 and 2404 bp, respectively. Bangia fuscopurpurea contained two group I introns at positions 516 and 1506, whereas $P$. leucosticta contained a single group I intron at the 516 position. Bangia atropurpurea (LM01) and Bangia sp. (VIS7) also contain introns at the 516 position (Müller et al., 1998). These introns will not be further analyzed here. Maximum likelihood analysis of the SSU rDNA data set resulted in the tree shown in Fig. 1 ( - Ln likelihood $=19963.4577)$. The distance analyses provided bootstrap support for most nodes in the ML tree. These analyses show the order Bangiales to be a well-supported monophyletic grouping (100\% bootstrap with both methods) in which Porphyra is polyphyletic within Bangia. The Bangiales is positioned as a sister group to the Florideophycidae in all the analyses, but without bootstrap support. To test the effect of the highly divergent Florideophycidae rDNAs on the position of the Bangiales, the Florideophycidae sequences were removed from the data set shown in Fig. 1 and the data were analyzed with the distance method (HKY-85 model). This phylogeny supported the monophyletic origin of the Bangiales and their distant relationship to other red algal orders (tree not shown).

The Porphyridiales form three well-supported, yet independent clades. The first clade (Porphyridiales 1) contains the unicells, Rhodella maculata, $R$. violacea, and Glaucosphaera vacuolata. Another unicell, Dixoniella grisea, also groups with high bootstrap support with Porphyridiales 1 (99\% LogDet, 98\% HKY-85) as a sister of G. vacuolata $(91 \%$ LogDet, $89 \%$ HKY-85). The length of the branch leading to D. grisea and its divergence position are shown in Fig. 1. This rDNA has been excluded from the analyses because its extreme divergence rate disrupts the phylogenies leading to the likely artifactual placement of Porphyridiales 1 as a sister group of the Florideophycidae (e.g., Zuccarello et al., 2000). This phenomenon is most certainly explained by long-branch attraction be- 


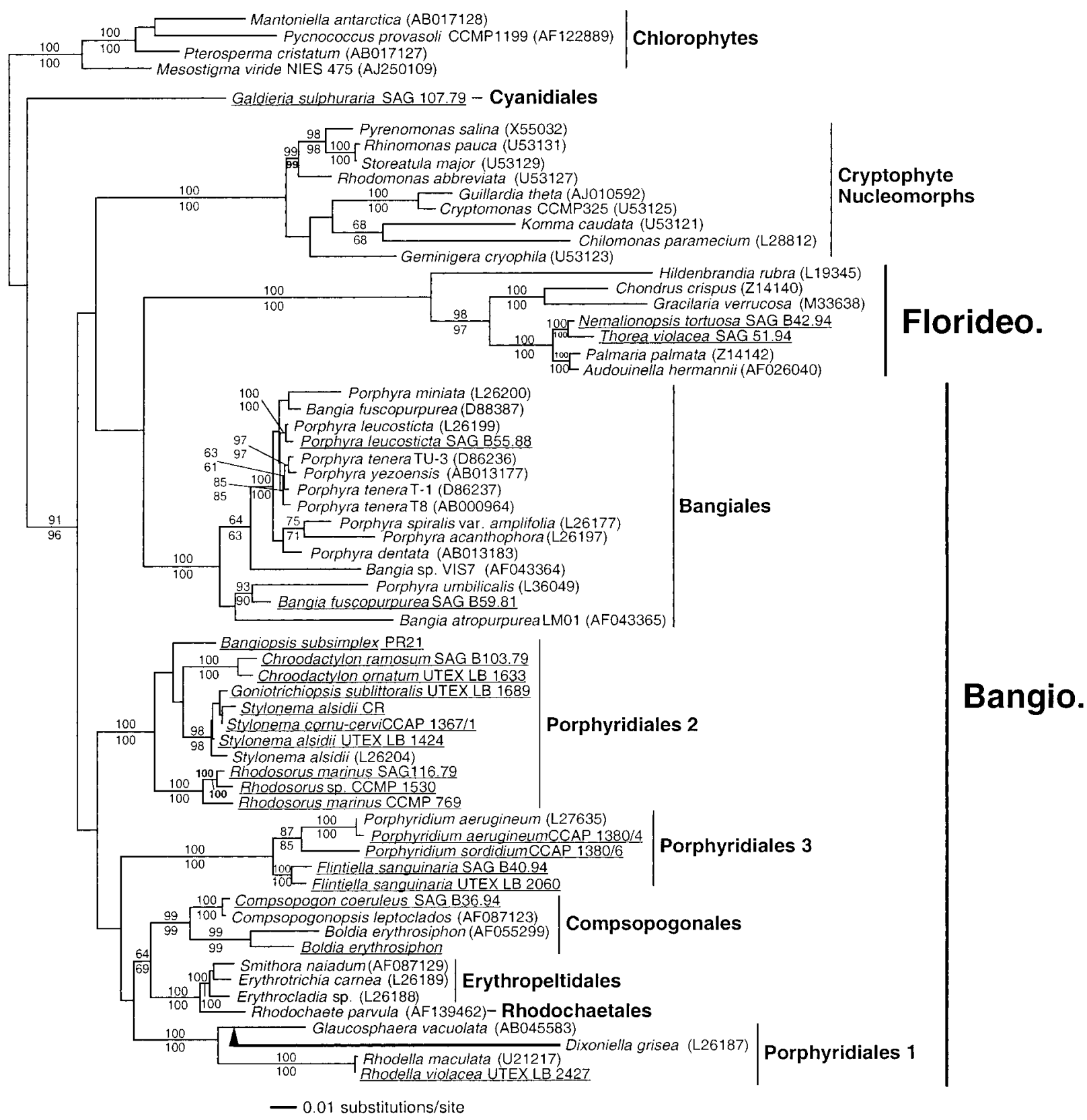

Fig. 1. Phylogeny of nuclear SSU rDNA coding regions (1582 positions) inferred using the maximum likelihood (ML) method. This tree has been rooted on the branch leading to the chlorophyte rDNAs. The results of neighbor-joining bootstrap analyses (2000 replications) using LogDet and HKY-85 (Hasegawa, Kishino, and Yano, 1985) distances are shown above and below the internal nodes, respectively. Only bootstrap values $\geq 60 \%$ for nodes shared by the ML and either distance bootstrap tree are shown. The dashes identify nodes in the ML tree that are not resolved in the distance bootstrap analyses. Lines are used to show the position of bootstrap values when they do not fit on the branches. Sequences determined in this study have been underlined, and the GenBank accession numbers for all existing rDNAs are shown after the species names. The position and approximate branch length of Dixoniella grisea when it is included in the LogDet and distance analyses are shown with the arrow. Florideo. is Florideophycidae and Bangio. is Bangiophycidae.

tween the highly divergent $D$. grisea and Florideophycidae rDNA sequences (see Fig. 1 and below).

Porphyridiales 2 consists primarily of pseudofilamentous forms, Stylonema alsidii, S. alsidii (CR), S. cornu-cervi, Goniotrichopsis sublittoralis, Bangiopsis subsimplex, Chroodactylon ornatum, and C. ramosum, but also two unicells, Rhodosorus marinus and Rhodosorus sp. This clade is well supported by the bootstrap analyses (100\%). Porphyridiales 3 contains the unicells Porphyridium aerugineum, $P$. sordidium, and
Flintiella sanguinaria and is also well supported by the bootstrap analyses (100\%). Monophyly of the Erythropeltidales, Erythrotrichia carnea and the closely related Erythrocladia sp. and Smithora naiadum, is strongly supported by the bootstrap analyses (100\%). Rhodochaete parvula, which is the only member of the order Rhodochaetales, is a derived taxon that is sister to the Erythropeltidales (100\% bootstrap; Fig. 1). Taxa within the Compsopogonales sensu stricto (Compsopogon coeruleus, Compsopogonopsis leptoclados, and Boldia erythrosi- 


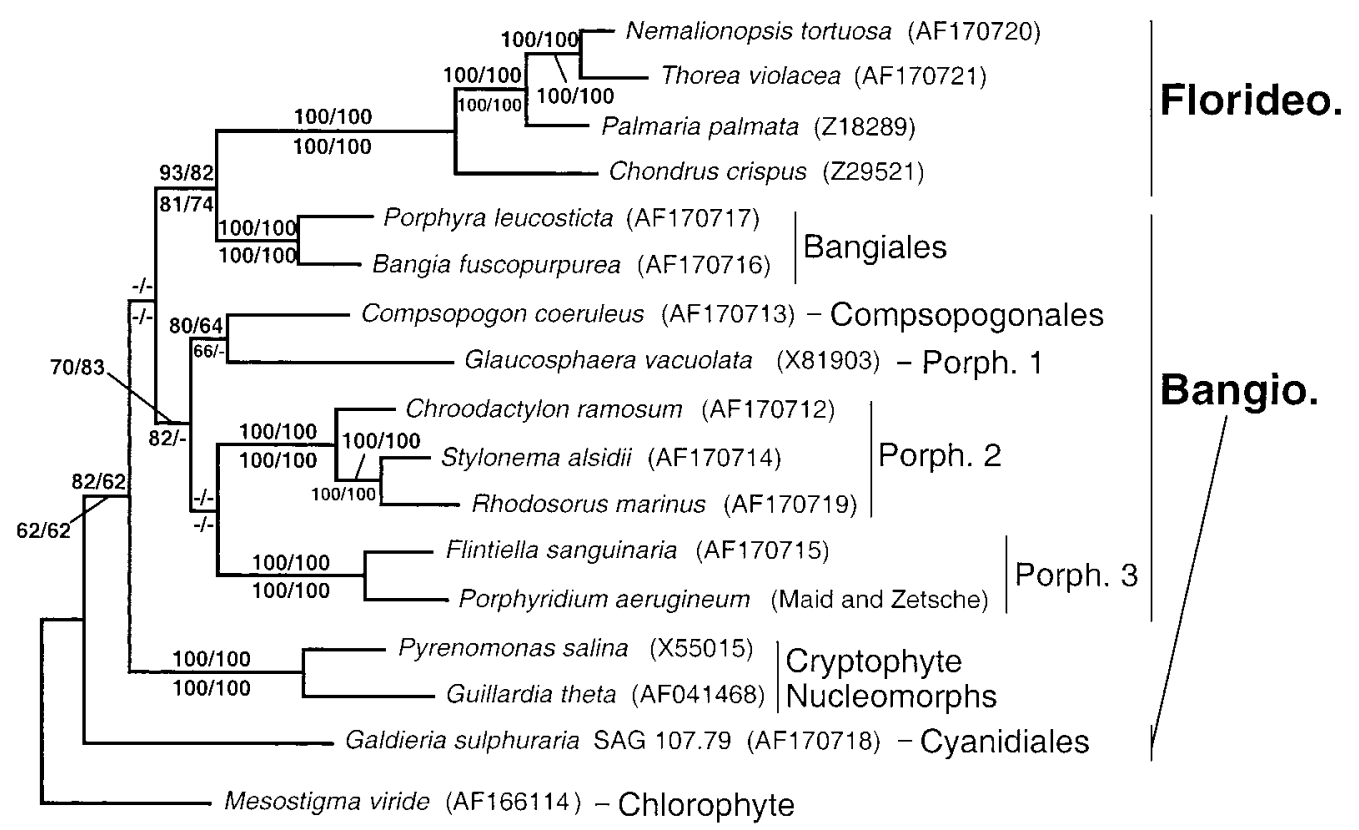

0.05 substitutions/site

Fig. 2. A maximum likelihood tree inferred from comparisons of concatenated nuclear and plastid SSU rDNA coding regions (2953 positions) showing the evolutionary relationships of Rhodophyta and the nucleomorph of cryptophytes. This tree has been rooted on the branch leading to the Mesostigma viride rDNA sequence. Bootstrap values (200 replications) from the ML analysis are shown above the branches on the left of the slash marks. The values shown to the right of the slash marks are from a distance (HKY-85; Hasegawa, Kishino, and Yano, 1985) bootstrap analysis (2000 replications). The bootstrap values (2000 replications) shown below the branches on the left of the slash marks are inferred from neighbor-joining using LogDet distances, whereas the values shown to the right of the slash marks are inferred from an unweighted maximum parsimony analysis. Only bootstrap values $\geq 60 \%$ for nodes shared by the bootstrap consensus trees inferred with the different phylogenetic methods are shown. The dashes identify nodes in the ML tree that are not resolved in the different bootstrap analyses. Lines are used to show the position of bootstrap values when they do not fit on the branches. GenBank accession numbers for all existing plastid SSU rDNAs are shown after the species names. Florideo. is Florideophycidae and Bangio. is Bangiophycidae.

phon), all of which inhabit freshwater environments, are positioned on a strongly supported branch (99\% bootstrap) with weak support for a sister group relationship with the Erythropeltidales/Rhodochaetales (64\% LogDet, 69\% HKY-85). The Galdieria sulphuraria sequence has strong bootstrap support as the earliest divergence within the Rhodophyta and the cryptophyte nucleomorphs form a well-supported monophyletic group in Fig. 1 with no obvious sister-group relationship to the bangiophyte orders in the analysis.

Phylogenetic analyses of the concatenated nuclear and plastid SSU rDNA sequences resulted in an identical tree with all methods in which virtually all nodes had strong bootstrap support. This tree is also remarkably similar to that shown in Fig. 1 . The ten random additions and heuristic search with the ML method identified a single tree $(-\mathrm{Ln}$ likelihood $=$ 17778.9589; see Fig. 2). This tree supports, with moderate to strong bootstrap support, the sister-group relationship of Bangiales and Florideophycidae, an early divergence of G. sulphuraria within the Rhodophyta, and the monophyly of previously identified bangiophyte orders and the cryptophyte nucleomorphs. The lack of plastid SSU rDNA sequences from Dixoniella and members of the Erythropeltidales/Rhodochaetales does not allow us to compare more precisely the nuclear vs. the nuclear + plastid rDNA phylogenetic frameworks.

The Rubisco tree shown in Fig. 3 is also generally consistent with the results of the rDNA analyses. The monophyly of the Bangiales and Florideophycidae is found in both protein- and DNA-level analyses, but only the protein distance method provides moderate bootstrap support (73\%) for this node, as does the protein quartet puzzling analysis (puzzle value $=71$ ). There is weak support for the monophyly of the Cyanidiales and heterokont plastids as was found with a recent analysis of plastid SSU rDNA (Oliveira and Bhattacharya, 2000). There is moderate to strong bootstrap support for the monophyly of the orders Bangiales, Erythropeltidales, and the Cyanidiales as there is for the monophyly of the secondary plastids in the haptophytes and of the secondary plastids in the heterokonts. The single sequence from the cryptophyte, Guillardia theta, groups with moderate bootstrap support with the haptophyte plastids. Surprisingly, the Compsopogonales do not have bootstrap support in the different Rubisco analyses, but all phylogenetic methods show the monophyly of this lineage, in agreement with the rDNA analyses (see Fig. 1).

Five different hypotheses about the phylogenetic history of bangiophytes were tested using the Kishino-Hasegawa test (Kishino and Hasegawa, 1989) with rearrangements of the "best" MP Rubisco tree shown in Fig. 3 (Tree 1). The hypotheses tested the strength of the following relationships: Bangiales/Florideophycidae (Tree 2), cryptophyte/haptophyte (Tree 3), and Cyanidiales/heterokont plastid (Tree 4), as well as the monophyly of the Compsopogonales (Tree 5) and the forced monophyly of cryptophyte/haptophyte/heterokont plastids (Tree 6; see Fig. 3). The results of the Kishino-Hasegawa test (Table 2) show that rearranged Trees 4 and 6 are significantly "worse" than the best tree shown in Fig. 3. This result provides strong support for the close evolutionary relationship of the plastids in the Cyanidiales and heterokont and argues against a single origin of the secondary plastids in the cryp- 


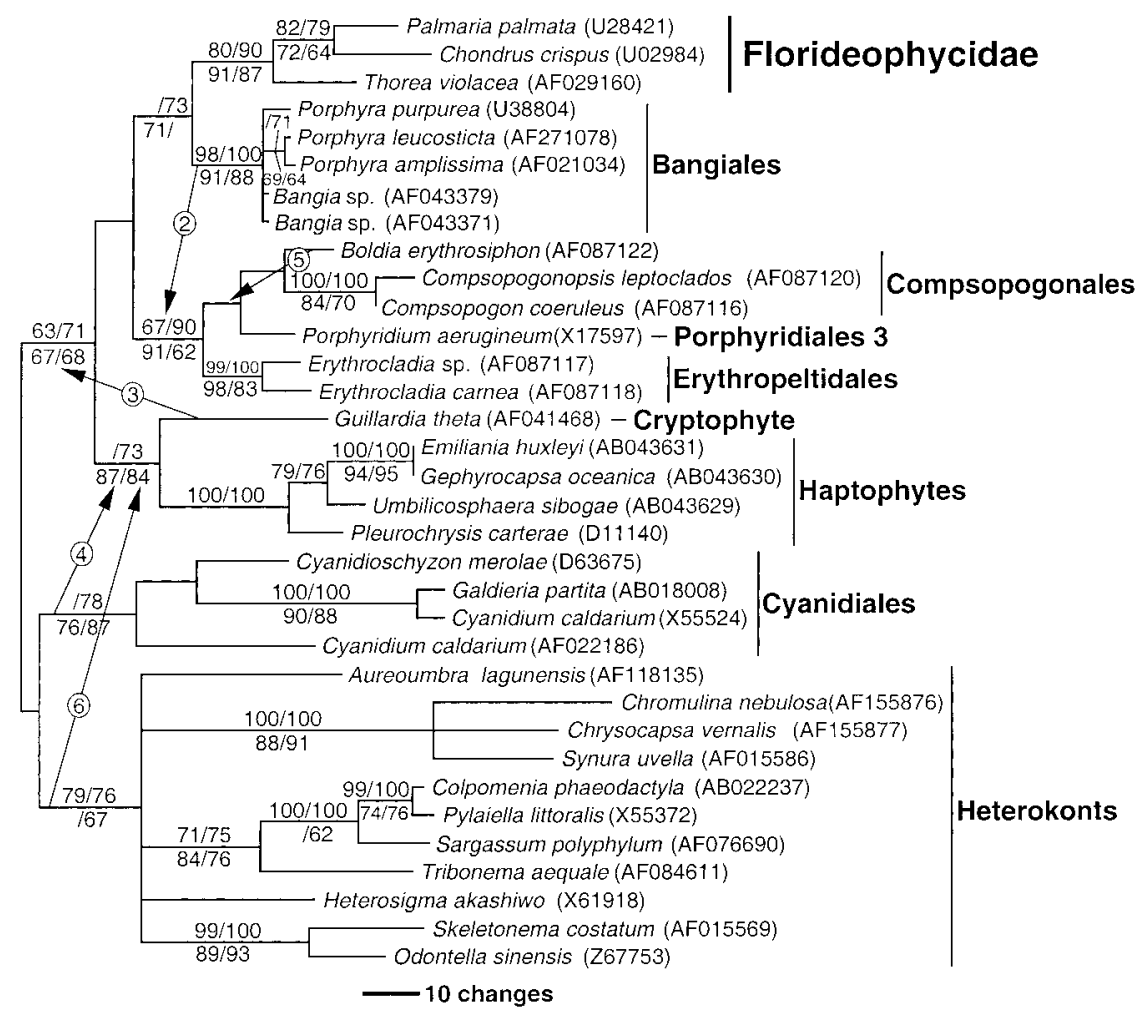

Fig. 3. (A) An unweighted maximum parsimony tree inferred from comparisons of 494 amino acids of the Rubisco protein. This tree is rooted on the branch leading to the heterokont and Cyanidiales Rubisco sequences. Bootstrap values (2000 replications) from the parsimony analysis are shown above the branches on the left of the slash marks. The values shown to the right of these slash marks are from a protein distance (mean difference) bootstrap analysis (2000 replications). The values shown below the branches on the left of the slash marks are inferred from a protein quartet puzzling analysis (10000 puzzling steps), whereas the values shown to the right of these slash marks are inferred from a DNA quartet puzzling analysis (10000 puzzling steps) using the first and second positions of Rubisco codons (954 bp). Both quartet puzzling analyses used minimum evolution as the optimality criterion. Only bootstrap values $\geq 60 \%$ for nodes shared by the bootstrap consensus trees inferred with the different phylogenetic methods are shown. The different rearrangements of the Rubisco tree are shown with the arrows. GenBank accession numbers for all existing Rubisco sequences are shown after the species names.

tophyte, haptophyte, and heterokont algae (Tree 6). Of the remaining trees, only rearranged Tree 2 showed a near significant difference $(P=0.0956)$ with respect to the best tree. Taken together, these data suggest that the Bangiales/Florideophycidae grouping has some support with the Rubisco data (as evident in the moderate protein distance bootstrap value), but the monophyly of the Compsopogonales sensu stricto and the cryptophyte/haptophytes are not robust results. In contrast, the nuclear rDNA trees clearly support the monophyly of the Compsopogonales, whereas there is little evidence for the

TABLE 2. Results of tests of tree congruence with the Kishino-Hasegawa test. The comparisons of the best maximum parsimony tree inferred from the Rubisco data set (see Fig. 3) with rearrangements $2-6$ are shown.

\begin{tabular}{cccccl}
\hline \hline Tree & $\begin{array}{c}\text { Length } \\
\text { (steps) }\end{array}$ & $\begin{array}{c}\text { Length } \\
\text { difference }\end{array}$ & $\begin{array}{c}\mathrm{sD} \\
\text { (difference) }\end{array}$ & $T$ & $P^{*}$ \\
\hline 1 & 851 & (best) & & & \\
2 & 856 & 5 & 2.99421 & 1.6699 & 0.0956 \\
3 & 852 & 1 & 3.00289 & 0.3330 & 0.7393 \\
4 & 860 & 9 & 3.58504 & 2.5104 & $0.0124^{*}$ \\
5 & 853 & 2 & 2.00000 & 1.0000 & 0.3178 \\
6 & 861 & 10 & 3.43644 & 2.9100 & $0.0038^{*}$ \\
\hline
\end{tabular}

* Probability of getting a more extreme $T$ value under the null hypothesis of no difference between the two trees (two-tailed test). Values marked with asterisks indicate significant difference at $P<0.05$. monophyly of cryptophyte and haptophyte plastids when a broad diversity of plastid SSU rDNA sequences are analyzed (see Fig. 2 in Oliveira and Bhattacharya, 2000).

\section{DISCUSSION}

In spite of several attempts at classification (Skuja, 1939; Fritsch, 1945; Kylin, 1956; Chapman, 1974; Garbary, Hansen, and Scagel, 1980; Magne, 1989), the taxonomy of the subclass Bangiophycidae remains uncertain. Much of the existing taxonomy is based on the presence of unicellular or multicellular form, a likely artificial character (Garguilo, De Masi, and Tripodi, 1987). Gabrielson, Garbary, and Scagel (1985) used cladistic methods to determine a phylogenetic ranking of orders within the Rhodophyta. Based on their analysis, there was little support for separating red algal orders into two distinct taxa of higher rank, the Bangiophycidae and Florideophycidae. In addition, the Porphyridiales were determined to be paraphyletic within the Bangiophycidae, whereas the Bangiales, Rhodochaetales, and possibly the Erythropeltidales were monophyletic (Gabrielson, Garbary, and Scagel, 1985).

A completely different evolutionary scenario was proposed by Magne (1989). Based on previous morphological analyses of thallus structure by the French school of phycology (e.g., Chadefaud, 1969), and his own studies on reproductive cells, called cysts, he divided the Rhodophyceae into three subclasses: (1) Archaeorhodophycidae, lacking naked fertile cell-pro- 
ducing cysts, with a single order Porphyridiales; (2) Metarhodophycidae, defined by the presence of metacystis (only part of the fertile cell produces the reproductive cell) including the orders Erythropeltidales, Rhodochaetales, and Compsopogonales; and (3) Eurhodophycidae, defined by the presence of eucystis (the entire content of the fertile cell is transformed into the reproductive cells) including the order Bangiales and all the orders of the former Florideophycidae.

Ragan et al. (1994) used the nuclear SSU rDNA sequences to infer a phylogeny of the Rhodophyta; however, their analysis contained only six bangiophyte genera belonging to three of the five orders. Despite this limited sampling, Ragan et al. (1994) postulated that the Bangiophycidae were paraphyletic because it included the Florideophycidae and probably encompassed three or more distinct lineages. Oliveira and Bhattacharya (2000) studied plastid SSU rDNA coding regions and showed that Porphyridiales formed three distinct lineages, that Cyanidiales was likely an independent order, and postulated a sister-group relationship between Bangiales and Florideophycidae as predicted by Magne (1989). The present study is, however, the first to include numerous bangiophyte taxa including all five orders in an analysis of the nuclear SSU rDNA gene to resolve the systematics of this pivotal group of red algae.

Bangiales - This order comprises two genera, Porphyra and Bangia within one family, the Bangiaceae, which has been well defined based on life history and developmental characteristics (Garbary, Hansen, and Scagel, 1980; Garbary and Gabrielson, 1990). In the present study, this order is strongly supported as being monophyletic in all analyses, and this finding is in agreement with previous molecular studies (e.g., Ragan et al., 1994; Oliveira and Bhattacharya, 2000). However, the taxonomic relationship between the two genera within this order is not clear. Oliveira et al. (1995), Müller et al. (1998), Broom et al. (1999) and Oliveira and Bhattacharya (2000), found that Porphyra is polyphyletic within Bangia. A great deal more work will have to be done with naturally occurring populations of Bangiales (e.g., Broom et al., 1999) before the evolutionary history of this complex species assemblage can be resolved.

Compsopogonales and Erythropeltidales-In most taxonomic schemes (e.g., Bird and McLachlan, 1992; Womersley, 1994; Stegenga, Bolton, and Anderson, 1997), the order Compsopogonales (= Erythropeltidales sensu Garbary, Hansen, and Scagel, 1980) consists of three families: the Compsopogonaceae, Boldiaceae, and Erythrotrichiaceae (= Erythropeltidaceae; Womersley, 1994). The first two families are typically freshwater in their occurrence (Sheath, 1984), although Compsopogon coerulus (Balbis) Montagne has also been collected from brackish waters (Tomas et al., 1980). In contrast, the Erythrotrichiaceae are composed of strictly marine representatives (Womersley, 1994; Silva, Basson, and Moe, 1996). The Compsopogonales were erected based primarily on the mode of monosporangium formation (Garbary, Hansen, and Scagel, 1980). The sporangia develop from undifferentiated vegetative cells that undergo oblique divisions by a curved cell wall, producing two cells, the smaller of which develops into a monosporangium (Garbary, Hansen, and Scagel, 1980). However, Silva, Basson, and Moe (1996) suggested that the Compsopogonales should circumscribe only members of the Compsopogonaceae because their morphology is considerably more complex than that of the Erythrotrichiaceae. In addition, Silva, Basson, and Moe (1996) noted that the Erythropeltidales are a valid order if they contain the Erythrotichiaceae, exclusive of the Compsopogonaceae. In contrast to this view, Rintoul, Vis, and Sheath (1999) concluded that the Compsopogonales sensu lato, including the three families, is supported as a valid taxonomic entity based on phylogenetic analyses inferred from the SSU rDNA and Rubisco genes. The much larger data set used in the current study shows that the Erythrotrichiaceae are well separated from the Compsopogonaceae and Boldiaceae. Therefore, the recommendation of Silva, Basson, and Moe (1996) to recognize the Erythropeltidales, which contains the single family Erythrotrichiaceae, is substantiated by our analyses. Thus, Erythrotrichia, Erythrocladia, and Smithora should be considered to be members of the family Erythrotrichiaceae within the order Erythropeltidales. Other genera believed also to belong to this family include Porphyropsis, Membranella, Porphyrostromium, and Sahlingia (Garbary, Hansen, and Scagel, 1980).

The Compsopogonales, as resolved in our study, contain the freshwater families Boldiaceae and Compsopogonaceae, each of which constitutes a well-supported monophyletic group. In terms of genera contained within this order, only Boldia and Compsopogon appear to be valid. The identical sequences of Compsopogon coeruleus and specimens formerly classified as Compsopogonopsis leptocladus (Table 1) is in accord with Rintoul, Vis, and Sheath (1999), who concluded that the Compsopogonaceae contains the single species, Compsopogon coeruleus.

Rhodochaetales - This order has only one family, the Rhodochaetacae, and a single species, Rhodochaete parvula (Garbary, Hansen, and Scagel, 1980; Gabrielson et al., 1990). This species is thought to be central to understanding red algal evolution because of its combination of characteristics, including filamentous organization with apical growth, triphasic and slightly heteromorphic life history, and pit plugs with no cap layers or membranes (Magne, 1960; Boillot, 1978; Pueschel and Magne, 1987; Gabrielson et al., 1990; Garbary and Gabrielson, 1990). Van den Hoek, Mann, and Jahns (1995) postulated that the remaining bangiophyte orders may be derived from an ancestral Rhodochaete-like group and have secondarily lost more "advanced" characters (e.g., Porphyridiales) or have evolved additional advanced characters (e.g., Florideophycideae). The present study and that of Zuccarello et al. (2000) do not support this idea. Instead, Rhodochaete parvula groups with members of the Erythropeltidales in a strongly supported clade in our SSU rDNA trees. These data suggest that the Rhodochaetales is not well supported as being a separate order and that $R$. parvula may best be reclassified in the Erythropeltidales.

In a cladistic analysis of red algal orders, Gabrielson, Garbary, and Scagel (1985) noted that the order Rhodochaetales is distinguished from the Compsopogonales (including members of the Erythropeltidales) by the presence of apical growth and sexual reproduction. The authors suggested that these characters may have been lost in members of the Compsopogonales. Later, Garbary and Gabrielson (1990) presented the argument that, based on similarity of sexual reproduction with Porphyrostromium and pit plugs with Compsopogon, one could argue that $R$. parvula is most closely related to the Compsopogonales (including the Erythrotrichiaceae). In the present study, $R$. parvula appears to be basal to members of 
the Erythrotrichiaceae, substantiating the concept of a reduction in sexuality, apical growth, and pit plugs in this family (for details, see Zuccarello et al., 2000). Given the clear separation of the Erythrotrichiaceae and $R$. parvula in this clade, the family Rhodochaetaceae should be retained.

Porphyridiales-Resolving the taxonomic status of the order Porphyridiales is the most difficult issue within the Bangiophycidae because this order does not form a single monophyletic group. In fact, there appear to be at least three wellsupported clades. The Porphyridiales has been separated into two families, the Porphyridiaceae and Phragmonemataceae. The first family has single stellate plastids with pyrenoids, whereas the taxa within the Phragmonemataceae do not have stellate plastids and pyrenoids are absent (Garbary, Hansen, and Scagel, 1980; Gabrielson et al., 1990). These families are not well supported in our study. In fact, both the Porphyridiaceae and Phragmonemataceae are polyphyletic within the Rhodophyta.

Porphyridiales 1 contain primarily unicells currently classified in the family Porphyridiaceae (Dixoniella and Rhodella). However, Dixoniella grisea is positioned on an extremely long branch within the distance analyses. Dixoniella and Rhodella differ in the thylakoid penetration and nuclear projection into the pyrenoid, Golgi association with other organelles, and presence of a peripheral thylakoid (Scott et al., 1992; Broadwater and Scott, 1994). These two genera are unique among the unicellular red algae that have been examined ultrastructurally because they have stellate-like plastids with deep lobing and excentric, unstalked pyrenoids (Broadwater and Scott, 1994). Hence, this grouping appears to represent a distinct taxonomic entity separated on the basis of plastid type, and the clade is well separated from the other red algal taxa currently classified in the Porphyridiales. Glaucosphaera vacuolata, which was positioned in this clade, is classified within the Glaucocystophyta (Kies and Kremer, 1986), but analyses of both nuclear- and plastid-encoded SSU rDNA sequences demonstrate that this taxon is not directly related to other glaucocystophytes and is a member of the Rhodophyta (Bhattacharya et al., 1995; Helmchen, Bhattacharya, and Melkonian, 1995). The suggestion, based on ultrastructural analyses, that G. vacuolata is a member of the Porphyridiales (McCracken, Nadakavukaren, and Cain, 1980; Broadwater et al., 1995) is substantiated by our analysis.

Porphyridiales 2 comprise unicellular (Rhodosorus) and multicellular (pseudofilamentous forms) taxa currently classified in the family Porphyridiaceae, with the exception of Goniotrichopsis sublittoralis (Phragmonemataceae; Garbary, Hansen, and Scagel, 1980; Gabrielson et al., 1990). The two species of Rhodosorus form a well-supported group in this large clade. They are unique among unicellular red algae in having a cup-shaped plastid without a peripheral thylakoid but with an eccentric pyrenoid (Broadwater and Scott, 1994). The pseudofilamentous genera Bangiopsis, Chroodactylon, Goniotrichopsis, and Stylonema are positioned on a weakly supported separate branch. All of these genera have a stellate plastid with a central pyrenoid, except for Goniotrichopsis, which has numerous discoid plastids without pyrenoids (Taylor, 1960; Abbott and Hollenberg, 1976; Womersley, 1994). Clearly, this diverse clade does not fit the currently conceived orders of the Bangiophycidae. The order Stylonematales and family Stylonemataceae can be reinstated to include Stylonema and Chroodactylon (Drew, 1956), as noted by Silva, Basson, and
Moe (1996). According to Abbott and Hollenberg (1976), Goniotrichopsis belongs to the same family as Stylonema (as Goniotrichum) and Chroodactylon (as Asterocytis), based on having branched, filamentous thalli in which cells are separated by gelatinous material. The remaining taxon, Rhodosorus, appears to be well associated with the above grouping and can be considered to be a member of the Stylonematales. Nonetheless, a new family is warranted for this genus based on its unicellular habit, unique plastids, and occurrence on a well-supported and separate branch in the SSU rDNA gene trees. Within the cluster containing the pseudofilamentous forms, Bangiopsis subsimplex (Porphyridiaceae) and Chroodactylon ornatum (Porphyridiaceae) are unresolved with respect to the cluster containing Stylonema (Porphyridiaceae) and Goniotrichopsis (Phragmonemataceae). Using plastid SSU rDNA sequences, Oliveira and Bhattacharya (2000) also found a well-supported group composed of four species of the Porphyridiales, C. richteriana, C. ramosum, S. alsidii, and R. marinus.

The well-supported Porphyridiales 3 lineage consists solely of unicellular forms-two species of Porphyridium and one species of Flintiella. This cluster contains the nominate genus and thus the order Porphyridiales and family Porphyridiaceae must accompany this genus. Flintiella has a branched plastid with no obvious pyrenoid in contrast to Porphyridium, which contains a stellate plastid with a central pyrenoid (Broadwater and Scott, 1994). Flintiella has been classified in the Porphyridiaceae by Bourrelly (1985) but Gabrielson et al. (1990) and Garbary, Hansen, and Scagel (1980) have placed this genus in the Phragmonemataceae based on plastid type.

Cyanidiales-Regarding Cyanidium and Galdieria, Seckbach and Ott (1994) have proposed that these genera should be united in a separate order, the Cyanidiales, within the Bangiophycidae. Our analyses support this idea, although Cyanidium spp. SSU rDNA sequences are needed to determine whether the Cyanidiales are a monophyletic or a paraphyletic order (see Oliveira and Bhattacharya, 2000).

Florideophycidae - The Florideophycidae examined in this study form a well-supported clade in the SSU rDNA gene trees with the Bangiales on a basal branch of this clade. This result has strong to moderate bootstrap support (see Figs. 2 and 3). The Bangiales/Florideophycidae association is supported by the type of reproductive cells, or cysts, defined by Magne (1989), by the association of the Golgi apparatus with the mitochondrion in these groups (Garbary and Gabrielson, 1990), the presence of pit connections in the Florideophycidae and in the Conchocelis phase of the Bangiales, the presence of group I introns in the nuclear SSU rDNA (in the Bangiales and in the Hildenbrandiales from the Florideophyceae; Oliveira and Ragan, 1994), and the results of Rubisco (Freshwater et al., 1994) and plastid SSU rRNA sequence comparisons (Oliveira and Bhattacharya, 2000). Based on nuclear SSU rDNA analyses, Ragan et al. (1994) have shown that the Florideophycidae are monophyletic, with the Hildenbrandiales as the first divergence and the NAP complex (Nemaliales, Acrochaetiales, and Palmariales) as the second diverging lineage. This finding supports the conclusion of some researchers that the Rhodophyta should be classified into one class, the Rhodophyceae with no subclasses (e.g., Garbary and Gabrielson, 1990).

Secondary symbiotic origin of red algal plastids-The sec- 
ondary origin of cryptophyte, haptophyte, and the heterokont plastids from a red algal endosymbiont has been previously documented on the basis of sequence comparisons and plastid gene order (Douglas et al., 1991; Bhattacharya and Medlin, 1995, 1998; Palmer and Delwiche, 1996; Daugbjerg and Andersen, 1997; Medlin et al., 1997; Douglas and Penny, 1999; Durnford et al., 1999; and see discussion in Oliveira and Bhattacharya, 2000). The Rubisco protein analyses support the origin of the heterokont plastid from a red alga in the Cyanidiales (Fig. 3), a result that is consistent with previous analyses of plastid coding regions (e.g., Bhattacharya and Medlin, 1995; Leblanc, Boyen, and Loiseaux-de Goër, 1995; Medlin et al., 1995, 1997; Oliveira and Bhattacharya, 2000). Our study provides, however, no clues to the bangiophyte source(s) of cryptophyte and haptophyte plastids. The position of the cryptophyte nucleomorphs as a separate lineage in Fig. 2 is consistent with the Rubisco analyses, which also show the plastids from these secondary symbionts to be an independent lineage within the Bangiophycidae (Fig. 3). The haptophyte plastids have moderate bootstrap support as a sister group of cryptophytes in the Rubisco tree. A rearranged tree in which this relationship is broken is, however, not significantly worse than that showing cryptophyte/haptophyte monophyly (Tree 3 in Table 2). These conflicting data may be explained by poor sampling of cryptophyte Rubisco sequences in our analysis. Limited sampling of cryptophyte and haptophyte plastid SSU rDNA, for example, also suggested monophyly of these organelles (compare Figs. 2 and 3 in Oliveira and Bhattacharya, 2000). Alternatively, our data may indicate that evolutionarily closely related bangiophytes may have given rise independently to the plastids in cryptophytes and haptophytes. We also find no support for the scenario that all bangiophyte-derived secondary plastids (and, thereby, their host cells) form a monophyletic group, an idea that was put forth largely on the basis of plastid characters, such as the existence of a plastid endoplasmic reticulum in these taxa (Cavalier-Smith, 1982, 2000). The rearranged Tree 6 that forced the monophyly of the cryptophyte, haptophyte, and heterokont plastids was significantly worse than the best MP Rubisco tree shown in Fig. $3(P=0.0038)$. This result agrees with analyses of plastid SSU rDNA sequences (Oliveira and Bhattacharya, 2000).

Consistent with the view of independent origins of the plastids in cryptophyte, haptophytes, and heterokonts is the separate evolutionary histories of the host cells containing these organelles. The cryptophytes, for example, are more closely related to glaucocystophytes than to the heterokonts or haptophytes (Bhattacharya and Medlin, 1995; Van de Peer et al., 1996; Gray et al., 1998). These results underscore the hypothesis that secondary symbiosis, and thereby the evolution of a plastid import system in each host lineage, may have evolved multiple independent times (McFadden, 1999). A broader sample of plastid genes needs to be studied to test the hypothesis of independent secondary plastid origins in cryptophytes, haptophytes, and heterokonts. In addition, more bangiophyte taxa need to be included in these analyses to identify possible plastid donors for the cryptophytes and haptophytes.

In summary, our expanded phylogenetic analyses help to improve the understanding of the evolutionary histories of the Bangiophycidae and the Florideophycidae. The subclass Bangiophycidae is found to be a paraphyletic assemblage that should be included in a single red algal class, the Rhodophyceae, which includes the Florideophycidae (Gabrielson, Garbary, and Scagel, 1985). In addition, we suggest that the cryp- tophyte, haptophyte, and heterokont plastids were derived from independent secondary endosymbiotic events involving members of the Bangiophycidae. This hypothesis is consistent with our present understanding of plastid and host phylogeny in these algal groups.

\section{LITERATURE CITED}

Aвbott, I. A., And G. J. Hollenberg. 1976. Marine algae of California. Stanford University Press, Stanford, California, USA.

Andersen, R. A., S. L. Morton, AND J. P. SEXton. 1997. Provasoli-Guillard National Center for Culture of Marine Phytoplankton: 1997 List of strains. Journal of Phycology 33 (Supplement): 1-75.

BhatTACHARYA, D. 1998. The origin and evolution of protist group I introns. Protist 149: 113-122.

- H. J. Elwood, L. J. Goff, AND M. L. Sogin. 1990. The phylogeny of Gracilaria lemaneiformis (Rhodophyta) based on the sequence analysis of its small subunit ribosomal RNA coding region. Journal of Phycology 26: 181-186.

, T. Helmchen, C. Bibeau, and M. Melkonian. 1995. Comparisons of nuclear-encoded small-subunit ribosomal RNAs reveal the evolutionary position of the Glaucocystophyta. Molecular Biology and Evolution 12: $415-420$.

- AND L. MEDLIN. 1995. The phylogeny of plastids: a review based on comparisons of small-subunit ribosomal RNA coding regions. Journal of Phycology 31: 489-498.

, AND —. 1998. Algal phylogeny and the origin of land plants. Plant Physiology 116: 9-15.

Bird, C. J., AND J. L. McLachlan. 1992. Seaweed flora of the Maritimes. 1. Rhodophyta - the red algae. Biopress, Bristol, UK.

BoILlot, A. 1978. Les ponctuations intercellulaires du Rhodochaete parvual Thuret (Rhodophycées, Bagniophycidées). Revue Algologique, Nova Scotia 13: 251-258.

BourRelly, P. 1985. Les algues d'eau douce—initiation à la systematique, tome III: Les algues bleues et rouges, les eugléniens, peridiniens et cyrptomonadines. Nouvelle Edition, Boubée, Paris, France.

BROAdWATER, S., AND J. SCOTT. 1994. Ultrastructure of unicellular red algae. In J. Seckbach [ed.], Evolutionary pathway and enigmatic algae: Cyanidium caldarium (Rhodophyta) and related cells, 215-230. Kluwer Academic, Dordrecht, The Netherlands.

$\longrightarrow$ - S. P. A. Goss, AND D. SAunders. 1995. Ultrastructure of vegetative organization and cell division in Glaucosphaera vacuolata Korshikov (Porphyridiales, Rhodophyta). Phycologia 34: 351-361.

Broom, J. E., W. A. Jones, D. F. Hill, G. A. Knight, And W. A. Nelson. 1999. Species recognition in New Zealand Porphyra using $18 \mathrm{~S}$ rDNA sequencing. Journal of Applied Phycology 11: 421-428.

Burger, G., D. Saint-Louis, M. W. Gray, AND B. F. Lang. 1999. Complete sequence of the mitochondrial DNA of the red alga Porphyra purpurea: cyanobacterial introns and shared ancestry of red and green algae. Plant Cell 11: 1675-1694.

CAvalier-Smith, T. 1982. The origins of plastids. Biological Journal of the Linnean Society 17: 289-306.

. 2000. Membrane heredity and early chloroplast evolution. Trends in Plant Science 5: 174-182.

Chadefaud, M. 1969. La morphologie des vegetaux inférieur: données fondamentales et problémes. Bulletin de la Societé Botanique France, Mémoires 115: 5-41.

Chapman, D. J. 1974. Taxonomic status of Cyanidium caldarium, the Porphyridiales and Goniotrichales. Nova Hedwigia 25: 673-682.

DaugbJerg, N., AND R. A. Andersen. 1997. Phylogenetic analyses of the rbcl sequences from haptophytes and heterokont algae suggest their chloroplasts are unrelated. Molecular Biology and Evolution 14: 1242-1251

Douglas, S. E., C. A. Murphy, D. F. Spencer, and M. W. Gray. 1991. Molecular evidence that cryptomonad algae are chimaeras of two phylogenetically distinct unicellular eukaryotes. Nature 350: 148-151.

- AND S. L. J. Penny. 1999. The plastid genome of the cryptophyte alga, Guillardia theta: complete sequence and conserved synteny groups confirm its common ancestry with red algae. Journal of Molecular Evolution 48: 236-244.

Drew, K. 1956. Conferva ceramicola Lyngbye. Botanisk Tidsskrift 53: 6774

Durnford, D. G., J. A. Deane, S. Tan, G. I. McFadden, E. Gantt, And 
B. R. GREEN. 1999. A phylogenetic assessment of the eukaryotic lightharvesting antenna proteins, with implications for plastid evolution. Journal of Molecular Evolution 48: 59-68.

Elwood, H. J., G. J. Olsen, AND M. L. Sogin. 1985. The small-subunit ribosomal RNA gene sequences from the hypotrichous ciliates Oxytricha nova and Stylonychia pustulata. Molecular Biology and Evolution 2: 399-410.

Felsenstein, J. 1985. Confidence limits on phylogenies: an approach using the bootstrap. Evolution 39: 783-791.

Freshwater, W., S. FredericQ, B. S. Butler, M. H. Hommersand, AND M. W. CHASE. 1994. A gene phylogeny of the red algae (Rhodophyta) based on plastid rbcL. Proceedings of the National Academy of Sciences USA 91: 7281-7285.

FritsCH, F. E. 1945. The structure and reproduction of the algae, vol. 2. Cambridge University Press, Cambridge, UK.

Gabrielson, P. W., AND J. D. Garbary. 1985. Systematics of the red algae (Rhodophyta). Critical Reviews in Plant Sciences 3: 325-366.

, - AND R. F. SCAGEL. 1985. The nature of ancestral red algae: inferences from a cladistic analysis. Biosystems 18: 335-346.

19 , M. R. SOMmERfeld, R. A. TOWNSEND, AND P. L. TYler. 1990. Phylum Rhodophyta. In L. Margulis, J. O. Corliss, M. Melkonian, and D. J. Chapman [eds.], Handbook of protoctista, 102-118. Jones and Bartlett, Boston, Massachusetts, USA.

Gantt, E., J. ScotT, AND C. Lipschultz. 1986. Phycobiliprotein composition and chloroplast structure in the freshwater red alga Compsopogon coeruleus (Rhodophyta). Journal of Phycology 22: 480-484.

Garbary, D. J., AND P. W. Gabrielson. 1990. Taxonomy and evolution. In K. M. Cole and R. G. Sheath [eds.], Biology of the red algae, 477-498. Cambridge University Press, Cambridge, UK.

, G. I. HANSEN, AND R. F. SCAGEL. 1980. A revised classification of the Bangiophyceae (Rhodophyta). Nova Hedwigia 33: 145-166.

Garguilo, G. M., F. De MASI, AND G. TRIPODI. 1987. Thallus morphology and spore formation in cultured Erythrocladia irregularis Rosenvinge (Rhodophyta, Bangiophycidae). Journal of Phycology 23: 351-359.

Gilbert, D. G. 1992. SeqApp, version. 1.9a169. Biology Department, Indiana University, Bloomington, Indiana, USA.

GrAY, M. W., ET AL. 1998. Genome structure and gene content in protist mitochondrial DNAs. Nucleic Acids Research 26: 865-878.

Gutell, R. R. 1996. Comparative sequence analysis and the structure of $16 \mathrm{~S}$ and $23 \mathrm{~S}$ rRNA. In R. A. Zimmermann and A. E. Dahlberg [eds.], Ribosomal RNA: structure, evolution, processing, and function in protein biosynthesis, 111-128. CRC Press, Boca Raton, Florida, USA.

Hasegawa, M., H. Kishino, AND T. Yano. 1985. Dating of the human-ape splitting by a molecular clock of mitochondrial DNA. Journal of Molecular Evolution 22: 160-174.

Helmchen, T., D. Bhattacharya, And M. Melkonian. 1995. Analyses of ribosomal RNA sequences from glaucocystophyte cyanelles provide new insights into the evolutionary relationships of plastids. Journal of Molecular Evolution 41: 203-210.

Kies, L., AND B. P. Kremer. 1986. Typification of the Glaucocystophyta. Taxon 35: 128-135.

KishinO, H., AND M. HASEgawa. 1989. Evaluation of the maximum likelihood estimate of the evolutionary tree topologies from DNA sequence data, and the branching order in hominoidea. Journal of Molecular Evolution 29: 170-179.

KyLIN, H. 1956. Die Gattungen der Rhodophyceen. CWK, Gleerups Forlag, Lund, Sweden.

Leblanc, C., C. Boyen, And S. LoiseauX-DE GoËr. 1995. Organization of the plastid genome from the rhodophyte Chondrus crispus (Gigartinales); sequence and phylogeny of the $16 \mathrm{~S}$ rRNA gene. European Journal of Phycology 30: 133-140.

Lockhart, P. J., M. A. SteEl, AND D. Penny. 1994. Recovering the correct tree under a more realistic model of evolution. Molecular Biology and Evolution 11: 605-612.

Maddison, W. P., AND D. R. MAdDison. 1997. MacClade, version 3.07. Sinauer, Sunderland, Massachusetts, USA.

Magne, F. 1960. Le Rhodochaete parvula Thuret (Bangioidée) et sa reproduction sexuée. Cahiers Biologie Marin 1: 407-420.

Magne, F. 1989. Classification et phylogénie des Rhodophycées. Cryptogamie, Algologie 10: 101-115.

McCracken, D. A., M. J. Nadakavukaren, and J. R. Cain. 1980. A biochemical and ultrastructural evaluation of the taxonomic position of Glaucosphaera vacuolata Korsch. New Phytologist 86: 39-44.
McFAdDEN, G. I. 1999. Plastids and protein targeting. Journal of Eukaryotic Mirobiology 46: 339-346.

Medlin, L. K., A. Cooper, C. Hill, S. Wrieden, and U. Wellbrook. 1995. Phylogenetic position of the Chromista plastids based on small subunit rRNA coding regions. Current Genetics 28: 560-565.

- , H. J. Elwood, S. Stickel, AND M. L. Sogin. 1988. The characterization of enzymatically amplified eukaryotic 16S-like rRNA-coding regions. Gene 71: 491-499.

- W. H. C. F. Koolstra, D. Potter, G. W. Saunders, and R. A. ANDERSEN. 1997. Phylogenetic relationships of the "golden" algae (haptophytes, heterokont chromophytes) and their plastids. In D. Bhattacharya [ed.], Origins of algae and their plastids, 187-220. SpringerVerlag, Wien, Austria.

Moreira, D., H. Le Guyader, And H. PhilipPe. 2000. The origin of red algae and the evolution of chloroplasts. Nature 405: 69-72.

Müller, K. M., R. G. Sheath, M. L. Vis, J. Crease, and K. M. Cole. 1998. Biogeography and systematics of Bangia (Bangiales, Rhodophyta) based on the rubisco spacer, rbcL gene and 18S rRNA gene sequences and morphometric analyses. 1. North America. Journal of Phycology 37: 195-207.

Oliveira, M. C., and D. Bhattacharya. 2000. Phylogeny of the Bangiophycidae (Rhodophyta) and the secondary endosymbiotic origin of algal plastids. American Journal of Botany 87: 482-492.

$\longrightarrow$ J. Kurniawan, C. J. Bird, E. L. Rice, C. A. Murphy, R. K. Singh, R. R. Gutell, and M. A. Ragan. 1995. A preliminary investigation of the order Bangiales (Bangiophycidae, Rhodophyta) based on sequences of nuclear small-subunit ribosomal RNA genes. Phycological Research 43: 71-79.

$\longrightarrow$, AND M. A. RAGAN. 1994. Variant forms of a group I intron in nuclear small-subunit rRNA genes of the marine red alga Porphyra spiralis var. amplifolia. Molecular Biology and Evolution 11: 195-207.

Olsen, G. J., H. Matsuda, R. Hagstrom, and R. Overbeek. 1994. FastDNAmL: a tool for construction of phylogenetic trees of DNA sequences using maximum likelihood. Computational Applications in Biosciences 10: 41-48.

Palmer, J. D., AND C. F. Delwiche. 1996. Second-hand chloroplasts and the case of the disappearing nucleus. Proceedings of the National Academy of Sciences, USA 93: 7432-7435.

Pueshel, C. M., AND F. MAGNe. 1987. Pit plugs and other ultrastructural features of systematic value in Rhodochaete parvula (Rhodophyta, Rhodochaetales). Cryptogamic Algology 8: 201-209.

Ragan, M. A., C. J. Bird, E. L. Rice, R. R. Gutell, C. A. Murphy, And R. K. SingH. 1994. A molecular phylogeny of the marine red algae (Rhodophyta) based on the nuclear small-subunit rRNA gene. Proceedings of the National Academy of Sciences, USA 91: 7276-7280.

Rintoul, T. L., M. L. Vis, AND R. G. Sheath. 1999. Systematics of the Compsopogonales (Rhodophyta) with emphasis on the freshwater families in North America. Phycologia 38: 517-527.

SAITOU, N., AND M. NEI. 1987. The neighbor-joining method: a new method for reconstructing phylogenetic trees. Molecular Biology and Evolution 4: 406-425.

SAUNDERS, G. W. 1993. Gel purification of red algal genomic DNA: an inexpensive and rapid method for the isolation of polymerase chain reaction-friendly DNA. Journal of Phycology 29: 251-254.

$\longrightarrow$, AND G. T. KRAFT. 1994. Small-subunit rRNA gene sequences from representatives of selected families of the Gigartinales and Rhodymeniales (Rhodophyta). 1. Evidence for the Plocamiales ord. nov. Canadian Journal of Botany 72: 1250-1263.

$\longrightarrow$, AND -1997 . A molecular perspective on red algal evolution: focus on the Florideophycidae. Plant Systematics and Evolution [Supplement] 11: 115-138.

SCHLÖSSER, U. G. 1994. SAG-Sammlung von Algenkulturen at the University of Göttingen. Botanica Acta 107: 111-186.

Scott, J. L., S. T. Broadwater, B. D. SAunders, J. P. Thomas, and P. W. GABRIELSON. 1992. Ultrastructure of vegetative organization and cell division in the unicellular red alga Dixoniella grisea gen. nov. (Rhodophyta) and a consideration of the genus Rhodella. Journal of Phycology 28: 649-690.

Seckbach, J., AND F. D. Otт. 1994. Systematic position and phylogenetic status of Cyanidium caldarium Geitler 1933. In J. Seckbach [ed.], Evolutionary pathway and enigmatic algae: Cyanidium caldarium (Rhodophyta) and related cells, 133-143. Kluwer Academic, Dordrecht, The Netherlands. 
SheAth, R. G. 1984. The biology of the freshwater red algae. Progress in Phycological Research 3: 89-157.

Silva, P. C., P. W. Basson, AND R. L. MoE. 1996. Catalogue of the benthic marine algae of the Indian Ocean. University of California Press, Berkeley, California, USA.

SkujA, H. 1939. Versuch einer systematischen Einteilung der Bangioideen oder Protoflorideen. Acta Horti Botaniska Universitets Latavia 11: 2340.

Starr, R. C., AND J. A. ZeIKus. 1993. The Culture Collection of Algae at The University of Texas at Austin: 1993 list of cultures. Journal of Phycology 29 (Supplement): 1-106.

Stegenga, H., J. J. Bolton, And R. J. Anderson. 1997. Seaweeds of the South African west coast. Contributions from the Bolus Herbarium Number 18, University of Cape Town, Cape Town, South Africa.

Stiller, J. W., And B. D. Hall. 1997. The origin of the red algae: implications for plastid evolution. Proceedings of the National Academy of Sciences, USA 94: 4520-4525.

STRIMMER, K., AND A. VAN HAESELER. 1996. Quartet puzzling: a quartet maximum-likelihood method for reconstructing tree topologies. Molecular Biology and Evolution 13: 964-969.

SWOFFORD, D. L. 2000. PAUP*: phylogenetic analysis using parsimony, version 4.0b4a. Smithsonian Institution, Washington, D.C., USA.

TAYLOR, W. R. 1960. Marine algae of the eastern tropical and subtropical coasts of the Americas. University of Michigan Press, Ann Arbor, Michigan, USA.

Tomas, X., P. Lopez, R. Margalef-Mir, and F. A. Comin. 1980. Distri- bution and ecology of Compsopogon occidentalis sp. nov. (Rhodophyta). Lilloa 35: 35-37.

VAN DEN HoEK, C., D. G. ManN, AND H. M. JAHns. 1995. Algae: an introduction to phycology. Cambridge University Press, Cambridge, UK.

Van De Peer, Y., J. Jansen, P. De Rijk, And R. De Wachter. 1997. Database on the structure of small ribosomal subunit RNA. Nucleic Acids Research 25: 111-116.

—, S. A. Rensing, U.-G. Maier, And R. De Wachter. 1996. Substitution rate calibration of small subunit rRNA identifies chlorarachniophyte endosymbionts as remnants of green algae. Proceedings of the $\mathrm{Na}$ tional Academy of Sciences, USA 93: 7732-7736.

VIS, M. L., AND R. G. SHEATH. 1997. Biogeography of Batrachospermum gelatinosum (Batrachospermales, Rhodophyta) in North America based on molecular and morphological data. Journal of Phycology 33: 520526.

White, T. J., T. Bruns, S. LeE, And J. TAYlor. 1990. Amplification and direct sequencing of fungal ribosomal RNA genes for phylogenetics. In M. A. Innis, D. H. Gelfand, J. J. Sninsky, and T. J. White [eds.], PCR protocols: a guide to methods and applications, 315-322. Academic Press, San Diego, California, USA.

Womersley, H. B. S. 1994. The marine benthic flora of southern Australia. Rhodophyta-part IIIA. Australian Biological Resources Study, Canberra, ACT, Australia.

Zuccarello, G., J. West, A. Bitans, and G. Kraft. 2000. Molecular phylogeny of Rhodochaete parvula (Bangiophycidae, Rhodophyta). Phycologia 39: 75-81. 


\title{
PHYLOGENY AND SYSTEMATICS OF THE MARINE ALGAL FAMILY GRACILARIACEAE (GRACILARIALES, RHODOPHYTA) BASED ON SMALL SUBUNIT rDNA AND ITS SEQUENCES OF ATLANTIC AND PACIFIC SPECIES ${ }^{1}$
}

\author{
Alexis M. Bellorin ${ }^{2}$ \\ Departamento de Biología, Universidad de Oriente, AP 245, Cumaná, Venezucla
}

Mariana C. Oliveira and Eurico C. Oliveira

Departamento de Botânica, Instituto de Biociências, Universidade de São Paulo, Caixa Postal 11461, CEP 05422-970, São Paulo, Brazil

We sequenced the small subunit rDNA and internal transcribed spacer region of Gracilariaceae from the tropical Atlantic and Pacific, with emphasis on flattened or compressed species. Sequence comparisons confirmed three main lineages of Gracilariaceae: Curdiea/Melanthalia, Gracilariopsis/Gracilariophila, and Gracilaria. The Curdiea/Melanthalia diverged early in the family. Gracilariopsis was paraphyletic, because at least one Gracilariophila species evolved from it. The Atlantic Gracilariopsis were monophyletic and separated from the Pacific lineages. The Gracilaria included all species referable to its own species and to Hydropuntia, which was paraphyletic, formed by distantly related lineages. The new combination Gracilaria pauciramosa (N. Rodríguez Ríos) Bellorin, M. C. Oliveira et E. C. Oliveira is proposed for Polycavernosa pauciramosa N. Rodríguez Ríos. Recognition of subgenera within Gracilaria, based on spermatangial arrangement, was not supported. Instead, infrageneric groups were delineated by geographic origins and combinations of reproductive characters. Most Pacific species with either "textorii" or "verrucosa" type spermatangia were deeply separated from Atlantic species. Within the Atlantic Gracilaria, a lineage encompassing mostly tropical cylindrical species with "henriquesiana" type spermatangia and distinctive cystocarp anatomy was recognized. A lineage was also retrieved for cold water stringy species with verrucosa type spermatangia. Several species from the western Atlantic are closely related to Gracilaria tikvahiae McLachlan with nearly identical morphology. On the other hand, most flattened species from the tropical Atlantic were closely related despite their diverse morphologies. The interpretation of our data in addition to the literature indicates that more populations from the Indo-Pacific must be studied before a general picture of Gracilariaceae evolution can be framed.

Key index words: agarans; agarophytes; Gracilaria; Gracilariaceae; Gracilariopsis; Hydropuntia; ITS; phylogeny; SSU rDNA

Received 14 August 2001. Accepted 19 February 2002.

Author for correspondence and present address: Departamento de Botânica, Instituto de Biociências, Universidade de São Paulo, Caixa Postal 11461, CEP 05422-970, São Paulo, Brazil. E-mail almiguel@ yahoo.com.
Abbreviations: G., Gracilaria; Gl., Gracilariophila; Gp., Gracilariopsis; GTR, general time reversible; ITS, internal transcribed spacer; ML, maximum likelihood; MP, maximum parsimony; NJ, neighbor joining; SSU, small subunit

The gracilarioid algae include some of the most valuable marine plants. They have been intensively investigated in the last 30 years and comprehensive information about biology (Oliveira and Plastino 1994), cultivation (Oliveira et al. 2000), and utilization (cf. Critchley and Ohno 1998) has been published. However, there is still much to be done to resolve the many remaining taxonomic problems (e.g. Bird 1995). Different approaches have been attempted to clarify the taxonomy of gracilarioid algae (sensu Oliveira et al. 2000 ), primarily the genera Gracilaria Greville (1830), Gracilariopsis E. Y. Dawson (1949), and the disputable genus Hydropuntia Montagne (1842; valid name for Polycavernosa C. F. Chang et B. M. Xia 1963, see Wynne 1989). Reproductive anatomy (e.g. Dawson 1949, Yamamoto 1978, Gargiulo et al. 1992), chemistry (Bird et al. 1987), crossability, and karyology (McLachlan et al. 1977. Bird et al. 1982, 1986, 1990a, Guiry and Freamhainn 1985, Plastino and Oliveira 1988, 1997, Yamamoto and Sasaki 1988, Godin et al. 1993, Kapraun 1993) and modern techniques, including DNA fingerprinting (Goff and Coleman 1988, Rice and Bird 1990, Wattier et al. 1997) and gene sequencing (Bird et al. 1990b, 1992, 1994, Destombe and Douglas 1991, Goff et al. 1994), have been the keystone aspects investigated. It has been concluded that species delimitation is reliable only when based on a combination of characters, preferably experimental data, because anatomical features may be equivocal and cryptic species have been reported (Bird and Rice 1990, Bird et al. 1994, Steentoft et al. 1995). Unfortunately, nonmorphological information is almost entirely restricted to the terete and economically valuable taxa, especially those from temperate waters. The large assemblage of compressed and flattened forms from tropical waters, which constitute most of the described gracilarioid algae, has been largely neglected.

Among the experimental tools for discriminating taxa within this group, the comparison of homologous gene sequences has several advantages over other ap- 
proaches. Gene sequencing is time saving compared with hybridization tests, is more informative at the species and genus level in Gracilariaceae than DNA fingerprinting or karyology, and provides testable phylogenetic and systematic hypotheses. With the techniques of PCR and automatic sequencing, this approach is also readily applicable to a large number of samples and small quantities of purified DNA.

Molecular phylogenetic studies in Gracilariaceae have been based on nucleotide sequences of nuclearencoded small subunit (SSU) rDNA (Bhattacharya et al. 1990, Bird et al. 1990b, 1992, 1994), internal transcribed spacer (ITS) regions of ribosomal nuclear repeats (Goff et al. 1994), plastid-encoded rbcL, and the RUBISCO spacer region (Destombe and Douglas 1991, Freshwater et al. 1994, Goff et al. 1994, Gurgel et al. 1999). Sequence data have confirmed various aspects of the systematics and phylogeny of gracilarioid algae, for example, 1) the ordinal rank and monophyletic nature of Gracilariales, previously proposed on anatomical grounds (Fredericq and Hommersand 1989a); 2) a closer relationship of Gracilariales to the Halymeniales, Rhodymeniales, and Plocamiales (Ragan et al. 1994, Saunders and Kraft 1997) than to other primary agar-producing orders; and 3) the distinct generic status of Gracilariopsis (Dawson 1949, Bird 1995), which appeared as a fast-evolving clade diverging early within Gracilariaceae (Bird et al. 1992, 1994). The genera Curdiea Harvey (1855) and Melanthalia Montagne (1843), with unique morphological features (Fredericq and Hommersand 1990a) and a restricted distribution, were also supported. On the other hand, Hydropuntia and the subgenera of Gracilaria proposed by Yamamoto $(1978,1984)$ on the basis of spermatangial configuration were not supported as consistent groups. However, it should be taken into account that only one species referable to Hydropuntia has been studied so far and that the diversity of the flattened Gracilaria spp. was poorly represented.

Here we provide data from part of the nuclear ribosomal cistron for 28 species/populations of Gracilariales, focusing on flattened forms from the tropical Atlantic. We also include some terete forms with deep compound spermatangial conceptacles ("henriquesiana" type, Yamamoto 1984) that could be assigned to Hydropuntia and two terete species from the Pacific. To allow for broad phylogenetic resolution, we compare sequences of the slowly evolving SSU rDNA and the fast-evolving ITS.

\section{MATERIALS AND METHODS}

DNA extraction and purification. All samples were taken from natural populations (Table 1). Voucher specimens were deposited in the herbarium of the University of São Paulo, Brazil. DNA was extracted from cleaned thalli tips previously dried and stored in silica gel. Tips were ground to fine powder with liquid nitrogen, and approximately $0.1 \mathrm{~g}$ of ground tissue was added to $2 \mathrm{~mL}$ lysis buffer $(1.5 \%$ CTAB, $1 \mathrm{M} \mathrm{NaCl}, 50 \mathrm{mM}$ EDTA, 0.1 M Tris pH 8.0, $0.2 \%$-mercaptoethanol) and incubated for $10 \mathrm{~min}$ at $65^{\circ} \mathrm{C}$. Lysates were cooled at room temper- ature, and $2 \mu \mathrm{L}$ of RNAse $\left(100 \mathrm{mg} \cdot \mathrm{mL}^{-1}\right.$; Qiagen, Santa Clarita, CA, USA) was added, incubating $30-60 \mathrm{~min}$ at $37^{\circ} \mathrm{C}$. An equal volume of phenol:chloroform:isoamyl alcohol (25:24:1) was used for extraction, followed by two washes in equal volumes of chloroform:isoamyl alcohol (24:1). DNA was precipitated with two volumes of absolute ethanol at $-20^{\circ} \mathrm{C}$ and collected with a sterilized glass capillary or by centrifuging at $\mathrm{ca}$. $15,000 \mathrm{~g}$ for $20 \mathrm{~min}$ at $4^{\circ} \mathrm{C}$. In the latter case, the supernatant was discarded and the DNA was resuspended in $0.5 \mathrm{~mL}$ of sterile MilliQ-filtered water (Millipore Products Division, Bedford, MA, USA). If a viscous emulsion was formed, 0.1 volumes of absolute ethanol was added, samples were centrifuged at ca. $2000 \mathrm{~g}$ for $20 \mathrm{~min}$ at $4^{\circ} \mathrm{C}$, and the supernatant recovered. DNA was precipitated by adding 0.1 volumes of $3 \mathrm{M} \mathrm{NaOAC}$, pH 5.2 , and two volumes of absolute ethanol, with subsequent incubation for $30 \mathrm{~min}$ at $-20^{\circ} \mathrm{C}$ and centrifugation at ca. $10,000 \mathrm{~g}$ for $20 \mathrm{~min}$ at $4^{\circ} \mathrm{C}$. After centrifugation, the DNA pellet was washed twice with $0.5 \mathrm{~mL}$ of $70 \%$ ethanol, and finally the DNA was dissolved in $100 \mu \mathrm{L}$ of sterile MilliQ-filtered water.

PCR amplification. The nuclear SSU rDNA was amplified using the svnthetic primers $1855^{\prime}$ and $1853^{\prime}$ (Table 2). Amplification of the nuclear ITS (i.e. ITS1, 5.8S rDNA, and ITS2) was accomplished with the primers 6F and 28SR (Table 2). Amplification conditions were $1 \times$ PCR buffer, $1.5 \mathrm{mM} \mathrm{MgCl}_{2}, 0.2 \mathrm{mM}$ each dNTP, $0.2 \mu \mathrm{M}$ each primer, $1.25 \mathrm{U}$ of Taq DNA polymerase (GibcoBRL, Life Technologies, Gaithersburg, Germany), and $\geq 2 \mathrm{ng}$ of genomic DNA per $50 \mu \mathrm{L}$ reaction. The PCR parameters for SSU rDNA were $94^{\circ} \mathrm{C}$ for $5 \mathrm{~min}, 35$ cycles of $94^{\circ} \mathrm{C}$ for $1 \mathrm{~min}, 60^{\circ} \mathrm{C}$ for $2 \mathrm{~min}$, and $72^{\circ} \mathrm{C}$ for $4 \mathrm{~min}$, followed by a final extension step at $72^{\circ} \mathrm{C}$ for $7 \mathrm{~min}$ in a GeneAmp PCR system 2400 (Applied Biosystems, Foster City, CA, USA). The same PCR protocol was followed for the ITS, except that the times of denaturing, annealing, and extension were reduced to one half.

Sequencing. For each taxon at least three independent PCRs were pooled together (Baldwin et al. 1995). The PCR products were purified with S-300 MicroSpin IIR columns (Amersham Pharmacia Biotech, Piscataway, NJ, USA) or QUIAquick PCR Purification Kit (Qiagen). The SSU rDNA and ITS were completely sequenced in both directions, using the Sanger dideoxy chain termination method for cycle sequencing with dye-labeled terminators (Applied Biosystems) on an ABI PRISM ${ }^{\text {TV }} 310$ Genetic Analyzer or 377 DNA Sequencer (Applied Biosystems). Sequencing primers were the amplification primers, plus the internal primers listed in Table 2. Divergent positions between closely related sequences were double-checked.

Each individual sequence was assembled manually, using ESEE 3.2 (Cabot and Beckenbach 1989). In the case of ITS, which includes three component sequences, the boundaries of each component were determined as follows: (1) the SSU rDNA-ITS1 boundary was obtained by comparison with the secondary structure model of SSU rRNA for Gracilariopsis sp. available at R. Gutell's webpage (http://www.rna.icmb.utexas.edu); (2) the 5.8S rDNA boundaries were obtained from Hershkovitz and Lewis' (1996) ITS alignment; and (3) the ITS2-large subunit rDNA boundary was determined by comparison with the functional secondary structure model of ITS2 for yeast (van der Sande et al. 1992).

Alignment. Manual multiple alignments were made in Se-Al v1.0 (Andrew Rambaut, Department of Zoology, University of Oxford, 1996). For SSU rDNA, the secondary structure-based multiple alignment for Rhodophyta from Van de Peer et al $(2000)$ was used as a model. Additional SSU rDNA sequences of Gracilariaceac from GenBank (Table 3) and the sequences of Coyptonemia undulata Sonder (GenBank accession no. U33125), Plocamium carlilagineum (Linnaeus) Dixon (no. U09619), and Sebdenia flabellata (J. Agardh) Parkinson (no. U33138), selected as outgroups, were included in the alignment. A matrix of 39 sequences and 1700 positions was assembled for SSU rDNA, excluding positions corresponding to amplification primers, indels, and ambiguously aligned positions.

For the ITS, we predicted probable secondary structure models (see below) and used them as guides to manual alignment. Available sequences of ITS of Gracilariaceae (Table 3) 
TABle 1. Gracilariaceae representatives sequenced in this study (SPF, Institute of Biosciences Phycological Herbarium, University of São Paulo, Brazil).

\begin{tabular}{|c|c|c|}
\hline Entity & Locality, data of collection, and collector & $\begin{array}{l}\text { Voucher } \\
\text { specimen }\end{array}$ \\
\hline G. caudala J.Agardh Araya & $\begin{array}{l}\text { Punta Escarceo, Península de Araya, Sucre, Venezucla / } 26 \text { Jan 99/ } \\
\text { A. M. Bellorin }\end{array}$ & SPF56 6116 \\
\hline G. caudala Ceará & Flecheiras, Trairi, Ceará, Brazil / 24 Jun 99 / D. Teixeira & SPF56117 \\
\hline G. caudata Coro & $\begin{array}{l}\text { Buchuaco, Península de Paraguaná, Falcón, Venezuela / } \\
29 \text { Dec } 98 / \text { A. M. Bellorin }\end{array}$ & SPF56118 \\
\hline G. caudata Santa Catarina & Itajaí, Santa Catarina, Brazil / 10 Mar 00 / E. C. Oliveira & SPF56119 \\
\hline G. cervicomis (Turner) J.Agardh & $\begin{array}{l}\text { Punta Escarceo, Península de Araya, Sucre, Venezuela } \\
26 \text { Jan } 99 / \text { A. M. Bellorin }\end{array}$ & SPF 56121 \\
\hline G. cornet J.Agardh Ceará & Flecheiras, Trairi, Ceará, Brazil / 24 Jun 99 / 1). Teixeira & SPF56122 \\
\hline G. cornea Coro & $\begin{array}{l}\text { Cabo San Román, Península de Paraguaná, Falcón, Venezuela / } \\
29 \text { Dec } 98 \text { / A. M. Bellorin }\end{array}$ & SPF56123 \\
\hline $\begin{array}{l}\text { G. crassissima (P.Crouan et H.Crouan in } \\
\text { Schramm et Mazé) P.Crouan et H.Crouan in } \\
\text { Schramm et Mazé }\end{array}$ & Arrecife, Vargas, Venezucla / 17 Mar 98 / E. C. Oliveira & SPF56124 \\
\hline G. cuneala Areschoug & $\begin{array}{l}\text { Recife de Candeias, Jaboatão, Pernambuco, Brazil / } 7 \text { Nov } 98 \text { / } \\
\text { E. C. Oliveira }\end{array}$ & SPF 56132 \\
\hline G. curtissiae J.Agardh & $\begin{array}{l}\text { Adícora, Península de Paraguaná, Falcón, Venezuela / } \\
29 \text { Dec } 98 \text { / A. M. Bellorin }\end{array}$ & SPF56125 \\
\hline G. domingensis (Kützing) Sonder ex Dickie Araya & $\begin{array}{l}\text { Punta Arenas, Península de Araya, Sucre, Venezuela / } 29 \\
\text { Jan } 99 \text { / A. M. Bellorin }\end{array}$ & SPF56126 \\
\hline G. domingensis Ceará & Flecheiras, Trairi, Ceará, Brazil / 24 Jun 99 / D. Teixeira & SPF56127 \\
\hline $\begin{array}{l}\text { G. foliifera (Forsskål) Børgesen var. angustissima } \\
\text { (Harvev) W.R.Taylor }\end{array}$ & $\begin{array}{l}\text { Punta Escarceo, Península de Araya, Sucre, Venezucla } \\
18 \text { Jun } 98 \text { A. M. Bellorin }\end{array}$ & SPF56128 \\
\hline G. lacimulata (Vahl) M.Howe prox. Bahia & Ilhéus, Bahia, Brazil / 24 Nov 00 / A. M. Bellorin & ND \\
\hline G. lacimulata prox. Cumaná & Cumaná, Sucre, Venezuela / 23 May 00 / A. M. Bellorin & SPF56129 \\
\hline G. mammillaris (Montagne) M.Howe Coro & $\begin{array}{l}\text { Adícora, Península de Paraguaná, Falcón, Venezuela / } \\
29 \text { Dec } 98 / \text { A. M. Bellorin }\end{array}$ & SPF 56130 \\
\hline G. mammillaris São Paulo & Praia Dura, Ubatuba, São Paulo, Brazil / 04 Feb 00 / E. C. Oliveira & ND \\
\hline $\begin{array}{l}\text { G. pauciramosa (N.Rodríguez Rios) Bellorin, } \\
\text { M.C.Oliveira et E.C.Oliveirat }\end{array}$ & $\begin{array}{l}\text { Punta Escarceo, Península de Araya, Sucre, Venezuela } \\
26 \text { Jan } 99 / \text { A. M. Bellorin }\end{array}$ & SPF56133 \\
\hline $\begin{array}{l}\text { G. lepocensis (E.Y.Dawson) E.Y.Dawson prox. } \\
\text { Santa Catarina }\end{array}$ & $\begin{array}{l}\text { Praia da Armacão, Florianópolis, Santa Catarina, Brazil / } \\
15 \text { Mar } 00 / \text { E. C. Oliveira }\end{array}$ & SPF56134 \\
\hline G. tepocensis prox. 2B & Lagoinha, Ubatuba, São Paulo, Brazil / 16 May 00 / E. M. Plastino & SPF56135 \\
\hline G. tepocensis prox. $4 \mathrm{~B}$ & Lagoinha, Ubatuba, São Paulo, Brazil / 16 May 00/E. M. Plastino & SPF56136 \\
\hline G. likvahiae McLachlan & $\begin{array}{l}\text { Pomquet Harbor, Halifax, Nova Scotia, Canada / } 23 \text { Oct } 00 / \\
\text { D. Garbary }\end{array}$ & ND \\
\hline Gracilaria sp. Araya & $\begin{array}{l}\text { El Rincón, Península de Araya, Sucre, Venezuela / } 9 \text { Jun } 98 \text { / } \\
\text { A. M. Bellorin }\end{array}$ & SPF56114 \\
\hline Gracilaria sp. Búzios & $\begin{array}{l}\text { Praia das Caravelas, Búzios, Rio de Janeiro, Brazil / } 17 \text { Jan } 00 / \\
\text { E. C. Oliveira }\end{array}$ & SPF56115 \\
\hline Gracilaria sp. Ceará & Flecheiras, Trairi, Ceará, Brazil / 24 Jun 99 / D. Teixeira & SPF56120 \\
\hline Gracilaria sp. México & $\begin{array}{l}\text { Estero de Punta Banda, Baja California, México / } 7 \text { Mar } 00 / \\
\text { J. M. Guzmán }\end{array}$ & SPF56131 \\
\hline $\begin{array}{l}\text { Gp. tenuifrons (C.J.Bird et E.C.Oliveira) } \\
\text { Fredericq et Hommersand }\end{array}$ & $\begin{array}{l}\text { El Rincón, Península de Araya, Sucre, Venezuela / } 9 \text { Jun } 98 \text { / } \\
\text { A. M Bellorin }\end{array}$ & SPF56138 \\
\hline Gracilariopsis sp. Ecuador & Posorja, Ecuador / Jun $97 /$ E. C. Oliveira & SPF56137 \\
\hline
\end{tabular}

were included. Because ITSs are fast-evolving sequences, unequivocal alignment among more distantly related species was possible only in regions that were probably constrained by secondary structure. Thus, two matrices were assembled for ITS excluding amplification primers, indels, and ambiguously aligned positions. ITS matrix 1 included 20 aligned sequences for material from the Pacific and Atlantic, including two Gracilaria species with several populations, and Gracilariopsis le maneiformis as an outgroup. This matrix was formed by 64 positions of the ITS1, 138 positions of the $5.8 \mathrm{~S}$ rDNA, and 132 positions of the ITS2. ITS matrix 2 included sequences of closely related flattened and compressed species from the Atlantic, including three species with several populations, with Gracilaria pacifica as an outgroup. This matrix included 14 sequences and comprised 128 positions of ITS1, 159 positions of $5.8 \mathrm{~S}$ rDNA, and 288 positions of ITS2. All the multiple alignments and sequences were submitted to GenBank (accession nos. AF468884 AF468918, AF472416-AF472420).
Secondary structure prediction for ITS sequences. To infer secondary structure of ITS, multiple alignments on ClustalX (Thompson et al. 1997) for groups of related species were first performed to search for conservative motifs. The individual sequences were folded in the mFold web server (Mathews et al. 1999, Zuker et al. 1999; http:/bioinfo math rpi.edu/ $z$ zerm/) at $25^{\circ} \mathrm{C}$ and $20 \%$ of thermodynamic optimality, with paired complementary flanking SSU and large subunit rDNA regions as the only initial constraints, following the secondary structure model proposed for yeast ITS2 (van der Sande et al. 1992). This produced up to 15-20 possible foldings for each sequence. The helices formed by two complementary conserved motifs found in most structures were later specified as constraints in new folds, and thus the phylogenetically supported structures were progressively produced. The alignments were also manually refined in accordance with common secondary structure information, and new conserved motifs were thus revealed. As a result most homologous positions in the ITS sequences of Gracilariaceac could be 
TABLE 2. Synthetic oligonucleotide primers used for PCR and sequencing of the SSU rDNA and ITS region.

\begin{tabular}{|c|c|c|}
\hline Primer & Sequence & Region and position in G. gracilis \\
\hline $1855^{\prime}$ & $5^{\prime}$-dCAACCTGGTTGATCCTGCCAGT-3' & SSU rDNA, $1^{\mathrm{a}}$ \\
\hline $536 \mathrm{R}$ & $5^{\prime}$-dGAATTACCGCGGCTGCTG-3' & SSU rDNA, $558^{\circ}$ \\
\hline $530 \mathrm{~F}$ & 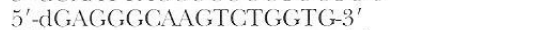 & SSU rDNA, 524 \\
\hline $920 \mathrm{R}$ & 5'-dCAATTCCTTTAAGTT TC-3' & SSU rDNA, $1117^{\mathrm{a}}$ \\
\hline $920 \mathrm{~F}$ & $5^{\prime}$-dGAAACT TAAAGGAATTG-3' & SSU rDNA, $1101^{a}$ \\
\hline $1055 \mathrm{R}$ & $5^{\prime}$-dCGGCCATGCACCACC-3' & SSU rDNA, $1252^{:}$ \\
\hline $1055 \mathrm{~F}$ & $5^{\prime}$-dGGTGGTGCATGGCCG-3' & SSU rDNA, $1238^{a}$ \\
\hline $6 \mathrm{~F}$ & $5^{\prime}$-dTGTACACACCGCCCGTCGC-3' & SSU $\mathrm{rDNA}, 1601^{\text {a }}$ \\
\hline $1800 \mathrm{~F}$ & $5^{\prime}-\mathrm{dGAGAAGTCGTAACAAGG-3^{ \prime }}$ & SSU rDNA, $1723^{\mathrm{a}}$ \\
\hline $18 \mathrm{~S} 3^{\prime}$ & 5'-dGATCCTTCTGCAGGTTCACCTACGGAA-3' & SSU rDNA, $1767^{\mathrm{a}}$ \\
\hline ITS3R & $5^{\prime}$-dGCTRCGTTCTTCATCG-3' & $5.8 \mathrm{~S}$ rDNA, $216^{\mathrm{b}}$ \\
\hline ITS3F & $5^{\prime}$-dCGATGAAGAACGYAGC- $3^{\prime}$ & $5.8 \mathrm{~S}$ rDNA, $20 \mathrm{I}^{\mathrm{b}}$ \\
\hline $58 S R$ & $5^{\prime}$-dGCGTTCAAARATTCGATGATTCAC-3' & $5.8 \mathrm{~S}$ rDNA, $273^{\mathrm{b}}$ \\
\hline $58 \mathrm{SF}$ & $5^{\prime}$-dGTGAATCATCGAATYT T TGAACGC-3' & $5.8 \mathrm{~S} \mathrm{rDNA}, 250^{\mathrm{b}}$ \\
\hline 28SR & 5'-dATATGCTTAART TCAGCGGGT-3' & LSU rDNA, $84^{\circ}$ \\
\hline
\end{tabular}

In GenBank ano. L26205, bno. U21342, cno. Y11508.

unambiguously aligned. Additional RVA secondary structure predictions were made in the GeneBee server (Brodsky et al. 1992, 1995; http://www.genebee.msu.su/services/rna2_reduced $\mathrm{h}(\mathrm{ml})$, which mav use alignments as data input, and most of the predicted conserved helices were confirmed.

Phylogenetic analyses. Mutational saturation in variable positions in SSU rDNA and ITS sequences in each multiple alignment was evaluated by plotting all pair-wise distances, uncorrected for multiple substitutions, against model corrected distances in Jukes and Cantor (1969; JC69) and Kimura (1980; K2P), estimated in PAUP* version 4 (Swofford 1998). Phylogenetic inferences were made by maximum likelihood (ML), maximum parsimony (MP), and neighbor-joining (NJ) methods for phylogenetic inferences within PAUP:. Confidence limits of individual clades were estimated as bootstrap supporting values (Felsenstein 1985) with 200-2000 replicates of heuristic searches on the $50 \%$ majority-rule consensus trees. Nodes with bootstrap values greater than $70 \%$ are significantly supported with $\geq 95 \%$ probability (Hillis and Bull 1993).

Appropriate substitution model, base frequencies, proportion of invariable sites, and rate heterogeneity among sites were estimated in Modeltest 3.04 (Posada and Crandall 1998) to establish details about the mode of evolution of sequences in each multiple alignment. For the SSU rDNA matrix, the selected model was that from Tamura and Nei (1993), with the following rate-substitution parameters: transversions $\mathrm{A} \leftrightarrow \mathrm{C}$, $\mathrm{A} \leftrightarrow \mathrm{T}, \mathrm{C} \leftrightarrow \mathrm{G}$, and $\mathrm{G} \leftrightarrow \mathrm{T}=1.0000$; transition $\mathrm{A} \leftrightarrow \mathrm{G}=3.1217$ and transition $\mathrm{C} \leftrightarrow \mathrm{T}=5.0463$. The base frequencies were unequal $(A=0.2338, C=0.2056, G=0.2862$, and $T=0.2543)$ the proportion of invariable sites was 0.6442 , and the gamma distribution shape parameter for heterogeneity of rates on variable sites was 0.8912 . For the ITS matrix 1 , the DNA sequence evolution properties were the following: JC69 one-parameter model of substitutions, proportion of invariable sites equal to zero, and rate heterogeneity among sites with gamma distribution shape parameter $=0.2574$. Finally, for ITS matrix 2 , K2P was the model of substitution selected, with rate-heterogeneity correction $(\mathrm{G}=0.2435)$. However, on bootstrap analyses for ML and NJ, these settings were not specified in all details because they are not necessarily appropriate for each bootstrap replicate. Because of computational constraints, bootstrapping in ML was realized with simple models (JC69). Bootstrapping in NJ for SSU rDNA (alignment with 1700 positions) was made using LogDet/paralinear distances (Lockhart et al. 1994) and general-time-reversible (GTR) model distances (Rodríguez et al. 1990), which are preferable over simple model distances when large sequences are compared (Swofford et al. 1996). For ITS (alignments with $300-600$ positions), bootstrapping in NJ was made either with models specified in Modeltest and with LogDet/paralinear or GTR distances.

\section{RESULTS}

SSU rIDNA. Complete SSU rDNA sequences were obtained for 23 species/populations of Gracilariaceae (Table 3). In general, the SSU rDNA gene sequenced for Gracilariaceae ranged from 1765 to 1781 base pairs (bp), and few gaps were inferred to align these sequences. The plotting of uncorrected against modelcorrected distances showed that the variable sites of these sequences were not mutationally saturated (data not shown).

Pair-wise comparisons in the multiple alignment revealed that intergeneric divergences on $\mathrm{SSU}$ rDNA of Gracilariaceae ranged from $1.47 \%$ to $6.35 \%$ (Table 4). The interspecific divergences ranged from $0.00 \%$ within Gracilaria to $2.88 \%$ within Gracilariopsis. Intraspecific divergences ranged from $0.00 \%$ within Gracilaria to $0.76 \%$ within Gracilariophila. We found that distinct species, as revealed by ITS comparison, morphology, or hybridization, may have identical SSU rDNA sequences. Such a situation was found between G. cornea of Venezuela and one undescribed cylindrical species from Brazil (Gracilaria sp. Ceará) and between the strap shaped species $G$. mammillaris from São Paulo and G. cuneata from Pernambuco, both from Brazil. On the other hand, we also found that populations of the same species may have up to two substitutions on the SSU rDNA sequences. In closely related Gracilaria species (as the several flattened tropical species studied here), the SSU rDNA sequences have not accumulated enough differences, which explains the lower bootstrap supports for the clades, including these species in the phylogenetic inferences and the equivocal relationships (Fig. 1).

Phylogenetic inferences from SSU rDNA comparisons based on ML and MP retrieved identical topologies (Fig. 1). Distance-based inferences differed in some branch orders and details. Three main lineages were consistently recognized: 1) the Curdiea/Melanthalia lineage, 2) the Gracilariopsis/Gracilariophila lineage, and 3) the Gracilaria lineage, which included all of the analyzed nonparasitic Gracilariaceae with sper- 
TABLE 3. SSU rDNA and ITS sequences of Gracilariaceae included in the analyses.

\begin{tabular}{|c|c|c|c|c|}
\hline Entity & Gross morphology/spermatangia type ${ }^{a}$ & $\begin{array}{c}\text { SSU rDNA } \\
\text { GenBank } \\
\text { accession no. }\end{array}$ & $\begin{array}{c}\text { ITS } \\
\text { GenBank } \\
\text { accession no. }\end{array}$ & Source \\
\hline C. flabellata V.J.Chapman & Flattened/? & L.26207 & - & Bird et al. (1992) \\
\hline G. caudata Araya & Cylindrical/"verrucosa"-"henriquesiana" & $\mathrm{AF} 468889$ & AF468908 & This work \\
\hline G. caudala Ceará & Cylindrical/"verrucosa"-"henriquesiana" & AF 468888 & ND & This work \\
\hline G. caudala Coro & Cylindrical/"verrucosa"-"henriquesiana" & $\mathrm{AF} 472415$ & AF 468909 & This work \\
\hline G. caudata Santa Catarina & Cylindrical/"verrucosa"-"henriquesiana" & ND & AF468910 & This work \\
\hline G. cervicornis & Compressed/"textorii" & AF468897 & AF468917 & This work \\
\hline $\begin{array}{l}\text { G. chilensis C.J. Bird, McLachlan et } \\
\text { E.C. Oliveria }\end{array}$ & Cylindrical/"lextorii" & L26217 & - & Bird et al. (1992) \\
\hline G. chilensis & Cylindrical/"textorii" & - & AF034265 & Goff et al. (1994) \\
\hline G. cornea Ceará & Cylindrical/"henriquesiana" & AF468891 & ND & This work \\
\hline G. cornea Coro & Cylindrical/"henriquesiana" & AF468892 & ND & This work \\
\hline G. comea Santa Lucia & Cvlindrical/"henriquesiana" & L.26212 & - & Bird et al. (1992) \\
\hline G. crassissima & Compressed/"henriquesiana" & AF468893 & AF468907 & This work \\
\hline G. cuneala & Flattened/"textorii" & AF468905 & ND & This work \\
\hline G. curtissiae & Flattened/"textori" & $\mathrm{AF} 468901$ & ND & This work \\
\hline G. domingensis Araya & Flattened/"verrucosa"-"henriquesiana" & AF468903 & AF468913 & This work \\
\hline G. domingensis Ceará & Flattened/ "verrucosa"-"henriquesiana" & AF 468902 & AF 472420 & This work \\
\hline G. foliifera var. angustissima & Compressed/"textori"" & AF468895 & $\mathrm{AF} 468912$ & This work \\
\hline $\begin{array}{l}\text { G. gracilis (Stackhouse) Steentoft, } \\
\text { L.Irvine et Farnham }\end{array}$ & Cylindrical/"verrucosa" & I.26205, L.26210 & - & Bird et al. \\
\hline G. gracilis & Cylindrical/"verrucosa" & - & U21342 & Golf et al. (1994) \\
\hline G. lacinulata prox. Bahia & Compressed/"lextorii" & $\mathrm{ND}$ & $\mathrm{AF} 472414^{\mathrm{c}}$ & This work \\
\hline G. lacinulata prox. Cumaná & Compressed/"lexlorii" & $\mathrm{AF} 468896$ & $\mathrm{AF} 472419$ & This work \\
\hline G. mammillaris Coro & Flattened/"textori" & AF 468900 & AF468916 & This work \\
\hline G. mammillaris São Paulo & Flattened/"textorii" & $\mathrm{AF} 468904$ & AF468914 & This work \\
\hline G. pacifica I.A.Abbott & Cylindrical/"verrucosa" & L26206 & - & Bird et al. (1992) \\
\hline G. pacifica & Cylindrical/"verrucosa" & - & U21341 & Goff et al. (1994) \\
\hline G. pauciramosa & Flattened/"henriquesiana" & $\mathrm{AF} 468887$ & ND & This work \\
\hline G. robusla Setchell & Compressed/"verrucosa" & - & U21340 & Goff et al. (1994) \\
\hline G. tenuistipitata C.F.Chang et B.M.Xia & Cvlindrical/"textorii" & - & U21343 & Goff et al. (1994) \\
\hline G. tepocensis prox. Santa Catarina & Compressed/"textorii" & AF468894 & AF472416 & This work \\
\hline G. tepocensis prox. $2 \mathrm{~B}$ & Compressed/"lextorii" & ND & $\mathrm{AF} 472417$ & This work \\
\hline G. tepocensis prox. $4 \mathrm{~B}$ & Compressed/"textorii" & ND & AF472418 & This work \\
\hline G. likvahiae & Cvlindrical-compressed/"textorii" & M33640 & - & Bird et al. (1990b) \\
\hline G. likvahiae & Cvlindrical-compressed/"lextori" & ND & AF468911 & This work \\
\hline Gracilaria sp. Araya & Compressed/"lextorii" & AF468898 & AF468918 & This work \\
\hline Gracilaria sp. Búzios & Flattened/"textorii" & AF468899 & AF468915 & This work \\
\hline Gracilaria sp. Ceará & Cvlindrical/"henriquesiana" & $\mathrm{AF} 468890$ & ND & This work \\
\hline Gracilaria sp. Elkhorn Slough & Cvlindrical/? & - & U21344 & Goff et al. (1994) \\
\hline Gracilaria sp. México & Cvlindrical/"verrucosa" & AF468886 & AF468906 & Goff et al. (1994) \\
\hline $\begin{array}{l}\text { Gl. oryzoides Setchell et H.L.Wilson in } \\
\text { H.L.Wilson }\end{array}$ & Parasitic/"chorda" & $\mathrm{U} 435557, \mathrm{U} 43555$ & U33139 & Goff et al. (1996) \\
\hline $\begin{array}{l}\text { Gip. lemaneiformis (Bory) E.Y.Dawson, } \\
\text { Acleto et Foldvik }\end{array}$ & Cylindrical/"chorda" & М54986, Х54263 & - & $\begin{array}{l}\text { Bhattacharya et al. } \\
\quad(1990)\end{array}$ \\
\hline Gp. lemaneiformis & Cvlindrical/"chorda" & - & U21243 & Goff et al. (1994) \\
\hline $\begin{array}{l}\text { Cip. longissima (S.G.Gmelin) } \\
\text { Steentoft, L.Irvine et Farnham }\end{array}$ & Cylindrical/"chorda" & L26208 & - & Bird et al. (1992) \\
\hline Gp. longissima & Crlindrical/"chorda" & - & U21339 & Goff et al. (1994) \\
\hline (ap. lenuifrons & Cvlindrical/"chorda" & AF468884 & ND & This work \\
\hline Gip. lenuifrons & Cvlindrical/"chorda" & - & U21246 & Goff et al. (1994) \\
\hline Gracilariopsis sp. China & Cvlindrical/"chorda" & - & U30348 & Goff et al. (1994) \\
\hline Gracilariopsis sp. Ecuador & Cylindrical/"chorda" & AF468885 & ND & This work \\
\hline Gracilariopsis sp. North Carolina & Cylindrical/"chorda" & L26256 & - & Bird et al. (1992) \\
\hline Gracilariopsis sp. North Carolina & Cvlindrical/"chorda" & - & U30347 & Goff et al. (1994) \\
\hline Gracilariopsis sp. Perú & Cylindrical/"chorda" & - & U21245 & Goff et al. (1994) \\
\hline M. obtusala (Labillardière) J.Agardh & Flattened/? & $\mathrm{L} .26215$ & - & Bird et al. (1992) \\
\hline
\end{tabular}

aTerminology from Yamamoto $(1978,1984)$.

'Male plants unknown.

'Only sequence of ITS

$\mathrm{ND}$, not determined.

matangia produced in conceptacles. Thus, the species bearing fused deep conceptacles ("henriquesiana" type; Table 3), segregated by some authors in the genus $\mathrm{Hy}$ dropuntia, were not phylogenetically separated from Gracilaria, based on the data presented in this work. These three main lineages of Gracilariaceae were al- ways retrieved as a monophyletic group in the Florideophycidae in phylogenetic analyses, including members of Acrochaetiales, Bonnemaisoniales, Halymeniales, Gigartinales, Ceramiales, and Plocamiales (A. Bellorin, data not shown). In MP, ML, and NJ with GTR distances with rate heterogeneity correction, the Curdiea/ 
TABLE 4. Percentage of sequence divergence in aligned SSU rDNA and ITS among the main taxonomic groups of Gracilariaceae.

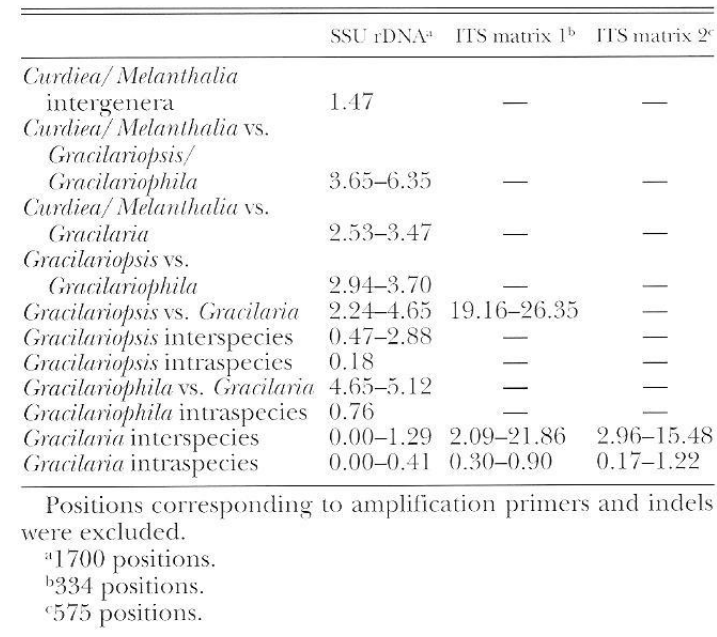

Melanthalia clade was retrieved as the first diverging lineage in the Gracilariaceae (Fig. 1). However, NJ inferences with LogDet/paralinear distances (data not shown) favored the Gracilariopsis/Gracilariophila clade as the first Gracilariaceae lineage.

In ML and MP the Gracilariopsis/Gracilariophila clade was separated into four lineages with strong bootstrap support at all nodes $(85 \%-100 \%)$ : (1) Gp. lemaneiformis as the first-diverging lineage, followed by the tricotomy of (2) Gracilariopsis sp. from Ecuador, (3) the Gracilariophila clade, and (4) the cluster of the Atlantic species of Gracilariopsis (Gp. tenuifrons, Gp. longissima, and Gracilariopsis sp. from North Carolina) (Fig. 1A). In the $\mathrm{NJ}$ trees, the Gracilariophila sequences were related to Gracilariopsis sp. Ecuador (bootstrap values $91 \%-92 \%$ ), and this clade was retrieved as a sister group of the Atlantic species clade (bootstrap values 100\%). Despite these variations, the fact remains that the parasite Gl. oryzoides has evolved from a Gracilariopsis host.

For the Gracilaria species studied, the ML and MP trees retrieved one initial polytomy (Fig. 1B) encompassing most sequences without any clear relationship among them. The following lineages with moderate to strong bootstrap support $(70 \%-100 \%)$ were resolved for Gracilaria in ML and MP: (1) the clade of $G$. caudata, G. comea, G. crassissima, and Gracilaria sp. Ceará (named collectively as "Atlantic cylindrical henriquesiana" lineage); (2) the clade of $G$. gracilis and $G$. pacifica ("gracilis" lineage); and (3) the clade of the two studied populations of $G$. domingensis. The trees produced by NJ were distinctive in some details. First, the sequences of G. chilensis and Gracilaria sp. México were separated from the rest of Gracilaria sequences. When LogDet/paralinear distances were used, the sequences of these species were united into a single clade (data not shown) but without significant bootstrap support (52\%). In NJ trees with GTR distances corrected for rate heterogeneity, G. chilensis and Gracilaria sp. México were not related.

ITS. Nineteen new complete ITS sequences (i.e. ITS1, 5.8S rDNA, and ITS2) and one ITS1 sequence were obtained for Gracilariaceae (Table 3). Size variation among ITS sequences was pronounced. The ITS1 sequences ranged from 105 to $521 \mathrm{bp}$, the $5.8 \mathrm{~S}$ rDNA genes from 140 to $163 \mathrm{bp}$, and the ITS2 from 562 to 778 bp. Sequence variation was also high, and positional homology was inferred with confidence only when moderately conserved motifs, presumably constrained by secondary structure (data not shown), were found. ITS sequence from Gracilaria sp. México was almost identical $(0.03 \%$ divergence) to that from Gracilaria sp. Elkhorn Slough studied by Goff et al. (1994) from California. Thus, these two samples are populations of an undescribed species from the northeastern Pacific often misidentified as G. pacifica. For G. tikvahiae, the ITS sequence we produced was almost identical $(0.003 \%$ divergence $)$ to that reported for the same population by Goff et al. (1994).

Gracilariopsis-Gracilaria divergences on ITS matrix 1 were $19.16 \%$ to $26.35 \%$ (Table 4 ). Interspecific divergence in Gracilaria ranges from $2.09 \%$ to $21.86 \%$ and intraspecific divergence from $0.30 \%$ to $0.90 \%$. ML, MP, and NJ with JC69 distances gave identical topologies. Gracilariopsis lemaneiformis is deeply separated from the Gracilaria clade (Fig. 2). Within Gracilaria, the following Pacific samples were grouped into a single clade with low bootstrap support $(65 \%-68 \%)$ : Gracilaria sp. México, Gracilaria sp. Elkhorn Slough, G. chilensis, and G. temuistipitata. All the other Gracilaria sequences are from Atlantic material, except for $G$. pacifica and G. robusta, and were retrieved in a single clade (bootstrap support 88\%-95\%). The "Atlantic cylindrical henriquesiana" lineage resolved from SSU rDNA sequences, represented by $G$. crassissima and sequences from three populations of $G$. caudata (only $G$. caudata from Península de Araya is shown in Fig. 2), was also supported in ITS sequence comparisons (82\%-89\% bootstrap values) and was retrieved as the first diverging lineage of the Atlantic taxa. The next diverging clade was the "gracilis lineage," encompassing G. gracilis, G. pacifica, and G. robusta, a fleshy species with "verrucosa" type spermatangia from the Pacific (bootstrap support $53 \%-80 \%$ ). After the separation of these two lineages, one polytomy was formed of the flattened or compressed Atlantic species, with low bootstrap support $(54 \%-57 \%)$. In this polytomy, G. tikvahiae from Canada was related to the Caribbean entity ( $)$ foliifera var. angustissima with strong bootstrap support (96\%-100\%), G. cervicornis was related to Gracilaria sp. Araya with low bootstrap support $(67 \%-69 \%)$, and $G$. mammillaris São Paulo was related to Gracilaria sp. Búzios, also with low bootstrap support $(52 \%-60 \%)$. The sequences of $G$. domingensis and $G$. mammillaris Coro were not specifically related to any other flattened or compressed Gracilaria. 


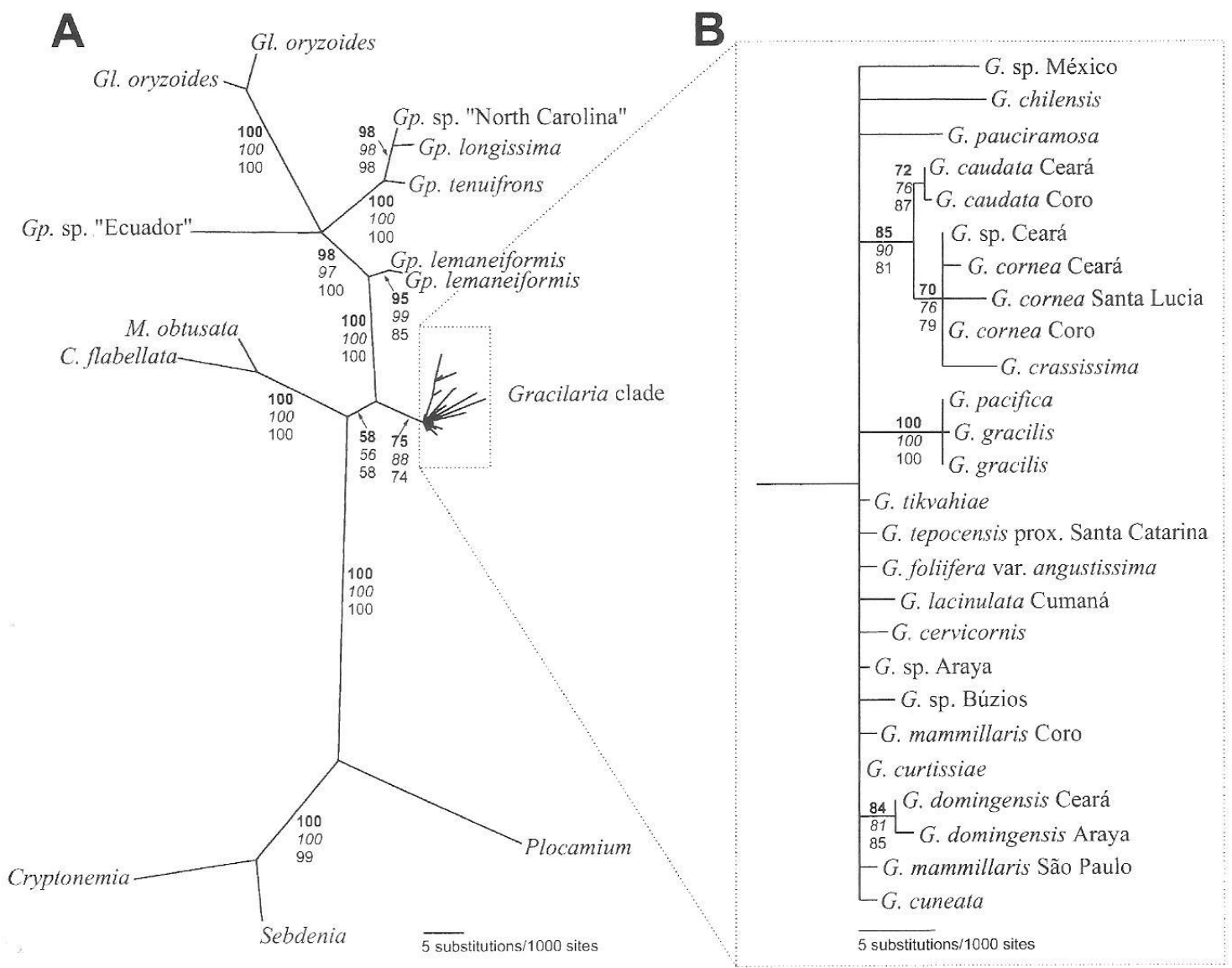

FIG. 1. Bootstrap 50\% majoritv-rule consensus ML tree for SSU rDNA sequences of Gracilariaceae. (A) Gracilariaceae plus outgroup sequences. (B) Detail of Gracilaria clade. ML calculations were made under the JC69. Numbers at nodes denote bootstrap values for ML (first row in bold typeface, 200 replicates), MP (second row in italics, 2000 replicates), and NJ (third row in normal typeface, 2000 replicates). Arrows indicate the position of bootstrap values when they do not fit on the branches.

For ITS matrix 2, the interspecific divergences in Gracilaria were $2.96 \%$ to $15.48 \%$ and intraspecific divergences were $0.17 \%$ to $1.22 \%$ (Table 4 ). The ML tree had identical topology to that retrieved under MP. NJ trees with K2P with rate-heterogeneity correction, LogDet, and GTR with rate-heterogeneity-correction distances were distinct in some details. All phylogenetic inferences showed that G. tikvahiae from Canada, G. tepocensis proximate from South America, and $G$. lacinulala proximate and G. foliifera var. anguslissima from the Caribbean were related species (bootstrap support $96 \%-97 \%$ ) (Fig. 3), forming the "tikvahiae" lineage. All these species are compressed to flattened forms (sometimes cylindrical), with "textorii" type spermatangia and very similar morphology. In this lineage, the temperate and subtropical isolates $G$. tikvahiae and G. Lepocensis proximate were closely related. Relationships among the tropical species, (i. lacinulata proximate from the Caribbean and north- eastern Brazil (as shown by ITSl sequence of $G$. lacinulata proximate Bahia) and G. foliifera var. angustissima from the Caribbean were supported by low to moderate bootstrap values $(56 \%-73 \%)$. The compressed species G. cervicomis and Cracilaria sp. Araya were grouped again with moderate to strong support $(64 \%-81 \%)$ in all phylogenetic analyses. This clade, named the "cervicomis" lineage, was related in ML and MP with low bootstrap support $(60 \%-66 \%)$ to G. domingensis, a morphologically very plastic species, usually flattened, with "verrucosa" or "henriquesiana" type spermatangia. However, the sequences of flattened ribbon-like species, G. mammillaris São Paulo from Brazil, G. mammillaris Coro from Venezuela, and Gracilaria sp. Búzios from Brazil, were not related to any group in ML, MP, and NJ. Although ITSI and ITS2 sequences were compared for a number of species of Gracilariopsis, no phylogenetic signal emerged from the multiple alignments attempted. 


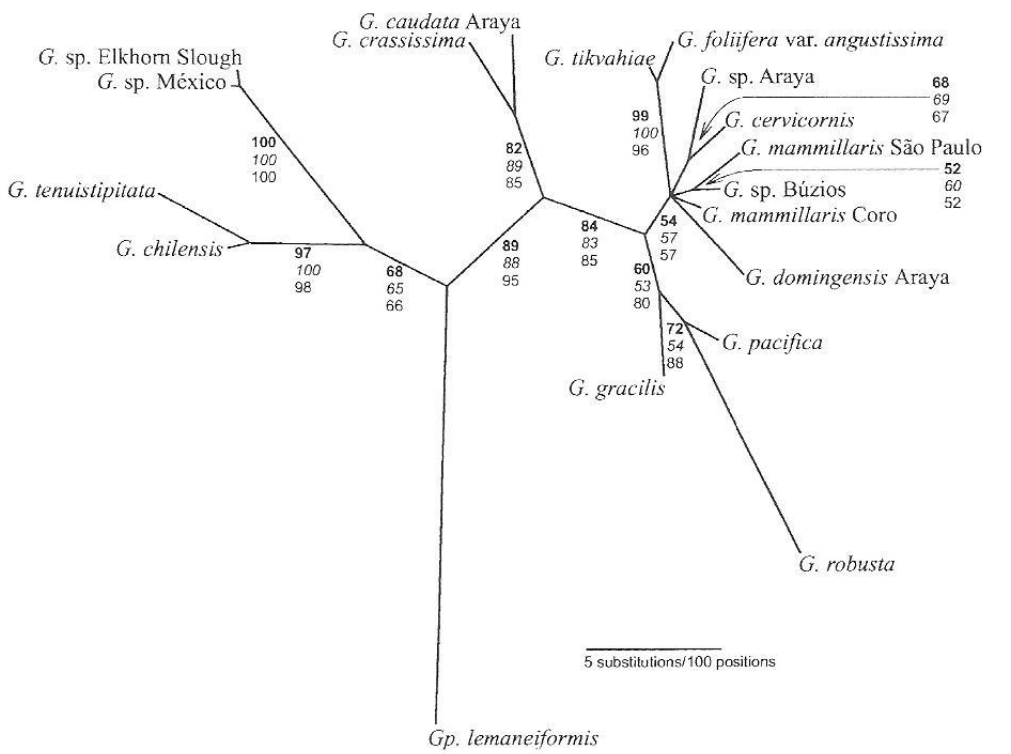

FIG. 2. Bootstrap $50 \%$ majority-rule consensus ML tree for IT'S matrix 1. ML calculations were made under the JC69. Numbers at nodes denote bootstrap values for ML (first row in bold typeface, 1000 replicates), MP (second row in italics, 2000 replicates), and NJ (third row in normal typeface, 2000 replicates). Arrows indicate the position of bootstrap values when they do not fit on the branches.

We propose a new combination: Gracilaria pauciramosa (N. Rodríguez Ríos) Bellorin, M. C. Oliveira et E. C. Oliveira comb. nov.

Basionym: Polycavernosa pauciramosa N. Rodríguez Ríos 1989 (Ernstia 56:1-7, fig. 1-3).

Homotypic synonym: Hydropuntia pauciramosa (N. Rodríguez Ríos) N. Rodríguez Ríos 1991 (Emstia 1:39).

\section{DISCUSSION}

Suprageneric and generic lineages of Gracilariaceae The sequence comparisons of ribosomal genes have shown that Gracilariaceae is a monophyletic clade within the Florideophycideae and has three main lineages, already reported in previous studies (Bird et al. 1992, 1994). In phylogenetic analyses, the additional sequences of Gracilariopsis and Gracilaria produced in this work always grouped unequivocally with their congeners, preserving these two lineages. However, the sequences of species bearing "henriquesiana" type spermatangia (one of the anatomical features used to segregate Hydropuntia species by the enthusiasts of this genus) were not always grouped, that is, G. paucir-

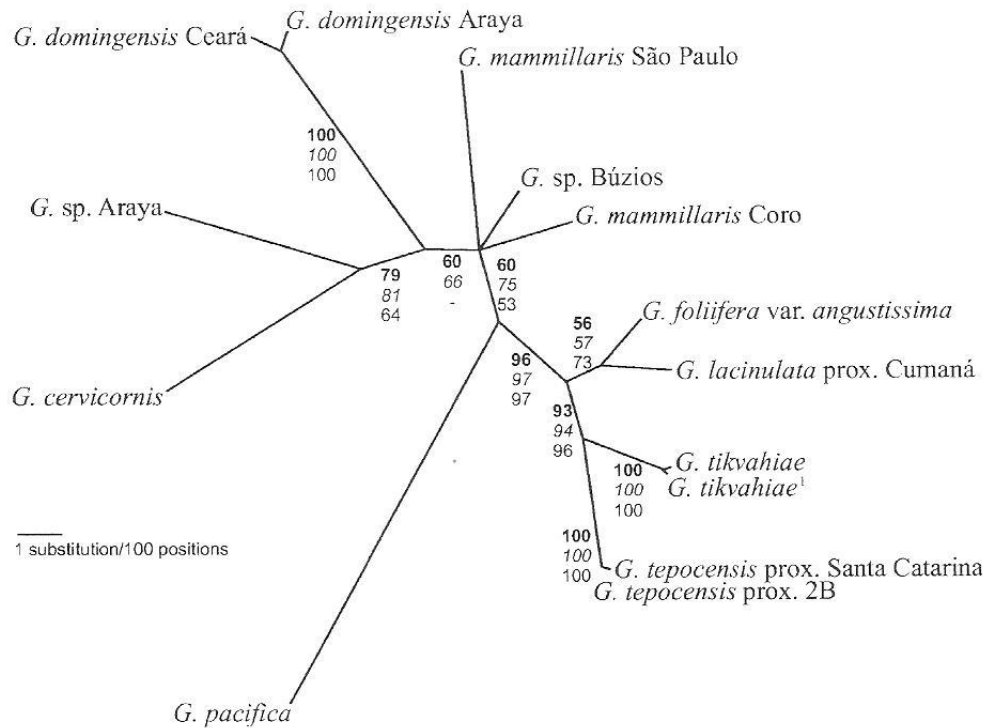

FIc. 3. Bootstrap $50 \%$ majority-rule consensus ML tree for ITS matrix 2. ML calculations were made under the JC69. The bootstrapped NJ unrooted tree using $\mathrm{K} 2 \mathrm{P}$ distances corrected for rate heterogeneity differed in not having the single node for the $G$. domingensis clade and the $G$, cervicomis-Gracilaria sp. Arava clade. Numbers at nodes denote bootstrap values for ML (first row in bold typeface, 1000 replicates), MP (second row in italics, 2000 replicates), and NJ (third row in normal typeface, 2000 replicates). ${ }^{1}$ Sequence of ITS from ( $x$. likvahiae produced by Goff et al. (1994, not available in GenBank).

G. pacifica 
amosa and $G$. domingensis, were not related to the rest of the "henriquesiana" species studied or to each other. Moreover, all these sequences were clearly included within the Gracilaria clade. Another main criterion used to segregate Hydropuntia from Gracilaria, that is, the production of tubular nutritive cells restricted to the floor of cystocarp (Chang and Xia 1963, Fredericq and Hommersand 1990a), has been repeatedly shown to be equivocal (cf. Bird 1995). Abbott et al. (1991), arguing against Hydropuntia, transferred to Gracilaric the Hydropuntia species known at that time, including the type species, although it is not clear if they studied the type. Thus, the generic status of Hydropuntia is doubtful in light of both morphological and molecular data, although sequences of the generitype species, H. urvillei Montagne from Torres Strait, Australia, are necessary to propose the formal synonymy between Gracilaria and Hydropuntia on molecular grounds.

As circumscribed in this work, Gracilariaceae includes four nomparasitic genera, Curdiea, Melanthalia, Gracilariopsis, and Gracilaria, although their discrimination is still strongly based on morphology rather than evolutionary information. For example, evolutionary divergence between SSU rDNA sequences of Curdiea and Melanthalia is on the same order of magnitude as among some species of Gracilaria (Table 4). On anatomical grounds, Curdiea and Melanthalia are closely related (Fredericq and Hommersand 1990a,b), both having sparse secondary pit connections in vegetative tissues, nemathecial production of tetrasporangia, and cystocarps lacking tubular nutritive cells, among other features. These two genera have remained distinct, based mainly on gross morphology. We suspect that if other species from these genera are included in molecular comparisons, the boundaries of Curdiea and Melanthalia may be obliterated. On the other hand, Gracilariopsis is a noteworthy example of incongruity between morphology-based taxonomy and molecular data. Gracilariopsis species are morphologically conservative: All have cylindrical thalli and superficial production of spermatangia, and cystocarps lack tubular nutritive cells, among other distinctive features (Fredericq and Hommersand 1989b, Bird 1995). But this homogeneity contrasts with a high degree of evolutionary divergence in SSU rDNA sequences (Table 4). The divergence levels within Gracilariopsis may be as large as divergences between Cryptonemia and Sebdenia, two genera of Halymeniales selected as outgroup taxa (Fig. 1A). Moreover, at least three strongly divergent lineages ( $G p$. lemaneiformis, isolates from the Atlantic, and the unidentified isolate from Ecuador) exist within Gracilariopsis. Finally, if we consider the evolutionary position of parasitic Gl. oryzoides, Gracilariopsis is a paraphyletic assemblage.

One remarkable result of the new set of SSU rDNA sequences compared in this work is the order of divergence within the three main lineages of Gracilariaceae. Gracilariopsis was retrieved as the first evolving lineage of Gracilariaceae by Bird et al. (1992, 1994), followed by the sister groups Curdiea/Melanthalia and
Gracilaria. Our phylogenetic inferences, based on character-by-character comparisons (ML and MP) and some distance-based analyses, instead resolve the Curdiea/Melanthatia clade as the first diverging lineage of Gracilariaceae, with Gracilariopsis as a sister group of Gracilaria (low bootstrap values for this node). Because Gracilariopsis species appear to have faster mutation fixation (revealed by the high intraspecific differences; Bird et al. 1994, Goff et al. 1994), the placement of Gracilariopsis/Gracilariophila clade as the first diverging lineage could be a longbranch attraction effect. From a morphological perspective, the hypothesis that the Curdiea/Melanthalia lineage divergence first appears likely because the nemathecial disposition of tetrasporangia and the delaved formation of secondary pit connections in vegetative tissues, not shared by other free-living genera of Gracilariaceae, are regarded as primitive features (Fredericq and Hommersand 1990b). Phylogenetic analysis of the $r b c \mathrm{~L}$ gene (M. Hommersand, personal communication) produced trees indicating that the Curdiea and Melanthalia lineage was the first divergence in the family.

Infrageneric lineages of Gracilariopsis. SSU rDNA sequence comparisons in both Gracilariopsis and Gracilaria indicate the presence of discrete infrageneric lineages, although there is not enough resolving power in these sequences when closely related Gracilaria species are compared. Three lineages of Gracilariopsis were deeply separated in phylogenetic inferences. Gracilariopsis lemaneiformis, the generitype species from the Pacific, diverged first in all the analyses, followed by the Atlantic species cluster and the material from Ecuador. Besides the entities studied in this work, no other Gracilariopsis species are known from the Atlantic. Hereafter, we can consider an Indo-Pacific origin for Gracilariopsis as a working hypothesis, with the Atlantic lineage considered as a derived group. However, there are few currently accepted species of Gracilariopsis (six in Bird 1995). This relatively low specific diversity, as compared with the sister group Gracilaria (nearly $100 \mathrm{rec}-$ ognized species, Oliveira and Plastino 1994), leads us to suspect that this number may be increased if more critical studies are undertaken in the Indo-Pacific. Species recognition within Gracilariopsis is difficult because distinctive morphological features are few or hard to recognize (especially anatomic details of the male sorus) and because sexually reproductive specimens are apparently absent in many populations. We believe that the utilization of hybridization and molecular sequencing techniques on widespread samples will reveal cryptic species of Gracilariopsis. Evidence supporting this conclusion is the recent recognition of several new taxa: 1) Gp. longissima, repeatedly mistaken as $G$. gracilis in Britain; 2) the distinct strains from North Carolina, Peru, and China studied by Bird et al. (1992) and Goff et al. (1994), misnamed as Gp. lemaneiformis; and 3) the material from Ecuador studied here. All these entities are possibly undescribed species that need further taxonomic clarification. The 
evolutionary relationships among some samples of Gracilariopsis and the parasite Gl. oryzoides are also striking. These relationships were studied by Goff et al. (1996), but the taxonomic implications of the paraphyletic nature of Gracilariopsis were not discussed. We strongly suggest that sequences from other species of Gracilariophila and Gracilariopsis should be studied, particularly those species of Gracilariophila that parasitize Gracilaria and not Gracilariopsis. The other parasitic genus, Congracilaria H. Yamamoto (1986), found on Gracilaria, has typical Gracilaria reproductive features (i.e. tubular nutritive cells produced by the gonimoblasts and spermatangia produced in conceptacles), expected for an adelphoparasite. However, these relationships should be addressed using molecular tools.

Infrageneric lineages of Gracilaria. Despite the overall low phylogenetic signal in SSU rDNA sequences in Gracilaria, at least two infrageneric lineages were consistently revealed by these sequences, the "Atlantic cylindrical henriquesiana" and the "gracilis" lineages. ITS sequences were more informative at the species level within Gracilaria, confirming the two previously mentioned infrageneric lineages and retrieving the additional "ikvahiae" and "cervicomis" lineages. The main divergence within Gracilaria shown in Figure 2 is between the Pacific (except G. pacifica and G. robusla) and Atlantic populations. In NJ inferences with LogDet/paralinear distances, the Pacific clade had moderate bootstrap support $(84 \%)$. These results suggest that the primordial divergences in Gracilaria are related more to geographic isolation than to broad morphological differences, such as have been used to delineate infrageneric taxa. The Pacific clade includes G. chilensis and G. tenuistipitata, which appear to be closely related entities, both slender and terete with "lextoriz" type spermatangial configuration despite their different respective habitats of cold and warm water. They are joined in the Pacific clade by an undescribed species from Baja California and Elkhorn Slough, which also has a stringy thallus, although with "verrucosa" type spermatangia. Unfortunately, there are no sequences from flattened Pacific or Indian material to test if these species will group with the cylindrical Pacific ones.

Based on ITS sequences, the first diverging group in the Atlantic clade, including G. pacifica and ( $r$. robusta, is the "Atlantic cylindrical henriquesiana" lineage, which encompasses the more "promising commercial agarophytes" from tropical Atlantic: G. caudata, G. cornea, G. crassissima, and an undescribed Gracilaria species from northeastern Brazil. All these species are from the tropical Atlantic (except G. caudata, which reaches subtropical waters), have cylindrical thalli (except G. crassissima), possess deep compound spermatangial conceptacles, have a fusion cell that is highly dissected and ramified, and have pseudo-parenchymatous sporogenous tissue present in cystocarps (cf. Fredericq and Norris 1985, Plastino and Oliveira 1997). Fredericq and Norris (1985), studying $G$. cornea and G. crassissima from the Caribbean, used these features to argue for retaining Hydropuntia (as
Polycavernosa). However, their taxonomic conclusions were not followed by many phycologists because they did not study the generitype species and because other authors (Bird and McLachlan 1984) consider that simple versus compound deep male conceptacles may be just a continuous gradation between extremes. For example, species that normally form simple male conceptacles may also form compound ones in some circumstances. We observed this last situation in the extremely morphologically variable Gracilaria domingensis. We also found that male plants of some populations of $G$. caudata form consistently "verrucosa" type spermatangia and that in other populations the spermatangia are produced in "henriquesiana" type conceptacles. The history of the genus Polycavernosa has been tortuous, and the last treatment of Polycavernosa (as Hydropuntia) was the subgeneric rank formally proposed by Tseng and Xia (1999), following a previous pattern established by Yamamoto (1984). However, as we have shown, "henriquesiana" type spermatangial conceptacles have appeared independently in several lineages of Gracilaria species. Therefore, taxonomic discrimination based uniquely on this feature is not phylogenetically coherent. Another character used to segregate Polycavernosa/Hydropuntia species from Gracilaria (i.e. the presence of tubular nutritive cells connecting gonimoblasts and pericarp only at the floor of the cystocarps) is also not exclusive to this group (Bird 1995). Although an "Atlantic cylindrical henriquesiana" lineage has emerged here despite the inconsistency of the morphological discriminants, it cannot be used to support the subgenus Polycavernosa/ Hydropuntia as it thus far does not include the type species. These and other Gracilaria species will have to be sequenced before a formal subgeneric taxon can be proposed for the "Atlantic cylindrical henriquesiana" lineage. In particular, additional sequences from Polycavernosa type species and from other Indo-Pacific taxa, as well as $G$. damaecornis J. Agardh from the Caribbean, a cylindrical species with many similarities to $G$. cornea, should be analyzed before any taxonomic conclusions can be reached. Further, relationships with G. pauciramosa, a Caribbean flattened species with "henriquesiana" type spermatangia (Rodríguez de Ríos 1989, 1991) that was not related to any infrageneric lineage, will require resolution. In distance analyses of SSU rDNA, G. pauciramosa diverged before all other Gracilaria isolates from the Atlantic.

After the divergence of the "Atlantic cylindrical henriquesiana" lineage, there is a separation of the "gracilis" lineage and the cluster formed by the flattened and compressed Atlantic species, as revealed in ITS analyses. Gracilaria gracilis and (r. pacifica are very similar morphologically. Both are terete and slender, with deep and simple spermatangial conceptacles and the same general pattern of gonimoblast anatomy (i.e. the typical features of the " $G$. verrucos $a$ " complex). By contrast, G. robusta is a fleshy species with compressed lower branches (Abbott and Hollenberg 1976), which does not satisfy the concept of the "G. verrucosa" complex, although its male conceptacles are also deep 
and simple. The "gracilis" lineage is noteworthy because it includes both Atlantic and Pacific species and likely will also include other Pacific and Indian representatives of the "G. verrucosa" complex. Gracilaria gracilis is apparently a primarily Atlantic entity, with isolated populations in Europe (Atlantic and Mediterranean), Argentina, and Namibia. The sample ascribed to G. gracilis from Japan may be another distinct but related species (Rice and Bird 1990, Wattier et al. 1997). Thus, as G. gracilis diverged first in this group from a node grouping Atlantic species, the most parsimonious explanation is that G. pacifica and G. robusta are taxa that evolved from an Atlantic ancestor. The secondary structure model for ITS2 predicted for these three species show that they are closely related.

In the cluster formed by compressed and flattened species from the Atlantic, the "tikvahiae" lineage was the most consistently retrieved clade. Initially, we considered that these entities might be populations of a single widespread and very plastic species, with wide tolerance ranges for environmental conditions. However, our molecular comparisons clearly demonstrate that these populations present enough molecular divergence to suggest that they are reproductively isolated and differ at the specific level. Guiry and Freamhainn (1985), through hybridization studies, showed that the North American populations identified as $G$. foliifera or G. foliifera var. angustissima are conspecific with $G$. tikvahiae from Canada, which led them to infer that the same is valid for the Caribbean populations and by extension for the South American ones as well. Phylogenetic inferences showed that subtropical and temperate representatives ( $G$. likvahiae and $G$. tepocensis proximate) of this lineage are closely related but distinct from tropical ones $(G$. lacinulata and a strain tentatively named as $G$. foliifera var. angustissima). Sequences from species morphologically similar to this group, such as G. multipartita (Clemente) Harvev from Europe and G. foliifera (Forsskål) Børgesen from the Indo-Pacific, should be included to clarify their relationships.

The tropical compressed species G. cervicornis and Gracilaria sp. Araya are closely related. These species are quite different in gross morphology but similar in reproductive anatomy. Both are widespread in the tropical Atlantic. Although G. cervicornis has been well characterized morphologically (Oliveira et al. 1983), we were unable to attribute a correct name to the entity named here as Gracilaria sp. Arava. In Venezuela Rodríguez de Ríos (1986) named this species G. textorii (Suringar) De Toni. According to this last author, $\mathrm{S}$. Fredericq suggested that this material could be the former Plocaria flabelliformis $\mathrm{P}$. Crouan et $\mathrm{H}$. Crouan in Schramm et Mazé (N. Rodríguez, personal communication). Kapraun (1993) adopted the combination $G$. flabelliformis for his collection from Isla de Margarita in Venezuela. The identity of this material will only be clarified with a critical revision of the species proposed by the Crouan brothers, including crossability tests and molecular comparisons on material from the type locality.
The studied populations of $G$. domingensis were not closely related to other flattened species in the alignment. Most of the ribbon-like species, namely G. cur lissiae, G. mammillaris Coro, G. mammillaris São Paulo, G. cuneala, and an apparently undescribed population from Búzios, Brazil, have similar if not identical SSU rDNA sequences, and ITS sequence comparisons did not resolve their evolutionary relationships. The morphological boundaries among these species are not well established, and we suggest that another region of the genome should be studied, together with critical morphological revisions, to elucidate their systematics and phylogeny.

Species complexes and conclusion. It has long been recognized that distinct gracilarioid species are morphologically so similar that they have been treated as a single taxonomic entity. The " $G$. verrucosa" complex is the best example of this conundrum (Bird and Rice 1990, Bird 1995). Our experience indicates other morphological complexes of gracilarioid algae in the Atlantic, as is the case of the "tikvahiae" lineage as defined here, which encompass related but distinct species. Other species complexes include entities that are not necessarily related, for example, the ribbon-like species complex (the two distinct entities named as (r. mammillaris, G. cuneala, G. pauciramosa, Gracilaria sp. Búzios, among others). Unfortunately, type material of many validly published names that could be applied in these complexes are so fragmentary and usually without spermatangial or cystocarpic specimens that comparison with contemporary collections is very difficult.

In conclusion, although substantial progress has been attained in the last two decades, a reliable recognition of Gracilaria species is still an arduous and expensive task. In many situations, critical inspection of morphology will reveal only the "group" of species to which material may be assigned. Therefore, hybridization tests and molecular comparisons are necessary for positive identification. To arrive at a validly published name (if there is one), we need to examine many fragmentary type collections often, and it will be necessary, where possible, to include these type samples in DNA analyses.

Supported by FAPESP, Brazil. A. M. B. acknowledges CONICIT, Venezuela, for a Ph.D. scholarship. M. C. O. and E. C. O. acknowledge CNPq, Brazil. We are grateful to D. J. Garbary, D. Teixeira, E. M. Plastino, and J. M. Guzmán for specimen collections, to Maria Cristina Costa for technical assistance, and to E. M. Plastino for manuscript review. A special thank you is owed to Carolyn J. Bird for careful revision of the manuscript and many valuable suggestions.

Abbott, I. A. \& Hollenberg G. J. 1976. Marine Algae of California. Stanford University Press, Stanford, $827 \mathrm{pp}$.

Abbott, I. A., Zhang. J. \& Xia, B. 1991. Gracilaria mixla sp. nov. \& other western Pacific species of the renus (Rhodophyta: Gracilariaceae). Pac. Sci. 45:12-27.

Baldwin, B. G., Sanderson, M. J., Porter, J. M., Wojciechowski, M. F. Campbell, C. S. \& Donoghue, M. J. 1995. The ITS region of nuclear ribosomal DNA: a valuable source of evidence of angiosperm phylogeny. Ann. Miss. Bot. Gard. 82:247-77. 
Bhattacharya, D., Elwood, H. J., Goff, L. J. \& Sogin, M. L.. 1990. Phylogeny of Gracilaria lemaneiformis (Rhodophyta) based on sequence analysis of its small subunit ribosomal RNA coding region. J. Phycol. 26:181-6.

Bird, C. J. 1995. A review of recent taxonomic concepts and development in the Gracilariaccae (Rhodophyta). J. Appl. Phycol. $7: 255-67$.

Bird, C. J., Helleur, R. J., Hayes, E. R. \& McLachlan, J. 1987. Analytical purolysis as a taxonomic tool in Gracilaria (Rhodophyta, Gigartinales). Hydrobiologia 151/152:207-11.

Bird, C. J. \& McLachlan, J. 1984. Taxonomy of Gracilaria evaluation of some aspect of reproductive structure. Hydrobiologia 116/117:41-6.

Bird, C. J., McLachlan, J. \& Oliveira, E. C. 1986. Gracilaria chilensis sp. nov. (Rhodophyta, Gigartinales) from Pacific South America. Can. J. Bot. 64:2928-34.

Bird, C. J., Nelson, W. A. Rice, E. L., Rvan, K. G. \& Villemur, R. 1990a. A critical comparison of Gracilaria chilensis and G. sordida (Rhodophyta, Gracilariales). J. Appl. Phycol. 2:375-82.

Bird, C. J., Ragan, M. A., Critchley, A. T., Rice, L. L. \& Gutell, R. R. 1994. Molecular relationships among the Gracilariaceae (Rhodophyta): further observations on some undetermined species. Eur. J. Phycol. 29:195-202.

Bird, C. J. \& Rice, E. L. 1990. Recent approaches to the taxonomy of the Gracilariaceae (Gracilariales, Rhodophyta) and the Gracilaria vernucosa problem. Hydrobiologia 204/205:111-8.

Bird, C. J., Rice, E. L., Murphy, C. A., Liu, Q. Y. \& Ragan, M. A. 1990b. Nucleotide sequences of $18 \mathrm{~S}$ ribosomal RNA genes from the red algae Gracilaria tikvahiue McLachlan, Gracilaria verrucosa (Hudson) Papenfuss and Gracilariopsis sp. Nucl. Acids Res. 18:4023-4

Bird, C. J., Rice, E. L., Murphy, C. A. \& Ragan, M. A. 1992. Phylogenetic relationships in the Gracilariales (Rhodophyta) as determined by $18 \mathrm{~S}$ rDNA sequences. Phycologia 31:510-22.

Bird, C. J., van der Meer, J. P. \& McLachlan, J. 1982. A comment on Gracilaria vermecosa (Huds.) Papenf. (Rhodophyceae, Gigartinales).J. Mar. Biol. Assoc. U.K. 62:453-9.

Brodsky, L. I., Ivanov, V. V., Kalaidzidis, Y. L., Leontovich, A. M., Nikolaev, V. K., Feranchuk, S. I. \& Drachev, V. A. 1995. GeneBeeNET: internet-based server for analyzing biopolymers structure Biochemistr? 60:923-8.

Brodsky, L. I., Vasiliev, A. V., Kalaidzidis, Y. L., Osipor, Y. S., Tatuzov, R. L. \& Feranchuk, S. I. 1992. GeneBee: the program package for biopolymer structure analysis. Dimacs 8:127-39.

Cabot, F. L. \& Beckenbach, A. T. 1989. Simultaneous editing of multiple nucleic acid and protein sequences with ESEE. Comput. Appl. Biosci. 5:233-4.

Chang, C. F. \& Xia, B.-M. 1963. Polycavernosa, a new genus of the Gracilariaceae. Stud. Mar. Sinica 3:119-26.

Critchley, A. T. \& Ohno, M. 1998. Seaweed Resources of the World. Japan International Cooperation Agency, Nagai, Japan, 431 pp.

Dawson, F. Y 1949. Studies of northeast Pacific Gracilariaceae. Atlan Hancock Found. Publs. Occ. Pap. 7:1-105.

Destombe, C. \& Douglas, S. E. 1991. Rubisco spacer sequence divergence in the rhodophyte alga Gracilaria verrucosa and closely related species. Curr. Genet. 19:395-8.

Felsenstein, J. 1985. Confidence limits on phylogenies: an approach using the bootstrap. Evolution 39:783-91.

Fredericq, S. \& Hommersand, M. H. 1989a. Proposal of the Gracilariales ord. nov. (Rhodophyta) based on an analysis of the reproductive development of Gracilaria verrucosa. J. Phycol. 25 213-27.

Fredericq, S. \& Hommersand, M. H. 1989b. Comparative morphol ogy and taxonomic status of Gracilariopsis (Gracilariales, Rhodophyta). J. Phycol. 25:228-41.

Fredericq, S. \& Hommersand, M. H. 1990a. Diagnoses and key to the genera of the Gracilariaceae (Gracilariales, Rhodophyta) Hydrobiologia 204/205:173-8.

Fredericq, S. \& Hommersand, M. H. 1990b. Taxonomy of Melanthalia oblusata var. abscissa and its placement in the Gracilariales. Cryptog. Bot. 2:4-11.

Fredericq, S. \& Norris, J. N. 1985. Morphological studies on some tropical species of Gracilaria Grev. (Gracilariaceae, Rhodophyta): taxonomic concepts based on reproductive morphol- ogy, In Abbott, L. A. \& Norris, J. N. [Eds.] Taxomomy of Economic Seaweeds. California Sea Grant College Program, La Jolla, California, pp. 137-5.5.

Freshwater, D. W., Fredericq, S., Butler, B. S., Hommersand, M. H. \&. Chase, M. W. 1994. A gene phylogeny of the red algac (Rhodophyta) based on plastid-encoded rbcL. Proc. Nat. Acad. Sci. USA 91:7281-5.

Gargiulo, G. M., De Masi, F. \& Tripodi, G. 1992. Morphology, reproduction and taxonomy of the Mediterranean species of Gracilaria (Gracilariales, Rhodophyta). Phycologia 31:53-80.

Godin, J., Destombe, C. \& Maggs, C. A. 1993. Unusual chromosome number of Gracilaria vernucosa (Gracilariales. Rhodophyta) in the Cape Gris-Ne\% area, northern France. Phycologia 32:291-4.

Golf, L. J. \& Coleman, A. W. 1988. The use of plastid DNA restriction endonuclease patterns in delineating red algal species and populations. J. Phycol. 24:357-68.

Goff, L. J., Moon. D. A. \& Coleman, A. W. 1994. Molecular delineation of species and species relationships in the red algal agarophytes Gracilariopsis and Gracilaria (Gracilariales). J. Phycol. 30:521-37.

Goff, L. J., Moon, D. A., Nyvall, P., Stache, B., Mangin, K. \& Zuccarello, G. 1996. The evolution of parasitism in the red algae: molecular comparisons of adelphoparasites and their hosts. $J$. Phycol. 32:297-312.

Greville. R. K. 1830. Aloae Britannicae. MacLachlan \& Stewart, Edinburgh, and Baldwin \& Cradock, London, 218 pp.

Guiry, M. D. \& Freamhainn, M. T. 1985. Biosystematics of Gracilarid foliifera (Gigartinales, Rhodophyta). Nord. J. Bol. 5:629-37.

Gurgel, C. F. D.. Fredericq, S. \& Norris, J. N. 1999. Characterization and biogeographic affinities of the red algal genus, Gracilaria (Gracilariales), in the Gulf of México. J. Phycol. 35(suppl.):13.

Harvey, W. H. 1855. Short characters of some new genera and species of algae discovered on the coast of the colony of Victoria. Australia. Ann. Mag. Nat. Hist. (London) 5:332-6.

Hershkovitz, M. A. \& Icwis, L. A. 1996. Deep-level diagnostic value of the rDNA-ITS region. Mol. Biol. Evol. 13:1276-95.

Hillis, D. M. \& Bull, J. J. 1993. An empirical test of bootstrapping as a method for assessing confidence in phylogenetic analysis. Syst. Biol. 42:182-92.

Jukes, T. H. \& Cantor, C. R. 1969. Evolution of protein molecules In Munro. H. N. [Ed.] Mammalian Protein Metabolism. Academic Press, New York, pp. 21-132.

Kapraun, D. F. 1993. Karyology and cytophotometric estimation of nuclear DNA content variation in Gracilaria, Gracilariopsis and $\mathrm{Hy}_{\mathrm{y}}$ dropuntia (Gracilariales, Rhodophyta). Eur. J. Phycol. 28:253-60.

Kimura, M. 1980. A simple method for estimating evolutionary rate of base substitutions through comparative studies of nucleotide sequences. J. Mol. Evol. 16:111-20.

Lockhart, P. J., Steel, M. A., Hendy, M. D. \& Penny, D. 1994. Recovering evolutionary trees under a more realistic model of se quence evolution. Mol. Biol. Livol. 11:605-12.

Mathews, D. H., Sabina, J., Zuker, M. \& Turner, D. H. 1999. Expanded sequence dependence of thermodvnamic parameters improves prediction of RNA secondary strucure. J. Mol. Biol. 288:911-40.

McLachlan, J., van der Meer, J. P. \& Bird, N. L. 1977. Chromosome numbers of Gracilaria foliefera and Gracilaria sp. (Rhodophyta) and attempted hybridizations. J. Mar. Biol. Assoc. U.K. 57:1137-41.

Montagne, J. F. C. 1842. Prodromus generum, specierumque phyceanum novarum. Apub Gide, Paris, $16 \mathrm{pp}$

Montagne, J. F. C. 1843. Quatrième centurie de plantes cellulaires... (dec. 8-10). Ann. Sci. Nat. Bot. Sér. 2, 20:352-79.

Oliveira, E. C., Alveal, K. \& Anderson, R. J. 2000. Mariculture of the agar-producing gracilarioid red algae. Rev. Fish. Sci. 8:345-77,

Oliveira, E. C. Bird, C. J. \& McLachlan, J. 1983. The genus Gracilaria Greville (Rhodophyta, Gigartinales) in the Western Atlantic. (G. domingensis Sond. cx Kütz., G. cervicomis (Turn.) J Ag. \& G. ferox J. Ag. Can.J. Bot. 61:2999-3008.

Oliveira, E. C. \&. Plastino, E. M. 1994. Gracilariaceac. In Akatsuka, I. [Ed.] Biology of Economic Algae. SPB Academic Publishing by, The Hague, The Netherlands, pp. 185-226.

Plastino, E. M. \& Oliveira, E. C. 1988. Sterility barriers among species of Gracilaria (Rhodophyta, Gigartinales) from the São Paulo littoral, Brazil. Br. Phycol. J. 23:267-71. 
Plastino, E. M. \& Oliveira, E. C. 1997. Gracilaria caudala J. Agardh (Gracilariales, Rhodophyta): restoring an old name for a common western Atlantic alga. Phycologia 36:225-32

Posada, D. \& Crandall, K. A. 1998. MODELTEST: testing the model of DNA substitution. Bioinformatics 14:817-8

Ragan, M. A. Bird, C. J., Rice, E. L., Gutell, R. R., Murphy, C. A. \& Singh, R. K. 1994. A molecular phylogeny of the marine red algae (Rhodophyta) based on the nuclear small-subunit rRNA gene. Proc. Nat. Acad. Sci. USA 91:7276-80.

Rice, E. L. \& Bird, C. J. 1990. Relationships among geographically distant populations of Gracilaria vernucosa (Gracilariales, Rhodophyta) and related species. Phycologia 29:501-10.

Rodríguez de Ríos, N. 1986. Gracilaria textorii (Suringar) De Toni, dríguez de Ríos, N. 1986. Gracilaria textorii (Suringar) De Toni,
una nueva adición a la flora de algas marinas de Venezuela (Rhodophyta, Gracilariaceac). Emstia 38:1-11.

Rodrígucz de Ríos, N. 1989. Una especie nueva de Polycavernosa Chang et Xia, del Mar Caribe (Rhodophyta, Gracilariales). Ermstia 56:1-7.

Rodríguez de Ríos, N. 1991. Hydropuntia pauciramosa (Rodríguc\%) Rodríguez, combinación nueva (Rhodophyta, Gracilariales). Emstia 1:39.

Rodríguez, F. I., Oliver, L., Marín, A. \& Medina, J. R. 1990. The general stochastic model of nucleotide substitution. J. Theor. Biol. $142: 485-501$.

Saunders, G. W. \& Kraft, G. T. 1997. A molecular perspective on red algal evolution: focus on the Florideophycidae. In Bhattacharva, D. [Ed.] Origins of Algae and their Plastids. Springer-Verlag, Wien, pp. 115-38.

Steentoft, M. Irvine L. M. \& Farnham. W. F. 1995. Two terete species of Gracilaria and (rracilariopsis (Gracilariales, Rhodophyta) in Britain. Phycologia 34:113-27.

Swofford, D. L. 1998. PAUP*, Phylogenetic Analysis Using Parsimony ("and other methods). Version 4. Sinater Associates, Sunderland, Massachusetts.

Swofford. D. L.., Olsen, (x. J., Waddell, P. J. \& Hillis, D. M. 1996. Phy logenetic inference. In Hillis, D. M., Moritz, C. \& Mable, B. K. [Eds.] Molecular Systematics. Sinauer Associates, Sunderland, Massachusetts, pp. $407-514$
Tamura, K. \& Nei, M. 1993. Estimation of the number of nucleotide substitutions in the control region of mitochondrial DNA in humans and chimpanzees. Mol. Biol. Evol. 10:512-26.

Thompson, J. D., Gibson, T. J., Plewniak, F., Jeanmougin, F. \& Higgins, D. G. 1997. The ClustalX windows interface: flexible strategies for multiple sequence alignment aided by quality analysis tools. Nucl. Acids Res. 24:4876-82.

Tseng, C. K. \& Xia, B.-M. 1999. On the Gracilaria in the western Pacific and the southeastern Asia Region. Bot. Mar. 42: 209-17.

van der Sande, C. A. F. M., Kwa, M., van Nues, R. W., van Heerikhuizen, H. Raué H A \&. Planta. J. J. 1992. Functional analysis of internal transcribed spacer 2 of Saccharomyces cerevisiae ribosomal DNA. J. Mol. Biol. 223:899-910.

Van de Peer, Y., De Rijk, P., Wuyts, J., Winkelmans, T. \& De Wachter, R. 2000. The European small subunit ribosomal RNA database. Nucl. Acids Res. 28:175-6.

Wattier, R., Dallas, J. F., Destombe, C., Saumitou-Laprade, P. \& Valero, V. 1997. Single locus microsatellites in Gracilariales (Rhodophyta): high level of genetic variability within (iracilaria gracilis and conservation in related species. J. Phycol. 33: 868-80.

Wynne, M. J. 1989. The re-instatement of Hydropuntia Montagne (Gracilariaceae, Rhodophyta). Taxon 38:476-9.

Yamamoto, H. 1978. Systematic and anatomical study of the genus Gracilaria in Japan. Bull. Fac. Fïsh. Holkaido Univ. 25:97-152.

Yamamoto, H. 1984. An evaluation of some vegetative features and some interesting problems in Japanese populations of Gracilaria. Hydrobiologia 116/117:51-4.

Yamamoto, H. 1986. Congracilaria babae gen. et sp. nov. (Gracilariaceac), an adelphoparasite orowing on Cracklaria salicornia of Japan. Bull. Fac. Fish. Hokkaido Univ. 37:281-90.

Yamamoto, H. \& Sasaki, J. 1988. Interfertility between so called Gracilaria verrucosa (Huds.) Papenfuss in Japan. Bull. Fac. Fish. Hokkaido Uniw. 39:1-3,

Zuker, M., Mathews, D. H. \& Turner, D. H. 1999. Algorithms and thermodvnamics for RNA secondary structure prediction: practical guide. In Barciszewski, J. \& Clark, B. F. C. [E.ds.] RNA Biochemistry and Biotechnology. NATO ASI Series, Kluwer Academic Publishers, Dordrecht, pp. 11-43. 


\title{
Purification of Plastid DNA From an Enriched Rhodoplast Fraction of the Red Alga Gracilaria tenuistipitata
}

\author{
JONATHAN C. HAGOPIAN ${ }^{1}$, PI NYVALL ${ }^{2}$ and MARIANA C. de OLIVEIRA ${ }^{1, *}$ \\ ${ }^{l}$ Departamento de Botânica, Instituto de Biociências, Universidade de São Paulo, Rua \\ do Matão, n. 277, São Paulo, SP, 05508-900, Brazil; ${ }^{2} U M R$ 1931, CNRS-Goëmar, \\ Station Biologique, CNRS-INSU-Université Paris 6, BP 74, F29682 Roscoff Cedex, \\ France
}

\begin{abstract}
We report a straightforward protocol for isolating plastid DNA from an enriched rhodoplast fraction of the red alga Gracilaria tenuistipitata. Plastids were purified using differential centrifugation and 2-step sucrose density gradients. We found that $10 \%$ polyethylene glycol 4000 was essential for maintaining plastid integrity prior to lysis. Plastid DNA isolated directly from the purified rhodoplasts was sufficiently pure for restriction endonuclease fragment analyses. Database comparisons of sequences generated randomly from a shotgun genomic library indicated that plastid DNA was $89 \%$ pure following ultracentrifugation in isopycnic cesium chloride equilibrium gradients. The protocol yields $30-50 \mu \mathrm{g}$ of plastid DNA per $100 \mathrm{~g}$ of fresh algal tissue.
\end{abstract}

Key words: Gracilaria tenuistipitata, plastid isolation, plastid DNA purification, ptDNA, red alga, Rhodophyta

Abbreviations: nDNA, nuclear DNA; ptDNA, plastid DNA.

\section{Introduction}

Red algae (Rhodophyta) play an important role in the dynamic arena of plastid endosymbiosis theory. Together with green plants (green algae and land plants) and glaucocystophytes, they represent a third distinct lineage containing plastids of primary endosymbiotic origin (Bhattacharya and Medlin, 1995). In addition, molecular phylogenies indicate that members of the red algae were the source of "complex" plastids in the secondary endosymbiotic lineages Cryptophyta, Haptophyta, and Heterokonta (Kowallik, 1997; Douglas and Penny, 1999; Oliveira and Bhattacharya, 2000). Complete plastid genome sequences provide the data necessary to elucidate patterns of endosymbiosis and evolution in these lineages. We set out to shotgun sequence the plastid genome of the agar-producing red alga Gracilaria tenuistipitata Chiang et Xia var. liui Chiang et Xia, attempting to produce the first complete plastid genomic sequence from a representative of

*Author for correspondence. e-mail: mcdolive@usp.br; fax: 55-11-3091-7547; ph: 55-11-3091-7630. 
the rhodophyte subclass Florideophycidae. We needed highly purified ptDNA to efficiently achieve this aim.

Most plastid sequences completed to date are those of green plants, reflecting that plastid purification efforts have concentrated on species of this lineage. The highest quality ptDNA preparations are achieved by incorporating organelle purification steps, such as differential centrifugation and sucrose or Percoll (Pharmacia) gradients, before lysis and subsequent separation of macromolecular components in cesium chloride (CsCl) (Herrmann, 1982; Palmer, 1986). Although plant cells are commonly ruptured with a blender in the presence of stabilizing buffer components, tough algal cell walls must often be frozen with liquid nitrogen and ground intensively to ensure thorough cell breakage. Because of the harsh nature of this process and the fragility of plastids, most studies of algal ptDNA bypass organelle purification steps.

Goff and Coleman (1988) demonstrated with various red algal species that multiple sequential $\mathrm{CsCl}$ gradients could be used to purify ptDNA from whole tissue extracts for restriction fragment banding analyses. The fluorescent intercalating dye bisbenzemide (Hoechst 33258) binds with higher affinity to the A-T rich plastid genome than it does to nDNA and so generates a difference in density between them sufficient for separation in isopycnic $\mathrm{CsCl}$ equilibrium gradients (Aldrich and Cattolico, 1981). Roell and Morse (1991) used CsCl gradients to isolate RNA and DNA species of the rhodophyte Polysiphonia boldii. The complete plastid genomes of several algal species (Reith and Munholland, 1995; Douglas and Penny, 1999; Zhang et al., 1999; Glockner et al., 2000; Lemieux et al., 2000) have been sequenced from ptDNA isolated directly on sequential $\mathrm{CsCl}$ gradients.

As reported for the green alga Nephroselmis olivacea (Turmel et al., 1999), we found that ptDNA of $G$. tenuistipitata could not be clearly resolved from the predominant $\mathrm{nDNA}$ band in $\mathrm{CsCl}$ gradients of whole tissue extracts. Plastid enrichment methods reported for the red alga Porphyra yezoensis (Shivji, 1991) and kelp species (Fain et al., 1988) proved ineffective primarily because of plastid instability. Our need for pure DNA to construct genomic libraries and the expense and time delay associated with multiple $\mathrm{CsCl}$ gradients encouraged us to improve current methods for algal ptDNA purification. We describe an optimized protocol for the purification of ptDNA from a plastid-rich fraction of G. tenuistipitata.

\section{Materials and Methods}

Equipment, reagents, and solutions

- Liquid nitrogen

- Mortar and pestle

- Vacuum filter apparatus with large-diameter porcelain Buchner filter funnel

- Miracloth (Calbiochem)

- Shaker

- Centrifuge, microcentrifuge, ultracentrifuge, HS-4 swing-out rotor, AH-629 swing-out rotor, T-880 fixed-angle rotor, and centrifuge tubes (Sorvall)

- Molecular biology grade $\mathrm{CsCl}$

- Hoechst 33258 (10 mg/mL in water) 
- Phenol

- Chloroform

- Isoamylalcohol

- Sodium acetate

- 18-gauge syringe needle

- Long-wave UV lamp

- Dialysis tubing (VWR)

- Isopropanol

- Absolute ethanol

- Resuspension buffer: $50 \mathrm{mM}$ Tris (pH 8), 25 mM EDTA, 1.6 M sorbitol (USB), 10\% (w/v) PEG 4000 (Polysciences, Inc.), 0.1\% (w/v) BSA, 1 mM DTT

- Two-step sucrose gradient: 45:60\% (w/v) sucrose $(15: 10 \mathrm{~mL}), 50 \mathrm{mM}$ Tris (pH 8), 25 mM EDTA, 10\% (w/v) PEG 4000

- Lysis buffer: $50 \mathrm{mM}$ Tris (pH 8), $100 \mathrm{mM}$ EDTA, $50 \mathrm{mM} \mathrm{NaCl}, 0.5 \%$ (w/v) SDS, $0.7 \%$ (w/v) $N$-lauroyl-sarcosine (Sigma), $200 \mu \mathrm{g} / \mathrm{mL}$ proteinase $\mathrm{K}$, $100 \mu \mathrm{g} / \mathrm{mL}$ Rnase

- TE: $10 \mathrm{mM}$ Tris (pH 8), $1 \mathrm{mM}$ EDTA

\section{Culture conditions}

G. tenuistipitata cultures were maintained at $25^{\circ} \mathrm{C}$ under a $14-\mathrm{h}$ light period (150-170 $\mu \mathrm{mol}$ photons $\left.\mathrm{m}^{-2} \mathrm{~s}^{-1}\right)$ with constant aeration in sterilized filtered seawater (20 psu) that was changed weekly and supplemented with von Stosch nutrients (Oliveira et al., 1995).

\section{Protocol}

\section{Plastid isolation}

- Select $100 \mathrm{~g}$ of algal tissue for plastid isolation, rinse with filtered tap water, and blot dry.

- Freeze with liquid nitrogen and macerate thoroughly with a mortar and pestle. ${ }^{1}$

- Suspend resulting fine dry powder in $300 \mathrm{~mL}$ of resuspension buffer, while maintaining the temperature at $0-4^{\circ} \mathrm{C}$. Additional steps are performed at $4{ }^{\circ} \mathrm{C}$.

- Filter the suspension through 2 sheets of miracloth. Resuspend in an additional $75 \mathrm{~mL}$ of resuspension buffer, and refilter.

- Transfer the filtrate to ten $45-\mathrm{mL}$ centrifuge tubes. Spin for $10 \mathrm{~min}$ at $250 \mathrm{~g}$ in a swing-out rotor. Transfer the supernatant to clean tubes and spin again. Transfer and then spin a third time.

- Centrifuge the final supernatants at $3000 \mathrm{~g}$ for $15 \mathrm{~min}$.

- Discard the supernatants. Add $2 \mathrm{~mL}$ of resuspension buffer to each of the enriched plastid pellets.

- Gently dislodge the pellets with a spatula. Resuspend by swirling on a shaker.

- Transfer the suspended plastids with a wide-bore pipette to a separate tube. ${ }^{2}$

- Load approximately $3 \mathrm{~mL}$ of plastid suspension over each of eight 2-step sucrose gradients. Centrifuge at $112,000 \mathrm{~g}$ for $1 \mathrm{~h}$ in a swing-out rotor. ${ }^{3}$

- Transfer the purified plastids from the dark bands at the density interfaces to sterile Falcon tubes with a wide-bore pipette. 


\section{Notes:}

1. The 100-g mass was divided into 4 separate mortars, and liquid nitrogen volumes were held above threshold levels required to sustain flow within the mortar. Total maceration time averaged $1 \mathrm{~h}$.

2. Remaining plastid clumps were resuspended in a small additional volume with a wide-bore pipette.

3. Sucrose gradients were prepared $24-36 \mathrm{~h}$ in advance to provide a semidiffuse interface.

\section{Lysis and ptDNA purification}

- Lyse the plastids with the addition of an equal volume of lysis buffer. Mix by inversion and incubate for $10-12 \mathrm{~h}$ at $25^{\circ} \mathrm{C}$, or $3-4 \mathrm{~h}$ at $37^{\circ} \mathrm{C} .{ }^{1}$

- Transfer to a plastic beaker. Add $\mathrm{CsCl}$ to a final concentration of $1 \mathrm{~g} / \mathrm{mL} .^{2}$

- Transfer to centrifuge tubes and spin at $27,000 \mathrm{~g}$ at $20^{\circ} \mathrm{C}$ for $30 \mathrm{~min}$ in a swing-out rotor.

- Transfer and dilute the cleared lysate with milli-Q water to $0.7-0.8 \mathrm{~g} / \mathrm{mL} \mathrm{CsCl}^{3}$

- Transfer to $11-\mathrm{mL}$ ultracentrifuge tubes. Add Hoechst 33258 to $40 \mu \mathrm{g} / \mathrm{mL}$.

- Centrifuge at $190,000 \mathrm{~g}$ at $20^{\circ} \mathrm{C}$ for $36-48 \mathrm{~h}$ in a fixed-angle rotor.

- Use a long-wave UV lamp to visualize the prominent ptDNA band above the faint and diffuse nuclear DNA band.

- Remove the ptDNA band from the gradient with an 18-gauge syringe needle.

- Extract Hoechst 33258 with isopropanol saturated with $1 \mathrm{M} \mathrm{NaCl}^{4}$

- Reduce $\mathrm{CsCl}$ concentrations 500-1000 fold by dialysis against TE. ${ }^{5}$

- Precipitate ptDNA with $2.5 \mathrm{vol}$ of absolute ethanol following the addition of 0.1 vol of $3 \mathrm{M}$ sodium acetate $(\mathrm{pH} 5.2)$. Incubate at $-20^{\circ} \mathrm{C}$ for $1 \mathrm{~h}$.

- Transfer to 36-mL centrifuge tubes. Spin at $18,000 \mathrm{~g}$ at $4^{\circ} \mathrm{C}$ for $2 \mathrm{~h}$.

- Dry ptDNA pellets and resuspend in $1 \mathrm{~mL}$ TE.

- Extract twice with phenol-chloroform-isoamylalcohol (24:24:1) and twice with chloroform-isoamylalcohol (24:1), mixing by inversion only.

- Perform ethanol precipitate as above. Wash pellets with $70 \%$ ethanol, dry, and resuspended in TE.

\section{Notes:}

1. RNase and proteinase $\mathrm{K}$ were freshly added from stocks. It was usually most convenient to lyse overnight at room temperature, and yields were consistent with those obtained using shorter lysis times at higher temperatures. Digital interference contrast microscopy was used to confirm complete lysis.

2. Glassware can bind DNA and reduce yields. To help the $\mathrm{CsCl}$ into solution, we ground it before addition and gently heated the solution while slowly mixing with a magnetic stirrer.

3 . The cleanest preps were achieved by perforating the centrifuge tube for bottom elution.

4. We used a long-wave UV lamp to verify complete removal. If precipitation occurred, we brought it back into solution with the addition of TE.

5. Provide for significant volume increases within tubing during dialysis. 


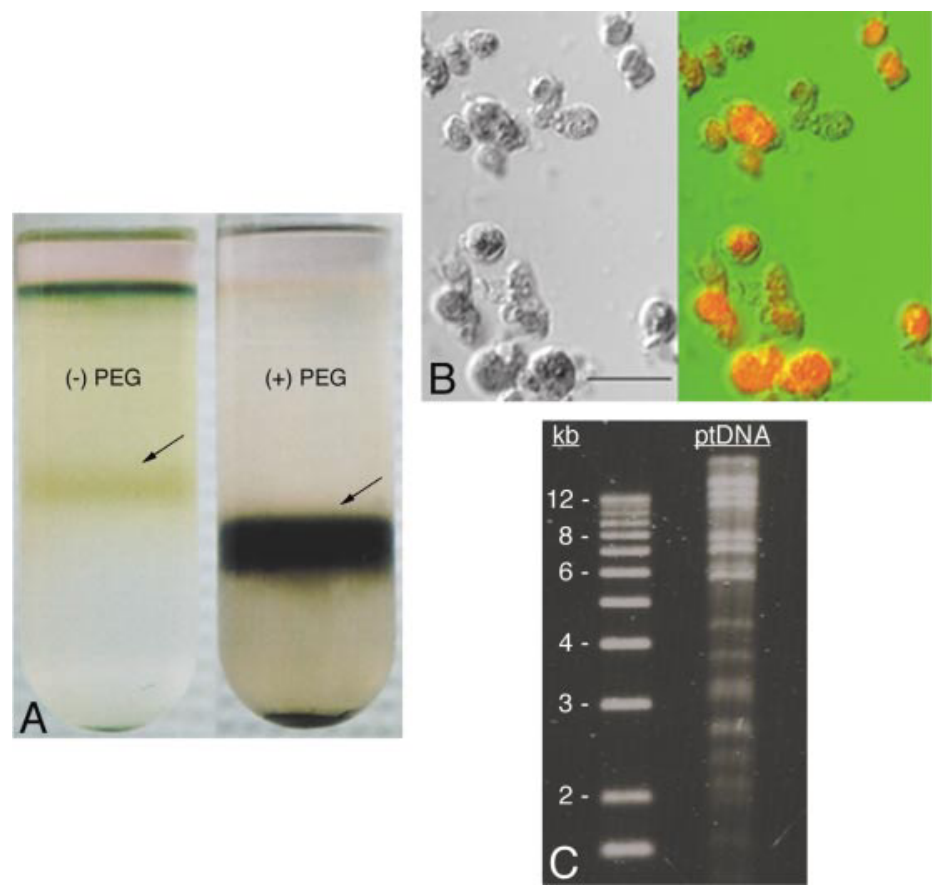

Figure 1. Plastid purification with 2-step sucrose gradient. (A) Plastids were highly unstable in control preparations deprived of PEG 4000 (-). Free phycobiliproteins and chlorophyll-associated thylakoids formed distinct bands in the top portion of the control gradient, while ruptured plastids lacking water-soluble accessory pigments (arrow) reached equilibrium above the density interface. In standard preparation gradients $(+)$, pigment release was minimum, and intact plastids (arrow) banded within the diffuse density interfaces. (B) Nomarski digital interference contrast micrograph (gray, green) and superimposed confocal autofluorescence (red) of plastids isolated from sucrose gradients; scale bar is $10 \mu \mathrm{m}$. (C) Agarose gel electrophoresis of ptDNA $(\sim 0.5 \mu \mathrm{g})$ isolated directly from plastids purified on sucrose step-gradients and digested with the restriction endonuclease EcoR I.

\section{Results and Discussion}

This protocol is the first described for large-scale isolation of intact plastids from a florideophycean rhodophyte. It is the only method reported for a nongreen alga that generates a highly enriched plastid fraction with the use of sucrose gradients and differential centrifugation. Damaging resuspension steps were minimized, while stabilizing buffer component concentrations were optimized. As reported for the fern Osmunda cinnamomea (Palmer and Stein, 1982), 10\% polyethylene glycol (PEG) 4000 was necessary for maintaining plastid integrity. Intact plastids maintain the color of the algae from which they come, and the release of pigments is a reliable indicator of plastid lysis. Miracloth filters were stained green with chlorophyll, supernatants were bright red with water-soluble phycobiliproteins, and intact plastids were absent on sucrose gradients in control preparations lacking PEG 4000. Plastid breakage was minimal during pellet resuspension and sucrose gradient centrifugation in the presence of PEG 4000 (Figure 1A). The integrity of the dark red-brown plastids purified in sucrose gradients was further 


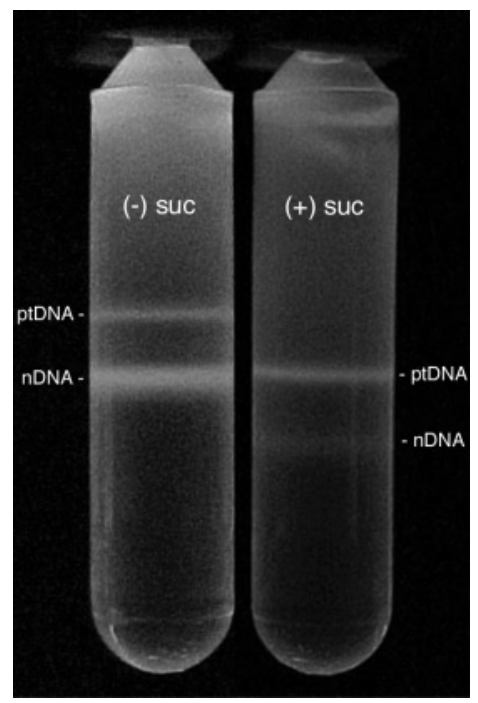

Figure 2. Separation of ptDNA and nDNA in $\mathrm{CsCl}$ equilibrium gradients. nDNA forms the major band in $\mathrm{CsCl}$ gradients prepared with plastid lysates following differential centrifugation (-). The nDNA fraction is significantly reduced in gradients prepared from extracts of plastids purified in sucrose gradients $(+)$.

confirmed by means of digital interference contrast micrographs and confocal scans that revealed uniform distribution of chlorophyll autofluorescence (Figure 1B).

Plastid DNA directly isolated from intact rhodoplasts purified in sucrose gradients was sufficiently pure for the visualization of restriction fragment banding patterns without further purification in $\mathrm{CsCl}$ (Figure 1C). Standard phenolchloroform extraction, dialysis, and ethanol precipitation procedures were used to isolate and purify ptDNA for restriction endonuclease digestion. Figure 2 provides a qualitative demonstration in $\mathrm{CsCl}$ gradients of the increase in purity achieved by incorporating 2-step sucrose gradients. We prepared $\mathrm{CsCl}$ gradients from pellet lysates following differential centrifugation and compared results with those obtained using the reported protocol. Although filtration and differential centrifugation remove most nuclear contamination, nDNA remains the dominant genomic fraction prior to plastid isolation in sucrose.

Our method yields $30-50 \mu \mathrm{g}$ of ptDNA per $100 \mathrm{~g}$ of G. tenuistipitata. This DNA was used to generate a shotgun genomic library with standard cloning procedures following nebulization. We were able to determine the purity of our ptDNA yield by analyzing sequences of randomly selected clones. Blast-X database searches (Altschul et al., 1997) revealed that of 3196 clones, 89\% (2840) contained insert sequences of plastid genomic origin. mtDNA composition was $0.9 \%$. Although this protocol was optimized for G. tenuistipitata, preliminary studies with another red alga, Pterocladiella capillacea, indicate that it will prove useful for various species. Methods described for the purification of intact plastids will facilitate future studies of plastid ultrastructure, gene expression, and protein purification. 


\section{Acknowledgments}

This study was funded by grants from FAPESP and CNPq (Brazil). J.C.H. is grateful to the US Fulbright Program, the Brazilian Fulbright Commission, and the Organization of American States for their generous support. P.N. thanks STINT (Sweden). We acknowledge Waldir Caldeira for assistance with microscopic analyses.

\section{References}

Aldrich J and Cattolico RA (1981) Isolation and characterization of chloroplast DNA from the marine chromophyte, Olisthodiscus luteus: electron microscopic visualization of isomeric molecular forms. Plant Physiol 68: 641-647.

Altschul SF, Madden TL, Schaffer A, Zhang J, Zhang Z, Miller W, and Lipman DJ (1997) Gapped BLAST and PSI-BLAST: a new generation of protein database search programs. Nucleic Acids Res 25: 3389-402.

Bhattacharya D and Medlin L (1995) The phylogeny of plastids: a review based on comparisons of small-subunit ribosomal RNA coding regions. J Phycol 31: 489-498.

Douglas SE and Penny SL (1999) The plastid genome of the cryptophyte alga, Guillardia theta: complete sequence and conserved synteny groups confirm its common ancestry with red algae. J Mol Evol 48: 236-244.

Fain SR, Druehl LD, and Baillie DL (1988) Repeat and single copy sequences are differentially conserved in the evolution of kelp chloroplast DNA. J Phycol 24: 292-302.

Glockner G, Rosenthal A, and Valentin K (2000) The structure and gene repertoire of an ancient red algal plastid genome. J Mol Evol 51: 382-390.

Goff LJ and Coleman AW (1988) The use of plastid DNA restriction endonuclease patterns in delineating red algal species and populations. J Phycol 24: 357-368.

Herrmann RG (1982) The preparation of circular DNA from plastids. In: Edelman M, Hallick R, and Chua NH (eds), Methods in Chloroplast Molecular Biology, pp 259-280, Elsevier, Amsterdam.

Kowallik KV (1997) Origin and evolution of chloroplasts: current status and future perspectives. In: Schenk HEA, Herrmann RG, Jeon KW, Müller NE and Schwemmler W (eds), Eukaryotism and Symbiosis, pp 3-23, Springer-Verlag, Berlin.

Lemieux C, Otis C, and Turmel M (2000) Ancestral chloroplast genome in Mesostigma viride reveals an early branch of green plant evolution. Nature 403: 649-652.

Oliveira EC, Paula EJ, Plastino EM, and Petti R (1995) Metodologías para el cultivo no axénico de macroalgas marinas in vitro. In: Alveal K, Ferrario ME, Oliveira EC and Sar E (eds), Manual de Métodos Ficológicos, pp 429-447. Universidad de Concepción, Concepción, Chile.

Oliveira MC and Bhattacharya D (2000) Phylogeny of the Bangiophycidae (Rhodophyta) and the secondary endosymbiotic origin of algal plastids. Amer J Bot 87(4): 482-492.

Palmer JD (1986) Isolation and structural analysis of chloroplast DNA. Methods Enzymol 118: $167-186$.

Palmer JD and Stein DB (1982) Chloroplast DNA from the fern Osmunda cinnamomea: physical organization, gene localization and comparison to angiosperm chloroplast DNA. Curr Genet 5: 165-170.

Reith M and Munholland J (1995) Complete nucleotide sequence of the Porphyra purpurea chloroplast genome. Plant Mol Biol Rep 13(4): 333-335. 
Roell MK and Morse DE (1991) Fractionation of nuclear, chloroplast, and mitochondrial DNA from Polysiphonia boldii (Rhodophyta) using a rapid and simple method for the simultaneous isolation of RNA and DNA. J Phycol 27: 299-305.

Shivji MS (1991) Organization of the chloroplast genome in the red alga Porphyra yezoensis. Curr Genet 19: 49-54.

Turmel M, Otis C, and Lemieux C (1999) The complete chloroplast DNA sequence of the green alga Nephroselmis olivacea: insights into the architecture of ancestral chloroplast genomes. Proc Nat Acad Sci USA 96: 10248-10253.

Zhang Z, Green BR, and Cavalier-Smith T (1999) Single gene circles in dinoflagellate chloroplast genomes. Nature 400: 155-159. 


\title{
Comparative Analysis of the Complete Plastid Genome Sequence of the Red Alga Gracilaria tenuistipitata var. liui Provides Insights into the Evolution of Rhodoplasts and Their Relationship to Other Plastids
}

\author{
Jonathan C. Hagopian, ${ }^{1}$ Marcelo Reis, ${ }^{2}$ João P. Kitajima, ${ }^{2, *}$ Debashish Bhattacharya, ${ }^{3}$ Mariana C. de Oliveira ${ }^{1}$ \\ ${ }^{1}$ Departamento de Botânica, Instituto de Biociências, Universidade de São Paulo, R. Matão 277, 05508-900, São Paulo, SP, Brazil \\ ${ }^{2}$ Laboratório de Bioinformática, Instituto de Computação, UNICAMP, Av. Albert Einstein 1251, Box 6176, 13083-970, Campinas, \\ SP, Brazil \\ ${ }^{3}$ Department of Biological Sciences and Center for Comparative Genomics, University of Iowa, 210 Biology Building, Iowa City, IA 52242, \\ USA
}

Received: 12 January 2004 / Accepted: 14 April 2004 [Reviewing Editor: Dr. W. Ford Doolittle]

\begin{abstract}
We sequenced to completion the circular plastid genome of the red alga Gracilaria tenuistipitata var. liui. This is the first plastid genome sequence from the subclass Florideophycidae (Rhodophyta). The genome is composed of $183,883 \mathrm{bp}$ and contains 238 predicted genes, including a single copy of the ribosomal RNA operon. Comparisons with the plastid genome of Porphyra pupurea reveal strong conservation of gene content and order, but we found major genomic rearrangements and the presence of coding regions that are specific to Gracilaria. Phylogenetic analysis of a data set of 41 concatenated proteins from 23 plastid and two cyanobacterial genomes support red algal plastid monophyly and a specific evolutionary relationship between the Florideophycidae and the Bangiales. Gracilaria maintains a surprisingly ancient gene content in its plastid genome and, together with other Rhodophyta, contains the most complete repertoire of plastid genes known in photosynthetic eukaryotes.
\end{abstract}

Key words: Gracilaria tenuistipitata - Molecular phylogeny — Plastid evolution — Plastid genome Red alga - Rhodophyta

\footnotetext{
*Present address: Alellyx Applied Genomics, Via Anhangüera km 104 (TechnoPark), R. James Clerk Maxwell 320, 13067-850 Campinas, SP, Brazil
}

Correspondence to: Mariana C. de Oliveira; email: mcdolive@ ib.usp.br; mcdolive@usp.br

\section{Introduction}

Plastids are the photosynthetic organelles of eukaryotes and their genomes range in size from approximately 35 to $200 \mathrm{~kb}$. Relatively few of these sequences have been determined ( 35 completed) in comparison to the mitochondrial genome (529 completed; see http://www.ncbi.nlm.nih.gov:80/genomes/ static/euk_o.html). Furthermore, most of the sequenced plastid genomes ( 25 in total) are of chlorophyll $b$-containing algae and plants. The handful that have been sequenced from the diverse group of "nongreen" protists include representatives of the Alveolata (Eimeria tenella, Toxoplasma gondii), Cryptophyta (Guillardia theta), Euglenozoa (Euglena longa and Euglena gracilis), Glaucophyta (Cyanophora paradoxa), Stramenopiles (Odontella sinensis), and Rhodophyta (Cyanidium caldarium, Cyanidioschyzon merolae, and Porphyra purpurea) (see Table 1). Importantly, these nongreen taxa comprise the wealth of protistan diversity including the major phytoplankton in the oceans (e.g., chlorophyll $c^{-}$ containing forms such as diatoms and haptophytes) and many toxic species (e.g., dinoflagellates and brown algae). Here we present the complete plastid genome sequence of the florideophyte red alga, Gracilaria tenuistipitata var. liui, with the aim of further elucidating plastid evolution.

It is now generally accepted that plastids originated through endosymbiosis, whereby a single-celled 


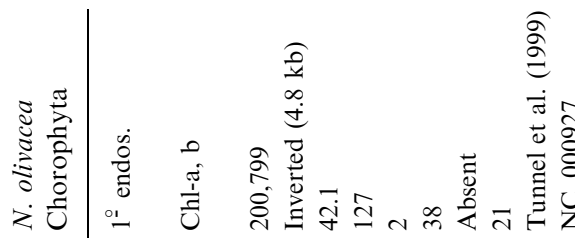

\&े

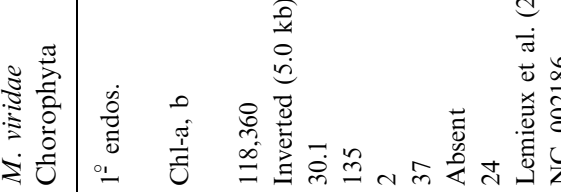

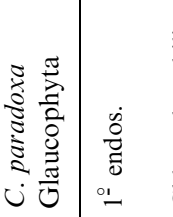

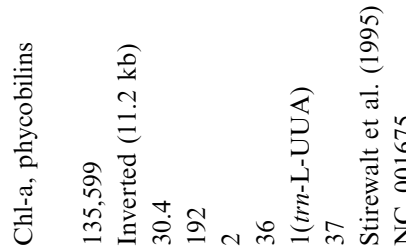

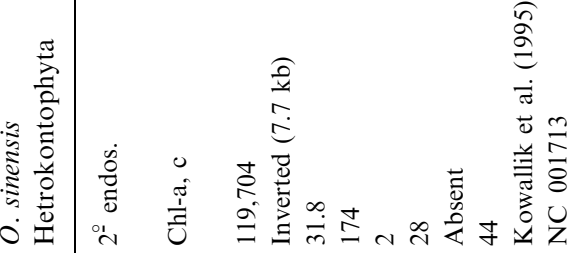
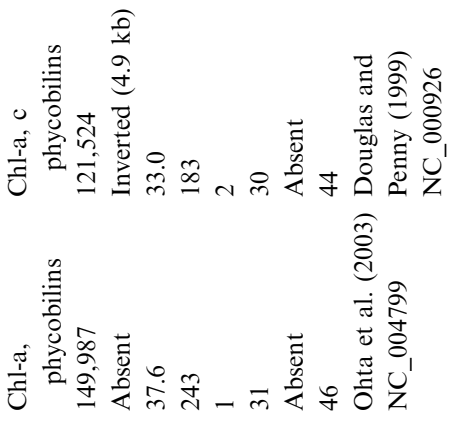

protist engulfed and retained a foreign photosynthetic cell inside a vacuole (Gray 1992; Bhattacharya and Medlin 1995). Over time, the foreign cell was reduced to a plastid and transmitted to subsequent generations. Plastid origin occurred via primary and secondary endosymbiosis. The first involves the engulfment of a photosynthetic prokaryote (cyanobacterium) and is believed to have occurred once in evolution (but see Stiller and Hall 1997; Stiller et al. 2003), giving rise to the protoalga that is the ultimate root of all plastids. This primary plastid eventually became established in the first algae that split into two lineages. The first produced the glaucophyte algae, whereas the second gave rise to the highly successful red algae and their sister group the green algae and land plants (Moreira et al. 2000; Palmer 2003). Once the three primary algal lineages were established, the stage was set for secondary endosymbiosis, whereby a protist engulfed an existing alga. This type of eukaryotic-eukaryotic endosymbiosis accounts for the vast majority of algal diversity (Bhattacharya et al. 2004). Secondary plastids are found in the ecologically and economically important chlorophyll $c$-containing chromalveolates that define a broadly diverse group including the Chromista (cryptophyte, haptophyte, and stramenopile algae) and the Alveolata (parasitic apicomplexans, apparently plastidless ciliates, and dinoflagellate algae). The chromalveolate hypothesis is based primarily on the idea that all taxa containing a chromophytic plastid share a common origin (Cavalier-Smith 1986). The chromalveolate plastid is believed to have originated from a single red algal secondary endosymbiosis that occurred ca. 1.2 billion years ago in the ancestor of this group with the ensuing evolution of chlorophyll $c 2$ (Yoon et al. 2002). This scenario, however, remains to be substantiated with analysis of nuclear genes from chromalveolates (Bhattacharya et al. 2004). The plastid was putatively lost in ciliates and parasitic/saprobic stramenopiles like oomycetes (e.g., the water mold Achlya), and the genome was reduced to a $35-\mathrm{kb}$ DNA circle in the apicomplexans (McFadden 2001; Andersson and Roger 2002). The red algae have, therefore, contributed the photosynthetic organelle to a major branch of the protist tree of life. Secondary endosymbiosis also explains the origin of the green (i.e., chlorophyll $b$-containing) plastids of the Euglenozoa (e.g., Hannaert et al. 2003; Martin and Borst 2003) and Chlorarachniophyta (Gilson and McFadden 1995; Archibald et al. 2003). However, it is unclear whether these organelles arose independently or from a single endosymbiotic event (Bhattacharya et al. 2004).

Important challenges that remain in the field of endosymbiosis research are to document genome evolution in different plastids, to understand the timing and nature of gene transfer to the nuclear 
compartment, to use the multigene approach with complete plastid genome sequences to generate a robust plastid phytogeny, to definitively test the monophyly of red algal-derived secondary plastids, and to provide a framework for mapping gene transfer and the evolution of other characters associated with photosynthesis. We used comparative methods with the complete Gracilaria plastid genome sequence to address these issues. Our data also open up the possibility for genetic engineering of this economically important red seaweed (Bock 2001; Gewolb 2002).

\section{Materials and Methods}

\section{Algal Cultures and Plastid DNA Purification}

Gracilaria tenuistipitata var. liui Zhang et Xia was collected in Haikou, China (5 June 1990) by E.C. de Oliveira. Tetrasporophyte cultures were maintained at $25^{\circ} \mathrm{C}$ under a 14-h light period (150$170 \mu \mathrm{mol}$ photons $\mathrm{m}^{-2} \mathrm{~s}^{-1}$ ) with constant aeration in sterilized filtered seawater $(20 \mathrm{ppm})$ that was changed weekly and supplemented with Von Stosch nutrients (Oliveira et al. 1995). Purification of plastid DNA from an enriched rhodoplast fraction was done as described by Hagopian et al. (2002).

\section{Genomic Library Construction and Sequencing}

The complete plastid genome sequence was generated using a combination of shotgun libraries and PCR strategies. Shotgun libraries were constructed with fragments $(1-3 \mathrm{~kb})$ of nebulized, purified plastid DNA cloned into pUC18 (Pharmacia). Sequencing reactions were performed with BigDye terminators and analyzed on ABI Prism 377 and 3700 automated sequencers.

\section{Genome Sequence Assembly}

Assembly was accomplished with the phred-phrap-consed package (Gordon et al. 1998), which was used to screen for vector and common contaminant sequences. The initial assembly of random clone sequences generated three large plastid contigs that contained $89 \%$ of all screened reads. This value provided an accurate estimate of plastid DNA purity. Contigs were unified and overall coverage was enhanced by reverse sequencing of selected clones. A final gap of about $500 \mathrm{bp}$ was amplified in multiple PCR reactions that were directly sequenced. The final sequence quality standard was achieved by sequencing select clones with 1 of 26 primers. Every base of the plastid genome has minimum quality with Phred value of at least 20 and was confirmed in both directions by a minimum of three reads. There are no unexplained high-quality discrepancies, and the overall error estimate is less than 0.001 in every 10,000 bases. A total of 4441 reads were used in the genome assembly, providing approximately nine-fold genome coverage. The genome sequence has been deposited in GenBank with the accession number AY673996.

\section{Genome Annotation and Analysis}

Biotechnology Information (NCBI) protein database using BLASTX (Altschul et al. 1997). BLASTX searches were carried out to find additional putative protein-coding genes at the intergenic spacers. All ORFs were inspected manually and checked against Cluster of Orthologous Groups of Proteins (COG), Protein Family Database (PFAM), and the Kyoto Encyclopedia of Genes and Genomes (KEGG). RNA species were identified using BLASTN (Altschul et al. 1997), secondary structure analysis, and tRNAscanSE (Lowe and Eddy 1997). Identified genes were named as in Stoebe et al. (1998). For a full list of ORFs, gene map, and comparative tables, refer to the supplementary material at http:// gracilaria.lbi.ic.unicamp.br/chloroplast. Whole plastid genomes were compared at the nucleotide level using the program CrossMatch (Gordon et al. 1998).

\section{Phylogenetic Analyses}

We analyzed a concatenated protein data set from 23 completely sequenced plastid genomes (including Gracilaria) and two cyanobacteria (Nostoc sp. PCC 7120 [GenBank NC 003272] and Synechocystis sp. PCC 6830 [NC_000911]) as the outgroup (see http://www.ncbi.nlm.nih.gov). The chosen taxa represent a broad sample of photosynthetic eukaryotes including Glaucophyta, Rhodophyta, Chromista, Chlorophyta, and Streptophyta (Martin et al. 1998, 2002). A total of 41 protein-coding genes shared by these evolutionarily divergent genomes were combined to create a data set of 8810 amino acids of unambiguously aligned sequence positions (alignment available at http://gracilaria.lbi.ic.unicamp.br/chloroplast). The proteins that we used in the phylogenetic analyses and the length of each aligned data set are as follows: atpA (451 aa), atpB (459 aa), atpE (116 aa), atpF (32 aa), atpH (80 aa), ccsA (156 aa), petA (263 aa), petB (214 aa), petD (159), petG (35 aa), psaA (743 aa), psaB (734 aa), psaC (79 aа), psaJ (36 aa), psbA (343 aa), psbB (504 aa), psbC (449 aa), psbD (338 aa), psbE (73 aa), psbF (34 aa), psbH (58 aa), psbL (36 aa), psbN (41 aa), psbT (30 aa), rp12 (236 aa), rpl14 (121 aa), rpl16 (128 aa), rp120 (80 aa), rpoA (176 aa), rpoB (667 aa), rpoC1 (406 aa), rpoC2 (475 aa), rps2 (217 aa), rps3 (121 aa), rps4 (158 aa), rps7 (128 aa), rps8 (97 aa), rps12 (122 aa), rps14 (75 aa), rps18 (52 aa), and rps19 (88 aa).

To assess if different proteins supported conflicting plastid phytogenies, we divided the data into functionally related groups under the assumption that interacting proteins could potentially share a common evolutionary history (e.g., de Queiroz et al. 1995 [but see Vogl et al. 2003]). The first major group was defined by photosystem (PSII + II) I and II proteins (i.e., psaX and psbX proteins) and was of total length 3498 aa and the second major group included proteins involved in transcription and translation ([T $+\mathrm{T}]$ i.e., ribosomal proteins and RNA polymerase subunits) and was of total length 3347 aa. We also generated data sets of only the ribosomal proteins (1623 aa), only the RNA polymerase subunits (1724 aa), the ATP synthase subunits (1138 aa), the pet proteins (671 aa), and the total photosynthetic apparatus (i.e., PSI + II, ATP synthase subunits, electron transfer [petA, B, D, and G], and $\operatorname{ccs} \mathrm{A}-5463$ aa).

A maximum likelihood (ML) approach was used to reconstruct the plastid trees and three other methods were used to infer support for nodes in these phylogenies. For the ML approach, PROML in PHYLIP V3.6b (Felsenstein 2003) was used to generate globally optimized protein trees (one random addition, JTT $+\Gamma$ model). The gamma parameter value was calculated using TREE-PUZZLE (V5.1; Schmidt et al. 2002; see below). To calculate support values, we first did unweighted maximum parsimony (MP) bootstrap analysis (2000 replications) using PAUP* V4.0b8 (Swofford 2002), with the number of random-addition replicates set to 10 with tree bisection-reconnection optimization. Second, we did Bayesian analysis of the plastid data (MrBayes 


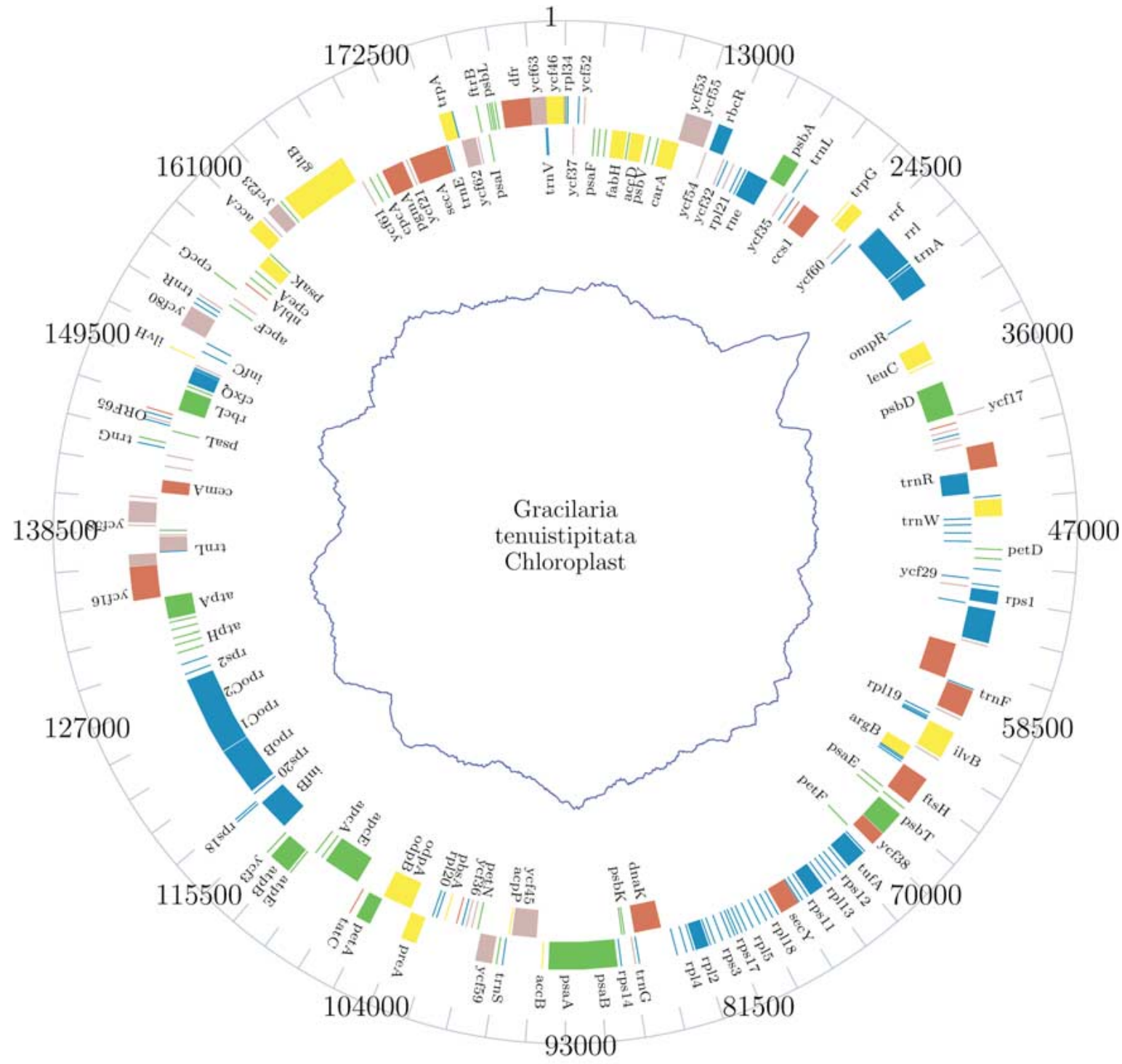

- Photosynthesis

- Transcription and translation Biosynthesis

Fig. 1. The Gracilaria tenuistipitata chloroplast genome. Genes on the outside circle are transcribed in a clockwise direction, whereas those in the middle circle are transcribed counterclockwise. The inside circle indicates $\mathrm{G}+\mathrm{C}$ content. Identified genes based on database comparisons were named as in Stoebe et al. (1998) and

V3.0b4; Huelsenbeck and Ronquist 2001) using the WAG model (Whelan and Goldman 2001). Metropolis-coupled Markov chain Monte Carlo from a random starting tree was initiated in the Bayesian inference and run for 500,000 generations (except for the full genome data, for which we used 350,000 generations due to the extreme run time), with trees sampled every 100th generation. Four chains were run simultaneously, of which three were heated and one was cold. Stationarity of the log likelihoods was monitored and a consensus phylogeny was made with the "post burnin" trees for each protein data set to determine the posterior probabilities at the different nodes. And third, quartet puzzling- hypothetical ORFs were named as "ORF" followed by the number of codons. The color indicates functional category, photosynthesis (green), transcription and translation (blue), biosynthesis (yellow), miscellaneous (orange), hypothetical, and conserved hypothetical (gray).

maximum likelihood analysis was done with the WAG $+\Gamma$ model using TREE-PUZZLE. Quartet puzzling support (QPS) values were calculated from 5000 puzzling steps.

\section{Tree Comparisons}

Trees were compared among the different data sets using the reciprocal $70 \%$ bootstrap support criterion (Mason-Gamer and Kellogg 1996). Under this criterion, if the same set of terminal taxa receives bootstrap support larger than $70 \%$ for a monophyletic 
relationship in a data partition and is not monophyletic with support values larger than $70 \%$ in a different data partition, then we interpret this as a topological conflict. We also tested the robustness of our findings by generating alternative topologies of the 41-protein, PS I + II, and T + T ML trees using MacClade (V4.05; Maddison and Maddison 2002). Groups of interest were positioned at alternate branch points in the ML trees and the log likelihoods of the "best" ML and the rearranged trees were calculated and compared using the one-sided Kishino-Hasegawa (KH) test (Kishino and Hasegawa 1989; Goldman et al. 2000) implemented in TREE-PUZZLE.

\section{Results}

\section{Genome Structure and Gene Composition General Features}

The complete circular plastid genome of Gracilaria tenuistipitata var. liui was $183,883 \mathrm{bp}$ in length (Fig. 1), with a GC content of $29.1 \%$ (Table 1). The genome does not contain inverted or direct repeats and encodes only a single copy of the ribosomal RNA (rRNA) operon. There are 238 predicted genes including 204 protein-encoding genes, 29 tRNAs, 3 rRNAs, 1 tmRNA, and 1 ribonuclease gene ( $r n p \mathrm{~B})$ (for the full list of genes, see Table 3 in the supplementary information at http://gracilaria.lbi.ic.unicamp.br/chloroplast). The coding sequences lack introns and span $84.1 \%$ of the genome. There are just two cases of overlapping genes ( $a t p \mathrm{~F} / a t p \mathrm{D}$ and $p s b \mathrm{C} /$ $p s b \mathrm{D})$. As expected, codon usage reflects the low GC content of the plastid genome, with codons ending in $\mathrm{G}$ or $\mathrm{C}$ comprising only $17.5 \%$ of the total. The termination codon TAA is used in $77.5 \%$ of the ORFs (see Table 4 in the supplementary information).

\section{Photosynthesis}

Based on databank comparisons, we have identified 57 genes related to photosynthetic function in the Gracilaria plastid genome. All the ATP synthase genes are present with the exception of $a t p \mathrm{C}$, which was transferred to the nucleus early in the evolution of plastids (Kowallik 1997). The ATP synthase genes are arranged in two clusters. The $a t p \mathrm{~B}$ and $a t p \mathrm{E}$ genes are adjacent, whereas $\operatorname{atpA}, \mathrm{D}, \mathrm{F}, \mathrm{G}, \mathrm{H}$, and I form a second cluster. There is an overlap of a single base in the $a t p \mathrm{~F}$ and $a t p \mathrm{D}$ genes as described for Synechococcus PCC 6301 (Cozens and Walker 1987). The genes pet $\mathrm{A}, \mathrm{B}, \mathrm{D}, \mathrm{F}, \mathrm{G}, \mathrm{J}$, and $\mathrm{N}(y c f 6)$ of the electron transfer chain are present, whereas pet $\mathrm{L}$ and pet $\mathrm{M}$ are missing. Twenty-seven genes for the assembly of photosystem I and II are present. The genes $p s b \mathrm{C}$ and $p s b \mathrm{D}$ share a 92-bp region of overlap. The genome encodes both subunits of Rubisco $(r b c \mathrm{~L}$ and $r b c \mathrm{~S})$ and all 10 phycobiliprotein genes.

\section{Transcription and Translation}

The consensus sequences for -10 (TATAAT) and -35 (TTTAAA and TTGACA) promoters were searched in the intergenic regions of Gracilaria plastid genome. The -10 consensus was detected for 102 ORFs and the -35 for 70 ORFs. Only three ORFs contained the promoter TTGACA (for the full list of genes see Table 5 in the supplementary information). A set of 46 ORFs contained both the canonical -10 and -35 sequences. We searched restricted regions for the -10 (from -1 to -25 ) and -35 (from -1 to -100 ) promoter sequences. These motifs were detected for just 17 and 39 ORFs, respectively. The ribosomebinding site (RBS) was detected for only 97 ORFs using the Shine-Dalgarno canonical sequences (AAGG, AGGA, GGAG, and GAGG) to search the intergenic regions immediately upstream of all start codons (Table 5). The number of hits decreased to 61 ORFs when we restricted the search from -1 to -50 . The absence of promoter regions and RBS for some ORFs is likely due to an alternative sequence being used and/or different location or may indicate an operon organization or "relay race"-type translation (Link 1996; Löffelhardt et al. 1997).

All four subunits of the eubacterial-like RNApolymerase are encoded in the Gracilaria plastid genome. The genes rpo $\mathrm{B}, r p o \mathrm{C} 1$, and $r p o \mathrm{C} 2$ form a cluster, whereas rpoA is part of a large cluster of ribosomal proteins. The presence of the putative transcription regulators $l y s \mathrm{R}(y c f 30), o m p \mathrm{R}(y c f 27)$, $t c t \mathrm{D}(y c f 29)$, and $n t c \mathrm{~A}(y c f 28)$ indicate the potential for regulation of gene expression in the plastid. The genes coding for the ATP-binding protein involved in Rubisco expression ( $c f x \mathrm{Q})$ and ribonuclease $\mathrm{E}(r n e)$ were also detected.

The Gracilaria plastid has a nearly complete set of ribosomal proteins (Table 1). It lacks rps 15 , which is present only in green plant plastids. The Gracilaria plastid genome contains 19 genes for 30S ribosomal subunit proteins and 28 genes for $50 \mathrm{~S}$ ribosomal subunit proteins. There is one major cluster of 29 genes, which includes 26 ribosomal protein genes, tuf A, rpoA, and $s e c \mathrm{Y}$, and is flanked by $d n a \mathrm{~K}$. Other ribosomal protein genes are scattered throughout the genome or are in "mixed" operons like $p s a \mathrm{~A}-p s a \mathrm{~B}$ rps14. Two ORFs coding for initiation factors IF-2 (inf $\mathrm{B}$ ) and IF-3 (inf C) and two ORFs coding for elongation factors EF-Ts (tsf) and EF-Tu (tufA) were found in the Gracilaria plastid genome but the ORF for IF-1 (infA) is missing.

The Gracilaria plastid genome contains only one set of rRNA genes organized in an operon encoding the $16 \mathrm{~S}, 23 \mathrm{~S}$, and $5 \mathrm{~S}$ subunits. The spacer region between $16 \mathrm{~S}$ and $23 \mathrm{~S}$ encodes two tRNA genes (tRNA $^{\text {Ile }}$ and tRNA ${ }^{\mathrm{Ala}}$ ). Twenty-nine tRNA genes, encompassing all 20 amino acids, are found either 
Table 2. Genes not shared between the Gracilaria tenuistipitata and the Porphyra purpurea plastid genomes

\begin{tabular}{|c|c|}
\hline Gracilaria tenuistipitata & Porphyra purpurea \\
\hline leu $\mathrm{C}^{\mathrm{a}, \mathrm{b}}$ (3-isopropylmalate dehydratase large subunit) & $\operatorname{chl} \mathrm{L}^{\mathrm{a}, \mathrm{b}}$ (photochlorophyllide reductase chlL subunit) \\
\hline \multirow{6}{*}{ leu $\mathrm{D}^{\mathrm{a}, \mathrm{b}}$ (3-isopropylmalate dehydratase small subunit) } & $\operatorname{chl} \mathrm{N}^{\mathrm{b}}$ (photochlorophyllide reductase chlN subunit) \\
\hline & $\operatorname{chl} / \mathrm{B}^{\mathrm{a}, \mathrm{b}}$ (photochlorophyllide reductase chlB subunit) \\
\hline & $g \ln \mathrm{B}^{\mathrm{b}}($ nitrogen regulatory protein $\mathrm{pII})$ \\
\hline & $f d x^{\mathrm{a}, \mathrm{b}}($ ORF75a) (ferredoxin) \\
\hline & pet $\mathrm{L}^{\mathrm{a}}$ (ycf7) (cytochrome b6/f complex subunit VI) \\
\hline & $\begin{array}{l}\text { petM } \mathrm{M}^{\mathrm{a}}(y c f 31) \text { (cytochrome } \mathrm{b} 6 / \mathrm{f} \text { complex subunit VII) } \\
y c f 41,{ }^{\mathrm{a}, \mathrm{b}} \text { ycf } 57,{ }^{\mathrm{a}, \mathrm{b}} \text { ycf } 64,{ }^{\mathrm{a}, \mathrm{b}}\end{array}$ \\
\hline 9 hypothetical proteins ${ }^{\mathrm{a}, \mathrm{b}}\left(\mathrm{ORF} 83,109,149,{ }^{\mathrm{c}} 160,198,{ }^{\mathrm{c}} 197,{ }^{\mathrm{c}} 220,245,446\right)$ & 3 hypothetical proteins ${ }^{\mathrm{a}, \mathrm{b}}(\mathrm{ORF} 62,121,148,621)$ \\
\hline
\end{tabular}

${ }^{\mathrm{a} O R F}$ s not present in Cyanidium caldarium.

${ }^{\mathrm{b}} \mathrm{ORF}$ s not present in Cyanidioschyzon merolae.

${ }^{\mathrm{c} O R F}$ not located within colinear regions in the comparison of G. tenuistipitata and P. purpurea.

singly or in clusters of two or three genes. The tRNA gene positions are highly conserved in the red algal plastid lineage (see Table 6 in the supplementary information). Two tRNA synthetases have been identified in Gracilaria, histidyl-tRNA synthetase (his $\mathrm{S}$ or $s y h)$ and phenylalanyl-tRNA synthetase beta chain (phe $\mathrm{T}$ or $s y f \mathrm{~B}$ ), which have homologs only in the Porphyra plastid, in cyanobacteria, and in other eubacterial genomes. The genes for tmRNA (K. Williams, personal communication) and ribonuclease $\mathrm{P}$ $(r n p \mathrm{~B})$ were detected based on secondary structure predictions.

\section{Biosynthesis}

Two unique genes involved in leucine biosynthesis, $l e u \mathrm{C}$ and $l e u \mathrm{D}$, were found in the Gracilaria plastid genome. Gracilaria contains many other genes involved in the biosynthesis of amino acids (e.g., ilv $\mathrm{B}$ and $\mathrm{H}$ ), fatty acids (e.g., $\operatorname{acc} \mathrm{A}, \mathrm{D}, \mathrm{B}$ ), and components of the photosynthetic apparatus (e.g., chlI, $m o e \mathrm{~B}, p b s \mathrm{~A})$. The chlorophyll biosynthesis genes $c h l \mathrm{~L}, c h l \mathrm{~N}$, and $c h l \mathrm{~B}$ were absent. The gene $g l t \mathrm{~B}$ that encodes a protein involved in nitrogen assimilation was detected, but the regulating gene $g \ln \mathrm{B}$ was absent.

\section{Miscellaneous}

Within the miscellaneous category, we detected the following genes in the Gracilaria plastid genome: (1) two homologs of bacterial genes involved in protein translocation across membranes $\sec \mathrm{A}$ and $\sec \mathrm{Y}$, (2) the chaperonin subunits $g r o \mathrm{EL}$ and $d n a \mathrm{~K}$, (3) the ATP-binding subunit $c l p C$, (4) the genes involved in replication and division $d n a \mathrm{~B}$ (this gene contained an intein of 143 amino acids) and $f t s \mathrm{H},(5)$ two adjacent genes coding for cytochrome C-type biogenesis proteins ( $c c d \mathrm{~A}$ and $c c s 1 / y f c 44)$, (6) a gene coding for phosphoglycerate mutase $(p g m \mathrm{~A})$ involved in glyco- lysis, and (7) the gene coding for a thioredoxin (trx $\mathrm{A})$ detected only in red algae.

\section{Conserved (ycfs) and Hypothetical ORFs}

We identified 33 conserved hypothetical genes in the Gracilaria plastid genome and attributed $y c f$ numbers (as proposed in Stoebe et al. 1998) for all but 1 gene (ORF65), which shares 69\% similarity with ORF58 of Porphyra purpurea. The gene coding for $y c f 17$ is truncated in Gracilaria. We identified nine hypothetical ORFs (Table 2) varying from 83 to 446 amino acids in length. No promoter sequences were detected for those ORFs. The codon usage for these hypothetical ORFs is quite similar to the average for all the ORFs, indicating that they are expressed (Table 4). Six of the hypothetical ORFs are clustered between position 136,053 and position 144,145 . The GC content of this region is $22.8 \%$, which is lower than the average value $(29.1 \%)$ for the genome.

\section{Comparisons with Porphyra purpurea}

The plastid genomes of Gracilaria and Porphyra are quite similar in gene content and share colinearity over large regions. Gracilaria lacks the duplication of the rRNA genes present as direct repeats in Porphyra as well as two genes $(c h l \mathrm{~L}$ and $c h l \mathrm{~N})$ flanking one of these direct repeats. Open reading frames that are exclusively present between the Porphyra and Gracilaria plastid genomes are listed in Table 2. Adjacent to the single rRNA operon in Gracilaria are the unique $l e u \mathrm{D}$ and $l e u \mathrm{C}$ genes ( $\mathrm{GC}$ content of this region is $32.6 \%$ ). Another interesting region in Gracilaria is between 136,053 and 144,145, which includes six hypothetical proteins (ORF245, 109, 446, 220, 198, and 197) that have no homologs in Porphyra. The corresponding region in Porphyra contains two exclusive ORFs (ORF62 and 621). Gracilaria has 29 of the 37 


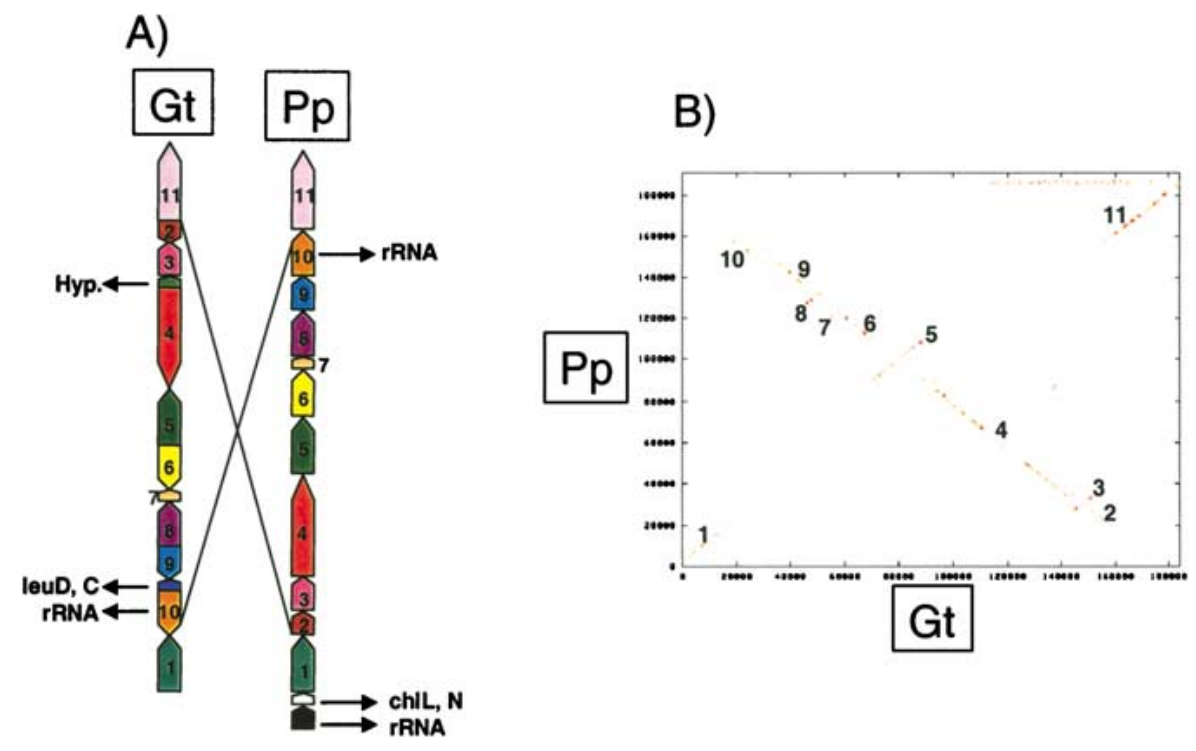

Fig. 2. Comparison of Gracilaria tenuistipitata (Gt) and Porphyra purpurea $(\mathrm{Pp})$ plastid genome structure. A Illustration of the backbone of both genomes with the relative position, size, and orientation of colinear regions (numbered 1 to 11 ). The arrow direction within each chromosome fragment indicates its relative orientation. The rRNA operons and regions exclusive to each genome are indicated (see Table 2). B The nucleotide alignment of both plastid genomes. The colinear regions are numbered as in $\mathrm{A}$.

tRNA genes present in Porphyra. The locations of all these genes are conserved between both genomes (see Table 5 in the supplementary information). Of the eight additional tRNA genes present in Porphyra, two are located at the intergenic spacer of the extra rRNA operon, and three are flanking rearrangement regions.

We identified 11 colinear regions in comparisons of the Gracilaria and Porphyra plastid genomes (Fig. 2). These 11 regions contain from 2 to 54 genes. The breaks in colinearity are due to a major inversion, four minor inversions, the deletion of the rRNA repeat, and the insertion of Gracilaria's exclusive $l e u \mathrm{C} /$ leu $\mathrm{D}$ and hypothetical ORFs. Genes coding for tRNAs are flanking 7 of the 11 breaks in colinearity. The inversion of region 5 occurred in Porphyra, breaking the conserved operon psaA-psaB-rps 14 . The inversions of regions 3,7 , and 8 appear to have occurred in Gracilaria, since the gene order of this region is conserved among Guillardia, Cyanidium, and Porphyra. When we align the Gracilaria and Porphyra plastid genomes, a clear " $\mathrm{X}$ " shape is observed (Fig. 2B), indicating inversions around the origin and/or terminus in these genomes. These Xalignments are a common feature of bacterial evolution and are evident for moderately closely related species (Eisen et al. 2000).

\section{Phylogeny}

Protein ML analysis of the 41-protein data set resulted in the phylogeny that is shown in Fig. 3A. This tree resolves nearly every node as indicated by the significant Bayesian posterior probabilities and robust support values in the MP bootstrap and quartetpuzzling analyses. The relationships within the chlorophyte and streptophyte lineages generally agree with well-accepted views, for example, the early divergences of the charophyte Chaetosphaeridium within the Streptophyta (Karol et al. 2001) and the prasinophyte Nephroselmis within the Chlorophyta (Steinkoetter et al. 1994). In addition, Gracilaria is resolved with strong bootstrap support as sister to the Bangiales red alga Porphyra purpurea. Three areas in the tree that lacked resolution were the position of the diatom Odontella sinensis within the clade of red algal and red algal-derived (i.e., chromist) plastids, the relative branching order of the hornwort + liverwort ([bryophytes] Anthoceros formosae, Marchantia polymorpha, respectively) and tracheophyte (Adiantum capillus-veneris, Psilotum nudum) lineages, and the relative position of the glaucophyte Cyanophora paradoxa with respect to the red and green plastid lineages. Use of the K-H test showed that the ML tree shown in Fig. 3A had a lower probability $(p=0.123)$ than the "best" rearranged tree that united the chromists (i.e., moving Odontella to Guillardia; difference in $\log$ likelihood units $=34.67$ is, however, nonsignificant [the converse rearrangement of moving Guillardia to Odontella was overwhelmingly rejected; $p<0.000]$ ). However, moving the bryophyte branch either inside the tracheophyte divergence or as sister to this group did not result in significantly worse trees $(p=0.363 ; p=0.066$, respectively). Moving Cyanophora to the base of all plastids also did not result in a significantly worse tree $(p=0.173)$. Interestingly, placing Mesostigma at the base of the streptophytes or the chlorophytes both resulted in significantly worse trees $(p=0.017$ and $p=0.010$, respectively). These data indicate that uncertainty remains about the divergence order of early land plants and Cyanophora and that ML analysis of the 41-protein data set does not convincingly resolve the issue of chromist monophyly. This 


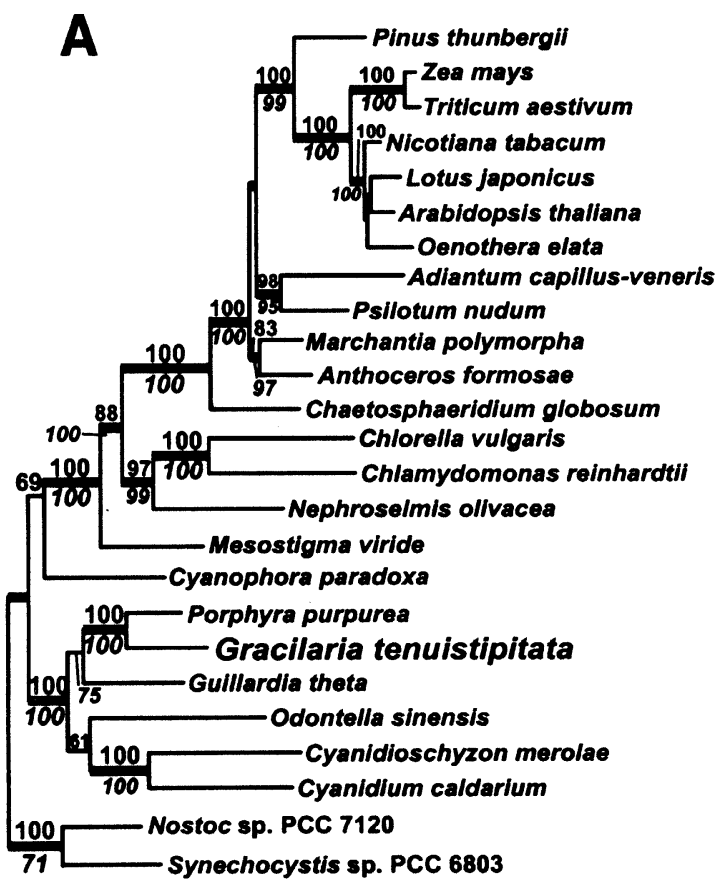

0.10 substitutions/site

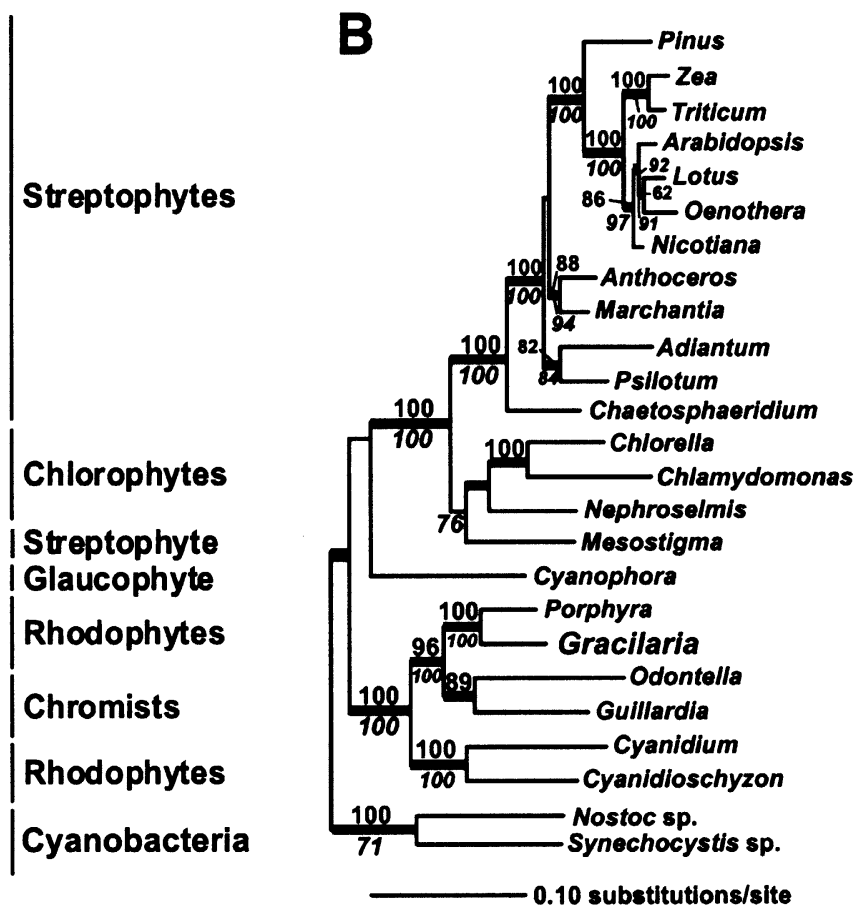

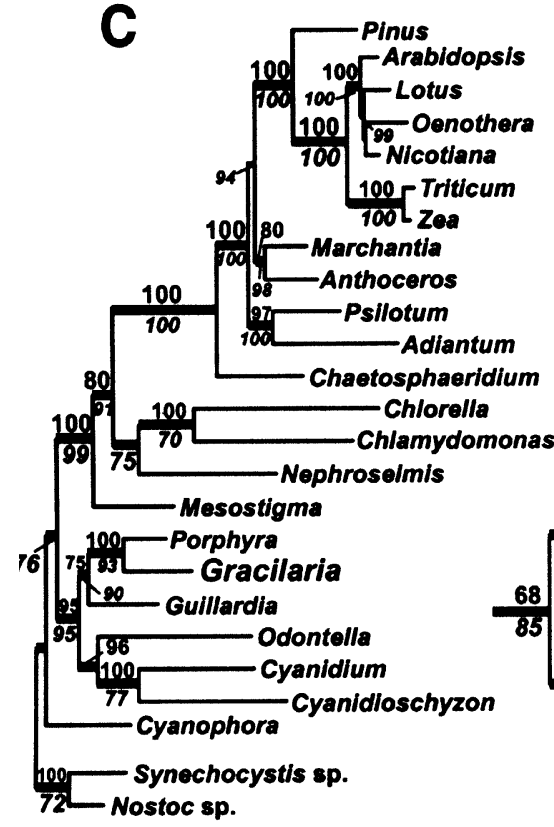

0.10 substitutions/site

Fig. 3. Phylogenetic relationships of algae and plants based on ML analysis of plastid genome data. The trees inferred from the concatenated data set of 41 proteins (A), from only PSI + II proteins $(\mathbf{B})$, and from the $\mathrm{T}+\mathrm{T}$ proteins $(\mathbf{C})$ are shown, as well as the red lineage portions of the ML trees inferred from the full photosynthesis (full PS apparatus), ATP-synthase, pet, ribosomal protein, and RNA polymerase subunit data sets (D). The Bayesian inference was run using the WAG model. The posterior probabilities (when $>95 \%$ ) inferred from this analysis are shown as the

tree strongly supports the position of Mesostigma at the base of all green plastids.

To gain additional insights into these results, we initially partitioned the 41-protein alignment into two functional groups (photosystem I + II proteins [PSI thicker branches. The values shown above the branches result from an unweighted maximum parsimony bootstrap analysis, whereas the values shown below the branches result from a quartet-puzzling maximum likelihood analysis (WAG $+\Gamma$ model). Only bootstrap or puzzle support $>60 \%$ is shown. The trees are rooted on the branch leading to the cyanobacterial sequences. The branch lengths are proportional to the number of substitutions per site (see scales in figures).

+ II, 3498 aa: psaA-C and J; psbA-F, H, L, N, and $\mathrm{T}]$ and transcription/translation proteins $[\mathrm{T}+\mathrm{T}$, 3347 aa: rp12, 14, 16, and 20; rps2-4, 7, 8, 12, 14, 18, and 19; rpoA, B, C1, and $\mathrm{C} 2]$ ) and did separate phylogenetic analyses with these data sets. The mo- 
tivation in this approach (see de Queiroz et al. 1995) was to assess whether the two different sets of interacting and presumably coevolving proteins would support congruent plastid phylogenetic histories, in particular, with regard to the areas that were unresolved in the 41-protein tree (Fig. 1A). ML analysis of the PSI + II data set (Fig. 3B) resulted in a tree that was identical to the 41-protein tree with one important well-supported difference. The stramenopile Odontella is positioned in the PSI + II as sister to the other chromist, Guillardia theta, with support in the MP and Bayesian analyses. Use of the K-H test with the PSI+II data set showed that breaking chromist monophyly by moving either Odontella $(p=0.027)$ or Guillardia $(p<0.000)$ to the base of the Cyanidiales (as in Fig. 3A) or by moving Odontella to the branch uniting Porphyra + Gracilaria $(p=0.007)$ resulted in significantly worse trees. Again, however, moving the bryophyte branch to either before the tracheophyte divergence $(p=0.424)$ or as sister to this group $(p=0.330)$ did not result in significantly worse trees. Moving Cyanophora to the base of all plastids resulted in a marginally better (difference in $\log$ likelihood units $=3.63$ is nonsignificant) tree than that shown in Fig. 3B and moving Mesostigma to the base either of the streptophytes $(p=0.243)$ or of all green plastids $(p=0.470)$ was not rejected by the K-H test. Analysis of the PSI + II data indicates therefore that considerable uncertainty remains about the divergence order of early land plants, Cyanophora, and Mesostigma but that the K$\mathrm{H}$ test (under the WAG $+\Gamma$ model) strongly supports the monophyly of chromist plastids.

ML analysis of the $\mathrm{T}+\mathrm{T}$ data set (Fig. 3C) resulted in a tree that showed ambiguity with respect to the position of Cyanophora and the relative branching order of the bryophyte and tracheophyte lineages. Odontella was, however, positioned with support as sister to the Cyanidiales red algae in the $\mathrm{T}+\mathrm{T}$ analyses. Use of the K-H test with these data showed surprisingly that despite bootstrap and Bayesian support for chromist polyphyly, uniting these taxa by moving either Odontella to Guillardia $(p=0.232)$ or vice versa $(p=0.308)$ did not result in significantly worse trees. Similar to the other data sets, moving Cyanophora either to the base of all green plastids or, in this case, to the base of the red plastids or rearranging the branch points of the bryophytes and tracheophytes relative to each other did not result in significantly worse trees. Placing Mesostigma at the base of the chlorophytes did, however, result in a significantly different log likelihood score $(p=0.024)$. Analysis of the $\mathrm{T}+\mathrm{T}$ data indicates therefore that despite bootstrap support for chromist polyphyly, this result does not hold up under the K-H test and that, like the 41-protein and PSI + II data, the divergence points of early land plants and
Cyanophora remain in question. Application of the reciprocal $70 \%$ bootstrap support criterion (MasonGamer and Kellogg 1996) showed that three wellsupported areas of conflict existed between the PSI+ II and the $\mathrm{T}+\mathrm{T}$ trees, the positions of Odontella and Mesostigma and the divergence of the first land plants. Despite considerable uncertainty about the branch points of some algal plastids (e.g., Cyanophora and Mesostigma), the monophyly of Gracilaria and Porphyra was robustly supported by the K-H test with all three data sets. Moving Gracilaria to either Odontella or Guillardia always resulted in significantly worse trees $(p<0.000)$.

Welookedinmoredetailatthephylogenyoftheredand chromist algal plastids using other functionally related subsets of the 41-protein data set. Here, the ML method was used to infer a phylogeny for the full photosynthetic protein data set (i.e., PSI + II plus ATP-synthase, ccsA, and pet proteins, $5463 \mathrm{aa}$ ), the ATP-synthase proteins (1138aa),thepetproteins(671 aa), theribosomalproteins (1623 aa), and proteins of the RNA polymerase subunits (1724 aa). The red + chromist portions of these ML trees are shown in Fig. 3D. The full photosynthesis and pet data sets supported chromist monophyly with support, whereastheATPsynthase, ribosomalproteins, andRNA polymerasedatasetsdid not.Inparticular, theribosomal protein data provided the strongest supportfor a specific association between Odontella and the Cyanidiales exclusive of Guillardia and Gracilaria + Porphyra. These sequencesmostlikelyaccountfor the phylogeneticsignal supportingchromistpolyphylyresolvedinthe41-protein tree (Fig. 3A). All the data sets, however, supported a specific evolutionary relationship between Gracilaria and Porphyra. We then compared the average WAG $+\Gamma$ distanceforeach proteindata set that wascalculated with TREE-PUZZLE. This analysis showed that the PSI + II proteins (average distance $=0.193$ ) evolve at a markedly lower rate than the $\mathrm{T}+\mathrm{T}$ proteins (average distance $=0.667-$ ca. $3.5 \times$ slower $)$. Within the $\mathrm{T}+\mathrm{T}$ data partition, the most divergent sequences were those encoding the RNA polymerase subunits (average distance $=0.736$ ). In comparison, the average pairwise distance in the ribosomal protein data set was 0.609.

\section{Discussion}

\section{Genome Structure and Gene Composition}

Red and green plastid genomes have many differences in organization in spite of the fact that they share a single origin through a putative cyanobacterial primary endosymbiosis (Bhattacharya and Medlin 1995). These discrepancies have accumulated during their long and separate evolutionary history. Green (land plants and green algae) plastid genomes contain around 110-118 genes, including 11 genes for the 
NADPH dehydrogenase complex, that are absent from nongreen lineages, and their gene content is highly conserved (Palmer 1991). In this group, the early-diverging green alga Mesostigma viride (see Fig. 3A) contains the largest known repertoire, with 135 genes (Lemieux et al. 2000). In contrast, the red lineage contains many genes that are not located on the plastid genome of green plants. Rhodophyte plastid genomes have an increased coding capacity (Reith and Munholland 1993), often containing more than twice the number of genes (232-251) common to species of the green lineage. The secondary plastids in the red lineage also encode a large number of genes (174-183), but not as many as in the primary plastids.

Most plastids from the green lineage, especially the land plants, have numerous introns. Exceptions are the ancient green algae Mesostigma viride and Nephroselmis olivacea (De Las Rivas et al. 2002). Cyanophora paradoxa (Stirewalt et al. 1995) has only one intron, an ancient group I intron in the $\operatorname{trn} \mathrm{L}$ (UUA) gene that is conserved in many cyanobacteria and plastid genomes of the green lineage (Tunnel et al. 2002; Besendahl et al. 2000; Simon et al. 2003). The $t r n \mathrm{~L}$ intron is absent from the red lineage with the exception of some brown algae (Xanthophyceae and Phaeophyceae), indicating that it was likely lost in most taxa and retained only in the stramenopiles (Simon et al. 2003). The invasion and proliferation of autocatalytic introns seem to have occurred secondarily in the green lineage and are probably associated with the substantial rearrangements seen in this lineage (Turmel et al. 2002).

Typically, plastid genomes possess two unique sequence regions and two large inverted repeats (5$30 \mathrm{~kb}$ ) containing the rRNA genes. As the number of reported genomic sequences increases, we see more and more variation in this general organization. Some angiosperm, gymnosperm, and green algal plastids do not contain the inverted repeats (Gillham 1994). In the red lineage, large repeats are absent in Gracilaria and in the Cyanidiales genera Cyanidium and Cyanidioschyzon. Porphyra purpurea has direct nonidentical repeats containing only the rRNA genes (Reith and Munholland 1993). The plastid genomes of other red algae have been mapped. The Florideophycidae species Griffithsia pacifica (Shivji et al. 1992) and Chondrus crispus (Leblanc et al. 1995) contain only one rRNA operon. In contrast, the Bangiophycidae Porphyra yezoensis encodes two operons for rRNA genes on inverted repeats (Shivji 1991), as does the cryptophyte Guillardia theta (Douglas and Penny 1999). The stramenopiles Odontella sinensis (Kowallik et al. 1995), Pylaiella littoralis (Goër et al. 1988), Olisthodiscus luteus, and Ochromonas danica (Shivji et al. 1992) contain two rRNA operons on inverted repeats. Analysis of the
rDNA operons and their flanking regions in Guillardia and Porphyra suggests that the directly repeated rDNA genes of the ancestral rhodophyte were transformed into inverted repeats in Guillardia (Douglas 1998). The Bangiales, which contains the genus Porphyra, is a sister group of the monophyletic Florideophycidae (Oliveira and Bhattacharya 2000; Müller et al. 2001). Therefore, it seems reasonable to assume that the rDNA direct repeat present in Porphyra was lost secondarily in the Florideophycidae. An independent loss of the rDNA repeat could also have occurred in Cyanidium. In the absence of additional data on basal rhodophytes, it remains unclear which arrangement of large repeats was present in the ancestral rhodophyte plastid genome.

In the red lineage, there is one major cluster that includes 26 ribosomal protein genes plus tufA, rpoA, and $\sec \mathrm{Y}$. This cluster is highly conserved in gene order and composition in the red lineage and present striking resemblance to the $s t r, \mathrm{~S} 10, s p c$, and $\alpha$ operons of E. coli (Ohta et al. 1997; Stoebe and Kowallik 1999). Ohta et al. (1997) proposed a model for the evolution of these operons in bacteria, plastids, and mitochondria. The conserved arrangement of these clusters between Synechocystis and plastids supports the monophyletic origin of plastids. They also proposed a translocation of the str cluster early after the separation of the rhodophyte lineage. In the green plastid lineage, more variability is seen in the organization of these operons. There is evidence that due to the presence of numerous introns, the plastid genome of the Streptophyta underwent substantial changes in its architecture (Turmel et al. 2002). In land plant plastid genomes, the initiation factor IF-1 (inf A) is present but they lack IF-2 and IF-3 (inf B, $\inf \mathrm{C}$, respectively [Gillham 1994]). Both inf B and $\inf \mathrm{C}$ are found only in Porphyra and Gracilaria. The cryptophyte Guillardia retains only inf B and Cyanidium only inf $\mathrm{C}$ (Glöckner et al. 2000). The diatom Odontella has lost all three genes (Kowallik et al. 1995). Given this distribution, we surmise that the ancestor of these plastids probably encoded all three translational initiation factors, which were differentially lost in the extant lineages.

Two unique genes involved in leucine biosynthesis were found in the Gracilaria plastid genome. These genes, leu $\mathrm{C}$ and $l e u \mathrm{D}$, have no homologs in any other plastid genome and are most similar to genes in Arabidopsis thaliana, the bacteria Chlorobium tepi$d u m$, and several Archaea species. Interestingly, leuC and $l e u \mathrm{D}$ are located between ORFs omp R (ycf27) and $p s b \mathrm{D}$, which are separated by only $206 \mathrm{bp}$ in Porphyra. In Cyanidium, this region (about 1200 bp) contains a hairpin loop flanked by two short repeated units that are thought to be involved in replication (Glöckner et al. 2000). The GC content of this region is $32.6 \%$, which is similar to the Gracilaria plastid 
genome GC content average of $29.1 \%$. Interestingly, when the leu $5^{\prime}$-flanking region is used to search for similarities using BLASTX (Altschul et al. 1997), the first two hits are two plasmids (3.9 and $7.2 \mathrm{~kb})$ described from Gracilaria chilensis, which have a GC content of 25\% (NC_002107, NC_002106). Considering the above, it seems probable that this region ( $\sim 4.6 \mathrm{~kb}$ ), containing the $l e u \mathrm{C}$ and $l e u \mathrm{D}$ genes, could have been originated through plasmid integration in the plastid genome of Gracilaria.

The genes chlI, B, L, and $\mathrm{N}$ that are involved in chlorophyll biosynthesis are present in Porphyra, Cyanophora, and the green alga Chlorella vulgaris (Stoebe et al. 1998), indicating their presence in the plastid common ancestor. It is interesting to note that $c h l \mathrm{~N}$ and $c h l \mathrm{~L}$ in Porphyra flank one of the direct repeats and this whole region was lost in Gracilaria. The same was observed for the green lineage, where the inverted repeat of Chaetosphaeridium globosum contains a pair of extra genes $(c h l \mathrm{~L}$ and $c h l \mathrm{~N})$ compared to the corresponding region in Marchantia cpDNA (Turmel et al. 2002).

Turmel et al. (2002) identified 12 blocks of colinear sequences when comparing the cpDNAs of the charophyte Chaetosphaeridium globosum and the bryophyte Marchantia polymorpha. We identified 11 colinear regions shared between the Gracilaria and the Porphyra plastid genomes. Seven breaks in colinearity could be due to recombination events across short repeated sequences within or near tRNA genes. The tRNA genes have been associated with cpDNA inversion in several Angiosperms (Cosner et al. 1997; Douglas 1998). The absence of tRNA genes at some break points indicates that other mechanisms must also be involved in generating inversions.

Gracilaria maintains a surprisingly ancient gene content in its plastid genome, containing one of the most complete repertoires of plastid genes known in photosynthetic eukaryotes. In this regard, Reith and Munholland (1993) concluded that the Porphyra plastid genome was more cyanobacterial-like than other algae based on the presence of a complete set of tRNAs, of genes encoding transcriptional regulators, of a larger number of genes, and of more operon-like structures similar to the ones found in cyanobacteria and the absence of introns. Based on these criteria, Gracilaria, which occupies a highly derived position in the red algal tree, in some aspects is even more cyanobacterial-like than Porphyra (e.g., the single base overlap of atpF and $\mathrm{D}$ and the presence of the $p s a \mathrm{~A}-p s a \mathrm{~B}-r p s 14$ operon). We will need, however, to get additional plastid genome data from both ancient and derived red algae to see if this is a general trend within the Bangiales-Florideophycidae lineage or whether most red algae maintain a relatively ancestral gene content and order.
Phylogeny of the Gracilaria Plastid Genome and the Red-Chromist Plastid Tree

Our concatenated protein phylogenies firmly place the plastid of Gracilaria (Florideophycidae) in the red algal lineage as sister to the bangiophyte Porphyra purpurea (Fig. 3). The close evolutionary relationship between Bangiales and florideophyte red algae has been previously proposed on the basis of morphological (e.g., type of reproductive cells [Magne 1989], association of the Golgi apparatus with the mitochondrion [Garbary and Gabrielson 1990], the presence of pit connections) and molecular phylogenetic data (Freshwater et al. 1994; Oliveira and Bhattacharya 2000; Müller et al. 2002; Yoon et al. 2002). The red algal plastids are monophyletic in all of our analyses with the exception of the highly divergent RNA polymerase and in the ATP synthase data sets.

The monophyly of the chromist plastids is recovered when the relatively more slowly evolving components of the photosynthetic apparatus such as the photosystem proteins are used in the phylogenetic analyses. The Chromista is united primarily on the basis of molecular sequence data (Fast et al. 2001; Yoon et al. 2002; Harper and Keeling 2003) and the shared character of chlorophyll $c 2$ in a four-membrane bound plastid that is located in the lumen of the endoplasmic reticulum (Cavalier-Smith 1986; Bhattacharya et al. 2004). A previous analysis by Yoon et al. (2002) that incorporated broad taxon sampling (36 species) from red and chromist algae and used a five-gene plastid data set (5827 nt) resulted in a robust tree in which nearly all the nodes had significant bootstrap and Bayesian support and which supported the monophyly of chromist plastids (i.e., supporting a single secondary endosymbiotic origin of this plastid from an early-diverging red alga). The addition of a sixth plastid gene to the DNA analyses and expansion of the taxon sampling to include green algae and land plants further strengthened this result, however, protein analyses did not provide bootstrap support for chromist monophyly (Yoon et al. 2004). Existing plastid genome trees inferred from a more limited sampling of taxa (i.e., that did not include a haptophyte) do not support chromist monophyly (e.g., Martin et al. 2002; Maul et al. 2003; Ohta et al. 2003), leaving in question the phytogeny of this plastid clade. Our present analyses do not convincingly settle this issue but provide insights into the behavior of different plastid proteins in tree reconstruction. We suggest that the lack of support for chromist monophyly, and possibly for the lack of resolution in other key nodes of the plastid genome tree (e.g., early land plant origin), may be caused by inadequate taxon sampling in these regions (e.g., Wheeler 1992; Rannala et al. 1998; Pollock et al. 2002; Zwickl and Hillis 2002) and the high diver- 
gence rates of some plastid proteins. Importantly, the K-H test results show that despite bootstrap and/ or Bayesian support to the contrary (see Fig. 3A and $\mathrm{C}$ ), the 41-protein and $\mathrm{T}+\mathrm{T}$ data sets do not robustly support the polyphyletic origin of chromist plastids.

Given large differences in divergence rates (e.g., proteins of the plastid transcription/translation apparatus evolve on average at a rate that is about $3.5 \times$ higher than photosystem proteins), a reasonable expectation is that the more slowly evolving proteins should be better markers for deep phylogenetic splits in the plastid tree. In contrast, the more highly divergent sequences would be better suited for resolving more recent phylogenetic splits. Concatenation of slowly and rapidly diverging sequences would result in the swamping of the phylogenetic signal in the former data by that in the latter. This potentially explains why the genome and $\mathrm{T}+\mathrm{T}$ trees both support chromist polyphyly, whereas the relatively more slowly evolving photosystem proteins (see also Morden and Sherwood 2002) support a different topology that is consistent with chromist monophyly (see Yoon et al. 2002; Nozaki et al. 2003; Yoon et al. 2004). In this regard, the splits in the red algal lineage are likely ancient based on molecular clock analyses that date the putative chromist secondary endosymbiosis at about 1.3 billion years ago (Yoon et al. 2004) and the fossil record which shows the potential existence of sexual red algae from this time (Butterfield 2001 [but see Cavalier-Smith 2002]). Convergence to a single well-supported chromist plastid tree will, however, likely require the addition of more genes to data sets with broad taxon sampling (e.g., Yoon et al. 2002) and the addition of more taxonomic breadth to the narrowly sampled plastid genome data sets (e.g., Martin et al. 2002; Maul et al. 2003; Ohta et al. 2003). In addition, there is a need for detailed analyses of single plastid proteins to assess their contribution to phylogenetic signal within the chromist and red algal plastid clades (H.S. Yoon, J.D. Hackett, S. Heard, D. Bhattacharya, unpublished data). The result that is apparent both here and in previous analyses (e.g., Vogl et al. 2003) is that a different plastid gene(s) often supports discordant phylogenies. Despite this vexing issue, it is also clear that most of the nodes in the plastid tree are in fact well supported. This suggests that more extensive taxon sampling may be the best approach to resolve this issue. Other aspects of the red-chromist plastid subtree that were strongly supported regardless of which data set was used are the monophyly of Gracilaria and Porphyra (also found in other studies; e.g., Oliveira and Bhattacharya 2000; Müller et al. 2002) and the resolution of the Cyanidiales as a monophyletic lineage in the red algae (Yoon et al. 2002; Ohta et al. 2003; Pinto et al. 2003; Ciniglia et al. 2004).
Acknowledgments. This work was supported by FAPESP and CNPq. D.B. was supported by a grant from the (U.S.) National Science Foundation (DEB 01-0774). J.C.H thanks the U.S. Fulbright Program, the Brazilian Fulbright Commission, and the Organization of American States for fellowships.

\section{References}

Altschul SF, Madden TL, Schaffer AA, Zhang J, Zhang Z, Miller W, Lipman DJ (1997) Gapped BLAST and PSI-BLAST: A new generation of protein database search programs. Nucleic Acids Res 25:3389-3402

Andersson JO, Roger AJ (2002) A cyanobacterial gene in nonphotosynthetic protists: an early chloroplast acquisition in eukaryotes? Curr Biol 12:115-119

Archibald JM, Rogers MB, Toop M, Ishida K, Keeling PJ (2003) Lateral gene transfer and the evolution of plastid-targeted proteins in the secondary plastid-containing alga Bigelowiella natans. Proc Natl Acad Sci USA 100:7678-7683

Besendahl A, Qiu YL, Lee J, Palmer JD, Bhattacharya D (2000) The cyanobacterial origin and vertical transmission of the plastid tRNA(Leu) group-I intron. Curr Genet 37:12-23

Bhattacharya D, Medlin L (1995) The phylogeny of plastids: A review based on comparisons of small-subunit ribosomal RNA coding regions. J Phycol 31:489-498

Bhattacharya D, Yoon HS, Hackett JD (2004) Photosynthetic eukaryotes unite: endosymbiosis connects the dots. BioEssays 26:50-60

Bock R (2001) Transgenic plastids in basic research and plant biotechnology. J Mol Biol 312:425-438

Butterfield NJ (2001) Paleobiology of the late Mesoproterozoic (ca. $1200 \mathrm{ma}$ ) hunting formation, Somerset Island, Arctic Canada. Precambr Res 111:235-256

Cavalier-Smith T (1986) The kingdoms of organisms. Nature 324:416-417

Cavalier-Smith T (2002) The neomuran origin of archaebacteria, the negibacterial root of the universal tree and bacterial megaclassification. Int J Syst Evol Microbiol 52:7-76

Ciniglia C, Yoon HS, Pollio A, Pinto G, Bhattacharya D (2004) Hidden biodiversity of the extremophilic Cyanidiales red algae. Mol Ecol 13:1827-1838

Cosner ME, Jansen RK, Palmer JD, Downie SR (1997) The highly rearranged chloroplast genome of Trachelium caeruleum (Campanulaceae): Multiple inversions, inverted repeat expansion and contraction, transposition, insertions/deletions, and several repeat families. Curr Genet 31:419-429

Cozens AL, Walker JE (1987) The organization and sequence of the genes for ATP synthase subunits in the cyanobacterium Synechococcus 6301. J Mol Biol 294:359-383

De Las Rivas J , Lozano JJ, Ortiz AR (2002) Comparative analysis of chloroplast genomes: functional annotation, genome-based phytogeny, and deduced evolutionary patterns. Genome Res 12:567-583

Delcher AL, Harmon D, Kasif S, White O, Salzberg SL (1999) Improved microbial gene identification with GLIMMER (306K, PDF format). Nucleic Acids Res 27:4636-4641

de Queiroz A, Donoghue MJ, Kim J (1995) Separate versus combined analysis of phylogenetic evidence. Annu Rev Ecol Syst 26:657-681

Douglas SE (1998) Plastid evolution: origins, diversity, trends. Curr Opin Genet Dev 8:655-661

Douglas SE, Penny SLJ (1999) The plastid genome of the cryptophyte alga, Guillardia theta: Complete sequence and conserved synteny groups confirm its common ancestry with red algae. J Mol Evol 48:236-244 
Eisen JA, Heidelberg JF, White O, Salzberg L (2000) Evidence for symmetric chromosomal inversions around the replication origin in bacteria. Genome Biol 1:0011.1-0011.9

Fast NM, Kissinger JC, Roos DS, Keeling PJ (2001) Nuclear-encoded, plastid-targeted genes suggest a single common origin for apicomplexan and dinoflagellate plastids. Mol Biol Evol 18:418-426

Felsenstein J (2002) PHYLIP (Phylogeny Inference Package) version 3.6. Department of Genetics, University of Washington, Seattle

Freshwater W, Fredericq S, Butler BS, Hommersand MH, Chase MW (1994) A gene phylogeny of the red algae (Rhodophyta) based on plastid $r b c$ L. Proc Natl Acad Sci USA 91:72817285

Garbary DJ, Gabrielson PW (1990) Taxonomy and evolution. In: Cole KM, Sheath RG (eds) Biology of the red algae. Cambridge University Press, Cambridge, pp 477-498

Gewolb J (2002) Plant scientists see big potential in tiny plastids. Science 295:258-259

Gillham NW (1994) Organelle genes and genomes. Oxford University Press, New York

Gilson P, McFadden GI (1995) The chlorarachniophyte: A cell with two different nuclei and two different telomeres. Chromosoma 103:635-641

Glöckner G, Rosenthal A, Valentin K (2000) The structure and gene repertoire of an ancient red algal plastid genome. J Mol Evol 51:382-390

Goër SL, Markowicz Y, Dalmon J, Audren H (1988) Physical maps of the two circular plastid DNA molecules of the brown alga Pylaiella littoralis (L.) Kjellm. Curr Genet 14:155-162

Goldman N, Anderson JP, Rodrigo AG (2000) Likelihood-based tests of topologies in phylogenetics. Syst Biol 49:652-670

Gordon D, Abajian C, Green P (1998) Consed: A graphical tool for sequence finishing. Genome Res 8:195-202

Gray MW (1992) The endosymbiont hypothesis revisited. Int Rev Cytol 141:233-357

Hagopian JC, Nyvall P, Oliveira MC (2002) Purification of plastid DNA from an enriched rhodoplast fraction of the red alga Gracilaria tenuistipitata. Plant Mol Biol Rep 20:399-406

Hannaert V, Saavedra E, Duffieux F, Szikora JP, Rigden DJ, Michels PA, Opperdoes FR (2003) Plantlike traits associated with metabolism of Trypanosoma parasites. Proc Natl Acad Sci USA 100:10677

Harper JT, Keeling PJ (2003) Nucleus-encoded, plastid-targeted glyceraldehyde-3-phosphate dehydrogenase (GAPDH) indicates a single origin for chromalveolate plastids. Mol Biol Evol 20:1730-1735

Huelsenbeck JP, Ronquist F (2001) MRBAYES: Bayesian inference of phylogenetic trees. Bioinformatics 17:754-755

Karol KG, McCourt RM, Cimino MT, Delwiche CF (2001) The closest living relatives of land plants. Science 294:2351-2353

Kishino H, Hasegawa M (1989) Evaluation of the maximum likelihood estimate of the evolutionary tree topologies from DNA sequence data and the branching order in hominoidea. J Mol Evol 29:170-179

Kowallik KV (1997) Origin and evolution of chloroplasts: Current status and future perspectives. In: Schenk HEA (ed) Eucariotism and symbiosis. Spring-Verlag, Berlin, pp 3-23

Kowallik KV, Stoebe B, Schaffran I, Kroth-Pancic P, Freier U (1995) The chloroplast genome of a chlorophyll a + c-containing alga, Odontella sinensis. Plant Mol Biol Rep 13:336-342

Leblanc C, Boyen C, Goër SL (1995) Organization of the plastid genome from the rhodophyte Chondrus crispus (Gigartinaels); Sequence and phylogeny of the 16S rRNA gene. Eur J Phycol 30:133-140

Lemieux C, Otis C, Turmel M (2000) Ancestral chloroplast genome in Mesostigma viride reveals an early branch of green plant evolution. Nature 403:649-652
Link G (1996) Green life: Control of chloroplast gene transcription. BioEssay 18:465-471

Löffelhardt W, Bohnert HJ, Bryant DA (1997) The complete sequence of the Cyanophora paradoxa cyanelle genome (Glaucocystophyceae). In: Bhattacharya D (ed) Origin of algae and their plastids. Springer-Verlag, Wein/New York, pp 149162

Lowe TM, Eddy SR (1997) tRNAscan-SE: A program for improved detection of transfer RNA genes in genomic sequences. Nucleic Acids Res 25:955-964

Maddison DR, Maddison WP (2002) MacClade V4.05. Sinauer Associates, Sunderland, MA

Magne F (1989) Classification et phylogéne des Rhodophycées. Crypt Algol 10:1-115

Martin W, Borst P (2003) Secondary loss of chloroplasts in trypanosomes. Proc Natl Acad Sci USA 100:765-767

Martin W, Stoebe B, Goremykin V, Hansmann S, Hasegawa M, Kowallik KV (1998) Gene transfer to the nucleus and the evolution of chloroplasts. Nature 393:162-165

Martin W, Rujan T, Richly E, Hansen A, Cornelsen S, Lins T, Leister D, Stoebe B, Hasegawa M, Penny D (2002) Evolutionary analysis of Arabidopsis, cyanobacterial, and chloroplast genomes reveals plastid phylogeny and thousands of cyanobacterial genes in the nucleus. Proc Natl Acad Sci USA 99:12246-12251

Mason-Gamer RJ, Kellogg EA (1996) Testing for phylogenetic conflict among molecular data sets in the tribe Triticeae (Gramineae). Syst Biol 45:524-545

Maul JE, Lilly JW, Cui L, DePamphilis CW, Miller W, Harris EH, Stern DB (2002) The Chlamydomonas reinhardtii plastid chromosome: Islands of genes in a sea of repeats. Plant Cell 14:2659-2679

McFadden GI (2001) Primary and secondary endosymbiosis and the origin of plastids. J Phycol 37:951

Morden CW, Sherwood AR (2002) Continued evolutionary surprises among dinoflagellates. Proc Natl Acad Sci USA 99:11558-11560

Moreira D, Le Guyader H, Phillippe H (2000) The origin of red algae and the evolution of chloroplasts. Nature 405:69-72

Muller, Oliveira MC, Sheath RG, Bhattacharya D (2001) Ribosomal DNA phylogeny of the Bangiophycidae (Rhodophyta) and the origin of secondary plastids. Am J Bot 88:1390-1400

Nozaki H, Ohta N, Matsuzaki M, Misumi O, Kuroiwa T (2003) Phylogeny of plastids based on cladistic analysis of gene loss inferred from complete plastid genome sequences. J Mol Evol 57:377-382

Ohta N, Sato N, Nozaki H, Kuroiwa T (1997) Analysis of the cluster of ribosomal protein genes in the plastid genome of a unicellular red alga Cyanidioschyzon merolae: Translocation of the str cluster as an early event in the Rhodophyte-Chromophyte lineage of plastid evolution. J Mol Evol 45:688-695

Ohta N, Matsuzaki M, Misumi O, Miyagishima SY, Nozaki H, Tanaka K, Shin-IT, Kohara Y, Kuroiwa T (2003) Complete sequence and analysis of the plastid genome of the unicellular red alga Cyanidioschyzon merolae. DNA Res 10:67-77

Oliveira EC, Paula EJ, Plastino EM, Petti R (1995) Metodologías para el cultivo no axénico de macroalgas marinas in vitro. In: Alveal K, Ferrario ME, Oliveira EC, Sar E (eds) Manual de métodos ficológicos. Universidad de Concepción, Concepción, pp 429-441

Oliveira MC, Bhattacharya D (2000) Phylogeny of the Bangiophycidae (Rhodophyta) and the secondary endosymbiotic origin of algal plastids. Am J Bot 87:482-492

Palmer JD (1991) Plastid chromosomes: Structure and evolution. In: Bogorad L, Vasil IK (eds) The molecular biology of plastids. Academic Press, San Diego, pp 5-53

Palmer JD (2003) The symbiotic birth and spread of plastids: How many times and whodunit? J Phycol 39:4-11 
Pinto G, Albertano P, Ciniglia C, Cozzolino S, Pollio A, Yoon HS, Bhattacharya D (2003) Comparative approaches to the taxonomy of the genus Galdieria merola (Cyanidiales, Rhodophyta). Crypt Algol 24:13-32

Pollock DD, Zwickl DJ, McGuire JA, Hillis DM (2002) Increased taxon sampling is advantageous for phylogenetic inference. Syst Biol 51:664-671

Rannala B, Huelsenbeck JP, Yang Z, Nielsen R (1998) Taxon sampling and the accuracy of large phytogenies. Syst Biol 47:702-710

Reith ME, Munholland J (1993) A high-resolution gene map of the chloroplast genome of the red alga Porphyra purpurea. Plant Cell 5:465-475

Reith ME, Munholland J (1995) Complete nucleotide sequence of the Porphyra purpurea chloroplast genome. Plant Mol Biol Rep 13:333-335

Schmidt, Strimmer K, Vingron M, von Haeseler A (2002) TREEPUZZLE: maximum likelihood phylogenetic analysis using quartets and parallel computing. Bioinformatics 18:502-504

Shivji MS (1991) Organization of the chloroplast genome in the red alga Porphyra yezoensis. Curr Genet 19:49-54

Shivji MS, Li N, Cattolico RA (1992) Structure and organization of rhodophyte and chromophyte plastid genomes: implications for the ancestry of plastids. Mol Gen Genet 232:65-73

Simon D, Fewer D, Friedl T, Bhattacharya D (2003) Phylogeny and self-splicing ability of the plastid tRNA-Leu group I intron. J Mol Evol 57:710-720

Steinkötter J, Bhattacharya D, Semmelroth I, Bibeau C, Melkonian M (1994) Prasinophytes form independent lineages within the Chlorophyta: Evidence from ribosomal RNA sequence comparisons. J Phycol 30:340-345

Stiller JW, Hall BD (1997) The origin of the red algae: implications for plastid evolution. Proc Natl Acad Sci USA 94:4520-4525

Stiller JW, Reel DC, Johnson JC (2003) A single origin of plastids revisited: convergent evolution in organellar genome content. J Phycol 39:95-105

Stirewalt VL, Michalowski CB, Luffelhardt W, Bohnert HJ, Bryant DA (1995) Nucleotide sequence of the cyanelle ge- nome from Cyanophora paradoxa. Plant Mol Biol Rep 13:327332

Stoebe B, Kowallik KV (1999) Gene-cluster analysis in chloroplast genomics. Trends Genet 15:344-347

Stoebe B, Martin W, Kowallik KV (1998) Distribution and nomenclature of protein-coding genes in 12 sequenced chloroplast genomes. Plant Mol Biol Rep 16:243-255

Swofford DL (2002) PAUP*: Phylogenetic analysis using parsimony (*and other methods), 4.0b8 Sinauer Associates, Sunderland, MA

Turmel M, Otis C, Lemieux C (1999) The complete chloroplast DNA sequence of the green alga Nephroselmis olivacea: Insights into the architecture of ancestral chloroplast genomes. Proc Natl Acad Sci USA 96:10248-10253

Turmel M, Otis C, Lemieux C (2002) The chloroplast and mitochondrial genome sequences of the charophyte Chaetosphaeridium globosum: Insights into the timing of the events that restructured organelle DNAs within the green algal lineage that led to land plants. Proc Natl Acad Sci USA 99:1127511280

Vogl C, Badger J, Kearney P, Li M, Clegg M, Jiang T (2003) Probabilistic analysis indicates discordant gene trees in chloroplast evolution. J Mol Evol 56:330-340

Wheeler W (1992) Extinction, sampling, and molecular phylogenetics. In: Novacek MJ, Wheeler QD (eds) Extinction and phylogeny. Columbia University Press, New York, pp 205 215

Whelan S, Goldman N (2001) A general empirical model of protein evolution derived from multiple protein families using a maximum-likelihood approach. Mol Biol Evol 18:691-699

Yoon HS, Hackett JP, Pinto G, Bhattacharya D (2002) The single, ancient origin of chromist plastids. Proc Natl Acad Sci USA 99:15507-15512

Yoon HS, Hackett J, Ciniglia C, Pinto G, Bhattacharya D (2004) A molecular timeline for the origin of photosynthetic eukaryotes. Mol Biol Evol 21:809-818

Zwickl DJ, Hillis DM (2002) Increased taxon sampling greatly reduces phylogenetic error. Syst Biol 51:588-598 


\title{
Gracilaria vermiculophylla: A western Pacific species of Gracilariaceae (Rhodophyta) first recorded from the eastern Pacific
}

\author{
Alexis M. Bellorin, ${ }^{1 *}$ Mariana C. Oliveira ${ }^{2}$ and Eurico C. Oliveira ${ }^{2}$ \\ 1Departamento de Biología, Escuela de Ciencias, Universidad de Oriente, Cumaná, Venezuela and 2Departamento de \\ Botânica, Instituto de Biociências, Universidade de São Paulo, Caixa Postal 11461, CEP 05422-970, São Paulo, Brazil
}

\section{SUMMARY}

We report Gracilaria vermiculophylla (Ohmi) Papenfuss from the Pacific coast of North America based on a morphoanatomical revision and comparison of sequences of the nuclear gene coding for the small subunit of ribosomal RNA and the internal transcribed spacers of populations from Baja California, Mexico and Hiroshima, Japan. It is the first convincing report of this species out of its center of distribution in western north Pacific, where it has been considered as a synonym of former ' $G$. verrucosa' records. G. vermiculophylla also occurs in central California as indicated by internal transcribed spacer sequences of a previously unknown Gracilaria Greville material. In the northeastern Pacific G. vermiculophylla is characterized by a robust somewhat vermiform, well-branched cylindrical thallus, with gradual cell size transition from cortex to medulla, deep spermatangial conceptacles, regular chains of carposporangia and carposporangial initials, downwardly oriented tubular nutritive cells, but rarely with upwardly oriented tubular nutritive cells. In some features of its cystocarp anatomy G. vermiculophylla is related to Gracilariopsis E. Y. Dawson or Hydropuntia Montagne and it is a relevant species for discussions about Gracilariaceae genera.

Key words: agarophytes, Gracilaria, Gracilariaceae, internal transcribed spacer, phylogeny, small subunit of ribosomal RNA.

\section{INTRODUCTION}

The well-known economic importance of gracilarioid algae (sensu Rice \& Bird 1990) as the main global sources of agar (Oliveira et al. 2000) has stimulated a number of authors to search for reliable means to identify species in this group. This interest has also been fueled through decades by the complexity of the taxonomic problems in the gracilarioids, most of which are far from being resolved. Superficially similar species may have totally different agar yields and gel quality and thus there is a need for sound identification at the species level, for utilization and marketing. Since 1980, a vast literature dealing with new species proposals, species merging, nomenclatural changes, reviews of taxonomic criteria, genera characterization and regional floras has been published (reviews in Oliveira \& Plastino 1994; Bird 1995). Almost all of the available taxonomic tools, such as anatomy and ontogeny, chemotaxonomy, antigenic studies, chromosome number, crossability, DNA fingerprinting and DNA sequencing, have been applied to species recognition, without much success except for DNA analysis and crossability tests. Recent studies have remarked that there are several species complexes, both in Gracilaria and Gracilariopsis, in which different species with similar gross morphology could be recognized only with higher-resolution taxonomic techniques (Bird et al. 1994; Goff et al. 1994; Wattier et al. 1997; Bellorin et al. 2002; Gurgel et al. 2003). Of these species complexes, the best studied has been the Gracilaria verrucosa complex (Bird \& Rice 1990; Rice \& Bird 1990), a group of cylindrical Gracilaria species with deep isolated spermatangial conceptacles recorded, erroneously in most cases, for most algal floras in the world.

Since the 1980s we have kept in our laboratory a culture of a species of the $G$. verrucosa complex from Pacific Mexico, whose correct name was suspected to be G. pacifica I. A. Abbott (Nunez-Lopez \& Valdez 1998; Garza-Sanchez et al. 2000). This name has been assumed to be the correct name for the G. verrucosa records throughout the northeastern Pacific. Hybridization trials in vitro showed that this species (as G. verrucosa Baja California) is reproductively isolated from species of the G. verrucosa complex from the Caribbean and South America (Plastino \& Oliveira 1996). In a previous paper about the phylogeny and systematics of Gracilariaceae based on DNA sequence comparisons (Bellorin et al. 2002) we established that this species is distinct from G. pacifica. However, no name

\footnotetext{
* To whom correspondence should be addressed.

Email: almiguel@yahoo.com

Communicating editor: J. A. West.
}

Received 28 February 2003; accepted 29 September 2003. 
was applied to the material from Mexico until molecular and morphoanatomical data of other species of the G. verrucosa complex from other regions was available.

Recently, we have determined the small subunit of ribosomal RNA (SSU rDNA) and internal transcribed spacer (ITS) sequences of $G$. vermiculophylla from Japan, a species of the $G$. verrucosa complex, so far known only from the northwestern Pacific (Tseng \& Xia 1999). The sequences we obtained are identical or nearly identical to those from Pacific Mexico. Likewise, no significant differences between these materials were observed in detailed morphoanatomical and reproductive ontogeny studies. Hence, we are extending the original distribution of G. vermiculophylla from the western Pacific to the Pacific coast of Mexico and California. We also discuss some reproductive anatomical features used commonly by species and generic discrimination in the Gracilariaceae.

\section{MATERIALS AND METHODS}

Anatomical observations were based on herbarium specimens housed in the Phycological Herbarium of the University of São Paulo, Brazil (SPF). The selected materials were soaked in seawater for $24 \mathrm{~h}$ and transverse or longitudinal sections were made with a razor blade or a microtome after embedding the material with historesin (Leica Instruments, Heidelberger, Germany). The sections were stained with aqueous $1 \%$ aniline blue $(A B)$, aqueous $1.6 \%$ toluidine blue $\mathrm{O}(\mathrm{Cl}$ 52040) (TBO) adjusted to $\mathrm{pH} 1.0$ with $\mathrm{HCl}$, or with Wittmann's aceto-iron-hematoxylin-chloral hydrate (WH) (Wittmann 1965). Semipermanent slides of handmade sections stained with aniline blue or toluidine blue were mounted in aqueous 30\% corn syrup (Karo, São Paolo, Brazil). Hand-sections stained with hematoxylin were mounted with $50: 50$ Hoyer's mounting medium (Hommersand \& Fredericq 1988). Microtome sections were stored dried.

DNA was extracted from a plant from Miyajima Island, Hiroshima, Japan (collected by E. C. Oliveira on 14 November, 2001; voucher specimen number SPF 56151). DNA extraction and purification, polymerase chain reaction amplification of SSU rDNA and ITS regions, and sequencing were carried out as described in Bellorin et al. (2002). The SSU rDNA and ITS sequences were compared with those from Gracilaria sp. México (GenBank accession no. AF468886 and AF468906). Phylogenetic inferences under maximum likelihood, maximum parsimony and neighbor-joining methods were maded using PAUP* 4.0 (Swofford 1998), based on datasets of Bellorin et al. (2002), updated with new published SSU rDNA and ITS sequences of Gracilaria. Robustness of inferred trees was estimated as bootstrap support values (Felsenstein 1985) with 1000-2000 replicates of heuristic searches on the $50 \%$ majority-rule consensus trees.

\section{RESULTS}

\section{Gracilaria vermiculophylla (Ohmi) Papenfuss, Papenfuss (1966)}

Synomym: Gracilariopsis vermiculophylla Ohmi, Ohmi (1956): 271, figs 1-4, pls 1,2.

Geographical distribution: This species was originally described from Akkeshi Lagoon, eastern Hokkaido, Japan (Ohmi 1956), and later for tropical and subtropical regions in the northwestern Pacific (Korea, China, Vietnam; Tseng \& Xia 1999). Here we extend the geographic distribution to the northeastern Pacific (Mexico and California), as revealed by the nearly identical ITS sequences among the specimens from Mexico (Bellorin et al. 2002; as Gracilaria sp. Mexico), California (Goff et al. 1994; as Gracilaria sp. Elkhorn Slough) and Japan (this work).

Habitat: This species forms extensive beds in the intertidal and upper sublittoral zones, attached to rocks or pebbles, often covered with sand and mud. The collection site in Baja California is an estuary. The records from California are also from an estuarine habitat (Goff et al. 1994), and the material from Miyajima Island, Japan, was found in the intertidal, on small pebbles, in the outflow of a small creek.

Specimens examined: Estero de Punta Banda (Ensenada, Baja California, Mexico), 9 October 1979, leg. M. A. Aguilar Rosas, SPF 55205 (infertile specimens); 28 April 1980, leg. R. Aguilar Rosas, SPF 55207 (seven female specimens); 28 May 1986, leg. R. Aguilar Rosas, SPF 55206 (two sheets, tetrasporangial, male and infertile specimens); July 1989, leg. E. C. Oliveira, SPF 54484 (two sheets, tetrasporangial specimens); July 1989, leg. E. C. Oliveira, SPF 54485 (seven sheets, tetrasporangial, female, male and infertile specimens obtained from in vitro cultivation); 7 March 2000, leg. J. M. Guzmán, SPF 56131, SPF 56139, SPF 56140 (tetrasporangial and female specimens); Miyajima Island (Hiroshima, Japan), 14 November 2001, leg. E. C. Oliveira, SPF 56141 (four sheets, female specimens), SPF 56142 (two sheets, male specimens), SPF 56143 (five sheets, tetrasporangial and infertile specimens).

Morphology and vegetative anatomy: This species has a thallus up to $100 \mathrm{~cm}$ long and $5 \mathrm{~mm}$ in diameter, but usually smaller and cylindrical throughout, with two to five orders of lateral branches of various sizes produced at irregular intervals in an alternate to unilateral pattern. The branches usually lack basal constrictions and are tapered toward the tips (Figs 1-3). Fresh material is fleshy and robust, somewhat vermiform, dark brown, becoming black on drying. The cell size transition from the medulla to the cortex is gradual (Figs 4-6). The cortex has three to four layers of well-pigmented cells (up to eight cell layers in tetrasporangial and spermatangial areas). Outer cortical cells are radially elongated, measuring 


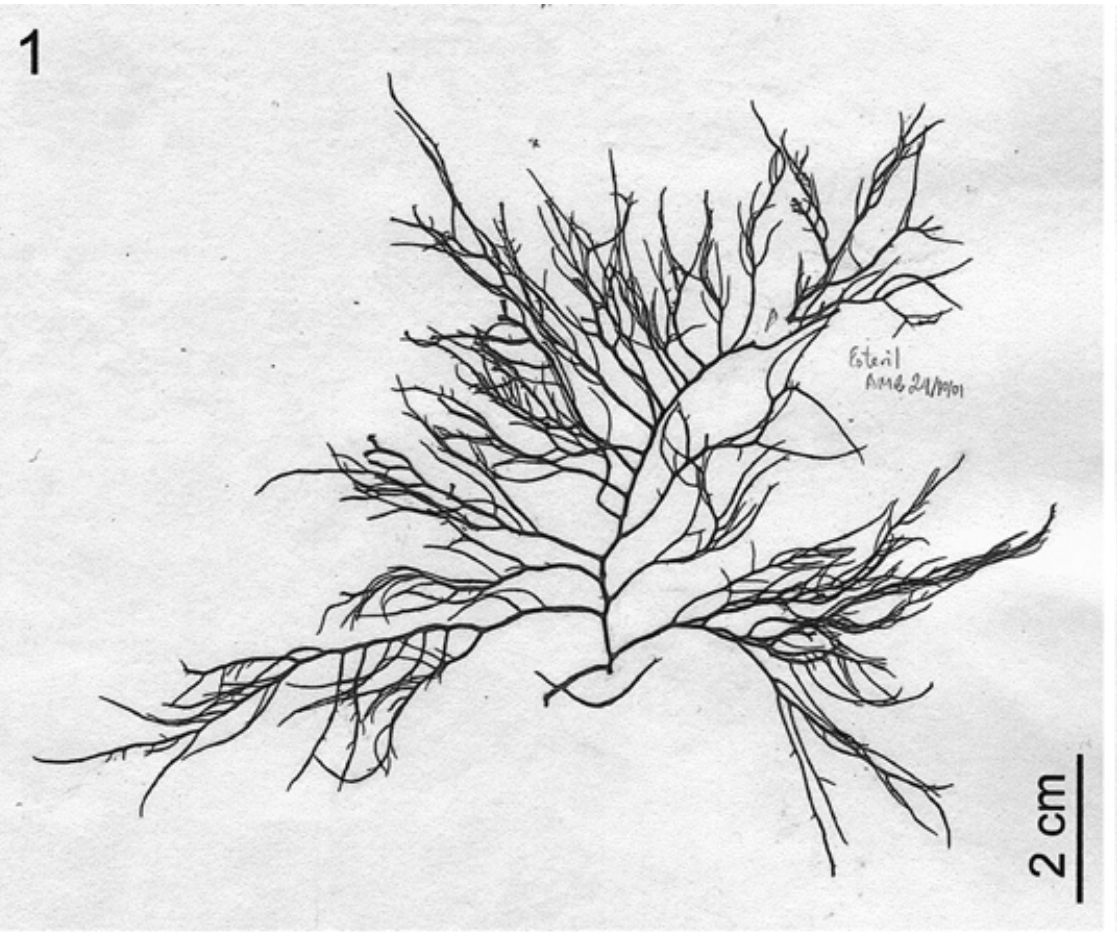

2
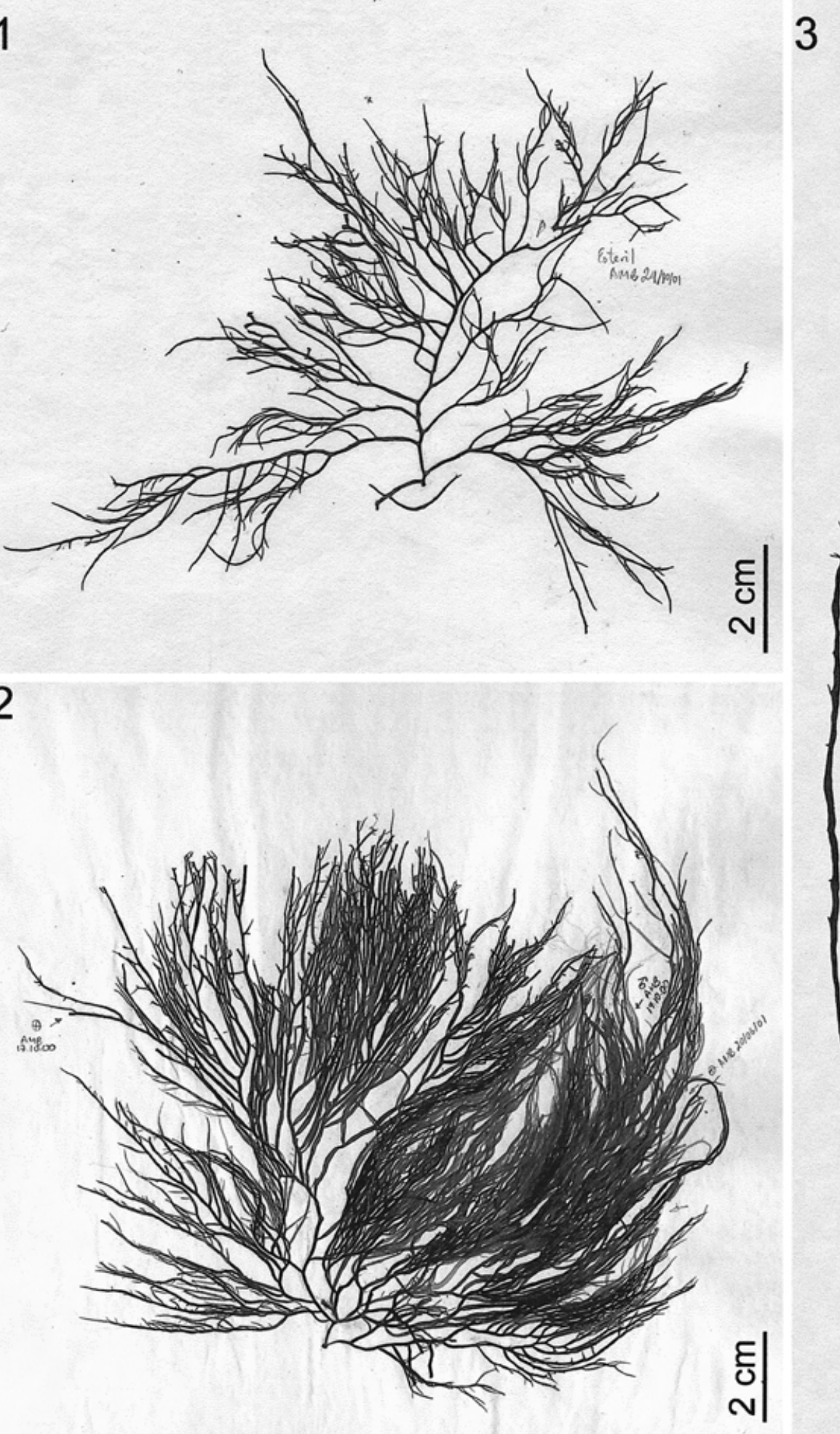

3

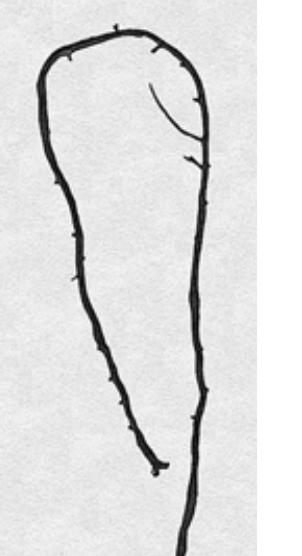



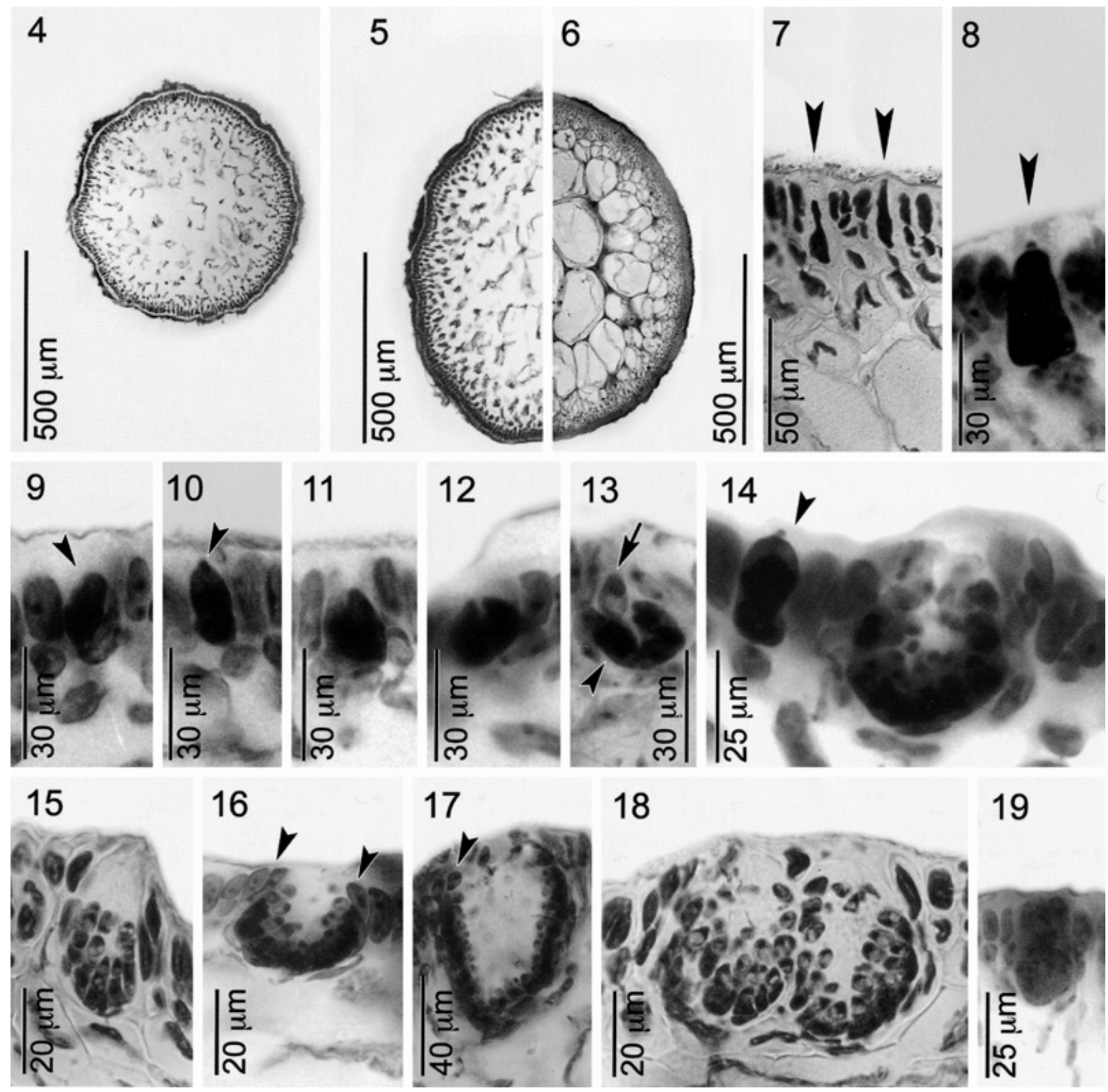

18

19

Figs 4-19. Gracilaria vermiculophylla. 4. Cross-section ( $A B)$ of female young axis (SPF 55207). 5. Cross-section ( $A B$ ) of tetrasporangial old axis (SPF 54485). 6. Cross-section (TBO) of female old axis (SPF 56139). 7. Cortex and subcortex (AB) in transverse section showing the basal cells of ephemeral hairs (arrowheads) (SPF 56139). 8. Basal cell of deciduous hair (arrowhead) (WH). Note that undifferentiated terminal cortical cells are multinucleated (SPF 55206). 9. Dividing terminal cortical cell (WH) with a longitudinal oblique concave/convex septum forming a spermatangial initial (arrowhead) (SPF 55206). 10. Differentiated spermatangial initial (arrowhead) (WH), which is a terminal cortical cell (SPF 55206). 11,12. Dividing spermatangial initials by a longitudinal oblique concave/convex septum (WH) (SPF 55206). 13. Formation of spermatangial mother cells (arrowhead) (WH) from a spermatangial initial. Note that one spermatangium (arrow) has been cut off at this stage (SPF 55206). 14. Developing shallow spermatangial conceptacle (WH) with filaments of spermatangial mother cells lining both floor and lateral walls of cavity. Note the enlarged basal cell of a deciduous hair (arrowhead) (SPF 55206). 15. Developing shallow spermatangial conceptacle (AB) with spermatangial mother cells lining only the floor of the cavity. Note that some spermatangial mother cells bear columns of two or more spermatangia (SPF 55206). 16. Developing spermatangial conceptacle (WH). Note the dividing terminal cells of spermatangial/mother cell filaments (arrowhead) (SPF 55206). 17. Deep isolated spermatangial conceptacle (WH), showing a dividing terminal cell of a spermatangial/mother cell filament (arrowhead) (SPF 55206). 18. Coalescing deep male conceptacles resembling 'henriquesiana' type (AB). Some spermatangial mother cells bears two sequentially produced spermatangia (SPF 55206). 19. Cortical decussate/cruciate tetrasporangium (WH) (SPF 54484). 
seen on old branches resulting in a partially hollow thallus. Deciduous cortical hairs are produced near the apex, as indicated by the presence of large and multinucleated, darkly stained hair basal cells (Figs 7,8,14).

Spermatangia: Spermatangia are produced in deep conceptacles (up to $90 \mu \mathrm{m}$ deep, $60 \mu \mathrm{m}$ wide) that reach the subcortex and open by an external pore ('verrucosa' type; Yamamoto, 1984) (Fig. 17). Young conceptacles may appear as shallow depressions with spermatangia limited to the cavity floor (resembling 'textorii' type) (Fig. 15) or both the cavity floor and lateral walls (Figs 14,16), becoming deeper at maturation. Conceptacles are mostly single, although some may coalesce (Fig. 18). Spermatangial mother cells produced from terminal uninucleate cortical cells ('spermatangial initials', Fredericq \& Hommersand 1989a) stain darkly with haematoxylin (Figs 9-10). Differentiated spermatangial initials can be seen near branch apices (approximately $10 \mathrm{~mm}$ ), linked to subcortical cells. A spermatangial initial first cuts off a spermatangial mother cell by a longitudinal oblique concave/convex division (Figs 11,12). Later on, both the subapical spermatangial initial and the daughter spermatangial mother cell, produce a system of filaments of spermatangial mother cells (Fig. 13). The terminal cells of these fertile filaments are elongated and divide actively, forming new spermatangial mother cells by longitudinally oblique concave/convex divisions (Figs 16-17). In a well-developed conceptacle these dividing cells are positioned at the opening of the conceptacle. Spermatangia are produced distally by an oblique division of the elongated spermatangial mother cells (Fig. 13). Usually only one spermatangium is cut off at a time from each spermatangial mother cell, although two or rarely more (up to four) sequentially produced spermatangia can remain united, resembling chains of spermatangia (Figs 15,16,18).

Female apparatus and cystocarp ontogeny: Typical gracilariacean two-celled carpogonial branches, with short trichogynes, are produced from a terminal cortical cell that acts as the supporting cell (Fig. 20). The supporting cell produces two short filaments of sterile flanking cells. A central, star-like, highly dissected fusion cell is distinguishable only at the initial stages of cystocarp development (Fig. 21). The cortical cells surrounding the fusion cell divide periclinally to form an incipient pericarp prior to gonimoblast production. These incipient pericarp cells are radially elongated, linked by primary pit connections. As the gonimoblast initials are produced from the fusion cell, the cystocarp cavity is produced progressively by a periclinal rupture, which separates the incipient pericarp from the gametophytic cells at the cystocarp floor. Few pericarp cells remain at the cystocarp floor and, therefore, no inner pericarp is formed as has been described for other species (Fredericq \& Norris 1985; Fredericq \&
Hommersand 1989b). The gonimoblast filaments arise first from the fusion cell. Later, fusions between gonimoblastic cells and gametophytic cells at the cystocarp floor give rise to a basal nutritive tissue of secondarily interconnected and highly dissected cells (Fig. 22). At this stage the fusion cell becomes indistinguishable from other cellular fusions. Upwardly oriented tubular nutritive cells (Fredericq \& Hommersand 1989a) connecting the gonimoblasts and the pericarp are observed rarely, and only in young cystocarps (Fig. 23). These cells remain linked by a primary pitconnection to sterile gonimoblastic cells close to carposporangial initials. The proximal region of tubular nutritive cells has a triangular outline and the distal region is star-like, because of secondary fusions with several gametophytic cells. Downwardly oriented tubular nutritive cells are also produced (Fig. 24) and the distal region of these cells is difficult to differentiate from other cellular fusions in the cystocarp floor. Mature cystocarps are prominent, up to $1.5 \mathrm{~mm}$ high in herbarium specimens, sometimes constricted at the base and rostrate. Inner gonimoblast cells are radially elongated, radiating from the cystocarp floor and connected by abundant secondary pit connections (Fig. 24). The carposporangia mature terminally from radially elongated chains of carposporangial initials (up to five cells) heavily stained with aniline blue. Mature carposporangia measure 15-29 $\mu \mathrm{m}$. Neither gonimoblast lobes nor upwardly oriented tubular nutritive cells were observed in mature cystocarps. Cellular fusions are still distinguishable at the floor of mature cystocarps (Fig. 24). Three cell types are usually recognized in the pericarp of mature cystocarps: (i) the outer cells (three to four cell layers), which are rounded, except the terminal ones that are radially elongated (from 5-7 to $10-17 \mu \mathrm{m})$ and not linked by secondary pit connections; (ii) the intermediate cells (6-10 cell layers), which become star-shaped due to abundant secondary pit connections; and (iii) the innermost cells, (1-4 cells in radial chains), rounded and connected only by primary pit connections (Fig. 24).

Tetrasporangia: Radially elongated tetrasporangia, up to $65 \mu \mathrm{m}$ long, are produced in the cortex (Fig. 19). Division is decussate cruciate or irregular. The cortical cells surrounding the tetrasporangia divide anticlinally, not forming a traditional nemathecial-type cortex.

Molecular data: The complete unambiguous sequence was obtained for SSU rDNA from G. vermiculophylla from Japan (GenBank accession no. AY465828). The ITS sequence was determined with some ambiguous positions (56 from $1640 \mathrm{bp}$ ) (GenBank accession no. AY465829). There are no differences between the SSU rDNA sequences of $G$. vermiculophylla from Mexico and Japan in pairwise comparisons. The actual sequence divergence between the ITS sequences in pairwise comparisons, excluding ambiguous positions, was $0.68 \%$. Based on these observations, we assume that 

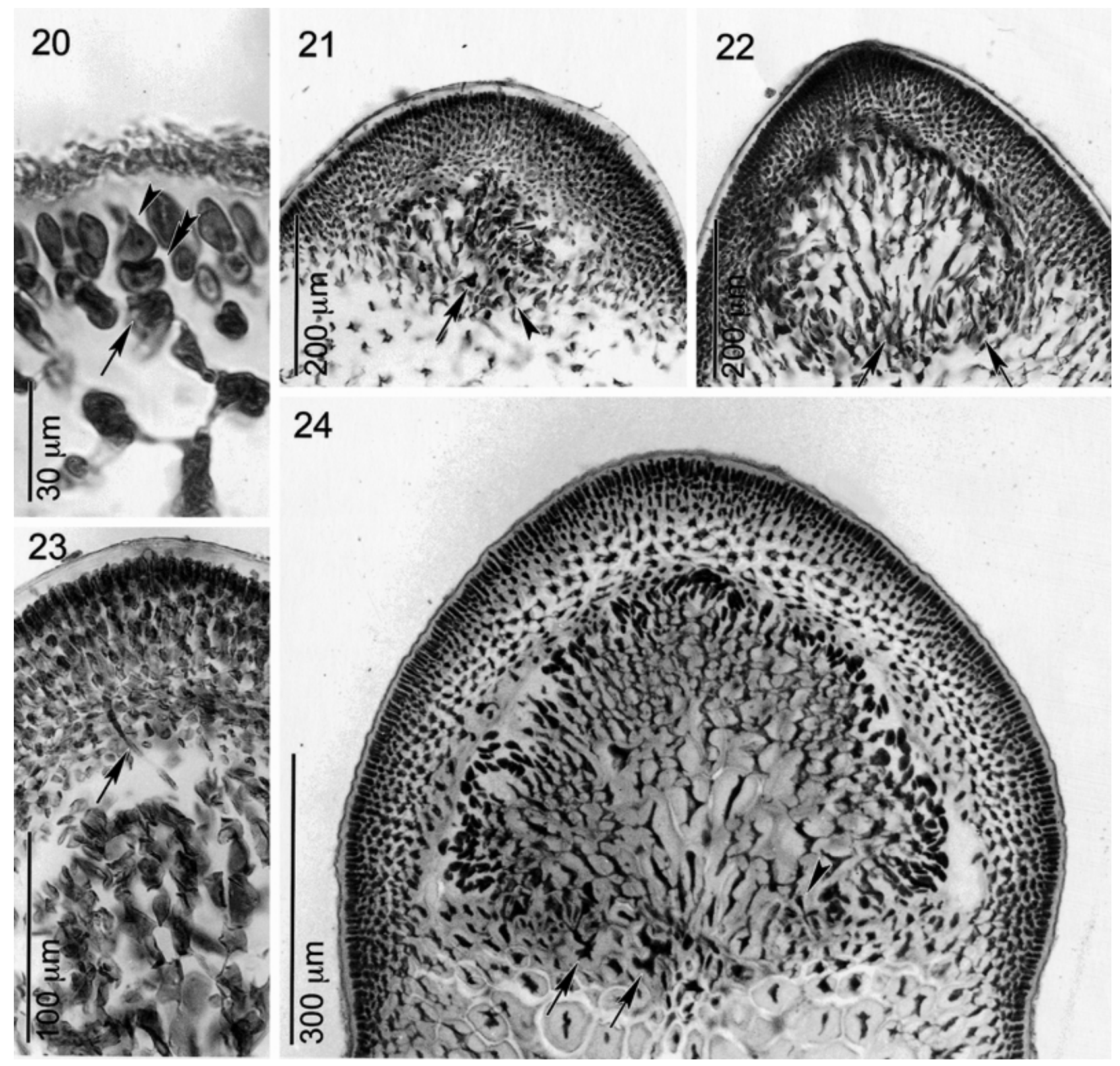

Figs 20-24. Gracilaria vermiculophylla. 20. Two-celled carpogonial branch (AB) with a terminal carpogonium (arrowhead) and a hypogynous cell (double arrowhead). One of the sterile flanking filaments produced by the support cell is shown at the left (SPF 54485). 21. Early stage of cystocarp development ( $\mathrm{AB}$ ), showing the fusion cell (arrow) and fusions between some of the inner gonimoblast cells with gametophytic cells at the cystocarp floor (arrowhead). Note that there is no inner pericarp on the cystocarp floor (SPF 56140). 22. Developing cystocarp (AB), with extensive cellular fusions at the cystocarp floor (arrows). Note that the carposporangial initials are differentiated from the distal sterile gonimoblastic cells (SPF 56140). 23. Upwardly oriented tubular nutritive cell (arrow) connecting the gonimoblast with pericarp in a young cystocarp (AB) (SPF 56140). 24. Mature cystocarp (AB) showing the basal cellular fusions (arrows) and a downwardly oriented tubular nutritive cell (arrowhead). Note that the pericarp cells are heavily connected by secondary pit connections, becoming stellate (SPF 56139).

the material studied corresponds to separate populations of a single widespread species. Phylogenetic inferences gave very similar trees to that of Bellorin et al. (2002) (results not shown). The sequences of G. vermiculophylla from Japan and Mexico were often related to other cylindrical Pacific species, namely G. chilensis and G. tenuistipitata, but strong bootstrap support was not found for this relationship.

\section{DISCUSSION}

Many taxonomic studies on Gracilaria have dealt with problems of correct identification of species around the globe that have been called $G$. verrucosa. The history of the binomial G. verrucosa (and the former synonym G. confervoides (Linnaeus) Greville) is complex and has already been reviewed exhaustively (Bird \& Rice 
1990; Rice \& Bird 1990; Irvine \& Steentoft 1995). In brief, the type locality of $G$. verrucosa is the British Isles, although this name was applied somewhat indiscriminately to any stringy and freely ramified cylindrical Gracilaria with deep spermatangial conceptacles worldwide (Fredericq \& Hommersand 1989a). Nevertheless, a convincing body of evidence from crossability tests, DNA methods and detailed morphology showed that most of these extra-European records are distinct entities from what is considered to be authentic G. verrucosa from Britain (McLachlan 1979; Bird et al. 1982; Abbott 1985; Zhang \& Xia 1985; Plastino \& Oliveira 1997). Even in the type locality, the binomial G. verrucosa was shown not to be monospecific but to encompass two distinct entities (Bird \& Rice 1990; Rice \& Bird 1990), one of which belongs to a distinct genus, Gracilariopsis longissima (S. G. Gmelin) Steentoft, L. Irvine et Farnham, and the other one to Gracilaria, now known as G. gracilis (Stackhouse) Steentoft, L. Irvine et Farnham (Steentoft et al. 1995). The former name G. verrucosa was abandoned because its lectotype belonged to a Gracilariopsis species. G. gracilis also occurs in Wales, Norway, France, Spain, Argentina and Namibia (Rice \& Bird 1990; Bird et al. 1994; Steentoft et al. 1995).

The most recent reviews of Gracilaria in the north Pacific advocate recognition of two species within the $G$. verrucosa complex, both distinct from $G$. gracilis: G. pacifica in the North American side, and G. vermiculophylla in the western side (Tseng \& Xia 1999). The records of $G$. verrucosa along the Pacific coast of North America were first treated as distinct from British Isles material because of sexual incompatibility in hybridization tests by Bird et al. (1982), based on a culture isolate from Vancouver Island. Later, Abbott (1985) proposed the binomial G. pacifica for the former G. verrucosa from California, remarking on the few morphoanatomical differences between the new species from the eastern Pacific and the British entity. Bird et al. (1992) ascribed their isolate from Vancouver Island to G. pacifica and showed that this species is closely related to $G$. gracilis (as G. verrucosa) on the basis of SSU rDNA sequences, which are nearly identical between these two species. The fast-evolving sequences of ITS and Rubisco spacer (Goff et al. 1994), as well as microsatellite comparisons (Wattier et al. 1997), confirmed later that G. pacifica is sufficiently distinct at the species level from G. gracilis, although both entities are closely related. Goff et al. (1994) also reported G. pacifica from Washington State, USA.

In the western side of the north Pacific, on the other hand, the identity of $G$. verrucosa samples remained largely uncertain. Zhang and Xia (1984) compared G. gracilis and G. pacifica (both as G. verrucosa) with the $G$. verrucosa from China and Japan, noting some differences in cystocarp anatomy. The following year these authors (Zhang \& Xia 1985) established G. asiatica J. F. Zhang et B. M. Xia to accommodate the specimens previously ascribed to $G$. verrucosa in China, also including a collection from Shinori, Hokkaido, Japan. Yamamoto and Sasaki (1988) investigated collections referred to as G.verrucosa in Japan, employing crossability tests and found interfertility between two populations identified as G. verrucosa from Hokkaido (including the material ascribed to $G$. asiatica from Shinori) and the topotype material of the poorly known $G$. vermiculophylla. They concluded that $G$. verrucosa should be merged with $G$. vermiculophylla rather than be placed under the later name $G$. asiatica, given the nomenclatural priority. The binomial G. vermiculophylla was later applied to all former G. verrucosa records in the northwestern Pacific, including China, Korea, Vietnam and Japan (Yoshida et al. 1995; Yoshida 1998; Tseng \& Xia 1999).

The first DNA sequence data of a $G$. verrucosa complex species from Asia was the SSU rDNA sequence of an isolate referred to as $G$. verrucosa from Hokkaido (unspecified locality), Japan (Bird et al. 1992). This sequence was nearly identical to others of the G. gracilis group (as G. verrucosa from Europe and Argentina) and it was suspected that this Japanese isolate belonged to the same species as European and Argentinean specimens (Bird et al. 1992). However, a reanalysis of DNA samples in the $\mathrm{C}$. J. Bird collection using four single loci microsatellites and ITS size variation (Wattier et al. 1997) showed that the isolate from Japan is distinct from authentic G. gracilis from Europe, Argentina and Namibia. At the moment, no name has been applied to this isolate and its taxonomic status remains uncertain.

Recently, one of us (E. C. Oliveira) collected G. verrucosa samples from Miyajima Island, Hiroshima, Japan. Our anatomical observation on this species confirmed the presence of deep, separate spermatangial conceptacles typical of the G. verrucosa complex, but the cystocarps differed from typical $G$. verrucosa in having few upwardly directed tubular nutritive cells (most were downwardly directed), small protoplasmrich gonimoblasts cells and rather regular chains of carposporangia (A. Bellorin, unpubl. data, 2002), among other features. We ascribed this material to G. vermiculophylla (Ohmi) Papenfuss sensu Yamamoto (1978). The SSU rDNA of this material was completely divergent from that of $G$. verrucosa from Japan determined by Bird et al. (1992). Instead, the SSU rDNA and ITS sequences of this entity were identical or nearly identical to those of the unknown Gracilaria species from California and Mexico previously studied by Goff et al. (1994; as Gracilaria sp. Elkhorn Slough) and by us (Bellorin et al. 2002; as Gracilaria sp. Mexico). We conclude that our materials from Mexico and Japan belong to the same species (G. vermiculophylla) and that this species is distinct from the $G$. verrucosa from 
Japan studied by Bird et al. (1992). This finding confirms the previous suspicion that at least two species have been confused under $G$. verrucosa in Japan (Yamamoto \& Sasaki 1988). The species studied by Bird et al. (1992) appears to be closely related to G. gracilis and G. pacifica, according to SSU rDNA sequences, while $G$. vermiculophylla has been weakly related to other Pacific species, namely G. chilensis and G. tenuistipitata (Goff et al. 1994; Bellorin et al. 2002). This increases considerably the distribution of G. vermiculophylla in the Pacific. The question of how many species of the $G$. verrucosa complex occurs in Japan and, by extension, in Asia remains open. Likewise, it should be concluded that the application of binomial G. vermiculophylla to all of the G. verrcuosa materials in Asia, as proposed by Tseng and Xia (1999), is questionable. The confusion that results from combining superficially similar species into a single taxon was already noticed for $G$. blodgettii in Japan (Terada \& Yamamoto 2000), in which G. shimodensis R. Terada and H. Yamamoto was confused with the presumably authentic G. blodgettii Harvey.

Gracilaria vermiculophylla was first proposed as Gracilariopsis vermiculophyla by Ohmi (1956), based on a population from Akkeshi Lagoon, Hokkaido Island, Japan. At that time, the generic concept of Gracilariopsis (Dawson 1949) was related to the absence of tubular nutritive cells and other cystocarpic features, without any consideration of spermatangial configuration. Thus, as Ohmi (1956) did not observe tubular nutritive cells in cystocarps of material from Akkeshi Lagoon, he treated his new species as Gracilariopsis. When Papenfuss (1966) called for the submergence of Gracilariopsis into Gracilaria, he transferred Gracilariopsis vermiculophylla to Gracilaria. Some downwardly directed tubular nutritive cells were later observed in material from Akkeshi Lagoon (Yamamoto 1978) and, as this species presents deep spermatangial conceptacles, a feature associated with the modern Gracilaria concept, the placement into Gracilaria was not further discussed. The SSU rDNA and ITS sequences of G. vermiculophylla from Japan and Mexico determined by us confirm this generic placement. Basic morphological and anatomical features of G. vermiculophylla have already been described for Japanese specimens by Ohmi (1956) and Yamamoto (1978). In this work, we provide a description of material from Mexico, describing for the first time the male apparatus and cystocarp formation in the species.

Gracilaria vermiculophylla was considered to be restricted to the type locality in the cold water regions of Japan (Yamamoto 1978, 1984). In fact, its general morphology was described based on specimens from a lagoon in which the plants maintain the vermiform morphology, the scarce to absent tubular nutritive cells in cystocarps and the small-celled gonimoblasts (Yamamoto 1978; Yamamoto \& Sasaki 1988). However, when G. verrucosa populations from other localities were studied and shown to be conspecific with G. vermiculophylla by Yamamoto and Sasaki (1988), it became clear just how morphologically variable this species is. Interestingly, the hybrids between G. vermiculophyla from the type locality and the former $G$. verrucosa from Japan showed intermediate numbers of tubular nutritive cells (Yamamoto \& Sasaki 1988), which corroborate the marked intraspecific variation of this character (see Bird 1995). The data of Yamamoto (1984) showing that G. vermiculophylla is a euryhaline and eurythermal species may explain the wider geographic distribution found in this study.

The weak evolutionary relationships among G. vermiculophylla, G. chilensis and G. tenuistipitata inferred from SSU rDNA and ITS nucleotide sequences (Bellorin et al. 2002) were also inferred from Rubisco spacer sequence comparisons (Goff et al. 1994, G. vermiculophylla as Gracilaria sp. Elkhorn Slough). Gracilaria chilensis and $G$. tenuistipitata were also considered to be related in comparisons of $r b c \mathrm{~L}$ sequences (Gurgel \& Fredericq 2002). These evolutionary relationships are morphologically supported by cystocarp anatomy, although these traits should be considered with caution as they may be quite variable intraspecifically (G. vermiculophylla is a good example of this). All of these cylindrical species: (i) rarely produce tubular nutritive cells connecting the gonimoblast to the upper pericarp, although downwardly or laterally oriented tubular nutritive cells are frequent; (ii) have gonimoblast inner cells highly connected by secondary pit connections; (iii) have cellular fusions at the cystocarp floor; and (iv) produce orderly arrays of carposporangial initials and a non-deeply lobed gonimoblast (A. M. Bellorin, unpubl. data, 2002). However, there are some important differences: (i) in G. chilensis and G. tenuistipitata, the generative fusion cell can be generally recognized even in mature cystocarps (A. M. Bellorin, unpubl. data, 2002), which is not the case in G. vermiculophylla; (ii) in G. chilensis, a differentiated inner pericarp (cytologically modified cells derived from cortical gametophytic cells in the cystocarp floor, see Fredericq \& Hommersand 1989b) is clearly distinguishable in mature cystocarps, as well as vertically elongated cellular fusions through secondary pit connections between some of the basal gonimoblast cells and inner pericarp cells (Bird et al. 1990; Nelson \& Ryan 1991; A. M. Bellorin, unpubl. data, 2002). An inner pericarp is not present in G. vermiculophylla or G. tenuistipitata (A. M. Bellorin, unpubl. data, 2002).

The mature male apparatus of $G$. vermiculophylla is distinct from G. chilensis and $G$. tenuistipitata in having deep male conceptacles rather than shallow ones. However, there are no fundamental differences in the ontogeny of male conceptacles between G. vermiculophylla and $G$. chilensis. In both species the spermatangial initials are terminal cortical cells that produce a system 
of filaments of spermatangial mother cells (Ryan \& Nelson 1991). In addition, the young spermatangial conceptacles of $G$. vermiculophylla are shallow and are quite similar to the textorii type described in G. chilensis (Nelson 1987; Ryan \& Nelson 1991). Unfortunately, we do not know the spermatangial ontogeny in $G$. tenuistipitata.

The position of the spermatangial initials was used to define discrete types of male conceptacles (Fredericq \& Norris 1985; Fredericq \& Hommersand 1989a, $1989 \mathrm{~b})$. According to these authors, in the textorii type the spermatangial initials are derived from terminal cortical cells, whereas in the verrucosa type the spermatangial initials are derived from intercalary cortical cells. G. vermiculophylla, however, has verrucosa-type spermatangia produced from terminal cortical cells. Moreover, we have observed verrucosa-type spermatangia originated from terminal spermatangial initials in other species (A. M. Bellorin, unpubl. data, 2002), thereafter the verrucosa and textorii types are not necessarily distinct in origin. These results, together with the conflicting observations about the male apparatus ontogeny already reported in the literature (Yamamoto 1973, Fredericq \& Norris 1985; Fredericq \& Hommersand 1989a; Abbott et al. 1991; Ryan \& Nelson 1991; Terada \& Yamamoto 2000), show that the recognized patterns of spermatangial types are not so clear cut as originally expected, at least among species that have spermatangia within conceptacles. Thus, although usually useful in species recognition, the 'types' of spermatangial conceptacles may not have major evolutionary importance and, in fact, can not be established as synapomorphies (Bird et al. 1992; Bellorin et al. 2002).

Gracilaria vermiculophylla presents some of the cystocarp features proposed as descriptors for the genus Gracilariopsis (Fredericq \& Hommersand 1990), as was discussed for $G$. chilensis by Nelson and Ryan (1991). The species also presents some features associated with the generic or subgeneric concept of Hydropuntia (Fredericq \& Hommersand 1990), a taxon that is currently unsustainable in light of morphological (Bird 1995) and molecular (Bellorin et al. 2002) data. Emphasis should be placed on the downwardly oriented tubular nutritive cells that were proposed as being of diagnostic value in the original Hydropuntia proposal (Chang \& Xia 1963, as Polycavernosa C. F. Chang et B. M. Xia). Our studies with $G$. vermiculophylla show that the orientation of these cells may be quite variable among populations. The other Hydropuntia basic feature, the compound henriquesiana-type spermatangia, is widespread in several unrelated groups of Gracilaria species (Bellorin et al. 2002), and can not be utilized as a descriptor for any generic or subgeneric taxon.

Gracilaria vermiculophylla and G. tenuistipitata, as was previously remarked for G. chilensis (Nelson \& Ryan 1991; Bird 1995), provide further support for the submergence of Hydropuntia into Gracilaria. Additionally, as these three species also combine Gracilariopsis and Gracilaria features, two genera sufficiently distinct according to a strong body of molecular evidence (Bird et al. 1992, 1994; Goff et al. 1994; Bellorin et al. 2002; Gurgel \& Fredericq 2002), the morphological boundaries between these genera should be redefined, specially in regard to the inner pericarp differentiation (a proposed feature of Gracilariopsis widespread into Gracilaria, A. M. Bellorin, unpubl. data, 2002) and the mode of production of carposporangia (as there are several Gracilaria species with straight chains of carposporangia, e.g. Terada et al. 2000, a proposed feature of Gracilariopsis). The next step in the systematics of gracilarioid algae should be the morphological characterization of the infrageneric lineages of Gracilariopsis and Gracilaria established in molecular comparisons, as well as a revision of the status of many poorly known species.

\section{ACKNOWLEDGMENTS}

We thank J. M. Guzmán for supplying material for DNA analysis and J. Zertuche for help in specimen collection. Financial support was provided by FAPESP, Brazil. AMB acknowledge CONICIT, Venezuela, for Ph.D. scholarship. MCO and ECO acknowledge CNPq, Brazil. We acknowledge C. J. Bird, M. Hommersand and W. Nelson for critically reviewing the manuscript and for valuable suggestions.

\section{REFERENCES}

Abbott, I. 1985. New species of Gracilaria Grev. (Gracilariaceae, Rhodophyta) from California and Hawaii. In Abbott, I. A. and Norris, J. N. (Eds) Taxonomy of Economic Seaweeds. California Sea Grant College Program, La Jolla, California, pp. 115-21.

Abbott, I. A., Zhang, J. and Xia, B. 1991. Gracilaria mixta sp. nov. and other western Pacific species of the genus (Rhodophyta: Gracilariaceae). Pacific Sci. 45: 12-27.

Bellorin, A. M., Oliveira, M. C. and Oliveira, E. C. 2002. Phylogeny and systematics of the marine algal family Gracilariaceae (Gracilariales, Rhodophyta) based on SSU rDNA and ITS sequences of Atlantic and Pacific species. J. Phycol. 38: 551-63.

Bird, C. J. 1995. A review of recent taxonomic concepts and development in the Gracilariaceae (Rhodophyta). J. Appl. Phycol. 7: 255-67.

Bird, C. J., Nelson, W. A., Rice, E. L., Ryan, K. G. and Villemur, R. 1990. A critical comparison of Gracilaria chilensis and G. sordida (Rhodophyta, Gracilariales). J. Appl. Phycol. 2: 375-82.

Bird, C. J., Ragan, M. A., Critchley, A. T., Rice, E. L. and Gutell, R. R. 1994. Molecular relationships among the Gracilariaceae (Rhodophyta): further observations on some undetermined species. Eur. J. Phycol. 29: 195-202. 
Bird, C. J. and Rice, E. L. 1990. Recent approaches to the taxonomy of the Gracilariaceae (Gracilariales, Rhodophyta) and the Gracilaria verrucosa problem. Hydrobiologia 204/ 205: 111-18.

Bird, C. J., Rice, E. L., Murphy, C. A. and Ragan, M. A. 1992. Phylogenetic relationships in the Gracilariales (Rhodophyta) as determined by $18 \mathrm{~S}$ rDNA sequences. Phycologia 31: 510-22.

Bird, C. J., van der Meer, J. P. and McLachlan, J. 1982. A comment on Gracilaria verrucosa (Huds.) Papenf. (Rhodophyceae, Gigartinales). J. Mar. Biol. Ass. UK 62: 453-9.

Chang, C. F. and Xia, B. 1963. Polycavernosa, a new genus of the Gracilariaceae. Stud. Mar. Sinica 3: 119-26.

Dawson, E. Y. 1949. Studies of northeast Pacific Gracilariaceae. Allan Hancock Found. Publs Occ. Pap. 7: 1-105.

Felsenstein, J. 1985. Confidence limits on phylogenies: an approach using bootstrap. Evolution 39: 783-91.

Fredericq, S. and Hommersand, M. H. 1989a. Proposal of the Gracilariales ord. nov. (Rhodophyta) based on an analysis of the reproductive development of Gracilaria verrucosa. J. Phycol. 25: 213-27.

Fredericq, S. and Hommersand, M. H. 1989b. Comparative morphology and taxonomic status of Gracilariopsis (Gracilariales, Rhodophyta). J. Phycol. 25: 228-41.

Fredericq, S. and Hommersand, M. H. 1990. Diagnoses and key to the genera of the Gracilariaceae (Gracilariales, Rhodophyta). Hydrobiologia 204/205: 173-8.

Fredericq, S. and Norris, J. N. 1985. Morphological studies on some tropical species of Gracilaria Grev. (Gracilariaceae, Rhodophyta): taxonomic concepts based on reproductive morphology. In Abbott, I. A. and Norris, J. N. (Eds) Taxonomy of Economic Seaweeds. California Sea Grant College Program, La Jolla, California, pp. 137-55.

Garza-Sanchez, F., Zertuche-Gonzalez, J. A. and Chapman D. J. 2000. Effect of temperature and irradiance on the release, attachment and survival of spores of Gracilaria pacifica Abbott (Rhodophyta). Bot. Mar. 43: 205-12.

Goff, L. J., Moon, D. A. and Coleman, A. W. 1994. Molecular delineation of species and species relationships in the red algal agarophytes Gracilariopsis and Gracilaria (Gracilariales). J. Phycol. 30: 521-37.

Gurgel, C. F. D. and Fredericq, S. 2002. Filogenética, taxonomia e biogeografia da família Gracilariaceae (Gracilariales, Rhodophyta). Abstract of IX Brazilian Meeting of Phycology. Brazilian Society of Phycology, Santa Cruz, Aracruz, Espíritu Santo, 261.

Gurgel C. F. D., Liao L. M., Fredericq S. and Hommersand, M. H. 2003. Systematics of Gracilariopsis (Gracilariales, Rhodophyta) based on rbcL sequence analyses and morphological evidence. J. Phycol. 39: 154-71.

Hommersand, M. and Fredericq, S. 1988. An investigation of cystocarp development in Gelidium pteridifolium with a revised description of the Gelidiales (Rhodophyta). Phycologia 27: 254-72.

Irvine, L. and Steentoft, M. 1995. Proposal to reject the name Fucus verrucosus Huds. (Rhodophyta). Taxon 44: 223-4.
McLachlan, J. 1979. Gracilaria tikvahiae sp. nov. (Rhodophyta, Gigartinales, Gracilariaceae) from the northwestern Atlantic. Phycologia 18: 19-23.

Nelson, W. A. 1987. The New Zealand species of Gracilaria Greville (Rhodophyta, Gigartinales). NZ J. Bot. 25: 87-98.

Nelson, W. A. and Ryan, K. G. 1991. Comparative study of reproductive development in two species of Gracilaria (Gracilariales, Rhodophyta). II. Carposporogenesis. Crypt. Bot. 2: 234-41.

Nunez-Lopez, R. A. and Valdez, M. C. 1998. Seasonal variation of seaweed biomass in San Ignacio Lagoon, Baja California Sur, Mexico. Bot. Mar. 41: 421-6.

Ohmi, H. 1956. On a new species of the genus Gracilariopsis with some considerations on its ecology. Bull. Fac. Fish. Hokkaido University 6: 271-9.

Oliveira, E. C., Alveal, K. and Anderson, R. J. 2000. Mariculture of the agar-producing gracilarioid red algae. Rev. Fish. Sci. 8: 345-77.

Oliveira, E. C. and Plastino, E. M. 1994. Gracilariaceae. In: Akatsuka, I. (Ed.) Biology of Economic Algae. SPB Academic Publishing, Netherlands, pp. 185-226.

Papenfuss, G. F. 1966. Notes on algal nomenclature V. Various Chlorophyceae and Rhodophyceae. Phykos 5: 95-105.

Plastino, E. M. and Oliveira, E. C. 1996. Approaches to the identification of terete Brazilian Gracilariaceae (Gracilariales, Rhodophyta). Hydrobiologia 326/327: 145-8.

Plastino, E. M. and Oliveira, E. C. 1997. Gracilaria caudata J. Agardh (Gracilariales, Rhodophyta): restoring an old name for a common western Atlantic alga. Phycologia 36: 225-32.

Rice, E. L. and Bird, C. J. 1990. Relationships among geographically distant populations of Gracilaria verrucosa (Gracilariales, Rhodophyta) and related species. Phycologia 29: 501-10.

Ryan, K. G. and Nelson, W. A. 1991. Comparative study of reproductive development in two species of Gracilaria (Gracilariales, Rhodophyta). I. Spermatogenesis. Crypto. Bot. 2: 229-33.

Steentoft, M., Irvine, L. M. and Farnham, W. F. 1995. Two terete species of Gracilaria and Gracilariopsis (Gracilariales, Rhodophyta) in Britain. Phycologia 34: 113-27.

Swofford, D. L. 1998. PAUP* Phylogenetic Analysis Using Parsimony (*and Other Methods), version 4. Sinauer Associates, Sunderland, MA, USA.

Terada, R., Baba, M. and Yamamoto, H. 2000. New record of Gracilaria firma Chang et Xia (Rhodophyta) from Okinawa, Japan. Phycol. Res. 48: 291-4.

Terada, R. and Yamamoto, H. 2000. A taxonomic study of two Japanese species of Gracilaria: Gracilaria shimodensis sp. nov. and Gracilaria blodgettii (Gracilariales, Rhodophyta). Phycol. Res. 48: 189-98.

Tseng, C. K. and Xia, B. 1999. On the Gracilaria in the western Pacific and the southeastern Asia Region. Bot. Mar. 42: 209-17.

Wattier, R., Dallas, J. F., Destombe, C., Saumitou-Laprade, P. and Valero, M. 1997. Single locus microsatellites in 
Gracilariales (Rhodophyta): high level of genetic variability within Gracilaria gracilis and conservation in related species. J. Phycol. 33: 868-80.

Wittmann, W. 1965. Aceto-iron-haematoxylin-chloral hydrate for chromosome staining. Stain Technol. 40: 161-4.

Yamamoto, H. 1973. The development of the male reproductive organ of Gracilaria verrucosa (Huds.) Papenfuss. Bull. Jap. Soc. Phycol. 21: 130-2.

Yamamoto, H. 1978. Systematic and anatomical study of the genus Gracilaria. Japan. Bull. Fac. Fish. Hokkaido University 25: 97-152.

Yamamoto, H. 1984. An evaluation of some vegetative features and some interesting problems in Japanese populations of Gracilaria. Hydrobiologia 116/117: 51-4.
Yamamoto, H. and Sasaki, J. 1988. Interfertility between socalled Gracilaria verrucosa (Huds.) Papenfuss and G. vermiculophylla (Ohmi) Papenfuss in Japan. Bull. Fac. Fish. Hokkaido University 39: 1-3.

Yoshida, T. 1998. Marine Algae of Japan. Uchida Roukakuho, Tokyo, $25+1222$ pp. (in Japanese).

Yoshida, T., Yoshinaga, K. and Nakajima, Y. 1995. Check list of marine algae of Japan. Jpn J. Phycol. 43: 115-71.

Zhang, J. and Xia, B. 1984. Some problems in the taxonomy of Chinese species of Gracilaria (Rhodophyta). Hydrobiologia 116/117: 59-62.

Zhang, J. and Xia, B. 1985. On Gracilaria asiatica sp. nov. and G. verrucosa (Huds.) Papenfuss. Oceanol. Limnol. Sinica 3: 175-80. 


\title{
Molecular phylogeny of Bangiales (Rhodophyta) based on small subunit rDNA sequencing: emphasis on Brazilian Porphyra species
}

\author{
Daniela Milstein and Mariana Cabral de Oliveira* \\ Departamento de Botânica, Instituto de Biociências, Universidade de São Paulo, Caixa Postal 11461, CEP 05422-970, \\ São Paulo, Brazil
}

\begin{abstract}
D. Milstein and M. C. De Oliveira. 2005. Molecular phylogeny of Bangiales (Rhodophyta) based on small subunit rDNA sequencing: emphasis on Brazilian Porphyra species. Phycologia 44: 212-221.

In an attempt to clarify the position of the Brazilian Porphyra species within the order Bangiales, phylogenetic trees were inferred on the basis of nuclear small subunit ribosomal RNA gene (SSU rDNA) sequences. The internal transcribed spacers ITS-1 and ITS-2 and the 5.8S rRNA gene were sequenced for discrimination of the closely related species Porphyra drewiana, $P$. spiralis var. spiralis and $P$. spiralis var. amplifolia. Occurrence of SSU rDNA group I introns is reported for some Porphyra species and a novel position for a group I intron is described for Bangiopsis sp. (Porphyridiales). The Brazilian species, $P$. acanthophora var. acanthophora, $P$. acanthophora var. brasiliensis, $P$. drewiana, $P$. spiralis var. amplifolia, P. spiralis var. spiralis and Porphyra sp. 'Piaui' formed a monophyletic group within a large polytomy that includes Bangia collections and Porphyra species from distinct locations. The Brazilian species Porphyra sp. 'Baleia' grouped strongly with $P$. suborbiculata from Japan and New Zealand, indicating that this cosmopolitan species also occurs in the South Atlantic. South African P. capensis grouped with two New Zealand species.
\end{abstract}

\section{INTRODUCTION}

The genus Porphyra C. Agardh occurs in several locations along the Brazilian coast, but it is more abundant and diversified in the subtropical region (Oliveira 1977). The species described for the Brazilian coast are $P$. acanthophora Oliveira \& Coll var. acanthophora, P. acanthophora var. brasiliensis Oliveira \& Coll, $P$. spiralis Oliveira \& Coll var. spiralis, $P$. spiralis var. amplifolia Oliveira \& Coll (Oliveira \& Coll 1975), P. drewiana Coll \& Oliveira (Coll \& Oliveira 2001), $P$. leucosticta Thuret in Le Jolis, $P$. pujalsii Coll \& Oliveira and $P$. rizzinii Coll \& Oliveira. The last three species were described from Uruguay (Coll \& Oliveira 1976) and were later found in an upwelling zone north of Rio de Janeiro (Yoneshigue 1985).

Before Oliveira \& Coll (1975), P. vulgaris C. Agardh, P. laciniata (Lightfoot) C. Agardh var. umbilicata C. Agardh, P. roseana Howe and $P$. atropurpurea (Olivi) De Toni had been recorded for the Brazilian coast. However, as these species were never found again in Brazil, those authors considered their occurrence as uncertain in the region.

Yoshida et al. (1997) refer to the existence of 133 species worldwide, remarking that the taxonomy of the group still remains problematic. The genus Porphyra has a simple morphology and includes cryptic species as well as species with phenotypic plasticity (Stiller \& Waaland 1993). These and other features make the identification of species quite difficult, which can be a problem in a genus of economic importance. Imprecision in the taxonomy of the genus also has serious implications in ecological studies (Brodie et al. 1996).

These difficulties have stimulated several authors to use molecular biological techniques to study this group. Isozyme analysis (Lindstrom \& Cole 1992, 1993), restriction fragment

* Corresponding author (mcdolive@ib.usp.br). length polymorphisms - RFLP (Stiller \& Waaland 1993; Teasdale et al. 2002) and random amplified polymorphic DNA RAPD (Kuang et al. 1998; Mizukami et al. 1998) have been used in the last decade in an attempt to throw some light on the genetic diversity, species recognition and phylogeny within the order Bangiales. Recently, gene sequencing has been the most-used technique in phylogenetic reconstruction of the group.

The nuclear small subunit ribosomal RNA gene (SSU rDNA) was sequenced for Porphyra phylogenetic reconstruction (Oliveira 1993; Oliveira et al. 1995; Broom et al. 1999), biogeographic and systematic studies of Bangia (Müller et al. 1998, 2003) and for discrimination of Porphyra species (Broom et al. 1999; Kunimoto et al. 1999a; Nelson et al. 2001; Klein et al. 2003). The internal transcribed spacers of the ribosomal array (ITS-1 and ITS-2), which evolve faster than SSU rDNA, are suitable for Porphyra-population identification (Kunimoto et al. 1999b) and for species recognition (Broom et al. 2002). The plastid-encoded ribulose-1, 5-biphosphate carboxylase-oxygenase (RuBisCo) large subunit gene $(r b c \mathrm{~L})$ and the intergenic spacer between it and the small subunit gene $(r b c \mathrm{~S})$ have also been used for distinguishing Porphyra species (Brodie et al. 1996, 1998; Neefus et al. 2000; Teasdale et al. 2002; Klein et al. 2003) and for phylogeny, biogeography and systematic analysis of Bangia (Müller et al. 1998, 2003) and Porphyra (Teasdale et al. 2000; Klein et al. 2003; Lindstrom \& Fredericq 2003).

The occurrence of group I introns inserted in the nuclear SSU rDNA of some collections of Bangia and some Porphyra species have been reported (Stiller \& Waaland 1993; Oliveira \& Ragan 1994; Müller et al. 1998, 2001a; Kunimoto et al. 1999a). These introns have been used as molecular markers for strain recognition (Oliveira \& Ragan 1994; Kunimoto et al. 1999b), for phylogenetic analysis (Müller et al. 2001a) and species discrimination (Broom et al. 2002). 
Table 1. Porphyra species sequenced in this study and collection information. (SFP, Institute of Biosciences Phycological Herbarium, University of São Paulo, Brazil).

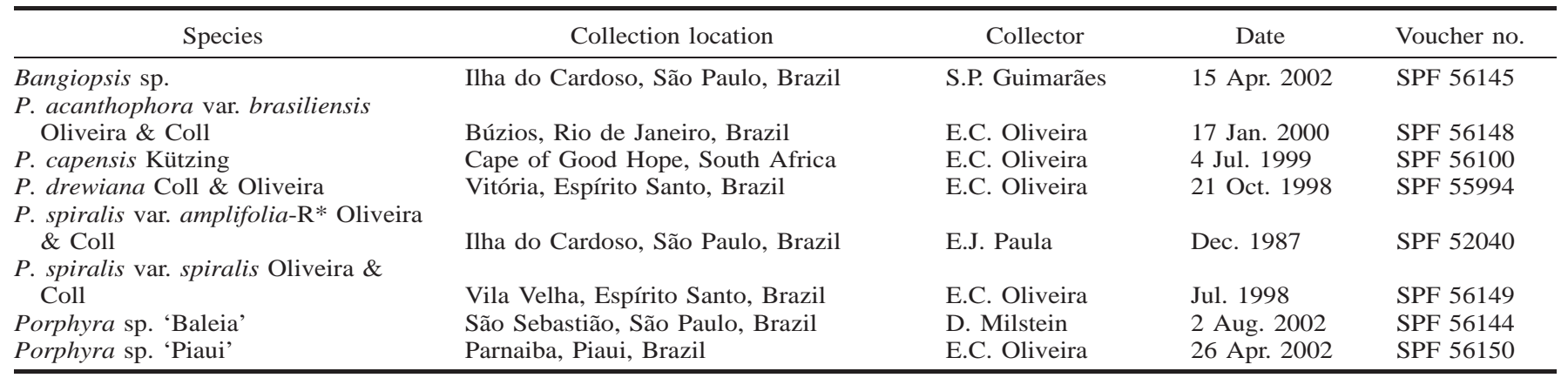

* Conchocelis phase in culture in the Marine Algae Lab (LAM) at University of São Paulo, São Paulo.

In this study, we have sequenced the nuclear SSU rDNA of five Brazilian and one South African Porphyra species and a Bangiopsis species for phylogenetic reconstruction and species discrimination. The SSU rDNA introns were sequenced when present. The nuclear ITS (i.e. ITS-1, 5.8S rDNA and ITS-2) were sequenced when the SSU rDNA sequences were conserved between specimens identified as belonging to different species. Some relevant Porphyra and Bangia SSU rDNA sequences available in the GenBank database were included in these analyses to provide a general view of the Brazilian taxa within the order Bangiales.

\section{MATERIAL AND METHODS}

\section{DNA extraction}

Samples collected for the present study and voucher specimens deposited in the herbarium of University of São Paulo (SPF) are listed in Table 1. The thalli collected for DNA extraction were previously screened for epiphytes using a stereomicroscope and stored in silica gel before being ground in liquid nitrogen. Total genomic DNA was extracted using the DNeasy Plant Mini Kit (Qiagen, Santa Clarita, CA, USA) according to the manufacturer's specifications.

\section{Polymerase chain reaction amplification and sequencing}

Primers for amplification and sequencing are listed in Table 2. Primers $18 \mathrm{~S} 5^{\prime}$ and $18 \mathrm{~S} 33^{\prime}$ were used for the amplification of the SSU rDNA; primers $1400 \mathrm{~F}$ and $28 \mathrm{~S}^{\prime} \mathrm{R}$ were used for the amplification of the ITS region. Due to the presence of introns in some samples, the size of the SSU rDNA was larger than $1.8 \mathrm{~Kb}$. Therefore, it was necessary to amplify the SSU rDNA in two overlapping pieces. In those cases, the primers 530F and 536R were combined with $18 \mathrm{~S} 3^{\prime}$ and $18 \mathrm{~S}^{\prime}$, respectively. For the ITS amplification, when an intron was present in the $3^{\prime}$ end of the SSU rDNA, the primer $1400 \mathrm{~F}$ was replaced by the internal primer $\mathrm{iF}(3)$ located next to the $3^{\prime}$ end of the intron.

Polymerase chain reaction (PCR) amplification conditions for a total volume of $50 \mu \mathrm{l}$ were $1 \times$ PCR buffer, $1.5 \mathrm{mmol}$ of $\mathrm{MgCl}_{2}, 0.2 \mathrm{mmol}$ of each dNTP, $0.2 \mu \mathrm{mol}$ of each primer, around $2 \mathrm{ng}$ of genomic DNA and $1.25 \mathrm{U}$ of Taq DNA polymerase (GibcoBRL, Life Technologies, Gaithersburg, MD, USA). All PCR reactions were performed in a thermocycler GeneAmp PCR System 2400 (Applied Biosystems, Foster City, CA, USA) as follows: $94^{\circ} \mathrm{C}$ for $4 \mathrm{~min}, 35$ cycles of $94^{\circ} \mathrm{C}$ for $30 \mathrm{sec}, 60^{\circ} \mathrm{C}$ for $1 \mathrm{~min}$ and $72^{\circ} \mathrm{C}$ for $2 \mathrm{~min}$, and a final extension step at $72^{\circ} \mathrm{C}$ for $7 \mathrm{~min}$. For amplifying the ITS region, the same parameters were used except for the annealing

Table 2. Synthetic oligonucleotide primers used for amplification and sequencing of the SSU rDNA and ITS. Primers obtained or modified from a. Sogin (1990); b. this paper, c. Bird et al. (1992); d. Oliveira \& Ragan (1994); e. Bellorin et al. (2002).

\begin{tabular}{|c|c|c|}
\hline Primers & Sequences & $\begin{array}{c}\text { Region and position } \\
\text { in } P . \text { spiralis var. amplifolia }\end{array}$ \\
\hline $18 \mathrm{S5}^{\prime}$ (a) & $5^{\prime}$-CAACCTGGTTGATCCTGCCAGT-3' & SSU rDNA, 1 \\
\hline $530 \mathrm{~F}(\mathrm{~b})$ & $5^{\prime}-$ GAGGGCAAGTCTGGTG-3' & SSU rDNA, 550 \\
\hline $536 \mathrm{R}(\mathrm{c})$ & $5^{\prime}-$ GAATTACCGCGGCTGCTG-3' & SSU rDNA, 584 \\
\hline $690 \mathrm{~F}(\mathrm{c})$ & 5'-TCTCAGAGGTGAAATTCT-3' & SSU rDNA, 912 \\
\hline $690 \mathrm{R}(\mathrm{c})$ & $5^{\prime}-\mathrm{AGAATTTCACCTCTG}-3^{\prime}$ & SSU rDNA, 929 \\
\hline $1055 \mathrm{~F}(\mathrm{c})$ & $5^{\prime}-$ GGTGGTGCATGGCCG-3' & SSU rDNA, 1286 \\
\hline $1055 \mathrm{R}(\mathrm{c})$ & $5^{\prime}-\mathrm{CGGCCATGCACCACC}-3^{\prime}$ & SSU rDNA, 1300 \\
\hline $1400 \mathrm{~F}$ (d) & $5^{\prime}-\mathrm{TGTACACACCGCCCGTC}-3^{\prime}$ & SSU rDNA, 1659 \\
\hline $1400 \mathrm{R}(\mathrm{c})$ & $5^{\prime}-\mathrm{ACGGGCGGTGTGTACA}-3^{\prime}$ & SSU rDNA, 1676 \\
\hline $\mathrm{iF}(3)(\mathrm{d})$ & $5^{\prime}$-CGCTGGATGGTAATAAGGTG-3' & Intron-1506, 2580 \\
\hline $18 \mathrm{~S} 3^{\prime}$ (a) & 5'-GATCCTTCTGCAGGTTCACCTACGGAA-3' & SSU rDNA, 2860 \\
\hline $18 \mathrm{~S} 3{ }^{\prime} \mathrm{F}(\mathrm{b})$ & $5^{\prime}-$ TAGGTGAACCTGCGGAAGGAT-3' & SSU rDNA, 2865 \\
\hline $5.8 \mathrm{SF}$ (b) & $5^{\prime}-$ GATACAACTCTTAGCG-3' & 5.8S rDNA, 3277 \\
\hline 5.8SR (b) & $5^{\prime}-$ CGCTAAGAGTTGTATC-3' & 5.8S rDNA, 3292 \\
\hline $285^{\prime} \mathrm{R}(\mathrm{e})$ & $5^{\prime}$-ATATGCTTAARTTCAGCGGGT-3' & LSU rDNA, 3941 \\
\hline
\end{tabular}


Table 3. SSU rDNA sequences from Bangia collections and Porphyra species included in this study. A, north Atlantic.

\begin{tabular}{|c|c|c|c|}
\hline Collection & $\begin{array}{c}\text { GenBank } \\
\text { accession nos. }\end{array}$ & Location & Reference \\
\hline Bangia fuscopurpurea & AF175530 & Antarctic & Müller et al. (2001a) \\
\hline B. fuscopurpurea & AF175531 & Australia & Müller et al. (2001a) \\
\hline B. fuscopurpurea & AF043363 & $\mathrm{NC}, \mathrm{USA}(\mathrm{A})$ & Müller et al. (1998) \\
\hline B. fuscopurpurea & AF043357 & Newfoundland, Canada (A) & Müller et al. (1998) \\
\hline Porphyra acanthophora var. acanthophora & L26197 & Brazil & Ragan et al. (1994) \\
\hline P. acanthophora var. brasiliensis & AY766359 & Brazil & This work \\
\hline P. amplissima & L36048 & Canada (A) & Oliveira et al. (1995) \\
\hline P. capensis & AY766361 & South Africa & This work \\
\hline P. cinnamomea & AF136418 & New Zealand & Nelson et al. (2001) \\
\hline P. coleana & AF136423 & New Zealand & Nelson et al. (2001) \\
\hline P. dentata & $\mathrm{AB} 013183$ & Japan & Kunimoto et al. (1999a) \\
\hline P. drewiana & AY766362 & Brazil & This work \\
\hline P. katadae & AB013184 & Japan & Kunimoto et al. (1999a) \\
\hline P. leucosticta & L26199 & Canada (A) & Ragan et al. (1994) \\
\hline P. miniata & L26200 & Canada (A) & Ragan et al. (1994) \\
\hline P. purpurea & L26201 & Canada (A) & Ragan et al. (1994) \\
\hline$P$. rakiura & AF136425 & New Zealand & Nelson et al. (2001) \\
\hline Porphyra sp. 'Baleia' & AY766358 & Brazil & This work \\
\hline Porphyra sp. 'Piaui' & AY766357 & Brazil & This work \\
\hline Porphyra sp. GRB 108 & AF136420 & New Zealand & Broom et al. (1999) \\
\hline Porphyra sp. LGD30 & AF136422 & New Zealand & Broom et al. (1999) \\
\hline P. spiralis var. spiralis & AY766360 & Brazil & This work \\
\hline P. spiralis var. amplifolia & L26177 & Brazil & Oliveira \& Ragan (1994) \\
\hline P. suborbiculata & AB013180 & Japan & Kunimoto et al. (1999a) \\
\hline P. suborbiculata & AF136424 & New Zealand & Broom et al. (1999) \\
\hline P. tenera & $\mathrm{AB} 013176$ & Japan & Kunimoto et al. (1999a) \\
\hline P. umbilicalis & L26202 & Canada (A) & Ragan et al. (1994) \\
\hline P. yezoensis & AB013177 & Japan & Kunimoto et al. (1999a) \\
\hline
\end{tabular}

temperature, which was reduced to $55^{\circ} \mathrm{C}$. To ensure the purity of the reagents in all PCR reactions, a negative control that included all reagents except DNA template was done. PCR products were purified using the MicroSpin S-300 HR Columns (Amersham Pharmacia Biotech, Piscataway, NJ, USA).

At least three independent PCR reactions were pooled together for each fragment sequenced (Baldwin et al. 1995). PCR products were directly sequenced using standard methods on an ABI PRISM 310 Genetic Analyser or 377 DNA Sequencer (Applied Biosystems).

Sequences were identified by comparison with available sequences in GenBank using BLASTN (Altschul et al. 1990). Sequences were manually assembled with ESEE 3.2 (Cabot \& Beckenbach 1989), and divergent positions within the same individual sequence were double checked. All sequences were submitted to GenBank, and accession numbers are listed in Table 3.

\section{Alignments and phylogenetics inferences}

Bangia and Porphyra SSU rDNA sequences were manually aligned using ESEE 3.2 according to the secondary structure prediction obtained from the European Small Subunit Ribosomal RNA database (Van de Peer et al. 2000). Complete sequences of the SSU rDNA from some relevant Bangia collections and Porphyra species were imported from GenBank (Table 3) and included in the alignments as well as the sequences from species chosen as outgroups: Bangiopsis subsimplex (Montagne) Schmitz (GenBank accession no. AF168627), Bangiopsis Schmitz sp. (this work, AY766363), Erythrotrichia carnea (Dillwyn) J. Agardh (L26189) and Erythrocladia Rosenvinge sp. (L26188). Sequences correspond- ing to the amplification primers $18 \mathrm{~S}^{\prime}$ and $18 \mathrm{~S} 3^{\prime}$, introns, insertions/deletions (indels) and variable regions that could not be unambiguously aligned were removed from the alignments. This yielded a final matrix of 32 sequences with 1733 positions.

All phylogenetic analyses were performed with PAUP $4.0 b 8$ (Swofford 2000). An appropriate evolution model was selected using Modeltest 3.06 (Posada \& Crandall 1998). The selected model estimated from our data was Tamura \& Nei (1993) with the following base frequencies: $\mathrm{A}=0.2591, \mathrm{C}=$ $0.2023, \mathrm{G}=0.2607, \mathrm{~T}=0.2780$. Base substitution model was determined as $[\mathrm{A} \leftrightarrow \mathrm{C}, \mathrm{A} \leftrightarrow \mathrm{T}, \mathrm{C} \leftrightarrow \mathrm{G}, \mathrm{G} \leftrightarrow \mathrm{T}]=$ 1.0000, $[\mathrm{A} \leftrightarrow \mathrm{G}]=2.1963$ and $[\mathrm{C} \leftrightarrow \mathrm{T}]=4.6683$. The proportion of invariable sites considered was 0.4787 and the gamma distribution rate parameter was 0.5571 for rate heterogeneity on variable sites.

The trees were inferred with three different methods. For the distance method, a neighbour-joining (NJ) tree (Saitou \& Nei 1987) was built with the Tamura \& Nei (1993) substitution model. A maximum parsimony (MP) tree was inferred by heuristic search, with starting trees obtained by stepwise addition, with random sequence addition (10 replicates) using the tree bisection-reconnection (TBR) branch-swapping algorithm. The number of parsimony-informative sites was 435 . In both NJ and MP trees, gaps were treated as missing data and all sites were weighted equally. Bootstrap analyses (Felsenstein 1985) were performed with 2000 replicates for the methods described above.

The maximum likelihood (ML) analysis was performed with heuristic search using the TBR algorithm, with starting trees obtained via stepwise addition as described for the MP 
Table 4. Percentage of sequence identity between SSU rDNA exon of the south Atlantic Porphyra species. Sequences corresponding to amplification primers $18 \mathrm{~S}^{\prime}$ and $18 \mathrm{~S}^{\prime}$ ' were excluded from the pairwise comparison. Paa, Porphyra acanthophora var. acanthophora; Pab, P. acanthophora var. brasiliensis; Pcap, P. capensis; Pdrew, P. drewiana; Psa, P. spiralis var. amplifolia; Pss, P. spiralis var. spiralis; Pbal, Porphyra sp., 'Baleia'; Ppia, Porphyra sp. 'Piaui'.

\begin{tabular}{lcccccccc}
\hline & Paa & Pab & Pcap & Pdrew & Psa & Pss & Pbal & Ppia \\
\hline Paa & - & - & - & - & - & - & - & - \\
Pab & 99.5 & - & - & - & - & - & - & - \\
Pcap & 90.7 & 90.9 & - & - & - & - & - & - \\
Pdrew & 93.6 & 93.9 & 91.2 & - & - & - & - & - \\
Psa & 93.5 & 93.8 & 91.2 & 99.8 & - & - & - & - \\
Pss & 93.4 & 93.7 & 91.0 & 99.7 & 99.7 & - & - & - \\
Pbal & 93.8 & 94.1 & 91.3 & 93.6 & 93.6 & 93.4 & - & - \\
Ppia & 95.1 & 95.4 & 90.6 & 93.0 & 92.9 & 92.7 & 93.1 & - \\
\hline
\end{tabular}

tree. Other specifications were estimated with Modeltest as described above. Bootstrap resampling was done for 42 replicates due to computational limitations.

For all analyses, bootstrap values were considered low up to $70 \%$, moderate from $71 \%$ to $90 \%$, and high above $90 \%$. The sequence alignments are available on request.

\section{RESULTS}

\section{SSU rDNA}

The complete SSU rDNA was sequenced for individuals belonging to all species in Table 1, except for $P$. spiralis var. amplifolia-R sequenced in Oliveira \& Ragan (1994). Exon length ranged from 1816 base pairs (bp) in P. capensis Kützing to $1840 \mathrm{bp}$ in $P$. acanthophora var. brasiliensis. Pair-wise comparisons between the species are shown in Table 4. The identity values between Brazilian species varied from $92.7 \%$ to $99.8 \%$ and between varieties of the same species from $99.5 \%$ to $99.7 \%$. The SSU rDNA exon of Porphyra sp. 'Baleia' was identical to that of $P$. suborbiculata Kjellman from Japan (AB 013180) and had 99.8\% identity with the SSU rDNA exon of $P$. suborbiculata from New Zealand (AF 136424), differing in four nucleotide substitutions. The SSU rDNA exon of Bangiopsis sp. with 1788 bp was $99.8 \%$ identical to Bangiopsis subsimplex SSU rDNA (AF168627) from Puerto Rico with only four nucleotide substitutions.

\section{ITS}

We have sequenced the ITS region for one individual per species: $P$. drewiana, $P$. spiralis var. spiralis and $P$. spiralis var. amplifolia-R (Table 1). We had access to the same culture material of $P$. spiralis var. amplifolia-R used for SSU rDNA sequencing by Oliveira \& Ragan (1994). The ITS array has 1028 bp in $P$. spiralis var. amplifolia- $\mathrm{R}$ and $P$. spiralis var. spiralis, and $1027 \mathrm{bp}$ in $P$. drewiana. The identity between $P$. drewiana and both varieties of $P$. spiralis was $99.6 \%$, whereas that between the two varieties $P$. spiralis var. amplifolia- $\mathrm{R}$ and $P$. spiralis var. spiralis was $99.4 \%$.

\section{Intron}

The occurrence of group I introns in the SSU rDNA was observed for some Porphyra species studied. Porphyra capensis and Porphyra sp. 'Baleia' presented two group I introns inserted in the SSU rDNA. The first one is inserted close to the SSU rDNA $5^{\prime}$ end at the position 516 (516 intron) and the second is inserted just before the $3^{\prime}$ end at the position 1506 (1506 intron). The locations of the introns are given according to the reference position in $E$. coli SSU rDNA. The $P$. capensis 516 intron had $665 \mathrm{bp}$ and the 1506 intron had $594 \mathrm{bp}$. The Porphyra sp. 'Baleia' 516 intron had 492 bp and the 1506 intron had 574 bp. Porphyra drewiana had only the 1506 intron with 1057 bp. Porphyra sp. 'Baleia' and P. capensis 516 introns were inserted in the exonic SSU rDNA flanking region GTCTGGTG-CCAGCAGCC. Porphyra sp. 'Baleia', $P$. capensis and $P$. drewiana 1506 introns were inserted in the exonic SSU rDNA flanking region CAAGGT-TTCCGTA.

Porphyra sp. 'Baleia', $P$. capensis and $P$. drewiana intron sequences were compared with other introns in Bangia and Porphyra specimens using BLASTN, with the following results: Porphyra sp. 'Baleia' 516 and 1506 introns were 100\% identical to $P$. suborbiculata (AF 378665$) 516$ and 1506 group IC1 introns, respectively.

The $P$. capensis 516 intron showed $64.4 \%$ identity with that of Porphyra sp. isolate GRB 108 (AF136420), whereas the 1506 introns of both species had $58.2 \%$ identity. The $P$. $c a$ pensis 1506 intron had $67.7 \%$ identity with that of Porphyra sp. isolate LGD 030 (AF136422). The 1506 intron of $P$. drewiana showed $99.6 \%$ identity with the $P$. spiralis var. amplifolia-R (L26177) 1506 group I intron, differing by three indels and one transition.

The individuals of $P$. acanthophora var. brasiliensis, $P$. spiralis var. spiralis and Porphyra sp. 'Piaui' analysed in this study did not possess introns in their SSU rDNA.

Bangiopsis sp. SSU rDNA presented an intron with $764 \mathrm{bp}$ inserted in the exonic SSU rDNA flanking region GGGGGGAGT-ATGGTCGCA, close to the 943 intron insertion site (Bhattacharya \& Oliveira 2000). This intron has shown $47.9 \%$ identity with the Ascomycota Pneumocystis carinii P. Delanoë \& Delanoë 26S rDNA group I intron (L13615).

\section{Phylogenetic analyses}

Figs 1 and 2 show bootstrap 50\% majority-rule consensus NJ and MP trees, respectively. Bootstrap values for the ML tree were plotted on the MP tree branches. The structure of the three trees was not identical, although the general topology was quite similar. The NJ tree diverged from the MP and ML trees in the branch leading to the Brazilian species. The only differences between the MP and ML trees concern the ordering of species that are not the main focus of the present study.

The order Bangiales is monophyletic with high support for all the analyses (100\% bootstrap), considering the outgroups here included. The trees revealed two monophyletic sister groups, G1 (bootstrap values: $80 \%$ for $\mathrm{NJ}, 83 \%$ for MP and 93\% for ML) and G2 (bootstrap values: $92 \%$ for NJ, 93\% for MP and $100 \%$ for ML). Both G1 and G2 include Bangia collections and Porphyra species from distinct geographic locations.

In G1, a well-supported (100\% bootstrap) clade of B. fuscopurpurea collections root a group of Porphyra species (bootstrap values: $80 \%$ for NJ and $87 \%$ for MP) that includes P. capensis from South Africa together with two Porphyra sp. 
80

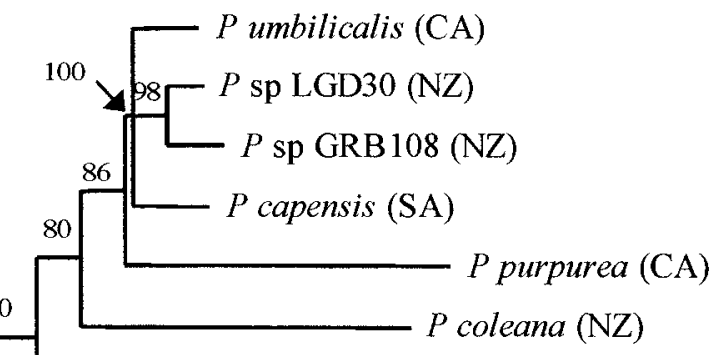

100

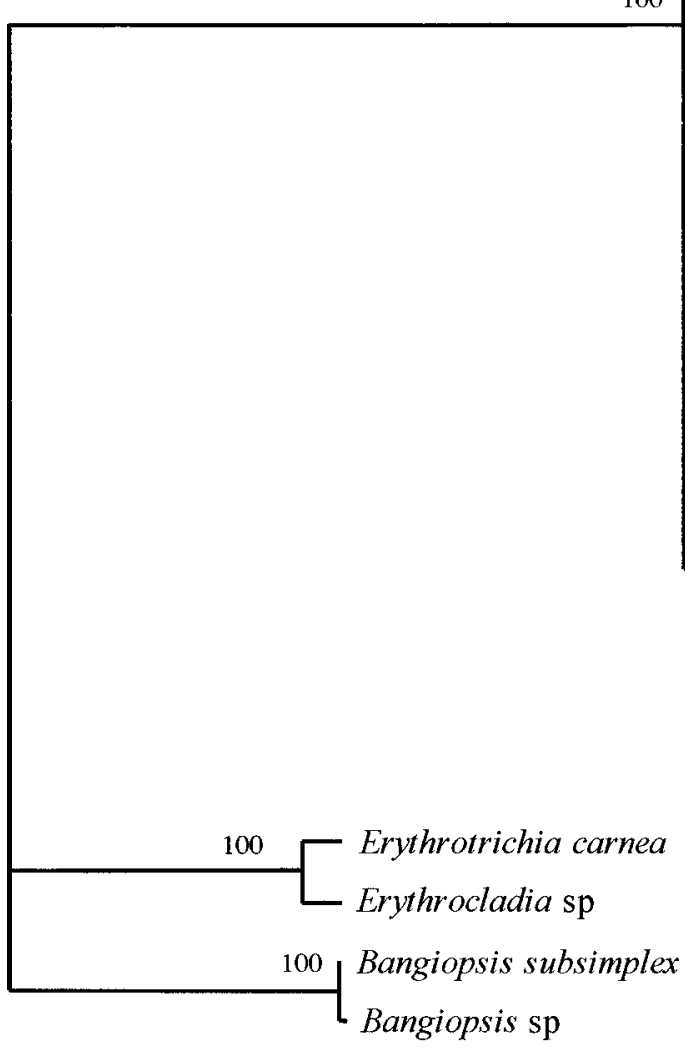

${ }^{64} P$ yezoensis $(\mathrm{JP})$

- B fuscopurpurea Antarctic
100 B fuscopurpurea Australia

B fuscopurpurea North Carolina (USA)

G1

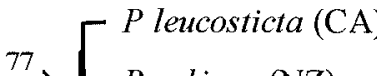

100

4

$P$ tenera (JP)

- $P$ katadae (JP)

$5 9 \longdiv { P }$ miniata $(\mathrm{CA})$

- $P$ amplissima $(\mathrm{CA})$

- $P$ dentata (JP)

P cinnamomea (NZ)

${ }_{100}^{P \text { sp Baleia (BR) }} \quad \mathrm{G} 2$

100

$P$ suborbiculata (NZ)

76

$\quad \begin{aligned} & P \text { drewiana (BR) } \\ & \quad P \text { spiralis var spiralis (BR) }\end{aligned}$

$92 \quad 89$

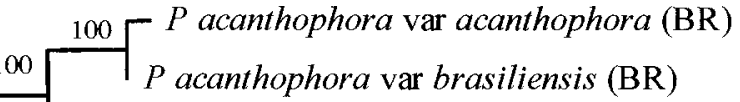
$P$ sp Piaui (BR)

B fuscopurpurea New foundland (CA)

-0.01 substitutions/site

Fig. 1. SSU rDNA NJ tree calculated with Tamura and Nei distances. Bootstrap values performed for 2000 replicates are indicated on the branches. Arrows indicate the position of bootstrap values when they do not fit on the branches. Abbreviations in parentheses indicate collection locations: BR, Brazil; CA, Canada; JP, Japan; NZ, New Zealand; SA, South Africa; USA, United States. G1, group 1; G2, group 2.

from New Zealand and $P$. umbilicalis from Canada (bootstrap values: $100 \%$ for NJ, $95 \%$ for MP and $93 \%$ for ML).

The internal structure of G2 varies according to the phylogenetic inference method. Bangia fuscopurpurea from Can- ada is at the base of a well-supported group (bootstrap values: $100 \%$ for NJ, 99\% for MP and $100 \%$ for ML) that includes a polytomy with several Porphyra species and B. fuscopurpurea from the Antarctic. Within this polytomy, the Brazilian 


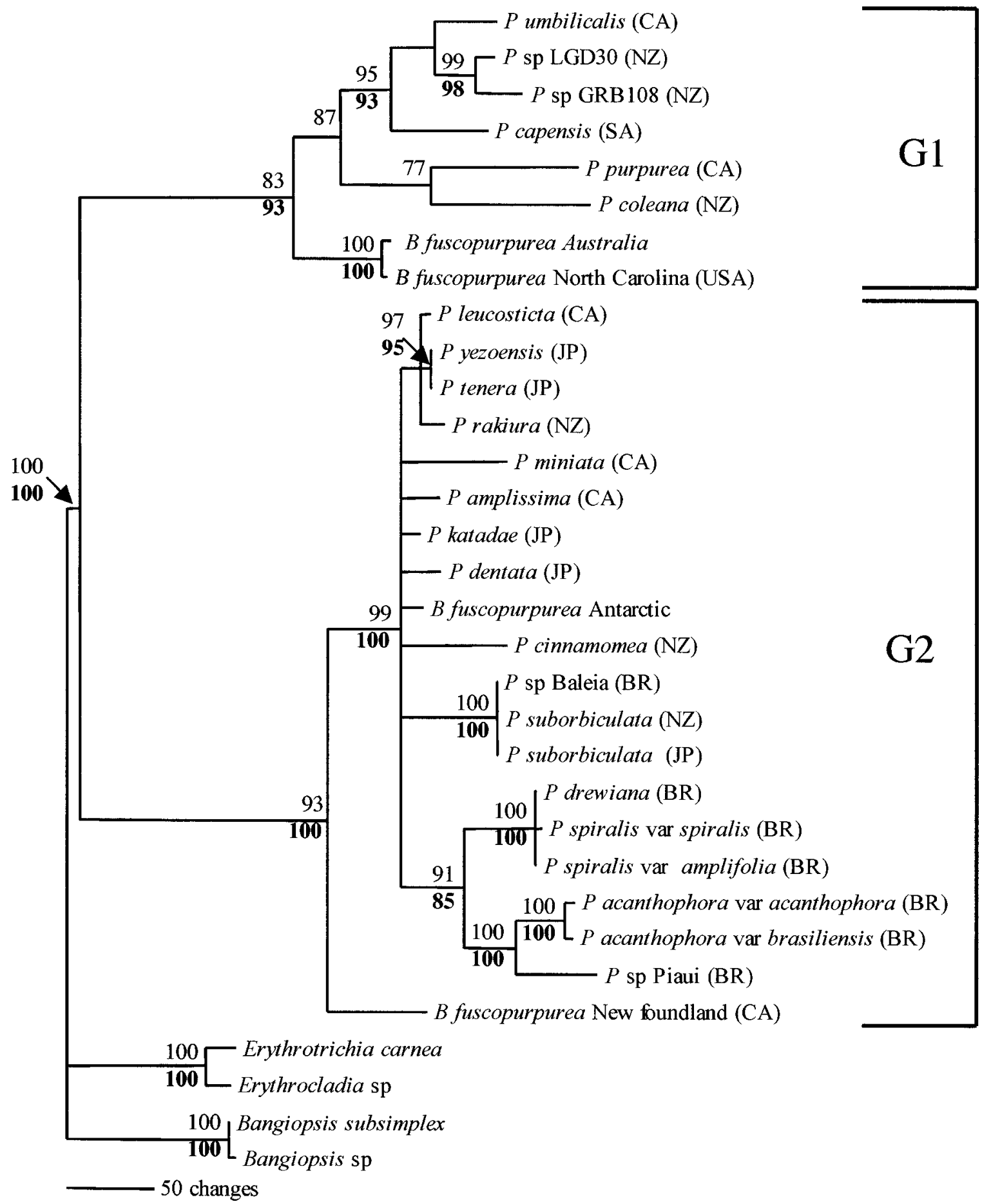

Fig. 2. SSU rDNA MP tree inferred by heuristic search. Bootstrap values performed for 2000 replicates are indicated on the branches (first line, normal typeface); for the ML tree, 42 bootstrap replicates (second line, bold typeface). Arrows indicate the position of bootstrap values when they do not fit on the branches. Abbreviations in parentheses indicate collection locations: BR, Brazil; CA, Canada; JP, Japan; NZ, New Zealand; SA, South Africa; USA, United States. G1, group 1; G2, group 2.

species, with the exception of Porphyra sp. 'Baleia', form a monophyletic group with moderate to high support (bootstrap values: $89 \%$ for NJ, $91 \%$ for MP and $85 \%$ for ML). Another well-supported group (100\% bootstrap in all analyses) comprises Porphyra sp. 'Baleia' collected on the southeast coast of Brazil and P. suborbiculata from New Zealand and Japan.

Within the Brazilian species group, it is possible to distin- guish two different lineages (100\% bootstrap in all analyses). The first lineage comprises $P$. drewiana and the two varieties of $P$. spiralis; the second contains Porphyra sp. 'Piaui' and the two varieties of $P$. acanthophora, which group together with high support (100\% bootstrap in all analyses).

In all three trees, Porphyra is a polyphyletic genus within Bangia; therefore, Bangia is paraphyletic. The outgroup spe- 
cies Bangiopsis sp. from Brazil grouped with strong support (100\% bootstrap in all analyses) with B. subsimplex from Puerto Rico.

\section{DISCUSSION}

The order Bangiales, which includes only the genera Bangia and Porphyra, is monophyletic, as observed previously by Ragan et al. (1994), Oliveira et al. (1995) and Müller et al. (2001b) for the nuclear SSU rDNA phylogenetic trees. Oliveira \& Bhattacharya (2000) have confirmed this result for the chloroplast SSU rDNA and Müller et al. (2001b) for the $r b c \mathrm{~L}$ gene.

In the phylogenetic analyses based on the SSU rDNA, $P$. capensis from South Africa grouped together with two Porphyra species (GRB108 and LGD30) from New Zealand and its 516 and 1506 introns have been shown to present similarity with equivalent introns in Porphyra sp. GRB108 (intron 516) and Porphyra sp. LGD30 (intron 1506). According to Wegener's theory of continental drift (Kious \& Tilling 1996), we expected $P$. capensis to be closer to the Brazilian species because Africa and South America separated about 65 million years ago. However, the South African species $P$. capensis seems to have a different origin, as it is closer to New Zealand species rather than to the Brazilian species.

Porphyra sp. 'Baleia' collected from the southeast coast of Brazil presented a distinct morphology from the other described Brazilian species. The perfect match between Porphyra sp. 'Baleia' and $P$. suborbiculata SSU rDNA and intron sequences was surprising. Broom et al. (2002) suggested that this cosmopolitan and diminutive Porphyra species ( $P$. suborbiculata) could disperse via ocean-going vessels. The algae could grow on hulls of ships and disperse from one region to another. The conchocelis phase of Porphyra is the most easily dispersed due to its endolithic growth in the calcareous shells of live invertebrates from the intertidal region (Paula \& Oliveira 1993). These bivalves can affix on the hulls of vessels, offering a more stable environment for the algae to thrive in its perennial phase. Another source of dispersal could be the introduction of the Japanese oyster (Crassostrea gigas), which has been transplanted for cultivation in several oceans for decades and is a suitable substrate for the conchocelis phase. This finding extends the distribution of P. suborbiculata to the south Atlantic, in addition to the north Atlantic and north and south Pacific. Validation by morphological analysis is necessary to state this conclusively and will be reported elsewhere.

The group including the Brazilian species $P$. acanthophora var. acanthophora, $P$. acanthophora var. brasiliensis, $P$. drewiana, $P$. spiralis var. amplifolia, $P$. spiralis var. spiralis and Porphyra sp. 'Piaui' is monophyletic. The two varieties of $P$. acanthophora are monophyletic, corroborating the consistency of morphological analysis (Oliveira \& Coll 1975). In all phylogenetic analyses, Porphyra sp. 'Piaui' was the sister taxa of the two $P$. acanthophora varieties with a high bootstrap support. The identity of values found between Porphyra sp. 'Piaui' SSU rDNA and the other Brazilian species (Table 4) suggests that Porphyra sp. 'Piaui' is a new species. Interestingly, Porphyra sp. 'Piaui' has marginal microscopic teeth, as does P. acanthophora (Oliveira \& Coll 1975). Detailed mor- phological analysis of Porphyra sp. 'Piaui' will be described elsewhere.

Porphyra acanthophora is mainly differentiated from $P$. spiralis by the presence of microscopical marginal teeth in the blade. Porphyra acanthophora var. acanthophora is characterised by the orbicular blades forming dense, rosulated tufts, whereas $P$. acanthophora var. brasiliensis has strap-shaped, isolated (or a few together) blades. Porphyra spiralis var. spiralis forms tufts with narrow, twisted, strap-shaped blades or with folded margin, whereas blades of $P$. spiralis var. amplifolia are not as narrow and twisted as the typical variety. The thallus of $P$. spiralis var. amplifolia is strap shaped or irregularly cleft, leaf like, with undulated margins (Oliveira \& Coll 1975), whereas that of $P$. drewiana consists typically of one entire, orbiculate, oblong, obovate or broadly lanceolate, umbilicate or cordate blade (Coll \& Oliveira 2001). All species cited above have a monostromatic thallus and one chloroplast per cell.

Porphyra spiralis is a paraphyletic species once it includes $P$. drewiana. The level of similarity between $P$. drewiana and $P$. spiralis var. amplifolia SSU rDNA (99.8\%) was comparable with that found between the two varieties of $P$. spiralis (99.7\%). Kunimoto et al. (1999a) found $99.8 \%$ similarity between the SSU rDNA of two different species, $P$. yezoensis Ueda and $P$. tenera Kjellman. In conserved loci such as SSU rDNA, significant divergence between taxa sequences indicates a long reproductive separation; conversely, doubt arises when specimens described as different species have only a few substitutions in this gene (Broom et al. 2001).

The SSU rDNA intron sequenced in $P$. drewiana is in the same position as that described for $P$. spiralis var. amplifolia (Oliveira \& Ragan 1994). The identity between the intron sequences of both taxa $(99.6 \%)$ was also high, considering that the intron is not a coding DNA and it is expected to be variable even within the same species (Oliveira \& Ragan 1994).

Morphological differences between $P$. drewiana and $P$. spiralis (Oliveira \& Coll 1975; Coll \& Oliveira 2001) contrast with their high level of identity in the molecular data and prompted the sequencing of more variable regions. Sequences from the ITS region have higher substitution rates and are therefore useful for evaluating divergence within genera and species when the taxa are too close to have accumulated divergence in SSU rDNA (Stiller \& Waaland 1993; Baldwin et al. 1995; Coat et al. 1998). Kunimoto et al. (1999b) have sequenced the ITS-1 in an attempt to identify individuals in $P$. yezoensis populations. The level of identity found between the ITS sequences was $96 \%$ among individuals of the same species, and varied from $88 \%$ to $90 \%$ between different species ( $P$. tenera and P. yezoensis). Broom et al. (2002) found a level of identity of $94.6 \%$ in the ITS-1 region in three Porphyra species that they considered to be synonymous. Nevertheless, in our analyses, the level of identity in the ITS region between $P$. drewiana and $P$. spiralis $(99.6 \%)$ is high when compared with the results described above for different species.

Coll \& Oliveira (2001) considered P. spiralis var. amplifolia to be morphologically the most similar species to $P$. drewiana. However, dissimilarities in the gross morphology of the thallus, the pluristromatic areas of vegetative cells, chloroplast division and the number of spermatia and carpospores per mother cell, reinforced by the respective chromosome siz- 
es and behaviour of the filamentous phases in culture, supported the classification of $P$. drewiana as a new taxon. Despite these differences, our results based on molecular data suggest that $P$. drewiana could be a new variety of $P$. spiralis. It would be interesting to sequence other regions (e.g. $r b c \mathrm{~L}$ and $r b c \mathrm{~L}-\mathrm{S}$ spacer) to test our taxonomic hypothesis.

If we consider the south Atlantic Porphyra species analysed here, there are at least three different phylogenetic lineages: the clade containing $P$. spiralis, $P$. acanthophora and Porphyra sp. 'Piaui'; the clade containing Porphyra sp. 'Baleia'; and the third clade, containing $P$. capensis. The number of different phylogenetic lineages might increase once the colder water species $P$. leucosticta, $P$. pujalsii and $P$. rizzinii, which occur in Uruguay and appear in the upwelling region in the southeastern of Brazil, and other South African species are analysed.

Group I introns have been reported as occurring in organelles, viruses and eubacteria (Lambowitz \& Belfort 1993), in SSU rDNA of fungi (Sogin \& Edman 1989; De Wachter et al. 1992; Nikoh \& Fukatsu 2001), filose amoebae (Bhattacharya \& Oliveira 2000), green algae (Bhattacharya et al. 1994, 1996) and red algae (Ragan et al. 1993; Oliveira \& Ragan 1994; Oliveira et al. 1995; Müller et al. 1998, 2001a; Kunimoto et al. 1999a; Broom et al. 2002). Porphyra sp. 'Baleia' and $P$. capensis 516 introns were inserted in an exonic SSU rDNA-flanking region described for other Porphyra species (Kunimoto et al. 1999a). Porphyra sp. 'Baleia', $P$. capensis and $P$. drewiana 1506 introns retained the conserved catalytic core (P, Q, R, and $\mathrm{S}$ regions) and were inserted in an exonic SSU rDNA-flanking region common to the SSU rDNA IC1 intron (Michel \& Westhof 1990).

Bangiopsis sp. was initially misidentified as Bangia fuscopurpurea. Both genera have a nonramified pluriseriate filamentous thallus (Joly 1967), which led to the confusion. The correct identification was possible only when the SSU rDNA sequence was obtained and found to be $99.8 \%$ identical to Bangiopsis subsimplex. The occurrence of an intron in Bangiopsis sp. SSU rDNA was unexpected. SSU rDNA group I introns in Rhodophyta were described only for the Florideophycidae Hildenbrandia rubra (Ragan et al. 1993) and for members of the order Bangiales of the Bangiophycidae (Oliveira \& Ragan 1994; Oliveira et al. 1995; Müller et al. 1998, 2001a; Kunimoto et al. 1999a; Broom et al. 2002). Therefore, this is the first description of an SSU rDNA intron in Rhodophyta outside the common branch leading to the order Bangiales and subclass Florideophycidae, which are considered sister groups (Freshwater et al. 1994; Oliveira \& Bhattacharya 2000; Müller et al. 2001b). This 943 intron is inserted at a novel position for Rhodophyta SSU rDNA. No identity was found between the Bangiopsis sp. 943 intron and the other red algal introns, but a low similarity was detected with the Ascomycota Pneumocystis carinii 26S rDNA group I intron, which suggests an origin for this intron different from the other Rhodophyta introns.

\section{ACKNOWLEDGEMENTS}

This project was supported by FAPESP and CNPq (Brazil). We thank Mutue T. Fujii, Nair S. Yokoya and Silvia P. Guimarães (Instituto de Botânica, Projeto Flora Ficológica do Es- tado de São Paulo 1998/04955-3) for help during specimen collections; Eurico C. Oliveira for supplying specimens and suggestions for the manuscript; Silvia R. Blanco and Rosario Petti for technical assistance.

\section{REFERENCES}

Altschul S.F., Gish W., Miller W., Myers E.W. \& Lipman D.J. 1990. Basic local alignment search tool. Journal of Molecular Biology 215: 403-410.

Baldwin B.G., Sanderson M.J., Porter J.M., Wojciechowski M.F., Campbell C.S. \& Donoghue M.J. 1995. The ITS region of nuclear ribosomal DNA: a valuable source of evidence of angiosperm phylogeny. Annals of the Missouri Botanical Garden 82: 247-277.

Bellorin A.M., Oliveira M.C. \& Oliveira E.C. 2002. Phylogeny and systematics of the marine algal family Gracilariaceae (Gracilariales, Rhodophyta) based on small subunit rDNA and ITS sequences of Atlantic and Pacific species. Journal of Phycology 38: $551-563$

BhatTACHARYA D. \& OliveIRA M.C. 2000. The SSU rDNA coding region of a filose amoeba contains a group I intron lacking the universally conserved $\mathrm{G}$ at the $3^{\prime}$-terminus. The Journal of Eukaryotic Microbiology 47: 585-589.

Bhattacharya D., Surek B., Rüsing M., Damberger S. \& MelkonIAN M. 1994. Group I introns are inherited through common ancestry in the nuclear encoded rRNA of Zygnematales. Proceedings of the National Academy of Sciences of the United States of America 91: 9916-9920.

Bhattacharya D., Friedl T. \& Damberger S. 1996. Nuclear-encoded rDNA group I intron: origin and phylogenetic relationship of insertion site lineages in the green algae. Molecular Biology and Evolution 13: 978-989.

Bird C.J., Rice E.L., Murphy C.A. \& Ragan M.A. 1992. Phylogenetic relationships in the Gracilariales (Rhodophyta) as determined by $18 \mathrm{~S}$ rDNA sequences. Phycologia 31: 510-522.

Brodie J., Hayes P.K., BARKer G.L. \& IRvine L.M. 1996. Molecular and morphological characters distinguishing two Porphyra species (Rhodophyta: Bangiophycidae). European Journal of Phycology 31: 303-308

Brodie J., Hayes P.K., Barker G.L., Irvine L.M. \& BArtsch I. 1998. A reappraisal of Porphyra and Bangia (Bangiophycidae, Rhodophyta) in the Northeast Atlantic based on the $r b c \mathrm{~L}-r b c \mathrm{~S}$ intergenic spacer. Journal of Phycology 34: 1069-1074.

Broom J.E., Jones W.A., Hill D.F., Knight G.A. \& Nelson W.A. 1999. Species recognition in New Zealand Porphyra using 18S rDNA sequencing. Journal of Applied Phycology 11: 421-428.

Broom J.E., Nelson W.A., Mutch J., FArR T.J. \& Jones W.A. 2001. How much is enough? SSU variation as a signal of speciation in New Zealand Porphyra. Phycologia 40, supplement: 64.

Broom J.E., Nelson W.A., Yarish C., Jones W.A., Aguilar Rosas R. \& Aguilar Rosas L.E. 2002. A reassessment of the taxonomic status of Porphyra suborbiculata, Porphyra carolinensis and Porphyra lilliputiana (Bangiales, Rhodophyta) based on molecular and morphological data. European Journal of Phycology 37: 227-235.

CAвот E.L. \& Beckenbach A.T. 1989. Simultaneous editing of multiple nuclei acid and protein sequences with ESEE. Computer Applied Biosciences 5: 233-234.

Coat G., Dion P., Noailles M.C., De Reviers B., Fontaine J.M., Berger-Perrot Y. \& LoISEAuX DE GoËr S. 1998. Ulva armoricana (Ulvales, Chlorophyta) from the coasts of Brittany (France). II. Nuclear rDNA ITS sequence analysis. European Journal of Phycology 33: $81-86$.

Coll J. \& Oliveira E.C. 1976. The genus Porphyra C.Ag. Rhodophyta-Bangiales in the American South Atlantic. II. Uruguayan species. Botanica Marina 19: 191-196.

Coll J. \& Oliveira E.C. 2001. Porphyra drewiana, a new species of red algae (Bangiales, Rhodophyta) from Brazil. Phycological Research 49: 67-72. 
De Wachter R., Neefs J.M., Goris A. \& Van de Peer Y. 1992. The gene coding for small ribosomal subunit RNA in the basidiomycete Ustilago maydis contains a group I intron. Nucleic Acids Research 20: $1251-1257$.

FELSENSTEIN J. 1985. Confidence limits on phylogenies: an approach using the bootstrap. Evolution 39: 783-791.

Freshwater D.W., FredericQ S., Butler B.S., Hommersand M.H. \& CHAsE M.W. 1994. A gene phylogeny of the red algae (Rhodophyta) based on plastid rbcL. Proceedings of the National Academy of Sciences of the United States of America 91: 7281-7285.

Joly A.B. 1967. Gêneros de algas marinhas da costa Atlântica latino americana. Editora da USP, São Paulo. 464 pp.

Kious W.J. \& Tilling R.I. 1996. This dynamic Earth: the story of plate tectonics. Web page: http://pubs.usgs.gov/publications/text/ dynamic.html. US Government Printing Office, Washington, DC.

Klein A.S., Mathieson A.C., Neefus C.D., Cain D.F., Taylor H.A., Teasdale B.W., West A.L., Herhe E.J., Brodie J., Yarish C. \& Wallace A.L. 2003. Identification of north-western Atlantic Porphyra (Bangiaceae, Bangiales) based on sequence variation in nuclear SSU and plastid rbcL genes. Phycologia 42: 109-122.

Kuang M., Wang S., Li Y., Shen D. \& Zeng C. 1998. RAPD study on some common species of Porphyra in China. Chinese Journal of Oceanology and Limnology 16, supplement: 140-145.

Kunimoto M., Kito H., Yamamoto Y., Cheney D.P., Kaminishi Y. \& Mizukami Y. 1999a. Discrimination of Porphyra species based on small subunit ribosomal RNA gene sequence. Journal of Applied Phycology 11: 203-209.

Kunimoto M., Kito H., Kaminishi Y., Mizukami Y. \& Murase N. 1999b. Molecular divergence of the SSU rRNA gene and internal transcribed spacer 1 in Porphyra yezoensis (Rhodophyta). Journal of Applied Phycology 11: 211-216.

LAMbowitz A. M. \& Belfort M. 1993. Intron as mobile genetic elements. Annual Review of Biochemistry 62: 587-622.

Lindstrom S.C. \& Cole K.M. 1992. The Porphyra lanceolata-P. pseudolanceolata (Bangiales, Rhodophyta) complex unmasked: recognition of new species based on isozymes, morphology, chromosomes, and distribution. Phycologia 31: 431-448.

Lindstrom S.C. \& Cole K.M. 1993. The systematics of Porphyra: character evolution in closely related species. Hydrobiologia 260/ 261: $151-157$

LindSTROM S.C. \& FREDERICQ S. 2003. $r b c L$ gene sequences reveal relationships among north-east Pacific species of Porphyra (Bangiales, Rhodophyta) and a new species, P. aestivalis. Phycological Research 51: 211-224.

Michel F. \& Westhof E. 1990. Modeling of the three-dimensional architecture of group I catalytic introns based on comparative sequence analysis. Journal of Molecular Biology 216: 585-610.

Mizukami Y., Hitoshi K., Kunimoto M. \& Kobayashi M. 1998. Effect of DNA preparation from laver (Porphyra yezoensis) thalli on reproducibility of RAPD (random amplified polymorphic DNA) patterns. Journal of Applied Phycology 10: 23-29.

Müller K.M., Sheath R.G., Vis M.L., Crease T.J. \& Cole K.M. 1998. Biogeography and systematics of Bangia (Bangiales, Rhodophyta) based on the RuBisCo spacer, $r b c \mathrm{~L}$ gene and $18 \mathrm{~S}$ rRNA gene sequences and morphometric analyses. 1. North America. Phycologia 37: 195-207.

Müller K.M, Cannone J.J., Gutell R.R. \& Sheath R.G. 2001a. A structural and phylogenetic analysis of the group IC1 introns in the order Bangiales (Rhodophyta). Molecular Biology and Evolution 18: $1654-1667$.

Müller K.M., Oliveira M.C., Sheath R.G. \& Bhattacharya D. 2001b. Ribosomal DNA phylogeny of the Bangiophycidae (Rhodophyta) and the origin of secondary plastids. American Journal of Botany 88: 1390-1400.

Müller K.M., Cole K.M. \& Sheath R.G. 2003. Systematics of Bangia (Bangiales, Rhodophyta) in North America. II. Biogeographical trends in karyology: chromosome numbers and linkage with gene sequence phylogenetic trees. Phycologia 42: 209-219.

Neefus C.D., Mathieson A.C., Yarish C., Klein A., West A., Teas-
DAle B. \& Hehre E.J. 2000. Five cryptic species of Porphyra from the Northwest Atlantic. Journal of Phycology 36, supplement: 73.

Nelson W.A., BRoom J.E. \& FARR T.J. 2001. Four new species of Porphyra (Bangiales, Rhodophyta) from the New Zealand region described using traditional characters and $18 \mathrm{~S}$ rDNA sequence data. Cryptogamie, Algologie 22: 263-284.

NikoH N. \& FukATsu T. 2001. Evolutionary dynamics of multiple group I introns in the nuclear ribosomal RNA genes of the endoparasitic fungi of the genus Cordyceps. Molecular Biology and Evolution 18: 1631-1642.

OliveIRA E.C. 1977. Algas marinhas bentônicas do Brasil. Thesis. University of São Paulo, São Paulo, Brazil. 407 pp.

Oliveira E.C. \& Coll J. 1975. The genus Porphyra C. Ag. (Rhodophyta-Bangiales) in the American South Atlantic. I. Brazilian species. Botanica Marina 18: 191-197.

OliveIRA M.C. 1993. Filogenia de Porphyra spp. (Rhodophyta): seqüenciamento do gene nuclear para o RNA da subunidade pequena do ribossomo (rDNA 18S) e estudos morfológicos da fase conchocelis. Thesis. University of São Paulo, São Paulo, Brazil. 160 pp.

Oliveira M.C. \& Bhattacharya D. 2000. Phylogeny of the Bangiophycidae (Rhodophyta) and the secondary endosymbiotic origin of algal plastids. American Journal of Botany 87: 482-492.

OLIVEIRA M.C. \& RAGAN M.A. 1994. Variant forms of a group I intron in nuclear small-subunit rRNA genes of the marine red alga Porphyra spiralis var. amplifolia. Molecular Biology and Evolution 11: 195-207.

Oliveira M.C., Kurniawan J., Bird C.J., Rice E.L., Murphy C.A., Singh R.K., Gutell R.R. \& Ragan M.A. 1995. A preliminary investigation of the order Bangiales (Bangiophycidae, Rhodophyta) based on sequences of the nuclear small-subunit ribosomal RNA genes. Phycological Research 43: 71-79.

Paula E.J. \& Oliveira M.C. 1993. Ciclo de vida de Porphyra spp e ocorrência sazonal de suas fases na natureza. Livro de resumos da $6^{\circ}$ Reunião brasileira de ficologia, Tramandaí, RS. pp. 110.

PosadA D. \& CRANDAll K.A. 1998. MODELTEST: testing the model of DNA substitution. Bioinformatics 14: 817-818.

RAGAN M.A., BIRD C.J., RiCE E.L. \& Singh R.K. 1993. The nuclear $18 \mathrm{~S}$ ribosomal RNA gene of the red algae Hildenbrandia rubra contains a group I intron. Nucleic Acids Research 21: 3898.

Ragan M.A., Bird C.J., Rice E.L., Gutell R.R., Murphy C.A. \& SINGH R.K. 1994. A molecular phylogeny of the marine red algae (Rhodophyta) based on the nuclear small-subunit rRNA gene. Proceedings of the National Academy of Sciences of the United States of America 91: 7276-7280.

Saitou N. \& NEI M. 1987. The neighbor-joining method: a new method for reconstructing phylogenetic trees. Molecular Biology and Evolution 4: 406-425.

SoGIN M.L. 1990. Amplification of ribosomal RNA genes for molecular evolution studies. In: PCR protocols. A guide to methods and applications (Ed. by M.A. Innes, D.H. Gelfand, J.J. Snisnky \& T.J. White), pp. 307-314. Academic Press, San Diego, CA.

Sogin M.L. \& Edman J.C. 1989. A self-splicing intron in the small subunit rRNA gene of Pneumocystis carinii. Nucleic Acids Research 17: 5349-5359.

STILLER J.W. \& WAALAND J.R. 1993. Molecular analysis reveals cryptic diversity in Porphyra (Rhodophyta). Journal of Phycology 29: 506-517.

SwOFFORD D.L. 2000. PAUP*. Phylogenetic analysis using parsimony (*and other methods), version 4. Sinauer Associates, Sunderland, MA.

TAMURA K. \& NEI M. 1993. Estimation of the number of nucleotide substitutions in the control region of mitochondrial DNA in humans and chimpanzees. Molecular Biology and Evolution 10: 512-526.

Teasdale B., Lindstrom S.C., FredericQ S., Neefus C.D., Mathieson A.C., Taylor H., West A.L., Mercado S.T., Piche N. \& Klein A.S. 2000. Analysis of Porphyra $r b c \mathrm{~L}$ demonstrates multiple migrations occurred between the North Atlantic and North Pacific. Journal of Phycology 36, supplement: 65.

Teasdale B., West A., Taylor H. \& Klein A. 2002. A simple restriction fragment length polymorphism (RLFP) assay to discrimi- 
nate common Porphyra (Bangiophycidae, Rhodophyta) taxa from the Northwest Atlantic. Journal of Applied Phycology 14: 293-298. Van de Peer Y., De Rijk P., Wuyts J., Winkelmans T. \& De WachTER R. 2000. The European small subunit ribosomal database. $\mathrm{Nu}$ cleic Acid Research 28: 175-176.

Yoneshigue Y. 1985. Taxonomie et ecologie des algues marine dans la region de Cabo Frio (RJ, Bresil). Doctoral thesis. Université d'Aix-Marseille, Aix-Marseille, France. 454 pp.
Yoshida T., Notoya M., Kikuchi N. \& Miyata M. 1997. Catalogue of species of Porphyra in the world, with special reference to the type locality and bibliography. Natural History Research, Special Issue 3: 5-18.

Received 16 September 2003; accepted 10 September 2004 Communicating editor: W. Nelson 


\section{Plastid origin: a driving force for the evolution of algae}

Alexis Miguel Bellorin ${ }^{1} \&$ Mariana Cabral de Oliveira ${ }^{2}$

${ }^{1}$ Dept. Biologia, Escuela de Ciencias, University of Oriente (UDO), Av. Universidad, Cumana, Venezuela. AP 245.

(e-mail: almiguel@yahoo.com)

${ }^{2}$ Dept. Botanica, Inst. de Biociencias, University of São Paulo (USP), R. do Matão, travessa 14 n. 321, São Paulo, SP, cep 05508-900, Brazil

(e-mail: mcdolive@ib.usp.br, euricodo@usp.br)

Address for correspondence: Mariana Cabral de Oliveira, Dept. Botânica, Inst. de Biociências, University of São Paulo (USP), R. do Matão, travessa 14 n. 321, São Paulo, SP, cep 05508-900, Brazil, e-mail: mcdolive@ib.usp.br 


\begin{abstract}
Chlorophyll $a$ is present in all organisms that release oxygen during the photosynthesis process. The development of this molecule altered the earth atmosphere causing a great impact in the history of the planet, redirecting the evolution of life. The oxygenic photosynthesis was developed early in the history of life by a group of prokaryotes, the cyanobacteria. This ability was later laterally transferred to the eukaryotic realm by the acquisition of photosynthetic organelles (plastids) through the engulfment and retention of formerly free living cyanobacteria by an ancient eukaryotic cell. Such kind of cellular merging, called primary endosymbiosis, likely occurred only once. Three lineages of extant algae (including the ancestors of land plants) vertically evolved from the cells which first acquired plastids. Later on, the photosynthetic apparatus was laterally transferred to other unrelated eukaryotic lineages through independent secondary endosymbiosis, i.e., the acquisition of plastids by engulfing an eukaryote, already equipped with plastids. This gave rise to the 'second-hand' or secondary plastidcontaining algae, a diverse assemblage including disparate organisms such as euglenoids, dinoflagellates and kelps. Thus, the history of photosynthesis acquisition by eukaryotes is extremely complex, making very difficult to briefly define algae and to discriminate them from other organisms. Current data support the view that plastid acquisition is a rather rare event and, accordingly, a single primary endosymbiosis followed by a few very ancient secondary endosymbiosis probably account for all extant plastid diversity. The following major issues will be discussed in this chapter: i. plastid acquisitions and losses by different eukaryotic lineages; ii. some recurrent themes on photosynthetic endosymbionts (e.g., genome reduction and genomic features, lateral gene transfer from plastids to nucleus and properties of proteins targeting systems to plastids); and iii. the placing of the plastid-containing eukaryotes into a probably global phylogeny for eukaryotes.
\end{abstract}


Key words: algae, protein-targeting, endosymbiosis, evolution, plastids

$\begin{array}{ll}\text { Abbreviations: } \\ \text { atpB } & \text { (ATP synthase } \beta \text { subunit) } \\ \text { COXII } & \text { (mitochondrial citochrome oxidase subunit 2) } \\ \text { EF-2 } & \text { (elongation factor 2) } \\ \text { FBA } & \text { (fructose-1,6-bisphosphate aldolase) } \\ \text { GAPDH } & \text { (glyceraldehyde-3-phosphate dehydrogenase) } \\ \text { LHCs } & \text { (Light Harvesting Chlorophyll binding proteins) } \\ \text { LSU rDNA } & \text { (large subunit ribosomal RNA gene) } \\ \text { PCR } & \text { (Polymerase Chain Reaction) } \\ \text { psbA } & \text { (photosystem II polypeptide D1 gene) } \\ \text { PsbO } & \text { (oxygen-evolving enhancer 1) } \\ r b c \mathrm{~L} & \text { (RuBisCO large subunit gene) } \\ r b c \mathrm{~S} & \text { (RuBisCO small subunit gene) } \\ \text { RPB1 } & \text { (RNA polymerase II large subunit) } \\ r p o C 1 & \text { (RNA polymerase } \beta \text { ' subunit gene) } \\ \text { rRNA } & \text { (ribosomal RNA) } \\ \text { RuBisCO } & \text { (ribulose 1,5-biphosphate carboxylase/oxygenase) } \\ \mathrm{SSU} \text { rDNA } & \text { (small subunit ribosomal RNA gene) } \\ \text { tufA } & \text { (plastid-encoded elongation factor Tu gene) } \\ & \end{array}$




\section{Introduction}

The algae were traditionally conceived as the simplest or 'lower' photosynthetic forms of life with chlorophyll $a$ from which evolved the 'higher' plants (bryophytes and tracheophytes, collectively known as land plants). This view of algae was sufficiently wide to permit that within them were included organisms so distinct as prokaryotes and eukaryotes, and within the last, some closely related to land plants, whereas others are clearly related to non-photosynthetic protozoans. Altogether, algae were supposed to be unified on the basis that all perform oxygenic photosynthesis, although now it is clear that the photosynthetic ability is not an unequivocal marker for vertical evolutionary relatedness. The oxygenic photosynthesis was developed early in the history of life by a group of prokaryotes, the cyanobacteria. This ability was later laterally transferred to the eukaryotic realm by the acquisition of photosynthetic organelles (plastids) through the engulfment and retention of formerly free living cyanobacteria by an ancient eukaryotic cell. Such kind of cellular merging, called primary endosymbiosis, likely occurred only once. Three lineages of extant algae (including the ancestors of land plants) vertically evolved from the cells which first acquired plastids [174]. Later on, the photosynthetic apparatus was laterally transferred several times to other unrelated eukaryotic lineages through independent secondary endosymbiosis, i.e., the acquisition of plastids by engulfing an eukaryote, already equipped with plastids [6]. This gave rise to the 'secondhand' or secondary plastid-containing algae, a diverse assemblage including disparate organisms such as euglenoids, dinoflagellates and kelps. Thus, the history of photosynthesis acquisition by eukaryotes is extremely complex, making very difficult to briefly define algae and to discriminate them from other organisms [178]. In fact, the heterogeneity of organisms traditionally designated as algae make the definition of this assemblage of organisms as a complete biological non-sense in view of the new evidences about the phylogeny of those groups.

In this chapter we will not discuss the evolutionary relationships of the cyanobacteria, are a well defined phototrophic clade of Gram-negative eubacteria [for some recent reviews see 94,95,117,229]. Therefore our discussion will be centered on plastid-containing eukaryotes (Table 1), including the land plants (ultimately, a specific 
lineage of green algae fully adapted to live in terrestrial habitats [139]) and some heterotrophic protozoans that have non-functional plastids and were never considered to be algae. The most striking of such protozoans are the apicomplexans, a phylum of obligate intracellular parasites, including the causative agents of malaria and toxoplasmosis, which have a highly reduced and peculiar plastid called apicoplast [71]. It also should be noted that recent literature suggests that many heterotrophic protozoans lacking plastid-like organelles probably evolved from plastid-containing ancestors [3,241], extending significantly the scope of the algae evolution and making it indissoluble from the resolution of the global phylogeny of eukaryotes.

Obviously, a central subject for evolution of photosynthetic eukaryotes is the plastid. This organelle, besides performing the photosynthesis, carry on other important functions in the cells, participating in the biosynthesis of fatty acids, isoprenoids, carotenoids, haeme and a number of amino acids, as well as, the reduction of nitrite to ammonia, among others [152,241]. There are different types of pigmented plastids, including the green 'chloroplast' of green algae and land plants (the most widely studied plastid), the red 'rhodoplast' of red algae, and the brown or golden 'chromoplast' of a diverse assemblage of organisms collectively known as chromophytes; besides, there are also colorless plastids as well, as the leucoplast and amyloplast of land plants, or the very reduced plastids contained in heterotrophic algae and protozoans (as in the euglenoid Astasia or in the apicomplexans). Besides biochemical and functional differences, plastids from different groups have variations in its ultrastructure, as the number of membranes surrounding them, which are believed to be the result of the type of endosymbiosis from which they evolved, and the disposition and grouping of the photosynthesizing lamellae, the thylakoids.

The idea that plastids are ultimately highly reduced endosymbiotic cyanobacteria is not new. It was outlined over a century ago by Schimper [195] and Mereschkowski [157] and, since 1970, gained compelling support on biochemical, ultrastructural and molecular biology grounds [for historical reviews see 80,152,153]. Likewise, the origin of mitochondria from an endosymbiont heterotrophic $\alpha$-proteobacteria was advanced by Altmann [1] and is now sufficiently supported [88]. In both cases, as well as in secondhand plastids, the genome of endosymbionts suffered a dramatic reduction in size and 
gene content leading to its dependence from the host cells (Figure 1). Most of the proteins necessary for plastids functioning are encoded in the nucleus of the host cell, what was achieved mainly through a massive lateral gene transfer from the endosymbiont genome to the nucleus [150]. The product of each plastid-related gene is expressed in the cytosol and targeted back to plastids by adding post-translationally transit peptides at the Nterminal $[35,151,235]$, which are recognized by specific translocator proteins (TICs and TOCs complexes) in the plastid membranes [119]. Current data support the view that plastid acquisition is a rather rare event and, accordingly, a single primary endosymbiosis followed by a few very ancient secondary endosymbiosis probably account for all extant plastid diversity $[18,33]$. A consequence of early acquisitions of plastids in the main lineages of eukaryotes is that multiple plastid losses occurred in a number of late diverging lineages, which may still contain plastid-derived genes in its nuclear genomes.

Currently, the evolution of photosynthetic eukaryotes and related organisms is a field of intense research, significantly fueled by the advent of molecular methods, and the existing literature is vast, precluding any intent to summarize all the available data here. The following major issues will be discussed in this chapter: i. plastid acquisitions and losses by different eukaryotic lineages; ii. some recurrent themes on photosynthetic endosymbionts (e.g., genome reduction and genomic features, lateral gene transfer from plastids to nucleus and properties of proteins targeting systems to plastids); and iii. the placing of the plastid-containing eukaryotes into a probably global phylogeny for eukaryotes. We will start with a historical review of the approaches applied to ascertain the evolutionary relationships in the protists.

\section{Assessing the algal and protists evolution}

Due to the delicate nature of these organisms the paleontological record for most of algal phyla is very incomplete and difficult to interpret. Therefore, evolutionary hypothesis should be inferred by comparing extant algae. The advent of the electron microscopy and effective preparation techniques in the second half of twenty century and, later, the development of molecular methods, revolutionized our view of life 
evolution and diversity [222]. Notwithstanding, some noteworthy visionary insights were gained using light microscope, as the original proposition of endosymbiosis reported by Schimper [195], Altmann [1] and Mereschkowski [157]. Biochemical studies also revealed important information, as the photosynthetic pigments, the composition of the cell wall and other cell coverings, the nature of storage product, among others, which were used to refine the accepted algal groups and to establish some relationships among them.

The basic ultrastructural characters of photosynthetic eukaryotes are: i. the number of membranes around the plastids and its relationships with other cytoplasmic membrane systems; ii. the number of thylakoids, and its arrangement (isolated, in small groups or in stacks); iii. the nature of the eye-spot or stigma, if present; iv. the presence and nature of flagellar hairs and other flagellar structures, as paraxonemal rods or flagellar swellings; v. the structure of the transition region between the flagellar axoneme and basal bodies; vi. the arrangement of microtubular roots or other associated structures, if present, that anchor the flagella; vii. the shape of mitochondrial cristae; viii. the behavior of the nuclear envelope and mitotic spindle during mitosis and the cytokynesis patterns, among others [87,110,178] (Table 1). All this information opened a window for unsuspected relationships among photosynthetic and non-photosynthetic eukaryotes, as well as confirmed some former evolutionary hypothesis. For example, the evolutionary relationship between green algae and land plants was assessed on the basis of mitosis, cytokynesis and flagellated cells architecture [181]. A sister group relationship between euglenoids and kinetoplastids (forming the 'euglenozoa') was also proposed on the basis of shared features of cell architecture, flagella, nuclei and mitochondria [46]. Moreover, it was recognized that many algae with chlorophylls $a$ and $c$ generally classified as separate groups (i.e. the brown algae, diatoms and chrysophytes sensu lato), as well as protozoans (e.g. opalinids, bicosoecids, proteromonads) and fungus-like organisms (e.g. oomycetes, hyphochytrids, labyrinthulids), are all closely related in having heterokont flagellate stages (cells with two dissimilar flagella, one smooth and the other carrying tubular tripartite flagellar hairs). This large and very diverse assemblage of protists presumably monophyletic was, accordingly, dubbed as Heterokonta [30] or Stramenopiles [177] and was erected as one of the main lineages of eukaryotes. 
Side by side to the development of the ultra-microscopy was the development of the molecular biology techniques, which allowed the direct manipulation and analysis of nucleic acids (DNA and RNA) and proteins. The hallmarks to study phylogenetic relationships were the development of the DNA sequencing method in the 70s [193] and the PCR (Polymerase Chain Reaction) in the 80s [191]. These techniques opened the way for the use of molecular markers to construct phylogenies [8]. Much progress was achieved by comparing homologous nucleotide sequences among different organisms. Initial studies were based on comparisons of a single molecule, namely the small subunit ribosomal RNA gene (SSU rDNA [see 182 for a review]), which established a 'standard model' to study global evolution of prokaryotes [245] and eukaryotes [203] for nearly ten years. In this model, the eukaryotes evolution was outlined as a basal 'stem' of deepbranching separated lineages of protists, followed by the radiation of the 'crown group', including fungi, animals and plants together with their protistan allies, as well as, several separated lineages purely composed of protists, as the heterokonts or the group called 'alveolates', including ciliates, apicomplexans and dinoflagellates. Several amitochondriate protists (diplomonads, microsporidia and parabasalids) were recovered as the first diverging eukaryotes, supporting the 'archezoa' hypothesis [29], which claims that these and other amitochondriate microbes evolved prior to the acquisition of mitochondria by endosymbiosis. However, the deep-branching position of most of these organisms in SSU rDNA trees was showed as artifactual when other sources of information were incorporated, especially proteins sequences [e.g. 23,67,127,189]. This and other discrepancies stimulated a period of significant revisionism, leading to the erection of new models of eukaryotic evolution based on: larger data sets including broader taxon sampling and/or concatenated multigene analyses $[11,12,133,161$, 166,248]; some rare and putatively irreversible genomics events, as ancient gene duplications, gene replacements or gene fusions that can be used as markers [70,103,176,204]; comparative genomics [47,149]; as well as on the synthesis of many different trees into an unique and plausible scenario [202].

In these new phylogenies most of the phylogenetic groups supported by the ultrastructure and SSU rDNA sequences, as the heterokonts, alveolates, euglenozoa, opisthokonts (fungi, animals and related protists), viridiplantae (green algae plus land 
plants), are still supported. Nevertheless, the emerging picture [e.g. 10,34] is striking in revealing a plausible deepest evolutionary diversification of eukaryotes: the nearly simultaneous radiation of five to eight major 'supergroups' from an unknown common ancestor (Figure 2). These supergroups are primarily composed by unicellular protists and do not have formal names or rank. Obviously, some of them are better supported than others and many important issues are still not settled, in fact, conflicting views are often proposed [e.g. 167], but it is currently accepted that eukaryotic early evolution was a rather explosive radiation [47]. An overall probable history of plastid acquisitions and transfers is also depicted in Figure 2, showing that plastid spreading through endosymbiosis was very effective in the sense that most of the major eukaryotic supergroups contain at least one member with plastids.

\section{Primary endosymbiosis: the birth of plastids}

Chlorophyll $a$ is present in all organisms that release oxygen during the photosynthesis process. The development of this molecule altered the earth atmosphere causing a great impact in the history of the planet, redirecting the evolution of life. Chlorophyll $a$ molecule and its associated chemical and photochemical systems are extremely complex to have been developed independently more than once. It is a wellestablished fact that plastids bounded by two membranes are the vertical descendant of cyanobacteria, which became fully adapted to live into eukaryotic host cells through primary endosymbiosis (Figure 1a-c). The two membranes of such plastids, called primary (or simple) plastids, have been explained in two different ways [80]. The most common is that the inner membrane was the plasmalemma of the endosymbiont while the outer membrane represents the phagosome (food vacuole) of the host. The other explanation is that the inner and outer membranes are the original cyanobacterial Gramnegative envelope, and assumes that the phagosomal membrane has been lost. This is supported by the peculiar carotenoid composition of the outer plastid membrane, which is similar to that of the cyanobacterial outer membrane [111] and, recently, by the discovery of some cyanobacterial proteins that are putatively homologues to translocator proteins 
located on the outer (Toc75 and Toc 34) and inner (Tic55) plastid membranes $[21,186]$. There are evidences that the cyanobacterial homologue of Toc75 may act as a voltagegated channel, which is related to secretory proteins of cyanobacteria $[104,186]$, bolstering the hypothesis that the protein import machinery of plastid could be derived from the secretory system of these prokaryotes.

Once the endosymbiosis occurs, there is a close contact between different genomes, opening the door for lateral gene transfer. The mechanism by which this transference occurs is not established, but transposable elements could be involved. Lateral gene transfer, as well as gene loss and replacement are probably random events, but there seems to be some kind of directionality once the host nucleus has a tendency to acquire genes from the endosymbionts, while the genome of those have a tendency of losing redundant genes [20]. One possible explanation for that apparent opposite tendency of host and endosymbiont genomes is that the nucleus would be a more genetically-stable 'environment' and therefore, less prone to gene loss. Interestingly, this process of transference of plastid genes leads to a partial dependence of the endosymbiont to the host, and is probably essential for the maintenance of a stable endosymbiotic association. The plastid genomes are greatly reduced ( $\sim 34$ to 200 thousand base pairs) if compared to extant cyanobacteria ( 1.7 to 9 million base pairs) [http://www.ncbi.nlm.nih.gov/]. The number and composition of genes will vary from lineage to lineage, as well as the presence and abundance of introns, repeats of rRNA genes and other characteristics [99]. Up to now, 40 plastid genomes were fully sequenced, of those 29 are from the viridiplantae (green algae plus land plants [http://www.ncbi.nlm.nih.gov/]).

The primary plastids are contained in three well-defined lineages of extant eukaryotes: the glaucophytes, the red algae and the green algae (including land plants) (Table 1), which probably descend from the first eukaryote that performed photosynthesis. All the other photosynthetic eukaryotes acquired plastids by engulfing not cyanobacteria, but one of those primary photosynthetic eukaryotes (Figure 3 ). The plastids of glaucophytes or glaucocystophytes, a small group of freshwater unicellular algae, provide compelling evidences for their cyanobacterial origin. These plastids, termed traditionally 'cyanelles', have retained a thin layer of peptidoglycan (the main component of the cyanobacterial cell envelope) between the plastid membranes, and a 
large central body resembling a cyanobacterial carboxisome [143]. In addition, these plastids, like those of the red algae, have cyanobacterial-like pigmentation (chlorophyll $a$ plus phycobilins) and ultrastructure (unstacked equidistant thylakoids with attached granules of phycobiliproteins called phycobilisomes). In both groups, glaucophytes and red alga, the plastid genomes, though significantly reduced if compared with free-living cyanobacteria $[62,121,122,163,164]$, contain the largest known gene repertoire for these organelles, including many fundamental genes for photosynthesis, as well as genes necessary for 'housekeeping' and other more specialized tasks [84,169,185,212, see Table 1 in Ref. 99]. The green algae, a very diverse assemblage of photosynthetic eukaryotes ranging from unicellular planktonic forms to macroscopic seaweeds, have plastids that depart somewhat from the cyanobacteria (e.g. lacking phycobilins, containing instead, chlorophylls $a$ and $b$, and having stacked thylakoids). Nevertheless these plastids have retained cyanobacterial ancestral features, as a gene involved in the growth of the peptidoglycan layer during septum formation [228] and many other features that suggest, without doubt, that these plastids also evolved from cyanobacteria [175].

Since 1980 the primary endosymbiotic origin of primary plastids (and by extension, all plastids) rarely has been doubted. The main questions have been: how many times did such endosymbiosis occur and who were the partners? [a subject widely reviewed in Refs. 51, 173, 174, 175]. While the presence of different photosynthetic pigments suggests separate origins for green algae plastids and glaucophytes/red algae plastids, involving independent endosymbiosis with differently pigmented prokaryotes (a polyphyletic scenario) [184], some conserved complex features of plastids, thought to be 'mutationally onerous', as the protein targeting and importing machinery, suggest a single origin. It is more parsimonious to think that the basics of this machinery evolved only once in a putative common ancestor and were inherited by the green algae, the glaucophytes and the red algae plastids (a monophyletic scenario), rather than by independent origins followed by convergent evolution [28] (Figure 3). There was in the last decade a considerable debate among these conflicting hypotheses, though the bulk of molecular data, especially from plastid genomes, favors the monophyletic origin of plastids. Almost all individual plastid sequences compared, such as plastid encoded SSU 
rDNA [e.g. 16,229] and other four plastid genes (tufA, atpB, rpoCl and psbA [175]), as well as light-harvesting antenna proteins [64,246], consistently indicate that the primary plastids, mainly the well sampled red and green algae plastids (glaucophytes plastids were not included in many of these analyses) form a single robust clade within the cyanobacteria. The only plastid genes that depart from this pattern are the ribulose 1,5biphosphate carboxylase/oxygenase (RuBisCO) genes $r b c \mathrm{~L}$ and $r b c \mathrm{~S}$, which are misleading in this regard, since those were the subject of multiple ancient gene duplications and lateral gene transfers [53]. Unfortunately, the published concatenated multigene analyses of plastids $[149,150,228]$ include only one representative of cyanobacteria and are, therefore, uninformative about the number of times that cyanobacteria were 'enslaved' by eukaryotes. Other plastid traits, as the rRNA-encoding inverted repeats and two distinctive gene clusters (namely $\mathrm{psbB} / \mathrm{N} / \mathrm{H}$ and $\mathrm{atp} / \mathrm{rps} / \mathrm{rpo}$ ) shared among most primary plastids, but absent in cyanobacteria, are often interpreted as derived post-endosymbiotic innovations suggesting a single plastid origin [175].

Additionally, the protein import machinery, which has the same general mechanism in these plastids (by post-translationally adding a transit peptide at the $\mathrm{N}$-terminal to each plastid-targeted protein [151]), also strongly suggests a monophyletic origin of plastids, as transit peptides of glaucophytes, red and green algae are interchangeable among these plastids with no significant loss of function [208]. On the other hand, a common genomic evidence assumed to favor plastid monophyly, the similarities in gene content among primary plastids, was recently showed as most consistent with a convergent evolution scenario and not as a direct support for single origin of plastids [210]. The primary endosymbiosis is a very ancient event (late paleoproterozoic, 1,600 MYA [249]) what makes it extremely difficult to recover its evolutionary history. Overall, plastid data strongly favor the single origin of plastid, although the alternative and almost untestable hypothesis of multiple origins involving closely related cyanobacteria cannot yet be fully discarded.

The monophyletic origin of primary plastids implies that host cells containing such plastids are vertically related. Comparisons of nuclear or mitochondrial genes can test this. If primary plastid-containing eukaryotes form a well supported clade to the exclusion of all other eukaryotes in nuclear or mitochondrial genes phylogenies, the most 
plausible scenario is that a putative common ancestor that first acquired plastid gave rise to the extant glaucophytes, red and green algae (and perhaps some unknown extinct lineages). This rather holophyletic clade is consistent with the proposal of revised Kingdom Plantae including only these primary photosynthetic eukaryotes [27] and named the 'Plantae' hypothesis. Contrarily, if there is no congruence between plastid and nuclear/mitochondrial genes, it is still possible that primary plastids were acquired only once (as is widely supported by plastid genes). If this is the case, from the cell that first acquired plastids, evolved not only the glaucophytes, the red and the green algae, but also other extant eukaryotes that secondarily lost their plastids. In such scenario, it is possible that the closest relatives of one of the primary plastid-containing group might be plastidlacking eukaryotes instead of the plastid-containing ones. In this regard, mitochondrial individual genes [e.g. 22] as well as multiple concatenated mitochondrial genes [24,171] strongly favor the first scenario, suggesting that at least red and green algae are sister groups to the exclusion of other eukaryotes. The split of red and green algae was calculated to have occurred about 1,500 MYA [249]. The statistical supports for the red and green algae clade are usually high, although these results have been disputed on the basis that other mitochondrial genes, not included in such analyses, favored the non sisterhood of red and green algae [211]. The nuclear genes, on the other hand, have yet not provided an unequivocal answer. Most of individual nuclear genes compared are uninformative [57]. Weak to moderate support for the monophyly of the primary-plastid lineages have been obtained only from the actin gene $[17,207]$ or some SSU rRNA phylogenies based on corrected models for sequence evolution [232]. A further strong support, at least for red and green algae sisterhood [183], was found in the nucleusencoded protein EF-2 [161]. Most authors welcomed this last result as an important piece of evidence toward the general acceptance of a monophyletic origin of primary plastidcontaining eukaryotes. The subject is not settled though, as it was argued that the phylogenetic signal of this gene is highly compartmentalized and only a half of the EF-2 sequence favor the red and green algae sisterhood [211]. Notwithstanding, the concatenated nuclear genes analyses favored the Plantae hypothesis, first with weak statistical supports $[11,161]$, but recently with a strong support based on an impressive larger data set (more than 100 nuclear genes) [12]. All these results seem to show that 
there is a tenuous, though meaningful, phylogenetic signal for the relatedness of primary plastid-containing eukaryotes in the nuclear genome. The only nuclear sequence that appears to tell a different history and that has in fact fueled most of debates about primary plastid origins is the RNA polymerase II large subunit (RPB1). This, in some analyses, retrieved the red algae as a deeply separate lineage from the green algae [208, 209]. Other studies of this protein $[48,144,161]$, however, did not support this separation. Likewise, a recent multigene study has challenged the view that primary photosynthetic eukaryotes are monophyletic [167]. This study was largely based on previous multigene datasets [11, 161] updated with new sequences and excluding fast-evolving sequences (e.g., those from amitochondriate protists and cryptomonads' nucleomorph) as well as bacterial outgroups. The red algae and glaucophytes were retrieved as basal separate lineages, whereas the green algae were a late diverging and related to euglenozoa and some amoebae. The statistical supports for these results, however, were rather low and, worthy to mention, when the EF-2 sequence was considered, the sisterhood of red and green algae was recovered with a higher statistical support. Concluding, if all the available evidences favoring primary plastid monophyly are compared to evidences unequivocally refuting it, one should accept that the most plausible scenario is the single origin of plastid, although more data are needed to establish it as a fact.

Another important issue on the origin of primary plastids is who where the two partners of such primary endosymbiosis? There is no specific candidate at the cyanobacterial side, mainly because the evolution of cyanobacteria is still poorly understood. The most well sampled gene among cyanobacteria (SSU rDNA) supports the view that these organisms suffered an explosive radiation after the splitting of the structurally simplest cyanobacteria [229], the Gloeobacter group. In this group, which lacks thylakoids, photosynthesis takes place in the plasmalemma, as is the case in other photosynthetic bacteria [187]. The recent published complete sequence of Gloeobacter genome [164] supports this separation. Based on SSU rDNA sequences, all the other extant cyanobacteria, including plastids, fall into at least six main lineages that radiate nearly simultaneously from a single node and there is no specific group consistently related to the plastid lineage [229]. Other SSU rDNA comparisons retrieve the plastids as a sister group of the whole cyanobacteria radiation [e.g. 107], or as a basal lineage, but 
none of the published phylogenetic analyses has revealed the extant cyanobacteria lineages that are more related to plastids, if there is one. On the other hand, plastid relationships with extant cyanobacteria were traditionally inferred by comparing biochemical features, especially pigment composition, but this approach have also significant caveats. This approach was initially bolstered with the discovery of the 'prochlorophytes' (oxygenic photosynthetic prokaryotes having chlorophylls $a$ and $b$ but no phycobilins) $[25,42,138]$, which were supposed to be the link between green plastids and prokaryotes. Further phylogenetic studies, however, rejected this view; the three described species of prochlorophytes correspond to separate lineages within the cyanobacteria, and none of them are related to the plastid clade [172,230]. Moreover, though prochlorophytes have chlorophylls $a$ and $b$ as main pigments, their core proteins of light harvesting antenna systems (called PCBs or Prochlorophyte Chlorophyll-Binding proteins) [134] are not related to eukaryotic Light Harvesting Chlorophyll binding proteins (LHCs), which are the core membrane plastid proteins to which the chlorophyll molecules (only chlorophyll $a$ in 'red plastids', chlorophylls $a / b$ in 'green plastids' and chlorophyll $a / c$ in 'brown plastids') are coupled [91]. These results, together with the discovery of phycobilins genes in prochlorophytes $[106,179,224]$ as well as the likely ancient presence of chlorophyll $b$ in cyanobacteria [227], suggest that cyanobacteria were probably ancestrally more diverse in their light harvesting antenna complexes, probably having phycobilisomes with cyanobacterial types of chlorophyll $a$ binding proteins (not LHCs, which are a plastid invention) and probably chlorophyll $b$ [89]. In this scenario, it is likely that the pigments were differentially lost in the plastids: in glaucophytes and red algae the chlorophyll $b$ of ancestral cyanobacteria was secondarily lost, whereas than in green algae the phycobilisomes were lost (Figure 3). An alternative scenario is the independent acquisition of chlorophyll $b$ more than once in the evolution of those lineages [172,230]. Chlorophyll $b$ differs from chlorophyll $a$ by presenting a formyl group $(\mathrm{CHO})$ in place of a methyl group $\left(\mathrm{CH}_{3}\right)$ on one of the pyrroles. This conversion reaction from chlorophyll $a$ to $b$ uses molecular oxygen and is catalyzed by chlorophyllide $a$ oxygenase (CAO) [66,219].

At the host side, if the Plantae are holophyletic, the features of putative common ancestor can be inferred by comparing extant glaucophytes, red algae and green algae 
[34]. So, it is likely that the Plantae ancestor was a biflagellate anterokont with a cruciate system flagellar rootlets and probably associated multilayered structures, flattened mitochondrial cristae, $\alpha-1,4$ linked glucans as main storage products, among other general features [34]. From this putative ancestor that acquired plastid, probably first evolved the glaucophytes, as the cyanobacterial-like cyanelles and most of multigene studies suggest, followed by the sister lineage that gave rise to the red and green algae. The red algae lost the flagella secondarily and evolved mainly as a multicellular group of marine benthic phototrophs [see 194 for a review]; on the other hand, many green algae maintained the unicellular or colonial flagellate way of life, although others evolved independently different degrees of multicellularity: filamentous, parenchymatous, coenocytic, etc., but, whatever the case, almost always producing flagellate stages for reproduction (zoospores and gametes) [see review in 139]. Early in its history, the green algae splitted into two main groups: the Chlorophyta, most of them with cruciate flagellar roots, and the Streptophyta, with a unique large flagellar root disposed laterally and open mitosis. This last group includes the land plants and its closest green algal relatives, the charophytes [86,123].

\section{Secondary endosymbiosis: spreading the plastids}

The gain of photosynthesis was not limited to the primary plastid-containing eukaryotes. Other extant eukaryotes perform photosynthesis using plastids ultimately acquired laterally from other plastid-containing eukaryotes, which were engulfed and retained by secondary hosts. Such secondary symbiogenesis account for plastids of a bewildering diversity of photosynthetic eukaryotes, most of them unicellular, as the euglenoids, the heterokont algae, the dinoflagellates, the haptophytes, cryptomonads, dinoflagellates and chlorarachneans (Figure 3). Moreover, there are non-photosynthetic second-hand plastids in the parasites of the phylum Apicomplexa, a sister group of the dinoflagellates (Table 1).

The first clue suggesting that all these plastids have eukaryotic origins was the presence of more than two membranes surrounding them [220], i.e., three membranes in 
euglenoids and most of dinoflagellates, and four membranes in heterokont algae, haptophytes, cryptomonads, apicomplexans and chlorarachneans. To explain the origin of such additional membranes different processes were invoked [28,78,79,137,198,240], but the most likely explanation is that all secondary plastids were formed ultimately by the same general way: the phagotrophic ingestion and further retention and reduction of an entire eukaryotic unicellular algae into a secondary host cell, leading to the establishment of a very reduced cell within other cell $[78,79]$ (Figure 1d-f). This is more apparent in cryptomonads and chlorarachneans, where the endosymbiont reduction was not fully accomplished and the plastids still keep several eukaryotic cellular features. The uptake of a complete eukaryotic cell by other cell implies that secondary plastids first arose as plastid bounded by four membranes; the two innermost membranes corresponding to the primary plastid envelope; the third membrane corresponding to the former plasma membrane of the primary host, now called periplastid membrane; and the fourth outermost membrane probably corresponding to a phagosomal membrane produced by secondary host (as is likely in chlorarachneans and apicomplexans) or to a rough endoplasmic reticulum membrane of secondary host (in cryptomonads, heterokont algae and haptophytes) $[32,35]$. The three membranes plastids of euglenoids and most dinoflagellates could have evolved later through the loss of one membrane, probably the periplastid membrane, from a previous four-membranes plastid [32,35,54].

The uptake of eukaryotic endosymbionts implies the acquisition of three distinct genomes by a host cell (the endosymbiont's nucleus, mitochondria and plastid genomes), which were also dramatically reduced. This is especially true in the case of mitochondria, which were completely lost in all secondary true plastids, and the endosymbiont nucleus, which was completely lost in most of secondary plastids, but still retained, though highly reduced, in plastids of cryptomonads and chlorarachneans. In other words, a massive gene loss and transfer from the nucleus and plastid of endosymbiont to the secondary host nucleus characterized the secondary symbiogenesis. This implies also in the evolution of effective protein trafficking machinery through the four or three membranes surrounding such plastids and the addition of specific targeting sequences to all transferred proteins [39]. All that seemed to have been achieved by utilizing the cell secretory and plastid importing systems in a two-step process that still is poorly understood in most of 
secondary plastid-containing eukaryotes: first, the nucleus-encoded, plastid-targeted proteins are placed in the lumen of the endomembrane system using standard signal peptides added at the $\mathrm{N}$-terminal; then the proteins are imported through the plastid membranes by Toc and Tic translocons, which recognize the standard transit peptides also added at the N-terminal of presequences [4,50,113,114,129,131,134,165,198,214, $236,237]$. Thus, in plastids bounded by four membranes, the former plasma membrane would have to acquire some kind of protein trafficking machinery [35], though this is still not well characterized in most of secondary plastids.

The eukaryotes that contain secondary plastids are so diverse, and the secondary plastids itself are so distinct, that the separate origins of such plastids rarely have been doubted. Currently, it is well established that there are two main kinds of secondary plastids: 1) those derived from green algae, which contain chlorophylls $a$ and $b$ as main pigments, and are present in euglenoids and chlorarachneans as well; and 2) those derived from red algae, some of which (the cryptomonads plastids) have retained the typical red algal pigmentation (chlorophyll $a$ and phycobilins) plus one postendosymbiotic and purely eukaryotic pigment, the chlorophyll $c$, whereas others (heterokont algae, haptophytes and dinoflagellates plastids) contain chlorophylls $a$ and $c$ together with carotenoids such as fucoxanthin or peridinin, but have lost the phycobilins (Table 1, Figure3). Altogether, the plastids with chlorophylls $a$ and $c$ make up the 'chromophyte' plastids. The origin of unpigmented apicomplexans plastids was largely controversial and still is disputed, but the most accepted hypothesis is that such non-photosynthetic plastids also evolved from red algae [174, 241]. Although we are almost secure about the eukaryotic ancestors of all known secondary plastids (green or red algae), we do not have confidence in the number of times that these algae were enslaved and converted into plastids. It has been argued $[31,32,35]$ that such complex process as secondary symbiogenesis is too 'evolutionary onerous', requiring first a massive and successful gene transfer from endosymbiont to host nucleus and second the evolution of an effective protein trafficking system across three or four distinct membranes; accordingly, such process may not be as frequent as it have been often claimed (e.g. seven separate endosymbiosis in the separate ancestors of each algal group containing secondary plastids, plus apicomplexans [176]). The most parsimonious view suggests only two 
secondary endosymbiosis, one implicating a green alga and other implicating a red alga [32]. However, the most supported current scenario is that three separate events account for all secondary plastids diversity: two separate endosymbiosis implicating distinct green algae (one leading to the plastids of euglenoids and one leading to plastids of chlorarachneans) and an independent endosymbiosis implicating a red algae (giving rise to plastids of cryptomonads, heterokonts, haptophytes, dinoflagellates and apicomplexans) $[6,18,125,241]$. This last event was calculated to have occurred about 1,300 MYA [249].

\section{The green secondary plastids}

The chlorarachneans or chlorarachniophytes are perhaps the best characterized case of a secondary endosymbiosis. These organisms are chimaeras of reticulofilose amoebae that belong to the eukaryotic lineage called Cercozoa $[7,15,36,37,108,124,126]$ with an unicellular green algae functioning as plastids $[81,116,155,234]$. There are few recognized species of chlorarachneans, most of them are benthic marine phagotrophic amoebae that can form naked flagellate dispersal stages or even walled unicellular nonflagellated coccoid stages. There are also purely flagellate planktonic species, as the most studied chlorarachnean, Bigelowiella natans Moestrup [158]. The endosymbiont green alga has lost most of its cell components although still keeps a vestigial cytoplasm with functional ribosomes (called periplastid space), a reduced nucleus (the nucleomorph) and, of course, its plastid. In total, the plastid stroma is separated from the secondary host cytosol by four distinct smooth membranes, none connected to the endoplasmic reticulum or to the nuclear envelope. The nucleomorph of chlorarachneans has a much reduced, compacted genome (380-455 kb) contained in three chromosomes [81,82,154]. This genome contains rRNA operons and a minimal set of genes for proteins implicated in expression and maintenance of the nucleomorph genetic system (housekeeping) as well as other tasks, including some plastid proteins with putative transit peptides; however, the bulk of plastid proteins were retransferred from the nucleomorph to the secondary host nucleus. Remarkably, all the genes for enzymes involved in the primary metabolism were lost in the nucleomorph. On the other hand, there are many introns but they are much reduced and in fact correspond to the smallest known spliceosomal introns [81]. 
Although very divergent and AT biased, the SSU rRNA and other nucleomorph genes have widely confirmed that this reduced nucleus belong to the green algae clade [81,155,234], probably an ulvophycean green alga [116].

For the euglenoids there are convincing data suggesting that the three membranebounded green plastid also is a reduced green algae [16,229]. The euglenoids together with kinetoplastids and diplonemids belong to the euglenozoa $[178,200]$, which in turn belongs probably to a very diverse supergroup of protists called excavates [34,201]. These peculiar unicellular flagellate algae have an anterior pocket where are inserted the flagella and a characteristic rodlike structure that lies parallel to the flagellar axoneme. This group also presents a nucleus with permanently-condensed chromosomes, with a special type of closed mitosis, and a complex proteinaceous, generally flexible, pellicle (or periplast) beneath the plasma membrane, among others interesting features. Most of euglenoids are mixotrophs, having plastids and performing photosynthesis together with osmotrophy, while others have non-photosynthetic plastids and are purely osmotrophic and still others lack plastids altogether and are phagotrophic. Although it was initially proposed that euglenoids plastids could be originated by a primary endosymbiosis [28], the green algal secondary origin for such plastids [78] has been widely supported both by individual plastid gene sequences $[16,53,146,176]$ as well as multiple concatenated plastid genes $[149,150,229]$. The ancient green alga endosymbiont was probably a prasinophycean (scaly green flagellates most of them marine) [146]. This endosymbiont was almost completely reduced, only remaining its plastid, which is enclosed by a phagosomal membrane produced by the host. An intriguing feature of the plastid genome of Euglena is that it is characterized by the proliferation of numerous introns: both group II introns and very small group III introns, as well as twintrons (introns-within-introns) [100]. There are also three tandem-like organized rRNA repeats instead of two, as in most plastids [100]. The plastid genome of the colorless euglenoid Astasia recently has been sequenced [85] and it was showed that this very small genome (73 $\mathrm{kb}$ ) is roughly similar to that of Euglena, except that it lacks almost all photosynthetic genes.

It is not clear when the plastids were acquired by euglenoids. Most of nucleusencoded SSU rDNA phylogenies show-that plastids-lacking phagotrophic euglenoids are the basal lineages and, accordingly, support the view that plastids were acquired later in 
this group by a phagotroph that gave rise to phototroph lineages. Thereafter, from some of these phototrophs evolved secondary heterotrophic colourless species $[142,147$, $159,168]$. Comparisons of the complete plastid-encoded rRNA operon also supported this view [146]. However, a recent study based on a broader sample of phagotrophic species has shown that they are not necessarily basally diverging [26]. On the other hand, the surprising discovery of putative plastid-derived genes in the parasitic kinetoplastids $[101,199]$ bolstered the view of a more ancient plastid origin in the euglenoids, suggesting as a most parsimonious scenario that both kinetoplastids and euglenoids evolved from an common ancestor with plastids, which were secondarily lost in the kinetoplastids as well as in the heterotrophic euglenoids. Many of these plastid-like genes in kinetoplastids have been disputed as methodological artifacts [190], but a striking organelle unique of kinetoplastids seems to support the idea that this group ancestrally contained plastids. This organelle, known as glycosome is not a relic of a plastid, but a kind of peroxisome that have sequestered most of the plastid-like enzymes of the putative former endosymbiont, including those of the glycolitic pathway, which are then topologically separated from cytoplasm [101].

Considering all the available data discussed above, especially the putative ulvophycean nature of the chlorarachniophyte plastids and the prasinophycean nature of euglenoid plastid, the 'cabozoan' hypothesis [32] suggesting that a single secondary endosymbiosis originated the chlorarachneans and euglenoids plastids is not supported. Likewise, there are no molecular data supporting that cercozoans and discicristates (the lineages to which belong chlorarachneans and euglenoids respectively) are related, although this should not be definitively discarded as we are still advancing in the understanding of eukaryotic mega-evolution.

\section{The 'red' secondary plastids}

A red algal origin was first proposed for plastids of cryptomonads [79,240], which are the unique plastids that contain phycobilins, bounded by more then two membranes. These plastids contain also chlorophyll $c$, a pigment also found in plastids of the heterokont algae, haptophytes and dinoflagellates (Table 1). On this ground, in 1962 it was proposed that all these algal groups are related and should be classified together in a single phylum, 
the Chromophyta [43,44], a revolutionary idea that later was refined by proposing a specific kingdom (Chromista) including only cryptomonads, heterokont algae, haptophytes and of course non-photosynthetic heterokonts, all of which have very similar plastid ultrastructure, but excluding dinoflagellates [30]. Since a red algal origin of cryptomonads plastids become widely adopted in the light of convincing ultrastructural and biochemical evidences, a red algal origin was also extended to the other chromists, as well as dinoflagellates plastids [79,240], a hypothesis that has been further supported by molecular data [59]. The origin of the plastids of Apicomplexans, on the other hand, has been more difficult to access and still is debated, although most evidences favor the red algal origin.

The cryptomonads are unicellular marine or freshwater flagellates with dorsiventrally constructed cells that have a distinctive ventral flagellar pocket lined by ejectisomes [178]. The secondary plastids of cryptomonads, like those of chlorarachneans, are cells within cells: they have a vestigial cytoplasm (the periplastid space) with ribosomes, and even stored granules of the main food reserve (starch). In the periplastid space are located also the endosymbiont reduced nucleus (the nucleomorph) and its plastid, which contains peculiar broad thylakoids, disposed in pairs, containing phycobilins in its lumen, not aggregated into phycobilisomes. There are four membranes separating the plastid stroma and host cytosol, but contrarily to chlorarachneans, the outermost membrane is continuous with the rough endoplasmic reticulum and with the outer membrane of the nuclear envelope. This membrane is called here as plastidial rough endoplasmic reticulum (pRER). Thus, the eukaryotic endosymbiont lies into the lumen of the host endoplasmic reticulum, and not into a phagosomal vesicle. The nucleomorph was first described in the cryptomonads plastids [93] and later it was verified that this compartment contained DNA [145]. The complete sequencing of the nucleomorph genome of the cryptomonad Guillardia theta D.R.A.Hill \& R.Waterbe [61] showed it to be a very reduced (ca. $551 \mathrm{~kb}$ with a total of 511 identified genes) eukaryotic genome contained in three linear chromosomes. The nucleomorph genes are very divergent and AT biased, but contrarily to chlorarachneans nucleomorph, they contain very few introns [61]. Phylogenies of many of these genes show that the nucleomorph belongs to the red algae [5,16,38,48,58,61,109,207,231], representing a monophyletic early diverging 
lineage radiating in many trees before the Bangiophycidae $[170,162]$. On the other hand, the sequencing of the plastid genome of cryptomonads endosymbiont [60] also confirms the red algal origin of cryptomonad endosymbiont, as this genome contains basically the same gene content and arrangement that have found in the red algae Porphyra [185] and Gracilaria [99].

The heterokont algae and the haptophytes have almost identical four-membrane plastids, which also are located in the lumen of the endoplasmic reticulum, but lack nucleomorphs. Besides chlorophylls $a$ and $c$, these plastids have the brown carotenoid fucoxanthin or fucoxanthin-derived pigments, and lack phycobilins. The periplastid space is almost completely reduced, lacking ribosomes and the food reserve (a soluble $\beta-1,3$ glucan) is stored in the host cytoplasm. An intriguing feature of such plastids, shared with cryptomonads, which may be implicated in protein trafficking [35], is a system of small vesicles located in the periplastid space between the nucleus and plastid envelope. The heterokont algae constitute the most diverse algal group, ranging from tiny picoplanktonic unicells to the large and complex multicellular kelps, including all the level of organization present in algae and thousands of described species [177]. There are many classes of heterokont algae, the most familiar being the brown algae, the diatoms, the chrysophytes and the xanthophytes. On the other hand, the haptophytes (also known as prymnesiophytes or coccolithophorids) are almost always planktonic marine unicellular flagellates, each cell bearing two smooth flagella and one additional locomotory/feeding filamentous appendage, the haptonema [92, for a review in heterokont algae and haptophytes see Ref. 2]. The genes contained in the plastid DNA of both heterokont algae and haptophytes have quite confirmed the red algal origin of such plastids $[16,52,160]$. The arrangement and nature RuBisCO genes also strongly support this origin. In the red algae the RuBisCO-encoding genes have a proteobacterial origin rather than a cyanobacterial one, as is the case of green algae, land plants and glaucophytes [176]. The plastids of heterokont algae and haptophytes (and also cryptomonads), as we should expect if they are originated from red algae, have also proteobacterial genes for RuBisCO. Moreover, both in red algae as in heterokont algae, haptophytes and cryptomonads, the two RuBisCO genes are encoded in the plastids, whereas in all other plastids the $r b c \mathrm{~S}$ was laterally transferred to nuclear genome [72]. 
Most confusing about its plastid origin are the dinoflagellates, mainly because the unique features of its plastid genomes which largely preclude gene amplifying and sequencing. As was already noted, these organisms encompass the largest known plastid diversity, which was soon assumed to be the result of multiple endosymbiosis [56]. About half of dinoflagellates have plastids, most of which are surrounded by three membranes and contain chlorophylls $a$ and $c$ plus the brown carotenoid peridinin [for a review see Ref. 96]. Now there is a compelling body of evidences supporting the view that this typical dinoflagellate plastid evolved from an endosymbiont red alga. In these dinoflagellates, termed 'peridinin' dinoflagellates, the plastid genome is radically distinct from all the other known plastids, consisting of several small (2-6 kb) circular chromosomes, each one encoding a single gene plus a non-coding region $[13,250,251,252]$. Two separate minicircles encode the SSU and LSU rRNA and, at least in one species, there are other seven minicircles encoding different typical plastid proteins. Phylogenetic analyses of these protein genes [252], as well as psbA [218], tufA and SSU and LSU rDNA [253] retrieved the peridinin dinoflagellates plastids as a monophyletic lineage into the red algal clade of plastids. Moreover, it was supported that a plastid was present in the latest common ancestor of all peridinin dinoflagellates, a group that encompass most of extant dinoflagellates; so, the extant numerous heterotrophic dinoflagellates have secondarily lost their plastids [192]. Further, strong support for a red algal origin of peridinin plastid was obtained from the nucleus-encoded, plastid-targeted genes, as the ones coding for light-harvesting chlorophyll-peridinin binding proteins [64], oxygen-evolving enhancer 1 (PsbO) protein [115]). However, the history of plastid evolution in dinoflagellates is very complex and some of the dinoflagellates that lost peridinin plastids, seemed to have replaced them later with distinct plastids acquired from other non-red algal eukaryotes [97,115,192,223], a subject that will be revised below. On the other hand, in several species that retain the peridinin plastids most of the typical plastid genes contained in minicircles have been transferred to nucleus $[9,98,132]$, so the plastid genome achieved a maximum of reduction compared with other algae [90].

Perhaps the most surprising finding on plastids evolution was the discovery of the apicoplast, the reduced and non-photosynthetic plastid that has been retained in many 
apicomplexans, as the important animal pathogens Plasmodium, Eimeria and Toxoplasma [71,243]. These organelles were first noticed in 1965, through electron microscopy, as an enigmatic membrane-bounded compartment of unknown function [see historical review in Ref. 83]. Later it was observed also by electron microscopy an extrachromosomal circular DNA [128], first assumed to be mitochondrial DNA, although further sequencing showed that this DNA had homology with plastid DNA instead of mitochondrial DNA. Striking plastidial features were discovered in this organelle, as rDNA inverted repeats and plastidial gene clusters [77,130,244]. The exact localization of this DNA into the enigmatic membrane bounded compartment $[130,156]$ definitively supported the idea that apicomplexans parasites have secondary plastids [77], bound by four membranes [130]. The apicoplasts have a very reduced and divergent genome (27$35 \mathrm{~kb})$, lacking genes directly related to photosynthesis, but have other important functional genes [130,156], especially the plastid rRNA genes and those for fatty acid and isoprenoid biosynthesis, as well as other important biochemical tasks [76,237,243]. Most of proteins functioning in the apicoplast are nucleus-encoded and such genes contain plastid-like targeting sequences [237], confirming the plastid nature of this organelle. Studies in malaria and toxoplasmosis have shown that both the organelle and its genome are essential for those pathogens, which consequently fueled an intense research about the nature of this plastid and its use as drug target [243]. However, to discern the origin of such plastids has been a very difficult task as has been discussed on the light of new evidences supporting a green algal origin [73,74] instead of the red algal origin that is commonly assumed [6, 238]. The apicoplast genes are so divergent and AT biased that a clear answer about its origin was not possible so far. Some single gene comparisons supported, albeit weakly, that apicoplasts have a red algal origin (e.g. the ORF 470 [242] or plastid-encoded SSU rRNA [252]), whereas others favored a green algal (tufA [130]) and even a euglenoid origin (rpoB [75]) and plastid-encoded SSU rRNA [65]). Similarities in gene content and order between apicoplast and red algae plastids [213], as well as non-common genomic structural features between green plastid and apicoplasts [19], were interpreted as supporting a red algal origin, though this interpretation may be unreliable as apicoplast genome is very reduced and these similarities can be an effect of convergent evolution, as was argued for primary plastids 
[210]. The strongest evidences in favour of red algal origin of apicoplast do not lie in this peculiar plastid. It is the evolutionary history of some nuclear-encoded, plastid-targeted enzymes, namely glyceraldehyde-3-phosphate dehydrogenase (GAPDH [70]), together with analyses of multiple nuclear genes [11] that have strongly supported the view that apicoplasts are 'red' in origin. It is better explained if we review the emerging whole evolutionary framework for the apicomplexans evolution in the light of chromalveolates hypothesis.

\section{The 'chromalveolate' hypothesis}

According to this hypothesis, from a single ancestor that acquired a red alga as endosymbiont evolved all the extant algae containing chlorophyll $c$ plus numerous related heterotrophic eukaryotes that presumably secondarily lost photosynthesis [32] (Figure 3). In other words, this hypothesis stipulates that chromists and alveolates share a common ancestor and were ancestrally phototrophic. The chromists encompass the cryptomonads, heterokonts and haptophytes, which were supposed to be related on the basis of some shared plastid features, especially the plastidial rough endoplasmic reticulum surrounding the endosymbiont [30], a suspicion that has been strongly supported by analyses of chlorophyll-fucoxanthin binding proteins [63] and recently by combined plastid genes phylogenies [99,248]. Besides algae, in the chromists are included colourless heterotrophic eukaryotes, as the oomycetes (e.g. Phytophthora and other plant pathogens that historically were treated as fungi), opalinids, labyrinthulids, bicosoecids and thraustochytrids, all of which form heterokont flagellate stages. According to chromalveolates hypothesis the plastids were lost in these heterotrophic chromists. Recently it was discovered a cyanobacterial gene for the enzyme 6-phosphogluconate dehydrogenase in oomycetes [3], which could be a remnant of the plastid supposed to be originally present in the ancestor of these organisms. The alveolates, on the other hand, include the ciliates, apicomplexans and dinoflagellates, a very diverse group of eukaryotes that share a distinctive system of vesicles beneath the plasma membrane subtended by microtubules (the cortical alveoli), plus tubular mitochondrial cristae and presumptive picnocytotic structures, called micropores [45,136,178, 221]. The monophyly of alveolates has been widely supported since first molecular data were 
available [203] and currently it is not doubted that this assemblage represents one of the major diversification of eukaryotes. If alveolates were ancestrally phototrophic, most of these organisms adopted modes of life radically distinct. For example, the ciliates are mainly predators that presumably lost their plastids and the apicomplexans are highly derived and specialized obligate parasites with very complex life cycles that maintained a colourless plastid. Finally, half of dinoflagellates are phototrophs or mixotrophs whereas other presumably lost their plastids (or at least the photosynthesis ability) and have adopted a predatory or parasitic way of life [192].

While the chromalveolate hypothesis was proposed in order to minimize the number of secondary endosymbiosis invoked to explain the red line of plastids $[32,35]$, the monophyly of this group had become supported both by plastid genes [248] and nucleus-encoded, plastid-targeted genes $[70,103,176]$. The first hard evidence for chromalveolates was the complex evolutionary history of the GAPDH enzyme in plastidcontaining eukaryotes. In photosynthetic eukaryotes there are two distinct isoforms of GAPDH, both nuclear-encoded: one eukaryotic functioning in the cytosol (GapC) and another functioning in the plastid (GapA), which must be targeted to the plastid by adding specific signal sequences $[141,148]$. The phylogenies of both GAPDHs have showed that in plants, green algae and red algae the primary plastid-targeted GAPDH is related, as expected, to cyanobacterial and eubacterial GapA isoforms $[68,141]$ and, accordingly, its gene probably was transferred from the ancient endosymbiotic cyanobacteria to the nucleus of the host cell in the course of the primary symbiogenesis, as occurred with most of the proteins functioning in the plastids. In the secondary plastid of euglenoids the plastid-targeted GAPDH is also homologue of the cyanobacterial form [105]. However, in the chromists and alveolates with plastids (dinoflagellates and apicomplexans) the plastid-targeted GAPDHs are related to eukaryotic cytosolic (GapC) instead cyanobacterial forms and form a robust monophyletic clade in phylogenies of this enzyme $[70,103,216]$. Such result has been explained invoking a probable single gene duplication of the GapC of the putative common ancestor of chromists and alveolates, which already was equipped with an endosymbiont red alga $[70,103]$. So, one of the host's cytosolic GapC copies, by incorporating targeting sequences, was successfully targeted to the endosymbiont, where it replaced in function the cyanobacterial isoform 
[70], and this endosymbiotic gene replacement occurred prior to the divergence of the chromists and alveolates, which inherited the shared GapC isoform. Some dinoflagellates, however, complicate severely this history. For example, one dinoflagellate departs from the typical chromalveolate plastid-targeted cytosolic eukaryotic GAPDH isoform, having instead a cyanobacterial like plastid-targeted GAPDH closely related to the Euglena plastid-targeted GAPDH $[69,215]$. Likewise, a much rare GAPDH have been also isolated from dinoflagellates, though it is apparently not targeted to plastids [215].

Further support for chromalveolates monophyly has been inferred from the nucleus-encoded, plastid-targeted gene for fructose-1,6-bisphosphate aldolase (FBA [176]), whose evolutionary history is characterized also by an unique gene replacement in the putative common ancestor of chromalveolates. Roughly, there are two distinct and unrelated classes of FBA: an eukaryotic isoform (class I) and a primarily prokaryote isoform (class II), which is present in cyanobacteria. In glaucophytes, as expected, the nucleus-encoded, plastid-targeted FBA is class II related to cyanobacteria. However, in the red algae the nucleus-encoded, plastid-targeted FBA is a class I isoform, which is supposed to have arisen from a duplication of the cytosolic red algal homologue and an endosymbiotic gene replacement of the cyanobacterial version [176]. Surprisingly, in photosynthetic chromalveolates (there are no plastid targeted FBA in apicomplexans), the nucleus-encoded, plastid targeted FBA is a class II isoform not directly related to cyanobacterial to the class II isoforms. More over, the phylogenies reveal that the class II isoforms of chromalveolates forms a monophyletic clade in the phylogenies suggesting a single origin of all chromalveolate plastids. So, probably the photosynthetic chromalveolates all acquired their plastid-targeted FBA from some source other than that of all other plastids prior their diversification in the extant lineages [176].

Overall, the results from GAPDH and FBA are congruent with those of highly divergent plastid SSU rDNA [252] in retrieving the apicoplast as sister group of dinoflagellates plastids, as well as with previous corrected nuclear SSU rDNA phylogenies [233], LSU rDNA [14] and RPB1 [48], that retrieve the heterokonts as related to alveolates to the exclusion of other eukaryotes. Multigene analyses of nuclear genes $[11,12,166]$ also support, albeit weakly, this hypothesis. However, it is still not 
easy to put the apicomplexans plastids into a simplified evolutionary picture. A recent study of the nuclear gene for COXII (mitochondrial citochrome oxidase subunit 2) in apicomplexans did support strongly a green algal origin of apicoplast $[73,74]$ instead of a red algal origin as is postulated in chromalveolates hypothesis. Although these results have been disputed on the basis that no ciliates were included in the phylogenies of COXII genes [238], some striking features of this protein call strongly for a green algal origin of apicoplast. For example, in apicomplexans as in some green algae, the cox 2 gene is nucleus-encoded and is present as two chromosomally separated fragments $(\operatorname{cox} 2 a, \operatorname{cox} 2 b)$, whereas than in almost all other respiring eukaryotes (including other chromalveolates and red algae) the cox2 gene is mitochondrial and not fragmented $[73,180]$. Accordingly, it was proposed that the splitted cox 2 genes were laterally transferred from an endosymbiotic green alga (the ancestor of apicoplast) to the apicomplexans ancestor, as is supported by cox2 genes phylogenies [73]. Besides, the $\operatorname{cox} 2 b$ gene contains an extension in the N-terminal probably related with mitochondria targeting that is shared with green algae, but not with ciliates $[73,74,180]$. This suggests that the apicomplexans acquired the cox 2 genes from a distinct source than other alveolates. As these evidences strongly claim for a green algal origin of apicoplast and, contrarily, the GAPDH enzyme claim for a red algal origin, it is still possible that ancestrally apicomplexans harbored plastid derived from red algae (as is predicted by the chromalveolates hypothesis), but these plastids were lost and apicomplexans later reacquired plastid by capturing a green alga, from which they acquired the cox 2 genes [174]. While this controversy remains open, there are convincing evidences that plastid replacement occurred in several dinoflagellates.

\section{Plastids replacements in dinoflagellates}

Recent molecular data have supported the view that dinoflagellates were ancestrally photosynthetic and that about a half of the extant dinoflagellate species have independently lost the photosynthesis ability and live as phagotrophs, although we do not know if they retain a relict plastid [192]. The most widely distributed plastid in 
dinoflagellates is the three membrane-bounded peridinin-containing plastid, which was probably inherited vertically from an alveolate ancestor and is red algal in origin. However, an irrefutable haptophytic origin is known for plastids of three related species, Karenia brevis (C.C.Davis) G.Hansen \& A.F.Moestrup, Karenia mikimotoi (Miyake \& Kominami ex Oda) G.Hansen \& A.F.Moestrup and Karlodinium micrum (B.Leadbeater \& J.D.Dodge) J.Larsen, which contain acylfucoxanthins (19'-hexanolyloxy- and/or 19'butanoyloxy-fucoxanthin), a kind of carotenoid only found in some haptophytes and in one heterokont $[49,102,120]$, instead peridinin. Additionally, these plastids are bounded by four membranes instead the typical three [205, 102]. Molecular comparisons of plastid-encoded genes (SSU rDNA [223]), psaA, psbA and $r b c \mathrm{~L}$ [247]) as well as nucleus-encoded, plastid-targeted protein (PsbO [115]) have quite confirmed that these fucoxanthin-containing plastids belong to the haptophyte clade of plastids. Host nuclear SSU rDNA phylogenies retrieve these species as a monophyletic cluster [192], suggesting a single haptophyte acquisition by their latest common ancestor. However, it is not clear from host phylogenies, when such plastid replacement did occur. Recently, a study of three plastid-encoded protein genes, $p s a \mathrm{~A}, p s b \mathrm{~A}$ and $r b c \mathrm{~L}$, individually or combined, recovered both the typical peridinin plastids and the fucoxanthin-containing plastids as sister groups forming a monophyletic clade radiating together the haptophytes, suggesting also a haptophyte origin for peridinin-plastids [247]. Nevertheless, the nucleus-encoded, plastid targeted GAPDH clearly support separate origins for the fucoxanthin-containing plastids of Karenia brevis and related species and the typical peridinin plastids of most dinoflagellates [216]. The most parsimonious explanation for fucoxanthin-containing plastids in dinoflagellates is that these plastids were acquired by a tertiary endosymbiosis between a haptophyte and an ancient heterotrophic dinoflagellate that lost the typical peridinin plastids [192] (Figure 4).

Independent plastid loss and replacement occurred in some members of Dinophysis, which harbor plastids very similar to those of cryptomonads in relation to the main pigments, chlorophylls $a$ and $c$ plus phycobilins, though these plastids are bound by only two membranes and do not contain nucleomorph [197]. It is not clear, however, if these plastids are true integrated organelles or are recent acquisitions that remain functional but that have still not transferred the bulk of its genes to the host [39]. Several 
predatory dinoflagellates, in fact, retain temporarily functional plastid from its photosynthetic preys ('kleptoplastidy' [e.g. 140]), but these plastids are not capable of reproduction into the host. Host phylogenies based on nuclear SSU rDNA retrieve the Dinophysis species as a monophyletic cluster into the peridinin containing dinoflagellates, supporting the view that these species ancestrally harbored peridinin plastids that were lost. Comparisons of plastid-encoded SSU rDNA [97,217] and $p s b A$ $[97,118]$ confirm the cryptomonad origin of such plastids, but, as the sequences show a very limited polymorphism among species it is believed that these plastids are recently acquired kleptoplastids and not true organelles [97,217]. There are also a dinoflagellate with green plastids, Lepidodinium viride M.Watabane, S.Suda, I.Inouye, T.Sawaguchi \& M.Chihara [239], which contain chlorophyll $a$ and $b$ as well as carotenoids similar to those of prasinophycean green algae and lacks peridinin and fucoxanthin. Two membranes bound the green plastids of $L$. viride and there are not other identifiable endosymbiont components. The only molecular data available for these species is the nuclear SSU rDNA of L. viride [192], which confirm that this species ancestrally contained peridinin plastids that where replaced by green four membranes-bounded plastids, though in the absence of plastid molecular data it is not clear the status of such aberrant plastids. A very peculiar feature of $L$. viride is that it produces, on its cell surface, scales very similar to those of prasinophycean algae, suggesting that presumably this host acquired and expresses non-photosynthetic genes from its endosymbiont [239].

The most bizarre endosymbiont, notwithstanding, are found in two related species of dinoflagellates, Peridinium foliaceum Biecheler and Peridinium balticum (Levander) Lemmermann, which contain an endosymbiotic pennate diatom $[41,112]$ that still is delimited by its own plasma membrane and contain its own heterokont four-membrane plastids with fucoxanthin, together with its own non-dinokaryotic nucleus, mitochondria, endoplasmic reticulum and other organelles [226]. These dinoflagellates were first famous by having two nuclei, the typical dinoflagellate ('dinokaryotic') nucleus, in which the chromosomes are permanently condensed and the DNA is not linked to nucleosomes [188], plus an endosymbiont typical eukaryotic nucleus [55]. During cell division these nuclei accomplish a very rare nuclear division [225]. Moreover, it was observed that during syngamy of two host cells, the endosymbiont nucleus of one cell fuses with its 
compatible of the other cell [40], which strongly suggests that these endosymbionts represent a transitional stage of an on going process (the tertiary plastid evolution) and still are not integrated into stable and fully enslaved organelles. Nucleus-encoded SSU rDNA of $P$. foliaceum [192] showed that this species ancestrally contained peridinin plastids.

Compared with other photosynthetic eukaryotes, the plastid genome of dinoflagellates is severely reduced and probably most of original red algal endosymbiont genes for photosynthesis were transferred to the dinoflagellates nucleus [90]. It has been speculated that dinoflagellates are particularly susceptible to plastids replacement because the residing nucleus-encoded, plastid-targeted genes obtained from the ancestral red algal plastid can be recycled in the tertiary endosymbiosis by assuming the functions of homologous genes of the new endosymbiont [223]. For PsbO, however, this is not the case, as this nucleus-encoded, plastid targeted gene has a clear haptophyte origin [115]. In any case, it is not doubted that dinoflagellates are the lineage that have developed more diverse means for endosymbiosis [96].

\section{Conclusions}

Most of this chapter has been devoted to the chloroplast origin and evolution, which is the basic driving force for the evolution of algae. To talk more about the host origin and evolution is to talk about the almost whole spectrum of eukaryotes, a subject that is growing very fast in the light of current molecular techniques. If we consider the eukaryotic diversification as depicted in the Figure 2, only one eukaryotic metalineages (Unikonts) do not contain algal groups. It is not surprising, however, that many fungi, which belong to this metalineage, have established very elaborated symbiosis with algae called lichens, as well as many metazoa as corals and hydra. So, the symbioses (including endosymbiosis) have really shaped the tree of life and the history of planet. In terms of eukaryotic genome sequencing, of the available list in GenBank [http://www.ncbi.nlm.nih.gov], only three of the nine lineages are represented by at least one complete genome sequence, one alveolate and all the others are in the fungi/metazoa 
group or angiosperms. It is clear that, so far, the diversity existing in the eukaryotic lineages is still understudied. Investigations of the host genomes already are, and will be even more crucial for the understanding of the origin and evolution of the algal groups.

\section{Acknowledgements}

We would like to thank Eurico C. de Oliveira and Debashish Bhattacharya for critical review of the manuscript. Alexis M. Bellorin is thankfull for support from the Consejo de Investigación-UDO, Venezuela (CI-N 258/2004) and M. C. de Oliveira is thankfull for support from CNPq, Brazil. 


\section{References Cited}

1. Altmann, R. Die Elementarorganismen und ihre Beziehungen zu den Zellen (Veit, Leipzig) 1890.

2. Andersen RA. Biology and systematics of heterokont and haptophyte algae. Am J Bot 2004; 91: 1508-22.

3. Andersson JO, Roger AJ. A cyanobacterial gene in nonphotosynthetic protists-An early chloroplast acquisition in Eukaryotes? Curr Biol 2002; 12: $115-9$.

4. Apt KE, Zaslavkaia L, Lippmeier JC, et al. In vivo characterization of diatom multipartite plastid targeting signals. J Cell Sci 2002; 115: 4061-9.

5. Archibald JM, Cavalier-Smith T, Maier U, et al. Molecular chaperones encoded by a reduced nucleus: the cryptomonad nucleomorph. J Mol Evol 2001; 52: 490-501.

6. Archibald JM, Keeling PJ. Recycled plastids: a 'green movement' in eukaryotic evolution. Trends Genet 2002; 18: 577-584.

7. Archibald JM, Longet D, Pawlowski J, et al. A novel polyubiquitin structure in Cercozoa and Foraminifera: evidence for a new eukaryotic supergroup. Mol Biol Evol 2003; 20: 62-6.

8. Avise JC. Molecular Markers, Natural History and Evolution. New York: Chapman \& Hall, 1994. 
9. Bachvaroff TR, Concepcion GT, Rogers CR, et al. Dinoflagellate expressed sequence tag data indicate massive transfer of chloroplast genes to the nuclear genome. Protist 2004; 155: 65-78.

10. Baldauf SL. The deep roots of eukaryotes. Science 2003, 300: 1703-6.

11. Baldauf SL, Roger AF, Wenk-Siefert I, et al. A kingdom-level phylogeny of eukaryotes based on combined protein data. Science 2000; 290: 972-7.

12. Bapteste E, Brinkmann H, Lee JA, et al. The analysis of 100 genes supports the grouping of three highly divergent amoebae: Dictyostelium, Entamoeba and Mastigamoeba. Proc Natl Acad Sci USA 2002; 99: 1414-9.

13. Barbrook AC, Howe AC. Minicircular plastid DNA in the dinoflagellate Amphidinium operculatum. Mol Gen Genet 2000; 263: 152-8.

14. Ben Ali A, De Baere R, Van der Auwera G, et al. Phylogenetic relationships among algae based on complete large-subunit rRNA sequences. Int J Syst Evol Microbiol 2001; 51: 737-49.

15. Bhattacharya D, Helmchen T, Melkonian M. Molecular evolutionary analyses of nuclear-encoded small subunit ribosomal RNA identify an independent rhizopod lineage containing the Euglyphina and the Chlorarachniophyta. J Eukaryot Microbiol 1995; 42: 65-9.

16. Bhattacharya $\mathrm{D}$, Medlin L. The phylogeny of plastids: a review based on comparisons of small-subunit ribosomal RNA coding regions. J Phycol 1995; 31: 489-98. 
17. Bhattacharya D, Weber K. The actin gene of the glaucocystophyte Cyanophora paradoxa: analysis of the coding region and introns, and an actin phylogeny of eukaryotes. Curr Genet 1997; 31: 439-46.

18. Bhattacharya D, Yoon HS, Hackett JD. Photosynthetic eukaryotes unite: endosymbiosis connects the dots. BioEssay 2003; 26: 50-60.

19. Blanchard J, Hicks JS. The non-photosynthetic plastid in malarial parasites and other apicomplexans is derived from outside the green plastid lineage. $\mathrm{J}$ Eukaryot Microbiol 1999; 46: 367-75.

20. Blanchard J, Lynch M. Organellar genes why do they end up in the nucleus? TIG 2000; 16: 315-20.

21. Bolter B, Soll J, Schulz A, et al. Origin of a chloroplast protein importer. Proc Natl Acad Sci USA 1998; 95: 15831-6.

22. Boyen C, Leblanc C, Bonnard G, et al. Nucleotide sequence of the cox3 gene from Chondrus crispus: evidence that UGA encodes tryptophan and evolutionary implications. Nucleic Acids Res 1994; 22: 1400-3.

23. Bui ETN, Bradley PJ, Johnson PJ. A common evolutionary origin for mitochondria and hydrogenosomes. Proc Natl Acad Sci USA 1996; 93: 96516.

24. Burger G, Saint-Louis D, Gray MW, et al. Complete sequence of the mitochondrial DNA of the red alga Porphyra purpurea. Cyanobacterial introns and shared ancestry of red and green algae. Plant Cell 1999; 11: 1675-94.

25. Burger-Wiersma T, Veenhuis M, Korthals HJ, et al. A new prokaryote containing chlorophylls a and b. Nature 1986; 320: 262-4. 
26. Busse I, Patterson DJ, Preisfeld A. Phylogeny of phagotrophic euglenoids (Euglenozoa): a molecular approach based on culture material and environmental samples. J Phycol 2003; 39: 828-36

27. Cavalier-Smith T. Eukaryote kingdoms: seven or nine? Biosystems 1981, $14: 461-81$.

28. Cavalier-Smith T. The origins of plastids. Biol J Linn Soc 1982; 17: 289-306.

29. Cavalier-Smith T. A six-kingdom classification and a unified phylogeny. Endocytobiology 1983; 2: 1027-34.

30. Cavalier-Smith T. The Kingdom Chromista: origin and systematics. Progress in Phycological Research 1986; 4: 309-47.

31. Cavalier-Smith T. A revised six-kingdom system of life. Biol Rev Camb Philos Soc 1998; 73: 203-66.

32. Cavalier-Smith T. Principles of protein and lipid targeting in secondary symbiogenesis: euglenoid, dinoflagellate and sporozoan plastids origins and the eukaryote family tree. J Eukaryot Microbiol 1999; 46: 347-66.

33. Cavalier-Smith T. Chloroplast evolution: secondary symbiogenesis and multiple losses. Curr Biol 2002; 12: R62-R64.

34. Cavalier-Smith T. The phagotrophic origin of eukaryotes and phylogenetic classification of protozoa. Int J Syst Evol Microbiol 2002; 52: 297-354. 
35. Cavalier-Smith T. Genomic reduction and evolution of novel genetic membranes and protein-targetin machinery in eukaryote-eukaryote chimaeras (meta-algae). Phil Trans R Soc Lond B 2003; 358: 109-134.

36. Cavalier-Smith T, Chao EE. Sarcomonad ribosomal RNA sequences, Rhizopod phylogeny, and the origin of Euglyphid Amoebae. Arch Protistenkd 1997; 147: 227-36.

37. Cavalier-Smith T, Chao EE. Phylogeny and classification of phylum Cercozoa (Protozoa). Protist 2003; 154: 341-58.

38. Cavalier-Smith T, Couch JA, Thorsteinsen KE et al. Cryptomonad nuclear and nucleomorph 18S rRNA phylogeny. Eur J Phycol 1996; 31: 315-328.

39. Cavalier-Smith T, Lee JJ. Protozoa as hosts for endosymbioses and the conversion of endosymbionts into organelles. J Protozool 1985; 32: 376-9.

40. Chesnick JM, Cox ER. Synchronized sexuality of an algal symbiont and its dinoflagellate host, Peridinium balticum (Levander) Lemmermann. Biosystems 1987 21: 69-78.

41. Chesnick JM, Kooistra WH, Wellbrock U, et al. Ribosomal RNA analysis indicates a benthic pennate diatom ancestry for the endosymbionts of the dinoflagellates Peridinium foliaceum and Peridinium balticum (Pyrrhophyta). J Eukaryot Microbiol 1997; 44: 314-20.

42. Chisholm SW, Olson RJ, Zettler ER, et al. A novel free-living prochlorophyte occurs at high cell concentrations in the oceanic euphotic zone. Nature 1988; 334: 340-3. 
43. Christensen T. Alger. In Böcher TW, Lange MC, Sorensen T, eds. Botanik, Bd. 2. Systematisk Botanik Nr. 2. Munksgaard, Copenhagen, 1962: 1-178.

44. Christensen T. 1989. The Chromophyta, past and present. In: Green JC, Leadbeater BSC, Diver WL, eds. The Chromophyte algae: problems and perspectives. Oxford: Clarendon Press, 1989: 1-12.

45. Corliss JO. Nuclear characteristics and phylogeny in the protistan phylum Ciliophora. BioSystems 1975; 7: 338-49.

46. Corliss JO. The kingdom Protista and its 45 phyla. BioSystems 1984; 17: 87126.

47. Dacks JB, Doolittle WF. Reconstructing/deconstructing the earliest eukaryotes: how comparative genomics can help. Cell 2001; 107: 419-25.

48. Dacks JB, Marinets A, Doolittle WF, et al. Analyses of RNA polymerase II genes from free-living protists: phylogeny, long branch attraction, and the eukaryotic big bang. Mol Biol Evol 2002; 19: 830-40.

49. Daugbjerg N, Henriksen P. Pigment composition and $r b c \mathrm{~L}$ sequence data from the silicoflagellate Dictyocha speculum: A heterokont alga with pigments similar to some haptophytes. J Phycol 2001; 37: 1110-20.

50. DeRocher A, Hagen CB, Froenlich JE, et al. Analysis of targeting sequences demonstrates that trafficking to the Toxoplasma gondii plastid branched off the secretory system. J Cell Sci 2000; 113: 3969-77.

51. Delwiche CF. Tracing the thread of plastid diversity through the tapestry of life. Am Nat 1999; 154: S164-77. 
52. Delwiche CF, Kuhsel M, Palmer JD. Phylogenetic analysis of tufA sequences indicates a cyanobacterial origin of all plastids. Mol Phylog Evol 1995; 4: 11028.

53. Delwiche CF, Palmer JD. Rampant horizontal transfer and duplication of Rubisco genes in eubacteria and plastids. Mol Biol Evol 1996; 13: 873-82.

54. Dodge JD. The fine structure of chloroplast and pyrenoids in some marine dinoflagellates. J Cell Biol 1968; 3: 41-8.

55. Dodge JD. A dinoflagellate with both mesokaryotic and a eukaryotic nucleus. I. Fine structure of the nuclei. Protoplasma 1971; 73: 145-57.

56. Dodge JD. A survey of chloroplast ultrastructure in the Dinophyceae. Phycologia 1975; 14: 253-63.

57. Douglas SE. Plastid evolution: origin, diversity, trends. Curr Opin Genet Dev 1998; 8: 655-61.

58. Douglas SE, Murphy CA. Structural, transcriptional and phylogenetic analyses of the atpB gene cluster from the plastid of Cryptomonas $\phi$ (Cryptophyceae). J Phycol 1994; 30: 329-40.

59. Douglas SE, Murphy CA, Spencer DF et al. Cryptomonad algae are evolutionary chimaeras of two phylogenetically distinct unicellular eukaryotes. Nature 1991; 350: 148-51.

60. Douglas SE, Penny SL. The plastid genome of the cryptophyte alga, Guillardia theta: complete sequence and conserved synteny groups confirm its common ancestry with red algae. J Mol Evol 1999; 48: 236-44. 
61. Douglas SE, Zauner S, Fraunholz M, et al. The highly reduced genome of an enslaved algal nucleus. Nature 2001; 410: 1091-6.

62. Dufresne A, Salanoubat M, Partensky F, et al. Genome sequence of the cyanobacterium Prochlorococcus marinus SS120, a nearly minimal oxyphototrophic genome. Proc Natl Acad Sci USA 2003; 100: 10020-5.

63. Durnford DG, Aebersold R, Green BR. The fucoxanthin-chlorophyll proteins from a chromophyte alga are part of a large multigene family: structural and evolutionary relationships to other light harvesting antennae. Mol Gen Genet 1996; 253: 377-86

64. Durnford DG, Deane JA, Tan S, et al. A phylogenetic assessment of plastids and eukaryotic light-harvesting antenna proteins. J Mol Evol 1999: 48: 59-68.

65. Egea N, Lang-Unnasch N. Phylogeny of the large extrachromosomal DNA of organisms in the phylum apicomplexa. J Eukaryot Microbiol 1995; 42: 679-84.

66. Eggink LL, Brutto R, Brune DC, et al. Synthesis of chlorophyll $b$ : Localization of chlorophyllide $a$ oxygenase and discovery of a stable radical in the catalytic subunit. BMC Plant Biol 2004; 4: 5.

67. Embley TM, Hirt RP. Early branching eukaryotes? Curr Opin Genet Dev 1998; 8: 624-9.

68. Fagan T, Hastings JW, Morse D. The phylogeny of glyceraldehydes-3phosphate dehydrogenase indicates lateral gene transfer from cryptomonads to dinoflagellates. J Mol Evol 1998; 47: 633-9. 
69. Fagan T, Hastings JW. Phylogenetic analysis indicates multiple origins of chloroplast glyceraldehydes-3-phosphate dehydrogenase genes in dinoflagellates. Mol Biol Evol 2002; 19: 1203-7.

70. Fast NM, Kissinger JC, Roos DS, et al. Nuclear-encoded, plastid-trageted genes suggest a single common origin for apicomplexan and dinoflagellate plastids. Mol Biol Evol 2001; 18: 418-26.

71. Foth BJ, Mcfadden GI. The apicoplast: a plastid in Plasmodium falciparum and other apicomplexan parasites. Int Rev Cytol 2003; 224: 57-110.

72. Fujiwara S, Iwahashi H, Someya J et al. Structure and cotranscription of the plastid-encoded $r b c \mathrm{~L}$ and $r b c \mathrm{~S}$ genes of Pleurochrysis carterae (Prymnesiophyta). J Phycol 1993; 29: 347-55.

73. Funes S, Davidson E, Reyes-Prieto A, et al. A green algal apicoplast ancestor. Science 2002; 298: 2155.

74. Funes S, Davidson E, Reyes-Prieto A, et al. Response to a comment "A green algal apicoplast ancestor”. Science 2003; 301: 49b.

75. Gardner M, Goldman N, Barnett P et al. Phylogenetic analysis of the rpoB gene from the plastid-like DNA of Plasmodium falciparum. Mol Biochem Parasitol 1994; 66: 221-31.

76. Gardner MJ, Hall N, Fung E, et al. Genome sequence of the human malaria parasite Plasmodium falciparum. Nature 2002; 419: 498-511.

77. Gardner MJ, Williamson DH, Wilson RJM. A circular DNA in malaria parasites encodes an RNA polymerse like that of prokaryotes and chloroplasts. Mol Biochem Parasitol 1991; 41: 115-23. 
78. Gibbs SP. The chloroplasts of Euglena may have evolved from endosymbiotic green algae. Can J Bot 1978; 56: 2883-9.

79. Gibbs SP. The chloroplasts of some algal groups may have evolved from endosymbiotic eukaryotic algae. Ann NY Acad Sci 1981; 361: 193-208.

80. Gillham, NW. Organelle Genes and Genomes. Oxford: Oxford University Press, 1994.

81. Gilson PR, McFadden GI. The miniaturized nuclear genome of a eukaryotic endosymbiont contain genes that overlap, genes that are constranscribed, and the smallest know spliceosomal introns. Proc Natl Acad Sci USA 1996; 93: $7737-42$.

82. Gilson PR, McFadden GI. Jam packed genomes -a preliminary, comparative analysis of nucleomorphs. Genetica 2002; 115: 13-28.

83. Gleeson MT. The plastid in Apicomplexa: what use is it? Int J Parasitol 2000; 30: 1053-70.

84. Glöckner G, Rosenthal A, Valentin K. The structure and gene repertoire of an ancient red algal plastid genome. J Mol Evol 2000; 51: 382-90.

85. Gockel G, Hachtel W. Complete gene map of the plastid genome of the nonphotosynthetic euglenoid flagellate Astasia longa. Protist 2000; 151: 34751.

86. Graham LE, Cook ME, Busse JS. The origin of plants: body plan changes contributing to a major evolutionary radiation. Proc Natl Acad Sci USA 2000; 97: 4535-40. 
87. Graham LE, Wilcox LW. Algae. New jersey: Prentice Hall, Inc., 2000.

88. Gray MW, Burger G, Lang BF. Mitochondrial evolution. Science 1999; 283: 1476-81.

89. Green BR. Was "molecular opportunism" a factor in the evolution of different photosynthetic light-harvesting pigment systems. Proc Natl Acad Sci USA 2001; 98: 2119-21.

90. Green BR. The Chloroplast Genome of Dinoflagellates - A Reduced Instruction Set? Protist 2004; 155: 23-31,

91. Green BR, Durnford DG. The chlorophyll-carotenoid proteins of oxygenic photosynthesis. Annu Rev Plant Physiol Plant Mol Biol 1996; 47: 685-174.

92. Green JC, Leadbeater BSC. The haptophyte algae. Oxford: Oxford Scientific, 1994.

93. Greenwood AD, Griffiths HB, Santore UJ. Chloroplasts and cell components in Cryptophyceae. Br Phycol J 1977; 12: 119.

94. Gupta RS. The phylogeny of proteobacteria: relationships to other eubacterial phyla and eukaryotes. FEMS Microbiol Rev 2000; 24: 367-402.

95. Gupta RS, Mukhtar T, Singh B. Evolutionary relationships among photosynthetic prokaryotes (Heliobacterium chlorum, Chloroflexus aurantiacus, cyanobacteria, Chlorobium tepidum and proteobacteria): implications regarding the origin of photosynthesis. Mol Microbiol 1999; 32: 893-906. 
96. Hackett JD, Anderson DM, Erdner D, et al. Dinoflagellates: a remarkable evolutionar experiment. Am J Bot 2004; 91: 1523-34.

97. Hackett JD, Maranda L, Yoon HS, et al. Phylogenetic evidence for the cryptophyte origin of the plastid of Dinophysis (dinophysiales, dinophyceae). J Phycol 2003; 39: 440-8.

98. Hackett JD, Yoon HS, Bento Soares M, et al. Migration of the Plastid Genome to the Nucleus in a Peridinin Dinoflagellate. Curr Biol 2004 14: 213 8.

99. Hagopian JC, Reis M, Kitajima JP, et al. Comparative analysis of the complete plastid genome sequence of the red alga Gracilaria tenuistipitata var. liui provides insights on the evolution of rhodoplasts and their relationship to other plastids. J Mol Evol 2004; 59: 464-77.

100. Hallick RB, Hong L, Drager RG, et al. Complete sequence of Euglena gracilis chloroplast DNA. Nucleic Acids Res 1993; 21: 3537-44.

101. Hannaert V, Saavedra E, Duffieux F, et al. Plant-like traits associated with metabolism of Trypanosoma parasites. Proc Natl Acad Sci USA 2003; 100: 1067-71.

102. Hansen G, Daugbjerg N, Henriksen P. Comparative study of Gymnodinium mikimoyoi and Gymnodinium aureolum, comb. nov. (=Gyrodinium aureolum) based on morphology, pigment composition, and molecular data. J Phycol 2000; 36: 394-410.

103. Harper JT, Keeling PJ. Nuclear-encoded, plastid-targeted glyceraldehydes-3phosphate dehydrogenase (GAPDH) indicates a single origin for chromalveolate plastids. Mol Biol Evol 2003; 20: 1730-5. 
104. Heins L, Soll J. Chloroplast biogenesis: mixing the prokaryotic and the eukaryotic? Curr Biol 1998; 8: 215-7.

105. Henze K, Badr A, Wettern M, et al. A nuclear gene of eubacterial origin in Euglena gracilis reflects cryptic endosymbioses during protist evolution. Proc Natl Acad Sci USA 1995; 92: 9122-6.

106. Hess WR, Partensky F, Van der Staay GW, et al. Coexistence of phycoerythrin and a chlrophyll a/b antenna in a marine prokaryote. Proc Natl Acad Sci USA 1996; 93: 11126-30.

107. Hess WR, Rocap G, Ting CS, et al. The photosynthetic apparatus of Prochlorococcus: insights through comparative genomics. Photosynth Res 2001; 70: 53-71.

108. Hibberd DJ, Norris RE. Cytology and ultrastructure of Chlararchnion reptans (Chlorarachniophyta divisio nova, Chlorarachniophyceae classis nova). J Phycol 1984; 20: 310-30.

109. Hoef-Emden K, Marin B, Melkonian M. Nuclear and nucleomorph SSU rDNA phylogeny in the Cryptophyta and the evolution of cryptophyte diversity. J Mol Evol 2002; 55:161-79.

110. Hoek C van den, Mann DG, Jahns HM. Algae. Cambridge: Cambridge University Press, 1995.

111. Hoiczyk E, Hansel A. Cyanobacterial cell walls: news from an unusual prokaryotic envelope. J Bacteriol 2000; 182: 1191-9. 
112. Inagaki Y, Dacks JB, Doolittle WF, et al. Evolutionary relationship between dinoflagellates bearing obligate diatom endosymbionts: insight into tertiary endosymbiosis. Int J Syst Evol Microbiol 2000; 50: 2075-81.

113. Inagaki J, Fujita Y, Hase T, et al. Protein translocation within chloroplast is similar in Euglena and higher plants. Biochem Bioph Res Co 2000, 277: 43642.

114. Ishida K, Cavalier-Smith T, Green BR. Endomembrane structure and the chloroplast protein targeting pathway in Heterosigma akashiwo (Raphidophyceae, Chromista). J Phycol 2000; 36: 1135-44.

115. Ishida K, Green BR. Second- and third-hand chloroplasts in dinoflagellates: Phylogeny of PsbO protein reveals replacement of a nuclear-encoded plastid gene by that of a haptophyte tertiary endosymbiont. Proc Natl Acad Sci USA 2002; 99: 9294-9.

116. Ishida K, Green BR, Cavalier-Smith T. Diversification of a chimaeric algal group, the chlorarachniophytes: phylogeny of nuclear and nucleomorph small subunit rRNA genes. Mol Biol Evol 1999; 16: 321-31.

117. Ishida T, Watanabe MM, Sugiyama J, et al. Evidence for polyphyletic origin of the members of the orders of Oscillatoriales and Pleurocapsales as determined by 16S rDNA analysis. FEMS Microbiol Lett 2001; 201: 79-82.

118. Janson S, Granéli E. Genetic analysis of the psbA gene from single cells indicates a cryptomonad origin of the plastid in Dinoplhysis (Dinophyceae). Phycologia 2003; 42: 473-7.

119. Jarvis P, Soll J. Tic, Toc, and chloroplast protein import. Biochim Biophys Acta 2001; 1541: 64-79. 
120. Jeffrey SW, Wright SW. Photosynthetic pigments in the Haptophyta. In Green JC, Leadbeater BSC, eds. The Haptophyte algae. Oxford: Clarendon Press, 1989: 111-32.

121. Kaneko T, Nakamura Y, Wolk CP, et al. Complete genomic sequence of the filamentous nitrogen-fixing cyanobacterium Anabaena sp. strain PCC 7120. DNA Res 2001; 8: 205-13.

122. Kaneko T, Sato S, Kotani H, et al. Sequence analysis of the genome of the unicellular cyanobacterium Synechocystis sp. strain PCC6803. II. Sequence determination of the entire genome and assignment of potential protein-coding regions. DNA Res 1996; 3: 109-36.

123. Karol KG, McCourt RM, Cimino MT, et al. The closest living relatives of land plants. Science 2001; 294: 2351-3.

124. Keeling PJ. Foraminifera and Cercozoa are related in actin phylogeny: two orphans find a home? Mol Biol Evol 2001; 18: 1551-7.

125. Keeling PJ. Diversity and evolutionary history of plastids and their hosts. Am J Bot 2004; 91: 1481-93.

126. Keeling PJ, Deane JA, McFadden GI. The phylogenetic position of alpha- and beta-tubulins from the Chlorarachnion host and Cercomonas (Cercozoa). J Eukaryot Microbiol 1998; 45: 561-70.

127. Keeling PJ, Doolittle WF. Alpha-tubulin from early-diverging eukaryotic lineages and the evolution of tubulin family. Mol Biol Evol 1996; 13: 12971305. 
128. Kilejian A. Circular mitochondrial DNA from the avian malarial parasite Plasmodium lophurae. Biochim Biophys Acta 1975; 390: 276-84.

129. Kishore R, Muchhal US, Schwartzbach SD. The Presequence of Euglena LHCPII, a Cytoplasmically Synthesized Chloroplast Protein, Contains a Functional Endoplasmic Reticulum-Targeting Domain. Proc Natl Acad Sci USA 1993; 90: 11845-9.

130. Köhler S, Delwiche CF, Denny PW, et al. A plastid of probable green algal origin in apicomplexans parasites. Science 1997; 275: 1485-9.

131. Kroth PG. Protein transport into secondary plastids and the evolution of primary and secondary plastids. Int Rev Cytol 2002; 221:191-255.

132. Laatsch T, Zauner S, Stoebe-Maier B, et al. Plastid-Derived Single Gene Minicircles of the Dinoflagellate Ceratium horridum Are Localized in the Nucleus. Mol Biol Evol 2004; 21: 1318-22.

133. Lang BF, O'Kelly C, Nerad T, et al. The closest unicellular relatives of animals. Curr Biol 2002; 12:1773-8.

134. Lang M, Apt KE, Kroth PG. Protein transport into "complex" diatom plastids utilizes two different targeting signals. J Biol Chem 1998; 273: 30973-8.

135. La Roche J, van der Staay GWM, Partensky F, et al. Independent evolution of the prochlorophyte and green plant chlorophyll $a / b$ light-harvesting proteins. Proc Natl Acad Sci USA 1996; 93: 15244-8.

136. Leander BS, Keeling PJ. Early evolutionary history of dinoflagellates and apicomplexans (Alveolata) as inferred from hsp90 and actin phylogenies. J Phycol 2004; 40: 341-50. 
137. Lee RE. Evolution of algal flagellates with chloroplast endoplasmic reticulum from the ciliates. S Afr J Sci 1977; 78: 179-82.

138. Lewin RA. Prochlorophyta as a proposed new division of algae. Nature 1976; 261: 697-8.

139. Lewis LA, McCourt RM. Green algae and the origin of land plants. Am J Bot 2004; 91: 1535-56.

140. Lewitus AJ, Glasgow HB, Burkholder JM. Kleptoplastidy in the toxic dinoflagellate Pfiesteria piscicida (Dinophyceae). J Phycol 1999; 35: 303-12.

141. Liaud M-F, Brandt U, Scherzinger M, et al. Evolutionary origin cryptomonad microalgae: two novel chloroplast/cytosolic-specific GAPDH genes as potential markers of ancestral endosymbiont and host cell components. J Mol Evol 1997; 44(suppl): S28-S37.

142. Linton EW, Nudelman MA, Conforti V, et al. A molecular analysis of the euglenophytes using SSU rDNA. J Phycol 2000; 36: 740-6.

143. Löffelhardt W, Bohnert HJ, Bryant DA. The cyanelles of Cyanophora paradoxa. Crit Rev Plant Sci 1997; 16: 393-413.

144. Longet D, Archibald JM, Keeling PJ, et al. Foraminifera and Cercozoa share a common origin according to RNA polymerase II phylogenies. Int J Syst Evol Microbiol 2003; 53: 1735-9.

145. Ludwig M, Gibbs SP. DNA is present in the nucleomorph of cryptomonads: Further evidence that the chloroplast evolved from a eukaryotic endosimbiont. Protoplasma 1985; 127: 9-20. 
146. Marin B. Origin and fate of chloroplasts in the Euglenoida. Protist 2004; 155 : $13-4$

147. Marin B, Palm A, Klingberg M, et al. Phylogeny and taxonomic revision of plastid-containing Euglenophytes based on SSU rDNA sequence comparisons and synapomorphic signatures in the SSU rRNA secondary structure. Protist 2003; 154: 99-145.

148. Martin W, Brinkmann H, Savonna C, et al. Evidence for a chimerical nature of nuclear genomes: eubacterial origin of eukaryotic glyceraldehydes-3phosphate dehydrogenase genes. Proc Natl Acad Sci USA 1993; 90: 8692-6.

149. Martin W, Rujan T, Richly E, et al. Evolutionary abalysis of Arabidopsis, cyanobacterial, and chloroplast genomes reveals plastid phylogeny and thousand of cyanobacterial genes in the nucleus. Proc Natl Acad Sci USA 2002; 99: 12246-51.

150. Martin W, Stoebe B, Goremykin V, et al. Gene transfer to the nucleus and the evolution of chloroplasts. Nature 1998; 393: 162-5.

151. McFadden GI. Plastids and protein targeting. J Eukaryot Microbiol 1999; 46: 339-46.

152. McFadden GI. Chloroplast origin and integration. Plant Physiol 2001; 125 : 50-3.

153. McFadden GI. Primary and secondary endosymbiosis and the origin of plastids. J Phycol 2001; 37: 951-9. 
154. McFadden GI, Gilson PR, Hofmann CJB, et al. Evidence that an amoeba acquired a chloroplast by retaining part of an engulfed eukaryotic alga. Proc Natl Acad Sci USA 1994; 91: 3690-4.

155. McFadden GI, Gilson PR, Waller RF. Molecular phylogeny of chlorarachniophytes based on plastid rRNA and $r b c L$ sequences. Arch Protistenkd 1995; 145: 231-9.

156. McFadden GI, Reith M, Munholland J, et al. Plastid in human parasites. Nature 1996; 381: 482.

157. Mereschkowsky C. Über natur und ursprung der chromatoporen im pflanzenreiche. Biologisches Centralblatt 1905; 25: 593-604.

158. Moestrup O, Sengco M. Ultrastructural studies on Bigelowiella natans, gen. et sp. nov., a chlorarachniophyte flagellate. J Phycol 2001; 37: 624-46.

159. Montegut-Felkner AE, Triemer RE. Phylogenetic relationships of select euglenoid genera based on morphological and molecular data. J Phycol 1997; 33: 512-9.

160. Morden CW, Delwiche CF, Kuhsel M et al. Gene phylogenies and the endosymbiotic origin of plastids. BioSystems 1992; 28: 75-90.

161. Moreira D, Le Guyader H, Philipe H. The origin of red algae and the evolution of chloroplasts. Nature 2000; 405: 69-72.

162. Muller KM, Oliveira MC, Sheath RG et al. Ribosomal DNA phylogeny of the Bangiophycidae (Rhodophyta) and the origin of secondary plastids. Am J Bot 2001; 88: 1390-1400. 
163. Nakamura Y, Kaneko T, Sato S, et al. Complete genome structure of the thermophilic cyanobacterium Thermosynechococcus elongatus BP-1. DNA Res 2002; 9: 123-30

164. Nakamura Y, Kaneko T, Sato S, et al. Complete genome structure of Gloeobacter violaceus PCC 7421, a cyanobacterium that lacks thylakoids. DNA Res 2003; 10:137-45.

165. Nassoury N, Cappadocia M, Morse D. Plastid ultrastructure defines the protein import pathway in dinoflagellates. J Cell Sci 2003; 116: 2867-74.

166. Nikolaev SI, Berney C, Fahrni JF, et al. The twilight of Heliozoa and rise of Rhizaria: an emerging supergroup of ameboid eukaryotes. Proc Natl Acad Sci USA 2004; 101: 8066-71.

167. Nozaki H. Matsuzaki M, Takahara M, et al. The phylogenetic position of red algae revealed by multiple nuclear genes from mitochondria-containing eukaryotes and an alternative hypothesis on the origin of plastids. J Mol Evol 2003; 56: 485-97.

168. Nudelman MA, Rossi MS, Conforti V, et al. Phylogeny of Euglenophyceae based on small subunit rDNA sequences: taxonomic implications. J Phycol 2003; 39: 226-35.

169. Ohta N, Matsuzaki M, Misumi, et al. Complete sequence and analysis of the plastid genome of the unicellular red alga Cyanidioschyzon merolae. DNA Res 2003; 10: 67-77.

170. Oliveira, MC, Bhattacharya D. Phylogeny of the Bangiophycidae (Rhodophyta) and the secondary endosymbiotic origin of algal plastids. Am J Bot 2000; 87: 482-92. 
171. Oudot-Le Sceq M-P, Kloareg B, Loiseaux-De Goër S. The mitochondrial genome of brown alga Laminaria digitata: a comparative analysis. Eur J Phycol 2002; 37: 163-72.

172. Palenik B, Haselkorn R. Multiple evolutionary origins of prochlorophytes, the chlorophyll b-containing prokaryotes. Nature 1992; 355: 265-7.

173. Palmer JD. A single birth of all plastids? Nature 2000; 405: 32-3.

174. Palmer JD. The symbiotic birth and spread of plastids: how many times and whodunit? J Phycol 2003; 39: 4-11.

175. Palmer JD, Delwiche CF. The origin and evolution of plastids and their genomes. In: Soltis PS, Soltis DE, Doyle JJ, eds. Molecular systematics of plants II. DNA sequencing. Boston: Kluwer Academic Publishers, 1998: 375409.

176. Patron NJ, Rogers MB, Keeling PJ. Gene replacement of Fructose-1,6 Biphosphate Aldolase supports the hypothesis of a single photosynthetic ancestor of chromalveolates. Eukaryotic Cell 2004; 3: 1169-1175.

177. Patterson DJ. Stramenopiles: chromophytes from a protistan perspective. In: Green JC, Leadbeater BSC, Diver WL, eds. The Chromophyte algae: problems and perspectives. Oxford: Clarendon Press, 1989: 357-79.

178. Patterson DJ. The diversity of eukaryotes. Am Nat 1999; 154: S96-124.

179. Penno S, Campbell L, Hess WR. Presence of phycoerythrin in two strains of Prochlorococcus isolated form the sub-tropical North Pacific Ocean. J Phycol 2000; 36: 723-9. 
180. Pérez-Martínez X, Antaramian A, Vázquez-Acevedo M, et al. Subunit II of cytochrome $\mathrm{c}$ oxidase in Chamidomonad algae is a heterodimer encoded by two independent nuclear genes. J Biol Chem 2001; 276: 11302-9.

181. Pickett-Heaps JD. Green algae: structure, reproduction and evolution in selected genera. Sunderland: Sinauer Associates, 1975.

182. Ragan MA. Ribossomal RNA and the major lines of evolution: a perspective. BioSystems 1988; 21: 177-88.

183. Ragan, M.A. Are red algae plants?. Botanical Journal of the linnean Society 1995, 118: 81-105.

184. Raven P. A multiple origin for plastids and mitochondria. Science 1970; 169: 641-6.

185. Reith M, Munholland J. Complete nucleotide sequence of the Porphyra purpurea chloroplast genome. Plant Mol Biol Reporter 1995; 13: 333-5.

186. Reuman S, Davila-Aponte J, Keegstra K. The evolutionary origin of the protein-translocating channel of chloroplastic envelope membranes: identification of a cyanobacterial homolog. Proc Natl Acad Sci USA 1999; 96 : 784-9.

187. Rippka R, Waterbury J, Cohen-Bazire G. A cyanobacterium which lacks thylakoids. Arch Microbiol 1974; 100: 419-36.

188. Rizzo PJ. Those amazing dinoflagellate chromosomes. Cell Res 2003; 13: 215-7. 
189. Roger AJ. Reconstructing early events in eukaryotic evolution. Am Nat 1999; 154: S146-63.

190. Rogers MB, Keeling PJ. Lateral gene transfer and re-compartmentalisation of Clavin cylce enzymes in plants and algae. J Mol Evol 2003; 58: 367-75.

191. Saiki RK, Scharf S, Faloona F, et al. Enzymatic amplification of beta-globin genomic sequences and restriction site analysis for diagnosis of sickle cell anemia. Science 1985; 230: 1350-4.

192. Saldarriaga JF, Taylor FJR, Keelin PJ, et al. Dinoflagellate nuclear SSU rRNA phylogeny suggests multiple plastid losses and replacements. J Mol Evol 2001; 53: 204-13.

193. Sanger F, Nicklen S, Coulson AR. DNA sequencing with chain-terminating inhibitors. Proc Natl Acad Sci USA 1977; 74: 5463-7.

194. Saunders GW, Hommersand M. Assessing red algal supraordinal diversity and taxonomy in the context of contemporary systematic data. Am J Bot 2004; 91: 1494-1507.

195. Schimper AFW. Uber die entwicklung der chlorophyll korner und farbkorner. Bot Zeit 1883; 41: 105-14.

196. Schnepf E, Deichgräber G. 'Myzocytocis', a kind of endocitosis with implications to compartmentalization in endosymbiosis: observations in Paulsenella (Dinophyta). Naturwissenschaften 1984; 71: 218-9.

197. Schnepf E, Elbraechter M. Cryptophycean-like double membrane-bound plastid in the dinoflagellate Dinophysis Ehrenb.: evolutionary, phylogenetic and toxicological implications. Botanica Acta 1988; 101: 196-203. 
198. Schwartzbach SD, Osafune T, Löffelhardt W. Protein import into cyanelles and complex chloroplasts. Plant Mol Biol 1998; 8: 247-63.

199. Siddiqui N, Kozlov G, D'Orso I, et al. Solution structure of the C-terminal domain from poly(A)-binding protein in Trypanosoma cruzi: A vegetal PABC domain. Protein Sci 2003; 12: 1925-33.

200. Simpson AG. The identity and composition of the Euglenozoa. Arch Protistenkd 1997; 148: 318-28.

201. Simpson AG. Cytoskeletal organization, phylogenetic affinities and systematics in the contentious taxon Excavata (Eukaryota). Int J Syst Evol Microbiol 2003; 53: 1759-77

202. Simpson AG, Roger AJ, Silbermann JD, et al. Evolutionary history of "earlydiverging" eukaryotes: the excavate taxon Carpediomonas is a close relative of Giardia. Mol Biol Evol 2002; 19: 1782-91.

203. Sogin ML. Early evolution and the origin of eukaryotes. Curr Opin Genet Dev 1991; 1: 457-63.

204. Stechmann A, Cavalier-Smith T. Rooting the eukaryote tree by using a derived gene fusion. Science 2002; 297: 89-91.

205. Steidinger KA, Truby EW, Dawes CJ. Ultrastructure of the red tide dinoflagellate Gymnodinium breve. 1. General description. J. Phycol 1978; 14: 72-9.

206. Steiner JM, Löffelhardt W. Protein import into cyanelles. Trends Plant Sci 2002; 7: 72-7 
207. Stibitz TB, Keeling PJ, Bhattacharya D. Symbiotic origin of a novel actin gene in the cryptophyte Pyrenomonas helgolandii. Mol Biol Evol 2000; 17: 1731-8.

208. Stiller JW, Hall BD. The origin of red algae: implications for plastid evolution. Proc Natl Acad Sci USA 1997; 94: 4520-5.

209. Stiller JW, Hall BD. Sequences of the largest subunit of RNA polymerase II from two red algae and their implications for rhodophyte evolution. J Phycol 1998; 34: 857-64.

210. Stiller JW, Reel DC, Johnson JC. A single origin of plastids revisited: convergent evolution in organellar genome content. J Phycol 2003; 39: 95-105.

211. Stiller JW, Riley J, Hall BD. Are red algae plants? A critical evaluation of three key molecular data sets. J Mol Evol 2001; 52: 527-39.

212. Stirewalt V, Michalowski C, Löffelhardt W, et al. Nucleotide sequence of the cyanelle genome from Cyanophora paradoxa. Plant Mol Biol Reporter 1995; 13: 327-32.

213. Stoebe B, Kowallik KV. Gene-cluster analysis in chloroplast genomics. Trends Genet 1999; 15: 344-7.

214. Sulli C, Fang Z, Muchhal U, et al. Topology of Euglena chloroplast protein precursors within endoplasmic reticulum to Golgi to chloroplast transport vesicles. J Biol Chem 1999; 274: 457-63.

215. Takishita K, Ishida K, Maruyama T. An enigmatic GAPDH gene in the symbiotic dinoflagellate genus Symbiodinium and its related species (the order 
Suessiales): possible lateral gene transfer between two eukaryotic algae, dinoflagellate and euglenophyte. Protist 2003;154: 443-54.

216. Takishita K, Ishida K, Maruyama T. Phylogeny of nuclear-encoded plastidtargeted GAPDH gene supports separate origins for the peridinin- and the fucoxanthin derivative-containing plastids of dinoflagellates. Protist 2004; 155 : 447-58.

217. Takishita K, Koike K, Maruyama T, et al. Molecular evidence for plastid robbery (Kleptoplastidy) in Dinophysis, a dinoflagellate causing diarrhetic shellfish poisoning. Protist 2002; 153: 293-302.

218. Takishita K, Uchida A. Molecular cloning and nucleotide sequence analysis of $p s b A$ from the dinoflagellates: origin of the dinoflagellate plastid. Phycol Res 1999; 47: 207-216.

219. Tanaka A, Hisashi I, Tanaka R, Tanaka NK, Yoshida K, Okada K. Chlorophyll $a$ oxygenase $(C A O)$ is involved in chlorophyll $b$ formation from chlorophyll $a$. Proc Natl Acad Sci U S A 1998; 95: 12719-23.

220. Taylor FJR. Implications and extensions of the serial endosymbiosis theory of the origin of eukaryotes. Taxon 1974; 23: 229-58.

221. Taylor FJR. Flagellate phylogeny: a study in conflicts. J Protozool 1976; 23: 28-40.

222. Taylor FJR. The collapse of the two-kingdom system, the rise of protistology and the founding of the International Society for Evolutionary Protistology (ISEP). Int J Syst Evol Microbiol 2003; 53: 1707-14. 
223. Tengs T, Dahlberg OJ, Shalchian-Tabrizi K et al. Phylogenetic analyses indicate that the 19'-hexanoyloxy-fucoxanthin-containing dinoflagellates have tertiary plastids of haptophyte origin. Mol Biol Evol 2000; 17: 718-29.

224. Ting CS, Rocap G, King J, et al. Phycobiliproteins genes of the marine photosynthetic prokaryote Prochlorococcus: evidence for rapid evolution of genetic heterogeneity. Microbiology 2001; 147: 3171-82.

225. Tippit DH, Pickett-Heaps JD. Apparent amitosis in the binucleate dinoflagellate Peridinium balticum. J Cell Sci 1976; 21: 273-89.

226. Tomas RN, Cox ER. Observations on the symbiosis of Peridinium balticum and its intracellular alga. I. Ultrastructure. J Phycol 1973; 9: 304-23.

227. Tomitani A, Okada K, Miyashita H, et al. Chlorophyll b and phycobilins in the common ancestor of cyanobacteria and chloroplasts. Nature 1999; 400: 159-62.

228. Turmel M, Otis C, Lemieux C. The complete chloroplast DNA sequence of the green alga Nephroselmis olivacea: Insights into the architecture of ancestral chloroplast genomes. Proc Natl Acad Sci USA 1999; 96: 10248-53.

229. Turner S, Pryer KM, Miao VP, et al. Investigating deep phylogenetic relationships among cyanobacteria and plastids by small subunit rRNA sequence analysis. J Eukaryot Microbiol 1999; 46: 327-38.

230. Urbach E, Robertson DL, Chisholm SW. Multiple evolutionary origins of prochlorphytes within the cyanobacterial radiation. Nature 1992; 355: 267-70.

231. Van der Auwera G, Hofmann CJB, de Rijk P, et al. The origin of red algae and cryptomonad nucleomorphs: a comparative phylogeny based on small and 
large subunit rRNA sequences of Palmaria palmata, Gracilaria verrucosa, and the Guillardia theta nucleomorph. Mol Phylog Evol 1998; 10: 333-42.

232. Van de Peer Y, Baldauf SL, Doolittle WF, et al. An updated and comprehensive rRNA phylogeny of (crown) eukaryotes based on ratecalibrated evolutionary distances. J Mol Evol 2000; 51: 565-76.

233. Van de Peer Y, De Wachter R. Evolutionary relationships among the eukaryotic crown taxa taking into account site to site rate variation in $18 \mathrm{~S}$ rRNA. J Mol Biol 1997; 45: 619-30.

234. Van de Peer Y, Rensing SA, Maier U-G, et al. Substitution rate calibration of small subunit ribosomal RNA identifies chlorarachniophyte endosymbionts as remnants of green algae. Proc Natl Acad Sci USA 1996, 93: 7732-6.

235. van Dooren GG, Schwartzbach SD, Osafune T, et al. Translocation of proteins across the multiple membranes of complex plastids. Biochim Biophys Acta 2001; 1541: 34-53.

236. Van Dooren GG, Su V, D’Ombrain MC, et al. Processing of an apicoplast leader sequence in Plasmodium falciparum and the identification of a putative leader cleavage enzyme. J Biol Chem 2002; 277: 23612-9.

237. Waller RF, Keeling PJ, Donald RGK, et al. Nuclear-encoded proteins target to the plastid in Toxoplasma gondii and Plasmodium falciparum. Proc Natl Acad Sci USA 1998; 95: 12352-7.

238. Waller RF, Keeling PJ, van Dooren GG, et al. Comment on "A green algal apicoplast ancestor". Science 2003; 301: 49a. 
239. Watanabe MM, Suda S, Inouye I, et al. Lepidodinium viride gen. et sp. nov. (Gymnodiniales, Dinophyta), a green dinoflagellate with a chlorophyll a- and b- containing endosymbiont. J Phycol 1990; 26: 741-751.

240. Whatley JM, John P, Whatley FR. From extracellular to intracellular: the establishment of mitochondria and chloroplasts. Proc R Soc Lond Ser B 1979; 204: 165-87.

241. Williams BAP, Keeling PJ. Cryptic organelles in parasitic protists and fungi. Adv Parasitol 2003; 54: 1-33.

242. Williamson DH, Gardner MJ, Preiser P et al. The evolutionary origin of the 35 Kb circular DNA of Plasmodium falciparum: new evidence supports a possible rhodophyte ancestry. Mol Gen Genet 1994; 243: 249-52.

243. Wilson RJM. Plastid functions in the Apicomplexa. Protist 2004; 155: 11-2.

244. Wilson RJM, Denny PW, Preiser DJ, et al. Complete gene map of the plastidlike DNA of the malaria parasite Plasmodium falciparum. J Mol Biol 1996; 261: 155-72.

245. Woese CR. Bacterial evolution. Microbiol Rev 1987; 51: 221-71.

246. Wolfe GR, Cunningham FX, Durnford DG, et al. Evidence from a common origin of chloroplasts with light-harvesting complexes of different pigmentation. Nature 1994; 367: 566-8.

247. Yoon HS, Hackett J, Bhattacharya D. A single origin of the peridinin- and fucoxanthin-containing plastids in dinoflagellates through tertiary endosymbiosis. Proc Natl Acad Sci USA 2002; 99: 11724-9. 
248. Yoon HS, Hackett J, Pinto G, et al. The single ancient origin of chromist plastids. Proc Natl Acad Sci USA 2002; 99: 15507-12.

249. Yoon HS, Hackett J, Ciniglia C, et al. A molecular time line for the origin of photosynthetic eukaryotes. Molecular Biology and Evolution 2004; 21: 809818.

250. Zhang Z, Cavalier-Smith T, Green BR. A family of selfish minicircular chromosomes with jumbled chloroplast gene fragments from a Dinoflagellate. Mol Biol Evol 2001; 18: 1558-65.

251. Zhang Z, Cavalier-Smith T, Green BR. Evolution of dinoflagellate unique minicircles and the partially concerted divergence of their putative replicon origins. Mol Biol Evol 2002; 19: 489-500.

252. Zhang Z, Green BR, Cavalier-Smith T. Single gene circles in dinoflagellates chloroplast genomes. Nature 1999; 400: 155-9.

253. Zhang Z, Green BR, Cavalier-Smith T. Phylogeny of ultra-rapid evolving dinoflagellate chloroplast genes: a possible common origin for sporozoan and dinoflagellate plastids. J Mol Evol 2000; 51: 26-40. 
Table 1. The plastid-containing eukaryotes, including 'canonical' algae (and land plants) as well some protozoans with plastids (apicomplexans).

\begin{tabular}{|c|c|c|c|c|}
\hline & $\begin{array}{c}\text { Plastid } \\
\text { membranes }\end{array}$ & Nucleomorph & $\begin{array}{l}\text { Main } \\
\text { pigments }\end{array}$ & Distinctive features \\
\hline \multicolumn{5}{|l|}{ Primary plastids } \\
\hline 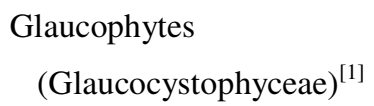 & 2 & absent & $\operatorname{chl} a, \mathrm{~PB}$ & 'Cyanelles': plastids with a peptidoglycan layer \\
\hline $\begin{array}{l}\text { Red algae } \\
\text { (Rhodophyta) }\end{array}$ & 2 & absent & $\operatorname{chl} a, \mathrm{~PB}$ & $\begin{array}{l}\text { Lack of flagellate stages, most are multicellular benthic marine } \\
\text { algae with 'pit-connections' among cells }\end{array}$ \\
\hline $\begin{array}{l}\text { Green algae } \\
\text { (Chlorophyta) }\end{array}$ & 2 & absent & $\operatorname{chl} a, \operatorname{chl} b$ & $\begin{array}{l}\text { Stellate structures at flagellar transition region, starch stored into the } \\
\text { plastids; it is a very diverse and successful group of algae, including } \\
\text { the ancestor of land plants }\end{array}$ \\
\hline \multicolumn{5}{|l|}{ Secondary plastids } \\
\hline $\begin{array}{l}\text { Cryptomonads } \\
\text { (Cryptophyta) }\end{array}$ & 4 & present & $\begin{array}{l}\operatorname{chl} a, \operatorname{chl} c, \\
\mathrm{~PB}\end{array}$ & $\begin{array}{l}\text { Unicells with a lateral flagellar groove lined by ejectisomes, both } \\
\text { flagella with tubular hairs, pRER around the plastids }\end{array}$ \\
\hline $\begin{array}{l}\text { Heterokont algae } \\
\text { (Stramenopiles) }\end{array}$ & 4 & absent & $\begin{array}{l}\operatorname{chl} a, \operatorname{chl} c, \\
\mathrm{Fu}\end{array}$ & $\begin{array}{l}\text { One flagella with distinctive tubular tripartite hairs, pRER; it is } \\
\text { highly diversified and successful group including diatoms, kelps, } \\
\text { crysophyceans sensu lato, etc. }\end{array}$ \\
\hline $\begin{array}{l}\text { Haptophytes } \\
\text { (Haptophyceae) }\end{array}$ & 4 & absent & $\begin{array}{l}\operatorname{chl} a, \operatorname{chl} c, \\
\mathrm{Fu}\end{array}$ & $\begin{array}{l}\text { Unicells with haptonema, an appendage involved in prey capture } \\
\text { and locomotion, pRER, most marine bloom forming algae }\end{array}$ \\
\hline $\begin{array}{l}\text { Dinoflagellates } \\
\text { (Dinophyceae) }\end{array}$ & $3^{[2]}$ & absent & $\operatorname{chl} a, \operatorname{chl} c, \mathrm{Pe}$ & $\begin{array}{l}\text { 'Dinokaryon' nucleus, two unequal flagella (one ribbon-like that } \\
\text { encircles the cell in a transversal groove; the other directed } \\
\text { posteriorly along a longitudinal groove); many form toxic algal }\end{array}$ \\
\hline
\end{tabular}


blooms

\begin{tabular}{lccll}
\hline & $\begin{array}{c}\text { Plastid } \\
\text { membranes }\end{array}$ & Nucleomorph & $\begin{array}{l}\text { Main } \\
\text { pigments }\end{array}$ & Distinctive features \\
\hline $\begin{array}{l}\text { Chlorarachneans } \\
\text { (Chlorarachniophyceae) }\end{array}$ & 4 & present & $\operatorname{chl} a, \mathrm{chl} b$ & $\begin{array}{l}\text { Marine reticulofilose amoebae, flagellate or coccoid cells with green } \\
\text { secondary plastids }\end{array}$ \\
$\begin{array}{l}\text { Euglenoids } \\
\text { (Euglenida) }\end{array}$ & 3 & absent & $\operatorname{chl} a, \mathrm{chl} b$ & $\begin{array}{l}\text { Green flagellates with an anterior flagellar pocket, discoid } \\
\text { mitochondrial cristae }\end{array}$ \\
$\begin{array}{l}\text { Apicomplexans } \\
\text { (Apicomplexa) }\end{array}$ & 4 & absent & non- & Obligate intracellular parasites with a very specialized cell invasion \\
\end{tabular}

$\operatorname{chl} a$ : chlorophyll $a$; chl $b$ : chlorophyll $b$; chl $c$ : chlorophyll $c$; Fu: fucoxanthin; PB; phycobilins; Pe: peridinin; pRER: plastidial rough endoplasmic reticulum. 1. The taxonomic classification of each algal group follows NCBI (http://www.ncbi.nlm.nih.gov/). 2.

Several dinoflagellates have plastids with two or four membranes and with a different pigmentation that those indicated in this Table. 

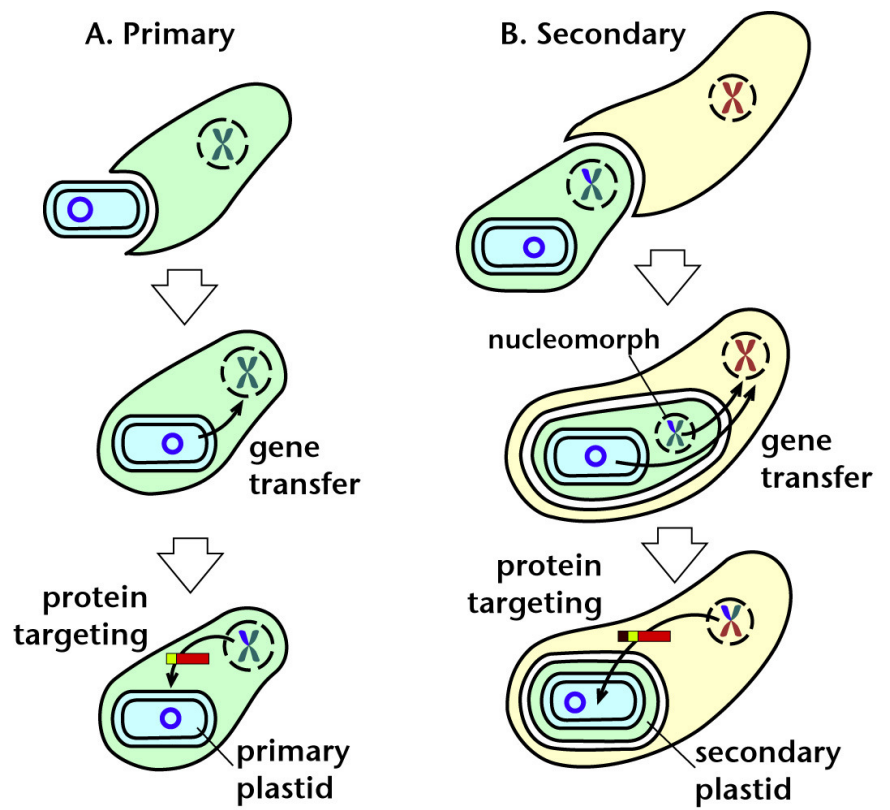

mature protein

$\square$ transit peptide

- signal peptide

Figure 1. Diagrammatic views of a primary (a-c) and a secondary endosymbiosis (d-f). The lateral gene transfer from endosymbiont to host place many genes in the nuclear genome, and the products of these genes are later targeted to the endosymbiont by adding targeting sequences (transit and signal peptides). The lateral gene transfer and the loss of many genes, lead to a reduction of the endosymbiont genome. 


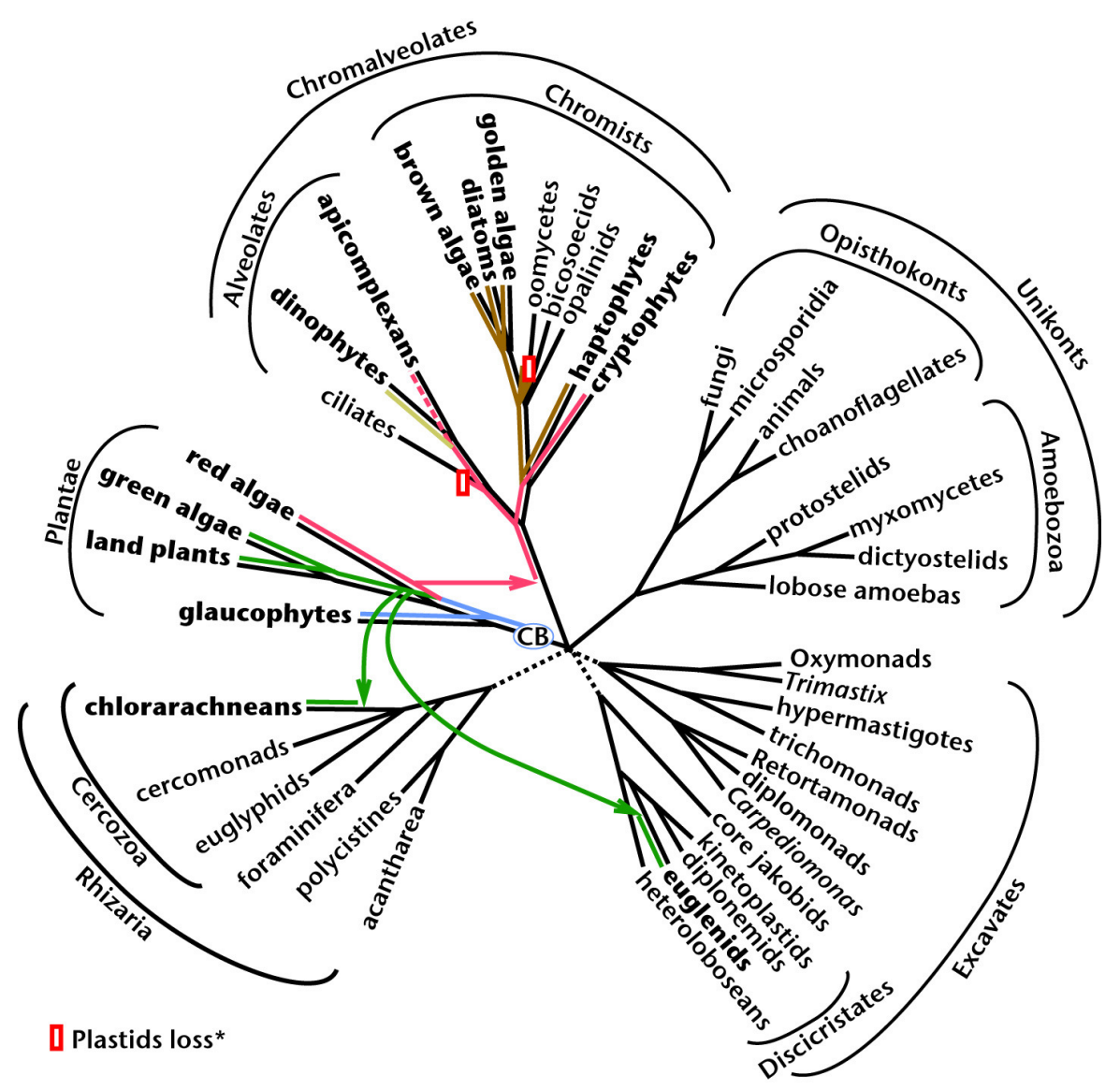

Figure 2. An unrooted hypothetical global phylogeny of eukaryotes based on the synthesis of many molecular data [based on Refs. 10, 34,125]. A plausible history of plastids (in coloured lines and arrows) is also illustrated. Dotted lines represent putative relationships, but more weakly supported. The groups that contain plastid are in bold typeface. CB indicates the first gain of plastids by one ancient plantae, which enslaved cyanobacteria through a primary endosymbiosis. The red arrow indicates a secondary endosymbiosis implicating a red alga, which occurred basally in the supergroup called chromalveolates. The green arrows indicate two independent secondary endosymbiosis implicating green algae, transferring green plastid to a cercozoan lineage (chlorarachneans) and to a discicristate lineage (euglenids). . 
Bellorin \& Oliveira 68

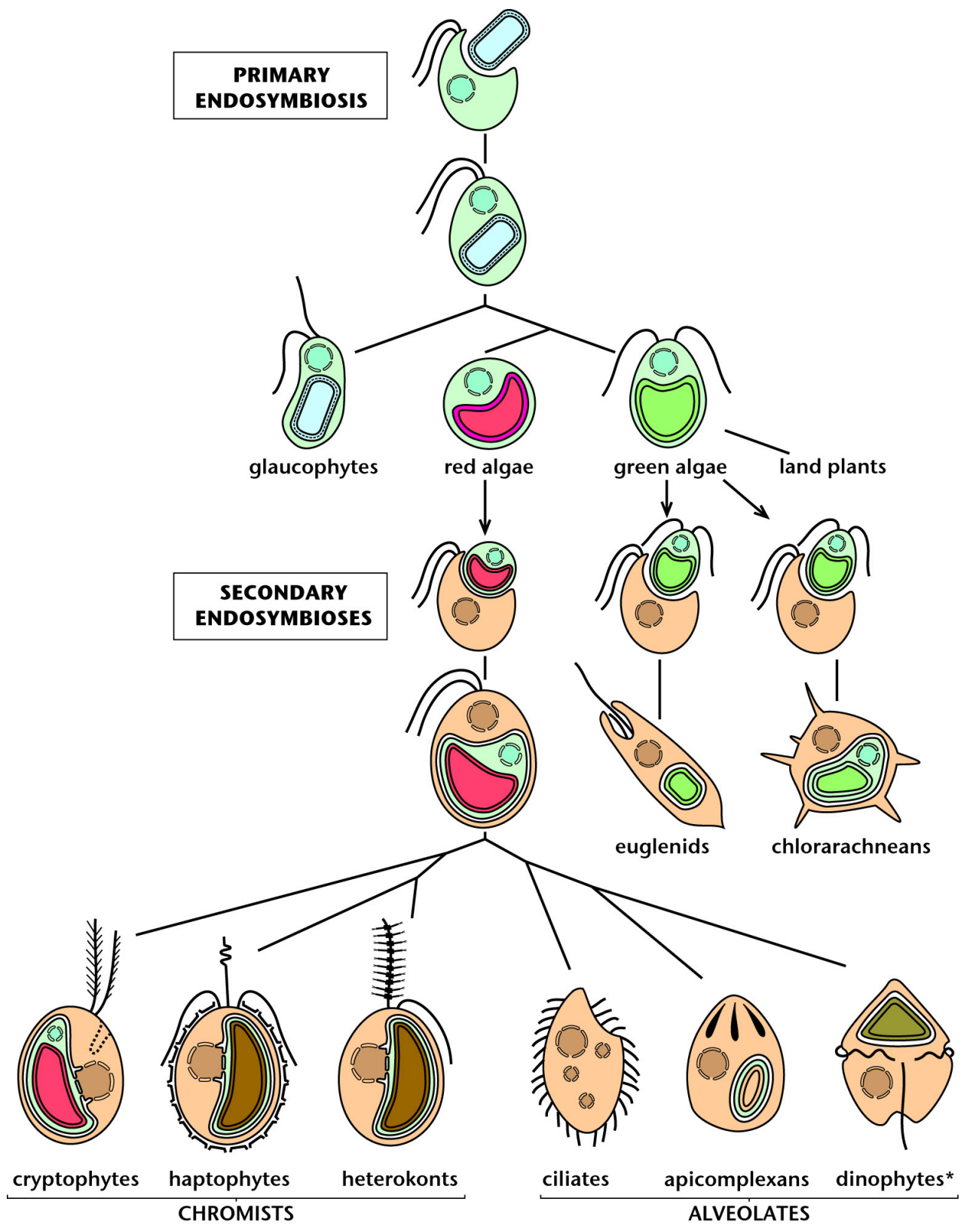

Figure 3. Schematic representation of plastid evolution through primary and secondary endosymbiosis. chl $a$ : chlorophyll $a$, chl $b$ : chlorophyll $b$, chl $c$ : chlorophyll $c$, Fu: fucoxanthin, PB: phycobilins, Pe: peridinin, pRER: plastidial rough endoplasmic reticulum. Plastid losses that occurred in other lineages than ciliates are not indicated. 


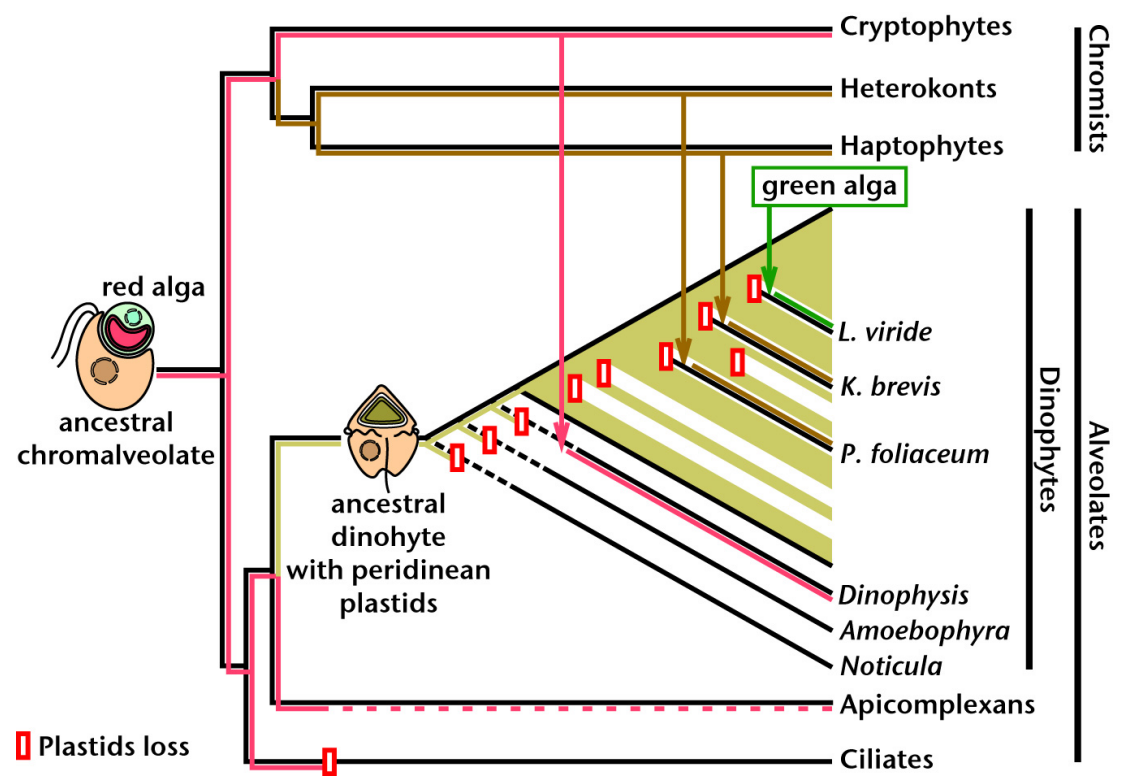

Figure 4. Diagrammatic phylogeny of chromists and alveolates with emphasis in dinoflagellates, showing independent losses of peridinin plastids. Several of these secondarily heterotrophic dinoflagellates later acquired distinct plastids from cryptophytes, heterokonts or haptophytes by tertiary endosymbiosis with chromists or green plastid from a green alga by serial secondary endosymbiosis [based on Refs. 41,68,69,70,90,97,98,112,192,217,223,239,247]. 


\title{
Analysis of expressed sequence tags from the agarophyte Gracilaria tenuistipitata (Rhodophyta)
}

\author{
Pi Nyvall Collén • Jonas Collén • Marcelo da Silva Reis • Marianne Pedersén • \\ João C. Setubal • Alessandro M. Varani • Pio Colepicolo • Mariana C. Oliveira
}

Received: 5 January 2011 / Revised and accepted: 8 April 2011/Published online: 4 May 2011

(C) Springer Science+Business Media B.V. 2011

\begin{abstract}
A total of 3,631 expressed sequence tags (ESTs) were established from two size-selected cDNA libraries made from the tetrasporophytic phase of the agarophytic red alga Gracilaria tenuistipitata. The average sizes of the inserts in the two libraries were $1,600 \mathrm{bp}$ and $600 \mathrm{bp}$, with an average length of the edited sequences of $850 \mathrm{bp}$. Clustering gave 2,387 assembled sequences with a redun-
\end{abstract}

P. Nyvall Collén · A. M. Varani · M. C. Oliveira Department of Botany, Institute of Biosciences, University of São Paulo,

Rua do Matão 277,

São Paulo, SP, Brazil

J. Collén $\cdot$ P. Colepicolo

Department of Biochemistry, Institute of Chemistry, University of São Paulo,

São Paulo, SP, Brazil

M. da Silva Reis

Departement of mathematics and statistics, University of São Paulo,

São Paulo, SP, Brazil

M. Pedersén

Department of Botany, Stockholm University, 10691 Stockholm, Sweden

J. C. Setubal

Virginia Bioinformatics Institute,

Virginia Polytechnic Institute and State University, Blacksburg, VA 24060, USA

P. Nyvall Collén $(\square)$

Université Pierre et Marie Curie, Paris VI, CNRS,

Marine Plants and biomolecules, UMR 7139,

Station Biologique, Place Georges Teissier,

29680 Roscoff, France

e-mail: nyvall@sb-roscoff.fr dancy of $53 \%$. Of the ESTs, $65 \%$ had significant matches to sequences deposited in public databases, $11 \%$ to proteins without known function, and $35 \%$ were novel. The most represented ESTs were a Na/K-transporting ATPase, a hedgehog-like protein, a glycine dehydrogenase and an actin. Most of the identified genes were involved in primary metabolism and housekeeping. The largest functional group was thus genes involved in metabolism with $14 \%$ of the ESTs; other large functional categories included energy, transcription, and protein synthesis and destination. The codon usage was examined using a subset of the data, and the codon bias was found to be limited with all codon combinations used.

Keywords Agarophyte - Codon bias - Expressed sequence tags $\cdot$ Gracilaria tenuistipitata $\cdot$ Rhodophyta

\section{Introduction}

The red algae occur globally; the large majority are multicellular and found in marine waters. The family Gracilariaceae includes the genus Gracilaria with more than 150 species (Fredericq and Hommersand 1989; Oliveira and Plastino 1994). Gracilaria species have a typical red algal triphasic life cycle with alternation between isomorphic, haploid and diploid generations, and separate sexes in the gametophyte generation. They have a wide geographical range although the majority of species are reported from tropical regions. Their main habitat is protected sandy or muddy areas in the intertidal or upper subtidal region where they grow attached or free floating. Many species in this family are economically important for the production of agar and agarose. Due to over-harvesting 
of natural populations and an increased demand for agar, mariculture of these seaweeds has been growing. This has also triggered an interest in understanding their physiology in order to improve the production of algae and yield of cell wall polysaccharides.

The species used in this study, Gracilaria tenuistipitata var. liui, exhibits a wide tolerance to salinity ( $3 \%$ to $50 \%$ ), temperature $\left(13^{\circ} \mathrm{C}\right.$ to $33^{\circ} \mathrm{C}$ ), and $\mathrm{pH}(5.5$ to 10.0$)$ (Haglund and Pedersén 1992). These characteristics together with a high growth rate and high agar yield make this strain suitable for cultivation, and it has been extensively cultivated in ponds in Southern China and Taiwan (Chiang 1981). G. tenuistipitata has also been increasingly used as a model species in studies on red algal physiology (Carnicas et al. 1999; Collén et al. 2003; Falcão et al. 2008, 2010; García-Sánchez et al. 1994; Haglund and Pedersén 1992, 1993; Haglund et al. 1996; Hu et al. 1996; Lee et al. 1999; Lee and Chang 1999; Lopes et al. 1997, 2002; Mercado et al. 2001; Nyvall et al. 1999; Nyvall Collén et al. 2004; Skriptsova and Nabivailo 2009; Xu et al. 2009; Yokoya et al. 2004; Yu and Pedersén 1993). Another example of the growing interest in this alga is the sequencing of its chloroplast (Hagopian et al. 2004) and mitochondrial (Takahashi 2010) genomes as well as completion of its life history in the laboratory (Barufi et al. 2010).

Relatively few gene sequences are available for red algae. This is especially true for the Florideophyceae, the largest class within red algae, to which the family Gracilariaceae belongs. The sequencing of expressed sequence tags (EST) has been proven a successful method for the investigation of gene expression at different scales and in various model systems. The approach has already been used successfully on the red algae Gracilaria gracilis (Lluisma and Ragan 1997), Porphyra yezoensis (Asamizu et al. 2003; Nikaido et al. 2000) Gracilaria lemaneiformis (Sun et al. 2002), Chondrus crispus (Collén et al. 2006), Porphyra haitanensis (Fan et al. 2007), Griffithsia okiensis (Lee et al. 2007), Gracilaria changii (Teo et al. 2007), and Eucheuma denticulatum (Aspilla et al. 2010).

The growing interest for G. tenuistipitata as a model organism increases the need of genomic knowledge of this species in order to facilitate further studies. Thus, in order to augment our knowledge of genes in red algae, and especially agarophytes, and to provide genomic information for future investigations, we decided to use the EST sequencing approach on $G$. tenuistipitata.

\section{Materials and methods}

Gracilaria tenuistipitata var. liui Zhang and Xia (Gracilariaceae, Rhodophyta) was originally collected from China in 1990 and has since been kept in unialgal culture in the laboratory in the tetrasporophytic phase. The culture was maintained at $25^{\circ} \mathrm{C}$ with $14 \mathrm{~h}$ of light $(150 \mu \mathrm{mol}$ photons $\mathrm{m}^{-2} \mathrm{~s}^{-1}$ ) and $10 \mathrm{~h}$ of darkness in seawater with a salinity of $20 \%$ (achieved by dilution of seawater with distilled water) and with constant air bubbling. The algal density was kept below $5 \mathrm{~g}$ fresh weight $\mathrm{L}^{-1}$ and nutrients were added every second to third day (Oliveira et al. 1995), and the medium was changed weekly. The average growth rate in these culture conditions was $5 \%$ day $^{-1}$ by weight. The algae were collected for RNA extraction $18 \mathrm{~h}$ after the last nutrient addition and $2 \mathrm{~h}$ after the light was turned on. Aliquots of the algae were rapidly rinsed in fresh water, blotted dry, frozen in liquid nitrogen, and stored at $-70^{\circ} \mathrm{C}$.

RNA extraction, cDNA library construction, and sequencing

Total RNA was extracted using the protocol of Mackay and Gallant (1991), and mRNA (12 $\mu \mathrm{g})$ was isolated from total RNA $(0.3 \mathrm{mg})$ by purification with an oligo dT spin column kit (United States Biochemical) following the manufacturer's instructions. The library was constructed using $10 \mu \mathrm{g}$ of mRNA and the Stratagene ZAP Express cDNA synthesis kit (Stratagene). The cDNA was size fractionated on a Sephadex column before it was directionally ligated into the EcoRI and XhoI digested phagemid vector pBKCMV and packaged into phage particles with the ZAP Express cDNA Gigapack III Gold Cloning Kit. Two separate libraries were made, one with fragments larger than $700 \mathrm{bp}$ (library 01) and one with fragments larger than $500 \mathrm{bp}$ (library 02 ). The primary libraries had titers of 0.7 and $0.5 \mathrm{Mpfu}$. The amplified libraries were used for mass excision according to the manufacturer's protocol and XLOLR cells were transformed with the phagemid vector. The average size of inserts in the two libraries was determined by the digestion of 48 clones from each library with $X h o I$ and EcoRI. Sequencing reactions were performed with BigDye terminators and analyzed on ABI Prism 377 and 3700 automated sequencers.

Sequence data processing, clustering, and annotation

Vector and adaptor sequences were automatically screened with the cross_match program (http://www.phrap.org). Each base was assigned a quality value, and $83 \%$ of the sequences surpassed a quality of 100 consecutive bases with a phred quality value greater than or equal to 20 . The number of nonredundant sequences was determined by clustering using the Paracel Transcript Assembler program (Paracel, USA), with default values. Sequences were considered redundant when more than 60 nucleotides with $80 \%$ identity were observed. A significant similarity to known 
Table 1 Overview of the major results from the G. tenuistipitata EST project

Total ESTs sequenced

3,631

Unique sequences

2,387

Redundancy

$53 \%$

Average insert size 01

Average insert size 02

$1,600 \mathrm{bp}$

Average sequence length

$600 \mathrm{bp}$

GC content

$850 \mathrm{bp}$

$49 \%$

genes was considered when BLAST (Altschul et al. 1997) $e$ values were less than or equal to $10^{-5}$.

All nonredundant sequences were annotated manually for function and classification. The functional annotation of each EST cluster was carried out by using BLAST searches (Altschul et al. 1997), Cluster of Orthologous Groups of Proteins, Protein Family Database, and the Kyoto Encyclopedia of Genes and Genomes databases.

For functional classification, the Functional Catalogue scheme from the Munich Information Center for Protein Sequences (MIPS) was used (Ruepp et al. 2004; Mewes et al. 2008).

The G. tenuistipitata nonredundant sequences were compared to other algal genomes and EST datasets by TBLASTX. For these analyses, nonredundant sequences annotated as hypothetical, conserved hypothetical, and of unknown function were removed.

The annotated ESTs have been deposited in GenBank with accession numbers HS977843 to HS981848. Supplementary information is available at http:/gracilaria.ib.usp.br/mirror/ gracilaria.

\section{Results and discussion}

Two directional size-selected cDNA libraries were produced from the tetrasporophytic phase of the red alga G. tenuistipitata. Their average insert sizes were 1,600 bp and $600 \mathrm{bp}$, for library 01 and 02 , respectively. A total of 3,648 clones, 3,072 from library 01 and 576 from library 02, were sequenced from the $5^{\prime}$ end of the cDNA inserts using the T3 primer, yielding 3,631 ESTs. In addition, 180 clones from library 01 were resequenced from the $3^{\prime}$ end using T7 primer. These $3^{\prime}$-end sequences are deposited in the database but were not included in the analyses.

After editing, the sequences had an average length of $850 \mathrm{bp} ; 3,147$ (87\%) of the ESTs surpassed a quality level of 100 consecutive bases with a phred score greater than or equal to 20. Assembly of our 3,631 reads yielded 447 assembled sequences and 1,940 singletons representing a redundancy level of $53 \%$. A summary of the results are shown in Table 1. Of the assembled sequences, 249 contained two reads and the largest contained 57 reads.

No ESTs were found that matched chloroplast sequences nor were any ESTs with suspiciously high similarity to bacterial or fungal sequences found. We therefore assume that even if the cultures used were not axenic, little or no contamination relevant to the EST project was present and that the ESTs represent, to our knowledge, G. tenuistipitata genes only.

The majority (65\%) of the ESTs and $56 \%$ of the assembled sequences had a significant similarity $\left(e \leq 10^{-5}\right)$ to sequences in the database using BLASTX. An example of the representation of genes is shown in Fig. 1. Genes not represented in this investigation are not found or are coded
Fig. 1 A representation of genes involved in carbon dioxide fixation identified among the ESTs from $G$. tenuistipitata. In black are the genes for which a significant match was found. In gray are the genes not identified among the ESTs. Both subunits of rubisco are known to be encoded in the red algal chloroplast, and the gene for the enzyme activity 4.1.2.9 has been identified so far only in bacteria and fungi

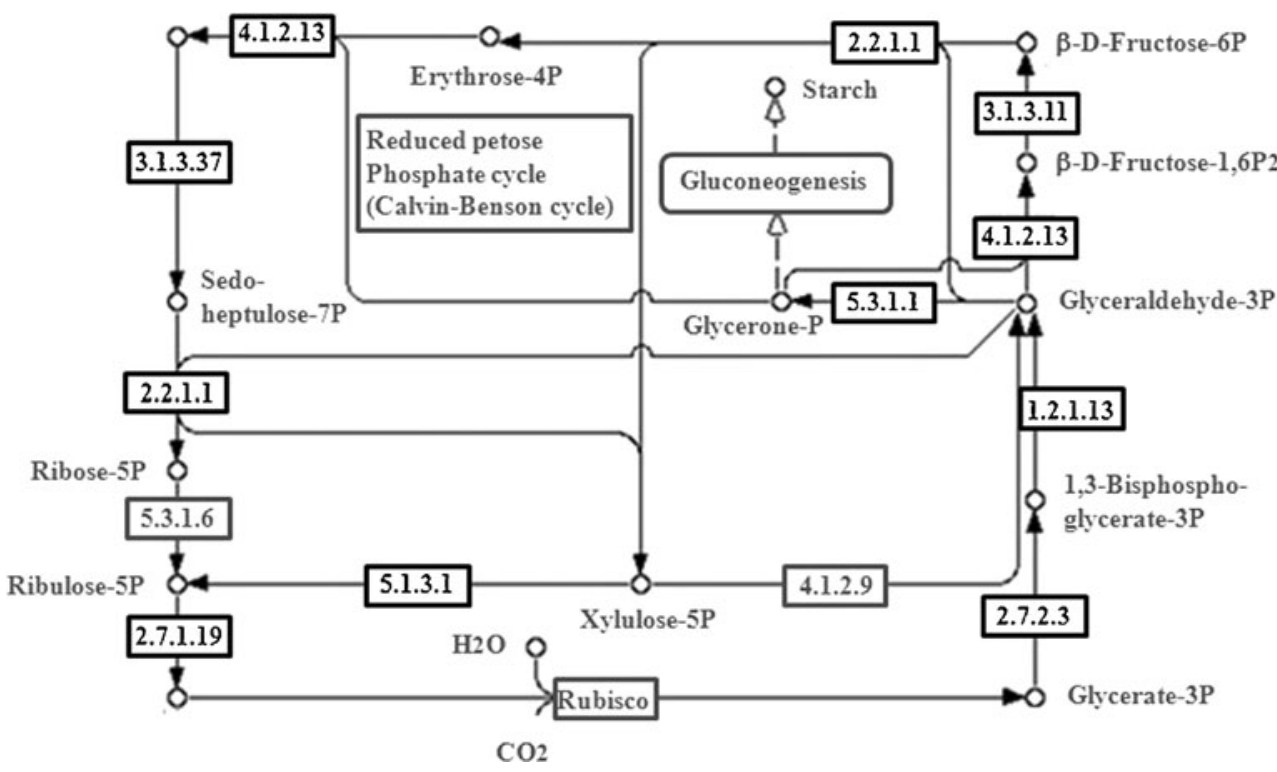


Table 2 Classification of G. tenuistipitata ESTs into functional categories according to the MIPS categories for Arabidopsis thaliana

${ }^{a}$ Indicate the percentage of clusters in each category compared to the total number of clusters

${ }^{\mathrm{b}}$ ESTs represent the percentages of ESTs in each category

${ }^{c}$ ESTs that did not fit in any of the categories

${ }^{\mathrm{d}}$ Indicates hit against protein with unknown function

${ }^{\mathrm{e}}$ Hypothetical protein indicates no hit with BLASTX at $\mathrm{e} \leq 10^{-5}$ against the NCBI nonredundant database

\begin{tabular}{|c|c|c|}
\hline Category & Assembled sequences ${ }^{\mathrm{a}}$ & $\mathrm{ESTs}^{\mathrm{b}}$ \\
\hline Metabolism & $11.9 \%$ & $14.2 \%$ \\
\hline Energy & $4.6 \%$ & $7.5 \%$ \\
\hline Cell growth, cell division, and DNA synthesis & $2.8 \%$ & $3.9 \%$ \\
\hline Transcription & $3.4 \%$ & $2.9 \%$ \\
\hline Protein synthesis & $4.8 \%$ & $4.7 \%$ \\
\hline Protein destination & $3.7 \%$ & $3.8 \%$ \\
\hline Transport facilitation & $2.8 \%$ & $4.2 \%$ \\
\hline Intracellular transport & $2.1 \%$ & $2.4 \%$ \\
\hline Cellular biogenesis & $0.5 \%$ & $0.6 \%$ \\
\hline Cellular communication/signal transduction & $2.9 \%$ & $3.2 \%$ \\
\hline Cell rescue, defense, cell death, and ageing & $3.1 \%$ & $3.0 \%$ \\
\hline Ionic homeostasis & $0.1 \%$ & $0.1 \%$ \\
\hline Cellular organization & $1.6 \%$ & $1.8 \%$ \\
\hline Transport elements, viral, and plasmid proteins & $0.7 \%$ & $0.6 \%$ \\
\hline Unclassified $^{\mathrm{c}}$ & $1.2 \%$ & $1.6 \%$ \\
\hline Conserved hypothetical protein ${ }^{\mathrm{d}}$ & $11.8 \%$ & $10.7 \%$ \\
\hline Hypothetical protein & $42.7 \%$ & $35.2 \%$ \\
\hline
\end{tabular}

in plastids. For example, the large and small subunits of Rubisco are coded in the chloroplast of $G$. tenuistipitata (Hagopian et al. 2004). This indicates that for common genes, most are represented in the EST collection.

The BLASTX result of each nonredundant sequence was manually inspected and annotated into categories according to MIPS (Table 2). In total, 52.5\% could be assigned a cellular role on the basis of sequence similarity to proteins with known functions. The remaining ESTs had no significant similarity to proteins or DNA sequences in the databases $(35.2 \%)$, or had a significant similarity to the genes of unknown function $(10.7 \%)$, or did not fit in any of the MIPS categories (1.6\%) and were placed in the category "unclassified." The majority of the identified ESTs were related to housekeeping functions. For example, the largest category was metabolism with $14.2 \%$ of ESTs; this represents $25.9 \%$ of ESTs with known function. The second largest category, with $7.5 \%$ of ESTs, was energy which includes genes important for photosynthesis and respiration. ESTs coding for protein synthesis and protein destination were also highly represented with a total of $8.5 \%$. When the representation of different genes rather than the number of ESTs was compared, a similar picture emerged. The rationale was to see if there were differences in the number of different genes in each category. The major difference was that a larger fraction of the genes had no similarity to known genes than when compared on an EST basis. Our explanation of this is that genes with low
Table 3 The 12 most abundant ESTs from the G. tenuistipitata library; $f$ frequency of ESTs

${ }^{\mathrm{a}}$ The closest match in GenBank

${ }^{\mathrm{b}}$ Represents the organism with the closest match to the different contigs

${ }^{\mathrm{c}}$ The e value

d The length of the contig assembled from the ESTs

\begin{tabular}{lllllr}
\hline Number & $f$ & Gene $^{\mathrm{a}}$ & Organism $^{\mathrm{b}}$ & $e^{\mathrm{c}}$ & Size $^{\mathrm{d}}$ \\
\hline 200036 & 57 & Na/K-transporting ATPase & Rattus norvegicus & $<10^{-100}$ & 1,838 \\
200065 & 29 & Hedgehog protein & Xenopus laevis & $2 \times 10^{-11}$ & 1,743 \\
200107 & 25 & Actin & Porphyra yezoensis & $<10^{-100}$ & 1,520 \\
200071 & 23 & Glycine dehydrogenase & Pisum sativum & $<10^{-100}$ & 2,447 \\
200010 & 22 & WD-40 repeat protein & Dictyostelium discoideum & $3 \times 10^{-71}$ & 2,106 \\
200006 & 20 & Aspartate aminotransferase & Aquifex aeolicus & $2 \times 10^{-46}$ & 1,052 \\
200164 & 19 & Ubiquitin & Aglaothamnion neglectum & $<10^{-100}$ & 832 \\
200021 & 19 & Taurine dioxygenase & Escherichia coli & $2 \times 10^{-25}$ & 1,514 \\
200027 & 18 & Actin & Chondrus crispus & $<10^{-100}$ & 1,553 \\
200059 & 18 & ATP/ADP transporter & Galdieria sulphuraria & $<10^{-100}$ & 2,148 \\
200070 & 17 & Adenylylsulfate kinase & Schizosaccharomyces pombe & $3 \times 10^{-66}$ & 886 \\
200077 & 17 & Proline-rich protein & Volvox carteri & $5 \times 10^{-13}$ & 784 \\
200180 & 16 & Phosphoglycerate kinase & Phaeodactylum tricornutum & $6 \times 10^{-77}$ & 913 \\
200146 & 15 & Zinc-finger protein & Mus musculus & $1 \times 10^{-21}$ & 1,040 \\
\hline
\end{tabular}


Table 4 Codon usage in G. tenuistipitata, as determined from the analysis of 878 sequences with an average length of 203 amino acids and a minimum length of 30 amino acids

\begin{tabular}{|c|c|c|c|c|c|c|c|c|c|c|c|}
\hline AA & Codon & Percentage & AA & Codon & Percentage & AA & Codon & Percentage & AA & Codon & Percentage \\
\hline Lys & AAA & 35 & Gln & CAA & 49 & Glu & GAA & 52 & Stop & TAA & 41 \\
\hline Lys & AAG & 65 & Gln & GAG & 51 & Glu & GAG & 48 & Stop & TAG & 25 \\
\hline Asn & AAC & 55 & His & CAC & 48 & Asp & GAC & 47 & Tyr & TAC & 59 \\
\hline Asn & AAT & 45 & His & CAT & 52 & Asp & GAT & 53 & Tyr & TAT & 41 \\
\hline Arg & AGA & 16 & Arg & CGA & 17 & Gly & GGA & 27 & Stop & TGA & 34 \\
\hline Arg & AGG & 10 & Arg & CGG & 8 & Gly & GGG & 13 & Trp & TGG & 100 \\
\hline Ser & $\mathrm{AGC}$ & 15 & Arg & CGC & 26 & Gly & GGC & 30 & Cys & TGC & 55 \\
\hline Ser & AGT & 12 & Arg & CGT & 23 & Gly & GGT & 30 & Cys & TGT & 45 \\
\hline Thr & $\mathrm{ACA}$ & 21 & Pro & $\mathrm{CCA}$ & 24 & Ala & GCA & 21 & Ser & TCA & 15 \\
\hline Thr & ACG & 18 & Pro & $\mathrm{CCG}$ & 28 & Ala & GCG & 18 & Ser & TCG & 15 \\
\hline Thr & $\mathrm{ACC}$ & 30 & Pro & $\mathrm{CCC}$ & 24 & Ala & GCC & 32 & Ser & TCC & 20 \\
\hline Thr & $\mathrm{ACT}$ & 30 & Pro & $\mathrm{CCT}$ & 24 & Ala & GCT & 29 & Ser & TCT & 23 \\
\hline Ile & ATA & 13 & Leu & CTA & 8 & Val & GTA & 13 & Leu & TTA & 7 \\
\hline Ile & ATC & 40 & Leu & CTG & 18 & Val & GTG & 30 & Leu & TTG & 21 \\
\hline Ile & ATT & 47 & Leu & CTC & 22 & Val & GTC & 28 & Phe & TTC & 53 \\
\hline Met & ATG & 100 & Leu & CTT & 25 & Val & GTT & 30 & Phe & TTT & 47 \\
\hline
\end{tabular}

$e$ values $\leq 10^{-20}$. Amino acid name, triplet, and occurrence of each triplet as percentage of each amino acid

expressions are less likely to have been studied, and thus ESTs with low representation will be overrepresented in the category "hypothetical proteins." The categories "energy" and "transport facilitation" also showed differences when the representation of ESTs and genes were compared; they showed an underrepresentation of genes. This can be explained by the relatively large clusters found in these groups.

The 12 most abundant ESTs are shown in Table 3. We are assuming that this, with some limitations, represents actual levels of transcripts at the moment of extraction (Ohlrogge and Benning 2000). The most abundant EST, and thereby possibly the most expressed gene, was a $\mathrm{Na} / \mathrm{K}$ transporting ATPase with 57 ESTs, corresponding to 1.6\% of all ESTs. The second most expressed EST was a hedgehog-like protein, putatively involved in cell communication. Another highly expressed gene was an actin gene with 25 ESTs. There were, however, more than one actin represented among the ESTs, and in total there were 54 ESTs coding for at least three different actins.

The codon usage is shown in Table 4. All codon combinations were used by $G$. tenuistipitata and in most cases with relatively low bias. What is notable is a much more even distribution of usage of the different codons than have been reported for Porphyra (Nikaido et al. 2000). The difference in the codon usage bias observed by Lee et al. (2007) between Florideophycean algae (Griffithsia and Chondrus; C-ending codon) and Bangiophycean algae (Porphyra; G-ending codon) is confirmed by Gracilaria.
Gracilaria tenuistipitata ESTs were compared to other available red algae EST datasets (Table 5). Not surprisingly, G. tenuistipitata ESTs are more similar to G. gracilis and G. changii, followed by C. crispus, another Florideophyceae. When comparing G. tenuistipitata ESTs to some of the available genomes for algae, it seems that it is more similar to the green algae than to the only available genome for a red alga, Cyanidioschyzon merolae. However, C. merolae is an

Table 5 G. tenuistipitata nonredundant sequences with an assigned function $\left(\mathrm{e} \leq 10^{-5}\right)$ compared to other algal genomes or EST datasets by TBLASTX

\begin{tabular}{lc}
\hline Organism & \% Identity \\
\hline Red algal ESTs & \\
Chondrus crispus & 54.8 \\
Gracilaria gracilis & 62.9 \\
Gracilaria changii & 62.3 \\
Porphyra yezoensis & 52.3 \\
Red algal genome & \\
Cyanidioschyzon merolae & 47.9 \\
Green algal genomes & \\
Chlorella vulgaris & 55.6 \\
Micromonas pusilla & 48.5 \\
Ostreococcus lucimarinus CCE9901 & 48.0 \\
Ostreococcus tauri OTH95 & 48.3 \\
Volvox carteri & 54.2 \\
\hline
\end{tabular}


extremophile and belongs to the Cyanidiophyceae, a basal and quite divergent group in the red algae (Yoon et al. 2006).

\section{Conclusions}

An EST approach was used to increase our genomic knowledge of $G$. tenuistipitata. Several genes of interest were identified using this approach. Therefore, this work will be a valuable source of information for further studies. We also show a limited codon bias in this red alga.

Acknowledgment This research was performed under a SwedishBrazilian research cooperation founded by The Swedish Foundation for International Cooperation in Research (STINT). Support was also obtained from the State of São Paulo Research Foundation (FAPESP) and the Brazilian National Council for Scientific and Technological Development $(\mathrm{CNPq})$. E.C. Oliveira collected the strain used in this work.

\section{References}

Altschul SF, Madden TL, Schäffer AA, Zhang J, Zhang Z, Miller W, Lipman DJ (1997) Gapped BLAST and PSI-BLAST: a new generation of protein database search programs. Nucleic Acids Res 25:3389-3402

Asamizu E, Nakajima M, Kitade Y, Saga N, Nakamura Y, Tabata S (2003) Comparison of RNA expression profiles between the two generations of Porphyra yezoensis (Rhodophyta), based on expressed sequence tag frequency analysis. J Phycol 39:923-930

Aspilla PS, Antonio AACB, Zuccarello GC, Rojas NRL (2010) A partial expressed sequence tag (EST) library of the economically important red alga Eucheuma denticulatum (N.L. Burham) F.C. Collins and Hervey. Phil Sci Lett 3:109-120

Barufi JB, Cabral de Oliveira E, Plastino EM, Cabral de Oliveira M (2010) Life history, morphological variability and growth rates of the life phases of Gracilaria tenuistipitata (Rhodophyta: Gracilariales) in vitro. Sci Mar. doi:10.3989/scimar.2010.74n2297

Carnicas E, Jiménez C, Niell FX (1999) Effects of irradiance on the pigment composition of Gracilaria tenuistipitata var. liui Zhang et Xia. J Photochem Photobiol B Biol 50:149-158

Chiang Y-M (1981) Cultivation of Gracilaria (Rhodophyta, Gigartinales) in Taiwan. In: Levring T (ed) 10th International Seaweed Symposium. Walter de Gruyter \& Co., Berlin, pp 569-574

Collén J, Pinto E, Pedersén M, Colepicolo P (2003) Induction of oxidative stress in the red macroalga Gracilaria tenuistipitata by pollutant metals. Arch Environ Contam Toxicol 45:337-342

Collén J, Roeder V, Rousvoal S, Collin O, Kloareg B, Boyen C (2006) An expressed sequence tag analysis of thallus and regenerating protoplasts of Chondrus crispus (Gigartinales, Rhodophyceae). J Phycol 42:104-112

Falcão VDR, Tonon AP, Oliveira MC, Colepicolo P (2008) RNA isolation method for polysaccharide rich algae: agar producing Gracilaria tenuistipitata (Rhodophyta). J Appl Phycol 20:9-12

Falcão VR, Oliveira MC, Colepicolo P (2010) Molecular characterization of nitrate reductase gene and its expression in the marine red alga Gracilaria tenuistipitata (Rhodophyta). J Appl Phycol 22:613-622

Fan X, Fang Y, Hu S, Wang G (2007) Generation and analysis of 5,318 expressed sequence tags from the filamentous sporophyte of Porphyra haitanensis (Rhodophyta). J Phycol 43:1287-1294
Fredericq S, Hommersand MH (1989) Proposal of the Gracilariales ord. nov. (Rhodophyta) based on an analysis of the reproductive development of Gracilaria verrucosa. J Phycol 25:213-227

García-Sánchez MJ, Fernández JA, Niell X (1994) Effect of inorganic carbon supply on the photosynthetic physiology of Gracilaria tenuistipitata. Planta 194:55-61

Haglund K, Pedersén M (1992) Growth of the red alga Gracilaria tenuistipitata at high $\mathrm{pH}$. Influence of some environmental factors and correlation to an increased carbonic-anhydrase activity. Bot Mar 35:579-587

Haglund K, Pedersén M (1993) Outdoor pond cultivation of the subtropical marine red alga Gracilaria tenuistipitata in brackish water in Sweden. Growth, nutrient uptake, co-cultivation with rainbow trout and epiphyte control. J Appl Phycol 5:271-284

Haglund K, Björklund M, Gunnare S, Sandberg A, Olander U, Pedersén M (1996) New method for toxicity assessment in marine and brackish environments using the macroalga Gracilaria tenuistipitata (Gracilariales, Rhodophyta). Hydrobiologia 326/327:317-325

Hagopian JC, Reis M, Kitajima JP, Bhattacharya D, Oliveira MC (2004) Comparative analysis of the complete plastid genome sequence of the red alga Gracilaria tenuistipitata var. liui provides insights on the evolution of rhodoplasts and their relationship to other plastids. J Mol Evol 59:464-477

$\mathrm{Hu}$ S, Tang CH, Wu M (1996) Cadmium accumulation by several seaweeds. Sci Total Environ 187:65-71

Lee T-M, Chang Y-C (1999) An increase of ornithine $\delta$ aminotransferase-mediated proline synthesis in relation to hightemperature injury in Gracilaria tenuistipitata (Gigartinales, Rhodophyta). J Phycol 35:84-88

Lee T-M, Chang Y-C, Lin Y-H (1999) Differences in physiological responses between winter and summer Gracilaria tenuistipitata (Gigartinales, Rhodophyta) to varying temperature. Bot Bull Acad Sin 49:93-100

Lee H, Lee HK, An G, Lee YK (2007) Analysis of expressed sequence tags from the red alga Griffithsia okiensis. J Microbiol 45:541-546

Lopes PF, Oliveira MC, Colepicolo P (1997) Diurnal fluctuation of nitrate reductase activity in the marine red alga Gracilaria tenuistipitata (Rhodophyta). J Phycol 33:225-231

Lopes PF, Oliveira MC, Colepicolo P (2002) Characterization and daily variation of nitrate reductase in Gracilaria tenuistipitata (Rhodophyta). Biochem Biophys Res Commun 295:50-54

Lluisma AO, Ragan MA (1997) Expressed sequence tags (ESTs) from the marine red alga Gracilaria gracilis. J Appl Phycol 9:287-293

MacKay RM, Gallant JW (1991) Beta-tubulins are encoded by at least 4 genes in the brown alga Ectocarpus variabilis. Plant Mol Biol 17:487-492

Mercado JM, Sánchez P, Carmona R, Niell FX (2001) Limited acclimation of photosynthesis to blue light in the sea-weed Gracilaria tenuistipitata. Physiol Plant 114:491-498

Mewes HW, Dietmann S, Frishman D, Gregory R, Mannhaupt G, Mayer KFX, Münsterkötter M, Ruepp A, Spannagl M, Stümpflen V, Rattei T (2008) MIPS: analysis and annotation of genome information in 2007. Nuc Acids Res 36:D196-D201

Nikaido I, Asamizu E, Nakajima M, Nakamura Y, Saga N, Tabata S (2000) Generation of 10,154 expressed sequence tags from a leafy gametophyte of a marine red alga, Porphyra yezoensis. DNA Res 7:223-227

Nyvall P, Pelloux J, Davies HV, Pedersén M, Viola R (1999) Purification and characterisation of a novel starch synthase selective for uridine $5^{\prime}$-diphosphate glucose from the red alga Gracilaria tenuistipitata. Planta 209:143-152

Nyvall Collén P, Camitz A, Hancock RD, Viola R, Pedersén M (2004) Effect of nutrient deprivation and resupply on metabolites and enzymes related to carbon allocation in Gracilaria tenuistipitata (Rhodophyta). J Phycol 40:305-314 
Ohlrogge J, Benning C (2000) Unraveling plant metabolism by EST analysis. Curr Opin Plant Biol 3:224-228

Oliveira EC, Paula EJ, Plastino EM, Petti R (1995) Metolodogias para cultivo no axenico de macroalgas marinas in vitro. In: Alveal $\mathrm{K}$, Ferrario ME, Oliveira EC, Sar Y (eds) Manual de métodos ficologicos. Universidad de Concepcion, Concepcion, ISBN 956227-113-7

Oliveira EC, Plastino EM (1994) Gracilariaceae. In: Akatsuka I (ed) Biology of economic algae. SSB Academic Publi, The Hague, pp $185-226$

Ruepp A, Zollner A, Maier D, Albermann K, Hani J, Mokrejs M, Tetko I, Güldener U, Mannhaupt G, Münsterkötter M, Mewes HW (2004) The FunCat, a functional annotation scheme for systematic classification of proteins from whole genomes. Nuc Acids Res 32:5539-5545

Skriptsova AV, Nabivailo YV (2009) Comparison of three gracilarioids: growth rate, agar content and quality. J Appl Phycol 21:443-450

Sun X, Yang G, Mao Y, Zhang X, Sui Z, Qin S (2002) Analysis of expressed sequence tags of a marine red alga, Gracilaria lemaneiformis. Prog Nat Sci 12:518-523
Takahashi MM (2010) Sequênciamento e análise do genoma mitocondrial de Gracilaria tenuistipitata (Gracilariales, Rhodophyta). Master Thesis, Institute of Biosciences, University of São Paulo. http://www.teses.usp.br/teses/disponiveis/41/41132/tde-06102010$164456 /$

Teo S-S, Ho C-L, Teoh S, Lee W-W, Tee J-M, Rahim RA, Phang S-M (2007) Analyses of expressed sequence tags from an agarophyte, Gracilaria changii (Gracilariales, Rhodophyta). Eur J Phycol 42:41-46

$\mathrm{Xu}$ Y, Wei W, Fang J (2009) Effects of salinity, light and temperature on growth rates of two species of Gracilaria (Rhodophyta). Chin J Oceanol Limnol 27:350-355

Yu S, Pedersén M (1993) $\alpha-1,4-G l u c a n$ lyase, a new class of starch/ glycogen-degrading enzyme. Planta 191:137-142

Yokoya NS, West JA, Luchi AE (2004) Effects of plant growth regulators on callus formation, growth and regeneration in axenic tissue cultures of Gracilaria tenuistipitata and Gracilaria perplexa (Gracilariales, Rhodophyta). Phycol Res 52:244-254

Yoon HS, Müller KM, Sheath RG, Ott FD, Bhattacharya D (2006) Defining the major lineages of red algae (Rhodophyta). J Phycol 42:482-492 